Copyright: The author, Joanne G. Wong, 2021.

\title{
Cultural Shift: The Canvas of Female Identity and Expression in the Evolution of the Shift Dress
}

\author{
Joanne G. Wong \\ Submitted to Swansea University in fulfilment of the requirements for the Degree of
} Doctor of History

Swansea University

2021 


\section{Suggested Layout of Declaration/Statements page}

\section{DECLARATION}

This work has not previously been accepted in substance for any degree and is not being concurrently submitted in candidature for any degree.

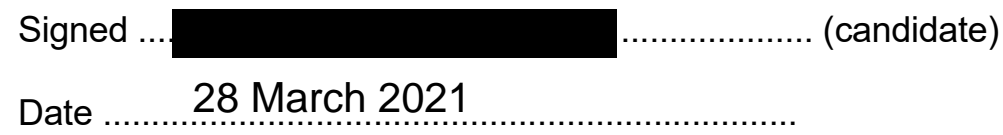

\section{STATEMENT 1}

This thesis is the result of my own investigations, except where otherwise stated. Other sources are acknowledged by footnotes giving explicit references. A bibliography is appended.

Signed

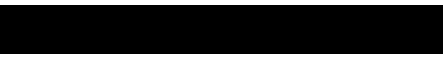
(candidate)

Date 28. March.20.21

\section{STATEMENT 2}

I hereby give consent for my thesis, if accepted, to be available for photocopying and for inter-library loan, and for the title and summary to be made available to outside organisations.

Signed (candidate)

Date 28. March.20.21

NB: Candidates on whose behalf a bar on access has been approved by the University (see Note 7), should use the following version of Statement 2:

I hereby give consent for my thesis, if accepted, to be available for photocopying and for inter-library loans after expiry of a bar on access approved by the Swansea University.

Signed (candidate)

Date 28. Mar.ch 2021 


\section{Summary (Abstract)}

This study explores, for the first time, an in-depth analysis of the social and cultural history of the shift dress. It provides a multidisciplinary approach which focuses on the significance of the shift dress in the changing context of women's work, education and their place in contemporary society in the twentieth century. It also locates the dress's contribution to elements and processes of modern fashion and beyond, into the broader contexts of American popular culture. From its origins, the shift dress evoked modern ideals. Its simple construction means it was an economical, versatile, and expressive garment. The shift dress's versatility afforded women the opportunity to move effortlessly between sport, work, and leisure. This thesis argues that its simple form is a blank canvas, which allowed women to express themselves individually and freely while propelling fashion forward in terms of innovation. Throughout the twentieth century, it has been reinterpreted, redesigned and reimagined, with the 1920s and the 1960s especially significant periods for this study. Its adaptability across time periods advanced women in the public sphere and in previously male dominated environments and workplaces. The shift dress allowed women to move away from societal expectations to create their own identity. The thesis contends that as a consequence of its attributes, the shift dress was an important vehicle for the evolving expression of women's strength and empowerment. It was the first dress to provide women freedom of choice, to allow freer movement, physically and socially, and to express self- identity. It is more than a garment clothing a woman's body, it provided women a new liberation and a way to be modern. The movement that the dress permitted aligned to the changing place of women in American society. This concept of movement is central to the thesis: the shift dress defines movement on multiple levels. It has moved women forward, it has moved fashion forward, and because of this, it is one of the most significant garments in fashion history. 


\section{Acknowledgments}

First and foremost, I would like to thank my team of advisors, Professor Stephen McVeigh, Professor Deborah Youngs and Professor Susan Miller, as I express extreme gratitude for your help. I am grateful for your areas of expertise which have guided me in developing this thesis. You each have not only challenged me in a way to sharpen my thesis, but continually encouraged me throughout the entire process. I appreciate Professor Susan Miller for accompanying me and offering her fashion insight on my trips to view exhibitions and fashion collections throughout the United States. I want to thank Annette Becker and her staff for welcoming us to view the Texas Fashion Collection. I am also grateful for the University of Central Oklahoma librarians who always helped me in finding sources that I needed.

My most sincere and heartfelt thanks to my friends and family. I thank my husband for his love and continual support during this process and keeping our household in order. I want to thank my children for being patient with me as I have gone through this journey. I am grateful for my parents who have instilled the importance of education at an early age and to my siblings who were always there for me and supported my education goals. To my friends, I appreciate you listening to my challenges and for your words of encouragement throughout these years. 


\section{Table of Contents}

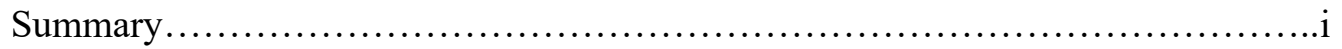

Acknowledgements........................................................

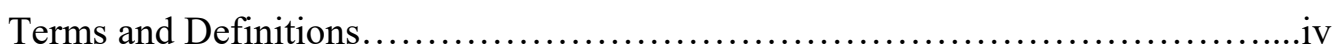

Chapter 1: Introduction...............................................

Chapter 2: The Blank Canvas: The Progressive Era............................. 32

Chapter 3: The Sexualized Canvas: The 1920s..............................91

Chapter 4: The Hidden Canvas: The Postwar Era...............................135

Chapter 5: The Painted Canvas: The 1960s.................................. 176

Chapter 6: Conclusion: The Movement from the Blank Canvas to the Painted

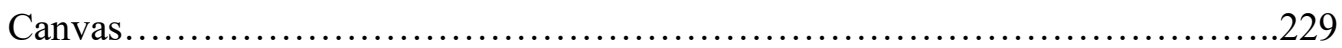

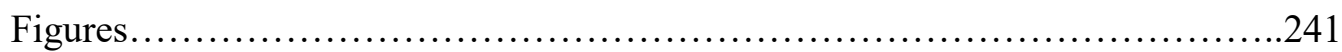

Bibliography ....................................................... 292 


\section{Terms and Definitions}

Chemise - a four-seamed garment that does not mold to the body. The chemise term for this study is a straight dress that extends from the upper calf to the floor.

Chiton -The chiton is constructed with two similar rectangular pieces sewn together at each side and left an opening at the arms and head. Women wore the Chiton as a long dress and usually girdled around the waist while men wore the Chiton both as a short or long garment.

Dart - A technique when you take two pieces of fabric and fold together to form a graduated point in the garment. Darts provide shape to the garment.

Directoire Period - (Directory The Directoire was the period of government in France from 1795 to 1799.

Directoire style - Directoire style incorporated Neoclassical styles of dress during the period of the Directory (1795-1799. Women dressed in chemises and empire waist gowns.

Empire waist gown - A dress with a seam under the bust instead of at the natural waistline. The skirt usually hangs straight or with a slight flare.

Ensemble - An outfit consisted of two-pieces, usually a top and bottom but can also include a dress accompanied with a jacket or sweater.

Fast fashion- Quick production of apparel replicating couture fashion.

Flapper - A woman in the nineteen-twenties which espoused untraditional behaviour for a woman.

Flapperism - Character of someone who obtains flapper behaviour. Slang in the nineteen-twenties.

Frock - A woman's dress. A generic term commonly used by a variety of fashion and women magazines from the 1890s to the 1950s for a dress.

Girdle - During the Greek and Roman periods, a piece of cloth wrapped around a woman's mid-section.

Juniors' Department - This term is relative to the definition during the nineteenfifties and nineteen-sixties for young sophisticated women marketed to a more petite size than women's clothing had offered.

Magazine spread - An editorial term which encompasses the pages inside a magazine. A half spread is one page of the magazine either the left side or the right side. Two consecutive pages that are directly opposite of each other consisting of one left side and one right side is referred to a full page spread. 
Modern - Relating to modernism. Involves recent techniques, methods, or ideas and a new or different way of thinking.

Modern Form - The outlining of the garment that uses similar principles of modern art in straight lines.

Modernize - To adopt modern ways.

Modernize Fashion- To adopt modern ways in fashion.

Motif - A single or repeated design or colour.

National Longitudinal Survey - (NLS) A set of surveys designed by the government to track labour and lifestyle activities for men and women.

Passementerie (pass-ment-er-ee) - An ornamental edging or trimming (such as tassels) made of braid, cord, gimp, beading, or metallic thread.

Peplos -A loose garment found in the Grecian period, the fabric was folded over along the upper edge so that the overfold would reach the waist. It was placed around the body and fastened at the shoulders with a pin or brooch and openings for the arms were left on each side. The peplos might not be secured at the waist with a belt or girdle.

President's Commission on the Status of Women - An advisory commission established in 1961 by John F. Kennedy. The goal was to investigate women's issues of equality in education and the workplace.

Remnants - Small pieces of fabric, unused end of piece goods.

Silhouette - The shape or form of a garment.

Seam - The method of combing two pieces of fabric, cloth, or other material together to construct a garment.

Sweep - The circumference at the bottom of a skirt, dress, jacket, or coat. For this research, I measured the sweep of the dresses with the garment lying flat, measured across the garment from each seam, end to end, then multiplied my number by two.

Tea gowns - a non-restrictive gown worn that was introduced in the 1870s. The purpose of this gown was to provide relief from the tight lacing. It was worn without a corset.

Topstitch - A sewing technique where a stitch is placed on top of the fabric either as a decorative effect or as a functional use.

Tulle - A netting material used in decoration or construction of dress. 
Value - The lightness or darkness of a colour or the amount of light reflected from a hue.

Women's wear - Collection of women's clothing. This term is used in the fashion industry. 


\section{Chapter 1: Introduction}

This study is a social and cultural history of the shift dress, its significance to the histories of women and to developments in their power and status in the United States during the twentieth century. The thesis will identify the pivotal contributors, those who designed and popularized the shift dress, and analyse the impact the shift dress has had on women's place in society as well as the meaning that the shift dress conveyed to the public. The study also details the historic path of the shift dress and provides discussion of its contribution to the fashion industry as well as to modernizing dress.

Historically, restless women have instigated change, ${ }^{1}$ and the same could be said about the shift dress. Although the structure of the shift dress looks predictable, its variability in length, expressionism of its canvas and the women who wore them were not. The article, 'Though History May Shift, The Shift Dress Remains A Constant Source of Inspiration', located on the popular blog, University of Fashion, claimed that 'one of the most recognizable silhouettes throughout history is the shift dress of the 1960s which designers have continually used the shift dress as a constant source of inspiration. ${ }^{2}$ It is as a valuable and constant source for the fashion industry that the shift dress has claim to be worthy of a significant historical study. This article piqued my interest as it drew to mind the association of the shift dress with freeing the flapper from the corset, and, more recently, fashion leaders claiming its inspiration and its continued relevancy in today's world. It appeared that key components of the shift dress were not only life changing for women but had played a part in movements that generated modern elements in fashion and women's freedom of movement. Consequently, with such important and significant claims of the shift dress, it raised

\footnotetext{
${ }^{1}$ Restless women is meant in the context of women who are discontent and dissatisfied with the statusquo of the culture, particularly in the area of women's culture. This phrase was sparked by the newspaper article written by Roslyn Rosen as she discussed dissatisfied housewives. She had claimed that restlessness in women can be productive as it causes them to participate in activities related to politics, economics, science and art. She further stated that women such as the suffragists were dissatisfied and they found outlets of change. I further phrased this as 'Historically, restless women instigated change'. Roslyn Rosen, 'Housewives-A Little Misery is O.K.', Chicago Daily Tribune, 13 October 1957. ProQuest <https://search-proquest-com.vortex3.uco.edu> (p. 1).

${ }^{2}$ Kara Laricks, "Though History May Shift, The Shift Dress Remains A Constant Source Of Inspiration', August 31, 2015. https://www.universityoffashion.com/blog/though-history-may-shiftshift-dress-remains-constant-source-inspiration, [accessed 10 November 2020].
} 
questions concerning how many other aspects in the development and history of the shift dress contributed to women's lives and fashion.

Academic work on the shift dress has been piece-meal and largely disjointed in both the fields of fashion and the history of women. While the shift dress has often been associated with the flapper as liberating women, and some scholars note it as the fashionable style of the 1960s with its close association to the art world, but little has been written on how it began, how it evolved, and how it impacted both women's lives and the fashion industry. In order to fill this gap, this thesis will analyse the evolution of the shift dress from its antecedents, to its early beginnings in the fashion industry in the 1920s and through its rebirth in the 1960s. This thesis will also include considering the time during the early twentieth century when it was less popular. Additionally, it will provide an in-depth analysis of how the shift dress contributed to the fashion industry, impacted women's lives, and examined the restless women who boldly stood up for change.

I utilize numerous research methods of intertwining culture within a fashion led narrative. This study encompasses the use of prevailing scholar literature, popular media, exhibition and fashion collections and a unique quantitative tracking method, which I devised. I aim to build substance and a comprehensive picture of the shift dress with focusing on and identifying its rich historical roots that helped shape women, modern fashion and the fashion industry itself.

In order to build a comprehensive picture, I have defined the shift dress in a specific manner to allow for clear categorisation and examination. Defining the shift dress was essential to gathering and sorting information for this study. The shift dress has been primarily defined as a straight silhouette, however, lengths of the garment varied throughout the twentieth century. Therefore, it is important to define the shift dress for this study. For the purposes of this study, I utilized two key components in order to define the shift dress, form and length. The shift dress is defined as a cylinder form, symmetrical in construction, has an undefined waistline, hangs straight down from the shoulder and the hemline extends no longer than below the upper calf section of the leg. There are similar styles of dresses which resemble the shift dress. The chemise, for example, is the same shape as the shift dress, however it is longer in length, extending from the mid-calf area of the leg to the floor. The sheath dress is similar in length to the shift dress but its shape contours closely to the body with the 
use of darts. In my analysis, I paid particular attention to the length as well as the construction of all dresses to help distinguish the shift dress from other styles.

\section{Literature Review}

Fashion has been studied from the perspective of one particular garment; such as, the corset, the shirtwaist dress, the t-shirt, the midi, and the denim jean. ${ }^{3}$ Fashion historian, Valerie Steele, examines the historical context of the corset and includes the men and women who wore them and provides insight of the health controversy that was central to wearing the coreset. ${ }^{4}$ Interestingly, the study of denim and specifically denim jeans have evoked a more in-depth approach from scholarly work within various fields of studies with different perspectives; for instance, the historical aspect of denim jeans, the environmental impact of denim jeans, and the social and cultural display of denim jeans. ${ }^{5}$ I believe the shift dress deserves a place in scholarly work similar to denim jeans. Christopher Breward claims that the field in academia of fashion is relatively young, and much needs to be explored. ${ }^{6}$ By looking at a singular style, it allows a broader scope of examining women's lifestyle, the contemporary

\footnotetext{
${ }^{3}$ Valerie Steele, The Corset: A Cultural History (London: Yale University Press, 2001). Steele has also published books focused on the red dress and black dress: Valerie Steele, The Red Dress (New York: Rizzoli, 2001).; Valerie Steele, The Black Dress (New York: Collins Design, 2007).; Heather A. Vaughan, 'Icon: Tracing the Path of the 1950s Shirtwaist Dress', The Journal of American Culture, 32.1 (2009), 29-37 (p. 32) < http://vortex3.uco.edu/login?url=https://www-proquestcom.vortex3.uco.edu/scholarly-journals/icon-tracing-path-1950s-shirtwaistdress/docview/200641627/se-2?accountid=14516 $>$ [accessed 20 January 2021].; Charlotte Brunel, The T-Shirt Book (New York: Assouline Publishing, Inc., 2002).; Maxine J. Johns, Fred D. Reynolds and William R. Darden, 'Why the Midi Failed', in Perspectives of Fashion, ed. by George B. Sproles (Minneapolis, Minnesota: Burgess Publishing Company, 1981), pp. 93-99. James Sullivan, Jeans: A Cultural History of an American Icon (New York: Gotham Books, 2006).; see also, Anne Hollander, 'The Little Black Dress', Connoisseur, December, 1984.; The "Mother Hubbard” dress by Sally Helvenston Gray, 'Searching for Mother Hubbard: Function and Fashion in Nineteenth-Century Dress', Winterthur Portfolio, 48.1 (2014), 29-74 (p. 29) < www.jstor.org/stable/10.1086/676031> [accessed 5 January 2021]. Maxine James Johns, 'Women’s Functional Swimwear, 1860-1920', (unpublished doctoral thesis, Iowa State University, 1997) in ProQuest Dissertations and Theses Global < http://vortex3.uco.edu/login?url=https://www-proquest-com.vortex3.uco.edu/dissertationstheses/womens-functional-swimwear-1860-1920/docview/304376249/se-2?accountid=14516 > [accessed 5 January 2021].

${ }^{4}$ Steele, The Corset.

${ }^{5}$ Daniel Miller, 'Anthropology in Blue Jeans.', American Ethnologist, 37.3 (2010) 415-428 $<$ http:/vortex3.uco.edu:2050/login?url=https:/www.jstor.org/stable/40784606> [accessed 9 February 2021].; Lynn Downey, 'My Adventures With Denim: Glimpses into Arizona's Fashion History from the Levi Strauss \& Co. Archives', The Journal of Arizona History, 54.1 (2013), 33-50 < http://vortex3.uco.edu:2050/login?url=https:/www.jstor.org/stable/24459197> [accessed 9 February 2021].; Bodil Birkebaek Olesen, 'When Blue Jeans Went Green', Anthropology Now, 3.1 (2011), 31-35 <. https://doi-org.vortex3.uco.edu/10.5816/anthropologynow.3.1.0031>.

${ }^{6}$ Breward, Fashion, p. 17.
} 
culture, and society's perceptions while containing an in-depth approach to one garment. Examining a singular style also captures the changes of the garment through time. Breward observed that fashion and clothing should be studied from a broad cultural approach. ${ }^{7}$

This study encompasses the analysis of the evolution of the shift dress and its place within the histories of women and contemporary culture. The most popular avenues that scholars have analysed the shift dress has been in relation to a specific time period, cultural roles of women, or from a broad theme approach. For example, scholars who have analysed fashion within a specific time period, such as over a course of a decade, a century or a millennium, may include the shift dress among other popular styles. In these instances, authors typically accompany a summary with the image of the dress. ${ }^{8}$ Moreover, scholars have studied the shift dress in terms of women's culture, but the shift dress plays a minor part to the central role of the women, an example of this would be the flapper. ${ }^{9}$ Additionally, when scholars have utilized the broad theme approach, such as exploring the fashion industry, modern dress, or art in relation to fashion, the shift dress is mentioned or included , and at times, can be significantly discussed, but the theme is central to the topic. ${ }^{10}$ Therefore, when the shift dress appears in literature, typically, it is not the primary

\footnotetext{
${ }^{7}$ Christopher Breward, 'Cultural, Identities, Histories: Fashioning a Cultural Approach to Dress', Fashion Theory, 2.4 (1998), 301-313 (pp. 302-303)

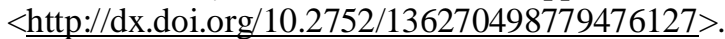

${ }^{8}$ Swinging Sixties: Fashion in London and Beyond, 1955-1970, ed. by Christopher Breward, David Gilbert and Jenny Lister (London: V\&A Publications, 2006).; Ellen Melinkoff, What We Wore: An Offbeat Social History of Women's Clothing, 1950-1980 (New York : Quill, 1984).; Valerie Steele, Fifty Years of Fashion: New Look To Now (New Haven: Yale University Press, 2000); Valerie D Mendes and Amy De La Haye, $20^{\text {th }}$ Century Fashion (London; New York: Thames and Hudson, 1999).; Bonnie English, A Cultural History of Fashion in the $20^{\text {th }}$ and $21^{\text {st }}$ Centuries: From Catwalk to Sidewalk, $2^{\text {nd }}$ edn (London: Bloomsbury, 2013).; Christopher Breward, The Culture of Fashion: A New History of Fashionable Dress (Manchester: Manchester University Press, 1995).; Phyllis G. Tortora and Sara B. Maracketti, Survey of Historic Costume, $6^{\text {th }}$ edn (New York: Bloomsbury Publishing, Inc., 2015).

9 Joshua Zeitz, Flapper: A Madcap Story of Sex, Style, Celebrity, and the Women Who Made American Modern (New York: Crown Publishers, 2006), p. 162.; Soohyun Park, 'Flapper Fashion: In The Context Of Cultural Changes Of America In The 1920s’ (unpublished master’s thesis, The City University Of New York, 2014) in ProQuest Dissertation and Theses Global < http://vortex3.uco.edu/login?url=https://www-proquest-com.vortex3.uco.edu/dissertationstheses/flapper-fashion-context-cultural-changes-america/docview/1551498384/se-2?accountid=14516> [accessed 2 January 2021].; Breward, The Culture of Fashion.; V\&A Publications, 2006.; ${ }^{10}$ Christopher Breward, Fashion (Oxford: Oxford University Press, 2003).; Anne Hollander, Sex \& Suits: The Evolution of Modern Dress (London: Bloomsbury, 2016).; Nancy J. Troy, 'Art', in Fashion and Art, ed. by Adam Geczy and Vicki Karaminas (London: Berg, 2012), pp. 29-41. (Nancy J. Troy provides significant research about the Mondrain shift dress, but the central topic is art and about the artists Piet Mondrian's work as it influences fashion).; see also, Nancy J. Troy, The Afterlife of Piet Mondrian, (Chicago: The University of Chicago Press, 2013).
} 
reason for their studies. As I have found, little substance of the shift dress exists, therefore, this study adds to and fills in questions, theories, and stories that are instrumental to the history of the shift dress.

The shift dress is commonly linked to the flapper and quickly summarized by her appearance with straight dresses, rolled stockings, bobbed hair, and rouged cheeks, however, little scholarship has been placed on the flapper dress. ${ }^{11}$ Most scholars first analysed the flapper, also known as the New Woman, in terms of how and why she came in existence, her manners and morals, and political reform and only mention a summarization of her dress. ${ }^{12}$ Kenneth A. Yellis went further and provided more substance and information with the flapper's dress. ${ }^{13}$ Yellis not only considered about how the flapper's behaviour and dress were both modern, but also described the dress in detail by noting style, shape, colours and fabrication along with accessories, cosmetics, and shoes worn with the outfit. Furthermore, he pinpointed specific culture factors for women during the 1920s that aided in the popularity of the dress, such as the independence of the working woman and her imprint on the economic structure of purchasing fashionable clothes. Although Yellis's article was informative, it was a lone voice in the literature and there is still much to be analysed and studied in terms of the shift dress. By 2015 the American historian, Einav Rabinovitch-Fox, noted the continual absence of scholarship dedicated to the New Woman and her appearance. ${ }^{14}$

\footnotetext{
${ }^{11}$ Makela, Maria, 'The Rise and Fall of the Flapper Dress: Nationalism and Anti-Semitism in EarlyTwentieth-Century Discourses on German Fashion', Journal of Popular Culture, 34.3 (2000), 183-208 <http://vortex3.uco.edu/login?url=https://www-proquest-com.vortex3.uco.edu/scholarly-journals/risefall-flapper-dress-nationalism-anti-semitism/docview/195363481/se-2?accountid=14516 $>$ [accessed 9 February 2021]. Many articles note a figurehead who wore the shift dress or characteristics of a flapper, however, most scholarship does not place the flapper dress as the central theme.

${ }^{12}$ James R. McGovern, 'The American Woman’s Pre-World War I Freedom in Manners and Morals', The Journal of American History, 55.2 (1968), 315-333 (p. 317) <. https://doiorg.vortex3.uco.edu/10.2307/1899561>.; Frederick Lewis Allen, Only Yesterday: An Informal History of the Nineteen-Twenties (New York: Harper and Brothers, Publishers, 1957), pp. 89-94.; Estelle B. Freedman, 'The New Woman: Changing Views of Women in the 1920s', The Journal of American History, 61.2 (1974), 372-393 <https://doi-org.vortex3.uco.edu/10.2307/1903954>.

${ }^{13}$ Kenneth A. Yellis, 'Prosperity’s Child: Some Thoughts on the Flapper', American Quarterly, 21.1 (1969), 44-64 < https://doi-org. vortex3.uco.edu/10.2307/2710772>.

${ }^{14}$ Einav Rabinovitch-Fox, '[Re]Fashioning the New Woman', Journal of Women's History, 27.2 (2015), 14-36, 194 (p. 15) <http://vortex3.uco.edu/login?url=https://www-proquestcom.vortex3.uco.edu/scholarly-journals/re-fashioning-new-woman-womens-dressoriental/docview/1689848825/se-2?accountid=14516>. [accessed 20 January 2021]. See also, Anne Marie Strassel, 'Designing Women: Feminists Methodologies in American Fashion', Women's Studies Quarterly, 41.1 \& 2 (2013), 35-39 (p.37) <http://doi.org/10.1353/wsq.2013.0043>. (Strassel claims the study of women's fashions have failed to understand the lasting impact in dress by women in the suffrage movement, artistic avant-garde and the health reform movements.)
} 
Another area where the shift dress has sometimes been discussed is in relation to its role as liberating women from the corset and giving them freedom of movement. ${ }^{15}$ This has formed part of a debate concerning whether the shift dress had a lasting effect on women's advancement in society. Carl Degler noted, although the dress allowed physical freedom it was other factors that brought a new equality for women, such as education, impact of war, and the arduous campaigning of women's suffrage. ${ }^{16}$ Yellis claimed that clothing, specifically the flapper dress, communicated to society women's needs about what they wanted and how they wanted to be perceived. He also claimed it was not only dress that emancipated women but also major economic, social and technological trends. Yellis concluded that although the liberation of women may have recessed during times of crisis, such as the Great Depression, the New Woman would gain presence within society and exercise her liberties in the future. ${ }^{17}$ Thus, noting that women of the 1920s had advanced in society and will come again in the future. However, Anne Hollander, fashion and art historian, declared 'women's clothes of 1920's and 1930's achieved the modern ideal; but they kept to the distinctively feminine scheme, and the sexes kept their traditional separation'. ${ }^{18}$ Hollander noted that although the shift dress was modern, society continued to practice gender disparities among women and thus no real advancement was made for women in the public sphere. Anne Marie Strassel observed scholars were hesitant of the flapper fashions as a symbol of emancipation and a lasting social change. She cited several scholars who have claimed that the flapper fashion of the 1920s was a sign of modern womanhood, but also at the same time, masked gender inequalities. ${ }^{19}$ Therefore, these historians' findings suggest that analysing the shift dress through the flapper can be complex and the shift dress needs further examination beyond the 1920s and including women's social and cultural roles.

\footnotetext{
${ }^{15}$ Steele, The Corset, pp. 152-53.

${ }^{16}$ Carl N. Degler, 'Revolution Without Ideology: The Changing Place of Women in America', Daedalus, 93. 2 (1964), 653-670 (p. 657) http://vortex3.uco.edu:2050/login?url=https://www.jstor.org/stable/20026849 [accessed 19 January 2021]. ${ }^{17}$ Kenneth A. Yellis, 'Prosperity's Child: Some Thoughts on the Flapper', American Quarterly, 21.1 (1969), 44-64 (pp. 53-55, 64) < https://doi-org.vortex3.uco.edu/10.2307/2710772>.; see also, Elizabeth Sage, A Study of Costume: From the Days of the Egyptians to Modern Times (New York: Charles Scribner's Sons, 1926), p. 215.

${ }^{18}$ Anne Hollander, Sex \& Suits, p. 5.

${ }^{19}$ Anne Marie Strassel, 'Designing Women: Feminists Methodologies in American Fashion', Women’s Studies Quarterly, 41. 1 \& 2 (2013), 35-39 (p.37) <http://doi.org/10.1353/wsq.2013.0043>. Anne Marie Strassel makes this claim from Roberts (1994), Yellis (1969), Degler (1965), Steele (2001).
} 
The shift dress was a significant fashion change, and the concept of fashion change has been explored through frameworks of traditional and modern theories. It is worth considering how scholars have framed their questions, and the three significant ones they have tried to answer: what are the initial triggers or influences for an adoption of a new fashion, how do styles diffuse throughout society once adopted, and what meanings do dress communicate to society?

In 1899, one of the earliest theorists on fashion change was Thorstein Veblen. In his work he concluded fashion change occurs within the economic structure of conspicuous consumption among the leisure class. ${ }^{20}$ In 1904, Georg Simmel extended Veblen's theory where he believed that people adopt fashion for two opposing purposes; to be aligned within society's guidelines; such as the social construct with general imitation and those who wish to differentiate themselves from others. ${ }^{21}$ Both Veblen and Simmel believed fashion change was initiated by the upper class then diffused down to the lower classes. ${ }^{22}$ Later, in 1931, Edward Sapir agreed with Veblen's and Simmel's theory in noting the upper class' desire of differentiation from the lower class. However, Sapir noted the significance of the prevailing culture where society's social norms influenced fashion. Thus, as fashion is closely connected to the culture, fashion change occurs from the immediately preceding fashion, which society has prescribed. ${ }^{23}$

Georg Simmel inscribed, adopting fashion as directed by society gives a person a sense of belonging, however, fashion allows for 'change and contrast' for those who desire to set themselves apart from the group. ${ }^{24}$ This same thought is apparent in the foundation of youth-based and sub-culture driven fashion theories;

\footnotetext{
${ }^{20}$ Thorstein Veblen, The Theory of the Leisure Class (New Brunswick, N.J.: Transaction Publishers, 2000).

${ }^{21}$ Georg Simmel, 'Fashion', American Journal of Sociology, 62.6 (1957), 541-558 (pp. 541, 543) < http://vortex3.uco.edu:2050/login?url=https://www.jstor.org/stable/2773129> [accessed 30 January 2021]. Reprinted in Perspectives of Fashion, ed. by George B. Sproles (Minneapolis, MN: Burgess Publishing Company, 1981) pp. 5-16.

${ }^{22}$ Thorstein Veblen, The Theory of the Leisure Class (New Brunswick, N.J.: Transaction Publishers, 2000).; Georg Simmel, 'Fashion', American Journal of Sociology, 62.6 (1957), 541-558 (p.545) < http://vortex3.uco.edu:2050/login?url=https://www.jstor.org/stable/2773129> [accessed 30 January 2021]. Reprinted in Perspectives of Fashion, ed. by George B. Sproles (Minneapolis, MN: Burgess Publishing Company, 1981) pp. 5-16.

${ }^{23}$ Sapir, Edward, 'Fashion', in Perspectives of Fashion, ed. by George B. Sproles (Minneapolis, MN: Burgess Publishing Co., 1981; repr. New York: Macmillan Publishing Co. Inc., 1931) pp. 23-27 (p.24).

${ }^{24}$ Georg Simmel, 'Fashion', American Journal of Sociology, 62.6 (1957), 541-558 (p. 543) < http://vortex3.uco.edu:2050/login?url=https:/www.jstor.org/stable/2773129> [accessed 30 January 2021]. Reprinted from International Quarterly (1904), 130-155. Reprinted in Perspectives of Fashion, ed. by George B. Sproles (Minneapolis, MN: Burgess Publishing Company, 1981) pp. 5-16.
} 
subculture is defined by Merriam-Webster dictionary as an "ethnic, regional, economic, or social group exhibiting characteristic patterns of behaviour sufficient to distinguish it from others within an embracing culture or society.”25 Many scholars highlight youth subculture as a means of fashion change, such as, Paul H. Nystrom, Dick Hebdige, Tony Bennett, Michael Brake, and David Fowler. ${ }^{26}$ Subcultures give a specific distinction within the group, as fashion is based on the adoption by a social set and a mutually understanding within the group. Fashion change may be evoked by identity of self, identity to others, or identity for or against a belief.

Nystrom claimed one of the most significant factors which encouraged fashion change is the revolt against 'too much convention and too much system'. He noted, characteristics of the youth find it difficult to fit into the current social system of customary practices. He claimed new fashion from the youth is promoted by appeals of freedom. ${ }^{27}$ Several scholars noted the result of youth's division or separation from adults. David Fowler highlighted Rolf Gardiner's theory of youth culture. Gardiner believed the youth culture would flourish only in youth-driven communities; separate and independent from their parents. ${ }^{28}$ Gardiner further noted the impact of the college setting as it created separate and distinct living quarters and freedom from adults. ${ }^{29}$ Gardiner claimed the initial trigger of the flapper culture in America attributed to movies and jazz music as college students attended movies often and jazz bands played at American universities. ${ }^{30}$ Clarke observed that subcultures are widely identified by their dress, such as 'the boot-laced tie and velvet-collared drape jacket of the Ted's or 'the close crop, parka coats and scooters of the Mods' ${ }^{31}$

\footnotetext{
25 'Subculture', in Merriam-Webster Dictionary [online], https://www.merriamwebster.com/dictionary/subculture [accessed 7 November 2020].

${ }^{26}$ Paul H. Nystrom, Economics of Fashion (New York: The Ronald Press Company, 1928); Hebdige, Dick. Subculture: The Meaning of Style (London: Routledge, 2003).; Culture, Ideology, and Social Process: A Reader, ed. by Tony Bennett and others (London: The Open University Press, 1981). (The book edited by Tony Bennett is structured based on subculture theories from a variety of scholars); Michael Brake, Comparative youth Culture: The Sociology of Youth Cultures and Youth Subcultures in America, Britain and Canada, (London: Routledge \& Kegan Paul, 1985).; David Fowler, Youth Culture in Modern Britain c, 1920-1970: From Ivory Tower to Global Movement (New York: Palgrave, 2008).; see also, Joanne Entwistle, The Fashioned Body: Fashion, Dress and Modern Social Theory (Cambridge, UK: Polity Press; Oxford: Blackwell Publishing Ltd, 2000), pp. 40-77.

${ }^{27}$ Nystrom, pp. 72-73.

${ }^{28}$ Fowler, p. 38-39. Fowler directed to see also, Rolf Gardiner Diary, Vol. 7, pt. 10, August-September 1923, CUL.

${ }^{29}$ Fowler, p. 38-39.

${ }^{30}$ Fowler, p. 38-39.

${ }^{31}$ John Clarke and others, 'Sub Cultures, Cultures and Class', in Culture, Ideology and Social Process: A Reader, ed. by Tony Bennett and others, (London: The Open University Press, 1985) pp. 53-79 (p. $69)$.
} 
However, they did not discuss the flapper in this article, only male oriented subgroups. Hebdige also focused primarily on the male youth subculture with examples of the hipsters, beats, teddy boys, mods, and punks. As music is a quintessential part of many subcultures, Hebdige wrote about the influences of jazz with the hipsters and the beats, however, he did not discuss the association of jazz music with the subculture of the flapper. ${ }^{32}$

This focus on male sub-cultures began to receive criticism in the 1980s. Angela McRobbie criticized Hebdige on his dismiss of analysing women's subcultures. McRobbie suggested the perspective of girl's culture needed to be further analysed to understand and answer questions about their political and social paths within society. ${ }^{33}$ Sociologist, Michael Brake, echoes McRobbie as he stated the studies of subculture are masculinized and overlooked from a feminine viewpoint. ${ }^{34}$ This study aims to understand a girl's culture interpretation through clothing and her political and social journey.

Many economic and social theories try to answer how fashion spreads throughout society. The theories of Veblen and Simmel laid a foundation of fashion change within a class structure society of the ‘trickle-down’ theory. However, scholars such as, Charles W. King, Herbert Blumer and George A. Fields have disputed the trickle-down theory, particularly because it was based on a class society. ${ }^{35}$ King debated the validity of the theory. He suggested the trickle-down theory is outdated as it does not account for modern living. He concluded the change in social environment, mass communications, and the fashion industry’s manufacturing and merchandising strategies have drastically changed in our society to which these factors effect fashion change from a 'trickle-across' or 'mass-market' process. ${ }^{36}$ Blumer disputed the trickle-down theory as it did not take into consideration the character of fashion as a social element in society. He believed that

\footnotetext{
${ }^{32}$ Hebdige, pp. 46-54.

${ }^{33}$ Angela McRobbie, 'Settling Accounts with Subcultures: A Feminist Critique', in Culture, Ideology, and Social Process: A Reader, edited by Tony Bennett and others (London: The Open University Press, 1981), pp. 111-123.

${ }^{34}$ Brake, p. 167-170.

35 See also, Andrew B. Trigg, 'Veblen, Bourdieu, and Conspicuous Consumption', Journal of Economic Issues, 35.1 (2001), 99-115 (p. 99)

$<$ http://vortex3.uco.edu:2050/login?url=https://www.jstor.org/stable/4227638> [accessed 10 February 2021].

${ }^{36}$ Charles W. King, 'Fashion Adoption: A Rebuttal to the “Trickle Down” Theory', in Perspectives of Fashion, ed. by George B. Sproles (Minneapolis, MN: Burgess Publishing Co., 1981), pp. 31-39 (pp. 32, 39). Reprinted from Toward Scientific Marketing, (1963), pp. 108-125.
} 
fashion was influenced by the applied arts, medicine, business management, history of modern philosophy, and political doctrine. Blumer stated that collective selection process is a large portion of adaptable fashion as he looked to the merchandising, manufacturing and process of the fashion industry. As designers are apt to design what buyers would like to purchase, this influences the business model of fashion and the availability to the public. Buyers read the same trade journals, look to other retailers, and use historical data to make their selections. In addition to buyers, the public becomes familiar with specific types of art, literature, and policies that are in the current culture. ${ }^{37}$ George A. Fields created the phrase, 'The Status Float Phenomenon', which described the movement upward from lower-class society to upper-class society. This has been seen as not only applicable to fashion, but other lifestyles and activities in our society. Such examples are jazz music from the African American culture and youthful fashions that were pioneered by the teenager and 'floated' up to the middle-aged consumer. This process of vertical movement from the lower to the upper class has also been named the 'trickle-up' theory. Through mass manufacturing processes, democratized fashion has evolved, and as Breward has observed, this democratized process ‘speeded up’ twentieth-century fashion, and as a direct consequence it created a change of consumption cycle and marketing patterns, one he claims as a central and defining feature of the time. ${ }^{38}$ Democratizing fashion can be clearly seen in the twenty-first century, with theories still applicable today, including all three types of movement and adaptation in fashion, the trickle-down, trickle-up and trickle-across, as well as other elements that are significantly important and have dramatically changed the fashion industry, such as the economic and production cycles of fast fashion. Simona Sergre Reinach observed fast fashion as 'a generic term that covers various types of products and brands: from simple, cheap items of clothing sold on street market-stalls, to proper brands', such as Zara, Mango and H\&M. Fast fashion is the result of speed, copying

\footnotetext{
${ }^{37}$ Herbert Blumer, 'Fashion: From Class Differentiation to Collective Selection', Sociological Quarterly, 10.3 (1969), 275-291

$<$ http://vortex3.uco.edu:2050/login?url=https:/www.jstor.org/stable/4104916> [accessed 30 January 2021]. Reprinted in The Perspectives of Fashion, ed. by George B. Sproles, (Minneapolis, MN: Burgess Publishing, 1981), pp. 49-57.; see also, Fred Davis, 'Herbert Blumer and the Study of Fashion: A Reminiscence and A Critique’, Symbolic Interaction, 14.1 (1991), 1-21 (pp. 5-12) < https://doiorg.vortex3.uco.edu/10.1525/si.1991.14.1.1>.

${ }^{38}$ Breward, The Culture of Fashion, p. 185.
} 
and trends. ${ }^{39}$ Gerard P. Cachon and Robert Swinney define the fast fashion system by two components: short production and distribution lead times and highly fashionable (trendy) product design. Cachon and Swinny claimed localized production, sophisticated information systems and expedited distribution methods allow companies to successfully and quickly distribute product in a fast fashion manner. They further noted fashionable and trendy product design is obtained by companies employing 'trend spotters' to identify products and rely on designer fashion shows, which they immediately copy and produce the garment. ${ }^{40}$ As information travels quickly along with increasingly advanced technology, this allows a shorter process from the development of new fashions to in-the-hands of the consumers. Therefore, the mass production schedule is a much shorter time frame than ever before. Stores, such as Zara and H\&M, directly copy designer’s garments with a quick turn-around time offering similar styles and designs at a significantly lower price. ${ }^{41}$

\section{Lifestyle: A Concept for Fashion Change}

Understanding and analysing fashion theories are important to decipher how a fashion begins and how it diffuses throughout society, but it is also important to evaluate women's daily life as a component of fashion change. Similar to McRobbie's theory, questions may be answered differently from a gendered perspective rather than from a focus of generalized culture in which the theories have proclaimed. Several scholars have identified components of women's daily life as an important attribute to fashion change. For example, Veblen included women’s

\footnotetext{
${ }^{39}$ Simona Segre Reinach, 'China and Italy: Fast Fashion Versus Prêt à Porter: Towards a New Culture in Fashion', Fashion Theory, 9.1 (2005), 43-56 (p. 47-48) <https://web-b-ebscohostcom.vortex3.uco.edu>.

${ }^{40}$ Gerard P. Cachon and Robert Swinney, 'The Value of Fast Fashion: Quick Response, Enhanced Design, and Strategic Consumer Behavior;, Management Science, 57.4 (2011), 778-795 (p. 778) < http://vortex3.uco.edu:2050/login?url=https:/www.jstor.org/stable/25835736> [accessed 7 March 2021].

${ }^{41}$ Since fast fashion distributes goods quickly, recent scholarship has focused on the environmental impact that fast fashion has caused. Fast fashion promotes consumers to buy more garments for less, therefore, expanding one's wardrobe significantly and putting more goods into the retail system. See Luz Claudio, 'Waste Couture: Environmental Impact of the Clothing Industry', Environmental Health Perspectives, 115.9 (2007) A448-A454

$<$ http:/vortex3.uco.edu:2050/login?url=https:/www.jstor.org/stable/4626880> [accessed 06 March 2021].; Louise Crewe, 'Ugly Beautiful?: Counting the Cost of the Global Fashion Industry', Geography, 93.1 (2008) 25-33 <http://vortex3.uco.edu:2050/login?url=https:/www.jstor.org/stable/40574213> [accessed 06 March 2021].; Stephanie Assmann, 'Consumption of Fast Fashion in Japan: Local Brands and Global Environment', in Consuming Life in Post-Bubble Japan: A Transdisciplinary Perspective, ed. by Katarzyna J. Cwiertka and Ewa Machotka (Amsterdam: Amsterdam University Press, 2018), pp. 49-68. <https://oiorg.vortex3.uco.edu/10.2307/j.ctv56fgjm.7>.
} 
participation in the workforce in terms of how they dressed. ${ }^{42}$ Additionally, Ann Beth Presley summarized designer Paul Poiret's fashion perspective which he expressed the fashion change prior to World War I was the result of more women displaying an independent spirt and changes in attitude. Presley concludes the changes in women's roles were reflected in the fashions of the time. ${ }^{43}$ Therefore, it is important to analyse women's lifestyle in terms of fashion change.

As early as 1884, Engels examined women's pattern of lifestyle and role within society by examining domestic duties, landownership, and division of labour. ${ }^{44}$ By the 1950s cultural historians were also considering morals and manners, as can be seen in the work of James R. McGovern who analysed the perceived changes in women during the 1920s. McGovern highlighted in his article that many scholars, such as Henry F. May, Arthur Link, and J. Joseph Huthmacher justified the effects of social change during the 1920's as the result of events prior to World War I and thus not a result of the Armistice. ${ }^{45}$ McGovern extended this conclusion further by applying the same theory of social change and interpreted this relationship to American women. He questioned if women's morals and manners were a response from social change rather than the effects of the aftermath of the war. McGovern examined popular culture, such as social and scholarly literature, magazine articles, and song lyrics to supply evidence of a pattern in social change before World War I. In addition, he examined demographic factors, which affected women's lifestyle, for example the migration shift from small communities to large cities, increase in employment, and women spending more time outside the home. ${ }^{46}$ Later, Arthur

\footnotetext{
${ }^{42}$ Veblen, p. 120.

43 Ann Beth Presley, 'Fifty Years of Change: Societal Attitudes and Women's Fashions, 1900-1950', The Historian, 60.2 (1998), 307-324 (p. 311)

$<$ http:/vortex3.uco.edu:2050/login?url=https://www.jstor.org/stable/24451728 > [accessed 20 January 2021].

${ }^{44}$ Friedrich Engels, The Origin of the Family, Private Property and the State (New York: Penguin Classics, 2010).

45 James R. McGovern, 'The American Woman’s Pre-World War I Freedom in Manners and Morals', The Journal of American History, 55.2 (1968), 315-333 (p. 316) <. https://doi-

org.vortex3.uco.edu/10.2307/1899561>.; see also, Henry F. May, 'The Rebellion of the Intellectuals, 1912-1917', American Quarterly, 8.2, (1956), 114-126 (p. 115) < https://doiorg.vortex3.uco.edu/10.2307/2710160>. May claims Freudianism to expatriation was present before the war although on a smaller scale.

${ }^{46}$ James R. McGovern, 'The American Woman’s Pre-World War I Freedom in Manners and Morals', The Journal of American History, 55.2 (1968), 315-333 (pp. 316-320) <. https://doiorg.vortex3.uco.edu/10.2307/1899561>.; see also, Ole Reinsch, 'Flapper Girls-Feminism and Consumer Society in the 1920's', Gender Forum: An Internet Journal for Gender Studies, iss. 40 (2013), 31-40 <http://genderforum.org/wp-content/uploads/2017/01/2013-40-ConsumerismComplete.pdf $>$ [accessed 20 January 2021].
} 
Marwick noted historians have studied the 1960s primarily analysing pop culture; such as, rock songs, poetry readings, experimental theatre, and teach-ins but many have underutilized the written text from the people who lived in the generation. Marwick believed the written text from newspapers, interviews, and opinion polls are invaluable types of sources and should not be ignored. ${ }^{47}$ Therefore, magazines and newspapers provide a well-rounded study as it takes into consideration the viewpoint and lifestyle of that generation.

The third factor which influences fashion styles and change is the meaning of dress that is communicated to society and thus reflects a certain perception of that culture. In 1976 Quentin Bell proclaimed that 'No one creates a fashion, for we are born into a society in which fashion already exists... ${ }^{48}$ As a result, Bell suggests our culture widely determines our fashion. Terence S. Turner notes the meaning of dress communicates social statues, attitudes, desires, beliefs and ideals to others and, because of this, it largely shapes individuals' personal and social identity. ${ }^{49}$ Therefore, dress expresses a particular meaning to society and communicates a particular personality attached to that dress. Early scholars who applied symbolic relationships to fashion were Edward Sapir and George Herbert Mead. Symbolic Interactionism, originated by George Herbert Mead, is a theory that proposes human interaction and communication are facilitated by words, gestures, or other symbols that have acquired conventionalized meaning. ${ }^{50}$ Linguist, Edward Sapir, acknowledged that meanings are not easily understandable and the unconsciousness and meanings may vary from one culture to another. Sapir expressed,

The chief difficulty in understanding fashion in its apparent vagaries is the lack of exact knowledge of the unconscious symbolisms attaching to forms, colors, textures, postures, and other expressive elements in a given culture. The difficulty is appreciably increased by the fact that the same expressive elements tend to have quite different symbolic references in different areas. ${ }^{51}$

\footnotetext{
${ }^{47}$ Arthur Marwick, 'The Cultural Revolution of the Long Sixties: Voices of Reaction, Protest, and Permeation', The International History Review, 27.4 (2005), 780-806 (p. 780) < http://vortex3.uco.edu:2050/login?url=https://www.jstor.org/stable/40109676 > [ accessed 19 January 2021].

${ }^{48}$ Quentin Bell, On Human Finery, $2^{\text {nd }}$ edn (New York: Schocken Books, 1976), p. 90.

${ }^{49}$ Terence S. Turner, 'The Social Skin', HAU: Journal of Ethnographic Theory, 2.2 (2012), 486-504 (n.p.) < http://vortex3.uco.edu/login?url=https://www-proquest-com.vortex3.uco.edu/scholarlyjournals/social-skin/docview/1850088748/se-2?accountid=14516 $>$ [accessed 16 December 2020].

${ }^{50}$ George Herbert Mead, Mind, Self and Society: From the Standpoint of a Social Behaviorist (Chicago: University of Chicago Press, 1934).

${ }^{51}$ Sapir, Edward, 'Fashion', in Perspectives of Fashion, ed. by George B. Sproles (Minneapolis, MN: Burgess Publishing Co., 1981; repr. New York: Macmillan Publishing Co., Inc., 1931) pp. 23-27
} 
Later scholars, such as Roland Barthes and Fred Davis, further studied the connected dialog and meaning of fashion to perceived thoughts and symbols within our society. Roland Barthes dissected symbols in accordance to fashion in terms of the signified and signifier, and as a result, clothing may be functional but it also has an identifier attached to it and as a society we breakdown these identifiers. Therefore, he claims that because an identity is attached to clothing 'by transforming our clothes, we transform ourselves'. ${ }^{52}$ Davis also noted how dress is linked to associations as he called it Collective Identity. Collective Identity is the code of dress which is prescribed by society; for example, angularity is associated as masculine while curvilinear forms are connected to feminine dress. ${ }^{53}$ According to Davis, symbolic interaction and significance of communication through what dress means or implies may alter the acceptance or rejection of a fashion. Davis believed change can occur through boredom and profit-conspiracy but he also looked at social identity through the communication with others. ${ }^{54}$ He claimed that it is important to understand how symbols function, especially from specific decades with heighted diversity of what some view as ominously and others as optimistically. ${ }^{55}$ Susan B. Kaiser, Richard H. Nagassawa and Sandra S. Hutton noted Davis's influence of semiotics and symbolic interaction. Davis believed the customs of each culture are deeply rooted into the identity men and women attach to themselves, therefore, fashion designers may use this information to display specific meanings. Furthermore, Kaiser, Nagassaw and Hutton believed the symbolic interactionist perspective is a significant factor in dress as it explains not only how and why styles of appearances change over time, but also how and why individuals negotiate visual and verbal understandings of styles. ${ }^{56}$

While scholars have discussed individual and segmented examples of how meanings change over time, they have not traced this theory on one garment

(p.24); Fred Davis, Fashion, Culture, and Identity (Chicago \& London: The University of Chicago Press, 1992), p. 25. Fred Davis also reached a similar conclusion that it is unknown as to how language in the form of text or unambiguous signs are derived.

52 Roland Barthes, The Fashion System, (London: University of California Press, 1983) p. 220, originally published 1967.

${ }^{53}$ Davis, Fashion, pp. 5-6.

${ }^{54}$ Davis, Fashion, p.16.

${ }^{55}$ Fred Davis, “On the 'Symbolic' in Symbolic Interaction”, Symbolic Interaction, 5. 1 (1982), 111-126 (p. 123) $<$ https://doi-org.vortex3.uco.edu/10.1525/si.1982.5.1.111>. Symbolic interaction is the collective meaning of symbols which are attached within a prescribed group of society.

${ }^{56}$ Susan B. Kaiser, Richard H. Nagassawa and Sandra S. Hutton. 'Construction of an SI Theory of Fashion: Part I Ambivalence and Change’, Clothing and Textiles Research Journal, 13.3 (1995), 172183 (pp. 173-174) < https://doi: 10.1177/0887302x9501300304>.; See also, Breward, 'Cultural', p. 306. 
throughout time. ${ }^{57}$ One of the earliest examples in U.S. history that could be used is the bloomer costume, which was distinctively representative of symbolic interactionism, collective identity and gender identity. ${ }^{58}$ The bloomer costume symbolized women's equality, freedom and movement as it was a shorter dress with pantaloons worn underneath. The bloomer outfit was worn by groups of women; such as Elizabeth Cady Stanton, Susan B. Anthony, and Amelia Bloomer, who all participated in the suffrage movement. ${ }^{59}$ Shortly thereafter, the bloomer costume was worn by a variety of women such as women in Seneca Falls to factory girls in Lowell, MA. ${ }^{60}$ Anne Marie Strassel noted the women in the early suffrage movement believed traditional dress was attached to 'domesticated confinement', 'economic dependence', and 'intellectual decay'. ${ }^{61}$ The traditional dress symbolized the domestic sphere restricting forward mobility, while the bloomer costume symbolized freedom of movement. Elizabeth Reitz Mullenix highlights a common theme that was discussed in progressive publications, such as The Lily and The Sibyl, that 'costumes, like actions, identify character.' As described from the publications, largely, the perception from society was that women would not stay within their domestic sphere

\footnotetext{
${ }^{57}$ Kingsley Widmer, 'The Rebellious Culture: Reflections on its Functions in American Society', The Centennial Review, 17. 4 (1973), 338-356 (p. 344) < http://vortex3.uco.edu:2050/login?url=https://www.jstor.org/stable/23738089> [accessed 20 January 2021]. Valerie Steele, 'Appearance and Identity', in Men and Women: Dressing the Part, ed. by C. G. Kidwell, (Washington DC: Smithsonian Institution Press, 1989), pp. 6-21.; Susan B. Kaiser, Richard H. Nagassawa and Sandra S. Hutton. 'Construction of an SI Theory of Fashion: Part I Ambivalence and Change’, Clothing and Textiles Research Journal, 13.3 (1995), 172-183 (pp. 173-174) <https://doi: 10.1177/0887302x9501300304>.; Phillip Vanni, 'Extending and Broadening Blumer's Conceptualization of Fashion: Adding Notions of Generic Social Process and Semiotic Transformation', Sociological Focus, 40.3 (2007), 306-319 (pp. 309-310) < http://vortex3.uco.edu:2050/login?url=https://www.jstor.org/stable/20832337> [accessed 20 January 2021].; Breward, 'Cultural', p. 306.

${ }^{58}$ Historians claim the bloomer costume as one of the first dress reform: Robert E. Riegel, 'Women's Clothing and Women’s Rights', American Quarterly, 15.3 (1963), 390-401 (p. 391) <https:/doiorg.vortex3.uco.edu/10.2307/2711370>.; Anne Marie Strassel, 'Designing Women: Feminists Methodologies in American Fashion', Women’s Studies Quarterly, 41. 1 \& 2 (2013), 35-39 (p.37) <http://doi.org/10.1353/wsq.2013.0043>.; Einav Rabinovitch-Fox, '[Re]Fashioning the New Woman', Journal of Women's History, 27.2 (2015), 14-36, 194 (p. 17) $<$ http://vortex3.uco.edu/login?url=https://www-proquest-com.vortex3.uco.edu/scholarly-journals/refashioning-new-woman-womens-dress-oriental/docview/1689848825/se-2 ?accountid=14516>. [accessed 20 January 2021].

${ }^{59}$ Bloomer, Amelia, “"The Bloomer Costume": A Letter From Amelia Bloomer’, Ladies' Home Journal, January 1890. ProQuest <https://www-proquest-com.vortex3.uco.edu> (p. 8).

${ }^{60}$ Hear Me Patiently: The Reform Speeches of Amelia Jenks Bloomer, ed. by Anne C. Coon (London: Greenwood Press, 1994), pp. 1-36, (pp. 10, 12).

${ }^{61}$ Anne Marie Strassel, 'Designing Women: Feminists Methodologies in American Fashion', Women's Studies Quarterly, 41. 1 \& 2 (2013), 35-39 (p.38) <http://doi.org/10.1353/wsq.2013.0043>.
} 
if dressed in non-traditional clothing. ${ }^{62}$ Hollander observed that during this time, dress easily defined specific gender identity. ${ }^{63}$

Although the bloomer costume gained some acceptance among women, the costume was short lived and never reached mainstream popularity within society. ${ }^{64}$ The unpopularity of the bloomer costume can be traced to several factors. First, as indicated above, the bloomer costume did not follow the current fashion mode or the 'collective' thought among society. The bloomer costume strayed too far from the prescribed fashion of the current culture. The bloomer costume's length was not only much shorter than the current styles, reaching up past the ankles, but also the dress was worn over a pant structure. ${ }^{65}$ After the French Revolution pants in the western worlds were identified with the male gender, therefore, the Turkish trousers worn underneath the dress associated these women as dressing like men, thus, a large departure from the current feminine dress of the time. ${ }^{66}$ Second, the bloomer costume was attached to a specific self-identity of women wanting more freedom similar to a man's lifestyle as they overstepped the boundaries of wearing men's dress. ${ }^{67}$ Third,

\footnotetext{
${ }^{62}$ Elizabeth Reitz Mullenix, 'Private Women/Public Acts: Petticoat Government and the Performance of Resistance’. TDR, 46.1 (2002), 104-117 (p.

109) <http//vortex3.uco.edu:2050/login?url=https:/www.jstor.org/stable/1146948>

[accessed 16 January 2021]. The term 'costume' used by Mullinex references the bloomer costume but also used interchangeably as everyday clothing. The Lily was a bi-weekly newspaper publication established by Amelia Bloomer in 1849 which focused on the subject of women suffrage. The Sibyl was founded by Dr. Lydia Sayer in 1856 and this was also a bi-weekly women reform newspaper publication.

${ }^{63}$ Anne Hollander, Seeing Through Clothes (Berkeley, Los Angeles and London: University of California Press, 1993), p. 346.

${ }^{64}$ Robert E. Riegel, 'Women’s Clothes and Women’s Rights', American Quarterly, 15.3 (1963), 390401 (p. 394) <https://doi-org.vortex3.uco.edu/10.2307/2711370>.

${ }^{65}$ Bloomer, Amelia, “"The Bloomer Costume": A Letter from Amelia Bloomer’, Ladies' Home Journal, January 1890. ProQuest $<$ https://www-proquest-com.vortex3.uco.edu $>$ (p. 8).; See also Ford, Tanisha, C., 'SNCC Women, Denim, and the Politics of Dress', The Journal of Southern History, 79.3 (2013) 625-658 (p. 651) < http://vortex3.uco.edu:2050/login?url=https:/www.jstor.org/stable/23795090> [accessed 10 February 2021]. The article, 'SNCC', displays the use of denim in a form of a skirt as women displayed a masculine fabric with a feminine structure.

${ }^{66}$ Phyllis G. Tortora and Sara B. Marcketti, Survey of Historic Costume, $6^{\text {th }}$ edn. (New York: Bloomsbury Publishing, Incorporated, 2015), p. 303. Tortora and Marcketti stated that men and women's clothing were equally grand, however, after the French Revolution, this had changed when men's clothing became simpler and more functional. Furthermore, a clear division between the genders in clothing became apparent as men's clothing was more functional, the tailor and fit of the garment became important, and ornamentation in women's clothing continued to be significant. See also, Kimberly Wilmot Voss, 'Who's Wearing the Pants? How The New York Times Reported the Changing Dress of Women', Media Report to Women, 39.2 (2011), 12-17,22-23 (p. 13)< http://vortex3.uco.edu/login?url=https://www-proquest-com.vortex3.uco.edu/trade-journals/whoswearing-pants-how-new-york-times-reported/docview/868310740/se-2?accountid=14516 >.; Lois W. Banner, American Beauty (New York: Alfred A. Knopf, 1983), p. 32.; Ida M. Tarbell, The Business of Being a Woman (New York: The Macmillan Company, 1919), pp.133-134.

${ }^{67}$ When Actress Fanny Kemble wore the bloomer costume she was accused of dressing beyond her sphere. Elizabeth Reitz Mullenix, 'Private Women/Public Acts: Petticoat Government and the Performance
} 
the women wearing the bloomer costume were radical, activist women who were thought to disturb the status quo standards in society, rather than the style worn by fashion influencers or released from the Parisian design houses. ${ }^{68}$

The bloomer costume evoked strong feelings of maliciousness toward women, who were pelted with mud and stones. ${ }^{69}$ Rabinovitch-Fox, noted the women's rights advocates hoped that the bloomer costume would be accepted and viewed as feminine since the pantaloons were borrowed from the Orient and symbolized female sensuality and sexuality. ${ }^{70}$ Thus, further concluding that the interpretation and communication of particular meanings in fashion are not as universal as one may think, since western society did not attach femininity to the bloomer costume. As previously stated, fashion is communicative, therefore, when the identity and meaning of dress matches society's principles, then the fashion will have a higher acceptance rate, but, when the identity or meaning of dress differs from those principles, then the fashion may be rejected.

\section{Methodology}

As exemplified in my literature review, fashion has been the subject of a substantial range of scholarship and from a number of disciplinary perspectives. Fashion has become increasingly an integral aspect of everyday life as what we wear is influenced by many elements within our society. Consequently, I have drawn on the analytical tools of a wide range of disciplines and the research is grounded in popular culture, fashion history, and the evolving place of women in the twentieth century. From a historical perspective, I have explored the shift dress in the contexts of American cultural history, women's history, and European history. I have analysed the shift dress using political, anthropological, sociological, and psychological approaches. In addition, I have placed the shift dress in a consumer context of economics, manufacturing, marketing and finance. I have also explored the cultural

of Resistance'. TDR, 46.1 (2002), 104-117 (p.

110) <http://vortex3.uco.edu:2050/login?url=https:/www.jstor.org/stable/1146948>

[accessed 16 January 2021].

${ }^{68}$ Banner, p. 94.

${ }^{69}$ Coon, p. 12.; see also Banner, p. 87.

${ }^{70}$ Einav Rabinovitch-Fox, '[Re]Fashioning the New Woman', Journal of Women's History, 27. 2

(2015), 14-36, 194 (p. 17) <http://vortex3.uco.edu/login?url=https://www-proquest-

com.vortex3.uco.edu/scholarly-journals/re-fashioning-new-woman-womens-dress-

oriental/docview/1689848825/se-2 ?accountid=14516>. [accessed 20 January 2021]. 
context of the shift dress and the implications of art, design, music, travel and textiles upon the form.

As befitting a study of this kind, it is based on a broad range of sources. Of particular importance has been the mainstream fashion media, notable newspapers and magazines, such as Vogue. Other print materials include government documents, novels and other popular literature during the first half of the twentieth century. Given its growing importance during this period, film and television feature prominently as important visual evidence of the dress used in different contexts. Finally, the dress as a material object has been examined through visits to the fashion collection at The University of North Texas and through attendance at major exhibitions such as the Christian Dior exhibit, 'Dior: From Paris to the World' (Dallas, Texas), which provided valuable information. All of these sources and how they have been analysed will be discussed further.

Not only is this study rooted in numerous disciplines, but significantly, it covers the dramatic and ever-changing time period from 1900 to 1970 . This study is broadly divided into two sections examining the birth and rebirth of the shift dress. The first section covers the Progressive Era and the 1920s while the second encompasses the 1950s and the 1960s. Although divided into two segments, the presence of the shift dress during the 1930s and 1940s is discussed in the beginning of chapter 4 , providing a continuous time line. This chronological order neatly tracks the presence of the shift dress in an evolution process while furnishing a clear understanding of women's place in society and fashion change. This chronological framework provides reference points from past styles and analyses the next subsequent style for each time period. Many of the same sources were used in all chapters in order to maintain continuity throughout the study, however, when new periodicals were published or new technology was introduced, the type of sources shifted accordingly; examples include the addition of Seventeen magazine and the invention of television.

Scholars have utilized experiences or events in order to define a decade, instead of using numerical delineators. For example, Marwick has defined the sixties decade as the 'long sixties' beginning from 1958 and marking the end point to $1974 .{ }^{71}$

\footnotetext{
${ }^{71}$ Arthur Marwick, The Sixties: Cultural Revolution in Britain, France, Italy, and the U.S., c 19581974, (Oxford: Oxford University Press, 1998), p. 5.; see also, Marwick, Arthur. 'The Cultural Revolution of the Long Sixties: Voices of Reaction, Protest, and Permeation', The International
} 
Marwick modelled his 'long sixties’ theory from Eric Hobsbawm who defined historical time periods within the construct of events rather than time. ${ }^{72}$ Using Marwick’s theory, the four timeframes studied are defined by experiences or events; not necessarily by the neat timeline that numerically represents a decade. Scholars continue to use this process, however the parameters of the starting and ending points of the decade are determined by each scholar's own particular lens. ${ }^{73}$ For each chapter, I determine starting and ending dates for each decade as I consider experiences or events from a political, cultural, women's or fashion perspective.

Within each time-frame, I quantify the visibility of the shift dress by using an innovative page-by-page tracking method with Vogue and Seventeen magazines. Vogue magazine was chosen for several reasons. First, it is it is viewed as the premier fashion publication as it is renowned for the latest fashion news and coverage in the world of fashion. Second, Vogue has actively published magazines from 1892 to today which covers extensive fashion news of the couture designers and fashion trends. Third, because of its longevity in the fashion industry, Vogue's consistency and quality furnishes a reliable periodical to utilize over this time period. Fourth, Vogue promotes a large amount of advertising and important social events around the world that are valuable to this study as it provides information of not only of the designers and companies producing the latest fashion, but also who is wearing these fashions and to what particular events. The second source used, Seventeen magazine, was first published during the 1940s as the teen market began to emerge. This makes it a valuable resource for the later period as this magazine was the premier choice for teenagers. Similar to Vogue, Seventeen has been known for its consistent leadership

\footnotetext{
History Review, 27.4 (2005), 780-806 (pp. 780-781) < http://vortex3.uco.edu:2050/login?url=https://www.jstor.org/stable/40109676> [ accessed 19 January 2021].

${ }^{72}$ Eric Hobsbawm characterized the twentieth century as The Short Twentieth Century, Marwick indicated using similar methodology from Hobsbawm in relation to time in his book The Sixties, p. 5.

${ }^{73}$ Mark Lytle, 'Making Sense of the Sixties', Irish Journal of American Studies, 10 (2001), 1-17 (p.12) $<$ http://vortex3.uco.edu:2050/login?url=https://www.jstor.org/stable/30002230> [accessed 19 January 2021].; Jonathon Green, “All Dressed Up: The Sixties 'Youth Revolution' in Retrospect”, Twentieth Century Architecture, no. 6 (2002), 10-16 (p. 12)

<http://vortex3.uco.edu:2050/login?url=https://www.jstor.org/stable/41859186> [accessed 7 January 2021].; Bloom, Alexander, Long Time Gone: Sixties America Then and Now, (Oxford: Oxford University Press, 2001), p. 4.; ${ }^{73}$ Wini Breines, Young, White and Miserable: Growing up Female in the Fifties, (Boston, MA: Beacon Press Books, 1992), p. xiii. Jonathon Green in 'All Dressed Up' notes the variance of scholars starting and ending points for the 1960s. He mentions some use popular literature, others use substantial events such as Kennedy Assassination, the first counter sit-in at Woolworth's in Greensboro, North Carolina, Beatlemania, the oil embargo, or economic decline.
} 
in the publishing world indicating fashion trends and popular culture but within the teen market.

The tracking method is a hybrid approach utilizing a similar method of Kroeber's statistical study of evening gowns and the product life cycle. Kroeber utilized fashion plates from several magazines, including Petit Courrier des Dames, Harper's Bazar, and Vogue and measured eight different dimensions of women's evening dresses. His sample set consisted of measuring 10 fashion plates for every year from 1844 to $1919 .{ }^{74}$ My tracking method is similar to Kroeber's as I utilized fashion magazines in chronological order to analyse fashion garments within a specific time frame. However, my analysis differs as I did not limit the number of fashion plates examined per year nor performed exact measurements, rather I employed a visual context of counting and analysing shift dresses that were present by examining every page of Vogue and Seventeen magazine for specific issues. Additionally, the time frames and garments differed as they were adjusted to meet the needs of this study. My tracking method also incorporates similar methods of the product life cycle model. The product life cycle model is used to show the life of a product from its inception to its obsolete stage. According to economist, George Sproles, the product life cycle is a graph that displays the number of consumers who adopt the style at each point in time. ${ }^{75}$ This indicates a style's initial adoption, rise of acceptance, and decline depending on consumers buying behaviour. The tracking method model is based on the frequency of the shift dress in Vogue and Seventeen magazine. In tracing the frequency of the shift dress, I examine this information to determine the introduction, rise, culmination, and decline phases of the shift dress. Although the frequency shown in Vogue magazine is not actual consumer sales, it is the best information I can retrieve based on consumer desires. It would be difficult to

\footnotetext{
${ }^{74}$ A.L. Kroeber, 'On the Principle of Order in Civilization as Exemplified by Changes of Fashion', American Anthropologist, New Series, 21.3 (1919), 235-263 (pp. 239-263) http://www.jstor.org/stable/660477 [accessed 4 June 2018]. Other scholars have extended Kroeber's study or performed a similar study tracking fashion change; see also Agnes Brooks Young, Recurring Cycles of Fashion 1760 - 1937, Harper \& Brothers Publisher, 1937.; John W. G. Lowe and Elizabeth D. Lowe, 'Cultural Pattern and Process: A Study of Stylistic Change in Women's Dress', American Anthropologist, New Series, 84.3 (1982), 521-544 $<$ http://vortex3.uco.edu:2050/login?url=https://www.jstor.org/stable/677331> [accessed 20 January 2021]. (Richardson \& Kroeber); Dorothy U. Behling and Lois E. Dickey, 'Haute Couture: A 25-Year Perspective of Fashion Influences, 1900 to 1925’, Home Economics Research Journal, 8.6 (1980), 428-436.

${ }^{75}$ George Sproles and Leslie Davis Burns, Changing Appearances: Understanding Dress in Contemporary Society (New York: Fairchild Publications, 1994), p. 95.
} 
account for how many consumers purchased or wore the shift dress from the 1920s through the 1970s. However, utilizing the appearance method I can assimilate consumers' wants and desires based on how frequent the style was shown in magazines on the assumption that the more frequent the shift dress appeared, the higher demand for the style. Not only did I count the frequency of the shift dress, but I also sorted and categorized data by issue which allowed me to analyse patterns of the shift dress. Within my analysis, I noted page numbers, how it was shown - either belted or unbelted, the appearance in the form of an advertisement, reoccurring column, or article, and additional notes concerning copy, styling, events, designers, and the prominent women who wore it. Categorizing specific issues enabled for detailed information to be utilized throughout the study.

As part of my tracking method, I incorporated a page-by-page technique where I examined nearly 200 issues of Vogue and Seventeen magazine over a 50-year time span. In order to obtain the best results, it was important to select the most extensive fashion issues and ones that influenced the American public. During the period under study, I examined issues that had the most comprehensive fashion styles not only when haute couture designers released their collections but also issues that highlighted American fashion. I accomplished this by utilizing Vogue's and Seventeen's cover titles that indicated the topics within those particular issues. For example, some of Vogue's titles that revealed the haute couture's release of their collections consisted of 'Paris Fashion Number', 'Paris Opening Numbers', 'Paris Fashion News' or 'Paris Collections'. When reviewing the titles on the fashion covers I had discovered that Vogue added an 'American Issue’ to its February $1^{\text {st }}$ publications during the late 1930s, therefore for the latter segment of the study, I used this issue in addition to the haute couture fall fashion release.

Throughout the duration of the study, Vogue magazine changed its publishing practices in several ways. First, Vogue's issues that indicated the latest fashion trends from the designers shifted in weeks and months throughout the duration of the study, second, as Vogue continued to publish issues they became longer in length, and third, the release of special issues had evolved over time. ${ }^{76}$ Therefore, I adjusted to the

\footnotetext{
${ }^{76}$ In the early 1900s, an industry standard of reporting fashion had not yet come into practice, therefore, the information from the Paris designers fluctuated with dates and months. For example, March 15, 1906 indicated no special issue on the cover, but the March 15 ${ }^{\text {th }}, 1918$ issue was titled "Spring Fashion Special Number." In addition, prior to 1910 Vogue publications were on a weekly schedule but after the February $15^{\text {th }}$ issue in 1910 it began as a bi-weekly publication. With the
} 
months and issues that provided the most information about the release of the designer's collections and the focus on American women. My purpose was not only to track the shift dress, but I also felt it was necessary to identify when the straight silhouette entered the marketplace and became popularized. In order to determine this, I examined more issues prior to the 1920s to pinpoint the refashioning of the sbend corseted dress to the unstructured silhouette. Vogue magazine noted an influential fashion change in 1910 from the traditional S-bend corset to straight silhouettes, therefore I investigated if Vogue had shown a socialite or opinion leader wearing a straight silhouette before 1910 to capture where the fashion may have started. Sources indicated that designers such as Fortuny, Paul Poiret, House of Doucet, and Lanvin were designing straight silhouettes around the same time, noting as early as $1908 .{ }^{77}$ In order to capture the most comprehensive study, I examined every year from 1900 to 1929 with a minimum of two issues per year. I extended this same thought process for my second period of the study and examined two issues every year from 1950 to 1970, and when needed, I analysed additional issues.

After identifying the most extensive fashion issues for my analysis, I utilized both microfilm and Vogue and Seventeen on-line database provided by ProQuest. What proved especially useful was the extensive microfilm collection provided by the University of Central Oklahoma. The microfilm was an important resource as it enabled me to continually scroll through the pages and view each page at a faster rate than the Vogue online database. At times when I needed to view intricate details, I would access that same page utilizing the Vogue on-line database with my computer and this enabled me to clearly identify if the garment was a shift dress. I repeated this same process for Seventeen magazine. Using both of these methods in unison aided my research immensely in covering nearly 200 issues. Vogue's and Seventeen's publications became increasingly thicker and during the 1960s at times issues exceeded 400 pages. This robust and intensive method provided me with a detailed data set as to what years the shift dress was present, how often the shift dress was shown, and who marketed the shift dress.

publication change in schedule, this also affected the coverage information with shifting weeks. Therefore, prior to 1920 the issues chosen may have represented different weeks or months from one year to the next.

${ }^{77}$ Valerie Steele, Fashion and Eroticism: Ideals of Feminine Beauty from the Victorian Era to the Jazz Age (New York: Oxford University Press, Inc., 1985), p. 226. 
Utilizing Vogue and Seventeen magazines, I quantified the presence of the shift dress by two key criteria, form and length. The first criteria, form, enabled me to identify the shift dress from the sheath style and the A-line silhouette. I looked particularly close at the form underneath the bust, the upper torso, and the sides of the dress to see if the fabric was loose. Primarily, sheath dresses have princess darts in the front or back to contour closely to the body. When darts were visible in the construction of the dress, then I discarded those garments in my study. When viewing the shift dress, at times, additional seams were placed in the front, back, or at the hips of the body for a decorative element. The garments that were easily detected as decorative seams I included in this study, but not the dresses that provided a functional seam which altered the garment's shape. Additionally, the dresses that I could not decipher from a decorative or functional seam, I erred on the cautious side and did not include in this study. I also analysed the form in terms of the sweep as this helped me decipher between the shift dress and the A-line silhouette. I visually determined the sweep and those dresses that exceeded a large variance of billowing out from the wearer, were determined as an A-line silhouette. As Table [1], [2] and [3] indicate, the shift dress may incur a small variance, but the garment continues to maintain a straight form. The second criteria, length, was determined by analysing shift dresses by the anatomy of the leg. The upper calf was the area that marked the difference between a shift dress and a chemise. A dress that reached from the upper calf and higher is defined as the shift dress, whereas a cylinder form dresses that extended below the upper calf is considered a chemise. It was beyond the realm of this study to obtain every dress published from these issues and to measure in person or even to measure every dress from the pages of the magazines as photographs were different sizes and models in various positions. ${ }^{78}$ This study's objective was to cover many decades and utilizing a visual method enabled me to do this while still upholding integrity in the results.

Although judgements can be made by examining photographs, it is important to measure dresses from the 1920s and 1960s in order to analyse the proportion of the bust, waist, and sweep. I have defined the shift dress as a straight form garment,

\footnotetext{
${ }^{78}$ I took into consideration dresses that were difficult to pinpoint the position of the leg, I made conservative judgements and when I could not decipher I did not include it in this study. I also utilized both the description and the image in determining each dresses validity for this study, when a description was absent I relied on the image.
} 
however, it is significant to understand if shift dresses that are labelled as such consist of an absolute straight form or if variances are present, and if so, as to what degree do they vary from each subsequent measurement.

I visited the Texas Fashion Collection at the University of North Texas to measure a number of shift dresses that were made between the 1920s through 1970s. This work involved selecting a variety of dresses that either looked like shift dresses or had been indicated as a shift dress from the description of the garment. I also examined the sheath and A-line dresses so I could identify a comparison and contrast model of these styles with the shift dress. My process was to take three measurements of each garment: the width of the bust, waist, and sweep. I measured 22 dresses. Out of the 22 dresses, the results of the variance from the bust to waist, the waist to the sweep and the bust to the sweep are as follows:

Table 1: Measurement of Dresses from the Bust to the Waist

\begin{tabular}{|c|l|r|}
\hline Number of Dresses & \multicolumn{1}{|c|}{ Variance } & \% Total \\
\hline 2 & $-3^{\prime \prime}$ or smaller & $9.1 \%$ \\
\hline 8 & $-2^{\prime \prime}$ & $36.4 \%$ \\
\hline 3 & $-1^{\prime \prime}$ & $13.6 \%$ \\
\hline 5 & $0^{\prime \prime}$ & $22.7 \%$ \\
\hline 2 & $1^{\prime \prime}$ & $9.1 \%$ \\
\hline 0 & $2^{\prime \prime}$ & $0.0 \%$ \\
\hline 2 & $3^{\prime \prime}$ or greater & $9.1 \%$ \\
\hline 22 & & \\
\hline
\end{tabular}

Sample set of shift dresses measured from the University of North Texas:

Texas Fashion Collection 
Table 2: Measurement of Dresses from the Waist to the Sweep

\begin{tabular}{|c|l|r|}
\hline Number of Dresses & Variance & \% Total \\
\hline 1 & -1 or smaller & $4.5 \%$ \\
\hline 4 & $0^{\prime \prime}$ to $5^{\prime \prime}$ & $18.2 \%$ \\
\hline 10 & $6^{\prime \prime}$ to $10^{\prime \prime}$ & $45.5 \%$ \\
\hline 6 & $11^{\prime \prime}$ to $15^{\prime \prime}$ & $27.3 \%$ \\
\hline 1 & Greater than $15^{\prime \prime}$ & $4.5 \%$ \\
\hline 22 & & \\
\hline
\end{tabular}

Sample set of shift dresses measured from the University of North Texas: Texas Fashion Collection

Table 3: Measurement of Dresses from the Bust to the Sweep

\begin{tabular}{|c|c|c|}
\hline Number of Dresses & Variance & \% Total \\
\hline 1 & -1 or smaller & $4.5 \%$ \\
\hline 5 & $0 "$ to $5^{\prime \prime}$ & $22.7 \%$ \\
\hline 9 & $6 "$ to $10^{\prime \prime}$ & $40.9 \%$ \\
\hline 6 & $11^{\prime \prime}$ to $15^{\prime \prime}$ & $27.3 \%$ \\
\hline 1 & $16^{\prime \prime}$ or greater & $4.5 \%$ \\
\hline $\mathbf{2 2}$ & & \\
\hline
\end{tabular}

Sample set of shift dresses measured from the University of North Texas: Texas Fashion Collection

One of the largest categories, consisting of $27 \%$ of the sample size, had a $0 \mathrm{in}$. variance in the width from the bust to the waist, therefore, these dresses were constructed with a straight seam extending from below the arm to the waist, seen in Figure [1]. However, most dresses sampled had a variance present, thus indicating that although shift dresses may appear straight they may also incur a slight variance from the bust to the waist. An example of this can be seen in Figure [2]. In Table [2] and [3], one of the most significant discoveries was the variance from the bust to the sweep and the waist to the sweep. In both of these tables, the largest variances were 6 in. to 10 in., an example of this is Figure [3]. Only one dress had a 0 in. variance 
throughout the entire structure of the garment. Sampling the garments revealed that although the shift dress is defined as a straight silhouette, a slight flare in the garment may be present. In Figure [4], the sheath style dress had a visible dart on the front torso and had a slight decrease of variance from the bust to the waist. Although, the sheath sampled was a more loose-fitting sheath than anticipated, this style usually contours closely to the body. At times the sheath may be difficult to decipher from the shift, when this occurred I paid particular attention to the fit on the model. If the garment hung loose, I counted it as a shift, since it indicates the same fit as the shift dress. Also, decorative seams and darts may look similar. The A-line dress variance from the waist to the sweep increased significantly. Some measured a variance of 14 in. and 16 in. while other styles measured less than 10 in. variance. In Figure [5] this Aline dress has a variance of 15 in. and visibly a defined curve at the side seam. This small sample set was used only as a guideline to decipher the shift dress from other styles. The primary purpose of this exercise was to examine closely those styles that correlated to the time of the study 1895-1970, and analyse the variances of the measurements. When counting shift dresses, if the sweep had a slight variance, I counted it in my data, but if the sweep looked significant, as it flared away from the model and/or a defined curved side seam was apparent, then I did not count those styles in my data.

My quantitative method also included analysing statistical reports from the Statistical Abstract of the United States, an authoritative and comprehensive report published by the Census Bureau utilizing data from a variety of federal agencies and private organizations compiled of data about the country's social, economic, and demographic information. ${ }^{79}$ I utilized this report extensively to deconstruct and analyse women's place within the education and work environment of the United States. I did this by categorizing and measuring variances from each decade from the statistical data focusing on level of education and types of jobs women occupied, such as unskilled versus skilled labour. Utilizing a variety of quantitative methods was significant as it not only tracked the presence, absence and popularity of the shift dress, but within the same time frame, I was able to make a comparison assessment of women's place in education and the work environment.

\footnotetext{
${ }^{79}$ Census History Staff of the U.S. Census Bureau, 17 December 2019 (last revision), $<$ https://www.census.gov/history/www/reference/publications/statistical abstracts.html $>$ [accessed 29 November 2020].
} 


\section{Qualitative Methods}

Similar to the variety of methods used for the quantitative analysis, I have qualitatively employed several different types of processes and literature to examine the shift dress and women's place in contemporary society. The qualitative methods include the three core categories of sources: literature, dress, and entertainment.

When analysing primary literature, a keyword search approach was performed in the expansive database of ProQuest. Primary sources included in the keyword search were fashion magazines, women's lifestyle magazines and newspapers. The primary fashion magazine used in the keyword search was Vogue. All of these sources were published in the United States and primarily, but not limited to, searched within the duration of the study from 1895 to $1970 .{ }^{80}$ Implementing a variety of magazines identified patterns for specific target markets, for example, Vogue's target market includes fashion conscious, affluent women, Seventeen magazine focuses on teenagers and young women, and Good Housekeeping audience is primarily middleclass housewives.

Not only were magazines key sources for this study, but newspapers published across America were useful in determining the culture, lifestyle and fashion for women. Examples of newspapers that were examined by the keyword search approach include Women's Wear Daily, the most admired publication for the retail industry, and local new sources, such as, the New York Times, The Washington Post, The St. Louis Dispatch, and the Chicago Tribune. I examined newspapers from all regions of the United States, including newspapers that supported large markets like New York City but also extended to smaller markets, for instance, Nashville, Tennessee. Newspapers were insightful as opinions were expressed by public leaders; such as, college presidents, professors, school principals, civic leaders, ministers, dignitaries and fashion experts.

Advantages to the keyword search was that it allowed easy access to a wide variety of primary sources and a large number of issues as well as provided information from a variety of perspectives, such as housewives, teens, or society members. Additionally, I was able to search and categorize the data by themes, such

\footnotetext{
${ }^{80}$ Vogue used in this study was the U.S. edition. Nine women's lifestyle magazines were used in the keyword search located in ProQuest's. Examples of women's magazines that were included in the keyword search were Ladies' Home Journal, Better Homes and Gardens, Cosmopolitan, Woman’s Day and Seventeen.
} 
as 'beach shifts', 'art' and 'travel', utilizing keyword searches. For example, the beach shift was popular in the early 1960s, therefore, I searched 'beach shift(s)' in magazines and newspapers to locate articles about this particular shift dress. I systematically categorized these articles to examine dates, publications, and topics.

This method was employed to understand the contemporary terminology used to describe the shift dress. For example, the term 'shift' had not yet been defined as a dress during the 1920s, therefore, I identified words that were popular in describing the shift dress during this time period. Some of the most common words used during the 1920s to describe the shift dress was 'flapper', 'simple', 'modern' or 'straight'. Although during the 1960s the term 'shift' was commonly used, other terms were also present, such as, 'skimmer' and 'shaft'. A significant drawback in utilizing the keyword search method was the difficulty to capture substitute words for the shift dress, such as when designers named dresses specific names or referred to them as part of their line. In Figure [6], the advertisement from Damon states, 'Lino Fresco" \#67 which refers to a specific shift dress in the Francesca for Damon line, a collection that was developed for Damon Creations. ${ }^{81}$ The tracking method helped me overcome this, but also, when searching with keywords, I used a variation of keywords together that were associated with the shift dress in order to capture the style. Another challenge of using the keyword search was when copy did not accompany the shift dress. A key word search only selects pages when the key word is within the body of the text, therefore, when text is absent the database cannot search the page. This occurred frequently in advertisements. Some advertisements had no copy describing the dress whatsoever and primarily listed the name and the location of where to purchase the garment. Examples of this can be seen in the advertisements of Malcolm Starr in Figure [7]. ${ }^{82}$ If only performing the keyword search method, these advertisements would have been missed. However, since I employed the tracking method, I was able to capture these advertisements and understand the marketing principles and tactics of the shift dress. Therefore, the

\footnotetext{
81 'Advertisement: Damon'. Vogue, 01 February 1966. ProQuest, $<$ http://vortex3.uco.edu/login?url=https://www-proquestcom.vortex3.uco.edu/magazines/advertisement-damon/docview/879255582/se-2 ?accountid=14516> (p. 71).; Fuzzylizzie, Francesca for Damon (2010), < https://vintagefashionguild.org/labelresource/francesca-for-damon/> [accessed 8 January 2021].

82 'Advertisement: Elinor Simmons (Elinor Simmons)', Vogue, 01 September 1966. ProQuest, $<$ http://vortex3.uco.edu/login?url=https://www-proquestcom.vortex3.uco.edu/magazines/advertisement-elinor-simmons/docview/904294490/se2?accountid=14516> (p. 11).
} 
tracking method was crucial to understand how the shift dress was marketed and the keyword search was vital as I was able to analyse a larger number of sources and significantly more issues. Highlighting the advantages and disadvantages of both processes demonstrates the importance of utilizing a multi-method approach in this study.

The second key category of sources utilized in this study was a hands-on approach analysing samples of dresses. The dress sources included calculations based on measuring a sample set of dresses from the Texas Fashion Collection and attendance at two fashion exhibits. The first fashion exhibit which I attended was inspired by the popular hit television series, Downtown Abby, called Decadence: Fashion from the 1920s, and there I was able to view Mariano Fortuny's iconic Delphos gown up close. ${ }^{83}$ Later, I attended the exhibit, Dior: From Paris to the World, and this visit proved helpful by viewing a large amount of pieces from the House of Dior which expanded from his early works to the present day. ${ }^{84}$

The third key category of sources utilized in this study was entertainment, analysed through film and television. Film and television media were vital to this research as they provided information of specific messages that were conveyed to the American public, especially how a woman was portrayed while wearing the shift dress. Initially, I planned to use film for both time frames and add television as an additional component for the 1950s and 1960s. Upon my research, the 1920s provided a breadth of information of the shift dress within the flapper film genre. Not only was the shift dress worn consistently throughout the flapper films but the flapper characterization was defined within a specific personality for the duration of the genre. Although the flapper films were made from multiple producers, the characterization of the flapper remained similar throughout the decade. Additionally, flapper films also attracted sizeable audiences, therefore, influences of the flapper films reached a large number of people. When I began researching films for the 1960s, I could not find a specific film genre that showed the shift dress consistently nor was attached to a well-defined characterization, like the flapper. The beach movies genre was the closest, however, the shift dress was primarily used as a beach cover-up and not utilized as a garment primarily worn as a dress. When I began

\footnotetext{
${ }^{83}$ Decadence: Fashions from the 1920s hosted by University of North Texas, at Galleria Mall (Dallas, TX, attended on 19 February 2016).

${ }^{84}$ Dior: From Paris to the World, at Dallas Museum of Art (Dallas, TX, attended on 10 August 2019).
} 
observing and examining television media, I discovered Bewitched had a large presence of the shift dress with well-defined characterizations throughout the series. Additionally, the length of time it was on TV meant Bewitched provided an opportunity, similar to the flapper film genre, to analyse it in a timeframe that was approximately over the course of a decade. ${ }^{85}$ Thus, the flapper film genre and Bewitched had the closest comparison because of the presence of the shift dress, specific characterizations attached to the actors, similar duration within their decades, and both attracted large audiences. I examined the relationship of dress to how women were portrayed in comparison to the culture, messages conveyed to audiences and society's perception.

\section{Outline of Chapters}

As noted previously, this thesis is broadly defined into two sections, which correspond to two periods of time. The first section charts the birth of the shift dress and the second section discusses the rebirth of the shift dress. For both time frames, I analysed the decade before the birth and rebirth of the shift dress to underpin the current fashion modes, the culture of the time, women's place in society, and society’s perception of women. Chapter 2, 'The Blank Canvas: The Progressive Era', analyses the Progressive Era which was the period prior to the shift dress's entrance into the fashion industry. Chapter 2 is especially important as it not only serves as a barometer for women's place and fashion evolution for this study, but it was also the beginning of modern fashion change which transitioned away from the constricted, corseted gown and to the free, unrestricted cylinder dress. This chapter also examines early influencers who were vital in this modern fashion change. Next, in chapter 3 , 'The Sexualized Canvas: The 1920s', I will identify the shift dress’s dynamic entrance into the fashion industry and discuss its unique and substantial contributions to the fashion industry while analysing pivotal economic, social and political changes for women. This chapter also focuses on influential designers, but more importantly, the American flappers who bravely displayed the shift dress as their uniform. I will further investigate society's perception of the shift dress and the symbolic meaning attached to the women who wore it. Next in chapter 4, 'The Hidden Canvas: The Post War Era', I analyse the antecedents of the 1960s explosive culture and fashion

${ }^{85}$ Bewitched aired for 8 seasons from September 1964 to March 1972. 
changes. Like the Progressive Era, this chapter is significant as it lays the foundation for the subsequent decade. This chapter investigates the presence of the shift dress as well as women's experiences that led to deep and historic change in the 1960s. Additionally, in this chapter I introduce the emerging consumer, the American teenager, which later, had a significant impact not only on the contemporary social culture but also an integral component of the shift dress that led to powerful and lasting changes in the fashion industry. Lastly, chapter 5, 'The Painted Canvas: The 1960s', considers the re-entry of the shift dress and the factors that attributed to its growth in the marketplace as well as the significant changes that the shift dress contributed to not only the fashion industry but also to modern dress. I will also analyse how the shift dress reimagined expressionism in fashion, what messages were conveyed to contemporary society in relationship with the shift dress, and how it aided women to recharge and enter the second wave of feminism. 


\section{Chapter 2: The Blank Canvas: The Progressive Era}

The Progressive Era is significant as it marks the beginning of the evolution of the shift dress. In 1910, an article in Vogue magazine recorded pivotal fashion changes. The article observed 'a strange twist the fashions have taken...' and proceeded to recall, in detail, a gown of 'not many seams' and the 'apparent absence' of the corset. ${ }^{86}$

This chapter will explore this 'strange twist' which led to a new form of dress, the conditions that brought about the transformation, and the women who wore it. It is divided into three sections. The first section provides historical background to a changing America and the roles women played in this new environment. I evaluate women's workplace, education, and involvement in social organizations. I demonstrate the challenges women faced in the industrial age and the obstacles they had to overcome. The second section systematically traces the rapid fashion change, from the corseted s-bend silhouette to the unrestricted, cylinder form. This section identifies important women, artists, and fashion designers who were significant fashion influencers of this modern fashion change. The third section examines the film, music and dance culture that conveyed important social roles and expectations that were connected to dress. I explore the new medium of silent films and analyse women's characterization in relation to the symbolism of their dress. Then I assess the dynamic change of tempo with the new, upbeat rhythm of Ragtime music, and as a result, the modification of popular dance methods which aided in the refashioning of dress. By deconstructing all of these components, this chapter will identify the connections between the place of women in society, the beginning of the evolution process of the shift dress, and provide a clear understanding of the initial influences that transformed the rapid change of dress.

For the purpose of this study the Progressive Era is defined as the period from 1895 to 1918. The Great Merger Movement indicated the beginning of this period and the day of the armistice of World War I is its end point. ${ }^{87}$ The Great Merger

\footnotetext{
86 'Fashion: Parisian Adaptation of Oriental Fashion', Vogue, 01 November 1910. ProQuest $<$ https://www-proquest-com.vortex3.uco.edu > (p. 34).

${ }^{87}$ Jackson Lears, Rebirth of A Nation: The Making of Modern America, 1877-1920 (New York: Harper Collins Publisher, 2009), p. 168. (Lears marks the Chicago Columbian Expo and the merger war of 1897 as a key movement in the shift from chaotic laizze-faire capitalism of the Gilded Age to the corporate, managed capitalism of the Progressive Era); Watts, Duncan, Dictionary of American
} 
Movement was a time in U.S. history from 1895 to 1905 when many small firms were engulfed by larger corporations that created dynamic change in the economic system in America. ${ }^{88}$ The armistice of World War I marks the end of the Progressive Era as American society emerged from the war with a new outlook of optimism that secured stability in the social and economic environment.

\section{The Progressive Era: Historical Background}

The Progressive Era was a period of contradiction. The implications of modernity created anxiety in terms of change but also offered new possibilities. Change reached into all aspects of American society, influencing economic, political, and intellectual contexts. ${ }^{89}$ Simultaneously, two large demographic shifts materialized, which altered the culture of America. The population shifted from a static, singular Protestant community to a mobile, multicultural society. The first demographic shift consisted of the large inflow of immigrants to the United States. With an estimated influx of twenty million immigrants from 1880 to 1910, this was considered one of the most significant periods of immigration in American history. ${ }^{90}$ Although immigrants were representative of many countries, they primarily were from southern and eastern Europe, many of whom were from Italy, Russia, and Austria-Hungary. ${ }^{91}$ The immigrants typically came from poor, working class backgrounds. Significant controversy surrounded the issue of how to assimilate the immigrants into America as well as anxiety about how this change could transform American culture. ${ }^{92}$ This multi-cultural blend exposed America to more diverse social issues and challenged the status quo of the Protestant community. According to

Government and Politics (Edinburgh: Edinburgh University Press, 2010), p. 241. ProQuest Ebook Central. (Watts defines the Progressive Era from 1890 to 1920. Progressive Era was an economic, political and social reform with the regulation of business practices, protection from health hazards, and improvement in working conditions.)

${ }^{88}$ Ellen F. Fitzpatrick, 'Late-Nineteenth-Century America and the Origins of Muckraking', in Muckraking: Three Landmark Articles, ed. by Ellen F. Fitzpatrick (New York: Bedford Books, 1994), pp. 1-39 (p. 4).

${ }^{89}$ Richard L. Watson, Jr., The Development of National Power: The United States 1900-1919

(Washington, D.C.: University Press of America, 1982), p. 59.

${ }^{90}$ Robert Higgs, The Transformation of the American Economy, 1865-1914: An Essay in Interpretation (New York: John Wiley \& Sons, Inc., 1971), p. 23.

${ }^{91}$ The Unfinished Nation-The Progressive Era, (Films Media Group, 2004), online film recording, Films On Demand, < https://fod-infobase-

com.vortex3.uco.edu/p_ViewVideo.aspx?xtid=71435\&tScript=0 > [accessed 10 February 2021].

${ }^{92}$ The Unfinished Nation-The Progressive Era, (Films Media Group, 2004), online film recording, Films On Demand, < https://fod-infobase-

com.vortex3.uco.edu/p_ViewVideo.aspx?xtid=71435\&tScript=0 > [accessed 10 February 2021]. 
Jackson Lears, the Protestants had a plain, soft spoken persona whereas the immigrants brought a different social order of 'painted' women and 'confidence' men. ${ }^{93}$ Joanna Levin observes, 'Coupled with suggestions of an even more alien, gypsy lifestyle, the scandalous Frenchness of Bohemia further disturbed notions of a national, Anglo-American consensus. ${ }^{94}$ The second demographic shift can be attributed to a change of internal factors. As primarily an agrarian nation, mechanization disrupted the fabric and the social construction of American society. The introduction of mechanization changed the landscape of farming. The introduction of machines reduced the demand for human labour. Farmers that were unable to afford the larger machinery could not compete economically. The result was a significant migration to the city and industrial centres where factories and jobs were abundant. ${ }^{95}$

The expansion of the large corporate factories absorbed both of these significant demographic shifts, providing jobs for the variety of skill levels, which advanced the U.S in becoming a mass-produced society. America metamorphosed from a simplistic, agrarian life based on a barter network to a decentralized, economic system dependent on monetary values. Large corporations were controlled by few individuals and governed with a laissez-faire attitude and this change of impetus transformed America's economic and political landscape. Corporations had immense power but they also offered opportunity for the U.S. to become an economic world leader. Factories became the central stage and the machines became its performers. The innovation in machinery maximized efficiency and improved profits as older machines were quickly replaced by faster machinery with greater output. ${ }^{96}$ The adaptation of new machines positioned the U.S. as a modern economy. This new modernization that engulfed America contributed to a variety of consumer goods. The textile industry was at the forefront of this change which attributed to the process of modernizing fashion.

\footnotetext{
93 Lears, p. 134.

${ }^{94}$ Joanna Levin, Bohemia in America, 1858 - 1920 (Stanford, CA: Stanford University Press, 2009), p. 18.

${ }^{95}$ Lears, p. 190.; see also, Higgs, pp. 3-4.

${ }^{96}$ Alan Trachtenberg, The Incorporation of America: Culture and Society in the Gilded Age, (New York: Hill and Wang, 1992), p. 55.
} 


\section{Fashioning the Progressive Era}

Prior to the onset of the U.S. industrial revolution, the earliest evidence of mass production for ready-to-wear clothing began in menswear suits. The combination of the simplistic lines of the suit along with the invention of the body proportion system allowed tailors to enter the mass production arena. Other similar garments were also mass produced such as, uniforms and work clothing, as these garments were not fitted closely to the body. ${ }^{97}$ Mass production in women's wear came much later than menswear since women's clothing fit was closely corseted to the bodice. In order to achieve the tightly wrapped bodice, women endured many fittings from their seamstress.

Mass production began during the nineteenth century with the custom tailors. ${ }^{98}$ Initially a tailor's measurement was specialized for each individual client in order to make a suit. According to Kidwell and Christman, the invention of the proportional system, that all bodies are proportionally similar based on key measurements, enabled tailors to begin the process of mass production. The proportional system allowed the tailor to take few measurements with the ability to remain accurate for their client. Since measurements were minimal, tailors were able to contract portions of the work production to offsite workers. The tailors realized women were advantageous for this work as women were already responsible for their own home sewing tasks. Therefore, tailors employed women to sew sections of the men's suits. The journeymen tailors were given the tasks that required training and skill, whereas, the women were contracted to complete the simple task of sewing straight lines of the trousers and waistcoats. Employing many women helped the tailors to produce more suits in a mass-produced capacity. ${ }^{99}$

Although the tailors provided an opportunity for women to earn additional income, they also offered women the easiest and least desirable jobs which continued later within the factories. Carl Degler argued the industrial revolution gave women unprecedented opportunities. He wrote,

\footnotetext{
${ }^{97}$ Nancy L Green, 'Art and Industry: The Language of Modernization in the Production of Fashion', French Historical Studies, 18.3, 1994, pp. 722-748, (738) < https:/doiorg.vortex3.uco.edu/10.2307/286690>.

98 Kidwell, Claudia B. and Margaret C. Christman, Suiting Everyone: The Democratization of Clothing in America, (Washington, D.C.: Smithsonian Institution Press, 1974), p. 39.

${ }^{99}$ Kidwell and Christman, pp. 41, 43, 44-45.
} 
It was the industrial revolution that provided the impetus to women's aspirations for equality of opportunity; it was the industrial revolution that carried through the first stage in the changing position of women the removal of legal and customary barriers to women's full participation in the activities of the world. ${ }^{100}$

Although women were given opportunities to participate in the public sphere during the industrial revolution, the mass-produced industry enforced inequalities for women workers. Women were given limited access to the public sphere, as they were characterized, associated, and intrinsically positioned with the less desirable jobs, minimum skills, and meagre pay rates.

Based on existing conventions, women were thought of as a fluctuating and temporary workforce due to their responsibilities of marriage and childbearing. According to Margaret Walsh, most commonly, women were placed in 'light industries' which consisted of textiles, clothing, footwear, and food processing. Many industries that women worked in were related to the domestic sphere. Furthermore, she noted women were segregated within the industry as male workers held supervisory and skilled positions whereas women obtained the unskilled and inferior jobs frequently paid by piece rates. ${ }^{101}$ Women's lives were separate from men in many aspects of society. Women working in the factories did not change this segregation. In Figure [8], this photograph confirms that women worked primarily alongside other women. Mass production established the hierarchy of men occupying the supervisor and higher paid positions while women occupied the lower status and lower paid positions.

The Masses, a controversial magazine which was devoted to the interests of working people, published a thought-provoking article accompanied with a drawing of women entering a factory, shown in Figure [9]. The article claimed, 'To be a woman in modern capitalist society means to be the cheapest commodity on the market.' ${ }^{102}$ The article in The Masses declared that the ill-treatment of women will negatively affect generations to come and urged the readers to oppose the existing

\footnotetext{
${ }^{100}$ Carl N. Degler, 'Revolution Without Ideology: The Changing Place of Women in America', Daedalus, 93.2 (1964), 653-670 (p. 654)

$<$ http://vortex3.uco.edu:2050/login?url=https://www.jstor.org/stable/20026849 > [accessed 19 January 2021].

${ }^{101}$ Margaret Walsh, 'Women's Place in the American Labour Force, 1870-1995,' History, 82. 268 (1997), 563-581 (p. 572) <http:/vortex3.uco.edu:2050/login?url=https:/www.jstor.org/stable/24424274> [accessed 19 January 2021].

102 'The Cheapest Commodity on The Market', The Masses, December 1911.

$<$ http://dlib.nyu.edu/themasses/books/masses012/5> [accessed 12 February 2021] (p. 5).
} 
social order. The author proclaimed, 'If you do not wish to be held responsible by future generations for this shame you must declare yourself openly against it. You must speak against it, write against it, and if you are a voter, vote against it.' 103

Inequality was not only limited to the poor working-class women, but inequality also extended to women within the professional fields. Many women in professional fields were not publicly recognized nor given appropriate titles for their work. The engineering industry provides a useful illustration.

Margaret Layne, P.E. wrote a book, Women in Engineering, which recognized women's professional challenges and successes in the engineering field. Layne measured women by several classifications in order to accurately count women who actively worked in the engineering field.

The five classifications were:

1) women who had earned engineering degrees

2) women who had not earned engineering degrees

3) women who were licensed engineers

4) women who were not licensed engineers

5) women who worked in engineering but held degrees in other areas.

According to Ruth Oldenziel, many of the first women engineers were forgotten or not fully recognized as many of these women worked beside their husbands, fathers, or brothers. ${ }^{104}$ For example, one of the earliest known women to perform engineering duties was Emily Warren Roebling (1843-1903). Ms. Roebling did not hold a degree in engineering, rather she was educated by her husband. In 1872, her husband had fallen ill during the Brooklyn Bridge project. With his guidance, Emily Warren Roebling performed civil engineering duties and facilitated the work among all of the engineers in order to complete the project. ${ }^{105}$ According to the American Society of Civil Engineers, Emily became so knowledgeable in the

\footnotetext{
103 'The Cheapest Commodity on The Market', The Masses, December 1911. $<$ http://dlib.nyu.edu/themasses/books/masses012/5> [accessed 12 February 2021] (p. 5).

${ }^{104}$ Ruth Oldenziel, 'Mulitple-Entry Visas: Gender and Engineering in the U.S., 1870-1945', in Women in Engineering: Pioneers and Trailblazers, ed. by Margaret E. Layne (Reston, VA: ASCE Press, 2009), pp. 35-77 (p 39).

${ }^{105}$ Alva T. Matthews, 'Emily W. Roebling: One of the Builders of the Bridge', in Women in Engineering: Pioneers and Trailblazers, ed. by Margaret E. Layne (Reston, VA.: ASCE Press, 2009), pp. $123-130$ (p. 127).
} 
subject that many suspected that it was her intelligence and direction that completed the bridge. ${ }^{106}$ Upon the completion of the project, Roebling was not publicly recognized as an engineer nor was a professional title given to her. Another example of inequality in the engineering field is that of Dr. Lillian Moller Gilbreth (18781972). Dr. Lillian Gilbreth was a pioneer in the field of time and motion studies, and like Emily Roebling, she worked alongside her husband. Upon their marriage in 1904, Lillian Gilbreth noted that Frank immediately began discussing plans for working together. ${ }^{107}$ Later, Lillian Gilbreth earned her PhD from Brown University for which she wrote a ground-breaking book that stemmed from her doctoral work, The Psychology of Management (1914). Initially, many publishers denied to publish her book, but she found Mr. Walton who agreed, but only if she used her initials and it was not publicized that a woman wrote the work. ${ }^{108}$ Dr. Lillian Gilbreth continued to work alongside her husband as they co-authored many papers. Martha Moore Trescott, author and professor, observed that Dr. Lillian Gilbreth was given less credit than her husband by engineers and historians, even though her husband never earned a degree. Trescott believed Dr. Lillian Gilbreth was the primary author and principal investigator on works that she co-authored with her husband. For example, Trescott revealed that in Dr. Lillian Gilbreth's application for membership in the American Society of Mechanical Engineers she noted, 'I was chiefly employed in the systems work, standardizing practice. The results were published in Field System, Concrete System, and Bricklayering System'. Trescott emphasized these publications only note Frank B. Gilbreth as the author. ${ }^{109}$ Additionally, Laurel D. Graham, noted Dr. Lillian Gilbreth’s role was ‘substantial' and she contributed largely to Frank's published work. ${ }^{110}$ After Frank's death, Dr. Lillian Gilbreth continued to make contributions to the field, although applying her scientific studies to a more domestic realm of how

\footnotetext{
${ }^{106}$ American Society of Civil Engineers, Emily Warren Roebling, < https://www.asce.org/templates/person-bio-detail.aspx?id=11203>[accessed 15 August 2020](para. 3 of 5).

${ }^{107}$ Lillian M. Gilbreth, As I Remember: An Autobiography (Norcross, GA: Engineering \& Management Press, 1998) pp. $102-104$.

${ }^{108}$ Gilbreth, p. 120. At this time when Mr. Walton agreed to publish Lillian Gilbreth's book he recently left Macmillan publishing to start his own publishing firm indicated in Gilbreth, p. 120.

${ }^{109}$ Martha Moore Trescott, 'Women in the Intellectual Development of Engineering: A Study in Persistence and Systems Thought', in Women in Engineering, Pioneers and Trailblazers, ed. by Margaret E. Layne, (Reston, VA.: ASCE Press, 2009), pp. 99-121 (p 114). Further notations about Dr. Lillian Gilbreth's contributions on pages: pp. 110-111, 114, 116.

${ }^{110}$ Laurel D. Graham, 'Lillian Gilbreth’s Psychologically Enriched Scientific Management of Women’s Consumers', Journal of Historical Research in Marketing, 5.3 (2013), 351-369 $<$ http://dx.doi.org.vortex3.uco.edu/10.1108/JHRM-02-2013-0009>.
} 
systems worked in the household. ${ }^{111}$ In 1949, much later in Dr. Lillian Gilbreth's life, she was recognized by the Society of Industrial Engineers as its first woman honorary member to the organization. ${ }^{112}$

In the late $19^{\text {th }}$ and early twentieth century, the cultural norms defined by upper and middle-class Americans required women to stay within the private sphere as they believed women's most important role was to take care of the family. ${ }^{113}$ As the examples illustrates, these intellectual women who were well versed in the sciences and mathematics fields were not fully recognized for their work outside of the home. Not giving women full acknowledgment of their work, suggests that the cultural values were to minimize women's involvement in the public sphere. Emily Roebling's work was overlooked during the building of the bridge that more recent scholarship has claimed her as the 'Secret Engineer' or the 'Silent Builder'. ${ }^{114}$ However, although it is argued as to how much contribution Dr. Lillian Gilberth made to her co-authored works and it is disputed that much of her scholarly literature may possibly have gone unpublished, her name did appear on published works. Comparing these two women, we do see that as time progressed women were gaining a little more public acknowledgement for their professional work.

As modernity progressed and society began slowly accepting women for a more visible role in the public sphere, the dress during these two women's lifetime dramatically changed. During Emily Roebling's lifetime, the mode of dress with corseted bodices and wide, flared skirts was appropriate by cultural norms. Shown in Figure [10], Emily Roebling's dress restricted women in certain capacities as it was difficult to move, similar to how women were restricted in their involvement within the public sphere. However, not only was Dr. Lillian Gilbreth’s work more publicly acknowledged than Emily Roebling's, but there was a significant difference in Dr. Lillian Gilberth's fashion as she primarily dressed in straight and simplistic gowns. As indicated in her autobiography, she naturally was not into fashion, and she had

\footnotetext{
${ }^{111}$ Lillian Moller Gilbreth: Pioneering Inventor \& Industrial Engineer,1878-1972, online film recording, UNLADYLIKE2020, <http://unladylike2020.com> [accessed 21 March 2021].

${ }^{112}$ Society of Industrial Engineers, Spring Convention', The Society of Industrial Engineers Bulletin, 3.5 (1949), 1-3 (pp. 1-3).

${ }^{113}$ Margaret Walsh, 'Women's Place in the American Labour Force, 1870-1995,' History, 82.268 (1997), 563-581(pp. 565-566) < http://vortex3.uco.edu:2050/login?url=https://www.jstor.org/stable/24424274> [accessed 19 January 2021]. ${ }_{114}$ Rachel Dougherty, Secret Engineer: How Emily Roebling Built the Brooklyn Bridge (New York: Roaring Brook Press, 1988). Marilyn E. Weigold, Silent Builder: Emily Warren Roebling and the Brooklyn Bridge, (Port Washington, N.Y: Associated Faculty Press, 1984).
} 
little interest in clothes. Her appearance was based on being clean, neat and inconspicuous. Her philosophy was that simplicity took much less time and effort and gave more pleasure to enjoy life than complicated standards, and she applied this to 'simple clothes', ‘simple meals' and a 'simple program'. ${ }^{115}$ In Figure [11], Dr. Lillian Gilbreth can be seen in a simple black dress. This photograph was taken from the waist up, therefore, I cannot view the length of the dress. However, the style of the dress is straight and simplistic. These two attributes are important as she did not adorn herself with overly decorated feminine details of frills, lace, and bows but rather wore 'simple' clothes that were closely associated to similar construction of the shift dress. ${ }^{116}$ Additionally, Dr. Lillian Gilbreth’s philosophy of dressing simply because it took less time is important to note as this was an element of the shift dress which is important in modern fashion. The active modern woman needed a garment that was versatile, required less fittings, and easy to maintain in its cleaning and repairing. The simplistic, straight structure of the shift dress fit an active woman's lifestyle better than a fashionable and overtly feminine dress.

The manner in which a woman dresses can be associated as to how women are perceived by society. For example, when Lillian Gilbreth was selected as the first woman to deliver a commencement speech at the University of California she was advised, 'Don't wear a stiff dress, wear one that is soft and has ruffles....Don't try to imitate a man - speak as a woman'. ${ }^{117}$ This exemplifies that society associated dresses with soft forms and ruffles as feminine whereas a stiff, simplistic dress represented a masculine identity. Additionally, this also suggests that society did not want women to have any characteristics of a man. Historian, Robyn Muncy, stated that women endured contradictions especially in the professional setting; if women wore the appropriate dress for professional life, such as a woman's suit, they were often criticized for being unfeminine, but if they refused to wear the suit, they lost professional authority. ${ }^{118}$ Dr. Lillian Gilbreth observed a woman in an office setting:

\footnotetext{
115 Gilbreth, pp. 64, 72, 135.

${ }^{116}$ Additional images of Lillian Gilbreth in the film recording: Lillian Moller Gilbreth: Pioneering Inventor \& Industrial Engineer,1878-1972, online film recording, UNLADYLIKE2020, $<$ http://unladylike2020.com> [accessed 21 March 2021]

117 Gilbreth, p. 73.

118 Robyn Muncy, Creating a Female Dominion in American Reform 1890 - 1935, (Oxford: Oxford University Press, 1991), p xiii. ProQuest Ebook Central.
} 
[T] he big new hat with the fluffy chiffon veil and the Vienna suit while the last word in imported style - seemed inappropriate and foolish in the busy office, and even more out of place on the construction jobs. ${ }^{119}$

Lillian Gilbreth noticed the ill-placement of feminine clothing in the workplace and also how a woman would be perceived especially on a construction site wearing fashionable dresses rather than practical clothing. Simmel claimed that many individuals seek for acceptance in a group and adhering to the fashion norms of dress gives one a sense of belonging. When an individual deviates from the social norm of dress, they may be seen as an outcast and different from the social group. This was exemplified with the bloomer costume, as it was negatively received by the public because this dress deviated too far from the prescribed social norm. Muncy indicated it was challenging for women to look like a woman, but wear appropriate dress for a professional environment.

\section{Women in Education: Pre-Progressive Era}

As women had large barriers in the workplace, working alongside their fathers, husbands or brothers, women often found it challenging to enter college and study professional fields. In the mid-1800s it was difficult for a woman to enter college for professional studies. Lucy Hobbs Taylor wanted to become a doctor but the Eclectic College of Medicine in Cincinnati denied her entry because she was a woman. ${ }^{120}$ Taylor was taught privately by a professor of the Eclectic but she did not receive the degree that was needed to practice medicine. Therefore, Taylor became a dentist. During this time, the dentistry field was easier for women to enter as the occupation was not considered a profession. ${ }^{121}$ In 1849, Elizabeth Blackwell was the first woman to obtain a medical degree in the United States. Upon applying, she was rejected by twenty-nine institutions; however, Geneva Medical College accepted her even if it was by accident. Although Blackwell graduated at the top of her class, she was prevented from working in the hospitals and dispensaries. In 1853, she established her own infirmary which later became an accredited medical college. ${ }^{122}$

\footnotetext{
${ }^{119}$ Gilbreth, pp. 94-95.

${ }^{120}$ Caroline Bird, Enterprising Women (New York: W.W. Norton \& Company, Inc., 1976), p. 110111

${ }^{121}$ Bird, p. 111.

${ }^{122}$ Cott, Nancy F., Root of Bitterness: Documents of the Social History of American Women (New York: E.P. Dutton \& Co., 1972), p. 299.
} 
Because a large number of conventional medical schools were closed to women, they had to find entrance into smaller offbeat medical schools of eclectic or homeopathic medicine. ${ }^{123}$ The path for success for women was disjointed and unclear. Similar to Elizabeth Blackwell's experience, professional work was difficult to find as a woman. Women continually received criticism about education, social issues, and demographic changes. A widely distributed book, Sex in Education, published in 1873 and authored by Dr. Edward Clarke, believed that women who studied as rigorously as men may incur undeveloped ovaries and become sterile. Dr. Clarke claimed, the brain and reproductive organs cannot simultaneously develop, therefore, when exercising the brain the reproductive organs do not mature. ${ }^{124}$ During the late Victorian Era, 1865-1890, the first generation of women college graduates were cited as contributing to the decrease in number of marriages and birth rates and an increase of divorces in the country. ${ }^{125}$

Many articles in Vogue discussed girls in college and the social consequences. ${ }^{126}$ In 1897, Vogue noted that a portion of society had an 'epidemic of apprehension' toward the college girl as she displayed 'self-assertion' and worried that her primary role as a caretaker would be diminished. ${ }^{127}$ An article in Vogue noted a doctor's research findings that their studies make girls 'celibate' as 'the scholastic knowledge dries up the springs of romance in the heart of a girl’. Vogue reassured their readers that Dr. Feltner's findings were inconclusive and not trustworthy. ${ }^{128}$ In 1906, President Theodore Roosevelt addressed to Congress the irreversible repercussions of the declining birth rate,

When all home ties are loosened; when men and women cease to regard a worthy family life, with all its duties fully performed, and all

\footnotetext{
123 Bird, p. 115.

${ }^{124}$ Lynn D. Gordon, ‘The Gibson Girl Goes to College: Popular Culture and Women’s Higher Education in the Progressive Era, 1890-1920’, American Quarterly, 39.2 (1987), 211-230 (p. 213) <https://doi-org.vortex3.uco.edu/10.2307/2712910>.; Edward H. Clarke MD., Sex In Education: A Fair Chance For The Girls (Boston: James R. Osgood \& Co., 1873), pp. 39-40.

${ }^{125}$ Lynn D. Gordon, ‘The Gibson Girl Goes to College: Popular Culture and Women’s Higher Education in the Progressive Era, 1890-1920’, American Quarterly, 39.2 (1987), 211-230 (p. 215) $<$ https://doi-org. vortex3.uco.edu/10.2307/2712910>.

126 'Editorial: Social Topics: The Defenseless Theories Regarding Women', Vogue, 19 December 1895. ProQuest <https://www-proquest-com.vortex3.uco.edu> (p. 420); 'Editorial: Social Topics: A "Womanliness" Panic again’, Vogue, 08 April 1897. ProQuest <https://www-proquestcom.vortex3.uco.edu> (p. 210).; ‘Editorial: Social Topics: The Eternal Girl Problem’, Vogue, 19 August 1897. ProQuest < https://www-proquest-com.vortex3.uco.edu> (p. 114);

127 'Editorial: Social Topics: The Eternal Girl Problem', Vogue, 19 August 1897. ProQuest $<$ https://www-proquest-com.vortex3.uco.edu $>$ (p. 114).

128 'Features: Alumnae Marriages', Vogue, 22 February 1906. ProQuest $<$ https://www-proquestcom.vortex3.uco.edu> (p. 234).
} 
its responsibilities lived up to, as the life best worth living; then evil days for the commonwealth are at hand. ${ }^{129}$

Roosevelt's words demonstrated the need to restore order with traditional home values and encouraged women to stay within the private sphere.

\section{Women in Community Service}

As men and women were highly segregated in the social, political, and economic arenas, many first-generation women college graduates were excluded from a traditional career based on their sex. Therefore, the American Settlement House Movement which began in the 1880s provided an opportunity for women to work professionally outside of the home. ${ }^{130}$ Many first-generation women college graduates became settlement house workers and serviced the poor immigrant communities. ${ }^{131}$ Settlement houses, located in these poor immigrant communities, provided programs for the immigrant families to help acclimatise to American life. The Settlement Houses in the United States provided a platform for women to immerse themselves in social and government reform and gain valuable leadership and work experience. ${ }^{132}$ The settlement house workers established a wide variety of programs, such as, homemaking, instruction in English, basic American history and provided childcare services for mothers who worked all day. ${ }^{133}$ They realized that change could not happen without legislation. Thus, many government programs were created because of the settlement house workers. They advocated for public policy in the areas of

\footnotetext{
129 'President's Message to Congress Deals with Nearly Every National Problem: Urges Law Specifically Providing for Naturaliation of Japanese-If Insurrection Becomes a Habit in Cuba the Island Cannot Remain Independent. More Complete Federal Control of Corporations is Declared Necessary. Takes a Firm Stand on Side of Congress Deals with Nearly Every National Problem Takes a Firm Stand on Side of the Japanese in the School Controversy Recommends Legislation to Control Divorce-Points Out the Wisdom of Ship Subsidy and Favors Change in Currency System, But is Silent on the Tariff-Would Increase the Navy by Building One Big Battle-Ship a Year', Washington Post, 05 December 1906. ProQuest < https://www-proquest-com.vortex3.uco.edu> (p. 8).; see also, University of Virginia Miller Center, Presidential Speeches: December 3, 1906: Sixth Annual Message, $<$ https://millercenter.org/the-presidency/presidential-speeches/december-3-1906-sixth-annualmessage $>$ [accessed 27 February 2021] (para 56 of 113).

${ }^{130}$ Kathryn Kish Sklar, 'The Historical Foundations of Women's Power in the Creation of the American Welfare State', in Mothers of a New World: Maternalist Politics and the Origins of Welfare States, ed. by Seth Koven and Sonya Michel (London: Routledge, 1993), pp. $43-93$ (p. 67).

${ }^{131}$ Cott, Root of Bitterness, p. 27.

${ }^{132}$ Muncy, Creating a Female Dominion in American Reform 1890-1935, (Oxford: Oxford University Press, 1991), p. xiv. ProQuest Ebook Central. Stanton Coit opened the First American Settlement House, Neighborhood Guild, in New York City in 1886. Jane Addams and Ellen Gates opened Hull House in 1889.

${ }^{133}$ Davis, Allen F., Spearheads for Reform (New York: Oxford University Press, 1976), p. 43.
} 
labour standards, housing improvements, conditions of women and children, sanitation, and parks and playgrounds. The settlement workers were effective as they established policies to improve the urban landscape for its citizens and persuaded society that parks and creative play was important. ${ }^{134}$ As a result, settlement house workers became a significant force as organizers, reformers, and initiators to develop a better city atmosphere and help reconstruct the urban social environment. ${ }^{135}$ Walter Lippmann, author and journalist, believed the ‘awakened women’ used creative energies for the needs, desires and purpose of human politics, such as the development of business. Numerous times Lippmann referred to women's issues with the development of women's clubs and Jane Addams' perspective on the importance of social play for society. ${ }^{136}$ Lippmann's choice of words to describe women as 'awakened' suggests his perception that women were active participants in the progress of society and added value to the human race.

The settlement workers involvement in legislation helped spur the women's suffrage movement as these women devoted time and energy to the campaign. ${ }^{137}$ In 1910, America experienced the height of the suffrage campaign, as women fought for equality in education, work, and suffrage. ${ }^{138}$ Some states in America allowed women to vote and hold political office while other states rejected women into the political arena. For example, a poster on woman's suffrage in Nebraska read: ‘Women Vote for President And for All Other Offices in All Elections on the Same Terms as Men in Wyoming, Colorado, Utah, and Idaho. Why Not in Nebraska?' 139

Lippman challenged the government during the Progressive Era and claimed that the nation operated systematically, like a machine, rather than from a psychological impact on human needs. In Lippmann's book, A Preface to Politics, he expressed,

\footnotetext{
${ }^{134}$ Davis, Spearheads, p. 64-65.

${ }^{135}$ Davis, Spearheads, p. 64-65.

${ }^{136}$ Walter Lippmann, A Preface to Politics (Ann Arbor: The University of Michigan Press, 1962), pp. 71, 36-37, 52

${ }^{137}$ The Unfinished Nation-The Progressive Era, (Films Media Group, 2004), online film recording, Films On Demand, < https://fod-infobasecom.vortex3.uco.edu/p_ViewVideo.aspx?xtid=71435\&tScript $=0>$ [accessed 10 February 2021]. ${ }^{138}$ Cott, Nancy F., The Grounding of Modern Feminism (New Haven: Yale University Press, 1987), p. 3.

${ }^{139}$ Kathryn Cates Moore, 'Woman Suffrage Was a Long Fought Battle in Nebraska', Lincoln Journal Star, 14 August 2010. < https://journalstar.com/lifestyles/misc/woman-suffrage-was-a-long-foughtbattle-in-nebraska/article_accee85a-a65f-11df-b727-001cc4c002e0.html > [accessed 10 February 2021] (image 1).
} 
We need a new sense of political values. These times require a different order of thinking. We cannot expect to meet our problems with a few inherited ideas, uncriticised assumptions, a foggy vocabulary, and a machine philosophy. Our political thinking needs the infusion of contemporary insights. The enormous vitality that is regenerating other interests can be brought into the service of politics. ${ }^{140}$

Lippmann believed the government did not solve issues until a revolution forced the government to change. Lippmann spoke against the government's ignorance towards women's issues. He stated that women wanted change. He believed the vote was a vehicle for change and concluded that women wanted a 'readjustment of their relations to the home, to work, to children, to men, to the interests of civilized life'. ${ }^{141}$

\section{Changes for Women}

Although contradictory, the late Victorian Era and the Progressive Era had instigated many changes for women. One of the most significant and far-reaching changes was the acceptance of women in universities. Prior to 1837, colleges were not open to women. By the close of the Progressive Era, 930 universities were open to women in the United States, consisting of 830 co-ed universities and 100 women-only colleges. ${ }^{142}$ In 1918, females comprised $44 \%$ of the student body on the collegiate level and $41 \%$ in graduate work. ${ }^{143}$ This not only provided education for women, but also created opportunities for women to pursue goals outside of the private sphere. Evidence of women continuing on-the-job training and working in the public sphere was demonstrated by the Settlement House Workers and individuals like Elizabeth Bragg and Elizabeth Blackwell, although primarily through their own endeavours. Since the American culture practiced gender segregation and limited jobs were available to women, a woman’s education did not necessarily translate to many

\footnotetext{
${ }^{140}$ Lippmann, p. 29.

${ }^{141}$ Lippmann, p. 16, 51, 73.

${ }^{142}$ U.S. Department of Commerce, Statistical Abstract of the United States: 1920, 'Undergraduate Students in Universities, Colleges, and School of Technology, 1918’ (Washington, D.C.: Government Printing Office, 1921), no. 43

<https://www.census.gov/library/publications/1921/compendia/statab/43ed.html> (p. 116).

${ }^{143}$ U.S. Department of Commerce, Statistical Abstract of the United States: 1920, 'Universities, Colleges, and School of Technology, Number and Sex of Instructors and Students, and Total Working Income, 1918’, (Washington, D.C.: Government Printing Office, 1921), no. 43

<https://www.census.gov/library/publications/1921/compendia/statab/43ed.html> (p. 115).
} 
available professional jobs in the public sphere. However, the education that was now available to women enabled them to create their own opportunities.

A second significant change for women during this era was the creation of specialized groups to help resolve issues involving the health and well-being of women and children, and as a result, advanced legislation progress for women. The formation of specialized groups for women is an example of the wide-spread gender segregation of the American culture during the Progressive Era. Women from various economic backgrounds contributed to the cornerstone of imminent change from factory women fighting for increased wages, better working conditions, and flexible hours to Settlement House Workers advocating to city officials on public policy for a better social environment.

Specific examples of women advocating for themselves were the variety of women's clubs established in this period. Initially, women joined temperance societies led by men; however, when The New York State Sons of Temperance denied Daughters of Temperance member Susan B. Anthony permission to speak, women withdrew and formed the New York Temperance Woman's Society in 1852. ${ }^{144}$ Women began actively crusading about issues of suffrage and protesting the sale of alcohol. In order to actively combat intemperance among men and the protection of women from unfair laws, The Woman’s Christian Temperance Union was founded. According to the book, Well-Tempered Women, the WCTU was 'a celebration of women, dedicated to improving the image of and conditions for women'. ${ }^{145}$ Following the success of the WCTU, many women's organization were founded during the Progressive Era as they provided a platform for women to advocate for women's issues and help change government policy. For example, the creation of the Women's Trade Union League was an attempt to reform women's and children's working conditions. The National Women Suffrage Association, National Consumers League, National Congress of Mothers and General Federation of Women's Club were all founded by women and became an important backbone of the Progressive Era reform movement. According to Carol Mattingly, she believed the

\footnotetext{
${ }^{144}$ Mattingly, Carol. Well-Tempered Women: Nineteenth Century Temperance Rhetoric (Carbondale, IL: Southern Illinois University Press, 1998), p. 23.

${ }^{145}$ Mattingly, p. 40.
} 
temperance reform reflected 'the widespread, if repressed, unhappiness of many women with the failure of the legal system to protect them'. ${ }^{146}$

Through these endeavours and experiences, some women were able to improve their quality of life and created their own opportunities in the public sphere, but this also illustrated that gender separation within the society was prevalent as women fought exclusively for their specific needs. Examples of women in segregated jobs can also be seen through the U.S census data. Consistently, the largest sector for women in occupations from 1890 to 1910 were manufacturing, agriculture, and domestic and personal services which many of these occupations are connected to the home. ${ }^{147}$

Society continued to actively discriminate against women in the public sphere by adhering to the traditional idea that women were not suitable for the working environment or were merely capable of serving in a secondary role, as expressed by Theodore Roosevelt. Although large numbers of women were enrolled in universities at the undergraduate and graduate level, few women attended professional schools, which include law, medicine, theology, dentistry, pharmacy, and veterinary medicine. ${ }^{148}$ In addition, the large attendance of women in undergraduate and graduate programs did not translate into complex and higher paying jobs for women. The traditional custom of women as head of the domestic sphere where responsibilities lie within the home and with the children overshadowed the new opportunities for women as her primary objective in life was to have children and raise a healthy family. Society continued to hold onto this traditional idea of women, while at the same time, women outwardly displayed themselves in a traditional style

\footnotetext{
${ }^{146}$ Mattingly, p. 15-16.

${ }^{147}$ U.S. Department of Commerce, Statistical Abstract of the United States: 1910, 'Table No. 137 Population 10 Years of Age and Upward Engaged in Gainful Occupations, Census Years 1890 and 1900: By Sex and Specified Occupations’ (Washington, D.C.: Government Printing Office, 1911), no. 33 < https://www.census.gov/library/publications/1911/compendia/statab/33ed.html> [accessed 14 February 2021] (pp. 224-228).; U.S. Department of Commerce, Statistical Abstract of the United States: 1930, 'Persons 10 Years of Age and Over in Each General Division of Occupations', (Washington, D.C.: Government Printing Office, 1930), no. 52 < https://www.census.gov/library/publications/1930/compendia/statab/52ed.html > [accessed 14 February 2021] (p. 50).

${ }^{148}$ U.S. Department of Commerce, Statistical Abstract of the United States: 1929, 'No. 130 Universities, Colleges, and Professional Schools by State’, (Washington, D.C., Government Printing Office, 1929), no. $51<$ https://www.census.gov/library/publications/1929/compendia/statab/51ed.html > [accessed 14 February 2021] (p. 118).
} 
of dress with long, full skirts and corseted bodices. Even women who orated about women's rights still adhered to the social norm of dress.

Dress is a complex issue for women, in some instances, she may appear too masculine, and in doing this, society identifies women as characteristically masculine and not abiding by the social customs of the culture. Simmel claims that individuals use dress for a sense of belonging in society. When an individual deviates from the social norms of dress, they may be seen as an outcast and different from the group. Therefore, a woman who already lectured on a sensitive topic, such as women reform, drastically changing dress may deter the social group support. This was exemplified with the bloomer costume, as it was negatively received by the public because the dress deviated too far from the prescribed culture.

\section{The Meaning of Dress in a Mass Consumer Economy}

Living in a mass consumer society, the development of an abundance of goods created a need for society to actively partake in its consumption. A change of buying and spending habits among society was imminent. Historian, Alan Tratchenberg, claimed department stores became a 'pedagogy of modernity', because they 'stood as a place of learning as well as buying'. He further stated, department stores offered 'infinite charm and cheap prices' as this was the basis for 'modern living' in an economic system. In addition, department stores were designed to entice people with their lavish buildings of marble, columns, and central courtyards which displayed goods that preyed on human desires and wants. ${ }^{149}$ Leon Fink highlighted the novel, Sister Carrie, and summarized it as depiction of a poor country girl's desire for beautiful things. ${ }^{150}$ In Sister Carrie, the narrator stated, 'The nature of these vast retail combinations...will form an interesting chapter in the commercial history of our nation.' ${ }^{151}$ Richard Ohmann also indicated the connection of human desires and wants. He believed consumers were prone to ‘seduction' as retailers created 'an environment of desire'. ${ }^{152}$

\footnotetext{
149 Trachtenberg, pp. 130-132.

${ }^{150}$ Leon Fink, Major Problems in the Gilded Age and Progressive Era: Documents and Essays (Lexington, MA: D.C. Heath and Company, 1993), p. 449.

${ }^{151}$ Theodore Dreiser, Sister Carrie (Cambridge, MA: Robert Bentley, Inc., 1971), p. 26.

152 Richard Ohmann, Selling Culture: Magazines, Markets, and Class at the Turn of the Century (London: Verso, 1996), p. 79. Ohmann based this idea from Richard Terdiman.
} 
Lears claimed that capitalism promised the 'magical self-transformation' through the 'renewal of consumer desire'. Lears further declared that Wanamaker and other department store owners used the department store as a tool to provide an array of mass merchandise, to acculturate the immigrants and provide an example of the standardized 'American look' which was a criteria for social acceptance. ${ }^{153}$ Therefore, adopting the 'American' way of dress identified those immigrants as American and less by their native land. Furthermore, newspapers and magazines noted the significant impact of immigrants adopting American dress so they would become more socially accepted in America. For example, Bruno Lessing, writer for Cosmopolitan magazine, published a story about an Italian immigrant, Marie, who has just come to America to retrieve her lover. Marie’s Italian friend who had been in America for a while warned her, 'you are now in America and you must dress as the American's dress'. ${ }^{154}$ The media taught the immigrants that dress was important as it identified you as an American. In addition, changing dress also helped unify the country as the immigrants not only looked similar to other Americans but they also demonstrated their willingness to discard their customs of their native land and accept the new American ways. For example, the Ford Motor Company had English classes for its foreign-born workers and upon graduation they discarded their traditional clothes and put on an 'American' suit and waved the American flag. This process cleansed them of their ethnic origin and transformed them into an American. ${ }^{155}$

The immigrant's transition to ‘American’ dress demonstrated their readiness to accept a new culture. As discussed, Sapir noted the social customs and conformity of society are significant as they influence the prevailing way of dress. ${ }^{156}$ Therefore, to dress within the social customs of America was important as it signified unity within society. Brake noted, many first-generation immigrants accepted the American culture as they wished to find a new identity in a new country. ${ }^{157}$ The Chicago

\footnotetext{
153 Lears, p. 122.

${ }^{154}$ Bruno Lessing, ““Alla Napolitana!": Being the Mulberry Street End of a Transoceanic

Romance.' Cosmopolitan, August 1908. ProQuest <https://www-proquest-com.vortex3.uco.edu> (p. 316).

${ }^{155}$ Prchal, Tim, 'Reimagining the Melting Pot and the Golden Door: National Identity in Gilded Age and Progressive Era Literature’, MELUS, 32.1 (2007), 29-51 (p. 33)

$<$ http://vortex3.uco.edu:2050/login?url=https://www.jstor.org/stable/30029705 $>$ [accessed 10 February 2021].

${ }^{156}$ Sapir, Edward, 'Fashion', in Perspectives of Fashion, ed. by George B. Sproles (Minneapolis, MN: Burgess Publishing Co., 1981; repr. New York: Macmillan Publishing Co., Inc., 1931) pp. $23-27$ (p. 24).

${ }^{157}$ Brake, p.21.
} 
Tribune published an article demonstrating the quick adoption of immigrant women wearing American style dresses. A before and after picture showed two immigrant women and their transformation of dress. This article featured the change from their traditional costume of their home country to an Americanized look as shown in Figure [12]. ${ }^{158}$ This is another example of how media encouraged and taught immigrants that dress was important to American society. The article may have slightly overdramatized some of the native costumes for every day wear but this article demonstrated that immigrants were accepting the American culture. The immigrants embraced modernity as they adapted to fashion change in a land where opportunity, progress, and innovation were encouraged.

The growth of urbanization created an environment where people interfaced among many different social classes, therefore, clothing was important because it identified one's personal social status. In the novel, Sister Carrie, fine raiment was noted repeatedly as a connection to wealth. Carrie compared herself to her friend,

Carrie had gotten herself up charmingly enough, but this woman pained her by contrast. She seemed to have so many dainty little things which Carrie had not. There were trinkets of gold, an elegant green leather purse set with her initials, a fancy handkerchief, exceedingly rich in design, and the like. Carrie felt that she needed more and better clothes to compare with this woman, and that anyone looking at the two would pick Mrs. Vance for her raiment alone. ${ }^{159}$

Scholars noted the significance of clothing during this time and how cities became a platform to display dress. Fashion historian, Joanne Entwistle, claimed that cities were dirty and dangerous, therefore, clothing become important among a large number of strangers to identify and read others as safe. ${ }^{160}$ Lears declared that because society was inherently 'mobile' and 'anonymous' fashion carried 'a heavier cultural weight' than analysing it as 'trivial impressions'. ${ }^{161}$ A head resident at The House on Henry Street, a settlement house that worked with immigrant families, recognized that young, immigrant working girls spent money on 'exaggerated raiment' and 'conspicuous dress'. The head resident concluded that the expression of dress could

\footnotetext{
158 'Cupids Teaches American Ways to Emigrants Recent Arrivals in Chicago.', Chicago Tribune, 08 September 1907. ProQuest <https://www-proquest-com.vortex3.uco.edu> (p. G8).

${ }^{159}$ Dreiser, p. 288.

160 Entwistle, p. 116.

${ }^{161}$ Lears, p. 56.
} 
possibly be construed as a sense of self-respect and self-importance. ${ }^{162}$ This exemplifies the importance of dress and its connection to social image and social identity.

Fashion historian, Valerie Steele, not only noted that modern cities provided a 'stage' for dress, but she further stated that the people in the cities became more competitive with their fashion and this inherently led to the creation of new styles. In general, people stay within the fashion rules and guidelines but may add a small variation to the existing style. ${ }^{163}$ Urbanization encouraged a freer, more independent way of life and the creation of new styles provided a sense of individuality. To summarize Steel, although designers dictated fashion styles it was the city environment that allowed the people on the streets to adjust these fashions for their own needs, wants, or desires. Simmel's fashion theory had recognized that fashion could either align one with society or differentiate themselves from society. Differentiating one's self in the city environment led to the origin of street fashion. With the increasing number of people in the cities, Lears believed that fashion played an integral part during this time, as dress became an 'instrument for refashioning the self'. ${ }^{164}$

\section{First Women as Stereotypes}

As urbanization created a 'stage' to display one’s self-identity through dress, the stereotype for women began to emerge attaching a specific type of dress to a specific type of lifestyle, thus, demonstrating the importance of dress in relation to prescribed codes and symbols in society. Carolyn Kitch noted the Gibson Girl was the first famous visual stereotype to define the American woman through mass media. ${ }^{165}$ The Gibson Girl was an image that society aimed to emulate. Charles Dana Gibson created the Gibson Girl in forms of drawings and his idea of the New Woman. The Gibson Girl first appeared in Life magazine in 1890 and gained rapid popularity

\footnotetext{
${ }^{162}$ Lillian D. Wald, The House on Henry Street (New York: Henry Holt and Company, 1915), pp. 190, 191, 192.

${ }^{163}$ Valerie Steele, Paris Fashion: A Cultural History, rev edn (London: Bloomsbury Publishing, 2017), p. 139.

${ }^{164}$ Lears, p. 56.

${ }^{165}$ Kitch, Carolyn, The Girl on the Magazine Cover: The Origins of Visual Stereotypes in American Mass Media (Chapel Hill; London: University of North Carolina Press, 2001), p. 37. In the endnotes, Kitch comments that other scholars have recognized that the Gibson Girl was the first famous visual type in America, p. 198.
} 
throughout the early 1900s. ${ }^{166}$ The Gibson Girl look possessed a tall, radiant woman with a large bust, small corseted waist, and voluminous upswept hair. ${ }^{167}$ Her lifestyle expressed a bold, confident, and independent new woman but her dress displayed tradition. Gibson utilized dress that stayed within the fashion styles and trends that was common for all women and did not necessarily fit the personality of the New Woman, nor did it adhere to the New Woman's activities. For example, the Gibson Girl in the drawing, 'Fore! The American Girl to All the World', was dressed in traditional clothes as she represented an active and modern woman. The traditional clothes consisted of a high collar, long sleeve blouse, a small corseted waist, and a full-length skirt. The drawn-up sleeves indicate the traditional clothing was adjusted to suit her active lifestyle. Shown in Figure [13], the Gibson Girl is depicted on the beach, the outer-most boundaries of America, with a golf club in one hand and the other hand is outstretched as she 'both hails and warns the world of her ascendance’. 168

From the popularity of Gibson Girl, the Fisher Girl and the Christy Girl emerged into American media. Both the Fisher Girl and the Christy Girl features were similar to the Gibson Girl with upswept hair and traditional dress. The Fisher Girl was a little more adventurous than the Gibson Girl as she was shown participating in more physical activities, such as, motoring, boating, and camping. The Fisher Girl was depicted primarily in corseted, long dresses, as illustrated in Figure [14]. However, her dress changed according to her activity. For instance, when Fisher Girls were depicted camping they wore a loose sailor style blouse untucked with a short skirt, reaching right below the knees and while motoring she was depicted wearing goggles and a duster coat, as shown in Figure [15-16]. ${ }^{169}$ Although the Fisher Girl's sporting outfits seemed less traditional than the corseted, long dresses, the age of the girls depicted camping also looked younger, therefore, shorter skirts were accepted on young adolescent girls. Harrison Fisher continued to follow the current fashion styles. For instance, it was acceptable for women to wear goggles and a duster while

\footnotetext{
${ }^{166}$ Kitch, p. 37.

${ }^{167}$ Martha H. Patterson, Beyond the Gibson Girl: Reimaging the American New Woman, 1895-1915, (Urbana, IL and Chicago: University of Illinois Press, 2005), p. 28.

${ }^{168}$ Patterson, Beyond the Gibson Girl, p. 36,

${ }^{169}$ Harrison Fisher, in 'Covers', Ladies’ Home Journal, August 1912. ProQuest <https://wwwproquest-com.vortex3.uco.edu> (cover).; Harrison Fisher, in 'Covers', Ladies' Home Journal, August 1914. ProQuest < https://www-proquest-com.vortex3.uco.edu> (cover).; see also, Kitch, p. 49.
} 
motoring. ${ }^{170}$ The Fisher Girl was closely associated with the themes of education, sports, and friendships in order to make them better wives and mothers. ${ }^{171}$

In 1913, Harrison Fisher captured this quintessential American girl graduating from college which was published on the cover of the Ladies’ Home Journal. ${ }^{172}$ Traditionally, women college students were perceived as masculine, but the depiction of the stereotypical American girl demonstrated that women college graduates were feminine and attractive. According to Lynn D. Gordon, numerous magazines published articles about the activities and lifestyle of the college girl. Many depicted girls giving plays, attending social parties, and playing pranks on one another. Good Housekeeping's, 'College Girls' Number', focused on articles pertaining to the ideal husband, allowances for wives, and students’ camping vacations. ${ }^{173}$ In 1908, Harrison Fisher produced a series, 'Harrison Fisher's College Girls' where he illustrated the life and interests of the college girl, although, he largely focused more on her socializing and friendships. ${ }^{174}$ The media did not give a good, clear picture of the accomplishments women were making in relation to their studies. This exemplifies that the college girl was not perceived by society as a studious and serious girl but

\footnotetext{
${ }^{170}$ Harrison Fisher illustrated a series, 'The Greatest Period in a Girl's Life', which represented the traditional moments of a young woman marrying, such as depicting the proposal, the trousseau, the wedding, the honeymoon and the first night at home all of which the Fisher Girl wore traditional dress. Fisher, Harrison. 'The Greatest Period in a Girl's Life: The Supreme Moment--The Proposal', in Ladies' Home Journal, 15 March 1911. ProQuest < https://www-proquest-com.vortex3.uco.edu> (p. 7).; Fisher, Harrison, 'The Greatest Period in a Girl's Life: A Series of Six Pictures, of Which this is the Second: The Trousseau’, in Ladies' Home Journal, 15 April 1911. ProQuest < https://wwwproquest-com.vortex3.uco.edu> (p.7).; Harrison Fisher, in 'Covers', Ladies' Home Journal, 15 May 1911. ProQuest < https://www-proquest-com.vortex3.uco.edu> (cover).; Fisher, Harrison. 'The Greatest Period in a Girl's Life: The Honeymoon Abroad', in Ladies' Home Journal, July 1911. ProQuest < https://www-proquest-com.vortex3.uco.edu> (p. 19).; Fisher, Harrison, 'The Greatest Period in a Girl's Life: Their First Evening in Their Own Home', in Ladies' Home Journal, August 1911. ProQuest < https://www-proquest-com.vortex3.uco.edu $>$ (p. 21).

${ }^{171}$ Kitch, p. 48.

${ }^{172}$ Harrison Fisher, in 'Covers', Ladies' Home Journal, June 1913. ProQuest < https://www-proquestcom.vortex3.uco.edu> (cover).; see also, Kitch, p. 50.

${ }^{173}$ Lynn D. Gordon, 'The Gibson Girl Goes to College: Popular Culture and Women's Higher Education in the Progressive Era, 1890-1920', American Quarterly, 39.2 (1987), 211-230 (pp. 215216) <https://doi-org.vortex3.uco.edu/10.2307/2712910>.

${ }^{174}$ In the Ladies' Home Journal, Harrison Fisher's 5 part series, 'Harrison Fisher's College Girls', illustrated activities of sailing at the lake, hoop rolling, attending a fudge party, studying, and upon graduation a dinner celebration. Harrison Fisher, 'Harrison Fisher's College Girls: The Lady of the Lake’, in Ladies' Home Journal, May 1908. ProQuest < https://www-proquest-com.vortex3.uco.edu $>$ (p. 9).; Harrison Fisher, 'Harrison Fisher's College Girls: The College Girl After the May-Day HoopRolling', in Ladies' Home Journal, March 1908. ProQuest < https://www-proquestcom.vortex3.uco.edu> (p. 9).; Harrison Fisher, 'Harrison Fisher's College Girls: A Fudge Party', in Ladies' Home Journal, August 1908. ProQuest < https://www-proquest-com.vortex3.uco.edu $>$ (p.7).; Harrison Fisher, 'Harrison Fisher's College Girls: The College Girl at Her Studies', in Ladies' Home Journal, April 1908. ProQuest < https://www-proquest-com.vortex3.uco.edu $>$ (p. 11).; see also, Kitch, p. 48.; Cott, The Grounding, p. 40.
} 
rather as social and frivolous. However, depicting the college girl in traditional clothing also promoted to society that the everyday girl was graduating from college instead of a radically different type of woman.

The Christy Girl was illustrated as a more contemporary and political woman than the Gibson or the Fisher Girl. The Christy Girl was depicted in helping with the war effort for World War I. Through these war campaigns, the Christy Girl was shown, at times, with risqué clothing or masculine military jackets. ${ }^{175}$ With the message to fight or buy bonds, the Christy Girl was illustrated in a Greek style dress made of soft, malleable fabric which hung loose over her body, exposing her shoulders and neckline, holding the American flag high over her head. ${ }^{176}$ In another illustration she was shown wearing a military jacket with the slogan, 'I Want You for the Navy'. It is important to note, that before the war, the depictions of the ideal woman remained with traditional standards. However, during the war, the Christy Girl was illustrated differently with having more liberty to show unorthodox images of women wearing types of clothing outside of the social norms of the culture.

\section{To Corset or to Un-corset}

In 1910, Vogue expressed, 'a strange twist the fashions have taken in a few months! ${ }^{177}$ An example of a gown featured in the article was described as,

A wonderful gown that, unlike many present evening gowns, cut to drag heavily on the floor in a slender, unlined, satin train, is made of rose colored liberty satin that sheaths the figure from the bust to the floor, not by means of many seams but flatly and closely, and revealing the apparent absence of any so-called corsets, its place being taken in reality by the most subtle form of unboned satin bandagings. ${ }^{178}$

\footnotetext{
${ }^{175}$ Howard Chandler Christy, 'Fight or Buy Bonds Third Liberty Loan’ [online] $<$ https://www.metmuseum.org/art/collection/search/390928> [accessed 27 February 2021].; Howard Chandler Christy, 'Clear the Way' [online] < https://www.metmuseum.org/art/collection/search/391027> [accessed 27 February 2021].; Howard Chandler Christy, 'I Want You for the Navy' [online] < https://www.metmuseum.org/art/collection/search/390926> [accessed 27 February 2021].

${ }^{176}$ Howard Chandler Christy, 'Fight or Buy Bonds Third Liberty Loan' [online] $<$ https://www.metmuseum.org/art/collection/search/390928> [accessed 27 February 2021].

177 'Fashion: Parisian Adaptation of Oriental Fashion', Vogue, 01 November 1910. ProQuest, $<$ https://www-proquest-com.vortex3.uco.edu $>$ (p. 34).

178 'Fashion: Parisian Adaptation of Oriental Fashion', Vogue, 01 November 1910. ProQuest < https://www-proquest-com.vortex3.uco.edu > (p. 34-35).
} 
Several key words in this article suggests the 1910 dress was similar to the shift dress. First, the phrase 'not by means of seams' suggests that a minimal number of seams made up the construction of this particular 1910 dress. It does not state how many seams, but one can infer that it was a simpler garment than the previous fashions. The article states clearly that the 1910 garment is 'unlike many present evening gowns'. Secondly, the word 'flatly' suggests that the garment is void of ruffles, tucks, or gathers. Thirdly, and perhaps, the most important detail acknowledged in this article is 'revealing the apparent absence of any so-called corsets'. The previous fashion from this era had been heavily corseted. The construction of the corset consisted of hard whalebones in which women proceeded to 'tight lace' their corsets. As a result, they cinched their waist significantly in order for proper fitting of their garments. Because of cinching the waist, women's health was heavily debated among physicians and other professionals during this time. Discarding the corset after centuries of abiding by this rule was a clear break from traditional values. Although undergarments were still worn, the brassiere, was referred to as 'most subtle form of unboned satin bandagings'. The brassiere was replaced by the corset; yet, the absence of the corset was a dramatic change. Similarly, the structure of the shift dress holds these same components, as it is a fourseamed garment, minimal seams for a dress, and the fabrication is a flat and smooth surface void of any manipulation of the fabric; such as, gathering, drapery, or folds of the garment. Lastly, the shift dress is a silhouette which requires little or no undergarments and the wearer can easily move.

A significant difference from the shift to the description of the 1910 gown was the fit. The words that identify the fit of the 1910 dress are 'sheaths the figure from the bust to the floor' and 'closely'. The article of 1910 implies that the structure outlined the body in a close fit. In addition, the phrase used in the excerpt, 'and revealing the apparent absence of any so-called corsets', indicates that the dress fits so closely to the body that one can notice if the wearer is not wearing proper undergarments. The shift dress hangs straight from the shoulder in which it does not cling or fit snug to the body. Only when the wearer moves does the shift dress reveal her body structure. Many of the garments discussed in the article signal inspiration from distant and exotic lands, such as, Japan, Greece, and Egypt. Consequently, the dominant fashion changed to a cylinder structure from 1910 to 1914 with influences from the orient and the Directory and Empire periods. Between 1910 and 1914, 
examples of fashionable styles from the haute couture designers include items such as, long tunics over narrow skirts, empire waist gowns, and Paul Poiret's popularized hobble skirt. ${ }^{179}$

Although designers borrowed from a variety of cultures that inspired a straight construction, by the latter part of 1914, the wider silhouette eased its way into fashion. An article in Vogue stated the fashion direction of skirts were ' 3 meters wide and 8 inches short' and illustrated several key designers promoting wider skirts, such as Callot and Premet. ${ }^{180}$ The widening of the silhouette also relates to the timing of World War I. Although designers were moving to a wider skirt, an article in Vogue highlighted designers' difference in style direction. For example, in the February $15^{\text {th }}$ issue in 1915 Vogue wrote, 'Paquin uses fullness and tightness' whereas 'Lanvin [uses] slimness and youth'. ${ }^{181}$ Vogue's summary of the fashions is illustrative,

This season also there are contradictory elements in fashion. On the one hand, there is the gown on semi-fitted lines, the gown that gives the rather straight silhouette; on the other, there is the gown with the close waist and full skirt. ${ }^{182}$

The wider skirt did prevail as the fashion mode and in September 1916, Vogue reported 'skirts remain wide and one welcomes this soft falling fullness which is less cumbersome than the hoop and certainly less trying than the narrow tubes in which we struggled about when that fashion was at its height'. ${ }^{183}$ The fullness of the garments continued in 1917 as Vogue expressed the demise of the straight silhouette, 'as if by one accord each house seems suddenly to have been inspired to bend if not

\footnotetext{
${ }^{179}$ C.H.L., 'Fashion: The Survival of the Fittest Fashions', Vogue, 05 April 1912. ProQuest $<$ https://www-proquest-com.vortex3.uco.edu> (pp. 17-19).; 'Fashion: A Finger on the Pulse of Fashion.', Vogue, 15 October 1912. ProQuest <https://www-proquest-com.vortex3.uco.edu $>$ (pp. 2325, 100).; 'Fashion: Noted at the Paquin Opening', Vogue, 01 October 1913. ProQuest <https://wwwproquest-com.vortex3.uco.edu> (p. 40).; 'Fashion: Dispatches from the Openings Read', Vogue, 15 September 1913. ProQuest <https://www-proquest-com.vortex3.uco.edu $>$ (pp. 27- 30, 118). (Example of Poiret's 'hobble' skirt on p. 30)

${ }^{180}$ E. G., 'Fashion: Fashion has Met the Enemy and —-', Vogue, 01 October 1914. ProQuest $<$ https://www-proquest-com.vortex3.uco.edu > (pp. 35-40, 35, 38).

181 'Fashion: Paquin Uses Fulness and Tightness, Half and Half', Vogue, 15 February 1915. ProQuest $<$ https://www-proquest-com.vortex3.uco.edu> (p. 19).; 'Fashion: Lanvin and Slimness and Youth', Vogue, 15 February 1915. ProQuest <https://www-proquest-com.vortex3.uco.edu > (p. 20) 182 'Fashion: The Conflicting Lines of the Spring Silhouettes', Vogue, 15 February 1915. ProQuest $<$ https://www-proquest-com.vortex3.uco.edu $>$ (p. 23).

183 'Fashion: The Straw Ballot of the Paris Openings', Vogue, 15 September 1916. ProQuest $<$ https://www-proquest-com.vortex3.uco.edu $>$ (p. 35).
} 
break the straight line, perhaps a preliminary step to breaking it altogether later on'. ${ }^{184}$ In such a definitive manner, this article claims that the wider skirts were here to stay and the straight silhouette would not return into fashion. Therefore, it is important to investigate and identify the factors which influenced the radical change of swiftly moving to a short and straight silhouette which became such an iconic symbol of the 1920s.

\section{Inspiration from Ancient Greece}

Although the shift dress was considered a new garment in the 1920s, its simplistic form had antecedents in antiquity. The shift dress's earliest form originated from the tunic. According to fashion historian Phyllis Tortora, the tunic was an essential part of dress in all of the civilizations of antiquity and different regions had variations from the fit, construction and use of garment. ${ }^{185}$ The tunic was worn short and long, by the rich and the poor and as an under-garment, overlay, or outergarment. Greek civilization utilized the tunic as their predominant form of dress with two specific types, the peplos and the chiton. ${ }^{186}$ The peplos differed from the chiton as it was created from one large rectangular cloth. ${ }^{187}$ The large cloth was 'formed into a cylinder and then folded along the topline into a deep cuff, creating an apoptygma, a cape-let like overfold'. The peplos was secured by a fibulae, brooch-like pin. ${ }^{188}$ The chiton's structure closely resembles that of the shift dress as they both are constructed by two side seams. Typically, a chiton was constructed by,

stitching two rectangular pieces of fabric together along either sideseam, from top to bottom, forming a cylinder with its top edge and hem unstitched. The top edges are then sewn, pinned, or buttoned together at two or more points to form shoulder seams, with reserve openings for the head and arms. ${ }^{189}$

\footnotetext{
184 'Fashion: A Forecast of the Spring Mode', Vogue, 01 February 1917. ProQuest, <https://wwwproquest-com.vortex3.uco.edu> (p. 27).

185 Tortora, p. 30.

${ }^{186}$ Department of Greek and Roman Art, ‘Ancient Greek Dress’ (2003), $<$ http://www.metmuseum.org/toah/hd/grdr/hd_grdr.htm> [accessed 26 January 2021] (para 1 of 2). 187 Carl Köhler, A History of Costume, (London: Constable and Company, 1963) pp. 103-104.

${ }^{188}$ Harold Koda, Goddess: The Classical Mode (New York: The Metropolitan Museum of Art; London: Yale University Press, 2003), p.21. (This book has been published in conjunction with the exhibition 'Goddess', held at The Metropolitan Museum of Art in NY from May 1, 2003 through August 3, 2003).; see also Department of Greek and Roman Art, para 1 and 2 of 2.

189 Koda, Goddess, p. 21.
} 
During ancient times both men and women wore tunics, however the length varied according to gender. Men typically wore both short and long tunics, yet, women wore primarily long versions, although with some exceptions: the Greek and Roman goddess of women and patroness of the hunt, Artemis and Diana, were both depicted with shorter versions of the chiton shown in Figures [17, 18]. ${ }^{190}$ From the records of ancient life, Grecian vases are a valuable source from which to analyse how women dressed and for what occasions. Many women were depicted on Greek vases dancing and playing musical instruments wearing full-length tunics of a variety of styles. As shown in Figure [19], some women were depicted with deep slits in their skirts that revealed most of the leg which allowed a freer range of movement. Another example of this is shown in Figure [20], a party scene displayed a group of women wearing short chitons, however, these women were dancing girls and not your typical Greek lady. Regardless of length, the tunics shown on the vases were primarily sheer and loose which enabled the body to move.

\section{Influencers of the Straight Form: Modern Dancers, Artists \& Designers}

At the turn of the twentieth century, three significant American women, Loie Fuller, Isadora Duncan and Ruth St. Denis, broke away from classical ballet and created their own form of dance, which in turn had a dramatic impact on the dresses worn. These three women are of particular importance as they were innovators of modern dance and they all expressed themselves through fluid, unstructured dresses which at this time was a drastic break from the corsets that traditional ballet had worn. By 1892, Loie Fuller moved to Paris where she began her adult career as she reimagined the traditional skirt dance. Isadora Duncan moved abroad in 1898 and developed dances centred around the purity and simplistic forms of ancient Greek dancing, and Ruth St. Denis started her solo career in 1905 and infused Eastern cultures with the art of dance. These modern dancers believed in a freer, more expressionist type of dance rather than a rigid, academic form that was taught through ballet. ${ }^{191}$ In 1917 Ruth St. Denis wrote an article for Vogue explaining the difference of the American point of view from classical ballet to modern dance. St. Denis

\footnotetext{
${ }^{190}$ Department of Greek and Roman Art, para 2 of 2.

191 'Modern Dance', in Canadian Encyclopaedia [online], ProQuest <https://www-proquestcom.vortex3.uco.edu>
} 
believed America's youth was not amenable to the strenuous, disciplinary of classical ballet as the ballet form is based on past generations of traditional movement and stifles the individual expression. ${ }^{192}$

Although the modern dancers' art forms differed, they all wanted to transform the art of dance to embody a soulfulness spirit and wear garments that expressed the same ethos of freedom. Ruth St. Denis expressed, 'Tights and corsets....and our ridiculous fashion in dress had so dwarfed our ideas and our bodies....' ${ }^{193}$ This same belief resonated with all three modern dancers, as modern dance was an expressionistic form comprising of total body movements, they believed dress should freely and unobtrusively assist in their art expressions. All three dancers were innovators in creating or reinventing a style of dress for their practice. Loie Fuller's dance method was similar to a traditional skirt dance, however, she developed a unique dress for her performance. Loie Fuller's drawing of her dress is shown in Figure [21] and this was noted on her patent for the costume,

In hanging the skirt from the head of the wearer, it will be readily seen that the curves or spread of the garment will have much more radial latitude than a garment secured around the waist or close under the arms, thus permitting the production of more rounded out and graceful evolutions of the garment. By use of a skirt of variegated colors in connection with white or colored projections of electric or calcium lights, beautiful scenic effects are produced. ${ }^{194}$

Loie Fuller wearing her dress can be seen in Figure [22]. Isadora Duncan's dance technique was the expression of her inner spirit connecting to the movement of nature and she infused Grecian heritage into her dance. Isadora Duncan choose to borrow from antiquity with adopting the short, Hellenistic style tunic as this garment provided her with the movement she expected and the Greek lifestyle she practiced. A photograph of Isadora Duncan in her Hellenistic style tunic can be seen in Figure [23]. Ruth St. Denis’ dance was closely related to the Eastern culture, yet, she performed many dances from a variety of cultures and clothed herself in relation to

\footnotetext{
192 Ruth St. Denis, 'Features: The Education of the Dancer', Vogue, 01 April 1917. ProQuest $<$ https://www-proquest-com.vortex3.uco.edu $>$ (pp. 63-64).

${ }^{193}$ Ruth St. Denis, 'Does the Tango Need a Defender? If So, Here She Is', Chicago Daily Tribune, 15 June 1913. ProQuest <https://www-proquest-com.vortex3.uco.edu> (para 6 of 10).

194 Sally R. Sommer, 'Loïe Fuller', The Drama Review: TDR, 19.1 (1975), 53-67 (p. 61) < https:/doiorg.vortex3.uco.edu/10.2307/1144969 > . From Patent for Costume Design, filed by Loie Fuller, October 1893)
} 
her dances. She used rags for her serpin dance, light draperies for the Greek dances, and yards of Indian silk for the Nautch girl dance. ${ }^{195}$ An example of Ruth St. Denis’ costumes are shown in Figures [24-27]. Ruth St. Denis differed from Loie Fuller and Isadora Duncan in that she utilized different types of dress from a variety of cultures, where the other dancers deeply committed themselves to one specific form of dress that closely resembled the shift dress. ${ }^{196}$ Initially, all three modern dancers were favoured in Europe but had difficulty gaining acceptance throughout the United States for their art form. The unorthodox, risqué modern dancing may not have aligned with conservative Protestant values. Eventually, these dancers became popular in America and filled theatre houses. ${ }^{197}$

Loie Fuller was the first of the American modern dancers to pursue her art form in Europe and she gained wide-spread recognition in Paris for her work almost instantly. ${ }^{198}$ In 1893, Loie fuller designed, developed, and patented her costume which resembled both traditional and modern fashion. The use of excessive fabric in her costume represented traditional dress, however, the unstructured silhouette, fabric extending beyond her form and the process of colour reflection are elements of modernism. Although this dress is not per se a direct evolution of the shift dress, many similarities do exist and Loie Fuller's innovative process in clothing is noteworthy. ${ }^{199}$ One of the most significant aspects of her garment was that the design

195 'Ruth St. Denis Defends Her Art--What She Thinks of Local Critic Who Assailed It', Nashville Tennessean and the Nashville American, 18 April 1914. ProQuest <https://www-proquestcom.vortex3.uco.edu> (p. 1).

196 Jane Sherman and Christena L. Schlundt, ‘Who’s St. Denis? What Is She?’, Dance Chronicle, 10.3 (1987), 305-329 (pp. 307, 310, 311, 314, 317) <http://www.jstor.com/stable/1567763> [accessed 10 February 2021].

197 'Recent Activities in the Society World: Triumphal Return of Isadora Recalls Early Life in Chicago’, Chicago Tribune, 26 March 1911. ProQuest $<$ https://www-proquest-com.vortex3.uco.edu $>$ (p. 9).; ‘Up and Down Broadway’, New York Times, 27 February 1916. ProQuest $<\underline{\text { https://www- }}$ proquest-com.vortex3.uco.edu> (p. 1).

${ }^{198}$ Sally R. Sommer, 'Loïe Fuller', The Drama Review: TDR, 19.1 (1975), 53-67 (p. 55, 58) < https://doiorg.vortex3.uco.edu/10.2307/1144969>.

${ }^{199}$ Loie Fuller became known in Paris as an expert in utilizing light and movement with fusing colours with one another to create a dramatic and beautiful effect. In 1893, the Daily American credited Loie Fuller to inspiring a fashion mode with the use of combining colours on fabrics of silk, satin gauzes and lightweight woollens that shift and reflect a rainbow of colours when moved. Additional newspapers had also highlighted Loie Fuller's ingenuity with working with colours and lightweight materials on her dresses. "'La Loie Fuller”: An American Maid Who Has Created a Style in Paris', Daily American, 02 June 1893. ProQuest <https://www-proquest-com.vortex3.uco.edu> (p. 3).;

'Ballrooms Lit by Electricity with Colored Rays_-White Dress Suits For Men', New York Times, 09 April 1893. ProQuest <https://www-proquest-com.vortex3.uco.edu> (p. 12).; Emma M. Hooper, 'The New Colors and Materials', Ladies’ Home Journal, September 1893. ProQuest $<\underline{\text { https://www- }}$ proquest-com.vortex3.uco.edu $>$ (p. 18). 
stemmed from an unstructured skirt hanging from the wearer's head. At the time when fashion was fitted closely to the waist, Loie Fuller recognized that her costume would be better suited as a garment that hung from her body allowing freedom from the waist in order to perform the movement she so desired. Both the hanging effect and the freedom of the waist are structural components similar to the shift dress. Her dress also had influences from Greek culture not only with its loose garment, but also the use of ultra-sheer silk which was similar to the tunics worn by the women dancers illustrated on the vases.

Initially, Isadora Duncan wore a straight, ankle-length white dress for her performances and it wasn't until several years later that she found inspiration in Greek culture. ${ }^{200}$ When she moved abroad, she visited museums and found inspiration in movement from the depiction of the Greek vases and centred her form of modern dance around their movements. ${ }^{201}$ Isadora Duncan was drawn to ancient Greek culture as it celebrated artists and performers which aligned with her ethos of artistry, equality, and movement. Isadora Duncan’s modern dance connected the body's senses and soul to depict nature's movement and dressed herself in a costume that would allow the total body such freedom. Although many modern dancers looked to ancient Greece for inspiration, Isadora Duncan embraced the Greek culture not only on stage but also as a philosophy of life. She claimed, 'I wanted not only New York, but all of America, to adopt the old free Greek dress!' In addition to her attachment to Greek dress, she believed Greek culture represented and promoted unity and equality among all people. For example, she compared Greek culture to Greek theatre, as there are no boxes or balconies to separate people of status rather it is a democratic theatre where all people are considered equal. ${ }^{202}$

The performance To Dance is to Live retold Isadora Duncan's story through her personal essays. This excerpt is from Isadora Duncan's point of view of the

\footnotetext{
${ }^{200}$ Deborah Jowitt, 'Images of Isadora: The Search for Motion', Dance Research Journal, 17.2 (1985) 21-29 (p. 25) < https://doi-org.vortex3.uco.edu/10.2307/1478076>. Around 1898, at the beginning of Isadora Duncan's solo career she was photographed in a straight, ankle-length white dress with traditional ballet shoes before she adopted the tunic.

${ }^{201}$ Edward Ross Dickinson, “"Must we dance naked?” Art, Beauty, and Law in Munich and Paris, 1911-1913’, Journal of the History of Sexuality, 20.1 (2011), 95-131 (p. 212) < http://vortex3.uco.edu:2050/login?url=https://www.jstor.org/stable/40986356> [accessed 21 January 2021].; Isadora Duncan, My Life, (New York: Liveright Publishing Corporation, 2013), pp. 53-54.

${ }^{202}$ Isadora Duncan, 'The Well-Known American Dancer, and Idealist. "Oh! Shame on America!:

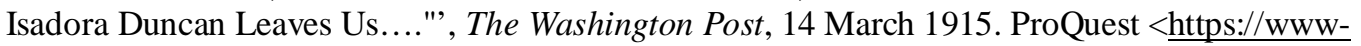
proquest-com.vortex3.uco.edu> (p. SM4),; see also, Isadora Duncan, “The Greek Theatre', in The Art Of The Dance, ed. by Sheldon Cheney (New York: Theatre Art Books, 1969), pp. 86-87.
} 
traditional ballet's use of costumes and she contrasted it with her belief that dress must not only allow freedom but also uplift, celebrate and respect the woman's body. Julie Ince Thompson, performer of the production To Dance is to Live, recited poetry from Isadora Duncan's writings,

Have you seen little children studying the ballet of today? Their feet are tortured into deform shapes, their tendered little bodies are forced into tight corsets, their natural movements restricted, tormented. My children watching ballet students are like swallows circling freely in the air watching caged canaries....The dancer of the future must realize the mission of woman's body and the holiness of its parts. She will dance the changing life of nature. Radiant intelligence will shine from her. She will dance the freedom of woman. ${ }^{203}$

While Isadora Duncan believed ballet was the dance of the past, with its orchestrated movements and horrid constraints of the corset, her method of dance was the dance of the future as it encouraged freedom of movement not only through the limbs of the body but with the entire body and soul. Isadora Duncan's dance stemmed from nature's movements which can be placid one minute then rapid the next, and so the tunic was an important component to allow the whole body to express such diversity of movement. Like the Grecian women depicted on the vases, Isadora Duncan adopted similar garments that were loose and free flowing, and sheer that allowed complete freedom of movement. ${ }^{204}$ Some of Isadora Duncan's tunics were so sheer that many claimed that she was seen almost naked. ${ }^{205}$

Isadora Duncan would wear different types of tunics and lengths and incorporated the use of heavy or light fabric depending on the mood of the dance. Isadora Duncan's short Hellenistic style tunic resembled closely to the tunic of the Greek goddess of the hunt, Artemis. Similar features of Isadora Duncan's and

\footnotetext{
203 'Duncan Dances', The Spirit of Dance, Community Television (C3TV), online video recording, Alexander Street, $<$ https://video.alexanderstreet.com/watch/duncan-

dances?context $=$ channel:academic-video-online $>$ [accessed 21 March 2021]. (These excerpts are from the performance To Dance is to Live in a composition form utilizing two different writings of Isadora Duncan's titled 'The Dance of the Future' and 'What Dancing Should Be.'); see also, Duncan, pp. 63, 73.

${ }^{204}$ Barbara Burman Baines, Fashion Revivals: From the Elizabethan Age to the Present Day, (New York: Drama Book Publishers, 1981), p. 56.

${ }^{205}$ Special Cable to The New York Times, 'Dances Shocked Paris: Flimsy Draperies Now BarredMiss Duncan Coming Home in a Temper', New York Times, 17 December 1911. ProQuest $<$ https://www-proquest-com.vortex3.uco.edu > (p. 1).; Special Cable to the Post-Dispatch and New York World, 'Isadora Duncan’s Pupils' Bare Legs Shock Berlin....', St.Louis Post - Dispatch, 14 January 1906. ProQuest $<$ https://www-proquest-com.vortex3.uco.edu $>$ (p. 1).
} 
Artemis's tunics include fabric wrapped or belted around the torso, a soft, tiered skirt and the hemline that extended right above the knee. Artemis' character was known as the goddess of wild nature, a protector of the young, and who danced, at times, wildly and lasciviously. ${ }^{206}$ The statue of Artemis depicts her in motion as this suggests the short tunic is the most suitable garment for a woman who is physically active. Isadora Duncan may have been inspired by Artemis as this goddess portrayed similar beliefs of caring for the young and dancing. Isadora Duncan's Hellenistic style tunic resembled closely to the flapper dress, which would come much later in the fashion system. In Figure [28] is a photograph of a 1920s flapper dress, note the similarities between length, neckline and form of Isadora Duncan's Hellenistic style tunic and the 1920s flapper dress.

Isadora Duncan's tunics were radically different from the current s-bend fashions, and in many instances, she was recognized and publicized for her style of dress in newspapers and fashion magazines. In 1908, Vogue's column, 'As Seen on the Stage' highlighted plays for the season. Although the article discussed multiple performers for upcoming events, Vogue chose to insert a large photograph of Isadora Duncan wearing her long, white tunic dress. Isadora Duncan's tunic can be seen in Figure [29]. ${ }^{207}$ This article particularly highlighted Isadora Duncan's tunic and her Grecian lifestyle. Therefore, this suggests that the public was interested in her unique dress and lifestyle choices. By 1915, The Washington Post reported a debutante ball in Palm Beach, Florida and referenced Isadora Duncan's dress. Within the subtitle of the article it read, 'One Pretty Girl Appears in Fluffy White Chiffon a la Isadora Duncan., 208 This example identifies not only Isadora Duncan synonymous with a white tunic dress but it also speaks favourably to Isadora Duncan and her fashion. Furthermore, it was an indication that Isadora's influence had reached the upper-class.

\footnotetext{
206 'Artemis: Greek goddess', in Encyclopedia Britannica [online], $<$ https://www.britannica.com/topic/Artemis-Greek-goddess > [accessed 24 July 2020].

207 'Theater: Seen on the Stage', Vogue, 27 August 1908. ProQuest $<$ https://www-proquestcom.vortex3.uco.edu> (p. 258).

Photographs indicate that Isadora wore both her short, Hellenistic style and her long, simple tunics interchangeably throughout her life both on and offstage. New York Digital Library shows variations of Duncan tunics spanning from 1904 to 1920’s.

208 'Debutantes Don Frilly Pantaloons at Gay Palm Beach Costume Ball: Ballet-Like Dresses Reaching to Knees, Finished Off by Trousers to the Ankles, Are Worn - One Pretty Girl Appears in Fulffy White Chiffon a la Isadora Duncan', Washington Post, 09 March 1915. ProQuest $<$ https://www-proquestcom.vortex3.uco.edu> p. 4.
} 
In 1904, Isadora Duncan opened her first school in Berlin to teach children her technique of dance. Not only did Isadora Duncan wear tunics both on and offstage, but she required her students to wear them as she believed the tunic was the most suitable garment for the movement associated with her type of dance. She taught her students to make their own tunics in a step-by-step process. This process included a unique step as to how to create pleats in a tunic. The process consisted of folding tiny pleats and twisting the fabric around a piece of rope. The pleats were not permanent, as during the wash, the pleats would fall out of the garment. ${ }^{209}$ What is interesting about Isadora's pleating process is that an artist and inventor, Mariano Fortuny, in 1907 created a straight chemise dress incorporating a similar pleat process within his fabric. Irma Duncan, one of Isadora Duncan's adopted daughters, claimed that Isadora Duncan must have shown this to Fortuny, who invented a secret process to keep his gown artificially though not permanently pleated. ${ }^{210}$

Mariano Fortuny first established himself as an artist, photographer, and a stage designer. He developed in 1907, and patented in 1909, a pleated chemise dress, called the Delphos Gown, shown in Figure [30]. ${ }^{211}$ Fortuny was unique, as he was not a traditional fashion designer who released a collection every year or attracted the fashion press, rather he was an artist with interests in textiles. ${ }^{212}$ Already 35-years old, Fortuny began designing clothing pieces in 1906, with his creation of the Knosses

\footnotetext{
${ }^{209}$ Nadia Chilkovsky Nahumch, Isadora Duncan: The Dances, (Washington D.C.: The National Museum of Women in the Arts, 1994), pp. 56-59.

${ }^{210}$ Irma Duncan, Duncan Dancer: An Autobiography (Middletown, CT.: Wesleyan University Press, 1966), p. 189-190.; see also Nahumch, p. 59.

${ }^{211}$ Amy De la Haye, 'Ethnic Minimalism: a contextual analysis of designs by Shirin Guild', The Journal of the Decorative Arts Society 1850 - the Present, no. 23 (1999), 102-110 (p. 107) <http://vortex3.uco.edu:2050/login?url=https://www.jstor.org/stable/41809287>

[accessed 20 January 2021].

${ }^{212}$ Vogue occasionally published articles about Fortuny's dress, introduction of Fortuny's work in 1912, O'Kane, Marguerite. 'Fashion: The Robes of Fortuny', Vogue, 15 December 1912. ProQuest $<$ https://www-proquest-com.vortex3.uco.edu> (p. 33).; Later articles, 'Fashion: A Connoisseur of Fashions’, Vogue, 01 April 1916. ProQuest < https://www-proquest-com.vortex3.uco.edu> (p. 74).; 'Fashion: Dramatis Persona--Dame Fashion', Vogue, 15 October 1915. ProQuest <https://wwwproquest-com.vortex3.uco.edu> (p. 45).; Fortuny’s name appeared in Vogue prior to 1912 highlighted for his artwork through exhibitions or auctions, examples of articles: 'Art', Vogue, 20 December 1900. ProQuest <https://www-proquest-com.vortex3.uco.edu> (p. vi).; 'Art: Art', Vogue, 16 May 1901. ProQuest $<$ https://www-proquest-com.vortex3.uco.edu $>$ (p. v).; 'Vogue's Society Supplement: Art', Vogue, 03 March 1904. ProQuest <https://www-proquest-com.vortex3.uco.edu $>$ (p. xi). Fortuny’s emphasis on textiles: George Mott, 'Fortuny Museum, Venice', The GPA Irish Arts Review Yearbook, (1988), 165-168 (p. 165) <http:/vortex3.uco.edu:2050/login?url=https:/www.jstor.org/stable/20492062> [accessed 28 February 2021].; Christa C. Mayer Thurman, 'The Magician of Venice-Mariano Fortuny: 18711949', Bulletin of the Art Institute of Chicago, 75.4 (1981), 4-5 (p. 4) <https://doiorg.vortex3.uco.edu/10.2307/4104229>.
} 
scarf and a year later the Delphos gown. Fortuny’s friend and colleague, Guillermo de Osma, defined his dress as,

The Delphos was made in the same way as the chiton, being sewn in a cylindrical shape with holes for the head and arms, but with the great difference that the material was silk, and not wool or linen like the Greeks used, and was also pre-pleated. The cut was simple, consisting of a long gown suspended from the shoulders and clinging to the body, three or four widths of material being used for each dress. ${ }^{213}$

He created the Delphos gown at a time when the S-bend corset was at the height of its popularity. Fortuny was an artist and an inventor, and according to the Fashion Institute of Design and Merchandising, he had a disinterest in the changing fashions. ${ }^{214}$ Why did Fortuny, an artist and inventor, begin designing clothing?

According to Osma, Fortuny's inspiration of the Delphos gown came from numerous fields and many individuals. Fortuny’s primary discipline was art, therefore, he was aware of the current art movements. From the 1850s to 1870s, the aesthetic movement grew out of Europe in reaction to industrialization and utilitarianism and attracted painters, designers, craftsmen, poets and writers. ${ }^{215}$ Artists who espoused the aesthetic movement in the late 1800s depicted women in loose tunics that celebrated the movement of the body. Artists, such as the English painters, Albert Joseph Moore, Frederic Leighton, and Edward Burne-Jones, provided excellent examples of the Aesthetes dress in Figure [31-32]. ${ }^{216}$ As Fortuny was familiar with and an active participant in the art world, these depictions of women in Grecian dress may have influenced him to create the Delphos gown. Additionally, the new excavations in Greece in the late 1800s brought popularity and awareness to the public. It was known that Fortuny had numerous illustrations of Grecian sculptures in his photographic archives, including the charioteer of Delphi, and was aware of the current excavations taking place. ${ }^{217}$ The Delphos gown was named after the bronze

\footnotetext{
${ }^{213}$ Guillermo de Osma, Mariano Fortuny: His Life and Work, (New York: Rizzoli International Publications, Inc., 1980), p. 96.

${ }^{214}$ FIDM Museum, (12 January 2011), 'Mariano Fortuny’ (blog), <https://blog.fidmmuseum.org/museum/2011/01/mariano-fortuny.html> [accessed 18 February 2021].

215 'Aesthetic Movement', in Philip's Encyclopedia [online], $<$ http://vortex3.uco.edu/login?url=https://search.credoreference.com/content/entry/philipency/aesthetic _movement/0?institutionId=1845> [accessed 10 February 2021].; see also, Tortora, p. 358-359.

${ }^{216}$ Osma, pp. 89-90.

${ }^{217}$ Osma, p. 96.; see also, Caitlin Mackenzie Schwarz, 'Body and Soul: How Mariano Fortuny Redefined the "Classical”', (unpublished master thesis, University of California, Davis, 2019) in ProQuest Dissertations and Theses Global <https://search-proquest-
} 
statue of the charioteer of Delphi and other sculptures proved noteworthy to Fortuny's inspiration; such as the Korai sculptures dating back from $6^{\text {th }}$ century B.C. ${ }^{218}$ Aside from art and sculpture, Fortuny also was active within the theatre where he was a technical stage designer and was surrounded by theatre performers. His Delphos Gown was initially to be worn as a tea gown and in a woman's own private home, however, it soon became popular among the avant-garde set, mostly dancers and actresses, who were daring and eccentric enough to wear these outside of the home. ${ }^{219}$ Both Isadora Duncan and Ruth St. Denis were patrons of Fortuny. Figure [33] illustrates Isadora Duncan's adopted daughters in the Delphos Gown and in Figure [34] is Ruth St. Denis in her Fortuny gown. Possibly one of his greatest influences but not well publicized or documented was his wife, Henriette Negrin. Osma, who intimately knew Fortuny and whose book is one of the most respected on the subject of Fortuny, provides only a minimal discussion of Henriette, with brief points regarding her role. Osma claimed that Henriette was an invaluable assistant, a skilled seamstress, and one 'who inspired and assisted in the realization of his first ensemble. ${ }^{220}$ Other sources had given Henriette more credit for the development of the Delphos gown than had Osma. Women's Wear Daily reported on the exhibition of Fortuny and stated that Fortuny designed the Delphos gown with his wife Henriette Nigrin, who is credited with inventing the signature pleating process. ${ }^{221}$ Dominic Green gives further credit to Henriette as he claimed that she played a primary role of not only the conception of the Delphos gown but also in the manufacturing and

\footnotetext{
com.vortex3.uco.edu/pqdtglobal/docview/2299779579/D3FD41F32EF44134PQ/1?accountid=14516> [accessed 10 February 2021] pp. 11-19.

${ }^{218}$ Osma, pp. 95-96.; See also, M.T.J., D.E.K. and K.C.B., 'Textiles and Costumes', The Museum Year: Annual Report of the Museum of Fine Arts, Boston, vol. 111 (1986-87), 44-45 (p. 45)

$<$ http://vortex3.uco.edu:2050/login?url=https:/www.jstor.org/stable/43482143>.

[accessed 20 January 2021].

${ }^{219}$ FIDM Museum, (12 January 2011), 'Mariano Fortuny' (blog), < https://blog.fidmmuseum.org/museum/2011/01/mariano-fortuny.html> [accessed 20 January 2021].; FIDM also notes that Fortuny's Delphos gown became acceptable by the 1920s to wear outside of the home). ; Mendes and De La Haye, p. 24.; A 1915 article 'Dramatis Persona-Dame Fashion', reviews fashion on the stage and Fortuny's gown was noted in the setting of the boudoir, thus implying the gown to be worn as a teagown or a type of lingerie. 'Dramatis Persona-Dame Fashion', Vogue, 15 October 1915. ProQuest <https://www-proquest-com.vortex3.uco.edu> (p. 45).

${ }^{220}$ Osma, pp. 44-45, 86, 102.

${ }^{221}$ Joelle Diderich, 'Eye: Palais Galliera Stages First Paris Retrospective on Mariano Fortuny: "Fortuny, a Spaniard Venice" Caps the Fashion Museum's Spanish Season’, WWD, 05 October 2017. ProQuest $<$ https://www-proquest-com.vortex3.uco.edu $>$ (p. 18). This article is in reference to the Palais Galliera’s Fortuny exhibition that took place from October 2017 to January 2018.
} 
business operations. ${ }^{222}$ The history of Henriette is inconsistent as to how much of the Fortuny's creations were her ideas and how much she contributed to the Delphos gown. Women working alongside their husbands, fathers or brothers is a pattern throughout this chapter, as exemplified earlier with Emily Roebling and Dr. Lillian Gilbreth. This pattern demonstrates women's work was subordinate to a man's and women's recognition was scattered, at best.

As Dominic Green suggested that Henriette played a significant role, if not a vital one in the creation of the Delphos, it may not have been Fortuny's idea but his wife’s. Furthermore, Daniela Ferretti uncovered an autograph note, written by Fortuny, where he credits his wife as the 'true creator' ${ }^{223}$ No one knows what he meant by the 'true creator' and how much of her idea was the Delphos gown. One may suggest, the Delphos gown was most likely Henriette's idea and they both executed the design and process.

The Delphos gown diverged from mainstream fashion with its fit, construction, and process. As stated previously, the fit of the garment stemmed from the simplistic forms of Grecian dress, however, the construction and process of forming the vertical pleats was complicated. Fortuny intricately and precisely formed small vertical pleats by hand that were anchored by glass beads. The pleated process was not only complicated but it also was never revealed as to how Fortuny specifically achieved the desired look. Osma's best guess of the process was that many of the steps were completed manually and he worked with the material when wet and applied heat later to ensure the pleats remained permanent. ${ }^{224} \mathrm{By}$ attending the exhibition, Decadence: Fashions from the 1920s, I was able to make an up-close examination of Fortuny's gowns. I had examined his 2-piece evening dresses which had the same pleating process as the Delphos Gown. The pleating process gives the garment suppleness, sheen and depth to the material which adds beauty and distinction to the garment as it is enhanced by light refraction with displaying

\footnotetext{
222 Dominic Green, ‘A Victorian Brace’, New Criterion, 35.2 (2016), 34-39. (pp. 35-36) < http://vortex3.uco.edu/login?url=https://search-proquestcom.vortex3.uco.edu/docview/1831704254?accountid=14516 > [accessed 21 January 2021].; see also A. S. Byatt, 'Lives Entwined: The Genius of William Morris and Mariano Fortuny', FT.Com, (2016), 1-8 (p. 6) < http://vortex3.uco.edu/login?url=https://search-proquestcom.vortex3.uco.edu/docview/1806384983?accountid=14516 > [accessed 20 July 2020].

${ }^{223}$ Daniela Ferretti, 'Portrait of a Muse', in Henriette Fortuny: Portrait of a Muse, ed. by Daniela Ferretti (Venice: Palazzo Fortuny, 2015), pp. 11-19, (p. 14). This book was released in conjunction with Palazzo Fortuny exhibition from 19 December 2015 to 1 May 2016.

${ }^{224}$ Osma, pp. 96-102.
} 
different hues. Fortuny's precision in manipulating the fabric to obtain a desired effect of depth and movement of colour indicates that he created this garment from an artistic perspective. Figures [35-36] are my personal photographs of Fortuny's gowns that I took while at the exhibition. These up-close images show intricate detail of Fortuny's work as one can notice the pleats and the effects of light refraction. Fortuny continued to use this process on other garments he created and remained true to the simplistic form. ${ }^{225}$ The simplistic form enabled him to showcase his signature artisan techniques as no other construction would allow.

As illustrated in Figure [30 and 33], the Delphos Gown hangs straight down and puddles to the floor extending the length of the gown beyond to the wearer's toes. Although the body of the garment provided a loose fit, the puddling effect of the gown limited the wearer's mobility. The lack of movement the Delphos gown provided aligns with its purpose of being worn as a tea gown since little movement takes place in the home. However, as shown in figure [34], Ruth St. Denis wore her Delphos gown shorter, at ankle-length, rather than the intended extended length that Fortuny showcased. It would appear, therefore, that Ruth St. Denis altered her gown to suit her needs for movement. The modern dancers chose clothing for utility, whereas, Fortuny designed clothing as an art form.

At the same time when Fortuny came out with the Delphos Gown, other designers were also developing similar shaped gowns. On April 2, 1908 Vogue reported a reception hosted by the American Ambassador and his wife for a housewarming of their new hotel, Francois Premier. Although royals were present displaying their coronets, tiaras, and jewels, Vogue noted the simplicity and artistic flare of the gowns. Fashion trends observed at the party were inspired by Greek, Roman, and Japanese cultures with a simplistic form and little decorations on the gowns. Some of the gowns displayed at the Ambassador's party were noted as unusual by Vogue and claimed the styles as 'oddly beautiful toilettes' ${ }^{226}$ Within this same issue, Vogue predominantly showed the S-bend silhouette within their reoccurring columns and fashion articles. ${ }^{227}$ Also noteworthy, the tracking method

\footnotetext{
${ }^{225}$ Fortuny had created the Delphos gown and from this creation he developed the 2-piece evening dress. He also developed robes, jackets, wraps, and other simple dresses for his collections. For examples of his other pieces, see figures $\mathrm{x}-\mathrm{x}$ in the Appendix.

226 'Features: Paris (From Our Own Correspondent)', Vogue, 02 April 1908. ProQuest < https://wwwproquest-com.vortex3.uco.edu> (p. 470).

227 'Fashion: What She Wears', Vogue, 02 April 1908. ProQuest <https://www-proquestcom.vortex3.uco.edu> (p. 474).; 'Fashion: Reception and Calling Gowns', Vogue, 02 April 1908.
} 
revealed after 1910 the S-bend began to lessen in appearances in Vogue and by 1915 the S-bend was inconsequential. Therefore, simple fashions displayed at the party were fashion-forward. An example of a chemise gown worn at the party is shown in Figure [37] and described as,

[T]he gown was cut straight across the bust and under the arms, showing no tendency at any point to mount into a conventional corsage line....Her gown, or rather drapery, for the material was wrapped simply and closely about the figure from bust to heels, dragging oh! ever so little, was composed of thick white crepe de chine embroidered lightly with white chenille, studded with bobbing chenille balls, in three broad bands, one about the bust, one about the thighs, the third, deeper at the petticoatless hem. ${ }^{228}$

Although the description is detailed with the embroidery and chenille balls, these balls on the dress look minimal from the photograph and are not the focus of the dress, rather it is the straight, simple form that is most important. Unfortunately, the guest nor the designer was noted for this particular gown. As this was a housewarming for the American Ambassador, it can be assumed that this guest was wealthy and an important role model in society and possibly had this dress specially made for this event. The article did highlight several noteworthy guests, for instance, Princess de Polignac, her gown was described as 'slimpsy as a Greek tunic'.229 Princess de Polignac's dress was not identified as by a specific designer. This article marks the first appearance which I identified the presence and illustration of a straight gown in Vogue magazine from my page-by-page technique. Therefore, these women can be considered as trendsetters and ones that displayed new fashions rather than abiding by the traditional fashion norms.

Like the two gowns described from the Ambassador's party, it was typical for the designers of the gowns to be omitted unless Vogue was covering the new release of fashion news from the designer's collections. Many wealthy women either employed personal seamstresses or visited the French couture fashion houses. At this time, many designers did not actively market their brand, especially in terms of what

ProQuest <https://www-proquest-com.vortex3.uco.edu> (p. 475).; 'Fashion: Pretty Dinner Frocks for Debutantes’, Vogue, 02 April 1908. ProQuest <https://www-proquest-com.vortex3.uco.edu> (p. 479). 228 'Features: Paris (From Our Own Correspondent)', Vogue, 02 April 1908. ProQuest <https://wwwproquest-com.vortex3.uco.edu> (p. 470).

229 'Features: Paris (From Our Own Correspondent)', Vogue, 02 April 1908. ProQuest < https://wwwproquest-com.vortex3.uco.edu> (p. 470). 
we are familiar with today. However, Paul Poiret, French couture designer, was one of the first fashion designers who promoted and marketed his label as a 'total lifestyle'. ${ }^{230}$ Unlike Fortuny, Poiret was a professionally trained fashion designer who worked at two of the most elite and revered fashion houses, Doucet and House of Worth, before opening his own salon in Paris. ${ }^{231}$ Nancy J. Troy has described Poiret as a great promoter of his clothes, perfumes, and furnishings. He toured the United States in autumn of 1913 for a publicity campaign and gave lecturers, made numerous appearances at major department stores, and received members of the press in his hotel rooms. ${ }^{232}$ With his self-promotion he became one of the most well-known fashion designers of this time. Many fashion historians claimed Poiret as 'the magnificent and revolutionary turn-of-the-century fashion designer' ${ }^{233}$ Poiret has been celebrated by scholars and designers alike, because he freed the woman of the corset. However, Valerie Steele has argued that while Paul Poriet is credited for releasing the woman from a constricted garment, many designers around the same time were also designing unrestricted dresses, for example, Fortuny, House of Doucet and Lanvin. ${ }^{234}$ Since Paul Poiret marketed himself well, and his fashions were more visible, therefore, he may be receiving false credit for being the first to revive straight gowns. Yet, his fashions were widely adopted, largely because of his marketing acumen, and he set the trends for the fashion industry. Poiret dominated haute couture in the first decade of the twentieth century and has been recognized with the title, 'King of Fashion'. ${ }^{235}$

During the same time Fortuny had patented his Delphos Gown, Poiret had commissioned Jean-Loui Boussingault to promote his new style of unrestricted dress. Boussingault depicted a matronly lady wearing a traditional S-bend silhouette while including a fashionable young lady in her Directoire Revival creation from Poiret. ${ }^{236}$ This illustration promoted the new Directorie fashion as youthful, indicating a fresh,

\footnotetext{
${ }^{230}$ Harold Koda and Andrew Bolton, Poiret, (London: Yale University Press, 2007), p. 13.

${ }^{231}$ Koda and Bolton, p. 13. By the time Poiret left Doucet he had risen to become head of the tailoring department.

${ }^{232}$ Nancy J. Troy, 'The Logic of Fashion', The Journal of the Decorative Arts Society 1850-the Present, no. 19 (1995), 1-7 (pp. 1-2) $<$ http://vortex3.uco.edu:2050/login?url=https://www.jstor.org/stable/41805869> [accessed 20 January 2021].

${ }^{233}$ Leymarie, Jean, Chanel (New York: Rizzoli International Publications, Inc., 1987), p. 38.

234 Steele, Fashion and Eroticism, p. 226.

${ }^{235}$ Koda and Bolton, pp. 13-14. The Metropolitan Museum of Art exhibition of Poiret was titled: 'Poiret: King of Fashion'.

${ }^{236}$ Alice Mackrell, Paul Poiret (New York: Holmes \& Meier, 1990), p. 21.
} 
new resurgence of fashion, whereas the S-bend silhouette was representative as an out-of-date relic. Completely revolutionary at the time, Poiret ignored the current fashion trend of a tightly fitted silhouette and created a free-flowing gown which hung from the shoulders. He discarded the use of pattern-making and replaced it with the technique of draping fabric onto the body. ${ }^{237}$ In Figures [38-39] is an example of the change from the traditional S-curve silhouette from 1905 to Poiret's new designs in 1910. The S-bend silhouette was achieved with a corset that pushed the bosom forward and thrust the buttocks out which created a S-shape with the woman's body. Poiret's Directoire style kept the woman's shape upright and did not accentuate the natural waist. His inspiration was from antiquity and regional dress styles, largely adaptations from the Greek chiton, the Japanese kimono, and the North African and Middle Eastern caftan. ${ }^{238}$ Although the form and structure of dress are simple in these cultures, decorations on the gowns can be elaborate. Unlike Isadora Duncan's tunic and Fortuny's Delphos Gown which were minimalistic in form and decoration, Poiret adhered to maintaining decorated elements on his simple forms. Figures [40, 41, and 42] provide examples of Poiret's collection, which nicely illustrate the variety of his garments as some are plain while others are elaborately decorated.

As a trained fashion designer, Poiret had to work within the confines of his reputation and his responsibilities of maintaining a steady business. Therefore, he could not completely and radically alter fashion trends. He was noted as revolutionizing fashion by creating the straight silhouette, but it would have been too far a financial risk as well as a risk to his reputation to shorten gowns at the same time as moving toward a slimmer silhouette. Although Poiret's straight silhouettes were radical at the time, the feminine details and floor length hemlines followed the evolution of fashion, and in a sense, Poiret continued to design what was expected for women to wear. Examples of his gowns can be seen in Figures [39 and 43].

Poiret's keen marketing skills and his unrestricted silhouette that maintained a consistency of fashion aided in the transition from the heavily S-bend corseted body form to the straight, simplistic free flowing shift dress. The straight form that Poiret popularized led the movement away from a full, circular silhouette to a longer, leaner

\footnotetext{
${ }^{237}$ Koda and Bolton, p. 14.

${ }^{238}$ Koda and Bolton, p. 14. Examples of Poiret's designs that were inspired from Grecian, Oriental, North African and Middle Eastern culture which can be seen in the catalogue section of Poiret, pp. 52201.
} 
line. ${ }^{239}$ Isadora Duncan's and Fortuny's garments brought popularity among niche groups, yet, it was Poiret who brought the unrestricted form into the fashion system and widely popularized it as a fashion trend.

The artists, dancers, and designers all contributed to the evolution of the shift dress as each one influenced the other. Although the modern dancers had soloist careers, they knew of one another and specifically, Isadora Duncan and Loie Fuller had briefly worked together. ${ }^{240}$ Fortuny was surrounded by women in the theatre and both Isadora Duncan and Ruth St. Denis frequently patronised his business. Fontanel observed, Paul Poiret greatly admired Isadora Duncan and he invited her to appear at the festivities of the release of his new collection. It is also known that Poiret was inspired by Léon Bakst’s costumes from the Ballet Russe. ${ }^{241}$ Léon Bakst admired Isadora Duncan and sketched her on a number of occasions. ${ }^{242}$ According to Osma, Diaghilev’s Ballet Russes made their first appearance in Paris in 1909 which was controversial yet liberating for art and the theatre. ${ }^{243}$ The costumes were designed as loose styles to give the dancers maximum freedom of movement as Bakst followed the example of Isadora Duncan. ${ }^{244}$ Therefore, Isadora Duncan was the root of inspiration for influencing Bakst's and, if not directly, than indirectly, Poiret. Osma noted the importance of previous works from painters and modern dancers,

This whole mood, this feeling for a new type of garment beyond the realms of fashion, which hung from the shoulders and allowed for complete movement, glorifying the human form like the clothes of ancient Greece, and which was stimulated by painting, dance and theatre and by artistic women, prepared the way for Fortuny's work. ${ }^{245}$

\footnotetext{
${ }^{239}$ Mendes and De La Haye, p. 40.; Koda and Bolton, pp. 13-14.; Sally R. Sommer, 'Loïe Fuller', The Drama Review: TDR, 19.1 (1975), 53-67 (p. 53) < https://doi-org.vortex3.uco.edu/10.2307/1144969 >.

${ }^{240}$ Sally R. Sommer, 'Loie Fuller's Art of Music and Light', Dance Chronicle, 4.4 (1981), 389-401, (p. 396) < http://vortex3.uco.edu:2050/login?url=https:/www.jstor.org/stable/1567418> [accessed 21 January 2021]. Sommer claims it was well known that Isadora Duncan had danced in Fuller's company briefly and Fuller had briefly managed Duncan.

${ }^{241}$ Béatrice Fontanel, Support and Seduction: The History of Corsets and Bras (New York: Abradale Press, Harry N. Abrams, Inc. Publishers, 1997), p. 82.

${ }^{242}$ Michelle Potter, 'Designed for Dance: The Costumes of Léon Bakst and the Art of Isadora

Duncan’, Dance Chronicle, 13. 2 (1990), 154-169 (p.158)

<http:/vortex3.uco.edu:2050/login?url=https:/www.jstor.org/stable/1567737>

[accessed 21 January 2021].

${ }^{243}$ Osma, p. 132

244 Osma, p. 132.; Bakst and Diaghilev had met and admired Isadora Duncan on her Russian tour in 1906.; see also, Michelle Potter, 'Designed for Dance: The Costumes of Léon Bakst and the Art of Isadora Duncan’. Dance Chronicle, 13. 2 (1990), 154-169 (pp. 157-158)

$<$ http://vortex3.uco.edu:2050/login?url=https://www.jstor.org/stable/1567737> [accessed 21 January 2021]

${ }^{245}$ Osma, pp. 94-95.
} 
Osma claimed that it was the artists and Isadora Duncan who laid a foundation for Fortuny. It is important to note, that the structure of the shift dress is the same as defined by Osma, 'which hung from the shoulders and allowed for complete movement.' Therefore, indicating the shift dress stemmed from a complex process of outside influences, rather than within the fashion system. Radically changing fashion occurs when it does not stem from the preceding fashion. Isadora Duncan's dress fashion was radical as it was adopted not from a preceding fashion but from the deep roots of antiquity. Although her dress was a direct resemblance of Greek tunics and not a new garment, it was a new fashion change.

Poiret has been recognized as the leader in shifting the S-bend silhouette to the straight form, but it was truly the work of the artists, modern dancers, and Fortuny that contributed largely to and initiated the idea of fashion shifting from a corset Sbend shape to the modern straight form. Although Fortuny used outside influences to create the Delphos gown, he too designed within the current fashion system as his dress was long and restricted movement by fitting closely to the body and puddling fabric at the woman's feet. Additionally, Fortuny was not the only designer that used outside influences for his ideas, Poiret was also inspired by art, theatre and other cultures, but most importantly, he had resources to bring fashion change to the fashion industry.

During this era, Isadora Duncan's tunics were similar to the shift dress. As the English artists, Loie Fuller, Mariano Fortuny and Paul Poiret helped with the changing of the modern form, Isadora Duncan's tunics had characteristics of a modern garment. Her tunics, although borrowed from antiquity, displayed not only the modern form but also had characteristics of the modern dress with the variations of length. Fortuny and Poiret both stayed within the guidelines of fashion evolution by offering only a long version of their dresses for women. Koda and Bolton observed, although Poiret introduced the modern form he did not embrace modernism. ${ }^{246}$ However, Isadora Duncan differed as she demonstrated wearing garments that varied in lengths, both long and short for women. In western civilization, it was not customary for women to wear short dresses as the shorter

\footnotetext{
${ }^{246}$ Koda and Bolton, p. 14.
} 
garments were typically reserved for men. ${ }^{247}$ Isadora Duncan reimagined a garment that was primarily worn by men, and with the exception, by the goddess Artemis, to adopt a modern dress for women. Additionally, she borrowed fashions from across the globe to find inspiration. Isadora Duncan act of borrowing fashion inspiration from another culture was a modern concept in the early 1900s, although this is commonly done today. Breward observes that in today's environment fashion change occurs 'across social and geographical boundaries'. ${ }^{248}$ Although, Breward was speaking within the context of the twenty-first century, fashion change from the sbend silhouette to the shift dress grew out of this same process, borrowing fashions from other cultures. However, as Isadora Duncan borrowed fashions from antiquity, unfortunately, her tunics with sheer fabrications and short lengths were too radical for the Progressive Era. As outside influencers changed the fashion form, in order to radically change fashion altogether, to sheerer fabrics and shorter lengths, the culture needed to change, therefore, outside influences, such as social, political or economic factors needed to occur.

\section{The Bohemian Community}

Isadora Duncan's tunics extended beyond a garment to clothe herself to become an embodiment of her Grecian principles and lifestyle. Isadora Duncan’s tunics allowed her the freedom that she so desired. Although Poiret had claimed that women's dress was changing because of her lifestyle, the current fashions continued to impede freedom of movement. Even the Gibson Girl who exemplified the modern woman was illustrated in corseted, long, feminine dresses, a fashion that does not espouse modernity. ${ }^{249}$

In 1914, a dressmaker from Greenwich Village, Miss Sara White, was featured in the New York Tribune for creating dresses for women while considering her client's character, personality, occupation and style. This was a new concept to design dresses around one’s lifestyle. The author noted Miss Sara White as 'not an ordinary dress maker'. Miss Sara White took inspiration from looking at the whole

\footnotetext{
${ }^{247}$ For example, men during the Renaissance era wore shorter skirts and trunk hose which displayed their legs. (Tortora, p. 212-16.)

${ }^{248}$ Breward, The Culture of Fashion, p. 229.

${ }^{249}$ Patterson, Beyond the Gibson Girl, p. 36. "Fore! The American Girl to All the World” illustrated in Americans (1900).
} 
woman in order to make dresses for her clients. Miss Sara White's observation for one particular design,

You are a slim boyish girl. Your hair is bobbed. You are impatient of restraints, yet you are loving and have a charming disposition. Adding these together and taking into consideration the color of your eyes, it is quite evident that the dress which I have conceived for you is eminently becoming. ${ }^{250}$

The dress that Miss White suggested based on all of these characteristics was a 'prune color gabardine, straight up and down, a one piece, loosely belted and finished at the top with a soft little tucker'. Miss White's characteristics of 'boyish girl' and 'impatient of restraints' with 'bobbed hair' led her to design a straight-line dress with a loose belt. She paired the theme 'boyish' with a straight-line dress, and someone who was 'impatient of restraints’ implying this individual was intolerant to conformity and welcomed freedom. Thus, the straight-line dress was chosen by Miss White as she believed it represented someone of an androgynous identity and one who challenged the current contemporary culture and welcomed freedom. ${ }^{251}$

Miss White also discussed Greenwich Village’s unique lifestyle with the New York Tribune. Miss White portrayed Greenwich Village as a unique part of New York City that challenged the current contemporary culture and lifestyle of America with its socialistic and feminists' ideals. She further noted, everyone supports each other in a group community role and all occupations and genders are thought of as equal. Miss White professed, 'There is nothing here that a man does that a woman does not do.' 252 Leslie Fishbein identified Greenwich Village as a place where radicals believed in a social revolution for women's liberation not only through political and economic power but also through liberating their daily lifestyle. Furthermore, Fishbein noted that Greenwich Village residents believed they could reshape their own lives and use

250 'Feminist Inhabitants of a Feminist Village', New York Tribune, 27 December 1914. $<$ https://chroniclingamerica.loc.gov/lccn/sn83030214/1914-12-27/ed-1/seq-27/> [accessed 10 February 2021] (p. 7, image 27).

251 'Feminist Inhabitants of a Feminist Village', New York Tribune, 27 December 1914. $<$ https://chroniclingamerica.loc.gov/lccn/sn83030214/1914-12-27/ed-1/seq-27/> [accessed 10 February 2021] (p. 7, image 27).

${ }^{252}$ 'Feminist Inhabitants of a Feminist Village', New York Tribune, 27 December 1914. $<$ https://chroniclingamerica.loc.gov/lccn/sn83030214/1914-12-27/ed-1/seq-27/> [accessed 10 February 2021] (p. 7, image 27). 
it as an example to promote feminism and set an example of greater human freedom for society. ${ }^{253}$

By 1914, a resident of Greenwich Village, Curt Josef Kisch, began giving tours to sightseers in Greenwich Village. ${ }^{254}$ In 1917, the New York Times published a story about a woman guide, Miss Kennedy, in Greenwich Village. Miss Kennedy spoke of how travellers from all over the country would go back to their hometowns and talk about the oddities of Greenwich Village. ${ }^{255}$ Evidently, this community was interesting and popular enough to the public as many tourists were attracted to Greenwich Village and newspapers across the nation promoted its unique characteristics. Even a small town, such as Saint Joseph, Louisiana published an article about Greenwich Village’s tours. ${ }^{256}$ It is important to note that the lifestyle of Greenwich Village’s residents was publicized across America which may have influenced the country with its unique lifestyle. Not only were newspapers publishing headlines about Greenwich Village but the film industry also released films about bohemians in Greenwich Village. In 1918, Irene Castle, a famous ballroom dancer, debuted in the film The Girl from Bohemia which took place in Greenwich Village. ${ }^{257}$ Leslie Fishbein claimed that Greenwich Village’s new radicalism set the tone for the rest of the country. ${ }^{258}$

Many articles noted women residents of Greenwich Village with bobbed hair and smocks as part of their everyday attire. ${ }^{259}$ For example, Miss Kennedy expressed,

\footnotetext{
${ }^{253}$ Leslie Fishbein, 'The failure of feminism in Greenwich Village before World War I', Women Studies, 9.3 (1982), 275-289 (p. 276) < doi:10.1080/00497878.1982.9978572>.

${ }^{254}$ Levin, pp. 376-377.

255 Times Photo Service, 'And Now Greenwich Village has Woman Guide!', New York Times, 07 October 1917. ProQuest <https://www-proquest-com.vortex3.uco.edu> (p. 79).

256 'Greenwich Village a Quaint Bit of Gotham', Tensas Gazette, 12 January 1917.

$<$ [https://chroniclingamerica.loc.gov/lccn/sn87090131/1917-01-12/ed-1/seq-

1/\#date1=1836\&index=1\&date2=1922\&searchType=advanced\&language $=$ \&sequence $=0$ \&words $=$ Gre enwich + village + Village \&proxdistance $=5 \&$ state $=$ Louisiana\&rows=20\&ortext $=$ \&proxtext $=$ greenwich + village\&phrasetext=\&andtext=\&dateFilterType=yearRange\&page=1> [accessed 10 February 2021] (image 1, col. 3).

${ }^{257}$ Mabel McElliott, 'Irene Castle’, Chicago Daily Tribune, 26 August 1918. ProQuest <https://wwwproquest-com.vortex3.uco.edu> (p. 14). The Girl from Bohemia starring Irene Castle is now a lost film. ${ }^{258}$ Leslie Fishbein, 'The failure of feminism in Greenwich Village before World War I', Women Studies, 9.3 (1982), 275-289 (p. 276) < doi:10.1080/00497878.1982.9978572>.

259 'Feminists Inhabitants of a Feminist Village', New York Tribune, Dec. 27, 1914, Image 27, p. 7.; 'Black Cat Raided By Police Squad:: ...Marked Usually By Bobbed Hair and Smocks', New York Times, 28 November 1920. ProQuest <https://www-proquest-com.vortex3.uco.edu> (p. 21).; Mabel Herbert Urner, 'The Married Life of Helen and Warren: A Dinner Adventure in Greenwich Village Proves Helen a Poor Bohemian’, Washington Post, 23 October 1921. ProQuest $<\underline{\text { https://www- }}$ proquest-com.vortex3.uco.edu> (p. 80).; Martyn, Marguerite, 'My Goodness but a New Rip Van Winkle Would Get a Terrible Shock Today’, St. Louis Post - Dispatch, 19 February 1921. ProQuest $<$ https://www-proquest-com.vortex3.uco.edu $>$ (p. 13).
} 
'we do have some radicals down here - and bob-haired girls wearing their studio smocks.' ${ }^{260}$ Therefore, this publicity from the newspapers, which reached across the U.S., attached the lifestyle of the women in Greenwich Village to a straight silhouette of the smock. In Figure [44], Edith Hayes, a shop owner, wears a smock over her daytime clothes.

The smocks symbolized equality as the garment was worn by both men and women, in addition, it displayed similar body structure for each gender as the smock concealed a woman's figure. The smock's concealment of a woman's figure was unconventional and radical for the time. In addition, the newspapers and magazines publicized the smock which brought attention to a straight constructed garment worn by women. According to Rabinovitch-Fox, the most significant dress item that was associated with Greenwich Village feminists was the 'Village smock'. The smocks were a popular fashion among artists and young women who wanted to identify with the Bohemian culture. ${ }^{261}$ The attention on the smock may have influenced American women to wear a more unstructured garment in the twenties. In Figure [45], this photograph was taken at a restaurant in Greenwich Village and provides an example of women wearing non-restricted dresses. The women in Greenwich Village typically did not wear girdles underneath their loose gowns. The woman in the forefront (right) of the picture is wearing a long, simplistic unrestricted dress with sleeves that stopped right above the elbow. Greenwich Village was known for their radical ideas as they challenged social issues and also brought attention to a change in dress.

\section{New Media: The Silent Films}

The dress styles of the women in Greenwich Village were publicized in newspapers throughout the U.S. and highlighted their unique lifestyle. Similar to newspapers, the film industry was also positioned to disseminate fashion to the public. As the cities provided a 'stage' for fashion, the films used its stage to express character personality traits in relationship to distinctive fashion modes. The boom of

\footnotetext{
260 Times Photo Service, ‘And Now Greenwich Village has Woman Guide!’, New York Times, 07 October 1917. ProQuest <https://www-proquest-com.vortex3.uco.edu> (p. 79).; see also, Geoffrey Perrett, America in the Twenties: A History (New York: Simon and Schuster, 1982) This book also noted travellers and sightseers often visited Greenwich Village.

${ }^{261}$ Einav Rabinovitch-Fox, '[Re]Fashioning the New Woman', Journal of Women's History, 27. 2 (2015), 14-36, 194 (p. 27) <http://vortex3.uco.edu/login?url=https://www-proquestcom.vortex3.uco.edu/scholarly-journals/re-fashioning-new-woman-womens-dressoriental/docview/1689848825/se-2?accountid=14516> [accessed 20 January 2021].
} 
cities created a social environment fitted for the film industry. The film industry capitalized on two major factors: the extended leisure time given to Americans from a shorter work week and the new demographic shift of the population living in urban areas.

Initially, the movie industry was considered an obscure and disreputable industry. Therefore, many of the first and second generation immigrants built the film industry while respectable business men associated making movies with bootlegging. ${ }^{262}$ Nickelodeons (1905-1914) were the first type of movie provided to the public showing one and two reel movies continuously which allowed customers to stay as long as they liked for only a nickel. ${ }^{263}$ The low cost model of the movies attracted the lower working class Americans, of which many were immigrants, to the theatre. ${ }^{264}$ The movies began with simple scenes, but by the middle of the progressive era had complex storylines. Through the characters and the storyline, many lessons were communicated to the audience about how to culturally assimilate. According to Eileen Bowser, distinguished archivist and film historian, the goal of the film industry was to 'involve the spectator in the thoughts, feelings, and motivation of the characters, ... , to draw on the emotions of the audience, to educate them, even perhaps, to change them'. 265

The traditional theatre houses surrounded its audience with bright, beautiful and ornate decorations and provided intermission for socializing. Yet at the same time, the movies consisted of plain, dingy theatres that were dark and proved unsocial as the movies kept continuously rolling. ${ }^{266}$ According to the novel, The Close-Up, movies offered the most democratic entertainment to society as every seat in the house cost the same amount. ${ }^{267}$ Traditional entertainment of the theatre and opera

\footnotetext{
${ }^{262}$ Michael E. Parrish, Anxious Decades: America in Prosperity and Depression, 1920-1941 (London: W.W. Norton \& Company, 1992), p. 72.

${ }^{263}$ Lears, p. 56.

264 James Card, Seductive Cinema: The Art of Silent Film (New York: Alfred A. Knopf, 1994), p. 26.; Lears, p. 248-49.; Some historians have disputed that the first audiences of the Nickelodeons may have also included middle-class Americans, however, this has not been substantially proven. See Ben Singer, 'Manhattan Nickelodeons: New Data on Audiences and Exhibitors', 34.3 (1995), 5-35 (pp. 5, 28-29) < https://doi-org.vortex3.uco.edu/10.2307/1225743>.; Judith Thissen, 'Beyond the Nickelodeon: Cinemagoing, Everyday Life and Identity Politics’, in Audiences: Defining and Researching Screen Entertainment Reception, ed. by Ian Christie, (Amsterdam: Amsterdam University Press, 2012), pp. 45-65 (p. 45). Ebook Central ProQuest.

${ }^{265}$ Eileen, Bowser, '1911: Movies and the Stability of the Institution', in American Cinema of the 1910s: Themes and Variations, ed. by Charlie Keil and Ben Singer, 10 vols (London: Rutgers University Press, 2009), II, pp. 48-68, (p. 52). ProQuest Ebook Central.

${ }^{266}$ Card, p. 24.

${ }^{267}$ Margaret Turnbull, The Close-Up (London: Harper and Brothers Publishers, 1918), pp. 33-34.
} 
houses was associated with a social hierarchy and power structure of the bourgeoisie and upper class. Since the movies were economical and affordable they were positioned to attract the growing middle-class and provide a product from a mass market structure.

\section{Women in the Silent Film Industry}

As the movies welcomed anyone to attend, this same philosophy extended to film making. Ally Acker uncovered an article written by Marc Wanamaker, head of the Bison Archives, which observed, 'more women worked in decision-making positions in film before 1920 than any other time in history'. ${ }^{268}$ It is staggering to realize that for more than 100 years of filmmaking, women were the pioneers and leaders in the beginning of the film industry and during such an arduous time for women. Early historical records about women before the 1920s in the film industry are rare. However, in the 1970s, Anthony Slide, had begun to uncover women's success in Hollywood during this time and beginning in 1990 Alley Acker had revived this subject matter. ${ }^{269}$

One might ask, 'why were women more prevalent in the film industry during the inception of film making?' Scholars believe women were involved in the decision making of the studios as the film medium was an experimental industry and was not yet a serious economic business. ${ }^{270}$ Therefore, women were welcomed in all positions of filmmaking as it was open to anyone with creativity and imagination. ${ }^{271}$ Not only were women acting in the movies, but many women were directors, producers, writers, editors and studio owners. ${ }^{272}$

\footnotetext{
${ }^{268}$ Ally Acker, Reel Women: Pioneers of the Cinema 1896 to Present (New York: Continuum, 1991), p. xviii.

269 Anthony Slide, Early Women Directors (South Brunswick, NJ: A.S. Barnes and Company, 1977).; see also, Anthony Slide, 'Afterword', in Reel Women: Pioneers of the Cinema 1896 to Present ((New York: Continuum, 1991), pp. 335-336.

${ }^{270}$ The Silent Era, dir. by Ally Acker (Reel Women Media, 2015) online film recording, Alexander Street, <https://video-alexanderstreet-com.vortex3.uco.edu/channel/academic-video-online> [accessed 09 March 2021].; Cari Beauchamp, Without Lying Down: Francis Marion and the Powerful Women of Early Hollywood (London: University of California Press, 1997), p. 12.

${ }^{271}$ The Silent Era, dir. by Ally Acker (Reel Women Media, 2015) online film recording, Alexander Street, < https://video-alexanderstreet-com.vortex3.uco.edu/channel/academic-video-online> [accessed 09 March 2021.; see also, Marjorie Rosen, Popcorn Venus: Women, Movies, and the American Dream (New York: Coward, McCann \& Geoghegan, 1973), p. 368.

${ }^{272}$ Pioneers of the Cinema: The Herstory, dir. by Acker, Ally (Reel Women Media, 2009) online film recording, Kanopy, <uco.kanopy.com> [accessed 05 June 2018].; see also, Hilary A. Hallett, 'Based on a True Story: New Western Women and the Birth of Hollywood', Pacific Historical Review, 80.2 (2011), 177-210 (p. 183) < www.jstor.org/stable/10.1525/phr.2011.80.2.177 > [accessed on 12 September 2020].
} 
Similar to the women in engineering, many women in film worked alongside their husbands. One example is Lois Weber. Lois Weber was one of the best known directors in Hollywood during the silent film era and she was a studio owner. ${ }^{273}$ Although women worked alongside their husbands, they were successful and created their own path in the industry. Lois Weber, for example, had a reputation at Universal as 'one of the screen's most noted, notorious, directors.' ${ }^{274}$ Weber was known for producing many films about serious women's social issues, such as advocating for birth control, and having female protagonists in her films. ${ }^{275}$ Weber stated, 'I think you women of this country today want to be individuals and to have freedom of thought and action. That is the kind of girl I am going to show in my story' ${ }^{276}$

Many photographs of women filmmakers during the silent era are difficult to locate as many archives of the film industry were destroyed or not saved. When photographs are available, many times women are sitting or obscured with equipment and it is difficult to decipher their clothing. However, I did obtain a photograph where Lois Weber is wearing a shift dress with exposed knees and stockings, an iconic style of the 1920s flapper. In Figure [46] is a photograph of Weber with Cecil de Mille. Weber was deeply committed to communicating women’s social issues in her films and we can further see, by this photograph, her public display of advocating women's freedom through her clothing. The shift dress communicated to society that women were no longer prisoners of the corset and inherently to constraints in life. The shift dress gave women physical freedom of movement as well as the hope, encouragement, and opportunity for women to participate in the public sphere as the constraints began to dematerialize. The shift dress symbolized equal empowerment and freedom and Lois Weber continually showed strong women in her films and freedom was an important component in her work.

\footnotetext{
${ }^{273}$ Early Directors on Directing, dir. by Acker, Ally (Reel Women Media, 2014), online film recording, Alexander Street, <https://video-alexanderstreet-com.vortex3.uco.edu/channel/academicvideo> [accessed 09 March 2021].; Slide, pp. 20, 36, 44-45.; Alice Guy Blache created Solax Company with herself as president and director in chief.

274 Slide, p. 39.

275 The Silent Era, dir. by Ally Acker (Reel Women Media, 2015) online film recording, Alexander Street, $<$ https://video-alexanderstreet-com.vortex3.uco.edu/channel/academic-video-online $>$ [accessed 09 March 2021].;; Lois Weber: Actor, Screenwriter \& First Woman to Direct a Feature Length Film: 1879-1939, online film recording, UNLADYLIKE2020, n.d. < http://unladylike2020.com> [accessed 20 December 2020].

${ }^{276}$ Lois Weber: Actor, Screenwriter \& First Woman to Direct a Feature Length Film, 1879-1939, online film recording, UNLADYLIKE2020, <http://unladylike2020.com> [accessed 20 December 2020].
} 
After the 1920s, few women remained in the film industry as many women were forced out of the industry because of mergers and big business acquisitions. In Figure [47], Lois Weber is surrounded by men indicating the absence of women. This photograph provides evidence that although women had success in the beginning of the film industry, few women were left by the late 1920s. However, this photograph also demonstrates the strength and success of Lois Weber. Although after 1921 she intermittently directed films, it is significant to note, that she did so in a predominantly man's industry. When analysing photographs of Lois Weber, she continually wore simple straight dresses that were not overly decorated. In Figure [47], Lois is surrounded by a large group of men and she is wearing a dark coloured shift dress. Because of its dark colour and simple design, the dress is identified as a garment that suggests a more masculine identity rather than conveying her personality as an overly decorated woman. The dress that Lois chose to wear while on the film set blends into her surroundings. Rather than wearing a traditional woman's garment decorated with lace, frills, and bows that would suggest feminine characteristics, Lois chose to present herself in an understated, conservative and sophisticated manner.

\section{Communicating Perceptions Through Silent Film}

As the film industry began to mature, the movies evolved into multiple reels and complex storylines. As described previously, Greenwich Village during the Progressive Era was known as an artist community. The movie industry connected the Bohemia spirit with Greenwich Village as exemplified with the 1918 film, The Girl From Bohemia. Scholarly work, such as journal articles and books on Bohemian culture is sparse and difficult to locate. However, newspaper articles, magazine stories and surviving film footage gave insight into the Bohemian lifestyle and the public opinion set forth by the media. The book, Bohemia in America, provided a historical background regarding the Bohemians. The Bohemian culture was of foreign origin. Initially, Bohemians were gypsies who originated from the European kingdom of Bohemia and migrated to Western Europe. Bohemianism was popularized by the musical La Vie de Boheme and the term bohemia was associated with idealistic beliefs and opposition of the bourgeois lifestyle. These values that the Bohemians practiced were much different from American Protestant culture. 
Stories were published about the lifestyle of the Bohemians in popular magazines, such as, the Ladies' Home Journal, Good Housekeeping and Cosmopolitan. ${ }^{277}$ The stories primarily focused on entertainment through dancing, smoking, and drinking. In addition, couples were portrayed as engaging in extreme sexual activity and clothing was frequently mentioned. For example, in the story, My New York: A Little Tale of a Big City, the main character, a middle-aged woman, is characterized as living a Bohemian lifestyle. Her gown was described in these terms: '[s]he wore a loose velvet gown every evening, whether she was alone or not, feeling herself part of a delectable picture.' This implies that the loose, velvet dress was part of the Bohemian spirit. The story then transitions to young adults visiting her studio, 'smoking' and 'romancing' which further accentuates the free lifestyle of the Bohemians. ${ }^{278}$ The word choice 'loose' described the dress not only from the physical structure of the gown but also the sexual behaviour of the Bohemians. The Washington Post described Bohemian dress as 'a loose affair of green chiffon', further suggesting that the words 'loose affair' were connected to not only a loose dress but used to describe the Bohemian's sexuality. ${ }^{279}$ Furthermore, a story in the Ladies’ Home Journal recommended that because of the loose morals of the Bohemians they were unfit to be parents. ${ }^{280}$ As Joanna Levin expressed, the consistent message of all Bohemians was 'to live with the utmost intensity and spirit'. ${ }^{281}$ Bohemian's were characterized as displaying excessive socializing and practicing sexual freedom. ${ }^{282}$

\footnotetext{
277 Elizabeth Jordan, 'In Gay Bohemia’, Good Housekeeping Magazine, March 1914. ProQuest <https://www-proquest-com.vortex3.uco.edu> (pp. 373-384).; Kathleen Norris, 'My New York: A Little Tale of a Big City’, Ladies' Home Journal, July 1916. ProQuest $<$ https://www-proquestcom.vortex3.uco.edu> (p. 14).; Chambers, Robert W., 'The Restless Sex: A Chronicle of Insurgent Youth." Cosmopolitan, November 1917. ProQuest <https://www-proquest-com.vortex3.uco.edu> (pp. 76-83, 142-148, 150-151).

${ }^{278}$ Kathleen Norris, 'My New York: A Little Tale of a Big City’, Ladies' Home Journal, July 1916. ProQuest $<$ https://www-proquest-com.vortex3.uco.edu $>$ (p. 14)

279 'Their Married Life: Helen Pays a Call on Frances at the Letter's Studio and Enjoys a Delightful Afternoon in the Bohemian Atmosphere -- Her Experience a New One', Washington Post, 28 June 1915. ProQuest $<$ https://www-proquest-com.vortex3.uco.edu $>$ (p. 9).

${ }^{280}$ Marie Conway Oemler, 'Anybody Want this Little Boy?: Why He Longed "Something Terrible" to Live with a Mother’, Ladies' Home Journal, February 1915. ProQuest $<$ https://www-proquestcom.vortex3.uco.edu> (pp. 16, 57-59).

${ }^{281}$ Levin, p. 6.

${ }^{282}$ Levin, p. 362.; Kathleen Norris, 'My New York: A Little Tale of a Big City', Ladies' Home Journal, July 1916. ProQuest <https://www-proquest-com.vortex3.uco.edu> (p. 14).; Marie Conway Oemler, 'Anybody Want this Little Boy?: Why He Longed "Something Terrible" to Live with a Mother', Ladies' Home Journal, February 1915. ProQuest < $\underline{\text { https://www-proquest- }}$ com.vortex3.uco.edu> (pp. 16, 57-59).
} 
Bohemians embodied similar beliefs and characterizations similar to those of the flapper. In the 1915 film, A Lily in Bohemia, the Bohemians participated in smoking, drinking and dancing, the very same habits associated with the flapper. The film's storyline portrayed a good versus evil theme; the good represented by the idyllic country living and wholesome family values while evil depicted Bohemians in an urban setting flaunting their sexuality. Additionally, this film utilized dress to further communicate the symbolism of good versus bad. According to Levin, many Bohemian plots exposed the relationship between propriety and license and the tension of American and European manners and morals. ${ }^{283}$ Levin reinforces the idea that the dichotomy of the Protestant views and European immigrant behaviours existed and tension between these two groups were present during this time.

A Lily in Bohemia portrays a wholesome country girl, Lillian, who moves to the city and encounters a fast lifestyle associated with city living. While Lillian was living in the country, she wore a traditional white, long dress that displayed her natural waist with a modest neckline and 3/4 sleeves to where only her forearms showed. For this time, Lillian's dress reflected the current fashion mode for a respectable lady. Hugh, the male lead character, visits the country to recover from an illness, where he meets Lillian. Hugh courts Lillian and then they marry. Hugh takes Lillian to the city and introduces her to his Bohemian friends. Upon their arrival, Hugh takes Lillian out dancing, however, Lillian has never danced like this before and is awkward and clumsy. ${ }^{284}$ In addition, Lillian's dress was out of place as the Bohemian women fashioned a looser and more risqué dress with low-cut necklines and thin straps. Many of the dresses worn by the Bohemian women were representative of the Directoire period, a period when fashion was known for radical change. ${ }^{285}$ In order for Lillian to feel part of the crowd, she learns to dance, smoke, drink and outwardly flirt. Once Lillian had learned these new traits, she changes into a dress that is different from anything else she has worn. She comes out in a short, knee-length dress with a low neckline and thin straps which exposed her full arms. ${ }^{286}$

\footnotetext{
${ }^{283}$ Levin, p. 180.

${ }^{284}$ A Lily in Bohemia, dir by Wilfrid North (Vitagraph, 1915), online film recording, Youtube, 28 May 2015 < https://www.youtube.com/watch?v=MUrYHKJsPrY\&t=502s > [accessed 10 February 2021], (10:15-11:15).

285 Tortora and Marcketti, p. 307.

${ }^{286}$ A Lily in Bohemia, dir by Wilfrid North (Vitagraph, 1915), online film recording, Youtube, 28 May $2015<$ https://www.youtube.com/watch?v=MUrYHKJsPrY\&t=502s $>$ [accessed 10 February 2021] $(12: 15-12: 54)$.
} 
This dress symbolized looser and freer morals and manners than the traditional prescribed behaviour of women. Once Lillian obtained these new traits, Hugh disliked her possessing them insinuating these habits are bad. ${ }^{287}$

Lillian mirrored the same mannerisms as Hugh, but Hugh did not like this. Thus, this sent a message to the public that men do not want their wives to display the same free manners of drinking, smoking, dancing and flirting. However, as a result of Hugh's discomfort, he gives up his Bohemian habitats in order for her to do the same. ${ }^{288}$ This film's lesson is that Bohemian habits are evil and destructive and should not be partaken by married couples. In addition, the film attached Lillian’s long, white dress to symbolize purity and unity whereas the dresses worn by the Bohemian women and Lillian's party dress represented indecency and immorality.

It is important to note, before the 1920s, it was not customary for costume designers to be employed in Hollywood, therefore, the costumes came from the actors or people working on the sets. ${ }^{289}$ A Lily in Bohemia was produced by Vitagraph Studios located in Brooklyn, New York. The garments in the film most likely came from the actresses living in the New York City area and garments they likely wore. As previously stated, the Directoire style was in fashion from 1910 through 1915. The film chose to utilize the current fashion mode of the Directoire style to represent the Bohemian woman and a traditional style of dress to represent a conventional lady.

Silent films, newspaper articles and stories in magazines disseminated information across the U.S. about the Bohemian lifestyle and dress. Through these media, opinions about the Bohemians were publicly expressed. Some articles spoke of horror and disgust with dress and behaviour of the lowest moral standard while other stories or articles wrote about their loose morals but with an underlying lesson

\footnotetext{
${ }^{287}$ A Lily in Bohemia, dir by Wilfrid North (Vitagraph, 1915), online film recording, Youtube, 28 May $2015<$ https://www.youtube.com/watch?v=MUrYHKJsPrY\&t=502s $>$ [accessed 10 February 2021] (14:17-15:20).

${ }^{288}$ A Lily in Bohemia, dir by Wilfrid North (Vitagraph, 1915), online film recording, Youtube, 28 May $2015<$ https://www.youtube.com/watch?v=MUrYHKJsPrY\&t=502s $>$ [accessed 10 February 2021] (15:35-16:05).

${ }^{289}$ Drake Stutesman, Clare West $<$ https://wfpp.columbia.edu/pioneer/ccp-clare-west/> [accessed 29 August 2020] (para. 1 of 6).; Michelle T. Finamore, 'Fashioning Early Cinema: Dress and Representation in American Film, 1905-1930', (unpublished doctoral thesis, University of Michigan: Ann Arbor, 2010) in ProQuest Dissertations and Theses Global < http://vortex3.uco.edu/login?url=https://search-proquestcom.vortex3.uco.edu/docview/250272906?accountid=14516 $>$ [accessed on 15 September 2020] pp. $42-43$.
} 
that Bohemians were upstanding citizens. ${ }^{290}$ In Good Housekeeping magazine, a story about Bohemian life highlighted the public's common prejudice against the loose morals of Bohemian culture as many people's prejudiced views did not allow them to clearly see a different perspective of the culture. The article noted, 'look at the room as the way they are not putting in your own stories, horrors, into the dialogue... learn that life is not black and white but gray.' ${ }^{291}$ This article suggests that, in order to keep evolving as a modern society, individuals need to look at their prejudiced views from a different lens, understanding the whole person and not looking at one specific detail. Those who do not look at social customs or ideas from a different perspective delay modernity. When a group begins to display new social trends, although this may spark controversy, a society that is open to dialogue has a greater opportunity for change. A similar thought was expressed by Hollander,

Whenever the chief desire of the eye is a reliance on immemorial forms, the prevailing esthetic spirt isn't modern. For visual satisfaction, modernity requires conflict and dialectic, uneasy combination, ambiguity and tension, irony, the look of dissatisfied search. ${ }^{292}$

The published articles about Greenwich Village, the Bohemian films and magazine stories may have helped acclimatize the American society later to the flapper.

\section{Music and Dance Entertainment}

As demonstrated in the movie, A Lily in Bohemia (1915), music and dance culture was evolving. The demand for musicians increased with the need to accompany for vaudeville shows and the opening of thousands of movie theatres. ${ }^{293}$ Ragtime brought an upbeat tempo to the public that inspired one's desire and emotion to dance. Simultaneously, dance crazes swept the nation. Many different dances were

\footnotetext{
290 'New York Like Rome: Magistrate Compares Morals to Times of Caesars. Public Drinking Increases Low-Cut Gowns at Opera and Taking of Young Women to Immodest Shows Not Worst of Evil, Which Extends to Dances of Poorer Classes in Public Halls - Aping Dress of Trial Heroine', Washington Post, 19 January 1908. ProQuest < https://www-proquest-com.vortex3.uco.edu $>$ (p. 3).; Elizabeth Jordan, 'In Gay Bohemia', Good Housekeeping Magazine, March 1914. ProQuest $<$ https://www-proquest-com.vortex3.uco.edu $>$ (pp. 373-384).

291 Jordan, p. 384.

${ }^{292}$ Hollander, Sex \& Suits, p. 19.

${ }^{293}$ Eve Golden, Vernon and Irene Castle's Ragtime Revolution (Lexington, KY: University Press of Kentucky, 2007), p. 52.; John Edward Hasse, 'Ragtime: From the Top', in Ragtime: It's History, Composers, and Music, ed. by John Edward Hasse (New York: Schirmer Books, 1985), pp.1-39 (p. 11).
} 
popular at the time; such as, the Grizzly Bear, Lame Duck, and Bunny Hop. Lears claimed that the new dances were related to 'tough dancing' that had originated from the whorehouses in San Francisco. This new form of dance encouraged closeness among partners and explicit sexual movements. Lears added that in the 1910's Irene and Vernon Castle, legendary ballroom dancers, helped sanitize these dance styles but many variations of the erotic versions survived. ${ }^{294}$

In 1910, the popularity of fast-tempo dancing increased as dance halls became more common, serving patrons of all classes. Multiple newspapers reported published reports of cities creating their own safe municipal dance halls for the youth and discussions about regulating and reforming dance halls. ${ }^{295}$ Some dance halls opened in wealthier areas, such as, the North Side of Chicago, where many debutantes had lived. ${ }^{296}$

Many controversial opinions were publicized about the new dances. An article in the New York Times reported a socialite held a demonstration of traditional dances in her home to discourage society women from dancing the Turkey Trot, Grizzly Bear, or Bunny Hop. The socialite called the new dances freakish and degrading. ${ }^{297}$ In addition, dancing masters in Chicago barred ragtime music in their dance halls and classes so to deter patrons from dancing the new types of dances. ${ }^{298}$ Irene Castle recalled, 'by the fall of 1913 America had gone absolutely dance - mad' while the 'whole nation seemed to be divided into two equal forces' of accepting these untraditional dances or rejecting them.'. 299

Cecil Beaton, a fashion, portrait, and war photographer also known for winning an Oscar in costume design, claimed that Irene Castle was equivalent to Stravinsky and Picasso as she was the 'embodiment of the "modern," in the social and fashion sense, as these artists were in the world of art'. Irene Castle’s dance

\footnotetext{
${ }^{294}$ Lears, p. 250.

${ }^{295}$ W, 'Municipal Dance Halls', St. Louis Post - Dispatch, 05 February 1910. ProQuest <https://wwwproquest-com.vortex3.uco.edu> (p. 6).; 'Reform in Dance Halls', Chicago Daily Tribune, 26 November 1914. ProQuest $<$ https://www-proquest-com.vortex3.uco.edu $>$ (p. 8).; 'City to Open Dance Halls', The Christian Science Monitor, 03 May 1913. ProQuest $<$ https://www-proquestcom.vortex3.uco.edu> (p. 15).

296 'Dance Halls Invade North Side Society', Chicago Daily Tribune, 30 October 1910. ProQuest $<$ https://www-proquest-com.vortex3.uco.edu $>$ (p. 1).

297 'Polite Dances Are Shown To Society', New York Times, 26 March 1912. ProQuest < https://wwwproquest-com.vortex3.uco.edu> (p. 13).

298 'Dancing Reform', Washington Post, 28 October 1912. ProQuest < https://www-proquestcom.vortex3.uco.edu> (p. 6).

${ }^{299}$ Irene Castle, Castles in the Air (New York: Doubleday \& Co., Inc., 1958), p. 85.
} 
movements were different from previous dancers, as her movements encompassed long strides and sharp hand movements. The Castle's form of ballroom dancing was innovative. Beaton acknowledged that Irene and Vernon Castle accelerated 'modernism' as their dancing symbolized a sense of equality with a freer and a more allusive exchange between partners. ${ }^{300}$

One night while Irene was a patron at a restaurant, a customer asked her to dance. She obliged, but to her dismay, she was ill-equipped with the gown she was wearing. Therefore, she altered it quickly as she took a pin from her blouse and pinned up the train of her dress so she could dance. On another occasion, Irene tried to dance in a hobble skirt; however, because of her inability to move, she recalled, 'I reached down and pulled the skirt up to my waist, depending on two shoulder straps I slipped my arms through to hold it up'. ${ }^{301}$ The current fashion was inefficient for dancing; therefore, Irene had her clothes made. She stated, 'The clothes I wore were practical for me and that is why I wore them.' Her dresses consisted of gowns with simple lines, light fabrics; such as chiffon, satin and crepe de chine, and skirts that would keep her legs free. ${ }^{302}$ In Figure [48], Irene is photographed in a two-piece dress with a tank style neckline, a tunic style top and a long straight skirt. Irene's skirts were known for a back slit to allow complete freedom for her legs. ${ }^{303}$ In this photograph, not only does her dress look similar to the upcoming flapper fashions displaying a low neckline and an undefined waist, but she also wore her hair in a bobbed style with a headband around her forehead, known as the 'Castle Band'. Irene was known for starting the trend called the 'Castle Bob' and it was adopted as a fad in many circles. ${ }^{304}$

Not only did Irene set trends for her bobbed hair, but she also was known as a trend-setter and an influencer in fashion. The New York Times noted a large following of Irene's fashions beginning with the dress from The Sunshine Girl

\footnotetext{
${ }^{300}$ Cecil Beaton, The Glass of Fashion (Garden City, NY: Doubleday \& Co., Inc., 1954), pp. 112, 11617,119 
(1913). ${ }^{305}$ When Irene debuted on Broadway in Watch Your Step (1914), she opened with a dress designed by Lucile. The next day, women stood in line at Lucile’s shop to order that same dress. Irene Castle claimed that this dress was widely copied and the Metropolitan Museum of Art had later asked for it to be stored in its permanent collection. . 306 Therefore, this dress, shown in Figure [49], was significant during this time, especially since the Metropolitan Museum of Art wanted to preserve the garment. Beaton claimed that Irene’s appearance was ‘unlike anyone else’s, yet overnight people accepted it and emulated her whenever possible'. ${ }^{307}$

Irene Castle adjusted her dress to fit the needs of her dancing; however, she worked within the confines of the standard fashion of the time. In doing this, Irene did not display a radical change in fashion. For example, in Figure [48] Irene's dress is different as it displayed a simple look, however, other components of her dress adhered to the Directoire style with the undefined natural waist and the long skirt length. She applied the same thought to her dancing. Irene and Vernon updated the current ballroom dances with unique hops and twists; however, they did not create a completely new form of dance. Irene Castle altered the current fashion styles as she challenged and modified the strict constrains of ballroom dancing. Because Irene and Vernon worked within the confines of the status quo, their dance and Irene's dress were socially accepted.

\section{Conclusion}

In 1906, President Theodore Roosevelt addressed to Congress the irreversible repercussions of the declining birth rate. He stated,

When all home ties are loosened; when men and women cease to regard a worthy family life, with all its duties fully performed, and all its responsibilities lived up to, as the life best worth living; then evil days for the commonwealth are at hand. ${ }^{308}$

\footnotetext{
305 'Mrs. Castle’s Gowns A Momentous Question', New York Times, 21 March 1915. ProQuest $<$ https://www-proquest-com.vortex3.uco.edu $>$ (p. 1). Specifically Providing for Naturalization of Japanese-If Insurrection Becomes a Habit in Cuba the Island Cannot Remain Independent. More Complete Federal Control of Corporations is Declared Necessary. Takes a Firm Stand on Side of Congress Deals with Nearly Every National Problem Takes a Firm Stand on Side of the Japanese in the School Controversy Recommends Legislation to Control Divorce-Points Out the Wisdom of Ship Subsidy and Favors Change in Currency System, But is
} 
Roosevelt's words demonstrated the need to restore order with traditional home values and encouraged women to stay within the private sphere. This message echoed consistently among public leaders. The media depicted the New Woman, utilizing such stereotypes as the Gibson Girl, Fisher Girl and Christy Girl. At times, the New Woman was illustrated involved in various activities, but primarily the drawings consisted of traditional moments in a girl's life adorned in traditional dress. The New Woman was illustrated as a collegiate, however, college women were continually blamed for declining marriage and birth rates. Although women were accepted into colleges, they were discriminated against in terms of job opportunities. Consequently, women had to take lower paid positions. In 1911, The Masses noted women as 'The Cheapest Commodity' labeling them as earning the lowest pay of all mankind. Some women did achieve success as they created their own opportunities in the public sphere. Through women's organizations and civil work of the settlement houses, women created opportunities in government roles and passed important legislation. However, for the majority of women, the traditional gender roles prevailed.

Some women achieved success, but largely women were 'placed' in traditional roles. Women's dress mimicked the same traditional values that was socially expected of women. Although, this era did experience a 'strange twist in fashion' and proceeded to transition away from heavily corseted gowns to a more, relaxed structure. The introduction of the un-corset gown was a drastic change from the Victorian age, thus, society's acceptance of the unstructured dress was fragmented and there was not a clear path to un-corset women. Designer, Paul Poriet's straight gowns were widely accepted while others, such as the Bohemians, were vilified for theirs as it was attached to loose morals and manners.

The most significant element of dress in this chapter was the introduction of the straight form. This process was not as direct as many believe, with its attribution to Paul Poiret as the source of change. Rather, it was a process of outside influences among artists, modern dancers, and designers, who embraced culture from across the globe, that contributed to this change. Trend setters, such as, Loie Fuller, Isadora Duncan, Irene Castle and Mariano Fortuny changed fashion in their own way. Irene

Silent on the Tariff-Would Increase the Navy by Building One Big Battle-Ship a Year', Washington Post, 05 December 1906. ProQuest < https://www-proquest-com.vortex3.uco.edu > (p. 8). 
Castle adjusted her dress to free her legs, Isadora Duncan embraced Grecian culture and Mariano Fortuny looked deep into the past to create a brand-new silhouette. These individuals, for reasons of their own, all discovered a need to change dress to a modern form. Although, Isadora Duncan had the most extreme change as she not only wore modern forms of dress, but she also displayed modern dress that included a wardrobe of variation in length consisting of short and long tunics. As the Progressive Era did see some change in women, many traditional ideals remained, in accordance to both culture and dress. Isadora Duncan alone could not change fashion to modern dress as traditional customs were still tied to women. As Davis observed, cultures have prescribed symbols, the western standard of dress represented masculine form by angular lines and feminine forms by soft, curvilinear lines. ${ }^{309}$ Poiret’s straight gowns flowed over the woman's figure in a soft form coupled with feminine details which was expected within the prescribed culture.

As the Progressive Era remained tied to these traditional social customs, the 1920s provided a gateway for distinctive fashion change as it was an environment of widespread prosperity, mass consumerism and political change. This decade also embraced a new lifestyle of rapid music, fast automobiles, and upbeat dancing. The 1920s, with its dynamism and new rhythms, would be coined the 'Jazz Age'.

${ }^{309}$ Davis, Fashion, pp. 5-6. 


\section{Chapter 3: The Sexualized Canvas: The 1920s}

Jazz music informs the characterisation of America in the 1920s. Jazz is defined as American music that was developed especially from ragtime and blues and characterized by propulsive syncopated rhythms, polyphonic ensemble playing, varying degrees of improvisation, and often deliberate distortion of pitch and timbre. ${ }^{310}$ According to Dr. Billy Taylor, it is the combination of the wide range and often distorted pitch and timbre, use of improvisation, and propulsive syncopated rhythms that creates a unique sound and rapid rhythm of music. ${ }^{311}$ Similar to jazz music, this combination also created a unique environment and rapid movement of fashion in the 1920s with its distorted hemlines, its contradictory opinions on women's characterisation, lifestyle and dress during a time when an ensemble of women improvised the modern form to the modern dress. This chapter examines the individualistic style that emerged in the fashion system and marks the dynamic entrance of the shift dress into the fashion industry. It not only focuses on women's lifestyle and their place in society, but also on the subculture of the flappers who were bold enough to adopt the shift dress as their uniform.

Like the rapid movement of rhythm in Jazz, this chapter will trace the rapid movements of change that occurred in the 1920s. I will first discuss the results from my tracking method where I systematically traced appearances of the shift dress in Vogue magazine to identify the prominence of this style as it was represented in the fashion media and designer's collections during the 1920s. I will then analyse women's place in society by examining their involvement in a range of social, political and economic contexts. The next section focuses on the most significant fashion development of the period: the American flapper. Within this section, I define the American flapper and examine her lifestyle, investigate the flapper's influence on the shift dress, and explore the role she played in disseminating fashion trends throughout America. In this section I also examine mass production, mass consumption, and mass media which all played an integral role in the cultural significance of the shift dress. Lastly, I analyse the messages that were conveyed to

\footnotetext{
310 'Jazz’, in Merriam-Webster Dictionary [online], < https://www.merriamwebster.com/dictionary/jazz> [accessed 10 February 2021].

${ }^{311}$ Dr. Billy Taylor, (Films Media Group, 1991), online film recording, Films On Demand, $<$ fod.infobase.com/PortalPlaylists.aspx?wID=103048\&xtid=2934> [accessed 10 February 2021].
} 
contemporary society about the flapper. I do this by providing an interpretation as to how the movies portrayed the flapper throughout the decade. Over the course of this chapter, I also refer to and challenge Anne Hollander's claim that she believed that although women's clothes during the 1920s achieved the modern ideal, women remained in their traditional roles. ${ }^{312}$

As outlined in the previous chapter, for the purposes of this thesis the 'twenties' will begin the day of the armistice of World War I and the optimism which launched the euphoria of the 1920s. By the end of the decade, this feeling fell quickly to fear as the onset of the Great Depression changed the momentum of the 1920s, marking the era's end.

\section{Tracking Method: Methodology and Results}

To examine the shift dress during the 1920s, I reviewed issues from the months of April and October to capture the spring and fall looks. With the exception of a few years, Vogue published an 'Early Fashion Opening' edition of designers that released their collections early followed by the subsequent issue, 'Paris Fashions Number', that included news from most of the designers. This pattern began in the fall of 1920 with October $1^{\text {st }}$ as the 'Early Paris Openings' edition followed by the October $15^{\text {th }}$ 'Paris Fashions Number' ${ }^{313}$ This sequence was mirrored in the spring as well, with April 1, 1921 highlighting the 'Early Paris Openings' followed by April 15, 1921 reporting on the 'Paris Fashions Number'. By 1928, Vogue had dropped the 'Early Paris Openings' edition and reported the Paris fashions in the mid-month issue. These editions were vital as they provided reporting on the designers' new collections for that season. Prior to the shift dress's primary appearances, I also reviewed additional issues especially from 1923 to 1926 as this was when the shift dress started to appear in Vogue magazine. I did this to capture the first presence of the shift dress.

As mentioned in my methodology section, I examined Vogue magazines in a page-by-page method to track the frequency of the shift dress. For the 1920s, I noted appearances of the shift dress in the spring (April 15 ${ }^{\text {th }}$ ) and fall issues (October 15 $5^{\text {th }}$ ) from every year between 1919 to 1929. Both of these issues were selected as this was not only the time when most designers released their collections but also when Vogue

\footnotetext{
${ }^{312}$ Hollander, Sex \& Suits, p. 5.
} 
reported on the new fashions and did so in a comprehensive manner. Analysing both of these issues allowed me to not only pinpoint the current fashion direction from the Parisian designers but also enabled me to view fashion changes within the most important seasons of the year. The spring and fall fashion seasons are vital as they set the stage and are the dominant fashion trends for the subsequent season.

Along with my tracking method, I developed a graph that represents the number of appearances from Vogue magazine from 1919 to 1929, which can be seen in Graph [1]. It shows a steep bell curve. Of particular note is the peak of the curve, which shows the most number of appearances; this occurred in 1926 with 85 appearances. This was when the shift dress was most visible and marketed significantly in Vogue magazine throughout the year. Additionally, on each side of the peak are two equal distribution points. The equal distribution points are marked by the years with a similar number of appearances within the rise and decline phases. For example, 1925 had 34 appearances of the shift dress and 1928 had 31 appearances. Between 1925 and 1928 is the period where the most appearances occurred during the decade. The years prior to 1925 include the introduction and rise phase while the years after 1928 include the decline and obsolete phase. The phases are marked by the appearances in Vogue magazine and not by the sales of the product. However, as stated in my methodology, the increase of marketing particular styles may have led to an increase of sales for those same styles. 


\section{Chart 1: Number of Appearances of the Shift Dress in Vogue} Magazine: 1920s

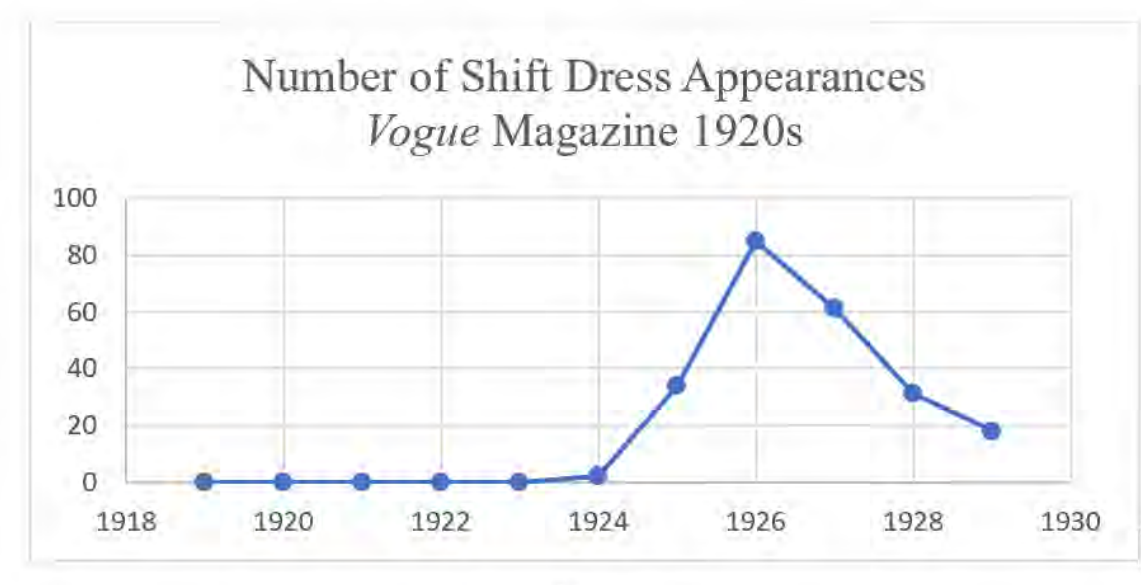

Years

Chart 1: Number of Appearances in Vogue magazine in April 15 th and Oct. $15^{\text {th }}$ issues. (Years 1928 and 1929 published on a Saturday instead of the numerical date on the $15^{\text {th }}$ )

One of the first appearances of the shift dress was in the October 15, 1924 issue. Two shift dresses advertised as a 'tunic frock' were shown by the haute couture designer, Lelong, and marketed as a skiing outfit. ${ }^{314}$ After the October $15^{\text {th }}$, 1924 issue, the shift dress appeared more frequently. Many shift dresses were present in the April 15, 1925 issue. The shift dresses were shown in a variety of advertisements, fashion articles, and regular columns. An advertisement of R.H. Macy \& Co. marketed the 'jersey dress' as a style of economy. ${ }^{315}$ In addition, many different shift dress styles were shown in the column 'Designs for Practical Dress Making' while at the same time a variety of Parisian designers included shift dresses in their collections. ${ }^{316}$ From its early appearances, the shift dress was equally marketed as an economic style as well as a designer style. Not only was this the case initially, but this same pattern occurred throughout the 1920s in Vogue magazine. Throughout the

\footnotetext{
314 'Fashion: The Mode for the Country'. Vogue, 15 October 1924. ProQuest $<\underline{\text { https://www-proquest- }}$ com.vortex3.uco.edu> (pp. 56-57, 136).

315 'Advertisement: R. H. Macy \& Co.', Vogue, vol. 65, no. 8, 15 April 1925. ProQuest <https://wwwproquest-com.vortex3.uco.edu> (p. 9).

316 'Designs for Practical Dressmaking', Vogue, 15 April 1925. ProQuest $<$ https://www-proquestcom.vortex3.uco.edu> (pp. 80-86). 'Fashion: Paris Presents the Pageant of the Spring Mode', Vogue, vol. 65, no. 8, 15 April 1925. ProQuest <https://www-proquest-com.vortex3.uco.edu> (pp. 41-42, 45, $46,56,58,60,61,62)$.
} 
decade the shift dress appeared in midlevel to upper level department stores, fashion articles from the Parisian designers, and patterns for dressmaking. Therefore, anyone with any amount of income could wear the shift dress. According to Joshua Zeitz, 'The flapper look that Chanel helped pioneer wasn't just for the rich Parisian. It belonged to every woman who wished to claim it as her own.' 317 This is exemplified by the range of marketing in which the shift dress was shown in Vogue establishing it as a dress of value and a dress of luxury.

Although the shift dress extended to a wide range of incomes, the details and fabrication of shift dresses differed between those that were economical and those that were luxurious. The shift dresses from designers were much more extravagant than those shown from department stores and dress patterns. In the April $15^{\text {th }}, 1925$ issue many haute couture designer's shift dresses included extra details of long trains, side panels, capes, shawls, and extra scarves. While the shift dresses from mid-level department stores and pattern making companies were much more basic with fewer and understated details. An example of Madame Lanvin's flying panel dress in comparison to the patternmaking dresses can be seen in Figures [50-52]. Note the large flying panels in Madame Lanvin's dress to the small side panels in the patternmaking dress.

\section{Women in the Workplace: The Aftermath of the War}

Although World War I was not the first war where women contributed and volunteered to the war effort, it was the first war where women were given unprecedented opportunities to expand into male dominated industries. In previous wars, women contributed as nurses or aided in domestic services. However, women during World War I not only contributed in their traditional roles, but were also noted as taxicab drivers, streetcar motormen, and elevator operators. ${ }^{318}$ The Chicago Daily Tribune published an article asking women to help fill jobs that were left open by men going to war. The article noted women were placed in a wide variety of positions to help alleviate the current labour shortage, such as, librarians, drafts-women, clerks, summer waitresses, munitions and government contract workers, dietitians, and

\footnotetext{
317 Zeitz, Flapper, p. 162.

${ }^{318}$ Special to The Christian Science Monitor from its Western Bureau, 'Work of Women in Minnesota', The Christian Science Monitor, 21 July 21 1917. ProQuest $<$ https://www-proquestcom.vortex3.uco.edu $>$ (p. 3).
} 
chemists. Many opportunities became available to women because of the war. Lynn Dumenil not only discussed the diversity of male dominated jobs that women occupied during the war but she also noted the variety of dress that women wore while working. Women who worked in factory jobs began to wear overalls and trousers, however, some women also continued to wear long skirts. ${ }^{319}$ During wartime, it was socially accepted for women to deviate from traditional dress as it symbolized supporting the war effort.

Newspapers and magazines published images and stories about women working in male dominated jobs and their competence in performing these new tasks. For instance, the Nashville Tennessean stated, 'War proves fallacy of theory that women are incapable of man's work.' 320 The Chicago Daily Tribune claimed, 'War opens new fields of work for young women.' ${ }^{321}$ In addition, Mr. Selfridge, owner of one of the largest department stores in London, complimented women workers and stated in specific positions they would no longer employ men, only women. ${ }^{322}$ As women gained acceptance in male dominated positions, women proved themselves as influential and active contributors to society. But they had their detractors too. In 1918, James M. Lynch, a member of the New York State Industrial Commission, related his thoughts on the effects of women working in the industry. He believed that women working in the industry would lead to 'the exploitation of women, without the least consideration either for the rights of labour, the rights of women, or the rights of society'. He criticized women occupying male jobs with lower pay as they inherently forced men out of work. Lynch further stated,

It will antagonize and demoralize male labor, and it may even result in open revolt; it will defeminize women and render them unfit for anything but a second place in industry and eventually incompetent for that; more serious than either of these contingencies, it will sap the structure of society by rendering women unfit to be mothers. ${ }^{323}$

\footnotetext{
${ }^{319}$ Lynn Dumenil, The Second Line of Defense: American Women and World War I (Chapel Hill: The University of North Carolina Press, 2017), pp. 160, 185, 214-16. Chapter 4 describes the women's work roles in male dominated jobs and chapter 5 discusses female dress while women occupied these new roles during World War I. Chapter 4, pp. 155 -203 and Chapter 5 pp. 204-254.

320 'Women A Success In Factory Work', Nashville Tennessean and the Nashville American, 18 August 1918. ProQuest <https://www-proquest-com.vortex3.uco.edu $>$ (p. B5).

321 Mary E. McDowell, 'War Opens New Fields of Work for Young Women', Chicago Daily Tribune, 14 October 1917. ProQuest <https://www-proquest-com.vortex3.uco.edu > (p. F5).

322 'Says Business Here Won’t Suffer In War', New York Times, 08 February 1918. ProQuest $<$ https://www-proquest-com.vortex3.uco.edu> (p. 12).

${ }^{323}$ Richard Barry, 'Female Labor Arouses Hostility: Union Leader Asserts That Men Workers Regard Substitutions as Exploitation of the Weaker Sex. Unnecessary as Yet and Tending to Cause Industrial
} 
Working women were continually plagued with the controversy of working outside of the home and the overall well-being and caring for the children. Although women were championed for their work during the war, during peace time, society norms expected women to remain in the private sphere. Similar to the Progressive Era, women were expected to continue the tradition of remaining in the home.

\section{Education for Women}

Continuing from the early trend in the Progressive Era, women continued to attend schools and colleges, although prejudices were placed upon them as some schools offered limited coursework or were difficult to enter. Examples of prejudices against women in education can be shown within the U.S. law schools as many gradually opened their doors to women. New York University, Cornell, and Boston University opened their law schools to women in the 1800s, Yale opened its law school to women after World War I, and Columbia finally opened its law school to women in $1926 .{ }^{324}$ Women attending law schools grew during the 1920s. Out of the top 12 law schools attended by women, attendance rose from 84 women students in 1920 to 370 by $1939 .{ }^{325}$ An important note, is that the Statistical Abstract of the U.S. in 1919 did not separate men and women attending its professional schools and only listed 'students', however, in 1929 those attending were reported separately by gender. ${ }^{326}$ This indicates that the Bureau of Education thought the number of women

Unrest', New York Times, 20 January 1918. ProQuest $<\underline{\text { https://www-proquest-com.vortex3.uco.edu }>}$ (p. 59).

${ }^{324}$ Bowman, Cynthia Grant, 'Women in the Legal Profession from the 1920s to the 1970s: What Can We Learn From Their Experience About Law and Social Change?’, Cornell University Law School Scholarship@Cornell Law: A Digital Repository, (2009) 1-25 (p. 3)

$<$ https://scholarship.law.cornell.edu/cgi/viewcontent.cgi?article=1011\&context=facpub $>$ [accessed 10 February 2021].

${ }^{325}$ Bowman, Cynthia Grant, 'Women in the Legal Profession from the 1920s to the 1970s: What Can We Learn From Their Experience About Law and Social Change?', Cornell University Law School Scholarship@ Cornell Law: A Digital Repository, (2009) 1-25 (p. 3)

$<$ https://scholarship.law.cornell.edu/cgi/viewcontent.cgi?article=1011\&context=facpub $>$ [accessed 10 February 2021].

${ }^{326}$ U.S. Department of Commerce, Statistical Abstract of the United States: 1919, 'Table No. 81 Professional Schools, School Year 1916: Number of Theological, Law, and Medical Schools, Instructors and Students, by States and Geographical Divisions', (Washington D.C.: Government Printing Office, 1920), no. 42

<https://www.census.gov/library/publications/1920/compendia/statab/42ed.html> [accessed 14 February 2021] (p. 113).; U.S. Department of Commerce, Statistical Abstract of the United States: 1929, ‘Table No. 130 -Universities, Colleges, and Professional Schools by States’ (Washington D.C.: Government Printing Office, 1929), no 51

$<$ https://www.census.gov/library/publications/1929/compendia/statab/51ed.html> [accessed 14 February 2021] (p. 118). 
students were significant enough to report them separately. In the school year 19251926, females comprised $5.4 \%$ of the student population in law school.

According to the U.S. Department of Education, the growth of women attending colleges was gradual during the late-nineteenth and early-twentieth century; however, during the twentieth century the years with the most rapid growth were the 1920s, 1940s, and 1960s. The rapid growth of education parallels to the presence of the shift dress. The shift dress was the dominant style in both the 1920s and 1960s, two out of the three decades that was the most significant years for women in education. The shift dress may have contributed to an increase in women's confidence as they entered school more readily. The Department of Education reported that between 1869-70 and 1909-10 women earning a bachelor's degree rose from $15 \%$ to 23\%. Women earning a bachelor's degree grew more rapidly during the 1910s and 1920 s, and by the $1929-1930$ school year women had reached $40 \%$ of the total student population. Similarly, master's degrees awarded to women had reached 26 percent of the total student population in 1909-1910 and increased relatively in the same manner as the bachelor's degrees. Women earning doctor's degrees were lower comparable to other degrees, however, they grew from $10 \%$ of the student population to $15 \%$ by 1929-30 school year. ${ }^{327}$ The U.S. Department of Education attributes the growth in the 1920s to the rising proportions of young people completing high school and becoming eligible for college. ${ }^{328}$ The increase of women earning degrees could have also contributed to women becoming more independent and gaining more confidence. Also what is significant to note, those schools that were previously reluctant to welcome women into their halls, such as Yale and Columbia, opened their enrolment during the 1920s, thus demonstrating that women were beginning to narrow the gender gap in education. As more women earned degrees, this not only placed women with more opportunities than past generations but it also established a precedent of women gaining similar education as men.

\footnotetext{
${ }^{327} 120$ Years of American Education, ed. by Thomas D. Snyder, National Center for Education Statistics, (January 1993), pp. 68- 70, 83 <https://nces.ed.gov/pubs93/93442.pdf> [accessed 15 January 2021]. School enrolment represents both private and public universities of total enrolment noted from the office of education and census bureau.

${ }^{328} 120$ Years of American Education, ed. by Thomas D. Snyder, National Center for Education Statistics, (January 1993), p. 67 < https://nces.ed.gov/pubs93/93442.pdf $>$ [accessed 15 January 2021].
} 


\section{Women in the Workplace}

As women continued to earn degrees, they continued to enter the public sphere. According to the U.S. census, the percentage change of women's employment from 1920 to 1930 was $21.1 \%$ while for men the percentage change was $13.5 \%{ }^{329}$ Therefore, this indicated that women were increasingly entering the workforce at a greater percentage rate than men. Additionally, when accounting for the change in the labour force in regards to the population rate, women's workforce increased by $1 \%$ from 1920 to 1930 whereas men's workforce decreased by $2 \% .{ }^{330}$ Another significant change in women's employment was the entrance into new fields. In 1910, the largest categories of women’s occupations were domestic services, manufacturing, and agriculture. ${ }^{331}$ In the beginning of the 1920s, the largest categories for women in the workplace continued to be in domestic and personal services, however, they were also pursuing roles in clerical positions, store clerks, decorators and window dressers. ${ }^{332}$ The U.S. Statistical Abstract report indicated the top three categories for women in 1920 and 1930 were domestic and personal services, manufacturing and clerical operations. ${ }^{333}$

A minority of women started to make advancements in professional fields that were dominated by men. Careers for Women, a book published in 1920, was created to inform women of the possibilities of a longstanding career. The book

\footnotetext{
${ }^{329}$ U.S. Department of Commerce, Statistical Abstract of the United States: 1955, 'Table No. 219Gainful Workers, 1910 To 1930, And Total Labor Force, 1940 And 1950, By Age And Sex [Decennially]', (Washington D.C.: Government Printing Office, 1955), no. 75 $<$ https://www.census.gov/library/publications/1955/compendia/statab/76ed.html > [accessed 14 February 2021] (p. 186).

${ }^{330}$ U.S. Department of Commerce, Statistical Abstract of the United States: 1955, 'Table No. 219 Gainful Workers, 1910 To 1930, And Total Labor Force, 1940 And 1950, By Age And Sex [Decennially]', (Washington D.C.: Government Printing Office, 1955), no. 75 $<$ https://www.census.gov/library/publications/1955/compendia/statab/76ed.html > [accessed 14 February 2021] (p. 186).

${ }^{331}$ U.S. Department of Commerce, Statistical Abstract of the United States: 1930, 'Persons 10 Years of Age and Over in Each General Division of Occupations', (Washington, D.C.: Government Printing Office, 1930), no. 52 <https://www.census.gov/library/publications/1930/compendia/statab/52ed.html> [accessed 14 February 2021] (p. 50).

${ }_{332}$ James R. McGovern, 'The American Woman's Pre-World War I Freedom in Manners and Morals', The Journal of American History, 55.2 (1968), 315-333 (p. 320) <. https://doiorg.vortex3.uco.edu/10.2307/1899561>.; Sophonisba P. Breckinridge, Women in the Twentieth Century: A Study of Their Political, Social and Economic Activities (New York: Arno Press, 1972), p. 174.

${ }^{333}$ Department of Commerce, Statistical Abstract of the United States: 1939, 'Table No. 50 - Gainful Workers 10 Years of Age and Over, by Occupation Groups, By Sex, Continental United States: 1920 And 1930' (Washington D.C.: Government Printing Office, 1940)

$<$ https://www.census.gov/library/publications/1940/compendia/statab/61ed.html > [accessed 14 February 2021] (p. 57) p. 50.; see also, Breckinridge, p. 174. (see table).
} 
showcased over 100 successful women in a large variety of jobs. This book's publication provided advice for women on how to obtain professional work and reflected on the perseverance of women who successfully entered occupations that may have been difficult to acquire. ${ }^{334}$ Other similar books include, for example, Occupations for Women, published in 1927, which highlighted opportunities for women in a variety of fields, such as, banking, dentistry, law and medicine. ${ }^{335}$ Both books cautiously warned women of the difficulty and prejudice that many fields have in place and suggest the best opportunity for women are those positions that are closely related to the domestic field. However, many women are celebrated in these books for their successes and provide examples of women overcoming obstacles in many different fields.

Careers for Women reported on a variety of both traditional and nontraditional occupations in which women were employed. Experts from each occupation noted the description of the position, training for the position, and opportunities of advancement within the position. A few examples of women who occupied atypical occupations in male dominated fields included advertising, government service, and medical care. Within these categories of jobs, many women held positions that were intended only to serve or manage women. For example, Dorothy R. Entwistle’s title stated, ‘In charge of Women’s Division, Advertising Department', and Mary N. Winslow worked in the Women’s Bureau, U.S. Department of Labor. In addition, Dr. Ellen C. Porter, a surgeon for the State Department of Health, advised that women have the greatest success in the 'obstetrics, diseases for women, and in public health work' rather than general surgery. ${ }^{336}$ Although few women were in male dominated fields, many of those women occupied positions closely related to the home industry or connected to women. ${ }^{337}$ However, many of these jobs provided a pathway for women to enter atypical jobs. Additionally, many jobs that were mentioned in the book, Careers for Women, did provide examples of women in male dominated jobs that were not solely

\footnotetext{
${ }^{334}$ Careers for Women, ed. by Catherine Filene Shouse (Cambridge, M.A.: The Riverside Press, Houghton Mifflin Company, 1922).

${ }^{335}$ Occupations for Women: Being the Practical Information Obtained by a Study Made for the Southern Woman's Educational Alliance, ed. by O. Latham Hatcher, Ph.D., $2^{\text {nd }}$ edn (Richmond, VA: L.H. Jenkins, Inc., 1927).

${ }^{336}$ Shouse, pp. 7, 158, 199.

337 Robyn Muncy, Creating a Female Dominion in America Reform, 1890-1935, (Oxford: Oxford University Press, 1991), p. xv. Proquest Ebook Central. She refers to women professionally helping children, 'This encouraged creators of new female professions....' See also, Dumenil, pp. 171-73.
} 
connected to domestic work or serviced women, such as, the corporate and patent lawyer, the paper chemist, and the policewoman.

By 1930, the largest percentage of professional fields for women were teachers and nurses. However, the largest percentage growth in professional fields were atypical positions consisting of veterinary surgeons, architects and engineers. Women began to enter the field of veterinary surgury in the 1920s with an increase growth of 91\% from 1920 to 1930. Although the numbers were small, consisting of 1 in 1920 and 11 in 1930, this shows that a new occupation became accessible to women. Women engineers grew from 41 in 1920 to 113 by 1930 which is a 64\% increase during the 1920s. Women architects experienced a similar percentage growth during the 1920s as to engineers, with 137 in 1920 and 379 in 1930. ${ }^{338}$ Although the total numbers of women occupying these positions were small, they should be recognized as a significant demographic shift of women entering professional fields that were dominated by men. Women entering these atypical professions challenges Anne Hollander's claim that men and women kept to their traditional separation. Women entering men's professional fields at a higher growth rate is an example of just the opposite, that women were beginning to work alongside men.

Another shift that should not be ignored during the 1920s was that many women were gaining acceptance in male only professional organizations. For example, Helen Innes was accepted into the American Society of Heating and Ventilation in 1918 as an associate member but then elevated her status to a full member in 1923. Occupations for Women noted several women had recently been admitted to membership in the Richmond Real Estate Exchange, and Jane Grant, writer for the New York Times, reported that Miss Ethel H. Baily was the first woman to be accepted in the Society of Automotive Engineers. ${ }^{339}$ Women's acceptance in male dominated professions and organizations demonstrated the cultural shift of

\footnotetext{
${ }^{338}$ U.S. Department of Commerce, Statistical Abstract of The United States: 1930, 'Table No. 51: Persons 10 years of age and Over Engaged in each Specified Occupation', (Washington, D.C.: Government Printing Office, 1930), no. $52<$

https://www.census.gov/library/publications/1930/compendia/statab/52ed.html> [accessed 14 February 2021] (p. 60). Based on the census, women engineers nearly tripled from 1920 to 1930, from 41 to 113 , respectively.

${ }^{339}$ Margaret Ingels, M.E., 'Petticoats and Slide Rules’, in Women in Engineering: Pioneers and Trailblazers, ed. by Margaret E. Layne, P.E. (Reston, VA: ASCE Press, 2009), pp. 85-97 (p. 91).; Hatcher, p. 184.; Jane Grant, 'High Honors for Woman Engineer,' New York Times, 10 January 1926.

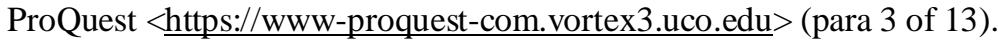


women more accepted in the public sphere and thus beginning to narrow the gap from a gender perspective.

In 1927, the Southern Woman's Educational Alliance claimed that the social context of women had completely shifted as women were now thinking of homemaking as a secondary career. ${ }^{340}$ From 1920 to 1930, women's employment in the U.S. increased by $21.1 \%$, while at the same time, women's population increased $17.8 \%$. Therefore, women entering the job market exceeded the growth of the female population. Additionally, women shifted to a corporate setting either in a clerical position or in a professional job. Therefore, this suggests that the social culture was changing as more women were working alongside men, thus decreasing occupational segregation.

\section{Dress for Women in the Workplace}

The numerous articles advising women of the most appropriate business attire suggests the growing numbers of women working in an office setting. The migration of men moving off the farms and into the office created a need for ready to wear suits. ${ }^{341}$ During the 1920s, we see this same shift with women as they readily entered the office setting. Therefore, women needed a garment that would fulfil the same requirement as the business suit had for men. In May 1920, an article in Women's Wear noted a greater importance of women's business attire and indicated that the past fashions were too feminine and the suit was too masculine, therefore, the straight dress is the best attire for women in the workplace. ${ }^{342}$ During the 1920 s, the social customs of wearing trousers publicly was only reserved for men and as indicated by Muncy, the women's suit was 'read' by society as unfeminine. ${ }^{343}$ Barthes introduced how messages relate to fashion through text, visual, and the historical cultural contexts. He further noted that messages based on a popular print over a solid shirt is easy to accept from one season to another, however, meanings that are based on cultural and social values, such as women wearing pants, which requires a new association from the established social norms is more difficult to change. ${ }^{344}$

\footnotetext{
${ }^{340}$ Hatcher, p. xiv.

341 Zeitz, Flapper, pp. 163-64.

342 'Dress for Business Women', Women's Wear, 15 May 1920. ProQuest <https://www-proquestcom.vortex3.uco.edu> (p. 34).

${ }_{343}$ Robyn Muncy, Creating a Female Dominion in America Reform, 1890-1935, (Oxford: Oxford University Press, 1991), p. xiii. ProQuest Ebook Central.

${ }^{344}$ Roland Barthes, The Fashion System, (London: University of California Press, 1983) p.184.
} 
Therefore, since pants were a symbol of masculinity and tied to traditional culture, this fashion was more difficult for society to accept as women's wear. The shift dress played a distinct role in fulfilling the need for a viable business option as it was simplistic and easy to mass produce, like the suit, but also socially appropriate for women at the time since it was a dress.

Retail store advertisements and events were also geared to the businesswoman. Many department stores and specialty shops held fashion shows for the business woman to help her navigate appropriate attire for the office. ${ }^{345} \mathrm{~A}$ store in Denver adopted a slogan from the men's clothing industry, 'Dress Well and Succeed', and applied it to its advertising message for the businesswoman. ${ }^{346}$

Vogue reported that they were receiving numerous requests from their readers inquiring about appropriate business attire. In order to fill this request, Vogue published reoccurring articles, 'Fashion: A Guide to Chic for The Business Woman', in 1924 and 1926. The article released in 1924 not only addressed how women should dress in the workplace but also highlighted the breadth of fields women were occupying. Thus, indicating women's success in the public sphere. The article suggested as women were in a variety of jobs the attire may be different, however, simple dresses are the most appropriate when working in a business setting especially with men. The article claimed dressing in a simplistic manner is perceived as smart. ${ }^{347}$ The increasing number of women working in the office setting was an opportunity to display themselves in more professional attire by wearing simple dresses rather than wearing dresses associated with femininity. Both Lillian Gilbreth and Lois Weber dressed in straight simplistic garments and were very successful working alongside men, and as Lillian Gilbreth had noted, wearing large hats with 'fluffy, chiffon veil', looked foolish in an office setting. ${ }^{348}$

\footnotetext{
345 'Campaign for Sensible Garb for Business Women', Women's Wear, 01 May 1922. ProQuest $<$ https://www-proquest-com.vortex3.uco.edu> (p. 5).; 'Dresses: Private Display of Business Women's Wear in Cleveland', Women's Wear, 30 September 1924. ProQuest < https://www-proquestcom.vortex3.uco.edu> (p. 27).; 'Dresses: Gimbel Brothers in Milwaukee Hold Fashion show for Business Women’, Women’s Wear Daily, 22 April 1929. ProQuest $<$ https://www-proquestcom.vortex3.uco.edu> (p. 1).

346 'Retail Promotion — Store News: Dress Well Slogan used in Business Women's Ads', Women's Wear Daily, 29 July 1924. ProQuest <https://www-proquest-com.vortex3.uco.edu > (p. 58).

347 'Fashion: A Guide to Chic for the Business Woman', Vogue, 15 September 1924. ProQuest $<$ https://www-proquest-com.vortex3.uco.edu $>$ (pp. 98-99)..

${ }^{348}$ Gilbreth, pp. 94-95.
} 
The articles in Vogue stressed with the utmost importance that the straight silhouette was the best option for the work environment. Vogue noted many reasons as to why the straight silhouette was most appropriate. First, the simplistic design was functional in the office as there was less opportunity for your clothes to snag on cabinets or desks. Second, the simple structure was versatile with the wide variety of fabrics, designs, and accessory options that created a unique look while at the same time not looking overly adorned. The versatility of the straight structure also worked well for a large variety of occupations. Third, Vogue noted the adaptability of the straight silhouette as it can go from the office to tea after work or even to the theatre, and as a result, it is the best option for modern living. ${ }^{349}$ As discussed in the previous chapter, the migration of Americans moving to the city made possible everyday experiences of shopping at department stores, attending films, vaudeville shows, and theatres, or dining out which created the new modern life. The shift dress was the first garment that was functional, versatile and adaptable and was suitable for all occasions. Previously types of dresses were specific in terms of function or time of day, such as day dresses, evening dresses, or tea gowns. Yellis noted that one of the most significant advantages of the shift dress was that it was easy to launder and was suitable for the working woman with limited time. ${ }^{350}$ However, although the shift dress was promoted as the best option for work, it was the American flapper who became synonymous with this garment.

\section{Defining the American Flapper}

The American flapper is one of the most recognizable images in American history. Many sources, such as, novels, movies and scholarly literature paint a comparable picture of the lifestyle, attitude, and dress of the American flapper during the 1920s. The lifestyle and dress of the flapper was different from other iconic symbols before her as she shocked society. Kitch noted that the American flapper was a silly, sexually promiscuous, dancing girl that was spread by mass media in the form of novels, movies and magazines. ${ }^{351}$

\footnotetext{
349 'Fashion: A Guide to Chic for the Business Woman', Vogue, 15 September 1924. ProQuest $<$ https://www-proquest-com.vortex3.uco.edu> (pp. 98-99, 134). 'Fashion: A Guide to Chic for the Business Woman', Vogue, 15 November 1926. ProQuest $<$ https://www-proquestcom.vortex3.uco.edu> (pp. 70-71, 142, 150).

${ }^{350}$ Kenneth A. Yellis, 'Prosperity's Child: Some Thoughts on the Flapper', American Quarterly, 21.1 (1969), 44-64 (pp. 53-57) < https://doi-org.vortex3.uco.edu/10.2307/2710772>.

${ }^{351}$ Kitch, p. 121.; see also, Perrett, p. 151.
} 
Scholars have widely debated the origins of the term 'flapper' in America. Many scholars, such as Yellis and Kitch, suggested the word 'flapper' was adopted from the English flapper who was a girl between 14 to 17 years old, had not yet reached maturity, and dressed to disguise any awkward body shapes. ${ }^{352}$ During the 1910s, store advertisements in the United States used the same definition as England referring to a flapper as a hard-to-fit girl. For example, Bonwit Teller \& Co. specifically stated in their newspaper advertisement, 'Flapper apparel originated by this shop for the hard-to-fit girl of 12 to 16 who has outgrown her age yet must be attired with the proper chic in a becoming girlish fashion' ${ }^{353}$ Furthermore, Ladies' Home Journal published a story in 1915 about a girl making her debut into society. She stated she had been 'dreadfully flapperish' and excited to 'strike right out and pick up some style'. ${ }^{354}$ Both of these examples defined a flapper as a young girl who had not yet hit maturity.

Nevertheless, while newspapers and magazines showed a flapper as a young girl, these print media also exposed the flapper as a woman possessing sexually aggressive behaviour. As early as1918, it was noted by The Evanston Woman’s club, that 'flapper types' were having escapades with sailors. One of the members had to persuade a 16-year-old to abandon a tramping trip with a sailor. ${ }^{355}$ The flapper was not only associated with sexually aggressive behaviour but by the 1920s she was defined closely as a dancing girl without rules and discovering new found freedoms. Much of the print media and books referred to the flapper by her morals and manners and almost always highlighted her appearance as if it was standard issue; rolled stockings, short, lightweight straight dresses, and bobbed hair. Yellis describes the flapper as,

The flapper covered her head and forehead with a cloche-style hat, tweezed her eyebrows, and used a whole range of other cosmetic devices, including trying to make her mouth look small and puckered,

\footnotetext{
${ }^{352}$ Kenneth A. Yellis, 'Prosperity’s Child: Some Thoughts on the Flapper', American Quarterly, 21.1 (1969), 44-64 (p. 49) < https://doi-org.vortex3.uco.edu/10.2307/2710772>.; Kitch, p. 121.; 'Exit the Flapper Via Longer Skirts.', New York Times, 25 June 1922. ProQuest < https://www-proquestcom.vortex3.uco.edu> (p. E2).

353 'Display Ad 7 -- no Title', New York Times, 28 March 1915. ProQuest < https://www-proquestcom.vortex3.uco.edu> (p. 3).; Bonwit Teller also advertised in Vogue magazine during the 1910s referring to the flapper as a hard-to-fit girl.

354 'Her Diary’, Ladies' Home Journal, October 1915. ProQuest < https://www-proquestcom.vortex3.uco.edu> (p. 10).

355 'Woman’s Club Acts To Protect City’s Flappers', Chicago Daily Tribune, 02 October 1918. . ProQuest $<$ https://www-proquest-com.vortex3.uco.edu $>$ (p. 3).
} 
“bee-stung” like Clara Bow's. Her dresses were tight, straight, short and rather plain, with a very low waist, usually about the hips, low necks for evening wear, and short sleeves, or none at all. She wore nude-colored silk or rayon stockings which she often rolled below the knee, or omitted altogether in hot weather, and high-heeled cut-out slippers or pumps. Underneath her outergarments she wore as little as possible. The corset was replaced by a girdle or nothing at all, and a brassière-like garment was worn to minimize the breasts. ${ }^{356}$

In 1922, the New York Times described the flapper as '[h]er short skirts flapped, her bobbed hair flapped and she came to be called the flappers'. ${ }^{357}$ According to Berg Fashion Library, shown in Figure [28], is a flapper dress from 1928, although these dresses varied in design and details, the simplistic, straight structure is the key element of the dress.

Inspiration for the flapper dress came from a historical perspective. The flappers bound their breasts and borrowed the shorter hemline from the historic man's chiton. The chiton from ancient Grecian times, as mentioned in the previous chapter, was a garment that was closely related to the shift dress. The style of the chiton for men and women were similar; however, the length of the garment varied between gender. Throughout ancient Greek times the women’s chiton was worn as a long dress; whereas, the men's chiton was worn at various lengths. For example, the ionic chiton worn by women extended to the floor but the men's chiton was either worn short or long. ${ }^{358}$ The men's shorter chitons were typically worn at knee-length or shorter. ${ }^{359}$ Although the chiton went through various changes in fit and fabrication, the primary length for women remained long, extending from the ankle length or to the floor. ${ }^{360}$ As discussed in chapter 2, Isadora Duncan was revolutionary in her clothing as she wore Grecian style dresses both short and long. Tortora and Marcketti claim the flapper was the first woman from the civilized west to wear short dresses and skirts that revealed her legs. ${ }^{361}$ Since the shift dress was shorter than the trajectory of current trends, this attached the flapper to radical and sexualized

\footnotetext{
${ }^{356}$ Kenneth A. Yellis, 'Prosperity’s Child: Some Thoughts on the Flapper', American Quarterly, 21.1 (1969), 44-64 (pp. 48-49) < https://doi-org.vortex3.uco.edu/10.2307/2710772>.

357 'Exit the Flapper Via Long Skirts: Fifth Avenue Fashion Arbiters Prophesy That Her Type Will Disappear. Fighting a Losing Battle Her Costumes and Manners Destilled to Join Gibson Girl in Attic Trunks. Why Flapper Styles Will Vanish. The Original Flapper', New York Times, 25 June 1922. ProQuest $<$ https://www-proquest-com.vortex3.uco.edu $>$ (p. E2).

358 Tortora and Marcketti, p. 65 (table 3.1).

${ }^{359}$ Department of Greek and Roman Art, para 2 of 2.

360 Tortora and Marcketti, p. 65 (table 3.1)

361 Tortora and Marcketti, 2015, p. 458.
} 
behaviour. The flapper and her dress lead to controversy that many community leaders and authors of print media expressed their own personal opinions about the flapper.

\section{American Flapper: Behaviour, Lifestyle, and Dress}

Many articles during the 1920s conveyed mixed messages on the flapper's freedom and behaviour, seeing them both in positive and negative terms. In 1922, The Washington Post published an opinion article about Miss Lucy Fox, a cast member of Sonny, who spoke of the American flapper as the 'spirit of the day-freedom...Her sophistry is for outside appearances only. Inside she is the same sweet, pure minded girl that her grandmother was. She has self-assurance, though'. ${ }^{362}$ Miss Fox felt that you should not judge the flapper for her appearance as she was still the same good girl as past generations but with added self-assurance, one trait her grandmother did not have. Other articles addressed the common question, what do we do with our flappers? Elinor Glyn, a British novelist, claimed that the flapper type was not properly raised by their parents, and she asserts, this 'is one of the greatest evils of our day' 363

In 1922, The Mansfield News printed an article, 'The Fable of the Flapper' detailing what was a true flapper and what qualities these type of women possessed. The interviewer chose four women that represented qualities of flapperism. These varied among each candidate, but all women portrayed some degree of flapper ideals. One interviewee was asked the question, ‘Do you consider yourself a flapper’? The interviewee responded,

If bobbed hair is typical of the flapper, I suppose I am. But I am not sorry I bobbed my hair and I am not going to get married until it grows out longer. Married women should not be flappers. ${ }^{364}$

\footnotetext{
362 'Praise for Flappers', Washington Post, 25 April 1922. ProQuest < https://www-proquestcom.vortex3.uco.edu> (p. 23).

363 'Elinor Glyn Defines “The Perfect Daughter”: Famous Novelist, Mother of Two Charming Girls, Gives Her Conception of the Ideal and Tells What's Wrong with the Younger Generation Today - It is Largely a Matter of Early Training, Says She, Discussing the Flapper Type', Washington Post, 27 July 1924. ProQuest $<$ https://www-proquest-com.vortex3.uco.edu $>$ (p. 1).; see also, Janis Elsie, 'If I Know what I Mean', Washington Post, 24 February 1924. ProQuest $<$ https://www-proquestcom.vortex3.uco.edu> (p. 1).

364 'The Fable of the Flapper', The Mansfield News, 13 August 1922. $<$ https://newspaperarchive.com/us/ohio/mansfield/mansfield-news/1922/08-13 > [accessed 20 February 2021] (p. 5).
} 
Another interviewee who had recently graduated from high school and was known for dressing in the latest fashions spoke about flapperism. She described flapperism as,

I love to have a good time in the right way.... I love to dance and go to parties. Mother doesn't allow me to go auto riding for she says that I have a home and if I entertain company, I must do it there. ${ }^{365}$

She was asked the question, 'Do you think girls think of other things today besides having a good time?' She responded, 'Yes, I do. There are hardly any girls who graduated with me who are not working some place, and like their work immensely.' 366 As noted by the interviewees, the qualities of flapperism were defined as wearing the latest fashion and hairstyle, an active social life, and an independent working girl. Furthermore, the article indicated that flappers used autos as an escape for privacy. The interviewer noted that a flapper is not a bad person but one that is 'youthful' and 'lively', 'loves to do things that are progressive', and 'has a decisive intelligence'. Additionally, the interviewer applauded the flapper for being open and upfront about her decisions and beliefs. In conclusion, the interviewer felt that the flapper was learning about all aspects of life. ${ }^{367}$

The flapper's elusive behaviour incorporated new freedoms, new manners and morals but equally controversial was her outlandish and unorthodox costume of short bobbed hair, rolled stockings, and short shift dresses. Life magazine repeatedly published pictures of the flapper drawn by the popular John Held Jr. Figure [53] is an image that appeared on the cover of Life magazine on February 18, 1926 with the flapper dancing the Charleston. Held's drawings were similar to Gibson's drawing of the Gibson Girl as he created a symbolic image of women, dress, and behaviour. The flapper was the true opposite of the Gibson Girl as she was said to enjoy a lifestyle of smoking, drinking, and living dangerously. According to Carolyn Kitch, while Fitzgerald christened the 1920s as the jazz age it was John Held Jr. who set the flapper’s styles and manners in motion throughout America. ${ }^{368}$

\footnotetext{
365 'The Fable of the Flapper', The Mansfield News, 13 August 1922. $<$ https://newspaperarchive.com/us/ohio/mansfield/mansfield-news/1922/08-13 > [accessed 20 February 2021] (p. 5).

366 'The Fable of the Flapper', The Mansfield News, 13 August 1922. $<$ https://newspaperarchive.com/us/ohio/mansfield/mansfield-news/1922/08-13 > [accessed 20 February 2021] (p. 5).

367 'The Fable of the Flapper', The Mansfield News, 13 August 1922.

<https://newspaperarchive.com/us/ohio/mansfield/mansfield-news/1922/08-13> [accessed 20

February 2021] (p. 5).

${ }^{368}$ Kitch, p. 121.
} 
Society at large appears to have felt that if someone dressed like a flapper, then she had all the characteristics of a flapper. Margery Wells noted that women who wore the flapper costume were disgusted at being put into one group called the 'flappers'. Wells further stated these women realized the flapper costume was attached to one personality. ${ }^{369}$ Some women went to great lengths as to separate themselves from the characteristics of a flapper. For example, Helen Gwendolen Jones was running for Mayor in 1927 and claimed that even though she had bobbed hair and wore short skirts she was not a flapper. ${ }^{370}$ One may assume that the candidate did not want to attach herself to the flapper persona due to the fact that she wanted the public to take her seriously. In The Mansfield News, one interviewee did not outwardly label herself as a flapper; however, the interviewer believed she was a flapper. ${ }^{371}$ The New York Times noted that there was not an exact definition of a flapper and no girls admitted to being a flapper, yet a month earlier, the same paper had published an article with a definition of the flapper. ${ }^{372}$ It is challenging to pinpoint an exact definition of the flapper, with any sub-culture, varying degrees exist as to how and what characteristics are adopted. However, the underlying identity of the flapper was that she represented modernity. Therefore, since the flapper was closely identified by her dress, the shift dress was attached to these same principles.

\section{Evolution of the Shift Dress: From the Chemise Silhouette to the Flapper Dress}

Initially, straight dresses were most commonly found in evening gowns. In 1918, Vogue described socialites wearing specific garments to a variety of events such as the opera or dining at the Ritz Carlton in New York City. Several socialite's gowns were described in the article as 'closely draped by the figure'. In Figure [54] is an illustration of a particular gown that was highlighted in the article. This gown

\footnotetext{
${ }^{369}$ Margery Wells, 'Flapper Becomes Weary of Sameness in Dress and Changes Her Style', St. Louis Post - Dispatch, 17 October 1922. 'Fable of the Flapper', Mansfield News, 13 August 1922. ProQuest $<$ https://www-proquest-com.vortex3.uco.edu $>$ (p. 30).

370 'A Girl Candidate', New York Times, 06 November 1927. 'Fable of the Flapper', Mansfield News, 13 August 1922. ProQuest <https://www-proquest-com.vortex3.uco.edu $>$ (p. E4).

371 'Fable of the Flapper', Mansfield News, 13 August 1922. 'Fable of the Flapper', Mansfield News, 13 August 1922. ProQuest <https://www-proquest-com.vortex3.uco.edu > (p. 5).

372 'Her Eternal Youth', New York Times, 02 July 1922. 'Fable of the Flapper', Mansfield News, 13 August 1922. ProQuest $<$ https://www-proquest-com.vortex3.uco.edu> (p. 74).; 'Exit the Flapper Via Long Skirts: Fifth Avenue Fashion Arbiters Prophesy That Her Type Will Disappear. Fighting a Losing Battle Her Costumes and Manners Destilled to Join Gibson Girl in Attic Trunks. Why Flapper Styles Will Vanish. The Original Flapper', New York Times, 25 June 1922. ProQuest <https://wwwproquest-com.vortex3.uco.edu> (para 12-16 of 19).
} 
had many characteristics of the shift dress and was noted by the author as 'unusual and graceful'. Furthermore, it was 'fashioned on very straight loose lines with straight loose sleeves, and bands of jet passementerie, accentuating the slender lines of the figure and arms, were its only ornamentation'. ${ }^{373}$ Not only was the dress a straight and loose design, but it also was simplistic without ornamentation of gathers, pleats, or drapery of the fabric.

Within the same issue, Vogue published an additional story regarding women wearing simpler designs. Not only were women beginning to wear simpler designs, but author, Jeanne Ramon Fernandez, commented on the political conversations that women were having and current books they were discussing. She commented that this was unusual as women most likely talked about the current fashions when gathered with friends. ${ }^{374}$ Less details on garments may lend fashion discussions to a minimal, therefore, women's conversation may shift to their hobbies and interests and less as to what they are wearing. Additionally, Fernandez may have perceived these ladies as more competent, not only because they discussed complex topics, such as politics, but also because they dressed in a sophisticated manner. Many styles appeared in this article, however, primarily two-piece dresses with an over-blouse of varied lengths were most frequently shown. Many of the ensembles looked similar to an apron style, long tunic over a skirt, or a loose chemise gown. See Figures [55 and 56] for examples of the apron style and chemise gown. Figure [55] is an apron style dress with an overlay and the sides appear open, designed by Doucet. Figure [56] is designed by Callot and consists of a straight dress made of velvet and embroidered in gold adorned with a black plumed hat. The caption stated, 'looked as if she had stepped out of an old painting'. ${ }^{375}$ As the dress was referred to an old painting, one may assume the designer may have been inspired by ancient Grecian or Roman heritage. Both dresses closely resembled the shift as it hangs straight down from the shoulders and does not constrict the body nor gather at any points of the garment. Although, the apron gown is a two-piece ensemble it takes on the character of a shift

\footnotetext{
373 'Fashion: New York Conforms to New Rules', Vogue, 01 March 1918. ProQuest <https://wwwproquest-com.vortex3.uco.edu $>$ (p. 126).

374 Jeanne Ramon Fernandez, 'Fashion: The World and Paris Grow Simpler', Vogue, 1 March 1918. ProQuest $<$ https://www-proquest-com.vortex3.uco.edu $>$ (p. 41).

375 Jeanne Ramon Fernandez, 'Fashion: The World and Paris Grow Simpler', Vogue, 1 March 1918. ProQuest $<$ https://www-proquest-com.vortex3.uco.edu $>$ (p. 42).
} 
dress as the apron is longer in length than a typical blouse. The Callot gown is adorned with a train. During this time, trains on simple dresses were very common.

By 1923, Vogue claimed the new winter mode was based on the tube-like silhouette. ${ }^{376}$ The straight silhouette was not only reserved for evening, but it also extended to daytime wear. A Chanel dress was suggested for day and night as it was referred to as 'straight and short', the illustration in Figure [57] reflects the length reaching just above the ankles ${ }^{377}$ In 1923, designer Doeuillet released a gown very similar to Callot's gown. Doeuillet's gown is shown in Figure [58]. The three distinct differences between the gowns of Callot and Doeuillet are the sleeves, the length and the train. Doeuillet's gown is sleeveless, shorter in length and absent of the train. They both were made from velvet and included three-banded embroidery designs. Doeuillet's gown had added fringe at each horizontal row of embroidery.

Coco Chanel gained popularity during the twenties and was recognized as the designer who initiated the change to simplicity. Chanel and her designs have frequently been described as revolutionary. Chanel's use of jersey material, traditionally used for men's undergarments, was a radical fabrication innovation for the use by women and demonstrated simplicity and comfort. Jean Leymarie referred to Chanel's use of jersey as the 'Jersey Revolution'. ${ }^{378}$ Chanel's fashion direction included simple dresses that were heavily accessorized. In 1920, Vogue described Chanel as ‘conservative' and one with 'impeccable taste'. Vogue further commented that Chanel 'shows no striking novelties, sponsors no daring or extreme modes, but presents eminently wearable and well-designed costumes'. ${ }^{379}$ Chanel's designs were revolutionary because they were so simplistic, unlike other designers, like Poiret, who utilized feminine details in his gowns. Vogue also referred to Chanel's costumes as 'neat and boyish'. ${ }^{380}$ The famous actress, Cecil Sorel, wore Chanel gowns on and off the stage. In L'Abbe Constantin, the hit stage adaptation of Ludovic Halevy's novel, Sorel wore a long straight silhouette accessorized in a 'flapper-like' manner with pink

\footnotetext{
376 'Fashion: The Early Paris Openings', Vogue, 01 October 1923. ProQuest < https://www-proquestcom.vortex3.uco.edu> (p. 43).

377 'Fashion: Silhouettes Which Inspire the Spring Mode', Vogue, 15 February 1923. ProQuest $<$ https://www-proquest-com.vortex3.uco.edu > (p. 27).

${ }^{378}$ Leymarie, p. 57.

379 'Fashion: Chanel Maintains the Normal Lines of the Figure', Vogue, 15 October 1920. ProQuest $<$ https://www-proquest-com.vortex3.uco.edu $>$ (pp. 50-51).

380 'Fashion: Chanel's Winter Collection', Vogue, 01 October 1923. ProQuest $<$ https://www-proquestcom.vortex3.uco.edu> (p. 44).
} 
beads described as 'here, there, everywhere from the dainty left wrist to the very tip of the pointed and wholly original train'. ${ }^{381}$ Accompanied with the pink beads was an elaborate headband and fringe. The fringe was a trademark of Chanel's.

Vogue's mid-October issue in 1924 marked a significant turning point for the establishment of the shift dress within the couture fashion realm. Two models shown in Figures [59 and 60] are both designed by Chanel. Although Figure [59] is longer in length than the definition of the shift, all of the elements are apparent in terms of the shift structure. Structurally the dress hangs straight from the shoulders consisting of four seams. This dress is elaborately decorated in beads and fringe; a quintessential element of the twenties' shift dresses. In Figure [60] this dress is also elaborately decorated but in shining silver lace. This silhouette was noted as having extreme style details, a 'very deep décolletage and the very short skirt', furthermore, the dress featured, 'loose panels [that] float from the shoulders'. The description of loose and a garment that 'floats' or hangs from the shoulder is a distinctive element of the shift dress. ${ }^{382}$ Figure [60] displayed a shorter dress than other models as the photograph shows more prominently her leg. ${ }^{383}$

Within the same issue as the Chanel dresses that were just discussed, Lelong presented the 'straight tunic-frock' for sportswear, shown in Figure [61]. Vogue applauded the 'tunic-frock' as smart for sports clothes and indicated that this style of dress for women is becoming increasingly important. Lelong's 'straight tunic-frock' was noted as worn with culottes underneath the tunic. The culottes are not apparent in the drawing and the article indicated that the culottes were for the only purpose of keeping the wearer warm.” 384 During the 1920s, the word 'frock' was a generic term for a dress. Therefore, this article suggested a 'tunic-frock' as similar to a straight dress. The shift dress was not a known entity at this time and the term 'tunic-frock' can be used interchangeably as a shift dress. Not only was the 'tunic-frock' comparable to the shift dress and indicated the importance of allowing freedom of movement but it also demonstrated the significance that the shift dress was suggested

\footnotetext{
381 'Fashion: Chanel Makes Three Charming Costumes', Vogue, 01 May 1918. ProQuest $<$ https://www-proquest-com.vortex3.uco.edu $>$ (p. 82).

382 'Fashion: A Portfolio from Six Great Creators', Vogue, 15 October 1924. ProQuest <https://wwwproquest-com.vortex3.uco.edu> (p. 65).

383 'Fashion: A Portfolio from Six Great Creators', Vogue, 15 October 1924. P ProQuest <https://wwwproquest-com.vortex3.uco.edu> (p. 62).

384 'Fashion: The Mode for the Country', Vogue, 15 October 1924. ProQuest < https://www-proquestcom.vortex3.uco.edu> (p. 57).
} 
as a sporting outfit. ${ }^{385}$ This illustration further demonstrated women's interests and engagement in strenuous sports. Lelong, expressed in 1925, that women had increased their amount of physical activity as well as extended their interests to unconventional pastimes. Lelong described the American New Woman: 'she is enthusiastic about sports, she walks, she drives her car, and she is even beginning to fly her own airplane. How then can she be held a prisoner by her clothes?'? ${ }^{386}$

In 1921, Suzanne Lenglen shocked the audience when she debuted a white, knee-length shift dress at Wimbledon. ${ }^{387}$ Suzanne Lenglen was one of the first professional tennis players to bring fashion to the tennis courts. Her shift dress was designed by Jean Patou and can be seen in Figure [61]. Her shift dress may have enabled her to move easily on the court, but the short length was considered socially unacceptable at this time. ${ }^{388}$ Sport was closely linked to being modern, and we can see a link between sports clothes and the modern woman. F. Scott Fitzgerald characterized this link with Jordan in The Great Gatsby. Fitzgerald paired sports and masculinity together for his perception of a modern woman. The references that are associated with Jordon is her disinterest in men, the symbolic resonance of her golf club and balls, and her stature. ${ }^{389}$ An excerpt from The Great Gatsby as narrated by Nick, makes this clear: 'I enjoyed looking at her. She was a slender, small-breasted girl with an erect carriage which she accentuated by throwing her body backward at the shoulders like a young cadet.' 390 The characterization of Jordan clearly parallels sports and masculinity, but it also suggests her clothes resembled the shift dress with a 'slender' figure and 'small breasts'. As the decade progresses, the increase involvement of women in sports can be seen in the vast amount of advertisements, feature stories, and sports clothing presented in Vogue magazine during the 1920s.

\footnotetext{
385 'Fashion: The Mode for the Country', Vogue, 15 October 1924. ProQuest <https://www-proquestcom.vortex3.uco.edu> (p. 57).

386 'Many Fashions for Women are Created by Mere Man: Male Sex is Best Judge of Feminine Appearance, Says Lucian Lelong, Paris Coutourier', New York Times, 08 November 1925. ProQuest $<$ https://www-proquest-com.vortex3.uco.edu $>$ (p. x20).

387 Jean Patou: Innovator (2014), < https://exhibitions.fitnyc.edu/1930s-fashion-blog/tag/tennis/ > [accessed 4 January 2021] (para 4 of 8).; see also, Beaton, p. 163.; Footage of Suzanne Lenglen in 1925 at Wimbledon: How I Play Tennis by Mlle. Suzanne Lenglen (British Pathé Production), online film recording, YouTube, 13 April 2014, < https://www.youtube.com/watch?v=_90PPjyGBgk> [accessed 3 January 2021].

388 The Museum at FIT, para 4 of 8.

${ }^{389}$ A.B. Paulson, 'Oral Aggression and Splitting', in Modern Critical Interpretations: F. Scott Fitzgerald's The Great Gatsby, ed. by Harold Bloom (New York: Chelsea House Publishers, 1986), pp. 71-85 (p. 82).

${ }^{390}$ F. Scott Fitzgerald, The Great Gatsby, (New York: Collier Books, 1992), p. 15.
} 
Many socialites were featured participating in sports, such as golf, tennis, or riding a motor buggy. ${ }^{391}$ Additionally, feature stories discussed outfits for specific sports as well as how sports clothing may also be suitable for other activities, such as travel. ${ }^{392}$ The sports clothing that Vogue displayed consisted of straight, simple shift dresses as well as 2-piece ensembles that closely resembled the shift dress. The shift dress was a key garment for women and it enabled them to become more active and competitive in sporting events.

\section{Flapper's Influence on the Fashion System: Hemlines Rise}

At this time, we begin to see the youth and the flapper disregard the traditional fashion protocols dictated by the designers. In 1921, an article posted in the New York Times suggested a conspiracy in the fashion and corset industry of keeping women in long gowns and corseting themselves for a lifetime. Helen Bullitt Lowry paid tribute to the American Flapper for rebelling against corseting. The flapper had inspired change in fashion. Lowry claimed,

Coming generations of women will remember our flapper with her perpetually waved bobbed hair, her lithe, boyish figure, her cigarette case and her rolled-under the knee stockings. It will be remembered, too, that her example in many things was followed by her elders. Every day the older women are loosening their stays, and even if they still wear armor, it must be of the flexible kind. ${ }^{393}$

This is an interesting observation that Lowry made, although this is her opinion, it suggests that the flapper was influential and her dress was different from the prescribed fashion. This article was accompanied with an illustration showing dresses with hemlines above the knees, as shown in Figure [63]. Also, important to note, a lifestyle magazine called The Flapper provides photographic evidence of the flapper in short skirts with rolled-up stockings. The front cover of their June 1922 issue can be seen in Figure [64]. Both of these examples demonstrate that the flapper wore her dress much shorter than the Parisian fashion.

\footnotetext{
391 'Features: Followers of Summer Sports', Vogue, 31 August 1929. ProQuest < https://wwwproquest-com.vortex3.uco.edu> (pp. 50-51).; 'Features: Long Island Tennis', Vogue, 6 July 1929. ProQuest $<$ https://www-proquest-com.vortex3.uco.edu $>$ (p. 46).

392 'Fashion: A Golf Course in Clothes', Vogue, 13 April 1929. ProQuest <https://www-proquestcom.vortex3.uco.edu> (pp. 116-117).; 'Fashion: Sports Clothes', Vogue, 15 October 1926, ProQuest $<$ https://www-proquest-com.vortex3.uco.edu> (pp. 66-67).

${ }^{393}$ Helen Bullitt Lowry, 'A Conspiracy in Restraint: A Conspiracy in Restraint', New York Times, 09 October 1921. ProQuest <https://www-proquest-com.vortex3.uco.edu> (p. 14).
} 
Kelly Boyer Sagert claimed the flapper clothing that came into style revolutionized women's fashion in the U.S. as the long skirt would never return as a primary fashion for women. ${ }^{394}$ In articles in popular magazines and journals, the flappers continually disputed an acceptable skirt length throughout the decade. The voice of the consumer during the 1920's was one of the first in history to deny the designer's complete direction of fashion. Marjorie Hillis highlighted the differences of opinions between Paris designers and the American women. While skirts in Paris were growing somewhat longer, skirts in America were shortening. ${ }^{395}$ Accordingly to Vogue, the fall silhouettes that Parisian designers created were a 'raggedy frock' technique with irregular floating panels. ${ }^{396}$ As Vogue suggested, the introduction of the irregular hemline may have been a compromise of the disparity of skirt lengths.

The practical side of everyday wear was evident in the changing dress silhouettes. The skirt lengths for the spring mode of 1922 were sufficiently short to be practical and as a general rule, the plainer the suit, the shorter the skirt. ${ }^{397}$ In 1922, we see this parity between the plain silhouette and short skirt. This general rule played a part in the simplicity and shortness of the shift dress. However, in June 1922, an article in the New York Times claimed that fashion was changing back to the long skirt. The attitude of the flappers according to the article, however, had not changed, 'the idea was fought in some circles and the flappers are still objecting by word and deed'. The article further stated, there is no objection if the flapper wants to wear knee length skirts as her own uniform, but the smart thing is to drop skirts to the ground. ${ }^{398}$ The article symbolizes the frustration and conflict between designer and consumer. Furthermore, a New York department store salesman reported that the flapper was asking for shorter skirts than he carried. Fashion experts warned that the flapper had to accept the longer skirt length as the true direction of the current fashion

\footnotetext{
${ }^{394}$ Kelly Boyer Sagert, Flappers: A Guide to an American Subculture (Oxford: Greenwood Press, 2010) p. 11.

${ }^{395}$ Marjorie Hillis, 'Fashion: The Spring Mode Drops Hints to Waiting Paris', Vogue, 15 March 1920. ProQuest $<$ https://www-proquest-com.vortex3.uco.edu $>$ (p. 49).

396 'Fashion: Dressing on a Limited Income', Vogue, 15 November 1920. ProQuest <https://wwwproquest-com.vortex3.uco.edu> (p. 49).

397 'Fashion: The Spring Mode in Three Chapters: I. Morning Dress', Vogue, 15 April 1922. ProQuest $<$ https://www-proquest-com.vortex3.uco.edu > (p. 33).

398 'Fashions: Style Hints for Fall Draping in Long Lines the Long Cost. Beads for Trimming. Straight Versus Bouffant Lines. Draping in Long Lines. Embroidery. Hats Growing Larger. Length of Skirts', New York Times, 25 June 1922. ProQuest <https://www-proquest-com.vortex3.uco.edu> (p. X4).
} 
modes. ${ }^{399}$ Harry Collins, costume creator, spoke to the Metropolitan Museum members about the current trends in dress. He stated, 'Flapper styles have the individuality of youth embodied in them and mark the dawn of a better, more sensible day of dress for women., 400

The rise of the hemline was dramatic during the mid to late twenties. It began to rise in 1924 and reached its most elevated position in $1927 .{ }^{401}$ In 1925, Ralph Mont, an executive officer of the Fashion Art League, reported that skirts' lengths for the Spring season were higher than ever before. ${ }^{402}$ By 1927, Paul Poriet developed a short fur skirt for the modern flapper. He felt that if she was going to wear short skirts, at least she should be warm. ${ }^{403}$ Poiret's statement exemplified the influential power of the flapper that extended to the couture houses and designs. Articles continued to argue for and against the short hemlines and the flapper. It is difficult to count how many articles were for or against the flapper and her dress. With a sample of 25 articles that were retrieved from women's magazines and newspapers, they were almost divided in half, with 14 articles that approved of the flapper and 11 against the flapper. The majority of the articles were published in 1922 and 1923, therefore, this may suggest that the debate was slowing down as the decade progressed.

Notably, as evidenced from the above articles, the flapper continually had a large voice and opinion that not only aided but directly affected the rise of the hemline. Blumer declared that fashion change is at the root of collective selection, such as, buyers read the same trade journals, look to other buyer's lines, and use historical data to make their selections. He also recognized that individuals outside of the fashion system may begin trends or new styles. ${ }^{404}$ Blumer justified this point by the example of the short skirt movement in the 1920s. Blumer claimed,

\footnotetext{
399 'Exit the Flapper Via Long Skirts: Fifth Avenue Fashion Arbiters Prophesy That Her Type Will Disappear. Fighting a Losing Battle Her Costumes and Manners Destilled to Join Gibson Girl in Attic Trunks. Why Flapper Styles Will Vanish. The Original Flapper’, New York Times, 25 June 1922. ProQuest $<$ https://www-proquest-com.vortex3.uco.edu $>$ (p. E2).

400 'Harry Collins Talks on "Dress of our Times”', Women's Wear, 25 April 1922. ProQuest $<$ https://www-proquest-com.vortex3.uco.edu $>$ (p. 2).

${ }^{401}$ Lynne Richards, 'The Rise and Fall of it All: The Hemlines and Hiplines of the 1920's', Clothing and Textiles Research Journal, vol 2 (1983-84), $42-48$ (p. 48).

402 'Skirts Will be Shortest Ever, Modesties Say', Los Angeles Times, 16 March 1925. ProQuest $<$ https://www-proquest-com.vortex3.uco.edu> (p. 1).

403 'Fur Skirt Latest Novelty.: Poiret Plans to Keep the Flappers Warm Next Winter.', New York Times, 19 June 1927. ProQuest <https://www-proquest-com.vortex3.uco.edu > (p. 13).

${ }^{404}$ Herbert Blumer, 'Fashion: From Class Differentiation to Collective Selection', Sociological Quarterly, 10.3 (1969), 275-291 (pp. 278-281)
} 
These manufacturers enlisted the cooperation of the heads of fashion houses, fashion magazines, fashion commentators, actresses, and acknowledge fashion leaders in an extensive, well organized and amply financed campaign to reverse the trend....Yet, despite this effective marshalling of all significant sources of prestige, the campaign was a marked failure; the trend toward shorter skirts, after a slight interruption, continued until 1929 when a rather abrupt change to long dresses took place. ${ }^{405}$

What Blumer had failed to mention, was the power of subgroups. He claimed that fashion is responsive to collective selection, as the common world is complex and constantly moving, society evolves and change their taste and expression in fashion, and within this effort, it moves in line to modern life. ${ }^{406}$ As noted by Blumer, the approval of the shift dress was not equally or commonly accepted, but the subgroup of the flappers not only created fashion history but were the symbol of modern women. Thus, the change of fashion that the flapper's imposed, as Blumer had discussed, was in-line with the modern woman.

\section{The Charleston}

A Vogue article published in 1920 foreshadowed the need of the shorter dress for dancing as it stated, 'the ideal dancing costume, one feels, would permit absolute freedom of the knees, such liberty as the Victorians did not dream'. ${ }^{407}$ A shift from the ragtime waltz dance to the upbeat, flailing Charleston dance was revolutionary. Just like the flapper herself, the Charleston rules of dance were completely different from the dances of the past. The Charleston upended normal dance rules and was thought of as wild with knees knocked and arms swinging high above heads. Jazz

\footnotetext{
$<$ http://vortex3.uco.edu:2050/login?url=https:/www.jstor.org/stable/4104916> [accessed 30 January 2021]. Reprinted in The Perspectives of Fashion, ed. by George B. Sproles, (Minneapolis, MN: Burgess Publishing, 1981), pp. 49-57.

${ }^{405}$ Herbert Blumer, 'Fashion: From Class Differentiation to Collective Selection', Sociological Quarterly, 10.3 (1969), 275-291 (p. 281)

$<$ http:/vortex3.uco.edu:2050/login?url=https:/www.jstor.org/stable/4104916> [accessed 30 January 2021].

Reprinted in The Perspectives of Fashion, ed. by George B. Sproles, (Minneapolis, MN: Burgess Publishing, 1981), pp. 49-57.

${ }^{406}$ Herbert Blumer, 'Fashion: From Class Differentiation to Collective Selection', Sociological Quarterly, 10.3 (1969), 275-291 (p. 282)

$<$ http://vortex3.uco.edu:2050/login?url=https:/www.jstor.org/stable/4104916> [accessed 30 January 2021]. Reprinted in The Perspectives of Fashion, ed. by George B. Sproles, (Minneapolis, MN: Burgess Publishing, 1981), pp. 49-57.

407 'Fashion: Yesterday Costumes the Dances of To-Day', Vogue, 15 March 1920. ProQuest $<$ https://www-proquest-com.vortex3.uco.edu > (pp. 66-67).
} 
music accompanied the Charleston and for the first time, improvisation was encouraged. Similar to a jazz band, although dancers were paired up, at times they danced independently and separate from each other. This separation encouraged each individual to experiment with their own dance moves and permitted women independence as they could dance without a man's guidance. In Figure [65], a drawing from John Held Jr. demonstrates the flapper dancing the Charleston, together but independently.

As noted by an article in the New York Times, by 1925, the Charleston had 'pranced into favor'. The paper reported how the popularity of the Charleston had spread to all regions of the country and to all classes. ${ }^{408}$ The popularity of the Charleston coincided with the increased popularity of the shift dress. As the Charleston gained favour in 1925, Vogue displayed an increased number of shift dresses, from 2 appearances in 1924 to 40 appearances in 1925. In 1925, Vogue featured an article about a bride's trousseau which connected the importance of the shift dress to dancing. The fashion consultant chose dresses that were suitable for a new bride on her honeymoon. Attending ceremonies and wearing ball gowns was not advised. Instead, a simpler gown was suggested as the current entertainment was more casual in nature with partaking in dining and dancing with friends. Thus, the consultant suggested a shift dress for her dancing frock, shown in Figure [66]. ${ }^{409}$

The new music culture, jazz, fuelled dancing. As more women danced, the shift dress was the most optimal silhouette to wear. Lelong stated that the American woman may be directly responsible for the changes of fashion, as they came as a direct reaction to the needs of the time. ${ }^{410}$ The new culture of music, dancing, and personal expression was part of the times and the shift dress aided in this change.

\footnotetext{
408 Jane Grant, 'The Charleston Prances Into Favor: New Dance Comes on Swiftly, but it Has Not Reached the Ballrooms of New York', New York Times, 30 August 1925. ProQuest $<$ https://wwwproquest-com.vortex3.uco.edu> (p. SM2).; 'Mrs. Berlin Writes on The Charleston: Former Ellin Mackay Says Step Captured Fifth Avenue, Which Strives to Learn it. Hails Prestige of Chorus Society Acquiring Respect for the Dancing Girls, She Asserts, by Trying to Rival Them.', New York Times, 07 February 1926. ProQuest $<$ https://www-proquest-com.vortex3.uco.edu $>$ (p. 6).

409 'Fashion: A Trousseau from the Spring Collections', Vogue, 01 April 1925. ProQuest $<$ https://www-proquest-com.vortex3.uco.edu $>$ (p. 50).

410 'Many Fashions for Women are Created by Mere Man: Male Sex is Best Judge of Feminine Appearance, Says Lucian Lelong, Paris Coutourier', New York Times, 08 November 1925. ProQuest $<$ https://www-proquest-com.vortex3.uco.edu $>$ (p. X20).
} 


\section{The Shift Dress and The Economic System}

\section{Mass Production}

Another major influence on the development and circulation of the shift dress was the growth in mass production. While the Industrial Revolution initiated conspicuous consumption, it was the 1920's that fuelled growth of corporate expansion, labour force, new markets, and consumerism. ${ }^{411}$ During the 1920 s, mass production became sophisticated through the use of new technology and innovation, and as a result, factories reached unprecedented levels of production. ${ }^{412}$ Thus, mass production created a new way of life. The Progressive Era lured people into department stores but it was during the 1920s where consumption became abundant. Mass produced goods reached all classes of America and involved all types of industry.

During the Industrial Revolution, the textile industry was a significant contributor to mass production methods particularly for men's clothing. The ready-towear industry took longer to adapt to women's clothing as it was increasingly difficult to produce on a large scale. Men's styles consisted of simplistic box coats and trousers, whereas, women's clothing was too complex for manufacturing as it was closely tailored which required multiple fittings and was heavily adorned with petticoats, lace, and bustles. ${ }^{413}$ According to Bird, mass production grew considerably after WWI and ready-to-wear became a significant source to the fashion industry. ${ }^{414}$ Mass production was easily achieved with the shift dress's straight form which hung loose from the body and did not require additional fittings. According to King, mass production is an element within the environment that effects fashion

\footnotetext{
${ }^{411}$ Robinson, Eugene, 'Industrial Role Models and Matinee Idols: Their Significance And Hollywood's Role In The Burgeoning Industrial Dream', (unpublished doctoral thesis, University of Maryland: College Park, 1984) in ProQuest Dissertations and Theses Global < https://search-proquestcom.vortex3.uco.edu/pqdtglobal/docview/303330034/8B8BFBF2354F4B99PQ/1 ?accountid=14516> [accessed 10 February 2021] pp. 27-28.

412 Parrish, pp. 31-33.

${ }^{413}$ Kidwell and Christman, pp. 41-45.; see also, Zeitz, Flapper, pp. 163-64.; Ross, Nancy L., ‘A Legacy of Fashion: “Suiting Everyone”: "Suiting Everyone”, Appreciating Fashion’s

Legacy', Washington Post, 15 September 1974. ProQuest $<$ https://www-proquestcom.vortex3.uco.edu> (pp. F1, F3).; Michelle T. Finamore, 'Fashioning Early Cinema: Dress and Representation in American Film, 1905-1930', (unpublished doctoral thesis, University of Michigan at Ann Arbor, 2010) in ProQuest Dissertations and Theses Global <

http://vortex3.uco.edu/login?url=https://search-proquest-

com.vortex3.uco.edu/docview/250272906?accountid=14516 > [accessed on 15 September 2020] p. 26.;

Banner, p. 31

${ }^{414}$ Bird, p. 190.
} 
change, known as the 'mass-market' process. ${ }^{415}$ The efficiency of mass production can contribute to fashion change as the production of garments can be more readily made, which in turn, can spread fashion trends more quickly. It has been suggested that mass production played an integral part of the adoption of the shift dress. Claudia Kidwell and Margaret Christman have claimed that 1920s fashion was significant as the French fashions were easily available to every American woman, either as an original, a copy, or an adaptation of one. Every American woman could not have a Paris gown, but every woman could have an adaptation at a reasonable cost. The simplistic design of Coco Chanel's dresses was easily copied, therefore an adaptation of a Chanel gown was not only affordable but a variety of ready-to-wear manufacturers mass produced her styles. As a result, similar dresses of Chanel's dresses were available from a broad price range. ${ }^{416}$ For the first time in history, women could not be identified or classified based on their dress. Zeitz professed, 'It [flapper dress] belonged to every woman who wished to claim it as her own. It was a radical concept'. ${ }^{417}$

It was in the latter part of the 1920s that the shift dress became highly mass produced as it reached beyond the subgroup of the flappers and gained widespread acceptance among American women. This is exemplified in Figure [67], Vogue's article, 'Paris Modes Are Launched in New York', with several women wearing shift or shift-like ensembles shown in a boat. The boat theme may be a nod that the fashions were as widespread and numerous as the American immigrants. The dress designs in the article were inspired by Paris designers, but offered more affordable options from other manufacturers. ${ }^{418}$ The simple structure of the shift dress enabled the efficiency of mass production which brought affordable clothes to women, but also, the ease in adaptation for a variety of designs. Although the construction of the shift dress is simple, the versatility in design can be seen in the Vogue article, 'Paris Modes Are Launched in New York'. ${ }^{419}$ For example, there is a wide variety in the design, fabrication, necklines and sleeve lengths. The necklines largely varied

\footnotetext{
415 King, pp. 32, 39.

${ }^{416}$ Kidwell and Christman, p. 189.; see also, Nancy J. Troy, Couture Culture: A Study in Modern Art and Fashion (Cambridge, MA: MIT Press, 2003), p. 383.

${ }^{417}$ Zeitz, Flapper, p. 162.

418 'Fashion: Paris Modes are Launched in New York', Vogue, 15 November 1925. ProQuest $<$ https://www-proquest-com.vortex3.uco.edu> (pp. 92-93).

419 'Fashion: Paris Modes are Launched in New York', Vogue, 15 November 1925. ProQuest, $<$ http://vortex3.uco.edu/login?url=https://www-proquest-com.vortex3.uco.edu> (pp. 92-93).
} 
consisting of scoop necks, V-necks, bateau necks, turtle-neck or collars. The same amount of variations on the skirts were also present of either straight, pleated, ruffled or handkerchief hemlines. The dresses ranged in diversification from a very simple dress consisting of a scoop neck, solid colour dress with a vertical stripe along the side, to a more detailed dress of a V-neck, multi-tiered ruffled skirt accompanied on a print fabric. Therefore, women could choose dresses that would fit their personal style.

\section{A Shift in the Film Industry}

Another significant factor and influence on the shift dress was the growing film industry. According to film historian, Janet Wasko, 1919 marked a significant transition for the film industry as it shifted from independent proprietors to corporate ownership. The firm Kuhn, Loeb \& Co., a prominent firm in the international and railroad financing, entered a financial agreement to supply money to the film industry. ${ }^{420}$ The cost of film production escalated. Thus, the independently owned film corporations transitioned to a leveraged banking operation system and fell victim to mergers and acquisitions. ${ }^{421}$ By 1920, First National Pictures controlled approximately 664 theatre houses. ${ }^{422}$ These mergers allowed the film industry to begin structuring movies as a mass-produced product as few vertically integrated companies controlled production, distribution and exhibition. ${ }^{423}$

During the Progressive Era, the nickelodeons appealed to the immigrant and working class, however, in the 1920s the movie expansion of new and beautiful theatres lured in the middle-class, and as a result, audiences merged into a larger diversification of classes. ${ }^{424}$ In 1918, Chicago boasted a deluxe movie house with its

\footnotetext{
${ }^{420}$ Janet Wasko, Movies and Money: Financing the American Film Industry (Norwood, NJ: Ablex Publishing Corporation, 1982), p. 17.

${ }^{421}$ Wasko, p. 21.

${ }^{422}$ Wasko, p. 21; see also, Howard T. Lewis, The Motion Picture Industry (New York: D.Van Nostrand, 1933). The Motion Picture Industry provides a good background of the development of the film industry.

${ }^{423}$ Maria A. Slowinska, 'Consuming Illusion, Illusions of Consumability: American Movie Palaces of the 1920s', American Studies, 50.4 (2005), 575-601 (pp. 589-590) < http:/vortex3.uco.edu:2050/login?url=https:/www.jstor.org/stable/41158182> [Accessed 21 January 2021]. The Loew's film exhibition company merged with MGM in 1924, the Chicago Balaban and Katz theater chain merged with Famous-Players Lasky in 1925 which became Paramount-Publix, Warner Bros. bought Stanley Company of America in 1928.

${ }^{424}$ Maria A. Slowinska, 'Consuming Illusion, Illusions of Consumability: American Movie Palaces of the 1920s’, American Studies, 50.4 (2005), 575-601 (pp. 578, 580)

$<$ http://vortex3.uco.edu:2050/login?url=https://www.jstor.org/stable/41158182> [Accessed 12 September 2020]
} 
interior of crimson, velvet and marble paintings hung on the walls, and the lobby with uniformed ushers. ${ }^{425}$ The popularity of movie-going can be gauged from sources such as the novel, The Close-Up, which suggested that everyone went to the movies. In the novel, Kate who was a film actress questioned her middle-class ex-fiancé, 'But I didn’t know you went to pictures', her ex-fiancé retorted, ‘Of course I do! Everyone does. ${ }^{426}$ An increase of leisure time afforded the American society to partake in social events on a mass scale as evident by the national movie-goer craze. As America once prided itself on individual craftsmanship and localized past-times it had now become a mass-produced economy with mass-produced leisure. ${ }^{427}$ By 1926, deluxe movie houses were common to almost every city seating from 2500 to 4500 people and the film industry saw enormous success with weekly attendance of 50 million people in 1926 to an increase of 90 million people by $1929 .{ }^{428}$

As movies brought in larger audiences and those with a more expendable income, this industry was an ideal vehicle to help shape consumerism. Americans in the 1920s learned more about the elusive 'American Way' from the movies than any other source. ${ }^{429}$ The movies showcased everyday items such as cosmetics, hairstyles, clothes, and cars. For example, Flaming Youth, a popular flapper movie, provided an excellent example of the use of cosmetic products. While the flapper was shown getting ready, she used multiple products on her neck, bare shoulders, and hair. She dabbed perfume behind her ears, powdered her face, and excitedly applied her

\footnotetext{
${ }^{425}$ Lloyd Lewis, 'The Deluxe Picture Palace', in The Twenties: Fords, Flappers \& Fanatics, ed. by George E. Mowry (Englewood Cliffs, NJ: Prentice-Hall, Inc., 1963), pp. $56-59$ (p. 57). Reprinted from 'The Deluxe Picture Palace', New Republic, 27 March 1929. p. 175.

${ }^{426}$ Turnbull, p. 256.

${ }^{427}$ Fink, Leon, Major Problems in the Gilded Age and the Progressive Era: Documents and Essay (Lexington, MA:. D.C. and Company, 1993), p. 448.

${ }^{428}$ Lewis, 'The Deluxe', p. 58.; Robinson, Eugene, 'Industrial Role Models and Matinee Idols: Their Significance And Hollywood's Role In The Burgeoning Industrial Dream', (unpublished doctoral thesis, University of Maryland: College Park, 1984) in ProQuest Dissertations and Theses Global < https://search-proquestcom.vortex3.uco.edu/pqdtglobal/docview/303330034/8B8BFBF2354F4B99PQ/1?accountid=14516 > [accessed 10 February 2021] p. 27.

${ }^{429}$ Michelle T. Finamore, 'Fashioning Early Cinema: Dress and Representation in American Film, 1905-1930', (unpublished doctoral thesis, University of Michigan at Ann Arbor, 2010) in ProQuest Dissertations and Theses Global < http://vortex3.uco.edu/login?url=https://search-proquestcom.vortex3.uco.edu/docview/250272906?accountid=14516 $>$ [accessed on 15 September 2020].; see also, Sumiko Higashi, '1927: Movies and the New Woman as Consumer', in American Cinema of the 1920s: Themes and Variations, ed. by Lucy Fisher, 10 vols (London: Rutgers University Press, 2009), III, pp. 188-210 (pp. 192-202).
} 
lipstick. ${ }^{430}$ Not only was the ritual of putting on make-up displayed to the movie goers, but also the wide variety of cosmetics available to women.

In the latter part of the 1920s when movies began to become more sophisticated with their business ventures, retailers began to collaborate with the film industry. A dress manufacturer, Lefkowitz \& Raschke promoted the motion picture Sandy in conjunction with producing replicas of the dresses in the film. An article in Women's Wear Daily suggested that this collaboration among films and clothing manufacturers would help stimulate dress sales. ${ }^{431}$ Additionally, Women's Wear Daily reported that 90 retailers throughout the country were under contract with film studios in conjunction with promotions. ${ }^{432}$ With multiple business ventures across the country this indicated the significance of the film industry's impact on clothing purchases, as well as, the deep interest the public had with the connection between movie stars and dress.

\section{A New Genre: Flapper Films}

The flapper had evolved and become popular in the 1920s, and not surprisingly, she was also imitated on the silver screen. ${ }^{433}$ In the Progressive Era, movies began with simple, independent film companies but in the 1920s it morphed into a large scale, mass-produced system. Many movies existed in the 1920s, therefore, it is hard to pinpoint every flapper film that was produced. Sara Ross noted that she used trade papers and secondary sources to 'pin-down' the first flapper

\footnotetext{
${ }^{430}$ Flaming Youth: Fragment of Film with Colleen Moore, dir. by John Francis Dillon (John McCormick Productions, 1923), online film recording, Youtube.com, 31 January 2012, $<$ https://www.youtube.com/watch?v=88PMhS1oYjs> [accessed on 14 September 2020].

431 'Dresses: To use Poster and Movies to Spur Sales of Dresses: Lefkowitz \& Raschke to Merchandise Frocks by Exploitation of Life-Size Picture of Screen Star on Poster', Women's Wear, March 20, 1926. ProQuest $<$ https://www-proquest-com.vortex3.uco.edu> (p. 27).

432 'Stores, Movies, Mfrs. in Plan to Spur Trade: Report 90 Retailers Throughout Country Already Under Contract to Carry Selected Styles of Various Producers to be Promoted in Films of Fashion Feature Studios', Women's Wear Daily, 14 August 1928. ProQuest $<\underline{\text { https://www-proquest- }}$ com.vortex3.uco.edu> (pp. 1-2).

${ }^{433}$ Before the flapper movie genre the vocal score, 'Florrie Was A Flapper' was written and composed by Wimperis and Finck in 1914 in London.; Day Francis, 'Florrie the Flapper' [online] < https://collections.vam.ac.uk/item/O1273369/florrie-the-flapper-sheet-music-finck/> [accessed 10 March 2021].; The Chicago Daily Tribune noted the play, 'Girl from Utah', at the knickerbocker theatre consisted of a rendition of the song 'Florrie the Flapper'.; ${ }^{433}$ Burns Mantle, 'The Theatrical Season Gets a Good Start in New York’, Chicago Daily Tribune, 25 August 1914. ProQuest $<$ https://www-proquest-com.vortex3.uco.edu $>$ (p. 9).
} 
movie. According to Ross, the first flapper film was released in 1920 called The Flapper. ${ }^{434}$

For the purpose of this study, I have analysed three flapper films that were released during the 1920s. Ross identified three distinct phases for the flapper film genre: the experimental phase from 1920 - 1922, the established phase from 1923 1924, and a maturity phase from 1925 - 1929. According to Ross, the experimental phase is when the flapper began appearing on the silver screen and established the flapper characterization. The established phase is when the flapper film genre gained a wider audience and a larger presence as a viable Hollywood product. By the maturity phase, the flapper film was well established with movie stars identified closely to the flapper. ${ }^{435}$

Using Ross's theory, I have chosen one film from each phase and on specific conditions: time of release, popularity, and the presence of the flapper. The three flapper films that I have chosen to analyse are The Flapper (1920), Black Oxen (1923), and Why Be Good (1929). I have chosen The Flapper to analyse as it was noted by Ross as the first flapper film, and therefore, provides a good benchmark for the initial characterization of the flapper. Next, I chose Black Oxen as this film was quickly adapted from a novel to the silver screen and had prominent flapper characters throughout the story. Why Be Good was chosen as it starred Colleen Moore, one of the most popular flapper celebrities, and was one of the last flapper films made. Therefore, this film provides an ending point for the flapper characterization during the 1920 s. $^{436}$

Although, I did not select these films based on the director, it is noteworthy that two of the three films discussed have directors born in New York City. These directors may have been influenced by the Bohemian culture in New York City.

\footnotetext{
${ }^{434}$ Sara Ross, 'Banking the Flames of Youth: The Hollywood Flapper 1920-1930’ (unpublished doctoral dissertation, University of Wisconsin-Madison, 2000) in ProQuest Dissertations \& Theses Global < http://vortex3.uco.edu/login?url=https://www-proquestcom.vortex3.uco.edu/docview/304639450?accountid=14516> [accessed 30 May 2018] p. 47. Ross claimed that it was difficult to 'pin down' the presence of the flapper character to a precise date, but she utilized trade papers and various secondary sources to determine the flapper's presence.

${ }^{435}$ Sara Ross, 'Banking the Flames of Youth: The Hollywood Flapper 1920-1930' (unpublished doctoral dissertation, University of Wisconsin-Madison, 2000) in ProQuest Dissertations \& Theses Global < http://vortex3.uco.edu/login?url=https://www-proquestcom.vortex3.uco.edu/docview/304639450?accountid=14516> [accessed 30 May 2018] pp. 6-7, 33, 47. ${ }^{436}$ For my in-depth analysis, I did not choose to examine Flaming Youth, even though it has been noted for creating a surge in the flapper genre. Flaming Youth is a lost film and only fragments of the film exist today.
} 
Additionally, many novels that represented the flapper were made into flapper movies, such as F. Scott Fitzgerald's novels. ${ }^{437}$ The adaptations from novels brought characterizations and fashion to life onto the silver screen. The flapper identity in both novels and films allowed society to get to know the flapper intimately and spread fashion change throughout America.

\section{Flapper Characterization Exposed in Film}

The flapper films during the 1920s were influenced significantly by the Bohemian movies of the 1910s. The flapper characterization became an extension and took on a similar definition of the Bohemian girl. The flapper displayed similar manners to the Bohemian girl, such as, smoking, drinking, and dancing which also became key characterizations of the flapper. Additionally, the flappers also displayed similar dress to the Bohemians, as they wore straight, loose gowns, although, the flapper dress progressed into a shorter hemline. Both the Bohemians and the flappers were publicized, but the flapper movies came at the same time as large film expansion, and as a result, key characteristics of new manners and morals for women spread quickly throughout the country by the mass media format.

Hollywood's portrayal of the flapper was significant since their characterization of the flapper reached mass audiences throughout America. By 1923, flapper films were one of the most financially successful films and seen as a viable Hollywood commodity. ${ }^{438}$ According to Ross, with the success of the flapper films and the consistency of the flapper characterization, this 'anchored' the identity for modern youth. ${ }^{439}$ The movies provided a specific stereotype to its audiences. As public opinion about the flapper differed and even the opinions of the flappers themselves, the movies also portrayed the flapper as a contradiction. The

\footnotetext{
${ }^{437}$ Sara Ross, 'Banking the Flames of Youth: The Hollywood Flapper 1920-1930’ (unpublished doctoral dissertation, University of Wisconsin-Madison, 2000) in ProQuest Dissertations \& Theses Global < http://vortex3.uco.edu/login?url=https://www-proquestcom.vortex3.uco.edu/docview/304639450?accountid=14516> [accessed 30 May 2018] p.122.; see also, Sara Ross, '1922: Movies and the Perilous Future', in American Cinema of the 1920s: Themes and Variations, ed. by Lucy Fischer (London: Rutgers University Press, 2009), pp. 70-94 (pp. 72-73). 438 Sara Ross, 'Banking the Flames of Youth: The Hollywood Flapper 1920-1930' (unpublished doctoral dissertation, University of Wisconsin-Madison, 2000) in ProQuest Dissertations \& Theses Global < http://vortex3.uco.edu/login?url=https://www-proquestcom.vortex3.uco.edu/docview/304639450?accountid=14516> [accessed 30 May 2018] p. 113. ${ }^{439}$ Sara Ross, '1922: Movies and the Perilous Future', in American Cinema of the 1920s: Themes and Variations, ed. by Lucy Fischer, 10 vols (London: Rutgers University Press, 2009), III, pp. 70-94, (p. 76). ProQuest Ebook Central.
} 
quintessential flapper was depicted on the silver screen as both sweet and wild, youthful and worldly, and innocent and sexual. ${ }^{440}$ It is important to analyse how this dichotomy of characterization aided in the development of women's progress and identify how it was managed by the film producers.

Initially, flapper characters were either a small supporting role or the main character but whose flapper characteristics were only temporary, teaching the audience that a lady would not take on this particular lifestyle for very long. The Flapper, released in 1920, centred around a sweet, innocent girl, Ginger, who turned to 'flapper' behaviour temporarily to sexually entice an older man. Ginger's flapperism was demonstrated through her 'stepping out' at a New York City café flirting and smoking. By the end of the film, Ginger had reunited with the boy her age keeping her reputation intact. ${ }^{441}$ The same formula, good girl turns bad, was consistently repeated in the flapper movies. In the end, the girl eventually succumbs to accepting the traditional behaviour of a woman and the character escapes any real damage to her reputation. ${ }^{442}$

Later, the flapper films became more sophisticated and the flapper characters took a central role in the film as well as their flapper behaviours. For example, in the Black Oxen, Janet, was a flapper and throughout the entire film showcased her flapper behaviour, of dancing, drinking and smoking. ${ }^{443}$ However, she was a supporting role in the film and not the main character. In Why Be Good, this film's main character, Pert, was a flapper and demonstrated flapper behaviour throughout the entire film. As the flapper films progressed, the flapper characterization played a more central role in the movie.

Hollywood developed signature flapper characterizations centred on the flapper's manners and behaviour, interests, and occupation. Many films showcased dancing, smoking, drinking, late-night entertainment, automobile riding and petting.

\footnotetext{
440 Sara Ross, 'Banking the Flames of Youth: The Hollywood Flapper 1920-1930' (unpublished doctoral dissertation, University of Wisconsin-Madison, 2000) in ProQuest Dissertations \& Theses Global < http://vortex3.uco.edu/login?url=https://www-proquestcom.vortex3.uco.edu/docview/304639450?accountid=14516> [accessed 30 May 2018] p.4.

${ }^{441}$ The Flapper, dir. by Alan Crosland (Alpha Home Entertainment, 2014) [on DVD].

${ }^{442}$ Sara Ross, 'Banking the Flames of Youth: The Hollywood Flapper 1920-1930' (unpublished doctoral dissertation, University of Wisconsin-Madison, 2000) in ProQuest Dissertations \& Theses Global < http://vortex3.uco.edu/login?url=https://www-proquestcom.vortex3.uco.edu/docview/304639450?accountid=14516> [accessed 30 May 2018] p. 112.

${ }^{443}$ Black Oxen, dir. Frank Lloyd (Frank Lloyd Productions, Inc., A First National Picture, 1923), online film recording, Youtube, < https://www.youtube.com/watch?v=iB2PYiZvx5o > [accessed 22 November 2020].
} 
These lifestyle choices were primarily labelled as 'bad' behaviour. In The Flapper, Ginger smoked for the first time when she was "stepping out" with a flapper friend. ${ }^{444}$ Smoking was the 'bad' behaviour. Smoking was also exemplified in the Black Oxen as bad behaviour, even to the extreme that the flapper puffs smoke in her father's face. Janet not only smoked but she also drank with men, danced cheek to cheek with men, and enticed men with inappropriate language. ${ }^{445}$ This 'bad' behaviour continued throughout the decade as Why Be Good displayed the same values. Although, Pert drank and danced with men she did not entice men with inappropriate language, but other supporting women in the film did. However, Janet and Pert both displayed a pattern of socializing with men. This display of behaviour, although deemed as improper, did demonstrate to film audiences that men and women were socializing together which helped reduce gender segregation within the social arena. Thus, challenging Hollander's claim that men and women were keeping to their traditional separation but rather building social relationships. This was demonstrated especially with the Black Oxen as Janet was shown with a large group of men and women rather than just with her date.

As the flapper behaviour was indicative as carelessness, Hollywood also portrayed her as a working girl. Therefore, the flapper was portrayed in opposition with her careless behaviour, yet responsible to manage a steady job and pay bills. Although, Hollywood did portray the flapper usually in a low-income job primarily as manicurist, usherette, or salesgirl. ${ }^{446}$ In Why Be Good, Pert, was a flapper and went out to dance every night but she also was a department store saleswoman who also helped pay bills at home. Therefore, communicating to the public that although flapper behaviour is immoral or bad, they still were good citizens.

\section{Flapper Dress in Film}

One of the primary associations of the flapper's bad behaviour was her dress. The loose gowns were deeply connected to 'loose’ behaviour, as this was discussed

\footnotetext{
${ }^{444}$ The Flapper, dir. by Alan Crosland (Alpha Home Entertainment, 2014) [on DVD]. (55:33-59:45).

${ }^{445}$ Black Oxen, dir. Frank Lloyd (Frank Lloyd Productions, Inc., A First National Picture, 1923), online film recording, Youtube, $<$ https://www.youtube.com/watch?v=iB2PYiZvx5o $>$ [accessed 22 November 2020].

${ }^{446}$ Robinson, Eugene, 'Industrial Role Models and Matinee Idols: Their Significance And Hollywood's Role In The Burgeoning Industrial Dream', (unpublished doctoral thesis, University of Maryland: College Park, 1984) in ProQuest Dissertations and Theses Global $<$ https://search-proquestcom.vortex3.uco.edu/pqdtglobal/docview/303330034/8B8BFBF2354F4B99PQ/1?accountid=14516> [accessed 10 February 2021] p. 132.
} 
earlier with the modern dancers and the Bohemians. During the Progressive Era, Hollywood did not employ costume designers for films, however, during the 1920s this had changed. From the three movies analysed, The Flapper did not employ a costume designer but the other two films did, demonstrating the evolution of a growing industry. When there was not a costume designer on the set, the actors and actresses were responsible for finding their own wardrobe. ${ }^{447}$ Therefore, one can assume in the film, The Flapper, actors and actresses wore clothing from their own closets. However, the Black Oxen and Why Be Good both employed male costume designers, Walter J. Isarel and Max Rée, respectively. ${ }^{448}$ Although the film’s costume designers were not consistent for all three films, the first film was absent a costume designer and the other two films employed different individuals, the flappers wore similar clothing. This further indicates that the flapper was largely associated with her dress as this variable was constant throughout the decade with her characterization. For example, in The Flapper the only time that Ginger wore a straight, loose gown was when she 'stepped out' as a flapper. When she was portrayed as the girl next door she wore a light, flowy hourglass shaped dress with a tight belt around the waist. ${ }^{449}$ The differences between her two looks is shown in Figure [68 and 69]. Ginger accessorized her straight, loose gown with a headband and a plume hand-held fan. Additionally, when Ginger was stepping out as a flapper, her friend from the boarding school who had a flapper identity, also wore a straight, loose gown with a headband and multi-strand of pearls. Although the straight silhouette was the mainstream fashion during 1920s, these dresses continued to reveal the waist in some manner, such as at the natural or elevated, empire waist. An example of these styles of dress can be seen in The Flapper during the scene at a socialite's home party where appropriate dress was worn. Additionally, the women attending the home party wore minimal accessories. ${ }^{450}$ Therefore, the loose, straight gowns accessorized with

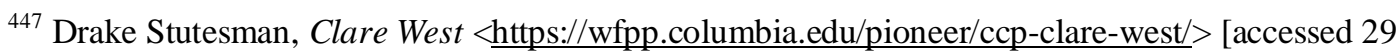
August 2020] (para. 1 of 6).

448 IMDb, Black Oxen Full Cast \& Crew, <https://www.imdb.com/title/tt0014721/fullcredits?ref_=tt_cl_sm\#cast $>$ [accessed 30 December 2020].; IMDb, Why Be Good? Full Cast \& Crew, $<$ https://www.imdb.com/title/tt0020585/fullcredits?ref_=tt_cl_sm\#cast $>$ [accessed 30 December 2020]. ${ }^{449}$ The Flapper, dir. by Alan Crosland (Alpha Home Entertainment, 2014)[on DVD].; Reference for pictures: ‘The Flapper (1920) Photo Gallery' [online] < https://www.imdb.com/title/tt0011193/mediaindex?ref_=tt_pv_mi_sm> [accessed 30 December 2020]. ${ }^{450}$ The Flapper, dir. by Alan Crosland (Alpha Home Entertainment, 2014) [on DVD].
} 
headbands, long, multi-strand pearls, and plumes were associated with the flapper characteristic.

Just shortly after The Flapper's release, Black Oxen portrayed many women in the long, straight silhouette. Additionally, the dresses worn were styled after the flapper with deep-cut necklines, sleeveless bodices and accessorized with long strands of pearls. Not only was this style worn by the flapper, but also by the main character who clearly did not present any flapper behaviour. In this movie the main character played a young socialite, Mary Ogden, the opposite of the young flapper, Janet Ogelthrope. The flapper behaviour consisted of drinking and dancing with men, but the young socialite participated in reading and going to the opera. ${ }^{451}$ What is significant about this film is that although the movie juxtaposed the flapper and the young socialite's behaviour, they both wore similar clothes and accessorized in a similar manner. Because the film portrayed different personalities wearing flapper style clothing, this indicated that this particular style was widely worn and had become fashionable. In Figure [70], several women are wearing flapper attire in the Black Oxen dinner scene. Analysing Figure [70], the similarities of the dresses are visible in all three women's dresses, they are sleeveless, lightweight fabric and straight in structure. Similar fashions with the long, straight dresses accessorized with strands of pearls and headscarves were also shown this year in Vogue magazine, as shown in Figure [71]. This film indicated the 'flapper' look of straight gowns accessorized with headbands and multi-strand pearls had expanded beyond the middle-class flapper and to a broader customer base.

By the latter part of the decade, the hemlines rose and the flapper films displayed a short shift dress. In Figure [72], Pert provides a good example of the shorter skirt lengths in Why Be Good. The first flapper dresses in films were floorlength gowns, but by the end of the decade, flapper films revealed women's knees. Out of the three films, Pert was the most active with participating in dance contests, autoing with her friends, and working in the department store. ${ }^{452}$ Pert's short dress enabled her to move freely with the movement of dancing the Charleston and quickly hopping into automobiles. In Figure [73] is a still image from a dance scene in Why

\footnotetext{
${ }^{451}$ Black Oxen, dir. Frank Lloyd (Frank Lloyd Productions, Inc., A First National Picture, 1923), online film recording, Youtube, < https://www.youtube.com/watch?v=iB2PYiZvx5o> [accessed 22 November 2020] See these sections to find flapper activities: 22:20-23:25, 26:16-27:20, 27:42-28:00. See 37:17-38:20 for opera scene.

${ }^{452}$ Why Be Good, dir. by William A. Seiter (First National Pictures, 1929) [on DVD].
} 
$B e$ Good, note the women spectators as they are wearing shift dresses with hemlines above the knee. Many of these short dresses were also simplistic in design with one prominent detail playing centre stage, such as a large flower pin attached to the upper left torso or a fringed skirt. Not only were these fashions shown at a dance hall, but also similar fashions were shown in the opening scene of Why Be Good at Winthrop Peabody Jr.'s exclusive penthouse apartment in New York City. ${ }^{453}$ This demonstrates that the shift dress had expanded from the middle-class to the upper-class echelon. Additionally, similar details were seen in Vogue, prior to the release of Why Be Good. Vogue's issue released in 1927 displayed evening gowns with elaborate decorations, but many were plain emphasizing one significant detail on the dress. Thus, this indicates that the flapper fashions were similar to what most women were wearing, as indicated by Vogue magazine.

\section{Perception of the Flapper}

As the flapper's role grew in the movies, so did their tenacious spirit. Pert was one of the best examples of a modern woman who had partaken in the traditional interests and behaviour of the flapper but she also displayed a head-strong personality. In Why Be Good, the male dominant role was apparent in many instances; however, Pert challenged this behaviour. For instance, Pert's father threatened that if she continued with this flapper behaviour that he would send her to reform school. Pert demanded, 'Pop listen to me! This is 1929—not 1899. I contribute as much money to this house as you do-and as long as I think it is harmless, I'm going to wear what I like, and do what I like.' 454 This exemplified her courage to speak up for what she believed in as well as to recognise that the twentieth century was modern times and women were able to decide for themselves what was appropriate. Later in the film Pert stood up to her lover. When her lover went to great lengths to test if she had good values, she blamed men for demanding 'the kissing', and 'the spooning'. She retorted, 'You men you insist on a girl being just what you want - and then you bawl her for being it! Listen! I'm a good girl! And what I do and what I wear - is because you fool men demand it!'! ${ }^{455}$ Pert accused men of

\footnotetext{
453 In Why Be Good, Winthrop Peabody Jr. was a young, vivacious millionaire, the son of Winthrop Peabody Sr. who was the president of a department store.

${ }^{454}$ Why Be Good , dir. by William A. Seiter (First National Pictures, 1929) [on DVD].

${ }^{455}$ Why Be Good, dir. by William A. Seiter (First National Pictures, 1929) [on DVD].
} 
wanting the idea of a modern women but at the same time they were afraid of modern women. Thus, men continually pushed the modern woman back in her traditional roles. This anxiety of women becoming something different from her prescribed traditional role may be aligned to what society still believed. In analysing reviews from this film, an article by Mae Tinee noted that more mothers and fathers should demonstrate similar parenting skills to Pert's as they were supportive. ${ }^{456}$ On the other hand, another article posted a reader's response to the film and thought that it was dangerous as it showed Pert partaking in dancing with men and going home with them with her safety still intact. This reader suggested that many women who go home with a stranger may not be so lucky as her safety may be at risk. ${ }^{457}$ Both of these articles demonstrate the anxiety and complexity of the flapper's lifestyle and characterization as to what is deemed as appropriate. Even Pert felt torn between what was socially respectable and being a flapper. Pert exclaimed, 'I have an awful time hiding it. I'd be disgraced if it were ever found out!'! But Pert also expressed that she knew she was a good girl. The flapper still felt conflicted about her actions of having a good time and how that translated to what society expected from women. At the end of Why Be Good, Pert was accepted as a flapper from her new father-in-law and the assumption that she can still have her freedom and lifestyle. The film demonstrated that flappers were good girls, therefore, also associating this sense of good and respectability to the shift dress, as the flapper was closely identified with her clothing. Why Be Good's lesson to its audiences was that flappers were harmless.

In the three films analysed the flapper dress changed throughout the decade. At first, it was a long, loose silhouette accompanied with headbands, long multistrand pearls, and plumes. In Why Be Good many women wore the knee-length shift dress as it was showcased as the primary garment worn and the film portrayed that flapperism was abundant, along with the flapper dress. Pert's flapper identity was part of her whole characterization rather than a temporary situation, like Ginger.

Additionally, the ending of each film was very different from the first film to the last film. Ginger, gave up her ‘flapperism’ and married her childhood sweetheart whereas

\footnotetext{
${ }^{456}$ Mae Tinee, 'Here are Two Movies Full of Moral Intent: Or "Why be Good?" and "The Godless Girl." "Why Be Good?”'. Chicago Daily Tribune, 20 March 1929. ProQuest < https://www-proquestcom.vortex3.uco.edu> (p. 37).

${ }^{457}$ C. S. G., 'Films with Doubtful Influence', Chicago Daily Tribune, 21 April 1929. ProQuest $<$ https://www-proquest-com.vortex3.uco.edu $>$ (p. 1).
} 
Pert continued to identify as a flapper with the acceptance from her father-in-law. The acceptance of her father-in-law in Why Be Good was not only sending the message to audiences that flappers are good women, but also that it was okay for women to celebrate socially and publicly. Although there remained some tension and contradiction about what society felt about the flapper, having films address and promote women's freedom was powerful.

\section{Conclusion}

What this chapter has shown is how changes in fashion and early prototypes of the shift dress reflected the growing achievements and confidence of women in the 1920s. According to the U.S. Department of Education, the growth of women attending colleges was gradual during the late-nineteenth and early-twentieth century; however, during the 1910s and 1920s women earning a bachelors and master's degree increased significantly. ${ }^{458}$ Women's success during the 1920 s was exemplified with women shifting jobs from domestic services to clerical positions, new legislative action for women, and an increase in literature, such as, magazines and books about women in the workplace. Significant too is that, although women occupied clerical positions, working in offices created an opportunity for women to excel and enter into more advanced positions. The abundance of literature published during the 1920s provided examples of women working outside the home, and as a result, encouraged women to excel in the workplace. These books were informative outlining specific jobs as they showcased personal interviews of women in a variety of occupations. In addition, they were inspirational as readers experienced real-life stories of everyday women. All of these women help create change.

The 1920s were significant, although this decade was still plagued with women being placed in lower-wage jobs and some occupations remained difficult for women to enter. However, this decade marked a radical time in history when women began to make inroads in education, the workplace and the social arena. Additionally, films promoted, for better or for worse, the flapper. Audiences viewing the flapper films may have helped acclimatize some of them to view women differently, in a less traditional way. By the end of the decade, Why Be Good promoted the flapper in a

\footnotetext{
458120 Years of American Education, ed. by Thomas D. Snyder, National Center for Education Statistics, (January 1993), pp. 68- 70, 83 < https://nces.ed.gov/pubs93/93442.pdf $>$ [accessed 15 January 2021].
} 
positive manner which was powerful. With the new culture, the flapper, and her dress women were discarding traditional roles and beginning to build social and working relationships with men. During the 1920s women reduced gender disparities, even though some traditional roles were still in place.

With women more active in the public sphere, fashion changed dramatically. While Isadora Duncan was unable to change fashion for the masses, the flappers were able to help instigate change into the fashion industry. Although, this trend was sparked by the flappers as they were responsible for shorter hemlines, many women in the latter half of the decade began adopting the shift dress for their own needs. The shift dress's ease and versatility was suitable for many women to wear for work, for sport, or for entertainment. The popularity of the shift dress can be seen in the presence of Vogue, especially in the article showcasing replica shift dresses from a boat, indicating the abundance of the dress and a nod to not only America's immigration but also a gesture to conspicuous consumption.

In the beginning of the decade, the flapper's behaviour and dress was highly debated. By the end of the decade, the shift dress was widely adopted in fashion magazines. Thus, by the end of the decade the shift dress became a staple in most women's wardrobes. In addition, the media portrayed the flapper from a different perspective from the beginning of the 1920s to the end of the decade. In the beginning of the decade, a respectable girl would only be a flapper temporarily as this reflected her 'experimental' phase, yet by the end of the decade, flapper films were reinforcing that flapperism is not bad behaviour and many flappers are respectable women.

Although the flapper is largely attributed to shortening skirts, which created the shift dress, many women helped the flappers achieve success. Every woman helped build upon one another to create change. According to Martha H. Patterson, the New Woman was not only the Gibson Girl or the flapper, but rather she was the bicyclist, the barren spinster, or the prohibitionist, among others. ${ }^{459}$ It was not only the flapper who changed dress and manners and morals for women, but it was also the men and women who came before them, such as Isadora Duncan, Mariano Fortuny, Settlement House workers, Lillian Gilbreth, Lois Weber, the Bohemians, Paul Poiret, Irene Castle and Coco Chanel who created building blocks to help generate change.

\footnotetext{
${ }^{459}$ The American New Woman Revisited: A Reader, 1894-1930, ed. by Martha H. Patterson (London: Rutgers University Press, 2008), pp. 1-25 (p. 1). ProQuest Ebook Central.
} 
The men and women who worked initially on fostering ideas and implementing change in both social roles and dress, coupled with the social changes in the 1920s, were aided by the power of the flapper. Flappers gained widespread attention and controversy about behaviour and dress which helped change the trajectory of lifestyle and fashion.

The flappers were the first sub-group of women in America to not only start breaking down cultural barriers but also laid the foundation to modernizing dress. The cultural shift of women during the 1920s was the initial onset of women's liberation as the flappers were the 'original grandmothers of girl power' ${ }^{460}$ It should also be noticed, they were the original group which initiated modernization of dress. This modernization of dress espoused self-confidence and freedom of movement that aided the flapper unequivocally as a historical figure in American culture.

${ }^{460}$ Flappers: The Birth of the 20th-Century Woman (Films Media Group, 1999) online film recording, Films On Demand, <fod.infobase.com/PortalPlaylists.aspx?wID=103048\&xtid=11563> [Accessed 30 December 2020]. 


\section{Chapter 4: The Hidden Canvas: The Postwar Era}

At the onset of the Great Depression, the young, tenacious flapper who once brought their style to mainstream America, lost their influence in fashion. According to historian, Zietz, after the 1920s the flapper and her dress slipped out of sight. ${ }^{461}$ It would not be until the 1960s that the youth would regain an influential position in fashion style. Instead, the short, modern shift dress was replaced with a long, feminine hourglass silhouette. The young, boyish look of the 1920s dissipated and femininity reasserted itself in women's fashion. Even though masculine elements of fashion emerged during the war years, I argue the feminine standard still remained important. Outside the factory walls, women were encouraged to wear make-up and to look their best during the war. Patriotism was expressed in women's cosmetics with lipstick names such as 'Victory Red' and 'Patriot Red'. Advertisements for Louis Philippe noted 'Wear Patriot Red “in defense of glamour.", 462 The feminine standard remained the dominant image even throughout WWII and into the 1950s.

When researching the $1920 \mathrm{~s}$, it was vital to pinpoint women's place in society and to understand the evolution of fashion. Similarly, it is imperative to lay the same groundwork for this second section of this study, understanding women's place and fashion styles that preceded the shift dress in the 1960s. This chapter has an additional layer of complexity as it will also cover two supplemental decades, 1930s and 1940s, to pinpoint the shift dress’ place in fashion between 1920 and 1950.

This chapter provides a background to 1950s culture and women's place in society while exploring the prominent fashions of this decade. Additionally, it will examine the antecedents of the shift dress which becomes the prevailing style in the 1960s. First, I evaluate the shift dress' place in fashion in the 1930s and 1940s, then explore the impact of World War II on women's place in society. Next, I analyse the predominant fashion of this decade, Christian Dior’s New Look. Subsequently, I examine the 1950s American culture and women's position within society. I further explore the new media of television and the emerging teenage consumer. Within these sections I also explore the context of fashion styles in the culture of the 1950s. Lastly, I detail the dramatic fashion change from the full-bodied New Look to the straight

\footnotetext{
${ }^{461}$ Zeitz, Flapper, pp. 278-79.

462 'Advertisement: Louis Philippe, Inc’, Vogue, 01 October 1940. ProQuest $<$ https://www-proquestcom.vortex3.uco.edu> (p. 124).
} 
shift dress. I do this by evaluating and categorizing designer's collections and appearances of the shift dress in Vogue and Seventeen magazine to determine the initial triggers that set-off the change in fashion style.

For the purpose of this discussion, the end of World War II marks the starting point of the 1950s. Not only was this an end to the war, but it also marked the beginning of economic growth and prosperity. In determining the end of the 1950s, I pinpoint the year 1957 as when new attitudes emerged. These new attitudes encouraged movement in both fashion and the wider American culture. In 1957, the sack dress was released by two designers who gained wide-spread attention, and as a result, began a shift toward looser styles. During this same year, Elvis Presley received extensive television coverage and Jack Kerouac published his novel, On the Road. ${ }^{463}$ Both of these events and the sack dress stimulated the new attitude of freedom and movement.

\section{What Happened to the Shift Dress?}

According to Zeitz, after the 1920s the flapper and her dress slipped out of sight. ${ }^{464}$ The shift dress had become a forgotten garment in the subsequent decades. However, the shift dress was not entirely absent after the 1920s, as it had on many accounts, appeared in Vogue magazine. Steele claimed to understand the language of clothes and what they express, it is imperative to know the history of the garment. ${ }^{465}$ Therefore, I paid particular attention not only to when the shift dress was at its height of popularity but also during times when the garment played a less prominent role in fashion. One of the most significant discoveries I have made about the shift dress during the 1930s and 1940s was that the term 'shift' applied to several different styles and was a loose term in the fashion industry. To fully understand the shift dress from a historical perspective, I included dresses that were labelled 'shift' in magazines and newspapers, even though the style differed from my definition. I did this because the

\footnotetext{
${ }^{463}$ Elvis Presley debut on the Ed Sullivan Show on 9 September 1956, however he had three contracted shows, the last one ending on 6 January 1957. Davis Troedson, Elvis Presley Biography: A Comprehensive History of Elvis Presley's Dynamic Life: Historical Television Guest Appearances, $<$ https://www.elvispresleymusic.com.au/pictures/1956-september-9-ed-sullivan-show.html > [accessed 11 February 2021] (para 4 of 6)

${ }^{464}$ Zeitz, Flapper, 2006, pp. 278-279.; Davis, Fashion, 1992, p. 107.; Lynne Richards, 'The Rise and Fall of It All: The Hemlines and Hiplines of the 1920s', Clothing and Textiles Research Journal, 2 (1983-1984), 42-48 (p. 48); Kenneth A. Yellis, 'Prosperity’s Child: Some Thoughts on the Flapper', American Quarterly, 21.1 (1969), 44-64 (p. 62) < https://doi-org.vortex3.uco.edu/10.2307/2710772>. 465 Steele, ‘Appearance and Identity’, (pp. 6-7).
} 
readers made an association with the term 'shift' and to a specific style. It is important to show the historic use, style and construction in order understand the transition of the shift dress from the 1920s to the 1960s.

The shift dress in the 1920s was not referred to as a 'shift dress' or a 'flapper dress', although the dress was associated with the flapper, rather the industry used adjectives to describe the shift dress, such as 'straight', 'youthful', 'modern' or 'boyish' and at times, the industry would refer to the shift dress as a 'one-piece' or 'dancing frock' ${ }^{466}$ According to my research, 1932 was the first time the word 'shift' appeared in Vogue magazine in reference to dresses. The term, 'shift', was commonly used for lingerie, however, I disregarded those entries as my research focuses on garments that function as a dress and not undergarments or sleepwear. In 1932, the shift dress was presented as a coverlet to go on top of a basic dress. As illustrated in Figure [74], the shift dress is red worn over a simple, white dress. The wearer could change the look by adding a coverlet to any simple dress and create essentially a new dress. Vogue stated, ‘A good and quick-change solution is Helene Yrande’s red woollen shift, it can be slipped on over any plain white sports dress with great effectiveness. $^{467}$ The shift dress was an economical solution as it allowed women to change the colours of their existing dresses and added variety to their wardrobe.

In the latter part of the 1930s, the term shift dress became more frequently used and the style changed from a coverlet and was seen in a variety of ways. The shift dress was noted for its many variations, such as its skirt length, sleeve length and function. ${ }^{468}$ Shown in Figure [75], an article in Vogue noted seven different versions of the shift dress, suggesting the shift style was used for coats, evening gowns, robes,

\footnotetext{
${ }^{466}$ Sample of articles using key terms for identifying the shift dress, 'Fashion: The Mode for the Country’, Vogue, 15 October 1924.ProQuest <https://www-proquest-com.vortex3.uco.edu (pp. 56-57, 136).; 'Designs for Practical Dressmaking: Daytime Frocks may be Straight and Simple', Vogue, 01 August 1926. ProQuest <https://www-proquest-com.vortex3.uco.edu> (p. 73).; 'Fashion: Youthful Costumes', Vogue, 11 October 1926. ProQuest <https://www-proquest-com.vortex3.uco.edu> (p. 67); 'Designs for Practical Dressmaking: The Simple One-Piece Frock for Daytime', Vogue, 01 February 1927. ProQuest <https://www-proquest-com.vortex3.uco.edu> (p. 88).; 'Vogue's Fortnightly Wardrobe’, Vogue, 15 June 1927. ProQuest <https://www-proquest-com.vortex3.uco.edu> (pp. 52-54). 'Fashion: Paris Points', Vogue, 31 August 1929. ProQuest $<\underline{\text { https://www-proquest- }}$ com.vortex3.uco.edu> (pp. 30-31).

467 'Fashion: Sandscapes of 1932', Vogue, 01 January 1932. ProQuest <https://www-proquestcom.vortex3.uco.edu> (p. 43).

468 'Success Story of the Shift Dress', Vogue, 01 December 1938. ProQuest <https://www-proquestcom.vortex3.uco.edu> (pp. 92-93).; 'Fashion: They all Like Long Sleeves', Vogue, 01 January 1939. ProQuest $<$ https://www-proquest-com.vortex3.uco.edu $>$ (p. 66).; 'Finds of the Fortnight: SouthboundClassics and Revised Classics', Vogue, 01 January 1939. ProQuest <https://www-proquestcom.vortex3.uco.edu> (p. 68).; 'Vogue Designs for Dressmaking: Midwinter Pick-Up', Vogue, 01 January 1939. ProQuest <https://www-proquest-com.vortex3.uco.edu> (p. 78).
} 
daytime dresses and exercise suits. ${ }^{469}$ Vogue introduced and defined the shift dress as a simple constructed garment with the option to wear two different ways: with a belt, and as a result, the dress would fall in pleats at the waist or to discard the belt for a straight look. ${ }^{470}$ Some shift dresses had pleats on the torso or near the shoulder, for example the shift dress shown in Figure [76], which added fullness to the skirt. In 1939 when Vogue reviewed the most significant styles from the recent year, the shift dress was noted as being one of the top ten styles of that year. ${ }^{471}$ The shift dress from this article can be seen in Figure [77]. In this same issue, Vogue also published three additional articles regarding the shift dress; one shift dress was suggested as a long dress, the second as a tennis outfit, and third as a great style to sew at home. Refer to Figures [78-80] to view these shift dresses.

The shift dresses in the 1930s were often belted, and as a result, had a soft flare or fullness to the skirt unlike the traditional shift dresses from the 1920s. Fashion historian, James Laver, claimed the Great Depression brought hemlines to the ground. ${ }^{472}$ I argue not only hemlines lengthened, but also emphasis on the waist became significant. This transition of accentuating the waist can be identified with examples of the shift dress. For example, although the article 'Success Story of the Shift Dress', defined the shift dress as either an unbelted or belted silhouette, shown in Figure [76], the text described most of the shift dresses as girdled and all the shift dresses photographed were belted. ${ }^{473}$ Additionally, the Vogue article, 'Day Shift, Night Shift' suggested the shift dress to be worn 'closely belted', shown in Figure [76]. ${ }^{474}$ When I performed a keyword search of the 'shift' dress for the 1930s, few articles were noted with the shift dress. Therefore, this suggests that the shift dress was not a popular style and the word 'shift' was not attached widely to garments.

\footnotetext{
469 'Success Story of the Shift Dress', Vogue, 01 December 1938. ProQuest $<$ https://www-proquestcom.vortex3.uco.edu> (p. 92).

470 'Success Story of the Shift Dress', Vogue, 01 December 1938. ProQuest $<$ https://www-proquestcom.vortex3.uco.edu> (p. 92).

471 'Vogue's Eye View: The Ten Great Plays of 1938.', Vogue, 01 January 1939. ProQuest

$<$ https://www-proquest-com.vortex3.uco.edu $>$ (p. 31).

472 Kathryn Weibel, Mirror Mirror: Images of Women Reflected in Popular Culture (Garden City, NY: Anchor Books, 1977), p. 205.

473 'Fashion: They all Like Long Sleeves', Vogue, 01 January 1939. ProQuest $<$ https://www-proquestcom.vortex3.uco.edu> (p. 66).; 'Finds of the Fortnight: Southbound-Classics and Revised Classics', Vogue, 01 January 1939. ProQuest <https://www-proquest-com.vortex3.uco.edu> (p. 68); 'Vogue Designs for Dressmaking: Midwinter Pick-Up’, Vogue, 01 January 1939. ProQuest < https://wwwproquest-com.vortex3.uco.edu> (p. 78).

474،Fashion: Day Shift, Night Shift', Vogue, 01 November 1938. ProQuest $<\underline{\text { https://www-proquest- }}$ com.vortex3.uco.edu> (p. 62)
} 
The increase of Vogue's articles in the latter part of the 1930s may have spurred additional interest in the shift dress as articles during the 1940s became more abundant in women's magazines, fashion magazines and newspapers. The variations of shift dresses continued throughout the 1940s as some were pleated at the bodice or shoulders and others were a straight silhouette, as shown in Figures [81-83]. Harper's Bazaar opened the 1940s with a noteworthy article reflecting back on the shift dress from the 1920s as revolutionary, not only for fashion, but also for the identity of women. The article claimed that, 'No such dress had ever been seen before and the woman it created was a startling innovation. ${ }^{475}$ In 1941, Vogue reintroduced the shift dress and stated, 'the new low-neck sleeveless dress called a shift.' ${ }^{476}$ Vogue and Chicago Tribune both published articles regarding the shift dress as an easy style to sew. Vogue further specified that the shift dress could be sewn within rationing guidelines. ${ }^{477}$ Bettina Bedwell, feature writer of the Chicago Tribune, suggested the shift dress may gain popularity during World War II since it was a simple garment to sew and easy to launder. ${ }^{478}$ In 1944, Vogue magazine’s Advanced Retail Trade editions suggested the shift dress to retailers, manufacturers, and advertising executives in multiple issues. In March, Vogue advised salespeople to suggest dresses to their customers based on simple lines and a basic cut. It further stated to accessorize a clip, belt, or scarf to create a waistline. In the April edition, Vogue suggested a bare-armed shift for daytime and in the July edition noted a jersey shift for night-time." ${ }^{479}$ Although articles about the shift dress increased in the 1940s, and Vogue and the Chicago Tribune suggested the shift dress as the best garment during wartime, my keyword search revealed that it was not the dominant style as it was shown sparingly in the magazines. ${ }^{480}$

\footnotetext{
475 'Fashions of the 1920's', Harper's Bazaar, May 1940. ProQuest <https://www-proquestcom.vortex3.uco.edu> (p. 67).

476 'Fashion: Skirt Lines Going South', Vogue, 15 November 1941. ProQuest < https://www-proquestcom.vortex3.uco.edu> (p. 71).

477 'Vogue Designs for Dressmaking: Ways to Snip Sewing-Time." Vogue, 15 February 1943. ProQuest <https://www-proquest-com.vortex3.uco.edu> (pp. 47, 78).; Bedwell, Bettina, 'Sheath Dresses Offer Variety; Save Material.’, Chicago Daily Tribune, 11 April 1943. ProQuest $<$ https://www-proquest-com.vortex3.uco.edu> (p. 1).

${ }^{478}$ Bedwell, Bettina, 'Sheath Dresses Offer Variety; Save Material.', Chicago Daily Tribune, 11 April 1943. ProQuest $<$ https://www-proquest-com.vortex3.uco.edu $>$ (p. 1).

479 'Features: Advance News for Retailers', Vogue, 15 March 1944. ProQuest $<$ https://www-proquestcom.vortex3.uco.edu> (p. A1).; 'Advertisement', Vogue, 01 April 1944. ProQuest <https://wwwproquest-com.vortex3.uco.edu> (p. A2).; 'Advertisement', Vogue, 01 July 1944. ProQuest $<$ https://www-proquest-com.vortex3.uco.edu $>$ (p. A2).

${ }^{480}$ During the 1940s the shift dress was shown in Women's Wear Daily, Vogue and Harper's Bazaar. The Chicago Tribune published 1 story about the shift dress in 1943. Women's Wear Daily and
} 


\section{Women in the Workplace: World War II}

Although the identity and opinions of the flapper were complex and often differed, the shift dress was associated with being modern. The shift was short, straight, and flimsy. However, as we enter the 1930s and continue through World War II definitions were not as consistent. Not only was the term 'shift' applied to different styles of dresses, but also, according to Chafe, the perception of women working fluctuated from the onset of the Great Depression and after World War II. ${ }^{481}$ During the Great Depression, it was the perception of society that if a woman worked she was taking a job away from a man. Nevertheless, women were encouraged by the government and through media to work during the war as it was thought of as patriotic. For example, Vogue not only encouraged women to work during the war but also recommended that all women should work to help the war effort. Vogue noted the abundance of work available for women and how she could translate her home skills into war jobs. For example, women could use their home sewing skills to make parachutes or airplane wing coverings. ${ }^{482}$ Vogue further claimed that there was a labour shortage during the war, and suggested it was the women's duty to fill positions or civilian life could become severely 'crippled'. ${ }^{483}$ These articles in Vogue exemplified the importance of women working during the war. Additionally, Vogue advocated all women to help with the war, regardless of class, as evidenced in an article, ‘Calling all women. Every woman. You!'! ${ }^{484}$ According to James T. Patterson, women significantly entered the workforce from 1940 to 1945, an increase from 13 million women to 19.3 million, and filled men's typical positions. ${ }^{485}$ Women proved successful at their jobs. Initially, society was doubtful whether women would be able to do the same job as men. A poster read, 'Good work, sister: we never

\footnotetext{
Harper's Bazaar had only a few articles on the shift dress. Many of the shift dresses shown in Vogue appeared during the year 1944 with 4 different articles mentioning the shift dress.

${ }^{481}$ William Henry Chafe, The American Woman: Her Changing Social, Economic, and Political Roles, 1920-1970 (London: Oxford University Press, 1972), pp. 135-36.

482 'Fashion: Woman's Work is Everywhere', Vogue, 01 July 1943. ProQuest <https://www-proquestcom.vortex3.uco.edu> (pp. 40, 72).

483 'People and Ideas: Why Aren't You Working?', Vogue, 01 September 1943. ProQuest $<$ https://www-proquest-com.vortex3.uco.edu> (pp. 96-97, 126).

484 'Fashion: Woman's Work is Everywhere', Vogue, 01 July 1943. ProQuest $<$ https://www-proquestcom.vortex3.uco.edu> (p. 40).

485 James T. Patterson, Grand Expectations: The United States, 1945-1974, (Oxford: Oxford University Press, 1996), pp. 32-33.
} 
figured you could do a man-sized job!'! ${ }^{486}$ Patterson claimed women advanced greatly during the war as they obtained unprecedented jobs. ${ }^{487}$

Although the media encouraged women to work during the war, there was evidence that many people believed working women caused negative repercussions for the home and family. Pope Pius XII claimed, work had brought 'woman's "abandonment of the home”'. Marshall Andrews, writer for The Washington Post, declared work among women was the reason for the high rate of juvenile delinquency and women's magazines connected working women to the increasing divorce rate. ${ }^{488}$ It was clearly communicated that the woman's primary role was dedicated to her home and family. Once the war was over, women were no longer needed to fill vacant jobs. By 1946, 2.25 million women were either forced out of a job by a veteran or voluntarily left on their own. ${ }^{489}$ Many women married earlier and started having children at a younger age than their mothers. Historian, William O’ Neill, claimed after the war women's life resembled a more traditional role compared to women in the Progressive Era who entered the law and medicine fields. 490

Significantly, women began re-entering the workforce after 1947. According to the U.S. census, from 1947 to 1959 there was a steady increase of female labour. The female labour force in 1947 accounted for $29.8 \%$ of the female population and by 1959 they had accounted for 35.2\%. ${ }^{491}$ The female labour force in 1959 reached

\footnotetext{
${ }^{486}$ Bressler Editorial Cartoons, Inc., 'Good Work, Sister: We Never Figured You Could Do a Man-Size Job!” America's Women Have Met the Test!//Packer', in Library of Congress, “Good Work, Sister: We Never Figured You Could Do a Man-Size Job!” America’s Women Have Met the Test!// Packer (1944), <https://www.loc.gov/item/97515638> [accessed 11 February 2021].

${ }^{487}$ Patterson, Grand Expectations, p. 33.

${ }^{488}$ Warren, Virginia Lee, 'Pope Urges Women to Vote and Scorn "Totalitarian” Lure: Calls Them to Political and Social Activity to Combat Misuse of Equal Rights Threat to Home is Seen Pius Warns That Domination by One Class Leads to War and Undermining of Family Gathered in Hall of Benedictions Pope Urges Women to Cast Votes and Shun “Totalitarian” Promises', New York Times, 22 October 1945. ProQuest <https://www-proquest-com.vortex3.uco.edu> (p. 6).; Marshall Andrews, 'Family is Losing Importance in Society, Educator Says: Family is Losing Importance in Society, Educator Says', The Washington Post, 07 May 1948. ProQuest <https://www-proquestcom.vortex3.uco.edu> (pp. 1-2).; see also Bertram Vogel, ‘A Divorce Every Minute!', Redbook, January 1947. ProQuest < https://www-proquest-com.vortex3.uco.edu > (pp. 34-37, 108-109).; Philip Wylie, 'What's Wrong with American Marriages?', Hearst's International Combined with Cosmopolitan, June 1946. ProQuest < https://www-proquest-com.vortex3.uco.edu $>$ (pp. 26-27, 154156).; Dorothy Marcus, 'Both Sides of the Question: Career Wife Versus Housewife', Hearst's International Combined with Cosmopolitan, January 1947. ProQuest $<$ https://www-proquestcom.vortex3.uco.edu> (p. 112).

489 Patterson, Grand Expectations, p. 33.

${ }^{490}$ William L. O’Neill, American High: The Years of Confidence 1945-1960 (New York: The Free Press, 1986), p. 41.

${ }^{491}$ U.S. Department of Commerce, Statistical Abstract of The United States: 1960, 'Table No. 274: Marital Status of Women in the Civilian Labor Force: 1940 to 1959' (Washington, D.C., Government Printing Office, 1960), no. 81
} 
similar percentages as during the war. The category of middle-class, middle-aged women saw significant gains in the workforce during this period. ${ }^{492}$ According to Elaine Tyler May, after World War II, 2 million women left their jobs which made room for older, middle-aged women to enter the workforce in an expanding pinkcollar service. Furthermore, although it seemed that women did not lose ground after WWII, the jobs shifted to a narrower range of employment. ${ }^{493}$ As May described, the war years were uncharacteristic of women's traditional work patterns as they had to compensate for the loss of men during those years. According to O’Neill, after the war women readjusted to the type of occupations they had traditionally obtained such as clerks and teachers and women remained at the low end of the wage scale. ${ }^{494}$ After World War II, the culture of America began regressing women back to the home and placing them in traditional jobs.

\section{Fashion in the Postwar Era: The New Look}

On February 12, 1947, Christian Dior revealed his Corolle line to the fashion world. This collection embodied such a departure from the current modes of fashion that Carmel Snow, fashion editor of Harper's Bazaar magazine, pronounced it revolutionary and claimed, 'your dresses have such a new look' ${ }^{495}$ Carmel Snow popularized the term New Look and the Corolle collection became known and identified with this term. ${ }^{496}$ The construction of the New Look consisted of a full, pleated skirt in an excess of 25 yards of fabric, nipped in waists, breasts emphasized, and hemlines lowered twelve to fourteen inches from the floor. ${ }^{497}$ The New Look displayed extreme femininity. Scholar and author Heather A. Vaughan called his

<https://www.census.gov/library/publications/1960/compendia/statab/81ed.html> [accessed 14 February 2021]

${ }^{492}$ Chafe, The American Woman, p. 195.

${ }^{493}$ Elaine Tyler May, Homeward Bound: American Families in the Cold War Era (New York: Basic Books, Inc., 1962), p. 76.

${ }^{494}$ O’Neill, pp. 41-45.

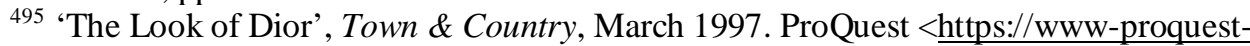
com.vortex3.uco.edu> (p. 66).

${ }^{496}$ In 1947 and 1948 several newspapers noted the 'New Look' as a common term, '1947 Brought Big Changes in Fashions', Globe and Mail, 27 December 1947. ProQuest $<$ https://www-proquestcom.vortex3.uco.edu> (p. 10).; Alison Settle, 'The Paris Shows: “New Look” Established', Observer, 08 February 1948. ProQuest $<$ https://www-proquest-com.vortex3.uco.edu> (p. 5).; Countess de Faucon, 'New Look's Creator Goes Conventional', Chicago Daily Tribune, 11 February 1948. ProQuest $\langle$ https://www-proquest-com.vortex3.uco.edu> (p. A3). The term 'New Look', is still popular today to identify the Corolle collection in reference from the past and historical point of view, such as scholarly journals, books and magazines.

${ }^{497}$ Barbara A. Schreier, Mystique and Identity: Women's Fashions of the 1950s (Norfolk, VA: The Chrysler Museum, 1984), p. 10. 
look 'hyperfemininity'. ${ }^{498}$ The radical changes of the silhouette came from the severity of the corseted bodice, the extended skirt length and the abundance of fabric around the figure. ${ }^{499}$ The underneath construction was a complex bone corset designed by Dior that compressed the waist and pushed up the breasts. ${ }^{500}$ Dior reintroduced women to the corset. Shown in Figure [84] is Christian Dior's taffeta dinner dress which used 25 yards of fabric to achieve the fan, pleated skirt look. In Figure [85] is another example of the New Look but in a suit form, known as his iconic 'Bar Suit'. Both of these images display the nipped in waists with long, full skirts.

When Dior was questioned as to why he designed the New Look. He responded, 'It was needed after the war...everybody feels this need, and to get away from the fashion restriction during the war'. ${ }^{501}$ Jayne Sheridan connected the costumes in the hit movie Gone With the Wind with Dior's New Look. ${ }^{502}$ The New Look corseted women's upper body and released the figure with large circular skirts similar to that of Scarlet O’Hare. Claire Wilcox, curator of the V\&A, suggested the New Look was inspired by the philosophy of using historical references. ${ }^{503}$ Designers who have altered the direction of fashion have looked deep into the past, like, Mariano Fortuny and Paul Poiret, as their gowns stemmed from ancient Grecian culture, whereas, Dior's New Look emphasized similar styles of Civil War dress. Richard Martin, curator at the MET, asserted that the Dior years were not an ‘advanced decade', unlike Chanel in the 1920s and Yves St. Laurent in the 1960s who defined modern fashion for the twentieth century. ${ }^{504}$ Conversely, Bernard Arnault, chief executive of LVMH, claimed 'In his time, Dior signified modernity and created

\footnotetext{
${ }^{498}$ Heather A. Vaughan, "Icon: Tracing the Path of the 1950s Shirtwaist Dress." The Journal of American Culture, 32.1 (2009), 29-37 (p. 32) < http://vortex3.uco.edu/login?url=https://wwwproquest-com.vortex3.uco.edu/scholarly-journals/icon-tracing-path-1950s-shirtwaistdress/docview/200641627/se-2?accountid=14516> [accessed 20 January 2021].

${ }^{499}$ Barbara Schreier claimed the most dramatic change was the length and cut of the skirt. Schreier, p. 10.

${ }^{500}$ Schreier, p. 10.

${ }^{501}$ Winn, Marcia, 'That Man Who Designed Long Skirts is Here’, Chicago Daily Tribune, 23 September 1947. ProQuest < https://www-proquest-com.vortex3.uco.edu> (p. 25).

${ }^{502}$ Sheridan, Jayne. Fashion, Media, Promotion: The New Black Magic. John Wiley \& Sons, Inc., 2010, pp. 20, 31-68.

${ }^{503}$ Sheridan, p. 61.; See also, Claire Wilcox, The Golden Age of Couture: Paris and London 19471957 (London: V \& A Museum, 2007), p. 22.

${ }^{504}$ Suzy Menkes, 'Dior Takes Manhattan: 50 Years on, a New 'New Look'?: [2 ${ }^{\text {nd }}$ Edition]', International Herald Tribune, 10 December 1996. ProQuest $<$ https://www-proquestcom.vortex3.uco.edu> (para 19 of 28).
} 
a romantic, feminine style and he changed everything' ${ }^{505}$ I disagree with Arnault's view. Although Dior had completely changed fashion, the silhouette itself overwhelmingly represented restriction, not only in the kinetic form, but also as a reflection of conservative, traditional ideals about the mannerisms and behaviour of women.

Although Dior's New Look was immediately applauded by the fashion editors, it received mixed reviews in the newspapers and magazines. Two of the most controversial issues of the New Look were the use of excess fabric and a longer hemline. Many thought the use of excess fabric was not conducive for women that were still recovering from the aftermath of the war and who were heavily laden with economic distress. ${ }^{506}$ Others thought the use of excess fabric was a creative method for the textile and fashion industry to increase sales. ${ }^{507}$ Multiple groups of protestors demonstrated their disgust in the longer skirt lengths as they believed it regressed women's fashion, and as a result, women themselves. In New York City, protestors outside of Bergdorf Goodman’s department store hailed, ‘Monsieur Dior, we abhor dresses to the floor'. The Little Below the Knee Club, founded by a young housewife, protested in Dallas by wearing a variety of hemlines from the 1890s and 1920s. These dresses were used to compare the longer lengths of the 1890s, which were associated with the traditional woman, to the shorter lengths of the 1920s, which were associated with the modern woman. Additionally, the Chicago chapter protested outside of an award ceremony honouring Dior with the slogan, 'The Alamo fell but our hemlines will not!'! ${ }^{508}$ The New Orleans chapter of the National Business and Professional Women's Club requested that the entire national membership resist the

\footnotetext{
${ }^{505}$ Suzy Menkes, 'Dior Takes Manhattan: 50 Years on, a New 'New Look'?: [2 ${ }^{\text {nd }}$ Edition]', International Herald Tribune, 10 December 1996. ProQuest $<$ https://www-proquestcom.vortex3.uco.edu> (para 20 of 28).

506 'British Battle of the Hemline', Ladies' Home Journal, December 1947. ProQuest $<$ https://wwwproquest-com.vortex3.uco.edu> (p. 4).; Jacques Decaux, 'The "New Look” In World Politics', The China Weekly Review, 05 June 1948. ProQuest <https://www-proquest-com.vortex3.uco.edu> (p. 20). ${ }^{507}$ Alison Settle, 'Background Of “New Look”: Bid To Focus All Eyes On French Textile Trade', The Scotsman, 18 February 1948. ProQuest <https://www-proquest-com.vortex3.uco.edu> (p. 6).; “"New Look” Styles Give Gentleness, Rhythm and Symmetry to Women so the Trade Says', The Globe and

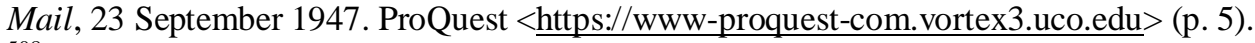

${ }^{508}$ Karal Ann Marling, As Seen on TV: The Visual Culture of Everyday Life in the 1950s (Cambridge, MA: Harvard University Press, 1994), p. 12.; see also, Schreier, pp. 10 - 14.; 'Texas Women Set to Bar Long Skirts: 1,300 in a New Club at Dallas Unite to Keep Clothes at a Little Below The Knee', New York Times, 18 August 1947. ProQuest < https://www-proquest-com.vortex3.uco.edu> (p. 14).; 'Women in Dallas Deride Long Skirts: Little Below The Knee Club Ties Up Traffic With Parade in Stuffy Garb’, New York Times, 24 August 1947. ProQuest <https://www-proquestcom.vortex3.uco.edu> (p. 24).
} 
New Look. ${ }^{509}$ Figures [86-87] are images of the Little Below the Knee Club protesting the New Look. The club women protested against longer hemlines which they felt represented women's enslavement. Additionally, they also feared an increase of prices for women's clothing as the skirts used a larger amount of fabric. Even a comic strip illustrated by Curt Gfroerer, shown in Figure [88], linked the New Look to old fashion values by depicting two ladies in traditional long dresses, one powdering her nose while the other one was bent down scrubbing the floor and a sign noting 'For That Sleek Look Try Our Fall Styles'. Underneath the cartoon image listed two comments from women readers. Joan Gridley stated, 'Wonder why the gals in the Little-Below-the-Knee club are complaining so bitterly about the new slightly-above-the- ankle skirts? Think of all the time, effort, and greenpacks we'll save in applying only half as much leg makeup!.' Daisy claimed, 'We won't have to worry about the seams of our stockings being straight'. ${ }^{510}$ These comments may have suggested some sarcasm, but the article does present a division of accepting or rejecting Dior’s New Look.

As some women protested the New Look, other women overwhelmingly embraced this new style. Marie France-Pochna noted at the time of Christian Dior's fashion show in 1947, the collection 'gave a whole new grace to the female figure, accentuating and highlighting its natural proportions' ${ }^{511}$ Although there were many disputes over the length of the skirt, women readily accepted the constraints of the cinched in waist. Many articles discussed the importance of women achieving a smaller waist from diet tricks to undergarment corsets so that they could wear the New Look. ${ }^{512}$ Articles on waist cinching were informative and suggested products, such as, waist belts, brassieres, and all in one foundation garments including a corset with bra support. An article describing the undergarments noted an oxymoron of comfort in relation to bones, 'These waist nippers are made of different fabric - of

\footnotetext{
509 '1947 Brought Revaluation in World of Fashion’, The Globe and Mail, 02 January 1948. ProQuest $<$ https://www-proquest-com.vortex3.uco.edu> (p. 8).

${ }^{510}$ Arch Ward, 'In the Wake of the News', Chicago Daily Tribune, 7 October 1947. ProQuest $<$ https://www-proquest-com.vortex3.uco.edu $>$.

${ }^{511}$ Marie France Pochna, Christian Dior: The Man Who Made the Whole World Look New, (New York: Arcade Publisher, 1996), p. 135.

${ }^{512}$ Rea Seeger, 'Curve Control Under “The New Look” is Vital', Chicago Daily Tribune, 16 October 1947. ProQuest <https://www-proquest-com.vortex3.uco.edu> (p. 30).; Jean Kain Ida, 'Three Moderate Meals a Day Will Help You Wear the "New Look” Fashions', The Washington Post, 27 September 1947. ProQuest <https://www-proquest-com.vortex3.uco.edu > (p. 1).
} 
light satin, of net, or batiste, and boned with such softness that you scarcely notice their flexible little bones. 513

Dior's New Look became the primary fashion for the next ten years. The same season that Dior's New Look was released, designer Molyneux had released a straight evening column dress. The New Look became the predominate fashion while Molyneux’s column dress had not. Several factors may have contributed to the overt popularity of the New Look. First, it was an extravagant change from current fashions, coming out of wartime where many restrictions were implemented with the reduction of fabric and details, the New Look celebrated abundance which gave society a dress that was not a reminder of the war. Second, Carmel Snow and the fashion press thought the New Look was fantastic and different so they widely marketed it in their magazines. Third, many other designers released hourglassshaped silhouettes similar to the New Look prior to Dior's release. Therefore, the New Look was in-line with the fashion evolution of building from previous styles, although, Dior's style was extreme. Finally, the New Look aligned with cultural factors within America that 'fit' into the woman's lifestyle, such as, formal mannerisms and conspicuous consumption, which made it appealing to adopt. ${ }^{514}$ For example, the nipped in waist guided women to adhere to formal mannerisms of proper ladylike standards as it was natural to move slowly and gracefully in an upright position while tightly corseted. Quite different from the flapper dress which provided freedom from the waist and allowed women to move freely without the constraints of refined womanly standards. Suzy Menkes quoted Dior, 'The [N]ew [L]ook was a success only because it reflected the mood of the time.' 515

Dior's New Look created a sensation that designers from all markets modified this style to fit in their price range, therefore, women of all classes could afford the

\footnotetext{
${ }^{513}$ Barbara E. Scott-Fisher, “New Look” Built-Up Waistlines Promoted by Styles in Corsets: Like Old-Time Garters Black Lace Over Satin’, The Christian Science Monitor, 10 December 1947. ProQuest $<$ https://www-proquest-com.vortex3.uco.edu $>$ (p. 14).

${ }^{514}$ Similar silhouettes before release of Corolle line: Elsa Schiaparelli's wool day coat with its nipped in waist from 'Fashion: Paris: First Reports from September Paris Collections', Vogue, 01 October 1946. ProQuest <https://www-proquest-com.vortex3.uco.edu> (p. 187). Molyneux’s blouse and skirt tightly belted and Piguet's tightly belted suit can be seen in 'Fashion: Paris Fashions: Molyneux/Paquin’, Vogue, 01 November 1944. ProQuest <https://www-proquest com.vortex3.uco.edu> (pp. 119-120).

${ }^{515}$ Suzy Menkes, 'Dior Takes Manhattan: 50 Years on, a New 'New Look'?: [2 ${ }^{\text {nd }}$ Edition]', International Herald Tribune, 10 December 1996. ProQuest $<$ https://www-proquestcom.vortex3.uco.edu $>$ (para 26 of 28).
} 
New Look. ${ }^{516}$ A new era of extreme femininity had arrived. ${ }^{517}$ Upon my visit to the Dior exhibit in Dallas, Texas it was clearly apparent that Dior's designs were overwhelmingly feminine. Although few styles were unfitted, many of Dior's designs catered to the feminine standard of nipped in waists, full skirts and extravagant details, such as large bows at the waist or neckline. ${ }^{518}$ One of Martin's observations about Dior is that '[w]e struggle to make him modern' ${ }^{519}$ In this article, many designers had conflicting ideas of Dior's New Look as some felt he adhered to traditional dress while others thought the change of the New Look had a traditional heritage but with a modern interpretation. ${ }^{520}$ While his fashion did present some sharp lines with a slight modern interpretation, it was overwhelming traditional and not modern, although it was undeniably 'in style'.

\section{Historic Background of the Postwar Era}

Dior's New Look displayed conspicuous consumption with the use of excessive and overabundance of fabric which paralleled the new economic state of Americans. Historian, James Patterson, labelled the Postwar Era as an economic 'boom' and claimed it as the 'most decisive force in the shaping of attitudes and expectations'. ${ }^{521}$ Patterson associated the boom in areas of economics, consumption, scientific innovation, home infrastructure, and population. During this time, America was the most prosperous nation. America led in scientific innovation and mass

\footnotetext{
${ }^{516}$ Heather A. Vaughan, "Icon: Tracing the Path of the 1950s Shirtwaist Dress." The Journal of American Culture, 32.1 (2009), 29-37 (p. 30) < http://vortex3.uco.edu/login?url=https://wwwproquest-com.vortex3.uco.edu/scholarly-journals/icon-tracing-path-1950s-shirtwaistdress/docview/200641627/se-2?accountid=14516> [accessed 20 January 2021].

${ }^{517}$ Rebecca J. Robinson claimed during the Postwar Era fashion was largely influenced by male designers: Robinson, Rebecca J., 'American Sportswear: A Study of the Origins and Women Designers From the 1930's to the 1960's', (unpublished master thesis, University of Cincinnati, 2003) in ProQuest Dissertations and Theses Global < http://vortex3.uco.edu/login?url=https://www-proquestcom.vortex3.uco.edu/dissertations-theses/american-sportswear-study-origins-womendesigners/docview/305329576/se-2?accountid=14516 > [accessed 11 February 2021] p. 17. One of the most important absences was Coco Chanel. Chanel left fashion during WWII and did not return until the mid-1950s. Chanel's absence greatly affected design. Not only were strong women discouraged from participating in the public sphere after the war, but also Dior's hour-glass design was a drastic departure of the simplistic designs that Chanel popularized.

${ }^{518}$ Dior: From Paris to the World, at Dallas Museum of Art (Dallas, TX, May 19- Oct. 27, 2019).

${ }^{519}$ Suzy Menkes, 'Dior Takes Manhattan: 50 Years on, a New 'New Look’?: [2 ${ }^{\text {nd }}$ Edition]', International Herald Tribune, 10 December 1996. ProQuest $<$ https://www-proquestcom.vortex3.uco.edu> (para 13 of 28).

${ }^{520}$ Suzy Menkes, 'Dior Takes Manhattan: 50 Years on, a New 'New Look'?: [2 ${ }^{\text {nd }}$ Edition]', International Herald Tribune, 10 December 1996. ProQuest $<$ https://www-proquestcom.vortex3.uco.edu>

${ }^{521}$ Patterson, Grand Expectations, p. 61.
} 
production output compared to other countries. According to Patterson, America composed 7\% of the world's population in the late 1940s, while at the same time, Americans accounted for $42 \%$ of the world's income and accounted for half of the world's manufacturing output. ${ }^{522}$ This prosperity changed the everyday lives of Americans. Author, William L. O’Neill coined this era the 'American High'. 523 Similar to the Progressive Era, the Postwar Era was characterized by significant cultural shifts. Although the shifts were different in nature, the shifts from each era implemented a new and different type of living. For example, during the Progressive Era the population shifted from an agrarian landscape to a city centre, while the Postwar Era population shifted from the city centre to suburban living. Both population shifts changed how Americans lived, worked, and played that ushered in a new way of life, and as a result, created changes to women's fashion. ${ }^{524}$ Similarly in both of these eras, corseted waists and femininity were important. With this economic 'high', women reverted back in time, echoing past eras where the primary role of women was decorative and feminine.

\section{Women in Education and the Workplace}

As women's fashion emphasized historical contexts honouring past civilizations, women also regressed in education and the workplace. One significant obstacle for women during the 1950s was the lack of assistance extended to women to go to college. The government aided male veterans with the GI Bill to help enter college and gain skills that would lead to a better occupation after the war; but few benefits were extended to women on a mass scale. Women who volunteered for the armed services, worked at the factories producing war goods, or were left behind to take care of the children received no extra benefit like the men who were actively fighting the war. In addition, those women who did serve close to the battlegrounds were limited as to how they could serve. Only those women who were part of the WAC and WARES received the same benefits as men. Elaine Tyler May, claimed that since women were considered dependents rather than providers in their homes they were not eligible for many of the veteran's benefits that the male counterparts

\footnotetext{
${ }^{522}$ Patterson, Grand Expectations, p. 61.

523 O’Neill.

${ }^{524}$ William H. Chafe, The Unfinished Journey: America Since World War II, $3^{\text {rd }}$ edn (Oxford: Oxford University Press, 1995) p. vii.
} 
received. ${ }^{525}$ Those women who did receive the GI Bill were at a disadvantage, as the men had enrolment preferences at the universities. Because the GI Bill was extended to all veterans, the male student population at universities exploded. Patterson claimed that the GI Bill was 'the most significant development in the modern history of American education'. Patterson noted a smaller percentage of women entering college; however, he failed to correlate the low college enrolment among women to the absence of legislation for women to help fund college. ${ }^{526}$ According to the U.S. census, in 1950, men constituted over $75 \%$ of those who graduated from college or earned a professional degree as 328,841 men graduated and only 103,217 women. ${ }^{527}$ As women reverted back to traditional roles, the same pattern existed with education. Although women were allowed to enter colleges, they were not encouraged nor supported like their male counterparts. Elaine Tyler May noted that the smaller percentage of women enrolled in college widened the gap between men and women in higher education and contributed to the polarization of the sexes in terms of educational content and achievement. She further noted that a college degree for a man allowed more opportunities in higher paying jobs than for women with a college degree. ${ }^{528}$

Women during the 1950s did not experience exponential growth in the social culture of the workplace as they did during the 1920s. Although women started reentering the workforce in 1947, women continued to hold jobs similar to those of women in the 1920s. Women working in the 1920s experienced significant growth as they had broken down gender segregation barriers in the workplace, however, women's employment in the 1950s was stagnant as they did not make any drastic changes of their own. Seventeen magazine highlighted a recent graduate from Vassar, Heath Williams. Williams could not find a job in television production unless she offered 'positive business skills', such as shorthand and typing. She went back to school to learn shorthand and quickly was hired by CBS-TV as a secretary to the

\footnotetext{
${ }^{525}$ May, Homeward Bound, p. 76.

${ }^{526}$ Patterson, Grand Expectations, pp. 69, 68.

${ }^{527}$ U.S. Department of Commerce, Statistical Abstract of The United States: 1960, 'Table No. 140: High School And College Graduates, By Sex: 1900 to 1956’ (Washington, D.C., Government Printing Office, 1960), no. 81 <https:/www.census.gov/library/publications/1960/compendia/statab/81ed.html > [accessed 14 February 2021] (p. 109). Patterson also noted similar numbers for the 'university boom'. His numbers were based from the 1949-1950 school year, Grand Expectations, p. 68.

${ }^{528}$ May, Homeward Bound, p. 78.
} 
manager of the network film department. ${ }^{529}$ The article noted her promotion from the manager's secretary to the vice-president's secretary, evidence that she could not escape the pink collared jobs. Additionally, some professional fields operated a quota for women to limit their participation in these jobs. For example, medical schools put a $5 \%$ quota on women, $70 \%$ of all hospitals refused to accept female interns and medical associations barred women members. ${ }^{530}$ If women could not enter medical school nor intern, thus, they would not be able to obtain a medical license and practice. Women practicing medicine correlated to the $5 \%$ quota dictated by medical schools. In 1945, Monthly Labor Review noted that women consisted of $4.6 \%$ of practicing physicians. The article also stated that the U.S. had a deficit of doctors, especially in rural areas. ${ }^{531}$ However, the article did not account for women and ignored their abilities in helping to fill doctor's positions. If the quota for medical school was removed and training became more available to women, then women could have filled the need for doctors. The American society expected doctors to be primarily a man's field and did not initiate new guidelines to help improve women's access to the medical field. Elaine Tyler May expressed, because the professional fields were limited to women, they thought the best option was to marry and raise a family. ${ }^{532}$

\section{The Suburban Landscape: The American Housewife}

As the social context of education and the workplace limited women, suburban living encouraged domesticity and motherhood with affordable homes that were designed for the conveniences of young children. The suburbs created a shift away from small apartment style living in the city to a more spacious yard and a larger footprint of a new home. Chafe noted during the 1950s the suburbs grew six times faster than the cities. ${ }^{533}$ The suburbs lured young families and as a result, demographic trends shifted. More women married younger, had more children and had multiple children spaced closer together. Patterson claimed these new trends

\footnotetext{
529 'Training for Your Future', Seventeen, June 1953. ProQuest $<$ http://vortex3.uco.edu/login?url=https://www-proquest-com.vortex3.uco.edu > (pp. 126-127).

${ }^{530}$ Chafe, The American Woman, p. 184-85. Chafe also stated this in The Unfinished Journey, p. 85.

${ }^{531}$ Anonymous, 'Postwar Outlook for Physicians', Monthly Labor Review, 61.6 (1945), 1094-1111 (p. 1094) $<$ ProQuest $<$ https://www-proquest-com.vortex3.uco.edu $>$.

${ }^{532}$ Elaine Tyler May, American Experience: Tupperware!, $<$ https://www.pbs.org/wgbh/americanexperience/features/tupperware-may/> [accessed 11 February 2021] (para 9 of 28).

${ }^{533}$ Chafe, The Unfinished Journey, p. 117.
} 
resulted in the baby boom with the birth of 3.8 million babies in 1947, 3.9 million in 1952, and 4 million every year from 1954 to $1964 .{ }^{534}$

One of the most significant contributions to the growth of the suburbs was the housing project called Levittown, designed by Levitt \& Sons. The suburban neighbourhood consisted of identical track homes made in a mass manufacturing process, similar to Henry Ford's process, assembling a line of houses in 27 distinct steps. ${ }^{535}$ Therefore, every house looked the same with the use of the same floor plans, same materials, and the same method. Using the mass-production method, this allowed Levitt \& Sons to keep the cost of home building down; therefore, ensuring an affordable product and attractive to working and middle-income families and largely the WWII veteran. ${ }^{536}$

As the houses themselves were affordable, ownership of a new house was expensive and encouraged conspicuous consumption through the purchase of consumer goods, such as new washing machines, new television sets, and new kitchen gadgets. Hildegarde Dolson, writer for the Ladies’ Home Journal, highlighted a suburban couple struggling to stay ahead of their debt. She noted that the couple bought large ticket items on instalment plans; such as, custom-made draperies, slipcovers, a deep freezer, a washing machine, and storm windows. ${ }^{537}$ Wini Breines, claimed that from 1954 to 1960 instalment credit rose from $\$ 4$ billion to $\$ 43$ billion and by the end of the decade $60 \%$ of Americans owned their homes. ${ }^{538}$ To live in the suburbs, the extra expense of a car was a necessity and it became an increasingly significant mode of transportation. ${ }^{539}$ Unlike the cars of the 1920s, the automobiles of the 1950s were much larger, more luxurious and offered many amenities. The large automobiles symbolized overindulgence, status, and wealth, akin to how the New Look displayed these same ideals. Additionally, the spacious interior allowed women to sit comfortably in the car with their layered petticoat skirts. During this time,

\footnotetext{
${ }^{534}$ Patterson, Grand Expectations, p. 79.

535 Parrish, p. 38.; Kenneth T. Jackson, Crabgrass Frontier: The Suburbanization of the United States (Oxford: Oxford University Press, 1985), p. 236.

536 Jackson, Crabgrass Frontier, pp. 234-35.; Patterson, Grand Expectations, pp. 73-75.; Rosalyn Baxandall and Elizabeth Ewen, Picture Windows: How the Suburbs Happened (New York: Basic Books, 2000), pp. 143-45.; Lewis Mumford, The City in History (New York: Harcourt Brace Jovanovich, 1961), p. 486.

${ }^{537}$ Hildegarde Dolson, 'The Scrambled Housewife’, Ladies' Home Journal, August 1954. ProQuest $<$ https://www-proquest-com.vortex3.uco.edu $>$ (p. 97).

${ }^{538}$ Breines, p. 3.

${ }^{539}$ Chafe, The Unfinished Journey, pp. 118-19.
} 
fashion echoed this same pattern of overindulgence and conspicuous consumption, not only through displaying wealth with the style of the New Look but also through accumulating a broader assortment of clothing.

The suburb's informality of backyard barbeques and outdoor activities created a lifestyle for a more casual culture, allowing women to expand their closets with a larger variety of clothing. Therefore, women's wardrobes now included more styles to meet the needs of specific activities, such as casual, daily and formal wear. According to Barbara A. Schreier, suburbia's casual atmosphere demanded a special set of play clothes with a wide variety of dresses and pants, such as, halter-style dresses, bared midriffs, shirtwaist dresses, pedal pushers, and slack suits. ${ }^{540}$ This wide variety of outfits can be seen in Redbook magazine, as shown in Figures [89-92]. Ruth Drake suggested multiple outfits for a busy housewife; such as a gardening dress, pedal pusher pants for children's playtime, a dress for an outdoor buffet and a cocktail dress for time alone with your husband. The dresses shown all consisted of a similar structure and lines to the New Look. They included variations in fabrication and details that suggested these garments for a specific use as they were not versatile enough to wear for all occasions. ${ }^{541}$ These dresses fostered the idea of changing clothing often which demonstrated not only a woman's large wardrobe but also the connection that she spent most of her time at home and close to her closet.

Furthermore, the activities suggested in this article were all activities that took place at one's home or backyard. Wearing different dresses, changing often, and the style of the New Look all displayed conspicuous consumption, whereas, the shift dress was noted as a garment of economy that was universal and versatile for multiple occasions which did not align with the mass-produced culture of the 1950s.

As the housewives had more children and were able to stay home, this further confined women to normative gender roles. One of the advantages of purchasing a new home in the suburbs was the amenities of the well-equipped kitchen appliances. ${ }^{542}$ The kitchens in the new suburban homes were designed to appeal to women with a wide selection of fashion colours, especially the use of pink, which

\footnotetext{
${ }^{540}$ Schreier, p. 14.

${ }^{541}$ Ruth Drake, 'You Always Look So Pretty You're a Busy Housewife, but You Want to Look Your Best. You Shop Carefully so You can have Pretty Clothes for Every Occasion', Redbook, June 1952. ProQuest <https://www-proquest-com.vortex3.uco.edu> (pp. 62-65). See also, 'Dresses of Moment', Good Housekeeping, October 1953. ProQuest < https://www-proquest-com.vortex3.uco.edu > (pp. 137, 281-284, 286-288).

542 Baxandall and Ewen, p. 136-37.
} 
further channelled women into these sterotypical gender roles. Ann Worden and Anne Anderson noted, 'Pink is everywhere' and 'holds a top position' in the latest kitchen trend. ${ }^{543}$ These functional yet fashionable appliances placed the idea that women belonged in the kitchen. Furthermore, in 1959, Vice-President Nixon, boasted to Mr. Khrushchev, the leader of the Soviet Union, that the new suburban household was equipped with the latest in-home appliances to make life easier for the housewife. ${ }^{544}$ Furthermore, advertisers targeted women in their ad campaigns for household appliances. For example, American Stove Company’s tagline stated, ‘More women cook on Magic Chef than any other range. ${ }^{545}$ Additionally, The Tappan Stove Company communicated that 'choosing a range is like choosing a husband...you'll be living with both for a long time'. ${ }^{546}$ By connecting appliances and the home to a specific gender identity, this further suggested women belonged in the domestic sphere.

Although the 1950s housewife and the 1920s flapper were approximately the same age and both from middle-class backgrounds, their fashion, lifestyle and gender roles were significantly different. As discussed previously, the simple flapper dress was versatile with a variety of fabrics, designs, and accessory options that created a unique look without looking overly adorned with feminine details. However, the 1950s fashions were inherently feminine as the dresses were adorned with dainty collars, pastel colours, and tiny floral prints with a structure of pleated fabric and layers of petticoats. ${ }^{547}$ The lifestyle of the flapper and the 1950s housewife differed as the 1950s housewife incurred a more mature and female gendered role. Since the 1950s housewife married earlier, she quickly gained grown-up responsibilities of running a household and caring for others, while the flapper had limited responsibilities of caring for herself as many remained single. ${ }^{548}$ Additionally,

\footnotetext{
${ }^{543}$ Ann Worden and Anne Anderson, 'Exciting Trends in Today's Kitchens', Better Homes and Gardens, August 1956. ProQuest < https://www-proquest-com.vortex3.uco.edu> (p. 52).

544 "The Two Worlds: A Day-Long Debate: Nixon: “I Am for Peace” Premier: “Eliminate Bases” The Day-Long Debate Between Vice President Nixon and Premier Khrushchev Visitor and Host Exchange Gibes American Challenges Soviet Leader to Competition in Free Trade of Ideas', New York Times, July 25, 1959. ProQuest <https://www-proquest-com.vortex3.uco.edu> (p. 1).

545 ‘Advertisement: American Stove Company’, Good Housekeeping, May 1950. ProQuest $<$ https://www-proquest-com.vortex3.uco.edu > (p. 197).

546 'Advertisement: The Tappan Stove Company', Ladies' Home Journal, June 1947. ProQuest $<$ https://www-proquest-com.vortex3.uco.edu > (p. 16).

547 Schreier, pp. 10-14.

548 According to the Statistical Abstract of the U.S. Census single women in 1920 composed of 24.1\% of the population while single women in 1950 represented $19.6 \%$ of the population and continued to decrease within the duration of the decade to $18.2 \%$ of single women in 1959. U.S. Department of
} 
maintaining a house in the suburbs and raising children attached the 1950s housewife to the private sphere. While the flapper worked alongside men and participated in a wider variety of activities, this placed her within the public sphere. The flapper's larger participation in the public sphere suggested she had more freedom within her lifestyle, and at times, interfaced more regularly with men.

Many articles appeared in women’s magazines specifically highlighting the frustration housewives felt with the ongoing duties of maintaining the household and being confined to the private sphere. ${ }^{549}$ The new appliances, which Nixon had boasted to Mr. Khrushchev, were designed to make life easier for housewives. However, there was a feeling among women that the housewife's job was much more difficult and time consuming than Nixon had promoted. The Ladies' Home Journal interviewed twenty housewives and surveyed their daily routine to determine how time consuming the duties of the housewife demanded. The article, 'Idle Women...Where Are They?', discovered that all the housewives interviewed had little or no time for themselves. The chores of the household combined with the daily routine of children left no time for a housewife to sit idle. One housewife who was raised on a farm noted that today's housewives did not have a support system to help them complete chores as the farm had offered. ${ }^{550}$ Historically, the housewife of earlier generations was laden with more work without technological conveniences, yet, her support system was close by and the work was shared among several women. The suburban housewife was left alone to perform all of the household duties herself. Additionally, the media portrayed images of the housewife as if it was their duty to create a perfect household environment. Thus, the workload for the suburban housewife was not as leisurely as many would assume.

The reoccurring social image that advertisers used for women and housewives to obtain a perfect household was not only the strict adherence to having a beautiful home but also looking beautiful while cleaning the house. Advertisers repeatedly

Commerce, Statistical Abstract of The United States: 1960, 'Table No. 36: Martial Status of the Population, by Sex: 1890 to 1959’ (Washington, D.C., Government Printing Office, 1960), no. 81 $<$ https://www.census.gov/library/publications/1960/compendia/statab/81ed.html > [accessed 14 February 2021] > (p. 38).

${ }^{549}$ Donald G. Cooley, 'What's Your Emotional Breaking Point?', Cosmopolitan, February 1955. ProQuest < https://www-proquest-com.vortex3.uco.edu> (pp. 12-16).; Hannah H. Betty, 'Help Wanted: Do You Just Live Through This Destructive, Disobedient Stage', Ladies’ Home Journal, July 1951. ProQuest <https://www-proquest-com.vortex3.uco.edu $>$ (pp. 107-110, 116-119).

${ }^{550}$ Hannah H. Betty, 'Idle Women... Where Are They?', Ladies' Home Journal, March 1949. ProQuest $<$ https://www-proquest-com.vortex3.uco.edu> (pp. 36-37, 218, 221-22). 
displayed woman in beautiful, hourglass shaped dresses worn with aprons and high heels. Figure [93] exemplifies the connection of dressed-up housewives as an advertisement for a mopping cleaner prominently displays the housewife in an apron and high-heel shoes. General Electric's slogan stated, ‘A model housewife - a model home’ and Western Stove Company and Thermic Ray claimed Peggy Singleton, an actress on radio, as America's \#1 housewife. ${ }^{551}$ To be perfect as a housewife was routinely suggested by advertisers. The Ladies’ Home Journal highlighted an everyday housewife and how she achieved perfection, 'All of us entertain the perfect performance, but Marjorie never stops trying to make it all a living part of her experience.' 552 According to Lelia J. Rupp, during the 1950s, the perfect image of the housewife was present in all areas of media; magazines, television, and advertisements. ${ }^{553}$

\section{Television and the Image of the Housewife}

A new form of media, television, became one of the most significant sources of entertainment in the twentieth century as well as a tool that broadcast stereotypical images into the household. Television sets were initially introduced in the 1930s, but gained popularity throughout the 1950s. In 1948 there were 172,000 television sets in American's homes, in 1950 there were 5 million, and by 196050 million television sets were in use. ${ }^{554}$ Author, Wini Breines, claimed the 1950s consisted of 'easy times' with backyard barbeques, soda fountains, and family television watching. ${ }^{555}$ Television sets had become the focal point in the family room.

Television was similar to silent films as it brought lessons to its audience. Just as the flapper films portrayed the lifestyle of the flapper, television of the 1950s emphasized the role model of the American family and the housewife. Patterson

\footnotetext{
551 'Advertisement: General Electric’, Better Homes and Gardens, March 1953. ProQuest < https://www-proquest-com.vortex3.uco.edu> (p. 129).; 'Advertisement: Western Stove Company, Inc', Good Housekeeping, April 1949. ProQuest <https://www-proquest-com.vortex3.uco.edu $>$ (p. 118).; 'Advertisement: Thermic Ray', Ladies' Home Journal, November 1948. ProQuest < https://www-proquest-com.vortex3.uco.edu> (p. 1).

${ }^{552}$ Margaret J. Weymouth, 'The Perfectionist Housewife: Meet Max and Marjorie Reeves, of Peoria Illinois', Ladies' Home Journal, September 1946. ProQuest $<\underline{\text { https://www-proquest- }}$ com.vortex3.uco.edu> (pp. 159-164, 186).

${ }^{553}$ Leila J. Rupp, 'The Survival of American Feminism: The Women's Movement in the Postwar Period', in Reshaping America: Society and Institutions, 1945-1960, ed. by Robert H. Bremner and Gary W. Reichard (Columbus: Ohio State University Press, 1982), pp. 33-65, (p. 35).

${ }^{554}$ Weibel, p. 48.

555 Breines, pp. 4-5.
} 
claims women characters primarily played the role of domesticity and the nurturer of the home; whereas, fathers were portrayed as career driven and all-knowing. ${ }^{556} \mathrm{We}$ can see examples of this in popular situation comedies, Father Knows Best and I Love Lucy. Just analysing the titles of these two shows, suggests the dynamics of gendered identity. Father Knows Best strongly implies that the male is dominant while I Love Lucy suggests a female's identity as a loving person rather than an educated or allknowing individual. Father Knows Best was centred around a father's knowledge which was expressed in lessons for the family. ${ }^{557}$ In I Love Lucy, the show portrayed Lucy as a typical housewife whose silly antics set the tone for the show. Both of these shows were popular among Americans and were rated as top programs according to Nielsen Media Research. ${ }^{558}$ I Love Lucy arguably was one of the most influential and best-known shows in the twentieth century. According to Brooks and Marsh, I Love Lucy was a 'major hit' and its success was 'unparalleled in the history of television'. I Love Lucy was the most watched television show in the U.S. four of its six seasons and was translated in a variety of languages as its reruns were distributed around the world. ${ }^{559}$ Thus, the behaviour of the characters reached a massive audience and it communicated a standard gender role to the American audience. Father Knows Best displayed a typical American family that gendered women by placing them in the home, but I Love Lucy is different as it provides an example of a female-centred sitcom with a lead female role, both unusual for this time. I Love Lucy was a successful television show which made it an optimal medium to show America what an average housewife looked like and how women were portrayed in gendered relationships.

I Love Lucy depicted a middle-class couple in everyday dilemmas. The dilemmas were mostly instigated by Lucy and her creative ideas and solutions. Lucy’s dresses consisted of the popular New Look, flared skirts with cinched-in

\footnotetext{
556 Patterson, Grand Expectations, p. 351.

${ }^{557}$ An example of the Father as a directive role can be seen in the first episode: 'Bud Takes Up the Dance'. Father Knows Best, NBC, 3 October 1954, online video recording, Youtube, < https://www.youtube.com/results?search_query=Father\%27s+Knows+Best $>$ [accessed 11 February 2021].

${ }^{558}$ Brooks, Tim and Earle Marsh, The complete Directory of Prime Time Network and Cable TV Shows: 1946-Present, $8^{\text {th }}$ edn (New York: Ballantine Books, 2003), p. 1455. The Nielsen Media Research rates programs ranked by audience size. According to Tim Brooks, the Nielsen rating is the percent of all TV-equipped homes turned to the program on an average night. For example, I Love Lucy rating for October 1952-April 1953 was 67.3, therefore, 67.3\% of all homes that had a TV were turned to this show.

${ }^{559}$ Brooks and Marsh, pp. xiv, xv, 566-568, 1456-1467.
} 
waist, which was the predominant fashion for the typical housewife. Even when doing housework, she would wear an apron with her belted skirts and high heels. What Lucy portrayed was the same image that the magazines were promoting for women, to always look beautiful even while doing chores around the house.

Not only did Lucy look feminine, but dressed in this way, she was also portrayed on many occasions as ignorant or empty-headed. For example, Lucy wanted to be ready on time for a dinner engagement, so she set the clocks to trick herself about the actual time. However, Lucy set the clock back one hour rather than ahead one hour which made Lucy and Ricky late to their dinner engagement. ${ }^{560}$ Not only was Lucy empty-headed on simple tasks, she also did not understand business matters. For example, in the episode, 'The Quiz Show', Ricky routinely checked the household accounts and determined if Lucy had done a good job with managing the money. While he reviewed the receipts, Ricky continually spoke to Lucy as a father or authoritative figure. Ricky stated "we need to get our finances in order and teach you a lesson.” ${ }^{561}$ Lucy frequently mismanaged money, but nonetheless, she continually went shopping with her friend, Ethel, and bought dresses. Lucy buying dresses demonstrated to viewers that expanding your wardrobe and participating in conspicuous consumption was important in order to be fashionable and uphold the standard of an American housewife. Additionally, her behaviour communicated to society that women do not understand the complexity of managing money nor have the aptitude for business matters. Her money spending habits demonstrated to society that it was the wives who were frivolous, irresponsible, and ignorant while the husbands were responsible, hard-working, and savvy. This spending pattern was further exemplified in the episode, 'Job Switching', when Frank says, 'When it comes to money there are two kinds of people, the earners and the spenders ... more popularly known as husbands and wives.' 562

Some episodes brought controversial women's issues to the I Love Lucy audience. For example, in the episode, 'Equal Rights', the wives were taught a lesson as Ricky and Fred teamed up to show their wives what equal rights would look like.

\footnotetext{
560 'Lucy’s Schedule', I Love Lucy, CBS, 26 May 1952, online video recording, CBS.com, $<$ https://www.cbs.com/shows/i_love_lucy/> [ accessed 15 July 2020].

561 'The Quiz Show', I Love Lucy, CBS, 12 November 1951, online video recording, CBS.com $<$ https://www.cbs.com/shows/i_love_lucy/> [ accessed 15 July 2020].

562 'Job Switching', I Love Lucy, CBS, 15 September 1952, online video recording, CBS.com, https://www.cbs.com/shows/i_love_lucy/> [accessed 28 October 2020].
} 
When the bill came after dinner, Ricky and Fred paid their bill and left the women to manage for themselves, and pay their own portion of the check. Both, Lucy and Ethel did not have money to pay the bill. This demonstrates that women during the 1950s did not have access to the husband's purse strings, or perhaps, they spent all of their money shopping. These women were penniless, and so they were forced to wash dishes to pay their debts, while wearing their fashionable and expensive dresses. The show demonstrated a juxtaposition of not having any economic power yet promoting wealth and stability. Both women complained that they had never worked so hard, suggesting that working outside of the home is more difficult than being a housewife and furthermore that women cannot handle the stresses of the public sphere. Ethel blamed Lucy for getting her into this situation as she claimed equal rights 'stink'. Ethel's comment suggests that women may not desire to have equal rights and may not want change. ${ }^{563}$ Although the show addressed women's issues and equal rights, it was displayed in an overtly joking manner from the men's point of view. The men thought it was absurd for women wanting equal rights and the women became convinced that it was not in their best interest to have them. The overall tone of I Love Lucy suggests that traditional roles for women were expected.

\section{The Women Beat Writers}

As housewives were confined to traditional roles and traditional clothing, the women beat writers fled the suburbs and moved to the city to live on their own terms, free from all constraints. In the latter half of the 1950s, social changes were emerging in America and the beat writers, also referred to as Beats or Beatniks, were a significant influence on these changes. Initially, the Beatniks began with a small, tight-knit group of men writers consisting of William S. Burroughs, Gregory Corso, Allen Ginsberg, Neal Cassidy and Jack Kerouac but soon other writers began adopting the same lifestyle and ethics. The Beats were the most provocative writers of this era, as they embraced a lifestyle of complete spontaneity to better allow free and natural ideas to transfer within their writing. ${ }^{564}$ The Beat writers wrote about controversial issues, such as, sex, politics, and capitalism. Parker Hodges, a 19-year

\footnotetext{
563 'Equal Rights', I Love Lucy, CBS, 26 October 1953, online video recording, CBS.com $<$ https://www.cbs.com/shows/i_love_lucy/> [accessed 28 October 2020].

${ }^{564}$ Mortenson, Erik, Capturing the Beat Moment: Cultural Politics and the Poetics of Presence (Carbondale, IL: Southern Illinois University Press, 2011), p. 1.
} 
old who spent time with the Beats, described them as 'not the most impeccable groomed people on the scene' as their clothing primarily was 'rugged, an easy look and inexpensive'. ${ }^{565}$ A small circle of women also engaged in the same philosophy and similar work as the Beat writers.

Many of the women Beat writers wrote about the freedom of clothing and its symbolism for women. As the flapper rebelled against the traditional lifestyle, she also discarded the traditional attire and replaced it with the shift dress. Although women Beat writers were not a cohesive group nor had specific garments that identified themselves as Beats, they believed that unrestricted garments gave them freedom. Many women Beat writers wrote or spoke about the importance of clothes. Hettie Jones, a Beat writer, believed that dress was just as important as the beat work itself. She expressed the liberation of dress,

[T] o take off your girdle was a radical move - first came the girdle and then came the bra - but to take off your girdle! Ah! To be able to think and walk and move without feeling blistered all the time...the idea that one could move freely. And taking off high-heeled shoes. I took off my high heels and threw them in the sewer one day when I first came to New York. ${ }^{566}$

As traditional dress was strapped onto her body, Hettie felt it was necessary to shed not only conformity in the sense of rules, but also in a sense of clothing. Upon moving to New York City in 1955, Hettie strived to have her own apartment, have her own job, and be a self-supporting individual which was radical at the time. She claimed, 'You [women] weren't supposed to leave home until you got married and lived under another man's hand.' 567 The examples of dress and lifestyle that Lucy and Ethel exposed and promoted were opposite of Hettie's values as she stood up against tradition.

Diana di Prima’s, Dinners \& Nightmares, utilized dress to symbolize birth and renewal in women. In the book di Prima recounts her first meal in New York, which she noted 'a very important episode', and referred to herself and her girlfriends as maidens. They dressed themselves in attire that they had 'invented', and described it

\footnotetext{
565 Parker Hodges, ‘The Beats: The Beats Like I Think I Know Them', Seventeen, October 1960. ProQuest $<$ https://www-proquest-com.vortex3.uco.edu $>$ (p. 162).

${ }^{566}$ Nancy M. Grace and Ronna C. Johnson, Breaking the Rule of Cool: Interviewing and Reading Women Beat Writers, (Jackson, MS: University Press of Mississippi) p. 160.

${ }^{567}$ Grace and Johnson, p. 160.
} 
as a half-slip which hung just above the breast and tied it with a sash, either under the breasts, around the middle, or low on the hips like the flapper style. The dresses were cool and comfortable. ${ }^{568}$ The accompanying text noted, while wearing the dresses, an endless breeze was felt passing through the body. ${ }^{569}$ The dress was not wrapped around them like a cocoon but rather hung loose with ease, like the shift dress, as it permitted their body to feel the presence of the breeze. The breeze symbolically represented freshness, cleansing and renewal. The shift dress in the 1920s embodied these same ideals as it cleansed women from traditional garments and renewed them as modern women.

The lifestyle led by the women of the beat generation was similar to the flapper. Both the beat women and the flapper discarded traditional social norms, abided by their own social values, and controlled their own self-identity. One of the primary differences was the flapper received widespread attention in the media, in newspapers, magazines, and film whereas the women beat writers received little media attention. Primarily the media described the Beat writers as male. Hettie Jones expressed that prior to the second wave of the women's movement it was unknown that women had discarded the cultural expectations of the 1950s, marrying and raising a family in the suburbs. ${ }^{570}$ However, many aspects of the suburban life followed the women Beat writers into the cities. Similar to the housewives, even progressive women like the Beat writers could not entirely shed feminine gendered roles. Diane di Prima articulated in her poem, 'The Quarrel', that sexual orientation confined women to domestic tasks. ${ }^{571}$ Although the women Beat writers could not escape many of the traditional roles that impeded women, it is important to note, they did defy social norms, obtained economic freedom and made choices of her own.

Betty Friedan, a housewife, published the novel, The Feminine Mystique, and claimed that women during the Postwar Era were discontent with their purpose which confined them to only the domestic sphere. Betty Friedan named this discontentment, 'the problem that has no name'. ${ }^{572}$ Friedan's book examined the gendered separation of women in many areas, such as, in education, the workplace, and in the media. ${ }^{573}$

\footnotetext{
${ }^{568}$ di Prima, Diane, Dinners \& Nightmares (New York: Corinth Books, 1974), p. 30.

569 di Prima, Dinners, p. 30

${ }^{570}$ Grace and Johnson, p. 159.

${ }^{571}$ Diane di Prima, 'The Quarrel', in A Different Beat: Writings by Women of the Beat Generation, ed. by Richard Peabody (London: High Risk Books, 1997), p. 46.

572 Betty Friedan, Feminine Mystique (New York: Norton Publisher, 1963), pp. 15-32.

${ }^{573}$ Friedan, pp. 16, 17, 22.
} 
Gender separation is a reoccurring theme, especially noted in the Progressive Era. During the 1950s, many women believed their only choice was domesticity, a choice which confined housewives to the home and perpetuated the loss of their self-identity. ${ }^{574}$ Roslyn Rosen suggested that if housewives are deeply discontent and dissatisfied then they are free to act upon their frustration. She noted that restlessness causes women to participate in activities; such as politics, economics, science, and art, like the suffragists and settlement house workers in the early 1900s. Rosen concludes, through women's discontent, women were innovative and brought changes within their communities as they advocated for women's suffrage, built settlement houses and nursery schools. ${ }^{575}$ Therefore, women acting upon their frustrations have incurred positive change, and historical change, in their lives. Historically, restless women instigate change.

\section{The Teenager}

Restlessness also stirred within the younger generation of the newly defined teenager. During the Progressive Era, the word 'Teen Age' describes young boys and girls in the teen years, however the concept of the modern teenager and the teenage market, as we know it today, did not emerge until later. One of the key factors for the emergence of the teenager was prolonged education coupled with increased economic prosperity. The 1920s experienced an increase of prolonged education and by the 1930s almost half the teenage population was high school students. Grace Palladino expressed, the teenage market emerged during the 1940s as a viable commercial market with the progressive philosophy of designing programs for teens. ${ }^{576}$ As the latter half of the 1940s experienced a consumption driven society with rapid economic expansion, the teen market evolved. Other key factors were instrumental, such as, the emergence of Seventeen magazine and rock-n-roll music. According to Patterson, prior to the 1950s all Americans listened to the same music as there was 'no sharply defined "teenage” music' ${ }^{577}$ As America became the world leader in technology and scientific innovation, education was vital. The growing middle-class

\footnotetext{
${ }^{574}$ Friedan, pp. 33, 69-79. Friedan highlights housewives that felt frustrated and chapter 3 focuses on the loss of self-identity for women.

${ }^{575}$ Roslyn Rosen, 'Housewives-A Little Misery is O.K.', Chicago Daily Tribune, 13 October 1957. ProQuest, <https://search-proquest-com.vortex3.uco.edu> (p. 1).

${ }^{576}$ Grace Palladino, Teenagers: An American History, (New York: Basic Books), p. xvi.

${ }^{577}$ Patterson, Grand Expectations, p. 12.
} 
in America enabled a higher percentage of younger people to attend college, therefore, they stayed in school and lived at home longer than past generations. The period from childhood to working adult was extended, therefore, the new teenage lifestyle became significant to society.

Helen Valentine, creator of Seventeen magazine, was revolutionary in realizing that teenagers wanted their own distinct marketing platform and in 1944 Seventeen magazine launched its first issue. Seventeen catered specifically to America's high school and college girls with its goal to help the teenager navigate life. Seventeen magazine claimed, 'In a world that is changing as quickly and profoundly as ours is, we hope to provide a clearing house for your ideas.' 578 Since the teenager was a new concept, according to Kelley Massoni, Seventeen magazine hired consultants in 1945 and 1946 to gain a better understanding of the teenager as they surveyed girls and their mothers about their likes, dislikes, and concerns. ${ }^{579}$ In an interview conducted by Massoni, Estelle Ellis, the first promotional director of Seventeen, claimed, 'Because there was no awareness - not only of teenagers-but there was no awareness of teenage girls, there was no awareness of how they dress, or the clothes they needed. ${ }^{580}$ It was a new concept and Seventeen magazine brought solutions to the typical teenager on a variety of topics, such as, how to dress, what to expect on the first date, and friendship dilemmas.

Although Seventeen magazine was created for this new teenage market, the fashions from Seventeen magazine followed similar fashion trends as directed by the fashion houses, and similar to Vogue. In the early 1950s, nipped in waists and full gathered skirts were predominant fashion, and at times, the sheath was important, particularly from 1954 to 1957. Consequently, during this time, teenagers did not have a distinct look of their own. As has been previously argued, the shift dress stemmed from the young, yet, it was generally absent in Seventeen magazine during the 1950s. The teenage market was still very new and the clothing manufacturers

\footnotetext{
${ }^{578}$ Helen Valentine, 'Seventeen Says Hello’, Seventeen, September 1944. ProQuest $<$ https://wwwproquest-com.vortex3.uco.edu> (p. 33).

${ }^{579}$ Kelley Massoni, 'Teena Goes to Market: Seventeen Magazine and the Early Construction of the Teen Girl (as) Consumer’, The Journal of American Culture, 29.1 (2006), 31-42 (p. 33) $<$ http://vortex3.uco.edu/login?url=https://www-proquestcom.vortex3.uco.edu/docview/200593656?accountid=14516 > [accessed 11 February 2021].

${ }^{580}$ Kelley Massoni, 'Teena Goes to Market: Seventeen Magazine and the Early Construction of the Teen Girl (as) Consumer', The Journal of American Culture, 29.1 (2006), 31-42 (p. 31) < http://vortex3.uco.edu/login?url=https://www-proquestcom.vortex3.uco.edu/docview/200593656?accountid=14516 > [accessed 11 February 2021].
} 
aligned their junior fashions to the women's trends and adjusted colours and details to the younger demographic. Many examples of this can be seen in Seventeen from its advertisements with the use of brightly coloured garments, school girl plaids, floral and novelty prints and rickrack trim while maintaining similar lines of the New Look. ${ }^{581}$ It is important to note that during this time, the fashions were driven by professionals in the fashion industry and not by the younger generation.

The fundamental significance of the youth lay in their growing numbers and in their spending power. In the age category of 5-19 years of age, the percentage of population from 1950 to 1960 rose from $23 \%$ to $27 \%$. ${ }^{582}$ The growing teen population coupled with the growing middle-class produced a large consumer group, and things began to change. In 1954, Seventeen magazine noted in its tenth anniversary issue that department stores were then creating separate junior sections for the teenager and the younger woman. ${ }^{583}$ Eugene Gilbert, an analyst who studied the youth market, indicated that the teenagers would emerge as a separate and distinct purchasing group. ${ }^{584}$ In 1959, Dr. Gainsborough, chief economist of the National Industrial Conference, forecasted positive sales for the textile industry, despite its sluggish performance in the late 1950s, because of the large number of teenagers entering the market in the near future. ${ }^{585}$

\footnotetext{
581 'Advertisements: Darlene Juniors, Inc.', Seventeen, February 1951. ProQuest < https://wwwproquests-com.vortex3.uco.edu> (pp. 64-65). See more examples in Seventeen, February 1951 issue on pages 7, 26, 74, and 76: 'Advertisement: The Gorham Company', Seventeen, February 1951. P ProQuest <https://www-proquest-com.vortex3.uco.edu> (p. 7).; 'Advertisement: D. H. Holmes Co., Ltd.’, Seventeen, February 1951. ProQuest $<$ https://www-proquest-com.vortex3.uco.edu $>$ (p. 26).; 'Advertisement: Gay Togs, Inc.', Seventeen, February 1951. ProQuest $<$ https://www-proquestcom.vortex3.uco.edu> (p. 74).; 'Advertisement: Grayson-Robinson Stores', Seventeen, February 1951. ProQuest $<$ https://www-proquest-com.vortex3.uco.edu $>$ (p. 76).

${ }^{582}$ U.S. Department of Commerce, Statistical Abstract of the United States: 1955, 'Table no. 21: Population, By Age And Sex, 1920 To 1950, And By Color And Rural Farm, 1950’ (Washington, D.C., Government Printing Office, 1955), no. $76<$ https://www.census.gov/library/publications/1955/compendia/statab/76ed.html> [accessed 14 February 2021] (p. 29).; U.S. Department of Commerce, Statistical Abstract of the United States: 1970, 'Table no. 7: Current And Projected Population, By Age And Sex: 1960 To 1990’ (Washington, D.C., Government Printing Office, 1970), no. 91

<https://www.census.gov/library/publications/1970/compendia/statab/91ed.html> [accessed 14 February 2021] (p. 8).

583 'Happy Birthday!', Seventeen, September 1954. ProQuest < https://www-proquestscom.vortex3.uco.edu> (p. 101).

${ }^{584}$ Eugene Gilbert, Advertising and Marketing to Young People (Pleasantville, NY: Printers' Ink Books, 1957), pp. 311-312.

${ }^{585}$ William M. Freeman, 'Textile Outlook Termed Brighter: Gainsbrugh Says Industry May Be Able to Halt Drop in Apparel Spending Five Factors Listed Economist Also Tells Cotton Institute Inventories of Retailers Are Low Textile Outlook Termed Brighter', New York Times, 21 March 1959. ProQuest < https://www-proquests-com.vortex3.uco.edu> (p. 26).
} 


\section{The Birth of Rock 'n' Roll}

Rock-n-roll was one of the most important popular phenomena for teenagers as it provided a platform for them to connect with one another and created a distinct division from their parent's music as the songs were about young love and youthful. living. Earlier, in 1954, one of the most significant turning points for the development of rock ' $n$ ' roll, according to author Jim Curtis, was when Elvis held his first recording session with Sun studios. ${ }^{586}$ Teens having their own style would spread to other consumer goods, such as clothing. Samuels Gertrude, writer for the New York Times, interviewed teenagers after attending a concert, and he noted how similar their clothing was to one another. The girls wore tight sweaters, colourful kerchiefs, skintight toreador pants, white woollen socks and loafers and the boy's typical outfit was a leather jacket worn with jeans and loafers. The overwhelming response from the teenagers interviewed was they liked the beat of the music, it felt good to dance and they could understand and relate to the lyrics. ${ }^{587}$

Rock ' $n$ ' roll stemmed from many different types of music; such as, ragtime, jazz, blues and country. ${ }^{588}$ Rock ' $n$ ' roll was largely taken from the heritage of black music and dominated by male performers. Elvis’s distinctive sound, sexual appeal, and creative dance moves made him marketable to the masses. ${ }^{589}$ Elvis's creative dance moves of his popular 'hip thrust' was thought of as too vulgar and inappropriate by adults. However, teenagers loved Elvis's dance moves and rock ' $n$ ' roll provided the beat for individuals to freely dance. Elvis not only popularized rock ' $n$ ' roll but he also inspired the dance craze in the latter part of the 1950s that extended into the 1960s. After World War II, young adults had families earlier and listened to the melancholy rhythms of classical music, therefore, dancing was not a large part of the social culture. ${ }^{590}$ The presence of rock ' $n$ ' roll and Elvis's upbeat and signature dance moves encouraged the youth to twist and shout. This emerging dance

\footnotetext{
586 Jim Curtis, Rock Eras: Interpretations of Music and Society, 1954-1984 (Bowling Green, OH: Bowling Green State University Popular Press, 1987), p. 37.

${ }^{587}$ Gertrude Samuels, 'Why They Rock 'n' Roll -- And Should They?: The Big Beat is More Insistent Than Ever and the Younger Generation is All Shook Up. A Reporter Attempts to Explain What It All Means. Why They Rock 'n’ Roll', New York Times, 12 January 1958. ProQuest < https://wwwproquests-com.vortex3.uco.edu> (pp. SM16-17, 19).

${ }^{588}$ Marwick, The Sixties, pp. 48-49.; Gene Busnar, It's Rock’n 'Roll (New York: Julian Messner, 1979), pp. 45-132.; Curtis, Rock Eras Interpretations, pp. 51-62.

589 Busnar, p. 30.

${ }^{590}$ Powers, Richard. Teen Dances of the 1950s,

<http://socialdance.stanford.edu/syllabi/teen_dances.htm> [accessed 11 February 2021] (para 1 of 13).
} 
and music culture coupled with a large youth presence was a similar climate to that of the 1920s. As The flapper dress was the quintessential outfit for the flapper's lifestyle, a similar pattern appears, when in 1958 Seventeen magazine published more youthful looks and frequently displayed the shift dress for the teenager. ${ }^{591}$

\section{The Movies}

The movies were also targeted at teenagers as television was primarily marketed to the family. ${ }^{592}$ According to Breines, three-fourths of American movie audiences were teenagers. ${ }^{593}$ In order for the movie industry to avoid direct competition with the television market, the movies catered to niche audiences and presented topics that television could not air. ${ }^{594}$ Television was tightly controlled by its advertisers, therefore, in order not to offend the advertising companies, television was more restricted in its subject matter. ${ }^{595}$ Many of the films during the 1950 s which were marketed to teenagers were about adolescent rebellion. One of the most significant of these was Rebel Without a Cause (1955) starring James Dean. ${ }^{596}$ This film portrayed teenagers not only as tough guys and rebels but it also put an emphasis on casual dress, and this film popularized denim jeans and black leather jackets. ${ }^{597}$ As the shift dress was associated with the flapper, so denim jeans and black leather jackets were associated with delinquent teenagers. The symbolic meaning and association that Americans had to denim and black leather jackets was a visual context related to rebellion.

Although the rebel films predominantly portrayed high school boys, some films featured high school girls acting rebelliously. An example of attaching black leather jackets and jeans to rebelliousness was portrayed in the film Violent Years. ${ }^{598}$ A rebellious girl group featured in the film wore pants and black leather jackets while

\footnotetext{
591 'Pick A Card...Any Card', Seventeen, February 1958. ProQuest $<$ http://vortex3.uco.edu/login?url=https://www-proquest-com.vortex3.uco.edu> (pp. 74-75).

${ }^{592}$ Weibel, p. 49.

593 Breines, p. 92

594 Weibel, p. 49.

595 Patterson, Grand Expectations, p. 349.; see also, Godfrey Hodgson, America In Our Time (Garden City, NY: Doubleday \& Company, Inc., 1976), p. 148.

596 Patterson, Grand Expectations, p. 347.

${ }^{597}$ Rebel Without a Cause, dir. by Nicholas Ray (Warner Bros., 1955), online film recording, Youtube, 08 July 2014, < https://www.youtube.com/watch?v=9tHbN3fykr0> [accessed 11 February 2021].

${ }^{598}$ Violent Years, dir by William Morgan (Headliner Productions, 1956), online film recording, YouTube, 31 December 2018, < https://www.youtube.com/watch?v=04NVmHd2EVE $>$ [accessed 1 November 2020].
} 
participating in criminal acts. However, these girls followed the cultural social norms of dress by also wearing sweaters with belted skirts and high heels. The rebellious girls only adopted the leather jacket and denim jeans temporarily, but continued to adhere to the social standards and femininity of dress.

High School Hellcats (1958) was a film about a rebel girl gang who defied all rules and created trouble in and out of school. ${ }^{599}$ The dresses worn by these rebellious girls were similar to those of their mothers with lines of the New Look. One distinct item that was claimed to belong to teenage girls in this movie were tight sweaters. The sweaters are a reoccurring theme, as the teenage girls from the concert were noted as wearing them as part of their 'uniform'. When the teenage girls were not at school or dressed up for a party, they wore pedal pushers or slacks. Changing clothes for specific occasions was suggested in women's magazines and for housewives. This was also expected by the teenager, as she too had to dress-up for certain occasions but then was allowed during her leisure time to wear pants. During this time, wearing pants at school was taboo, even for the teenager. In the film High School Hellcats, the new girl in town, Joyce, was told by the class bully that it was appropriate to wear slacks to school. Once Joyce entered school the next day as the only girl wearing pants, she realized that she was tricked and was so upset that she ran out of school. Thus, further demonstrating that even rebellious characters abided by the social culture of dress.

\section{The Antecedents of the Shift Dress}

The fashion implemented by Christian Dior was unstoppable, as his New Look was the dominant fashion from its release until the end of the 1950s. Nevertheless, some designers during the 1950s released dresses reminiscent of the 1920s flapper dress with loose, dropped waist styles. Norman Norell, an American designer, created a shift dress with a loose, elongated torso with a soft, gathered skirt. This silhouette was shown in Vogue magazine in the 1 September 1950 issue.

\footnotetext{
599 High School Hell Cats, dir by Edward L. Bernds (American International Pictures, 1958), online film recording, YouTube, 12 March 2016, < https://www.youtube.com/watch?v=c_q44_2jgZE> [accessed 30 October 2020].; see also, Sydney Redigan-Barman, Portrayls of Female Teen Rebellion in Hollywood Films of the 1950s, < https://sydneyredigan.com/media-studies/media-studiessamples/portrayals-of-female-teen-rebellion-in-hollywood-films-of-the-1950s $>$ [accessed 1 November 2020].
} 
Norell's dress in Vogue, Figure [94], displayed two different versions of his dress. ${ }^{600}$ The left figure is shown without a belt while the right figure is shown belted. This image demonstrated that the waist was still important, but also too, that the loose style was significant.

One year after Norell's release of his shift dress, Cristobal Balenciaga created two very similar dresses. Balenciaga's dresses were highlighted in the article, 'New Paris Collections' for the fall season, which can be seen in Figures [95-96]. ${ }^{601}$ Balenciaga's dresses caught the eye of The New Yorker which responded fiercely to his unfitted dresses. The New Yorker stated, 'a photograph [Balenciaga’s dress on page 171] clearly foreshadows dark and evil days to come - unless we can stop and take a stand.' The article compared the 1920s in terms of the waistlines reaching their lowest point while at the same time women during the 1920s were at their lowest point in her desire to please. The article further stated that women in the 1920s did not display femininity and proper behaviour. Furthermore, the article claimed that men are pushed pretty hard in today's world and they would not know how to cope with women in baggy, malformed attire. ${ }^{602}$ This article articulated many points, but primarily it underpinned women in a subordinate role to men and their loose clothing would reflect loose behaviour.

In 1957, the fashion industry acknowledged Balenciaga and Givenchy for transforming the silhouette to a loose bodice, however, Norell designed this style before them but did not attract attention. ${ }^{603}$ The New Yorker did not write about Norell's dress and therefore it appeared that Norell's dress went unnoticed. Although Norell's dress was photographed in Vogue, it was published in a two-page fashion article, whereas, Balenciaga's dress was noted in a larger article highlighting the release of the new Paris collections. The editors and writers of The New Yorker may

\footnotetext{
600 'Fashion: Half-Trumpet Skirt / The Chemise Dress', Vogue, 01 September 1950. ProQuest $<$ https://www-proquest-com.vortex3.uco.edu > (p. 145). This dress was referred to as a chemise dress in the article. However, the style shown in this article looks the same as my definition of the shift dress as it is approximately knee-length. Since Norell's dress aligns with my definition, I am referring it as a shift dress to eliminate confusion.

601 'Fashion: The New Paris Collections', Vogue. 01 September 1951. ProQuest < https://wwwproquest-com.vortex3.uco.edu> (pp. 171, 179).

602 'Notes and Comment', New Yorker, 22 September 1951, p. 23. Article reprinted in 'Fashion: The Position of the Waistline in America', Vogue, 01 February 1952. ProQuest <https://www-proquestcom.vortex3.uco.edu> (p. 163).

${ }^{603}$ Bernadine Morris, 'Chemise Returns at Saint Laurent', New York Times, late edn, 28 July 1983. ProQuest < https://search-proquest-com.vortex3.uco.edu $>$ (para 1 and 16 of 18). I discuss this further in later pages under the subtitle of 'The Sack Dress'.
} 
have not noticed Norell's chemise dress especially if they were not frequent readers of Vogue magazine. When analysing fashion, on most occasions, fashion change is created by a variety of designers and dictated by societal norms and acceptable cultural behaviour. The shift dress did not gain wide-spread acceptance at this time. Based on The New Yorker's article, this style did not fit inside the cultural norm of appropriate attire for women.

However, while the shift dress did not gain widespread attention in the early 1950s, later in the decade, the sheath dress became a significant fashion style. According to the database of Vogue magazine entries, the sheath dress was shown frequently from 1955 to 1957 . The sheath is different from the shift, as it contours closely to the body, thus revealing the woman's curves. Since the sheath revealed the woman's figure, it did align with the cultural norms at the time of displaying femininity.

\section{Anne Klein}

Designer Anne Klein, along with her husband, founded the Junior Sophisticates company in 1948. Although she designed a variety of styles, her unfitted silhouette makes her a pioneer. According to Klein, her company focused on freshness, a touch of sophistication and special sizing at modest prices. Junior Sophisticates specialized in the smaller, petite woman of all ages. ${ }^{604}$ By 1954, Women's Wear Daily referred to Klein's summer collection as a 'little-girl look' and a reinterpretation of a 'slick boyish feeling' for her fall collection. ${ }^{605}$ In 1955, the New York Times noted that Klein was credited for popularizing the unbelted chemise in the junior market. ${ }^{606}$ Klein explained to Women's Wear Daily, the first time she showed a drastic deviation of fashion to buyers initially they were shocked. However, after the buyers had seen the silhouette several times, they become

\footnotetext{
604 'Dresses: Says Misses' Dress Market Can Learn from Juniors: Designer Believes Juniors Give Taste, Freshness, Sophistication, Sizing to Satisfy Customer Demand', Women's Wear Daily, 27 April 1954. ProQuest $<$ https://www-proquest-com.vortex3.uco.edu $>$ (p. 51).

605 'Dresses: Says Misses' Dress Market can Learn from Juniors: Designer Believes Juniors Give Taste, Freshness, Sophistication, Sizing to Satisfy Customer Demand', Women's Wear Daily, 27 April 1954. ProQuest <https://www-proquest-com.vortex3.uco.edu $>$ (p. 51).

${ }^{606}$ Agnes MCCarty, 'Winners: Young Designers, Youthful Fashions: Quartet of Local Designers Honored With Coty Awards', New York Times, 03 October 1955. ProQuest $<$ https://www-proquestcom.vortex3.uco.edu> (p. 24). During the 1950s the term shift dress was not widely used. In 1958, Vogue had called a dress, 'The Leg-Showing Chemise', where the hemline was right below the knee. 'Fashion: A New Look in American Fashion Based on Legs', Vogue, 1 February 1958. ProQuest $<$ https://www-proquest-com.vortex3.uco.edu $>$ (pp. 106-107).
} 
acclimated to the style and purchased the item. Anne Klein recalled that 75 percent of her collection for Fall 1957 was unfitted. Women's Wear Daily called Klein’s firm a 'pioneer' in the development of the unfitted silhouette. ${ }^{607}$

Prior to 1958, Vogue showed several of Junior Sophisticates unfitted silhouettes, however, they were all worn with an aid of a belt. ${ }^{608}$ Vogue mostly showed Junior Sophisticates fitted silhouettes, however, in 1958 a significant tone changed as more unfitted silhouettes were published. On 1 April 1958, Vogue published an unbelted shift dress from Junior Sophisticates on the cover of the magazine, however, the cover shot only captured the collar of the dress. The dress in its entirety was shown inside the magazine. The dress photographed on the cover was reminiscent of the flapper as the dress had a dropped waist and a vertical, pleated skirt. ${ }^{609}$ One month later in Vogue's May $1^{\text {st }}$ issue, the article, 'Revolution in Looks' displayed a large spread of dresses that were reminiscent of the flapper dress from various designers. The article claimed, 'There's a new daring in fashion, changing everything from the look of the clothes to the looks of make-up, hair, even underpinnings...a new dress shape, a new skirt length...."610 In Figure [97] are examples of dresses that were shown in the article. Clearly, the shift dress increased its presence in 1958 and the media associated the revolution of the flapper to the new revolution of the shift dress.

Additionally, during this same year, Junior Sophisticates advertised the shift dress frequently in Vogue. ${ }^{611}$ The frequency of Junior Sophisticate’s shift dresses in Vogue magazine suggests that the style was emerging and that Anne Klein was readily designing a loose, straight silhouette. As noted above, Anne Klein was cited as creating the shift look as early as 1954 and by 1957 Women’s Wear Daily reported

\footnotetext{
${ }^{607}$ Bernadine Taub, 'Designer Builds A Junior Business Success on the Chemise Dress: Subjective Approach', Women's Wear Daily, 22 August 1957. ProQuest <https://www-proquestcom.vortex3.uco.edu> (p. 5).

608 'Fashion: For Vogue's Young Nillionaire-The Trans-Season Dress: In Cotton and Silk', Vogue, 01 July 1953. ProQuest <https://www-proquest-com.vortex3.uco.edu> (p. 99).; 'Fashion: More Taste than Money: The Next 32 Fashions’, Vogue, 15 September 1954. ProQuest <https://www-proquestcom.vortex3.uco.edu> (p. 138).; 'Cover: Vogue', Vogue, 01 August 1956. ProQuest <https://wwwproquest-com.vortex3.uco.edu>.; 'Fashion: New Take, the T-Shirt Dress', Vogue, 01 August 1953. ProQuest $<$ https://www-proquest-com.vortex3.uco.edu $>$ (pp. 122-123).

609 'Fashion: Cover Dress: The Buster Brown Chemise', Vogue, 01April 1958. ProQuest <https://wwwproquest-com.vortex3.uco.edu> (p. 147).

610 'Fashion: Revolution in Looks', Vogue, 01 May 1958. ProQuest < https://www-proquestcom.vortex3.uco.edu> (pp. 123, 126).

611 'Advertisement', Vogue, 01 May 1958. ProQuest <https://www-proquest-com.vortex3.uco.edu $>$ (p. 58).; 'Advertisement: Orion (Du Pont Company, Inc.)', Vogue, 01 February 1958. ProQuest $<$ https://www-proquest-com.vortex3.uco.edu $>$ (p. 59).
} 
that $75 \%$ of Junior Sophisticates collection was comprised of unfitted silhouettes. Most of Junior Sophisticates unfitted silhouettes were not shown in Vogue until 1958. Therefore, it is possible that prior to 1958, Vogue did not want to show unfitted silhouettes while the sheath was still present and the prominent fashion direction of accentuating women's curves. Both Seventeen and Vogue showed the shift dress frequently in their 1958 issues, but by 1959, the sheath was again the prevailing fashion in both of these magazines.

\section{The Sack Dress}

In 1957, Givenchy and Balenciaga simultaneously released a new silhouette. Women's Wear Daily noted that a completely new fashion had emerged since the New Look. Both designs by Givenchy and Balenciaga were similar as they concealed the waist and raised the hemlines to the knees. Several names were attached to this new style, such as, the sack, shift and chemise dress. Givenchy's design was described as 'balloon-like, with loose, rounded lines that curve away from the figure' and Balenciaga's design was noted as a silhouette which emphasized 'bulk at the shoulder and tapers down to a narrow, knee-high hem'. ${ }^{612}$ The sack dress was similar in structure to the shift dress as it was loose and the fabric floated away from the body. Women's Wear Daily made this same comparison of the 1920s shift dress and Givenchy's new sack dress. ${ }^{613}$

Figure [98] exhibits Givenchy’s new designs from Vogue magazine. The third figure from the left illustrates the balloon-like structure sack dress with a banded, knee-length hemline. The figure to the right is a narrow, straight under-slip dress that is a narrower version of the shift dress. ${ }^{614}$ In the same issue that Givenchy was highlighted for his sack dress, Vogue also reviewed Balenciaga’s collection. Figure [99] displays Balenciaga’s silhouettes which he showed with his new fall collection.

\footnotetext{
${ }^{612}$ Evelyn Livingstone, 'Paris Silhouette--Just a Hint of Figure--Put on Parade Here', Chicago Daily Tribune, 10 September 1957. ProQuest <https://www-proquest-com.vortex3.uco.edu> (p. B1).; 'Grandpa's Nightshirt Makes Good', The Washington Post and Times Herald, 28 August 1957. ProQuest $<$ https://www-proquest-com.vortex3.uco.edu $>$ (p. 1).

613 'They Were Wearing' in the '20’s', Women's Wear Daily, 05 August 1957. ProQuest $<$ https://www-proquest-com.vortex3.uco.edu > (p. 5). This article uses the term 'short chemise', but it was the shift dress. The image has an addition of a cape over the dress. See also, John B. Fairchild, 'U. S. Style Leaders in Paris Back Shorter Skirt Decree: Top Fashion Minds Forecast Lengths just Below Knee are due for Spring Selling', Women's Wear Daily, 01 August 1957. ProQuest $<\underline{\text { https://www- }}$ proquest-com.vortex3.uco.edu> (p. 1, 32).

614 'Fashion: Givenchy', Vogue, 15 October 1957. ProQuest < https://www-proquestcom.vortex3.uco.edu> (pp. 66 - 67).
} 
Examining these spreads in Vogue, Givenchy's sack dress was noted whereas Balenciaga's sketches focused on his coat and evening dress, leaving his sack dress unpublished from Vogue magazine. While Balenciaga and Givenchy both received wide-spread attention from the newspapers for their sack dresses, Vogue did not release Givenchy's sketches of his sack dress until October, a month after they highlighted the fall season of the new Paris collections. Vogue released these sketches after the sack dress became a debated topic. Therefore, originally, they chose not to expose these fashions to their readers.

The sack dress was highly controversial and had varied opinions. Upon its reveal, John B. Fairchild claimed fashion leaders hailed Balenciaga’s and Givenchy’s sack dresses. ${ }^{615}$ The New York Times had mixed views calling it 'extremely unfeminine, too often grotesque’, but also 'inventive, daring and masterfully executed.' ${ }^{616}$ Chicago Tribune noted these new fashions had a 'double shock value' with the extremity of not showing the waistline along with the shorter hemline to the knees. ${ }^{617}$ June Weis published the pros and cons of the sack dress and claimed many U.S. fashion designers and manufacturers are 'carefully examining the unfitted silhouette and shorter skirts' as some have a 'wait and see' attitude while others purchased a limited quantity for the junior market as a test group. This article also claimed that the unfitted silhouette has been previously sold by the $7^{\text {th }}$ avenue designers, but not with as short a hemline as Balenciaga and Givenchy had shown. ${ }^{618}$ Almost a year from the sack dress's release, the Wall Street Journal reported that men disliked the style and had violent and negative opinions against the dress. Many department store managers claimed high returns as the husbands demanded their wives to return the dress. ${ }^{619}$

\footnotetext{
615 John B. Fairchild, 'U. S. Style Leaders in Paris Back Shorter Skirt Decree: Top Fashion Minds Forecast Lengths Just Below Knee are due for Spring Selling’, Women's Wear Daily, 01 August 1957. ProQuest <https://www-proquest-com.vortex3.uco.edu> (p. 1, 32).

${ }^{616}$ Special to the New York Times, 'Fall Fashion Trends from Abroad: Paris: Givenchy Changes Body’s Proportions’, New York Times, 27 August 1957. ProQuest $<\underline{\text { https://www-proquest- }}$ com.vortex3.uco.edu> (p. 46).

617 'De Givenchy Goes "Surrealist”, Chicago Daily Tribune, 27 August 1957. ProQuest < https://wwwproquest-com.vortex3.uco.edu> (p. A2).

${ }^{618}$ Weis, June, 'Pro and Con Views Expressed, But: Chemise Dress Headed for Spring', Women's Wear Daily, 05 August 1957. ProQuest <https://www-proquest-com.vortex3.uco.edu> (p. 5). 619 'Sack's Success: The Men Still Grumble but New Dress Style Passes Big Sales Test Dressmakers, Stores Jubilant; Chemise Also Bows in Bathing Suits, Sweaters Mr. Pepys and a 1669 "Sac” Sack's Success: Men Still Grumble But Dress Retailers Are Jubilant’, Wall Street Journal, 29 April 1958. ProQuest $<$ https://www-proquest-com.vortex3.uco.edu > (p. 1).
} 
Even before the release of Givenchy and Balenciaga's sack dresses, others outwardly made jokes about the sack dress. In 1956, two-piece ensembles that were similar to the sack dress appeared on I Love Lucy. The episode, 'Lucy Gets a Paris Gown', exposed a parody of the sack dress with the famous fashion designer, Jacques Marcel. Upon seeing the models wearing the dress, Ricky suggested the fashions were made for Halloween and Frank accused the model of borrowing his bath robe. ${ }^{620}$ These fashions were ridiculous and laughable to the men. In 1958, another parody of the sack dress was made by the manufacturer, Damars, which created a shift dress from an actual potato sack with the message printed on the dress: 'Be beautiful in a potato sack: Looks like a sack, Feels like a sack, Is a Sack. Fill with a 100lb or more of charm, and save money on newest French inspired fashion' ${ }^{621}$ A picture of the 'potato sack' dress is shown in Figure [100]. This particular dress was a one size fits all and came as a cut-out pattern.

Given these associations, what inspired Givenchy and Balenciaga to design the sack dress? This has proved difficult to answer. The sack dress released in 1957 was not the first unfitted silhouette released by haute couture designers. As discussed, Norell came out with a loose, bodice chemise in 1950, although he did keep in line with the feminine standard of attaching a gathered skirt to the silhouette. Balenciaga followed what Norell had done the next year. Balenciaga's silhouettes appeared in Vogue magazine, but prior to 1957, like Anne Klein, many unstructured dresses were not published in Vogue but designers had created them for their collections. Research collections held by The Metropolitan Museum of Art and Victoria and Albert Museum provide additional styles from Balenciaga that were not published in Vogue. These examples are shown in Figures [101-104]. Balenciaga's dress, shown in Figure [101] was part of his 1955-1956 collection. This dress is similar to Givenchy’s 1957 sack dress in that they both were full-bodied in the torso and with a short hemline. Balenciaga also created a shift dress, Figure [102], at the same time of his sack dress debut in 1957. It is interesting that Balenciaga’s tapered chemise dress, Figure [101], was not publicized but his sack dress was commented on in numerous papers and later

\footnotetext{
620 'Lucy Gets a Paris Gown', I Love Lucy, CBS, 19 March 1956, online video recording, CBS.com, $<$ https://www.cbs.com/shows/i_love_lucy/> [accessed 28 October 2020].

621 'Advertisement', Vogue, 01 October 1958. ProQuest <https://www-proquest-com.vortex3.uco.edu $>$ (p. 103).
} 
released by Vogue. This publicity most likely was because two designers released similar dresses at the same time, which were also deemed as radical styles.

Givenchy’s and Balenciaga’s sack dress generated mixed responses and was highly publicized, but designers, like Anne Klein, from the moderate market should be given more credit for designing and aiding in the popularity of the unfitted silhouette. In 1957, Marylou Luther noted the sack, shift, and chemise were first introduced from moderate priced designers rather than from Paris fashion houses, noting that this style 'trickle-up' to the designers and was an exception to the traditional path of fashion styles. ${ }^{622}$

Although the cultural norm of formality was still present in 1957 with the sheath's continued presence and suggestions to belt the chemise, a change was apparent from my page by page tracking method as it revealed the emergence of the unfitted silhouette in lengths similar to those of the 1920s, measuring right below the knee or upper calf. ${ }^{623}$ In 1957, Vogue's September $1^{\text {st }}$ issue highlighted Dior's unbelted dress and called it 'Dior Extremes' with 'figure masking' reminiscent of the 1920s flapper dress. ${ }^{624}$ Although it is difficult to gauge from the drawing exactly where this dress measures, either on the upper or lower calf area, it is an indication that the unfitted silhouette was significant. With the combination of Dior's unfitted silhouette, Balenciaga's and Givenchy's sack dresses of shorter hemlines and free flowing dresses, and the presence of the shift dress in Vogue and Seventeen magazines, this indicated a pivotal change for fashion was approaching, even though Vogue hesitated to publish the unfitted silhouette.

\section{Conclusion}

Society's opinion of women's participation in the public sphere changed based on the social climate in America. When at war, women were expected and needed to

\footnotetext{
${ }^{622}$ Marylou Luther, 'New York Varies Paris Theme: Sack Most Popular at Medium Prices', Chicago

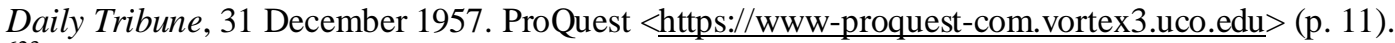
${ }^{623}$ Articles suggesting the belt is important to sell the chemise: Essie Pinsker, 'Resident Buyers Report:: Active \& Casual Outerwear, Blouses, Skirts, Knitwear, Swimwear Sportswear and Separates: Enthusiasm for Chemise Dress Mounts as Season Gets Under Way: Semi-Fit Styles Best: Knits, Silk, Linen Active', Women's Wear Daily, 05 February 1958. ProQuest $<$ https://www-proquestcom.vortex3.uco.edu> (p. 19).; 'Rose Pink, Rose Red: Sea Shirts', Harper's Bazaar, May 1957. ProQuest $<$ https://www-proquest-com.vortex3.uco.edu $>$ (pp. 158-159).

624 'Fashion: Paris Quick Report', Vogue, ProQuest $<$ https://search-proquest-com.vortex3.uco.edu $>$ (para 2 of 2).
} 
participate in the public sphere; however, at times of peace, women were expected to stay home and raise children. Unlike the 1920s, the perception of how women looked remained constant from the 1930s through the 1950s with the feminine standard dominant. During the 1950s, the New Look by Christian Dior strengthened the feminine standard more deeply than previous decades. Not only did the New Look give women the status of abundance and beauty but it also aligned within the culture of formality and conspicuous consumption. The constriction of the New Look guided women to adhere to proper ladylike standards as it was natural to move slowly and gracefully in an upright position while tightly corseted.

As indicated by Seventeen magazine, the fashions for teenagers followed similar styles to that of women's wear while the teenage market was in its infancy. The choices given to teenagers were primarily driven by professionals in the fashion industry rather than from outside influencers of young women, unlike that of the 1920s with the flapper's influence and flapper movies that attracted younger audiences. At the same time that the teenager's fashions were following closely to women's wear, the shift dress was absent from Seventeen magazines. Since the shift dress was not consistently shown in Seventeen magazine this validates that the shift dress was not a popular style among the youth market. Therefore, the styles stemmed from women's wear was more prevalent. Additionally, the culture of the 1950s was a time of conspicuous display, femininity, and strict womanly mannerisms which the New Look clearly aligned in a way the shift dress did not.

The initial disturbance of the 1950s culture was outwardly expressed by musicians, authors, housewives, and designers. The women that shared their discontentment with the media and the artists that expressed change in their art form together spurred a sense of movement that mirrored the 1920s. Similar patterns of movement from the 1920s began to emerge in the latter part of the 1950s, such as the change in up-tempo music, quicken dance movements, and fashion direction toward a looser style. When kinetic movement was prevalent in the 1920s, this was the time when the shift dress gained wide-spread popularity.

As noted, the shift dress was present during the 1930s through the 1950s, however, it did not gain wide-spread attention. When concepts of movement began to change in the latter part of the 1950s, interest in looser styles of dress began to emerge. Thus, the ethos of movement was connected to the shift dress. This connection of the shift dress with freedom of movement has been part of its historical 
past and underpins its identity. Based on its historical roots, the shift dress was popularized at times when the culture embraced movement and a looser set of morals and beliefs were in place. As exemplified from The New Yorker, during the 1950s, the shift dress continued to symbolize sexuality and not a dress for proper women. However, the parodying of the sack dress revealed that society was making lighthearted associations with the straight structured dress, and as a result, this helped set the tone for the next decade as the 1960s embraced clothing in a more carefree manner. Not only was movement important for the shift dress to resurface and experience wide-spread adoption, but also the 1960s social culture was complex with various experimentation and morals to embrace this change. 


\section{Chapter 5: The Painted Canvas: The 1960s}

The 1950s remained tied to traditional social customs, however, after 1957, American culture began to shift as rock ' $n$ roll changed the rhythm of music, the beat writers changed the tone of literature, and designers changed the direction of fashion. When movement began to change in the latter part of the 1950s, interest in looser styles began to emerge not only with the release of Balenciaga and Givenchy's sack dress, but also in 1958 when more appearances of these styles were present in Vogue and Seventeen magazines.

This chapter identifies the climate in which the shift dress becomes the predominant style, the men and women who were bold enough to re-structure the fashion system utilizing the shift dress, and the youth who reclaimed the shift dress not only as 'THE fashion style' but also to modernize dress. This chapter is divided into five sections. In the first section I review the existing literature specifically focusing on the 1960s as this was a tumultuous and challenging time for the United States. I then discuss the results from my tracking method with the number of appearances of the shift dress in Vogue and Seventeen magazines with visualizations. The third section considers how modern ideas underpinned cultural change. The fourth section interrogates the power of the shift dress as a marker of change and the way this power was communicated to contemporary society. The last section discusses women's place within society and explores the shift dress in relation to its expressionism and versatility which gave women more confidence and empowerment to enter into the second wave of feminism.

As discussed, the shift dress had been profoundly associated with the concept of movement. The discussion of the 1920s revealed motion played an integral part to both the advancement of women and the shift dress. I have demonstrated in the previous chapter that the 1950s has been identified as a static environment for women and the 1960s was a decade synonymous with change. Consequently, the element of movement is a distinctive feature as it is an identifiable contradiction shift between the 1950 s and the 1960 s.

While analysing the shift dress in the 1950s, it was apparent in the latter half of the decade movement became significant within American society. As previously discussed, I have pinpointed 1957 as the beginning of the 1960s as in this year there emerged new attitudes in dress and American culture. I used August 26, 1970 as the 
ending point of the 1960s, as this day marked a significant event in women's history and a new era for women as it re-ignited women's liberation. Kate Millet, author of Sexual Politics, stood among a crowd of 10,000 men and women and declared, 'At last we have a movement'. ${ }^{625}$ This day, was a renewed beginning for women, and a new start to the next decade.

\section{Existing Literature of the 1960s}

Scholars have analysed the 1960s through a range of political and cultural lenses. ${ }^{626}$ Scholarship on the sixties has a central focus on politics, and rightly so, as domestic and foreign affairs were chaotic and momentous changes within legislation and foreign events were established. ${ }^{627}$ Historians focusing on cultural developments in the sixties explored areas such as, youth, political organizations, demographics, racial and discrimination issues, the effects of war and political movements, gay rights and the women's rights movement. ${ }^{628}$ The scholarship about women during the sixties has primarily focused on feminism and legislative policies. ${ }^{629}$ The breadth of women's liberation and feminism studies in the 1960s have been largely dedicated to the women's rights movement, whereas, few scholars have explored the role of fashion during the 1960s as it relates to the advancement of women and change in

\footnotetext{
625 'It was a Great Day for Women on the March', New York Times, 30 August 1970. ProQuest $<$ https://www-proquest-com.vortex3.uco.edu > (p. 125).

${ }^{626}$ Patterson, Grand Expectations.; Frederick F. Siegel, Troubled Journey: From Pearl Harbor to Ronald Regan (New York: Hill and Wang, 1984).; Chafe, The Unfinished Journey.; Andrew Hunt, “'When Did the Sixties Happen?' Searching for New Directions”, Journal of Social History, 33. 1 (1999), 147-161 <. http://vortex3.uco.edu:2050/login?url=https:/www.jstor.org/stable/3789465 $>$ [accessed 20 January 2021].; Fowler.

${ }^{627}$ Siegel.; Andrew Hunt, “'When Did the Sixties Happen?” Searching for New Directions’, Journal of Social History, 33. 1 (1999), 147-161 <. http://vortex3.uco.edu:2050/login?url=https://www.jstor.org/stable/3789465> [accessed 20 January 2021]. (Hunt's article primarily covers the issues about Students for Democratic Society (SDS). This article includes the policies of SDS, only one statement about Betty Friedan and Rachel Carson's book Silent Spring); John Patrick Diggins, The Proud Decades: America in War and in Peace, 1941-1960 (London: Norton, 1988);; John A. Andrew, III, The Other Side Of The Sixties: Young Americans for Freedom and the Rise of Conservative Politics (London: Rutgers University Press, 1997).

${ }^{628}$ Reshaping America: Society and Institutions 1945-1960, ed. by Bremmer, H. and Gary W. Reichard. (Columbus: Ohio State University Press, 1982).; Todd Gitlin, The Sixties: Years of Hope, Days of Rage (London: Banton Books, 1987).; O’Neill.

${ }^{629}$ Judith Hole and Ellen Levine, Rebirth of Feminism (New York: Quadrangle Books, Inc., 1971).; Breckinridge.; Susan Lynn, Progressive Women In Conservative Times: Racial Justice, Peace, and Feminism, 1945 to the 1960s (New Brunswick, NJ: Rutgers University, 1992).; Serena Mayeri, 'Constitutional Choices: Legal Feminism and the Historical Dynamics of Change', California Law Review, 92.3 (2004), 755-839 < https://doi-org.vortex3.uco.edu/10.2307/3481454>.; Zeitz, J., 'Rejecting the Center: Radical Grassroots Politics in the 1970s - Second-Wave Feminism as a Case Study', Journal of Contemporary History, 43.4 (2008), 673-688 $<$ http://vortex3.uco.edu:2050/login?url=https:/www.jstor.org/stable/40543229> [accessed 11 February 2021].
} 
their lives. Scholars who have reviewed the link between fashion and women during the 1960s have done so in primarily a relationship of clothing and gender presentation of women. ${ }^{630}$ Additionally, when scholars have reviewed fashion and culture it has been largely analysed from the perspective of a variety of fashions within the sixties rather than focusing on one particular garment. ${ }^{631}$ Others, such as Nancy J. Troy, examined fashion from a centralized focal point of art. Specifically in her article, 'Art', she explored the relationship of the shift dress and Piet Mondrian's artwork. ${ }^{632}$ I will examine the impact of the shift dress and its connection to the lifestyle and experiences of women during the 1960s. By looking at a singular silhouette, it allows me to concentrate on the culture of women, evolution of the shift dress, and the journey women experienced through wearing this particular garment.

\section{Results from the Tracking Method}

Using the same methodology I applied in chapter 2, I examined Vogue and Seventeen magazines with the page-by-page tracking method counting the appearances of the shift dress. For the duration of the 1960s, I chose to analyse the February $1^{\text {st }}$ and September $1^{\text {st }}$ issues in Vogue's biweekly publication and the same months for Seventeen's monthly publication. Vogue published its 'Americana Issue' on February $1^{\text {st }}$ which presented an expansive selection of American ready-to-wear clothing as well as a focus on the fashion taste of American women. The September $1^{\text {st }}$ issue reported on the Paris fashion designers with their release of the new fall collections. Therefore, I was able to analyse the perspective of design and styles from the American ready-to-wear market as well as from the Paris fashion houses.

The results from my tracking method, shown in Chart [2], indicated two separate small rises before 1965. After that time, the shift dress experienced a dramatic increase until the peak in 1967. The initial rise or small uptick of the shift dress occurred in 1958 which may have been the result of the wide-spread attention of the sack dress. The second small curve, although larger than the first, occurred in 1964. Both 1966 and 1968 had similar appearances of the shift dress with 31 and 33,

\footnotetext{
${ }^{630}$ Betty Luther Hillman, “"The Clothes I Wear Help Me to Know My Own Power”: The Politics of Gender Presentation in the Era of Women's Liberation’. Frontiers: A Journal of Women Studies, 34.2 (2013), 155-185 < https://doi-org.vortex3.uco.edu/10.5250/fronjwomestud.34.2.0155>.

${ }^{631}$ Melinkoff,; Mendes and De La Haye.; Steele, Fifty Years of Fashion.; Breward, Gilbert and Lister.; English.

632 Troy, 'Art'.
} 
respectively. The peak of the shift dress occurred in 1967 with the highest number of appearances. Therefore, the culmination phase is the sum of the appearances from 1966 to 1968 which marked the highest frequency of the shift dress within the decade. As I plotted the appearances, the results indicated a pattern of two distinct groups. The first two small upticks reveal either it was marketed to a sub-group of women or utilized as a specific use garment and the large peak indicated widespread adoption of the shift dress.

The year of 1964 indicated a significant change in the shift dress with appearances, marketing, and how the dress was worn. This particular year saw a significant increase of 13 appearances as compared to the years before which had only two to three appearances per year. The spring issue in 1964 was composed of 9 appearances with 4 shift dresses highlighted in the article 'Bargains in Chic USA' .”633 Almost half of the shift dresses were contained in this one article suggesting Vogue marketed the affordability of the shift dress, as well as, strategically marketed to a subgroup of thrifty American women. Similar to the 1920s, the shift dress was touted as an economy style. In addition to the increase in appearances and identifying a marketing niche, 1964 marked a pivotal point as it was shown more frequently as an unbelted garment.

The period of greatest change was between the years from 1965 to 1967, when the number of appearances steeply rose from a total of 6 to 60 appearances. This represents a tenfold increase of appearances within three years. Notably, in 1965, Yves St. Laurent's famous Mondrian shift dress was featured in a large multi-page fashion article from Paris, 'Paris the News as We See It'. ${ }^{634}$ This article is significant as it marks the beginning of when the design and production of the shift dress was released from fashion houses as well as the large marketing and presence of the unfitted silhouette that Vogue provided to its readers. This marketing presence of Yves St. Laurent's shifts occurred right before the culmination phase, which may have sparked the dramatic increase in the shift dress.

\footnotetext{
633 'Fashion: Bargains in chic U.S.A.', Vogue, 01 February 1964. ProQuest $<\underline{\text { https://www-proquest- }}$ com.vortex3.uco.edu> (pp. 189, 194-197).

634 'Fashion: Paris the News as we See it', Vogue, 01 September 1965. ProQuest $<\underline{\text { https://www- }}$ proquest-com.vortex3.uco.edu $>$ (pp. 256-257).
} 


\section{Chart 2: Number of Appearances of the Shift Dress in Vogue}

Magazine: $1960 \mathrm{~s}$

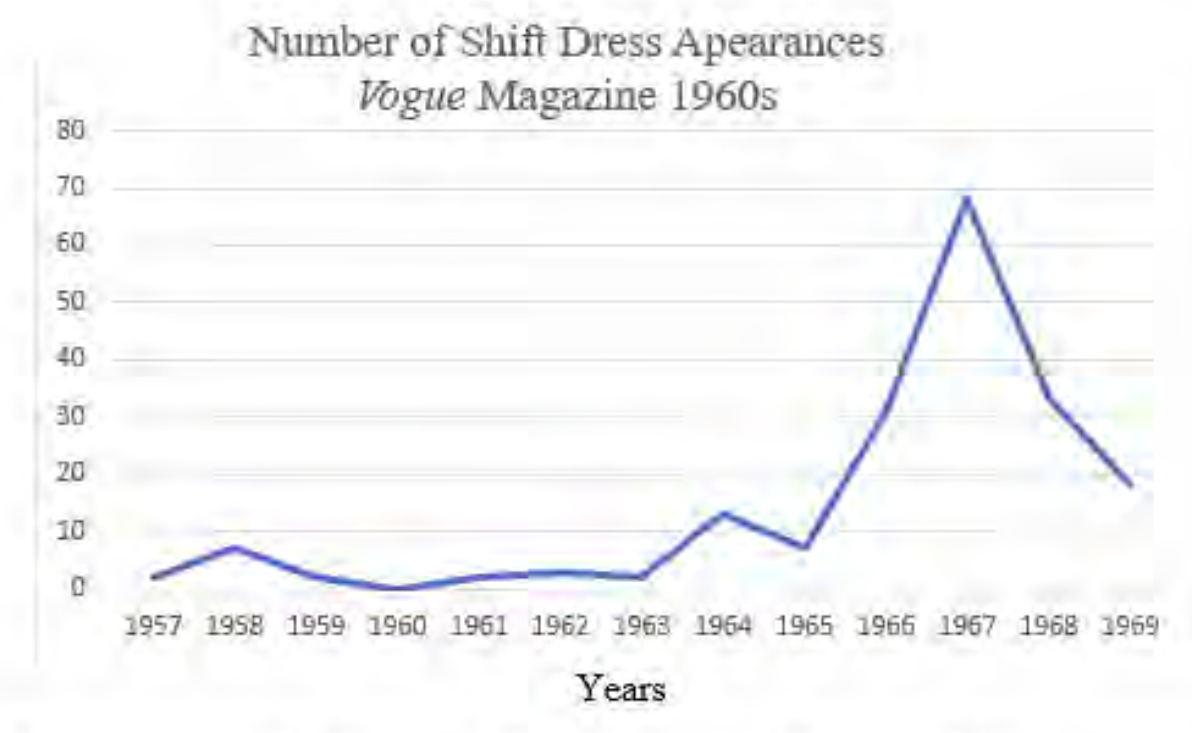

Every year includes February $1^{\text {st }}$ and September $1^{\text {st }}$ issues of Vogue magazine

In contrast, Seventeen magazine’s results were quite different from Vogue's. Instead of two small upticks and one large peak, the appearances in Seventeen had one small uptick, during the same time as Vogue, however, the appearances incurred a steady increase from 1961to 1964. In 1965, the shift dress appearances almost doubled from the previous year and dipped down slightly the following year. This uptick in the September 1965 issue may have been the result of Seventeen introducing the pinnacle designers who popularized the shift dress look in a 12-page spread, highlighting 13 shift dresses. Therefore, this issue may have skewed to more shift dresses than other issues. However, by 1967, the number of appearances peaked over 65 , the largest number represented for that decade. After 1967, there is a steady decline of the shift dress for the remainder of the decade. The results indicated that the shift dress appealed to the youth market as it consistently was shown over the span of the decade and earlier than Vogue magazine. Interestingly, both Vogue and Seventeen peaked the same year and with a similar number of appearances. This indicates, that the adoption of the shift dress was wide-spread and attracted women from different demographics, such as, age and income status. Therefore, the shift dress was a significant garment for the fashion industry and for women during the 
1960s. It is also important to analyse the swift American culture change which influenced the refashioning from the New Look to the shift dress.

\section{Chart 3: Number of Appearances of the Shift Dress in Seventeen \\ Magazine: $1960 \mathrm{~s}$}

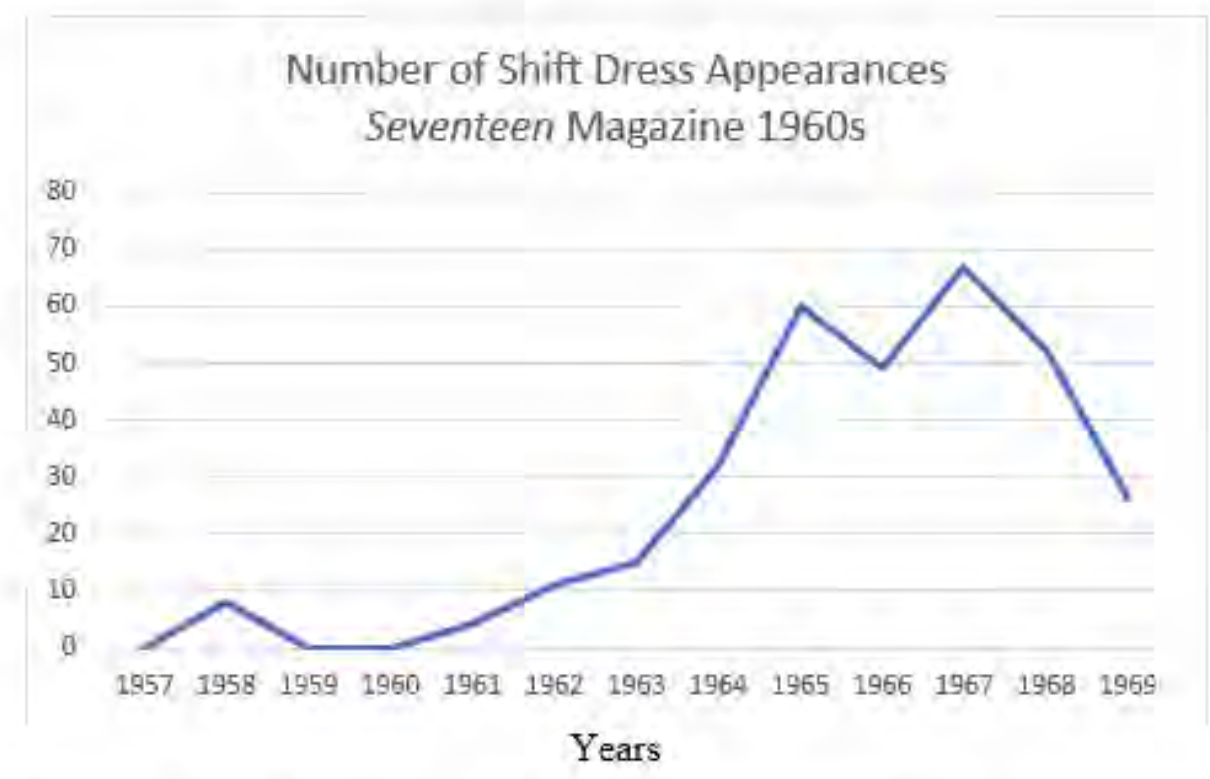

Every year includes February and September issues in Seventeen magazine

\section{The Landscape of the 1960s: Cultural Shifts}

\section{A Shift in Space}

The years 1956 and 1957 were marked as pivotal years in the realm of music, literature and fashion, but this period was also a crucial turning point of space exploration with the launce of Sputnik on October 4,1957. ${ }^{635}$ Sputnik, the first satellite to successfully orbit Earth and developed by the Soviet Union, created an atmosphere of competition and tension among Americans as a communist country spearheaded the entrance into space exploration. ${ }^{636}$ With the tension of the Cold War,

${ }^{635}$ William J. Jorden, ‘560 Miles High: Visible with Simple Binoculars, Moscow Statement Says Due Over Moscow Today Five Miles a Second Several Years of Study Soviet Launches Earth Satellite an Aid to Scientists Hinted of Launching', New York Times, 05 October 1957. ProQuest $<$ https://wwwproquest-com.vortex3.uco.edu> (pp. 1,3).

${ }^{636}$ Eisenhower, Dwight, D., 'Sputnik and “The Fears of Our Own People”, in The Papers of Dwight David Eisenhower: The Presidency: Keeping the Peace, ed. by Louis Galambos and others, 21 vols. (London: Johns Hopkins University Press, 2001), XVIII, pp. 471-600 (p. 598).; Jack Raymond, 'Bridges and Stennis Seek A Powerful Missiles Chief: Soviet Missiles Assessed Quantity Output Likely Bridges and Stennis Bid U.S. Appoint Powerful Missile Chief Killian Called Adviser’, New 
the success of space exploration was vital for the United States. This competition advanced into space exploration and the space race became another 'battleground' of the Cold War. ${ }^{637}$ A group of members from the committee of the International Policy of the National Planning Association expressed concern about of the strength in the Soviet Union's scientific discovery and feared they would become the dominant world power. ${ }^{638}$ President Eisenhower was plagued with increased expenditures, delays and failures of satellites from the American program while at the same time the Soviet Union consistently displayed success within their program. ${ }^{639}$ Richard L. Strout claimed 'The stake is nothing less than America's scientific and engineering superiority' and further notes, 'A feeling is growing in Washington that to maintain (or regain) this previously held scientific position will require sacrifices’ ${ }^{640}$ Compared to the advancements of the Soviet Union's space program, the American space program lagged behind significantly. Atomic scientist, Edward H. Teller, claimed the success of Sputnik I and II 'was a greater defeat for our country than Pearl Harbor’ ${ }^{641}$ On January 31, 1958 American’s were successful in launching a satellite into space.

Although the Soviet Union was the first country to put satellites into orbit, in 1961, President Kennedy formally proposed before a joint session of Congress to put

York Times, 24 November 1957. ProQuest <https://www-proquest-com.vortex3.uco.edu > (pp. 1,70); John W. Finney, 'U.S. Found To Lag In Race To Space: Pentagon Survey Cities Soviet Gain in Ballistics Missiles as Shown by Satellites Soviet Claims Appraised Accuracy is in Doubt U.S. Separates Programs', New York Times, 06 November 1957. < $\underline{\text { https://www-proquest- }}$ com.vortex3.uco.edu> (p. 13).

${ }^{637}$ Space Race: Race For A Space Man, (Films Media Group, 2005), online film recording, Films on Demand, < https://fod-infobase-com.vortex3.uco.edu/p_ViewVideo.aspx?xtid=199666\&tScript=0 > [accessed 11 February 2021].

${ }^{638}$ The Papers of Dwight David Eisenhower: Presidency: Keeping the Peace XVIII, ed. by Elizabeth S. Hughes and others, 21 vols. (London: The Johns Hopkins University Press, 2001), p. 494.

639 Jack Raymond, "Bridges and Stennis Seek A Powerful Missiles Chief: Soviet Missiles Assessed Quantity Output Likely Bridges and Stennis Bid U.S. Appoint Powerful Missile Chief Killian Called Adviser', New York Times, 24 November 1957. ProQuest $<$ https://www-proquest-

com.vortex3.uco.edu> (pp. 1,70).; Milton Bracker, Special to The New York Times, 'Vanguard Rocket Burns On Beach; Failure To Launch Test Satellite Assailed As Blow To U.S. Prestige: Sphere Survives But Carrier Rises Only 2 to 4 Feet Before Flames Wreck it Satellite Undamaged Data to be Studied Satellite Rocket Burns on Beach According to Plan', New York Times, 07 December 1957. ProQuest $<$ https://www-proquest-com.vortex3.uco.edu $>$ (p. 13).

${ }^{640}$ Richard L. Stout, 'Sputnik and Budget: An Intimate Message from Washington', The Christian Science Monitor, 07 November 1957. ProQuest <https://www-proquest-com.vortex3.uco.edu $>$ (p. 30).; see also Max Frankel, 'Izvestia Gloats at U.S. "Hysteria”: Boasts Satellites Prove Soviet SuperiorityCalls Americans Uncultured’, New York Times, 21 November 1957. ProQuest $<$ https://www-proquestcom.vortex3.uco.edu> (p. 11).

${ }^{641}$ The Papers of Dwight David Eisenhower: Presidency: Keeping the Peace XVIII, ed. by Elizabeth S. Hughes and others, 21 vols. (London: The Johns Hopkins University Press, 2001, p. 598. 
the first man on the moon. On May 25, 1961, John F. Kennedy asked permission from Congress,

But in a very real sense, it will not be one man going to the moon - if we make this judgement affirmatively, it will be an entire nation. For all of us must work to put him there. ${ }^{642}$

John F. Kennedy's aggressiveness in committing to put the first man on the moon demonstrated his desire for the U.S. to regain its leadership in scientific technology. ${ }^{643}$ Additionally, the goal of putting a man on the moon in a short time span bespoke of the swift advancement of technological discoveries needed to implement a drastic change. Therefore, the space race reflected the belief that change was encouraged and essential. Furthermore, Kennedy claimed 'it will not be one man going to the moon...it will be an entire nation', and he called upon all Americans to work together to reach the common goal of putting a man on the moon. Kennedy's speech claimed with the collective help among all citizens, the American space program would thrive and reach unprecedented goals. Kennedy's speech highlighted the awareness of the space program as this can be seen in the abundant news stories in the media focusing on its progress. ${ }^{644}$

As the space race encouraged change for an entire nation, space and military themes were reflected in clothing. For example, in 1962, Seventeen magazine presented, 'The Military Look Airs Space-Age Knits', which showcased women’s fashions in conjunction with the military. The article noted, 'Ready for launching, at the United States Air Force Academy, new knits, fluid and wearable, leather-bound for soaring fashion future.' The shift noted in this article was named 'space-age shift'.

\footnotetext{
${ }^{642}$ Theodore C. Sorensen, Let The Word Go Forth: The Speeches, Statements, and Writings of John F. Kennedy 1947-1963 (New York: Dell Publishing, 1988), p. 174.

${ }^{643}$ Garber, Steve, The Decision to Go to the Moon: President John F. Kennedy's May 25, 1961 Speech Before a Joint Session of Congress, (2013), <https://history.nasa.gov/moondec.html> [accessed 12 February 2021] (para 1 of 3).

644 'Eye From A Front Row Seat', Life, 26 October 1962, pp. 34-37.; Walter Schirra, 'A Real Breakthrough I thought the Capsule was all Mine.', Life, 26 October 1962, pp. 39-43.; Ronald Bailey, 'The U.S. Mission To Mars.', Life, 16 January 1965, pp. 41-42, 44.; 'The Earth Seen from Gemini 5', Life, 24 September 1965, pp. 30-39, 84C, 84D, 87.; Edwin Diamond, 'That Moon Trip: Debate Sharpens: The U.S. Plans to Send Three Men to the Moon within the Decade. Now the Question is being Asked: Is this Trip Necessary? That Moon Trip’, New York Times, 28 July 1963, ProQuest $<$ https://www-proquest-com.vortex3.uco.edu> (p. 150).; John Noble Wilford, Special to The New York Times, 'U.S. Prepares Moon Shot in December: Apollo 7 Splashes Down in Atlantic After 11Day Earth-Orbiting Test for Moon Shot Perfect Mission’ Buoys Nasa Aides U.S. Prepares for Flight in December That May Send Men Around the Moon', New York Times, 23 October 1968, ProQuest $<$ https://www-proquest-com.vortex3.uco.edu $>$ (p. 1).
} 
645 This article incorporated space terms, such as, 'launch' and “soaring” into the copy to make a correlation to the space program.

In 1964, André Courrèges, a Parisian Couture designer, created one of the most progressive fashion collections. ${ }^{646}$ Courrèges' design was progressive as he created space-age shift dresses which bared the kneecaps, shown in Figure [105]. His shift dresses represented space exploration with the use of all white dresses and futuristic accessories. Three white shift dresses were shown accompanied with stately bucket hats and moon boots. ${ }^{647}$ Courrèges' models and his shift dresses represented progress as they were associated with space which was connected to innovation and technological advances. Furthermore, the models exhibited strength and confidence with their stately presence of accessories and the dresses' sharp lines. The overall image embodied modernism, as to say, like space, fashion is moving forward. Courrèges presented these 'space-like' shifts in a modern dialect which symbolized the shift dress as a modern garment. Courrèges was noted as the 'space age designer' and for the 'space-age generation' ${ }^{648}$ Furthermore, the strong elements he portrayed in his style as well as the use of unrestricted dress associated Courrèges with liberating women. Journalist, Marylin Bender, applauded Courrèges for his progressive designs and noted him as a primary influencer who liberated young modern women away from the corset and high heels and into a relaxed, free form.”649

\section{A Shift in Art}

Similar to the space race, the art of the 1960s embodied themes of movement and change. The opening of the Guggenheim museum exemplified both physical and emotional movement. Designed by Frank Lloyd Wright, the Guggenheim museum espoused physical movement with the design of his building encompassing a

\footnotetext{
645 'The Military Look Airs Space-Age Knits’, Seventeen, February 1962. ProQuest <https://wwwproquest-com.vortex3.uco.edu> (p. 89).

646 Troy, 'Art', p. 35.

647 'Fashion: Paris: The Return of Coquetry', Vogue, 15 March 1964. ProQuest < $\underline{\text { htps://www- }}$ proquest-com.vortex3.uco.edu> (pp. 86-87).

${ }^{648}$ Paris Bureau: Cable Fairchild News Services, 'St. Laurent: Look Raffiné: Buyers Don’t Give a Fig for Yves' Eve', Women's Wear Daily, 04 August 1964. ProQuest < https://www-proquestcom.vortex3.uco.edu>(p. 40).; 'Eye', Women's Wear Daily, 03 September 1964. ProQuest $<$ https://www-proquest-com.vortex3.uco.edu> (p. 2).; Marylin Bender, 'Is this Courrèges Vision of Space-Age Women?’, New York Times, 28 May 1965. ProQuest < https://www-proquestcom.vortex3.uco.edu> (p. 28).

${ }^{649}$ Marylin Bender, 'Is this Courrèges's Vision of Space-Age Women?’, New York Times, 28 May 1965. ProQuest <https://www-proquest-com.vortex3.uco.edu> (p. 28).; 'Eye', Women's Wear Daily, 03 September 1964. ProQuest <https://www-proquest-com.vortex3.uco.edu> (p. 2).
} 
simplistic concrete structure of a spiralling ramp. While viewing art, the ramp gradually moves its subjects upward to a dramatic dome skylight. Together, each piece of artwork subsequently moves the viewer upward. Frank Lloyd Wright expressed the movement of the Guggenheim museum through his philosophy,

It says we are finished with nineteenth-century architecture. This is for our time. It is part of a crusade, not only by me but by humanity all over the world, saying that we are through with the past and aiming for the better things in life. ${ }^{650}$

The building was designed to dramatise the movement of modernity, as Wright discarded the past and created a structure of new aesthetic expression. Wright expressed discarding past influences and future innovation was important. As demonstrated by Kennedy's address to Congress, the 1960s embraced this philosophy as a time for new developments, ideas and change.

Although Ada Louise Huxtable, writer at the New York Times, reported controversy over the Guggenheim structure, the first Sunday the museum opened it had an unprecedented attendance of 10,000 people. ${ }^{651}$ The crowd was larger than the capacity of the museum. Vogue claimed the Guggenheim as "the biggest hit in town" and noted after its opening it continually drew large crowds of approximately 24,000 people a week. ${ }^{652}$ The large number of attendees at the Guggenheim demonstrated the interest in art among the general public. This interest in art continued to grow in the early sixties as many museums were heavily attended. In 1961, two years after the Guggenheim opened, McCandlish Phillips reported that not only the museums in New York City had seen a sharp increase in attendance but also cities across the United

\footnotetext{
${ }^{650}$ Herbert Mitgang, 'Sidewalk Views of That Museum: On Upper Fifth Avenue the Talk is of the New Wright-designed Guggenheim Museum. Is it a Marvel or a Monstrosity? Views of That Museum', New York Times, 12 October 1958. ProQuest <https://www-proquest-com.vortex3.uco.edu> (p. 73).

${ }^{651}$ Ada Louise Huxtable, 'That Museum: Wright or Wrong: Frank Lloyd Wright's Unconventional Structure Has Opened Amid Fiery Debate. Is it a Museum, or a Monument to Mr. Wright? That Museum', New York Times, 25 October 1959. ProQuest $<$ https://www-proquest-com.vortex3.uco.edu $>$ (p. SM16).; Lawrence O’Kane, ‘10,000 Flock to Wright Museum, But Only 6,039 Manage to Get In: Art Lovers and Tourists Queue Up on Upper 5th Ave. -- Some See Just the Cafeteria from the Outside’, New York Times, 26 October 1959. ProQuest $<$ https://www-proquest-com.vortex3.uco.edu> (p. 31).; Huxtable, Ada Louise, 'What should a Museum Be: It Should, Says a Critic, be a Fusion of Art and Architecture. But, in Many New Examples, They Threaten Not to Fuse. What Should A Museum Be?', New York Times, 08 May 1960. ProQuest <https://www-proquestcom.vortex3.uco.edu $>$ (p. 4).

652 'Features/Articles/People: The Biggest Hit in Town - the Guggenheim Museum', Vogue, 01 June 1960. ProQuest <https://www-proquest-com.vortex3.uco.edu> (pp. 108-109).
} 
States. Museum curators called it a 'renaissance' of popular appreciation of the arts. 653

Piet Mondrian, an abstract and modern artist, utilized the theory of movement and modernity within his discipline. Mondrian aspired to capture the movement, balance, and speed in the city. According to the film, In Mondrian's Studio, he studied the movement of people, the movement of transportation, and the process in which they moved together. He studied how people and transportation moved around stationary buildings. Mondrian's paintings utilized the discipline of geometry as he sought to capture the orchestrated movements of the city. He had many rules and guidelines for his paintings, such as, the use of only primary colours, the use of only straight and perpendicular lines, and the use of only rectangles and squares.

Additionally, Mondrian's interest in jazz and Boogie-Woogie music was applied to his paintings. For example, his painting titled, 'Broadway Boogie-Woogie', combined the rhythm of the music to the rhythms of the city. ${ }^{654}$

The popularity of modern art in America can be demonstrated by the work of Piet Mondrian. Upon his death in 1944, Nancy J. Troy claimed Mondrian’s work had become significantly known to the masses as his work was cited in a variety of sources and displayed at the Museum of Modern Art. She identified that Mondrian's work was published not only in art magazines, but also in a variety of women's magazines and newspapers. Troy further noted that although Mondrian's art was not always favoured, the reoccurring presence of his work laid a foundation for the awareness of modern art in America. ${ }^{655}$

In the early 1960s, an abundance of articles from a variety of sources recognized Piet Mondrian’s artwork. Vogue depicted Mondrian’s artwork in several different types of articles. For example, an interior decorating segment suggested to paint a door in 'Mondrian' style and a Vogue writer had indicated the similarities of

\footnotetext{
${ }^{653}$ McCandlish Phillips, 'Attendance Soars at Museums Here: Revitalized Outlook of Museum Curators Pays Off in Attendance-Records Years Since War Marked by Rise Metropolitan was in a Peak Period Even Before it Brought Rembrandt', New York Times, 27 November 1961. ProQuest $<$ https://www-proquest-com.vortex3.uco.edu $>$ (pp. 1, 32).

${ }^{654}$ In Mondrian's Studio, (Films Media Group, 2010), online film recording, Films On Demand, < https://fod-infobase-com.vortex3.uco.edu/p_ViewVideo.aspx?xtid=54995\&tScript=0 $>$ [accessed 11 February 2021] (47:30 - 47:49).

655 Troy, 'Art', pp. 32-34.; Noted in Troy’s article 'Art', 'You'll Find Yourself Sleeveless', Harper's Bazaar, April 1944. ProQuest <https://www-proquest-com.vortex3.uco.edu> ( p. 69).; 'Fashion: Uncluttered Sweater Look', Vogue, 01 January 1945. ProQuest $<$ https://www-proquestcom.vortex3.uco.edu> (p. 46).; 'Fashion: New Hat Forms, New Art Forms', Vogue, 01 June 1945. ProQuest $<$ https://www-proquest-com.vortex3.uco.edu (pp. 110-111).
} 
the aerial terrain to a 'Mondrian' painting. ${ }^{656}$ Furthermore, an advertisement in Vogue magazine from The Villager, a shop in New York City, displayed a shift dress named the Rickrack Shift, shown in Figure [106], and described it as 'simple and exact as a Mondrian'. ${ }^{657}$ In addition to Vogue, Women's Wear Daily also noted Mondrian in their texts. Women's Wear Daily made a correlation to Mondrian's work to a slim shirtdress by Oleg Cassini, Incorporated, 'The abstractions, asymmetrically inserted and patterned like a Mondrian painting, striped, blocked off or elongated down front - are vividly set off in paisleys to solid silks. ${ }^{958}$ During this same period, The New York Times published many articles that either noted art exhibitions that displayed Mondrian's artwork in the United States or referenced his artwork. ${ }^{659}$ Not only was Mondrian referenced in a variety of publications, his work was also referenced in a variety of forms from exhibitions, interior design techniques, and advertisements. Thus, we can infer that his paintings were widely known in the United States. Scholar, Fredrique van Reij, noted Piet Mondrian’s art was significantly more familiar to the general public in the United States than France. ${ }^{660}$

In August of 1965, Yves St. Laurent released a group of shift dresses that were closely patterned after Mondrian's paintings. ${ }^{661}$ The shift dresses, shown in Figure [107], were recognized immediately as a success. ${ }^{662}$ The day after Laurent's reveal of

\footnotetext{
656 'Fashions in Living: Decorating Around One Star Piece', Vogue, 15 February 1960. ProQuest $<$ https://www-proquest-com.vortex3.uco.edu > (p. 135). ; Rosemary Blackmon, 'Features/Articles/People: The Horsey Life in Pakistan', Vogue, 01 May 1962. ProQuest $<$ https://www-proquest-com.vortex3.uco.edu $>$ (p. 129).

657 'Advertisement: Villager, Incorporated’, Vogue, 01 February 1964. ProQuest $<$ https://wwwproquest-com.vortex3.uco.edu> (p. 94).

658 'Shirts Over Sheaths, Abstract Inserts', Women's Wear Daily, 11 February 1959. ProQuest $<$ https://www-proquest-com.vortex3.uco.edu> (p. 4).

${ }^{659}$ Howard Devree, 'In Retrospect: Mondrian's Long Voyage of Discovery -Diversity of Modern Sculpture Sculpture Survey', New York Times, 15 December 1957. ProQuest $<$ https://www-proquestcom.vortex3.uco.edu> (p. 139).; Stuart Preston, 'The Forerunners: Show Recalls Abstract Beginnings - Contemporary American Artists’, New York Times, 31 January 1960. ProQuest < https://wwwproquest-com.vortex3.uco.edu> (p. 1).; Stuart Preston, 'First Moves On The 1962 Exhibition Front: Mondrian, Eugenie Baizerman and Some Contemporary Americans Stylistic Poet Happy Union for the Cognoscenti American in Rome’, New York Times, 07 January 1962. ProQuest <https://www-proquestcom.vortex3.uco.edu> (p. 131).

${ }^{660}$ Frederique van Reij, 'Wearing Mondrian Yves Saint Laurent's Translation from High Art to Haute Couture', The Rijksmuseum Bulletin, 60.4 (2012), 342-359 (p. 353) < http://vortex3.uco.edu:2050/login?url=https:/www.jstor.org/stable/23646887> [accessed 20 January 2021]. 661 'Fashion: Paris The News as We See It', Vogue, 01 September 1965. ProQuest <https://wwwproquest-com.vortex3.uco.edu> (pp. 256-257).

662 'St. Laurent is A Sensation: King Yves Reigns Supreme in Paris', Women's Wear Daily, 03 August 1965. ProQuest <https://www-proquest-com.vortex3.uco.edu> (pp. 1, 10).; 'Features: Why Paris is Great: Friday at St. Laurent Salon’, Women's Wear Daily, 09 August 1965. ProQuest <https://wwwproquest-com.vortex3.uco.edu> (p. 3).; 'Buyers, Press, Makers Sing of St. Laurent', Women's Wear Daily, 09 August 1965. ProQuest <https://www-proquest-com.vortex3.uco.edu > (pp. 1, 9).
} 
his collection, buyers claimed that his 'new fall collection was his best' and the dress that drew the most attention was 'the shift dress in black and white sections with an emerald green square on one shoulder. ${ }^{663}$ Many manufacturers widely copied Yves St. Laurent's shift dress right after his reveal of his fashion show. ${ }^{664}$

Yves St. Laurent was not the first designer to use Mondrian's work for inspiration; but he was the first designer to achieve widespread acclaim for his efforts. Unlike past designers, Yves Saint Laurent used similar discipline as Mondrian did in painting. For example, Yves Saint Laurent utilized the shift dress as a blank canvas which allowed freedom of expression without any intrusions of buttons, zippers, pleats, or seams. Additionally, Yves Saint Laurent used a heavy material and pieces of fabric sewn together to create texture, similar to an artist paint. ${ }^{665}$ Furthermore, he used the same concept of bold lines and primary colours, similar principles of a Mondrian painting. Stella Brownie, designer of The Foxbrownie Company, in 1945 produced a collection inspired from Mondrian’s work. Nancy J. Troy claimed that Stella Brownie's use of colour and placement of lines was not executed as to Mondrian’s rules or methods. ${ }^{666}$ Brownie utilized an interpretation of Mondrian's art, but from the direction of placing an image on the sweater, rather than encompassing the entire garment. Additionally, the sweater did not provide a vast space for a direct interpretation of the painting. The sweater can be seen in Figure [108]. In 1955, the label Isabel, produced a sweater with an interpretation of Mondrian's work, as shown in Figure [109]. ${ }^{667}$ This interpretation was closer than Foxbrownie's as the art was depicted over a larger area of the sweater. But again, the sweater did not provide a pure structure as the sweater had sleeves and buttons that interfered with the pattern. In 1961, designer Anne Klein created a two-piece ensemble, shown in Figure [110], with the blouse as an interpretation of Mondrian's paintings. According to author and historian, Frederique van Reij, she claimed Klein’s two-piece silhouette was

\footnotetext{
${ }^{663}$ Gloria Emerson, 'St. Laurent and Givenchy’, New York Times, 03 August 1965. ProQuest $<$ https://www-proquest-com.vortex3.uco.edu $>$ (p. 27).

${ }^{664}$ Enid Nemy, 'Everybody, almost, is in the Mondrian Race', New York Times, 20 August 1965. ProQuest <https://www-proquest-com.vortex3.uco.edu $>$ (p. 32).

${ }^{665}$ Frederique van Reij, 'Wearing Mondrian Yves Saint Laurent's Translation from High Art to Haute Couture', The Rijksmuseum Bulletin, 60.4 (2012), 342-359 (p. 353) < http://vortex3.uco.edu:2050/login?url=https://www.jstor.org/stable/23646887> [accessed 20 January 2021]. 666 Troy, 'Art', pp. 29-30.

667 'New Concept in Sweater Makes it Star in any Wardrobe', New York Times, 19 April 1955.

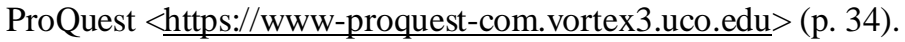


inadequate as the separation of the skirt and blouse broke-up the unity of the design. Additionally, she noted that Klein's use of colour and slim dividing black lines were woven as a whole, therefore, the colours were not distinctly separated as a Mondrian painting. ${ }^{668}$ However, Klein's two-piece ensemble resembled Yves Saint Laurent's dress more so than previous designs as she utilized the entire surface of the blouse as well as chose a garment that did not have sleeves or notions.

Troy questioned, why did the style of Mondrian’s painting suddenly become popular when Yves St. Laurent released the dress and not when Stella Brownie's collection had been launched? Troy's response was that by the mid-1960s Mondrian's name had become synonymous with the elite and popular spheres. Additionally, Troy attributed the success of the dress to the rise and popularity of Pop art and fashion journalists describing the shift dress as a youthful and modern design. ${ }^{669}$ I concur with Troy, as the success of Yves Saint Laurent's dress largely attributed to its reflection of the current culture, but also, in my opinion, the garment was successful because he was able to express his image more clearly on a vast space that only the shift dress can offer. Yves Saint Laurent was the first designer that created a direct representation of Mondrian's artwork onto a continuous, flat piece of garment. The shift dress provided Yves St. Laurent with a similar space to an artist's canvas. Therefore, he was able to work more precisely within the format of Mondrian's rules, and his design was unmistakably a direct representation of Mondrian’s painting. As with other silhouettes, zippers, buttons, sleeves and seams broke the image and do not provide a clear space for the designer to communicate in an artistic manner or a direct message. Van Reij claimed that it was the colour, construction, fabric, and detail of Yves St. Laurent's process which ensured the dress became a direct representation of Mondrian's painting as it was a dress that created an illusion of wearable art. ${ }^{670}$

Both Mondrian's painting and the shift dress have similar characteristics of movement, balance, and modernity. The shift dress provides movement with the absence of undergarments and the historical connection of the flapper with dancing and jazz music. Mondrian was inspired by jazz music as well as the movement of the

\footnotetext{
${ }^{668}$ Frederique van Reij, 'Wearing Mondrian Yves Saint Laurent's Translation from High Art to Haute Couture', The Rijksmuseum Bulletin, 60.4 (2012), 342-359 (p. 352) < http://vortex3.uco.edu:2050/login?url=https://www.jstor.org/stable/23646887> [accessed 20 January 2021]. 669 Troy, 'Art', p. 38.

${ }^{670}$ Frederique van Reij, 'Wearing Mondrian Yves Saint Laurent's Translation from High Art to Haute Couture', The Rijksmuseum Bulletin, 60.4 (2012), 342-359 (p. 353) < http://vortex3.uco.edu:2050/login?url=https://www.jstor.org/stable/23646887> [accessed 20 January 2021].
} 
city. The shift dress provided balance in its structure as it is a minimalistic garment providing a vast unobtrusive space for the designer. Mondrian used balance through applying geometric forms and strong divisional lines in his paintings. Lastly, Mondrian's painting methodology was based on the form of modern art, and, the shift dress symbolized modernity. ${ }^{671}$ Women's Wear Daily quoted Yves Saint Laurent as he claimed the Mondrian dress had 'no drapes, no bows, no frills- everything modern'. ${ }^{672}$ The shift dress was a representation of modern design because of its simplicity.

According to the film, Uncertainty: Modernity and Art, Mondrian's balance and use of geometric theory in his paintings are relevant in any civilization at any time. ${ }^{673}$ When an object is simple, there is a broader spectrum for interpretation, therefore, with many different interpretations, the object becomes relevant to society in different time frames. Because of its simplicity in design, the shift dress allows a broader spectrum of interpretation. For example, the ability for Yves St. Laurent to use the dress as a conduit of art while the shift dress originally had been sexualized exemplifies that the dress can be reinvented, reinterpreted, and redefined. Therefore, the shift dress's modern element of its straight structure and unobtrusive canvas allows it to easily convey different meanings from different epochs, thus its style effortlessly evolves with time.

Similar to Modern art, Pop art was gaining notoriety during this time. Andy Warhol and Pat Hackett defined Pop art as,

[I]mages that anybody walking down Broadway could recognize in a split second - comics, picnic tables, men's trousers, celebrities, shower curtains, refrigerators, Coke bottles - all the great modern things that the Abstract Expressionists tried so hard not to notice at all. ${ }^{674}$

\footnotetext{
${ }^{671}$ In Mondrian's Studio, (Films Media Group, 2010), online film recording, Films On Demand, < https://fod-infobase-com.vortex3.uco.edu/p_ViewVideo.aspx?xtid=54995\&tScript $=0$ > [accessed 11 February 2021] (44:00-45:00).

672 Table of contents, Women's Wear Daily, 02 August 1965. ProQuest < $\underline{\text { https://www-proquest- }}$ com.vortex3.uco.edu> (p. 2).

${ }^{673}$ Uncertainty: Modernity and Art, (Films Media Group, 2007), online film recording, Films On Demand, < https://fod-infobase-com.vortex3.uco.edu/p_ViewVideo.aspx?xtid=39858\&tScript=0 > [accessed 12 February 2021]. (18:40-18:46).

${ }^{674}$ Andy Warhol and Pat Hackett, Popism: The Warhol Sixties (London: A Harvest Book, Harcourt, Inc., 1980), p. 3.
} 
Like Mondrian, Pop artists generally used the primary colours, the use of bold black lines, and were inspired by movement and action. Pop artists were inspired from these everyday products and reflected their artwork with absurd or larger than life images. For example, Andy Warhol's most iconic painting was his Campbell’s condensed soup can painting. His painting consisted of large Campbell Soup cans repeated in multiple rows. The Campbell Soup painting became so popular that even the Campbell Soup company made a paper shift dress inspired from Andy Warhol's painting, shown in Figure [111]. Campbell's paper dress was not for sale, instead it was used for their marketing campaign which customers could mail in one dollar and two soup can labels in exchange of the dress. ${ }^{675}$ This demonstrates the shift dress is an important style which easily incorporates innovation in new materials for fashion, such as paper, and also, the inexpensive cost structure allowed the garment to be used as a marketing campaign to sell non-fashion related goods.

The Pop art movement quickly spread in America. Several articles reported the significance of the new Pop art movement and Time reported it as 'the biggest fad since art belonged to Dada' ${ }^{676}$ Aline B. Saarinen stated, 'there was no organized "Pop art” movement or group, but these days the bandwagon is getting crowded'. 677 The popularity of Pop art demonstrates that society's values have shifted from the rigid structure of the 1950s to a looser attitude toward everyday life as they begin to embrace a more satirical art form.

During the rise phase of the shift dress, designers began to draw inspiration from Pop art. One of the earliest indications of Pop art that was interpreted onto fashion during the 1960s was exemplified in Seventeen magazine in the February 1965 issue. The article, 'Pop!' had ten continuous pages of Pop art and fashion. Within these pages the spread had a variety of shift dresses, pant ensembles, and skirt and blouse outfits. These outfits were featured as influenced by Pop art with the use

\footnotetext{
675 Susan Curtis, Campbell's Soup Paper Dress, $<$ https://www.ndsu.edu/erhcc/gallery/collection_highlights/2010.05.01/15 > [accessed 12 February 2021] (para 1 of 1 ).

676 'Pop art - Cult of the Commonplace', Time, 03 May 1963. Ebscohost <vortex3.uco.edu/login?url=http://search.ebscohost.com/login. aspx?direct=true\&db=aph\&AN=542117 $39 \&$ site=ehost-live $>$ [accessed 12 February 2021] (para 1 of 15).; Aline B. Saarinen, 'Features/Articles/People: Explosion of Pop art', Vogue, 15 April 1963. ProQuest < ProQuest $<$ https://www-proquest-com.vortex3.uco.edu $>$ (p. 86).

677 Aline B. Saarinen, 'Features/Articles/People: Explosion of Pop art', Vogue, 15 April 1963. ProQuest <https://www-proquest-com.vortex3.uco.edu> (p. 86).
} 
of colour and highlighting the importance of zippers and belts in the outfits. ${ }^{678}$ However, the pages following the 'Pop!' sequence included a full page spread of a direct representation of Pop art utilizing the shift dress with screen printing. The shift dresses were amassed with oversize screen prints of everyday items, such as, a zipper, tie or belt which directly related to the Pop art message of the 'larger than life' representation of society. In Figure [112], is an example of one of the shift dresses which was inspired from the flapper with large, multiple strand of beads printed on the dress. Not only were the beads 'larger than life' but also the representation of movement was present in this dress as the model additionally accessorized 'real life' beads and was shown swinging in motion. ${ }^{679}$ Even though the Pop! sequence used several different types of outfits to show the influence of Pop art, it was the shift dress that was chosen to make a direct interpretation of Pop art.

Joseph Klein, stylist for Kelita, Incorporated, utilized the shift dress for Pop art motifs. He stated in an article the Pop art dresses were selling well and the company was looking to expand the Pop art motif to separates. ${ }^{680}$ Joseph Klein’s statement validates the idea that the shift dress was one of the first experimental garments to apply Pop art motifs. As such it is clear that the shift dress was a vital garment not only for its own purpose of liberating women, but also to advance modern clothing.

\section{A Shift in Travel}

The atmosphere of the sixties evoked a sense of newness and innovation, such as President Kennedy's declaration to go to the moon and Wright's philosophy of building the Guggenheim museum. This newness and innovation can also be applied to the growth of modern travel. A significant growth in commercial air travel occurred during the 1960s with the new transatlantic flight. The transatlantic flight

\footnotetext{
678 'Pop! More T's of Every Type', Seventeen, February 1965. ProQuest <https://www-proquestcom.vortex3.uco.edu> (pp. 94-95).; 'Pop! What’s the Buzz? Zip-Zip-Zip!', Seventeen, February 1965. ProQuest <https://www-proquest-com.vortex3.uco.edu> (pp. 96-97).; 'Pop! The Zip Looks Always Win', Seventeen, February 1965. ProQuest $<$ https://www-proquest-com.vortex3.uco.edu $>$ (pp. 98-99).; 'Pop! Belts Go Round The World', Seventeen, February 1965. ProQuest < https://www-proquestcom.vortex3.uco.edu> (pp. 100-101).; ‘Pop! A Belt Can Get You Everywhere’, Seventeen, February 1965. ProQuest ProQuest $<$ https://www-proquest-com.vortex3.uco.edu $>$ (pp. 102-103).

679 'Larger Than-Life Prints Go Pop!', Seventeen, February 1965. ProQuest < https://www-proquestcom.vortex3.uco.edu> (pp. 104-105).

${ }^{680}$ Paul Hanenberg, 'The Sportswear \& Leisure Living: Pop art may Paint Big Sales “Canvas”, Women's Wear Daily, 03 February 1965. ProQuest $<$ https://www-proquest-com.vortex3.uco.edu $>$ (p. 26).
} 
significantly reduced travel time to six and half hours compared to the traditional ocean liner which took days. ${ }^{681}$ An article posted in Vogue demonstrated the ease of air travel through the example of Mrs. Murray Vanderbilt. Vogue highlighted Mrs. Vanderbilt's round-trip, leaving from America and going to Paris, for a portrait sitting with the famous painter, Kees van Dongen. Within 24 hours, Mrs. Vanderbilt flew from New York City, arrived in Paris, had her portrait painted and flew back to New York City. ${ }^{622}$ This article demonstrated the convenience of air travel as well as the ability to move people quickly from one continent to another. Further evidence of the increasing travel trend was visible in articles from a variety of magazines. In 1962, Life magazine published a two-part story emphasizing the importance of travel among Americans and called it a 'phenomenal postwar travel boom'. ${ }^{683}$ During the same year, Newsweek claimed American travel expenditure increased by 10 percent from the previous year's record highs. Newsweek had attributed the interest in travel with the reduced travel time that airplanes provided, an increase of disposable income, and the availability of new jets. ${ }^{684}$ Travel became increasingly and progressively popular throughout the decade.

Not only did airplanes differ from ocean liners in mobility and reduced time for travel, but also the space for the passengers was significantly different. The ocean liners were spacious with full bedrooms, large open decks, dining rooms and ballrooms. However, the airplane offered limited space as passengers were confined to an assigned seat. During the 1920s, flappers were shown in the movies hopping in and out of automobiles quickly as the shift dress allowed the wearer freedom of movement and to fit into small spaces. ${ }^{685}$ Frederick Worth, known as the founder of haute couture, had expressed in 1912, 'If crinoline returns, however, there is little chance of its remaining long unless the motor car gives way to the stately old

\footnotetext{
${ }^{681}$ Robert E. Cubbedge, 'Americans on the Go’, Management Review, 49.7 (1960), 26-28 (p. 26) < https://www-proquest-com.vortex3.uco.edu> [accessed 12 February 2021].

682 'Fashion: 1961 New Time Scheme', Vogue, 01 January 1961. ProQuest < https://www-proquestcom.vortex3.uco.edu> (pp. 74-79).

683 'Room and Board in the Grand Style: Age of World Travel, Part II', Life, 13 July 1962, p. 52.

${ }^{684}$ Robert E. Cubbedge, 'Americans on the Go', Management Review, 49.7 (1960), 26-28 (p. 26) < https://www-proquest-com.vortex3.uco.edu> [accessed 12 February 2021].

${ }^{685}$ Black Oxen, dir. Frank Lloyd (Frank Lloyd Productions, Inc., A First National Picture, 1923), online film recording, Youtube, 12 July 2014, < https://www.youtube.com/watch?v=iB2PYiZvx5o> [accessed 22 November 2020].; Why Be Good , dir. by William A. Seiter (First National Pictures, 1929) [on DVD].
} 
carriage, built low and broad to allow for flowing skirts. ${ }^{, 686}$ The 1960 s airplane was similar to the 1920s automobile as it offered limited space to its passengers. As shown in the flapper movies, women were able to sit comfortably in the car, likewise, for women in the 1960s, the shift dress offered the same comfort on an airplane. Not only did the shift dress provide women with ease and comfort while in flight, but also, for first time in transatlantic travel, luggage was significantly reduced. Trunks were commonly used to transport women's wardrobes on ocean liners, but they would no longer fit onto these planes. Therefore, many items in a women's wardrobe had to be compact to fit in small suitcases. As a result of the shift dress's adaptability to small spaces, it was readily suggested for travel. ${ }^{687}$

In line with Life magazine's noteworthy claim of the 'phenomenal postwar travel boom', an increasing number of articles and advertisements were apparent, noting the shift dress as a premier outfit to use while traveling. A New York Times article published in 1962 observed, 'Bloomingdale’s realizes that no vacationer can do without a casual shift dress this year.' ${ }^{688}$ Later that year, Vogue declared the shift dress as a perfect silhouette for travel: 'Nothing could be simpler - to wear, to pack, to look smashing in.' 689 Woolworth's, an original five and dime store, advertised in the Chicago Tribune a printed jersey shift dress and claimed the dress 'packs in a tiny space' ${ }^{690}$ These examples provided evidence that the shift dress was marketed as a premier outfit for travel. Furthermore, the wide range of stores that carried the shift dress demonstrated that it was affordable for everyone. The shift dress was readily available as a beach outfit, however, stores marketing the shift dress for travel increased its versatility and its significance in the fashion industry.

Many clothing retailers collaborated with cruise-lines, airlines, hotels, and luggage companies to attach a feeling of luxury and adventure to their products. The retailers and travel companies published editorial advertisements which provided

\footnotetext{
${ }^{686}$ Margaret Alice Friend, 'Fashion: An Interview with Monsieur Worth', Vogue, 01 March 1912. ProQuest <https://www-proquest-com.vortex3.uco.edu $>$ (p. 25).

${ }^{687}$ Additionally, during the 1960s was the introduction of compact cars, for example, Chrysler's Valant, the Dodge Dart, and the Ford Mustang.

${ }^{688}$ Marylin Bender, 'Many Styles of Summer are in Shops: Separates Galore Beach Accessories', New York Times, 19 July 1962. ProQuest <https://www-proquest-com.vortex3.uco.edu $>$ (p. 17).

689 'Fashions: The Midwinter Smash of White', Vogue, 01 December 1962. ProQuest <https://wwwproquest-com.vortex3.uco.edu> (p. 157).

690 'Display Ad 49 -- no Title’, Chicago Daily Tribune, 01 November 1962. ProQuest < https://wwwproquest-com.vortex3.uco.edu > (p. d5).
} 
information about activities and suitable outfits to wear for each destination. ${ }^{691}$ For example, United Airlines and Best \& Company, a moderate department store, collaborated and published a seven-page advertisement from the inspiration of the movie release, Hawaii. The advertisement highlighted things to do in Hawaii and what clothing to wear while sightseeing. Nearly half of the outfits shown in the advertisement consisted of shift dresses. Additionally, one of the shift dresses was highlighted on its own page with an enlarged picture on half of a spread of the magazine. ${ }^{692}$

The shift dress was one of the most prominent styles shown in travel related advertisements with backdrops of cars, ships, and airplanes. For example, Eastern Airlines and Burdine, Incorporated collaborated on an advertisement of a woman pictured inside a convertible sports car wearing a shift dress. As illustrated in Figure [113], the shift dress was accompanied by a structured jacket, accessorized with long strands of beads and the model was holding a cigarette. ${ }^{693}$ The shift dress paired with the convertible sports car exuded authority, confidence and independence in the model. The model wearing a structured jacket with the shift dress may have represented conformity as the jacket was over the shift dress. However, I believe the structured jacket symbolized masculinity and the shift dress was the only dress that represented similar ideals of strength with its simplicity and straight-line construction. As masculinity is identified with strength, this advertisement sends a message that women were strong like men.

If earlier in the decade, it was noted that travel was becoming more frequent among Americans, later in the decade, articles were published regarding women traveling more often as well as alone or with a woman companion. In 1965 and 1966, a variety of newspapers reported on the frequency of women traveling. ${ }^{694}$ For

\footnotetext{
691 'Advertisement: Burdine's, Inc. (Eastern Airlines, Inc.)’, Vogue, 01 January 1964. ProQuest $<$ https://www-proquest-com.vortex3.uco.edu> (pp. 35-38).; 'Advertisement: Holiday Inn', Vogue, 15 November 1965. ProQuest $<$ http://vortex3.uco.edu/login?url=https://www-proquestcom.vortex3.uco.edu> (pp. 29-34).; 'Advertisement: Costa Del Sol (Best \& Co.)', Vogue, 01 January 1966. ProQuest $<$ https://www-proquest-com.vortex3.uco.edu $>$ (pp. 6-11).; 'Advertisement: Best \& Co. (Best \& Co.)', Vogue, 01 November 1966. ProQuest $<$ https://www-proquest-com.vortex3.uco.edu $>$ (pp. 11-17).; 'Advertisement: Vivo Fashions (Best \& Co., Inc.)', Harper's Bazaar, September 1966. ProQuest <https://www-proquest-com.vortex3.uco.edu> (pp. 98-103).

692 'Advertisement: Best \& Co. (Best \& Co.)’, Vogue, 01 November 1966. ProQuest $<$ https://wwwproquest-com.vortex3.uco.edu> (p. 14).

693 'Advertisement: Burdine's, Inc. (Eastern Airlines, Inc.)’, Vogue, 01 January 1964. ProQuest $<$ https://www-proquest-com.vortex3.uco.edu $>$ (p. 35).

694 'Fair Sex Travels More Than Men’, The Washington Post, Times Herald, 28 August 1966. ProQuest $<$ https://www-proquest-com.vortex3.uco.edu> (p. 1).; 'Housewives Hit the Road', The Washington
} 
example, the Chicago Tribune stated, 'Not so many years ago the idea of women traveling alone was rare. How times have changed!' ${ }^{695}$ In 1968, The Washington Post advised women of the best practices for choosing a travel companion. ${ }^{696}$ Women traveling alone suggests their increased independence as they journeyed not only to unfamiliar places but also without escorts. This new trend of women traveling more often demonstrates the physical movement of women, a characteristic that was not common among women during the 1950s. Women in the 1950s were static and confined to the household, whereas, women in the 1960s were reported as having more freedom. Additionally, the frequent news stories of women traveling independently communicated to society that women were becoming more independent.

\section{A Shift in Youth Culture}

One of the most important aspects of the sixties was the place of youth in society. The citizens of the United States elected one of the youngest, most charismatic presidents in American history. President Kennedy summoned the younger generation to lead the nation: 'Let the word go forth this time and place, to friend and foe alike, that the torch has been passed to a new generation of America.' ${ }^{697}$ President Kennedy’s words, 'the torch has been passed to a new generation of America', gave the youth permission to lead the nation with their youthful characteristics of bravery, curiosity and spirit. It is a popular view that Kennedy gave the country a new direction, a new focus, and a new tone to Americans. ${ }^{698}$ The combination of the youth's spontaneity fuelled by their changes in music, literature, art trends and fashion set the pace of the sixties. Arthur Marwick

\footnotetext{
Post, Times Herald, 27 March 1966. ProQuest <https://www-proquest-com.vortex3.uco.edu> (p. 1); Shirley R. Higgins, 'Basic Cruise Rules for Women Who Travel Alone’, Chicago Tribune, 28 November 1965. ProQuest <https://www-proquest-com.vortex3.uco.edu> (pp. 1-3).

${ }^{695}$ Shirley R. Higgins, 'Basic Cruise Rules for Women Who Travel Alone', Chicago Tribune, 28 November 1965. ProQuest <https://www-proquest-com.vortex3.uco.edu> (pp. 1-3).

${ }^{696}$ Frances Koltun, 'Pick Travel Buddy with Care: The Woman Traveler', The Washington Post, Times Herald, 28 April 1968. ProQuest <https://www-proquest-com.vortex3.uco.edu> (p. E5).

${ }^{697}$ Sorensen, p. 12.

${ }^{698}$ Bruce Bawer, 'The Other Sixties', The Wilson Quarterly, 28.2 (2004), 64-84 (p. 65) < http://vortex3.uco.edu:2050/login?url=https://www.jstor.org/stable/40261250> [accessed 20 January 2021].
} 
believed the youth's influence on trends was a significant characteristic that made the sixties unique from past decades. ${ }^{699}$

One of the most influential factors of the youth's influence during the 1960s was the large number of teenagers and their spending power. As a result of the baby boom in the 1950s, the youth population increased significantly. The age category from five to nineteen years of age rose from 23\% to 27\% in ten years and by 1965 it had increased to $29 \%$ of the total U.S. population. ${ }^{700}$ As stated in chapter 4 , the large increase in teenagers coupled with growth from middle-class families, created an opportunity for teenagers to become a large consumer entity.

In 1959, the Chicago Tribune published an article related to the large purchasing power of teenagers and how manufacturers are shifting their products to service the teenager. Furthermore, the article suggested a recently published book, Money in Your Pocket, to help teenagers make educated decisions about spending their money wisely and not to succumb to the lure of advertising." ${ }^{701}$ Numerous articles about teenage spending were apparent; The Washington Post published an article, 'Teens Taste Counts' and Chicago Tribune printed an article titled, 'Teens are Taking Over - And It Is Just a Beginning'. Forecasters believed youth would dictate products and choices in the marketplace. ${ }^{702}$

Writers and analysts during the late 1950s placed a large value on teens' increased spending on their entertainment and clothing, however, there was debate as to what they would wear. For example, Eugene Gilbert, author and analyst who studied the youth market, claimed that 'teenagers readily accept adult fashions

\footnotetext{
${ }^{699}$ Marwick, The Sixties, p. 17.; Becky E. Conekin, 'Eugene Vernier and "Vogue” Models in Early "Swinging London”: Creating the Fashionable Look of the 1960s', Women's Studies Quarterly, 0.41 (2012), 89-107 (p. 91) < http://vortex3.uco.edu:2050/login?url=https://www.jstor.org/stable/23611773> [accessed 20 January 2021].

${ }^{700}$ U.S. Department of Commerce, Statistical Abstract of the United States: 1955, 'Table no. 21: Population, By Age And Sex, 1920 To 1950, And By Color And Rural Farm, 1950’ (Washington, D.C., Government Printing Office, 1955), no. $76<$ https://www.census.gov/library/publications/1955/compendia/statab/76ed.html> [accessed 14 February 2021] (p. 29).; U.S. Department of Commerce, Statistical Abstract of the United States: 1970, 'Table no. 7: Current And Projected Population, By Age And Sex: 1960 To 1990’ (Washington, D.C., Government Printing Office, 1970), no. 91

<https://www.census.gov/library/publications/1970/compendia/statab/91ed.html> [accessed 14 February 2021] (p. 8).

701 Joan Beck, 'Many Bid for Teens' Dollars: Book Advises Youth on Spending Wisely', Chicago Daily Tribune, 01 October 1959. ProQuest <https://www-proquest-com.vortex3.uco.edu> (p. B3).

702 Joan Beck, 'Teens are Taking Over and it is just a Beginning', Chicago Daily Tribune, 08 October 1959. ProQuest <https://www-proquest-com.vortex3.uco.edu> (p. C5).; McCormick, Patricia, 'Teen Tastes Count', The Washington Post, Times Herald, 25 May 1960. ProQuest <https://www-proquestcom.vortex3.uco.edu> (p. C1).
} 
adapted for their particular figures and even clamour for the grown-up styles.' Eugene Gilbert forecasted that teenagers would emerge as a separate and distinct purchasing group, however, he believed teenagers would wear clothing similar to their mothers. ${ }^{703}$ In contrast, in 1961, Jean Shrimpton, an influential model of the 1960s, claimed that London was becoming a fashion resource and was 'showing the rest of the world that girls did not have to dress like their mothers, it was OK to look young' ${ }^{704}$

As the teen market was in its infancy, professionals within the fashion industry struggled to identify the best methods for merchandising, styling, and location of the youth department. An article in Women's Wear Daily noted retailers carrying merchandise for pre-teen, sub-teen, and juniors' departments, but stores rarely had a separate teen section. A Denver store was featured in the article with their creativity for having a separate teen department as it helped transition girls from preteen to juniors. The placement of the teen department varied among retailers as to where to place the teen section. Women's Wear Daily noted the teen section would be most beneficial next to the juniors' department. ${ }^{705}$ Not only was there confusion as to where to place these niche groups, but also there was no industry standard from preteen, sub-teen, teen, and juniors’ market as stores had their own sections. In 1959, a buyer from a store located in Omaha claimed she was 'enthusiastic' about the teen market but felt 'a lack of resources' existed for this segment. ${ }^{706}$ Throughout the 1960s, many articles were published about the expanding teen market. ${ }^{707}$

As discussed, the dresses shown in Seventeen magazine followed closely to the Paris fashion designers and silhouettes shown in Vogue magazine. Primarily during the 1950s, the styles of the teenagers were representative of the junior market which offered styles similar to their mothers. Like Vogue, Seventeen magazine also

\footnotetext{
${ }^{703}$ Gilbert, pp. 27-28, 311-13.

704 Jean Shrimpton, Jean Shrimpton: An Autobiography (London: Ebury, 1990), p. 56.

705 'Young Juniors (Teens): Strictly Teen Departments Rare in Denver Stores: Best Location', Women's Wear Daily, 02 September 1959. ProQuest < https://www-proquest-com.vortex3.uco.edu> (p. $60)$.

706 'Young Juniors (Teens): Omaha Store Sees Profit in Separate Teen, Junior Areas', Women's Wear Daily, 02 September 1959. ProQuest <https://www-proquest-com.vortex3.uco.edu> (p. 60).

707 'Kaufman's Widens Youth Operation', Women's Wear Daily, 06 August 1963. ProQuest $<$ https://www-proquest-com.vortex3.uco.edu> (p. 31).; 'The Infants-Children: Lytton's Enlarges PreTeen Department', Women's Wear Daily, 27 May 1968. ProQuest $<$ https://www-proquestcom.vortex3.uco.edu> (p. 23).; Lillian Chatov, 'Looking Towards Holiday-Resort...: Juniors: Dresses: Young Designers Air Views’, Women's Wear Daily, 09 August 1960. ProQuest $<$ https://wwwproquest-com.vortex3.uco.edu> (p. 31).; 'The Youth Snap: Poor Boy’, Women's Wear Daily, 02 November 1965. ProQuest <https://www-proquest-com.vortex3.uco.edu> (p. 25).
} 
had appearances of the shift dress in 1958. This surge in shift dresses and shift-like styles may have been the result from the sack dress's release in 1957. Notably, the 1958 September issue of Seventeen magazine had similar characteristics as the fashion magazines in the 1960s with spreads containing modern art, space technology, and shift dresses. Additionally, many unfitted silhouettes were also shown, for example two-piece ensembles, over-blouses, and box suit jackets. However, in 1959 most of the garments reverted back to emphasizing the waist, such as, sheath dresses, belted waists, and gathered skirts. Seventeen magazine marketed to teenagers and young adults and they covered the middle priced designers. However, Vogue magazine catered to the upper-class fashionable woman and they primarily showcased high end designers. Interestingly, the shift dresses shown in Vogue in February 1958 were from both middle priced junior designers and American high-end designers. Although some haute couture designers may have released shift dresses in their line, none were shown in Vogue in the February 1958 issues, therefore, I assume that shift dresses were not a large part of the Parisian designer's assortment.

\section{Beach Shift: A Shift in Purpose}

Although the shift dress did not gain wide-spread attention during the 1950s, the beach shift appeared on America's coastlines and became a predominant fashion in the resort setting. Initially, the beach shift was known as a swim suit. In 1958, Vogue magazine highlighted a red plaid chemise bathing suit, shown in Figure [114]. The plaid bathing suit was a straight, shift style with the hemline near the thigh. ${ }^{708}$ The beach shift began to evolve as a separate piece from the swimsuit. In 1961, Women's Wear Daily highlighted the beach shift as a 'provocative shape for 1961', as well as the 'hottest promotional item for juniors'. The beach shift was suggested for multiple uses; such as cover-ups for swimwear, to wear in conjunction with pants or to wear alone while shopping or attending a sporting event. In addition, this article noted the beach shift was available in bold colours of solids, prints, and stripe combinations and suggested it could be belted at will. ${ }^{709}$ This same year, Frances

\footnotetext{
708 'Fashion: Beach Change: Undiluted Colour', Vogue, 01 January 1958. ProQuest $<$ https://wwwproquest-com.vortex3.uco.edu> (p. 109).

${ }^{709}$ Etta Froio, 'Sportswear Designers' Summer Plan: Beach Shifts, No Sleeves, Bold Prints, Lots of White', Women's Wear Daily, 17 January 1961. ProQuest $<$ https://www-proquestcom.vortex3.uco.edu> (p. 27).
} 
Corey, Vice President of Catalina, Incorporated, announced that the beach shift began as a fad but now has turned into a fashion piece. ${ }^{710}$ Many different designers were producing beach shifts. Initially, common fabrics consisted of terry cloth, cotton and seersucker then moved to materials like wool and Dacron. ${ }^{711}$ Numerous articles stated multiple uses for the beach shift as a casual garment, for example, on a shopping trip, at a spectator sport, on the terrace or in the garden. ${ }^{712}$

Lilly Pulitzer, a socialite from Palm Beach Florida, began selling beach shifts as early as 1959. As discussed in chapter 4, many housewives were discontent during the 1950s and Betty Friedan wrote about housewives feeling a sense of emptiness from being confined to the domestic sphere. Lilly Pulitzer experienced this same emptiness, and on the advice of her doctor, she started selling juice as a hobby. ${ }^{713}$ She initially sold juice from her husband's fruit farm, but instead of using an apron she created a shift dress from fabric bought at F.W. Woolworth Company, a five-anddime store. ${ }^{714}$ While Pulitzer sold her juice, her customers inquired about the beach shift she wore. According to Arnold Karr, Pulitzer's beach shifts became instantly popular. ${ }^{715}$ Although she began selling juice on her husband's farm, she turned her shifts into a viable business. Hermine Mariaux claimed that Lilly’s husband did not help her with the business as she was solely in charge of the designing, manufacturing

\footnotetext{
710 'Advertisement (Catalina)', Women's Wear Daily, 22 November 1961. ProQuest <https://wwwproquest-com.vortex3.uco.edu $>$ (p. 3).

711 'Shop Hound: New Sights', Vogue, 01 April 1960. ProQuest $<$ https://www-proquestcom.vortex3.uco.edu> (p. 98).; Charlotte Curtis, 'Beach Shift Now Popular on Terraces', New York Times, 30 May 1962. ProQuest <https://www-proquest-com.vortex3.uco.edu> (p. 7).; 'Fashion: The

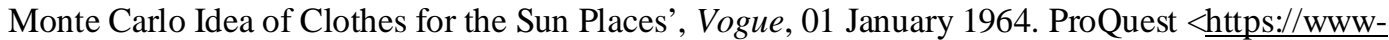
proquest-com.vortex3.uco.edu> (pp. 118-119).

${ }^{712}$ Etta Froio, 'Sportswear Designers' Summer Plan: Beach Shifts, No Sleeves, Bold Prints, Lots of White', Women's Wear Daily, 17 January 1961. ProQuest <https://www-proquestcom.vortex3.uco.edu> (p. 27).; 'Advertisement (Catalina)', Women’s Wear Daily, 22 November 1961. ProQuest $<$ https://www-proquest-com.vortex3.uco.edu> (p. 3).; Charlotte Curtis, 'Beach Shift Now Popular on Terraces', New York Times, 30 May 1962. ProQuest <https://www-proquestcom.vortex3.uco.edu> (p. 7).; Jane Cahill, 'Patricia Ponders when to Bounce for Spring: Ideas and Fashions for Smaller Stores', Women's Wear Daily, 07 December 1962. ProQuest $<$ https://wwwproquest-com.vortex3.uco.edu> (p. 6); 'The Infants - Children: Birmingham Teens Go for ShirtShifts', Women's Wear Daily, 06 July 1964. ProQuest < https://www-proquest-com.vortex3.uco.edu $>$ (p. 12).; 'Fashion: Sparks from the Sun Circuit', Vogue, 15 November 1962. ProQuest $<\underline{\text { https://www- }}$ proquest-com.vortex3.uco.edu> (p. 124).

${ }^{713}$ Robert Klara, 'Lilly Pulitzer', Adweek, 05 June 2017. ProQuest < https://www-proquestcom.vortex3.uco.edu> (p 31).

${ }^{714}$ Robert Klara, 'Lilly Pulitzer', Adweek, 05 June 2017. ProQuest < https://www-proquestcom.vortex3.uco.edu> (p. 30).

${ }^{715}$ Arnold J. Karr, 'Designer Lilly Pulitzer, 81', Women's Wear Daily, 08 April 2013. ProQuest $<$ https://www-proquest-com.vortex3.uco.edu> (para 4 of 31).; 'The Sportswear and Leisure Living: Two Girls from Palm Beach', Women's Wear Daily, 09 October 1962. ProQuest $<$ https://wwwproquest-com.vortex3.uco.edu > (p. 21).
} 
and distribution of her products. ${ }^{716}$ Her boarding school classmate, Jaqueline Kennedy, requested a shift be made for her. Lilly Pulitzer created a one-of-a-kind shift for Jackie using kitchen curtains and Pulitzer claimed that 'people went crazy' over the shift. ${ }^{717}$

Jackie exuded fashion as she became the fashion icon of the time. A White House staff member recalls the influence of Jackie's style, 'I don't think everyone really paid attention to how a first lady dressed before she [Jackie] arrived. She was a fashion plate, she had so much panache and style and a mysterious quality about her. She set the pace in Washington.' 718 Several news reporters wrote about Jaqueline’s importance, presence, and leading role in fashion, 'If ever a woman altered the fashion course of North America, that woman is Jacqueline Kennedy. ${ }^{719}$ Shown in Figure [115], Jacqueline was photographed wearing her beach shift dress by Lilly Pulitzer while she was on holiday at Cape Cod. The photograph of Jacqueline wearing the beach shift was published in Life magazine. ${ }^{720}$ On November 15, 1962 Vogue published the article, 'Sparks from the Sun Circuit', which introduced Lilly Pulitzer's shift dress as "this shift is so famous it has a name - Lilly, after its designer..." and acknowledged that she had a 'growing cross-country cult' following. ${ }^{721}$ Many decades later, authors noted Jacqueline Kennedy’s strong influence in fashion and noting specifically the shift dress and the appearance of Lilly Pulitzer's shift in Life magazine. ${ }^{722}$ Furthermore, Daily Mail also concluded that the Life magazine photograph of Jacqueline in the Lilly Pulitzer shift was quickly adopted

\footnotetext{
${ }^{716}$ Hermine Mariaux, 'The House That Lilly Lives In’, Town \& Country, January 1968. ProQuest, $<$ https://www-proquest-com.vortex3.uco.edu $>$ (pp. 68-73).

${ }^{717}$ Robert Klara, 'Lilly Pulitzer', Adweek, 05 June 2017. ProQuest < https://www-proquestcom.vortex3.uco.edu> (p. 30).

${ }^{718}$ Lars-Erik Nelson, 'Jacqueline Kennedy Onassis - A City Mourns Family Was Her Priority a First Lady Who Charmed a Generation', Newsday, 21 May 1994. ProQuest < https://www-proquestcom.vortex3.uco.edu> (p. A4).

719 Joyce Carter, 'Long Sleeves for a Winter without Shivers', The Globe and Mail, 08 December 1962. ProQuest < https://www-proquest-com.vortex3.uco.edu> (p. 3).

${ }^{720}$ Michael Solomon, Lilly Pulitzer's Flower Power, (2013), <https://www.elle.com/fashion/g8322/lilly-pulitzer-flower-power/?slide=1 > [accessed 10 March 2021] (image 4 of 13).

721 'Fashion: Sparks from the Sun Circuit', Vogue, 15 November 1962. ProQuest $<\underline{\text { https://www- }}$ proquest-com.vortex3.uco.edu> (p. 124).

${ }^{722}$ Arnold J. Karr, 'Designer Lilly Pulitzer, 81', Women's Wear Daily, 08 April 2013. ProQuest $<$ https://www-proquest-com.vortex3.uco.edu> (para 4, 19 of 31).; 'The First Lady of Fashion: She Was the Most Stylish Presidential Wife in U.S. History - A Truly Global Icon. Fifty Years After the Tragedy that Left Her a Widow at 34, the Pictures that Reveal the Real Woman Behind the Public Face [Eire Region]', Daily Mail, 16 November 2013. ProQuest <https://www-proquestcom.vortex3.uco.edu $>$ (para 11,12 out of 16).
} 
by America’s 'prep set'. ${ }^{723}$ The publicity of Jacqueline Kennedy’s beach shift from Lilly Pulitzer aided in popularizing the shift dress.

The increased presence in the marketplace was a good indicator that the shift was beginning to transform into a wide-spread fashion trend. The beach shift dress was expanding from the grass-roots designers, like Lilly Pulitzer, to couture designers of Emilio Pucci. For example, the article, 'Sparks from the Sun Circuit', showcased shifts from a wide variety of designers, price points, and retail establishments. The most expensive shift was represented by designer Emilo Pucci for $\$ 140.00$ and the least expensive shift was from Mr. Gee’s label retailed at $\$ 17.00 .^{724}$ In 1963 , Women's Wear Daily stated, 'the switch to shifts is on' and noted the increased popularity of the shift dresses in the marketplace. In addition to reporting the increased popularity of the shift dress, the article also expressed the wide variety of manufacturers that were producing shift dresses; such as the blouse manufacturers, the dress and lingerie firms, beachwear producers and children's wear suppliers. ${ }^{725}$ The variety of firms manufacturing the shift dress indicated that the beach shift dress was not only intended for the beach but also for daily wear. Therefore, production from multiple types of firms and manufacturing houses is significant as it indicated a movement from the singular definition of the beach shift to a broader definition of the shift dress which encompassed a variety of uses.

\section{Boutiques: A Shift in Retail}

Historically, department stores, specialty shops, and haute couture designers encompassed the retail landscape. However, in the 1960s, a large shift within the retail sector developed when boutiques emerged into the marketplace. A new retail concept, boutiques, were independently owned and operated stores that designed their own clothing. Boutiques differed from specialty shops and department stores which purchased their clothing from vendors. Boutiques designed and created their own products. Supermodel Twiggy recalled that department stores had 'no imagination'

\footnotetext{
723 'The First Lady of Fashion: She Was the Most Stylish Presidential Wife in U.S. History - A Truly Global Icon. Fifty Years After the Tragedy that Left Her a Widow at 34, the Pictures that Reveal the Real Woman Behind the Public Face [Eire Region]', Daily Mail, 16 November 2013. ProQuest $<$ https://www-proquest-com.vortex3.uco.edu $>$ (para 12 of 16).

724 'Fashion: Sparks from the Sun Circuit', Vogue, 15 November 1962. ProQuest $<$ https://wwwproquest-com.vortex3.uco.edu> (pp. 124-127).

${ }^{725}$ Hannenberg, Paul, 'The Sportswear and Leisure Living: Shifts Move into High Gear as More Women Learn Comfort Features; Available at all Prices', Women's Wear Daily, 27 March 1963. ProQuest $<$ https://www-proquest-com.vortex3.uco.edu $>$ (p. 30).
} 
and 'no wow factor' as they were not aesthetically pleasing and only catered to grown-ups. ${ }^{726}$ The boutique owners primarily were known to design, produce, and sell youthful fashions within a thriving, stimulating and young setting.

Boutique owners played a significant role in the retail sector as they produced clothing that challenged the current fashion process. The boutique owners managed all facets of the business which provided a closer relationship with their customers as well as a shorter distribution process. ${ }^{727}$ The styles boutiques produced were much different from the current trends. Not only did the boutique owners utilize their own design methods, but they also communicated with their customers to discover their wants and desires in clothing styles. The boutiques were the first retail stores which reacted quickly to the changing tastes of youth and as a result, they revolutionized the fashion industry. ${ }^{728}$ The boutique's idea is similar to what was suggested in the media during the 1930s about the ease of making the shift dress, but the women of the 1960s turned it into a viable business. As a result of the new business model, boutiques democratized the fashion industry from their handcrafted dresses selling at affordable prices.

Mary Quant’s boutique, Bazaar, played a significant role in changing the retail landscape. Before opening Bazaar she sold fashion accessories to young girls. Her stock depleted quickly and she realized that the youth wanted fashion chosen by someone of their own age. Mary stated, 'The young were tired of wearing essentially the same as their mothers. ${ }^{\text {, }}{ }^{79}$ Mary Quant, only 25 years old when she opened Bazaar, was not a trained fashion designer but her aspirations were to design clothing for the youth as she wanted them to have their own fashions. ${ }^{730}$ Originally she looked to purchase clothing for her shop, however, she could not find styles that suited her taste. Therefore, she used Butterick paper patterns as her template and adjusted the patterns to incorporate elements that appealed to the youth. ${ }^{731}$ Her signature designs were fun, bold, and quirky shift dresses and shift-like styles paired with low-heeled shoes and boots. A sample of Mary Quant's designs are shown in Figures [116-118].

\footnotetext{
${ }^{726}$ Twiggy: The face of the 60's, dir. by Philip Priestley (Program33 \& Arte Geie), online film recording, Youtube, 16 September 2016, $<$ https://www.youtube.com/watch?v=R8O7Li1rah4\&t=588s $>$ [accessed 12 February 2021]. (8:50-9:20)

${ }^{727}$ Elizabeth Rouse, Understanding Fashion (London: BSP Professional Books, 1989), p. 302-303.

${ }^{728}$ Rouse, p. 302.

${ }^{729}$ Mary Quant, Quant by Quant: The Autobiography of Mary Quant (London: V \& A Publishing, 2018), p. 41.

${ }^{730}$ Quant, p. 43.

${ }^{731}$ Quant, p. 43.
} 
Quant emphasized that her youthful, free-flowing, and relaxed designs were intended to be worn by the emancipated woman as her styles allowed women to move. ${ }^{732}$

Quant was a pioneer, not only in the structure and design of her clothing but also in her pricing strategy. Quant made her clothing affordable for all as she believed everyone should be able to afford designer clothes. ${ }^{733}$ This pricing strategy began a new trend in the fashion industry, and as a result, exposed a breakdown between classes. The wealthy and the middle-class youth both began shopping at the same boutiques.

Quant's boutique, Bazaar, was unlike any other shopping experience. Bazaar's atmosphere exuded a youthful spirit in its combination of music and clothing. Quant played jazz music in her boutique which offered a club type atmosphere. In addition, she freely stayed open late which further identified her boutique as unique. Not only did Quant play jazz music in her boutique, but she also infused jazz music into her fashion shows. While other designers showed their models walking down the runway, Quant had her models dance to the music. Quant described the first time she presented her clothes, 'The models dressed up here and as they danced...literally danced...down the open stairway, a wind machine caught their skirts and blew them this way and that to create an even greater sense of speed and movement.' Quant expressed that she wanted to show the clothes moving. ${ }^{734}$ By 1963, Seventeen introduced Mary Quant to America with the article, 'Young Headliners Arrive from England!'. The article noted, 'She’s a famous creator of bold young looks, now available for the first time as made-in-England imports.' The fashions highlighted were shift dresses and pants. ${ }^{735}$

Similar to Bazaar, boutiques in the United States increased their presence in the retail industry by producing and selling youthful and affordable styles. In 1962, an article was published in the New York Times indicating Greenwich Village as an ideal retail shopping environment for eccentric clothing, good values, and personal service. The article highlighted store owner, Bob Morris, who used fabric remnants

\footnotetext{
${ }^{732}$ Lister, Jenny, 'Kaleidoscope: Fashion in Sixties London', in Swinging Sixties: Fashion in London and Beyond, 1955-1970', ed. by Christopher Breward, David Gilbert and Jenny Lister (London: V \& A Publications, 2006), pp. 22-41 (p. 40).

${ }^{733}$ Maureen Cleave, 'Mary Quant, Limited-- Kinky Success Story: Mary Quant', New York Times, 19 March 1967. ProQuest <https://www-proquest-com.vortex3.uco.edu $>$ (p. 53).

${ }^{734}$ Quant, p. 94.

735 'Young Headliners Arrive from England!', Seventeen, September 1963. ProQuest < https://wwwproquest-com.vortex3.uco.edu $>$ (pp. 108-109).
} 
from manufacturers to make shift dresses. Because the shifts were simple in design and made from remnants, the dresses were not only affordable but were also offered in a wide variety of fabrics. Mr. Morris claimed his best customers came from $5^{\text {th }}$ Avenue and not necessarily from his neighbourhood. ${ }^{736}$ The location of Mr. Morris's shop in Greenwich Village was an indicator the shift dress began as a grass roots fashion where fashion designers and labels were not present. Mr. Morris noted his store was becoming popular with the upscale consumer, thus, one can infer the highend consumer could not find similar youthful clothing in the haute couture shops or high-end department stores.

Other boutiques had a similar philosophy of offering the shift dress with many different types of fabrics and at affordable prices. Boutique Monique, located in New York City, was owned and operated by two young women, Monique Mathieu and Isabel Allen, who made custom dresses. Boutique Monique offered eight different styles, including the shift dress, in a made-to-order process in which customers were able to choose a print from the stores' collection of cotton and silk fabrics. The store owners offered shift dresses and other simple styles, such as, straight two-piece ensembles and gathered skirts. Because these designs had simple construction, they were easy to produce and required only one fitting. ${ }^{737}$ In 1964, Vogue featured numerous fashion boutiques located in New York City in their column 'Shop Hound'. Boutiques mentioned in the column 'Shop Hound' noted similar processes to that of Boutique Monique's custom made-to-order dresses. The Tape Measure, a boutique in New York City, offered made-to-order dresses that required only one fitting and available in a large choice of fabrics. Additionally, several other boutiques in 'Shop Hound' advertised shift dresses available in a wide variety of fabrics, and one boutique offered shift dresses made from fabrics from India. ${ }^{738}$ The simplicity and straight form of the shift dress offered more flexibility than other styles as it was wellsuited for a larger variety of fabrics. This versatility of creating a dress from a variety of materials inspired non-professionally trained designers to use innovative methods for fashion design. Even a paper company entered the fashion industry with its paper

\footnotetext{
736 'Village' Stores Attract Clientele from Fifth Ave', New York Times, 16 January 1962. ProQuest $<$ https://www-proquest-com.vortex3.uco.edu $>$ (p. 37).

737 'Custom Apparel a Feature of Boutique', New York Times, 30 April 1963. ProQuest < https://wwwproquest-com.vortex3.uco.edu> (p. 56).

738 'Shop Hound: Boutique Hopping...the New York Idea', Vogue, 15 January 1964. ProQuest <https://www-proquest-com.vortex3.uco.edu $>$ (pp. 115-116).
} 
shift dresses. In 1966, Scott Paper Company initiated a new trend for selling paper shift dresses and many other companies and boutiques followed with this unconventional material. For example, a boutique in Beverly Hills added an artistic flare to their paper shift dresses by offering painted motifs or unique cut-out designs. ${ }^{739}$

Mary Quant's designs continued to gain popularity. In 1965, Seventeen published several articles about the influence of fashion and current music culture in London. The articles highlighted three different fashion designers and every designer exhibited shift dresses as part of their collection. The shift dresses were infused with the music culture of London as the models were photographed wearing shift dresses while dancing and performing with The Who. ${ }^{740}$ This article presented the shift dress as the style to move in with the fast tempo of music and the swift motion of the youth.

The boutiques were started by women with little or no formal fashion education or training, but from 1966 to 1968 several couture houses followed the boutique owner's footprint and expanded into the boutique arena. Haute couture designers, such as Yves St. Laurent, Courrèges and Givenchy opened free standing ready-to-wear boutiques that catered to the younger customer by offering moderate price points. ${ }^{741}$ Traditionally, haute couture designers dictated the current fashion trends and catered only to the most wealthy and well-established women. The boutiques were different as the young boutique owners brought new and fresh styles that appealed to youth at affordable prices. The boutiques were inclusive and available to the mass market while couture designers were exclusive and available only to the wealthy. However, with the new trend of boutiques and the large number

\footnotetext{
739 Taylor, Angela, 'Fashions to Buy, Wear and then Throw Away’, New York Times, 19 August 1966. ProQuest $<$ https://www-proquest-com.vortex3.uco.edu $>$ (p. 41).

${ }^{740}$ 'How Did It Begin?', Seventeen, March 1965. ProQuest < https://www-proquestcom.vortex3.uco.edu> (pp. 108-109).;

'Mary Quant's Clean-Cut London Look', Seventeen, March 1965. ProQuest <https://www-proquestcom.vortex3.uco.edu> (p. 110).; 'Caroline Charles's Soft and Skinny London Look', Seventeen, March 1965. ProQuest <https://www-proquest-com.vortex3.uco.edu> (p. 111).; 'Angela Cash's Pert and Pretty London Look.', Seventeen, March 1965. ProQuest <https://www-proquestcom.vortex3.uco.edu> (p. 112).; 'The Dotty Brown Voiles', Seventeen, March 1965. ProQuest $<$ https://www-proquest-com.vortex3.uco.edu $>$ (p. 117).

${ }^{741}$ Bill Cunningham, 'Article 7 -- no Title’, Chicago Tribune, 26 August 1968. ProQuest $<$ https://www-proquest-com.vortex3.uco.edu> (p. B4).; Gloria Emerson, 'News of Fashion: New Yves St. Laurent Boutique', New York Times, 07 October 1965. ProQuest <https://www-proquestcom.vortex3.uco.edu> (p. SU4_3). Gloria Emerson, 'New Courrèges Boutique: Heaven One Flight Down’, New York Times, 03 March 1967. ProQuest <https://www-proquest-com.vortex3.uco.edu> (p. 30).; 'Breaks from Old Guard: Givenchy Changes Mind, Opens Boutique', The Globe and Mail, 05 March 1968. ProQuest <https://www-proquest-com.vortex3.uco.edu> (p. 11).
} 
of young women, couture designers wanted to capitalize on the new youth movement. ${ }^{72}$ Therefore, couture designers opened boutiques and sold their fashions at moderate prices to appeal to the mass market. The Globe and Mail attributed mass commercialism, shrinking of private clientele, and the desire to reach younger women as reasons for the haute couture to enter the boutique arena. ${ }^{743}$

As a result of the boutiques’ success, from 1965 to 1971 Vogue published a column called, 'Vogue’s Own Boutique', which reported on items sold and who shopped at the boutiques. For example, Vogue reported on the boutique phenomenon that had spread to the Los Angeles area, 'Hollywood - home of the stars, celeb heavens - now becoming a boutique bunny's heaven too.... New boutiques sprouting up faster than a star is born'. Vogue highlighted celebrities, such as, Elizabeth Ashley, Susannah York, and Sonny and Cher. ${ }^{744}$ By the end of the decade, boutiques became such a significant business, that it had changed the retail landscape all over the world. Vogue reported the global presence of boutiques in countries such as Britain, France, United States, Sweden and Iran. ${ }^{745}$ After the flapper, young women lost their influence in fashion but Mary Quant helped them regain their voice as fashions for the youth were once again inspired by the youth.

Individuals like Mary Quant, Lilly Pulitzer, Bob Morris, and owners of Boutique Monique were pioneers as they produced and customized the shift dress at affordable prices. Mary Quant's shifts were of modern lines, Lilly Pulitzer's shifts were of lightweight floral prints, Bob Morris used a variety of materials made from remnants and Boutique Monique provided the shift as a custom made-to-order garment. The simplistic construction of the shift dress made it easy to produce and customize which made it a versatile garment and one that appealed to many people. It was a mass-produced garment with a customized style.

\footnotetext{
742 'Vogue's Own Boutique’, Vogue, 01 December 1966. ProQuest <https://www-proquestcom.vortex3.uco.edu> (p. 260).; 'Breaks from Old Guard: Givenchy Changes Mind, Opens Boutique’, The Globe and Mail, 05 March 1968. ProQuest $<$ https://www-proquestcom.vortex3.uco.edu> (p. 11).

743 'Breaks from Old Guard: Givenchy Changes Mind, Opens Boutique', The Globe and Mail, 05 March 1968. ProQuest <https://www-proquest-com.vortex3.uco.edu $>$ (p. 11).

744 'Vogue's Own Boutique: Los Angeles: Boutiqueing with the Sparkles/Yes, Elizabeth Ashley...', Vogue, 01 February 1967. ProQuest $<$ https://www-proquest-com.vortex3.uco.edu $>$ (p. 200).

745 'Vogue's Own Boutique: Leaping Lizards', Vogue, 15 October 1969. ProQuest <https://wwwproquest-com.vortex3.uco.edu> (pp. 152-156).; 'Vogue's Own Boutique: A Head of Hair', Vogue, 15 February 1969. ProQuest <https://www-proquest-com.vortex3.uco.edu> (pp. 142-146).; 'Fashion: Vogue's Own Boutique of Suggestions, Finds, and Observations; Tehran: Boutique’, Vogue, 01 December 1969. ProQuest <https://www-proquest-com.vortex3.uco.edu> (p. 236).
} 
The shift dress was driven by the grass-roots of ordinary women creating a new fashion trend. Mary Quant and Lilly Pulitzer had success before Vogue magazine recognized the shift dress and the boutiques as a phenomenon. Vogue began covering boutiques in its reoccurring column, 'Vogue’s Own Boutique' in 1965, even though Mary Quant had already created a following by 1961. By 1966 a year after Vogue started covering the boutique scene, Mary Quant had reached \$14 million in sales. ${ }^{746}$ By 1967, Lilly Pulitzer had established ten boutiques and expanded her assortment to bikinis and tennis dresses. ${ }^{747}$ The significance of Mary Quant's and Lilly Pulitzer's successes before the wide-spread attention in Vogue is important as this suggests the shift dress did not begin with couture houses but rather from boutiques. As fashion had traditionally started from couture houses and trickled-down to other manufactures, boutiques changed this trajectory, as fashion now trickles-up to couture houses.

\section{A Shift in Expression}

Although Lilly Pulitzer's and Mary Quant's shifts were universal in structure, their unique patterns and colours communicated individual style. Lilly Pulitzer's signature look included shift dresses composed of brightly coloured hues of predominantly pink, green, yellow, and blue tones which were primarily worn by wealthy women who vacationed on the coast. Shown in Figures [119-121] are examples of Lilly Pulitzer's. Mary Quant's shifts expressed a quirky, youthful, and fun style that was demonstrated through the use of bold stripes and geometric shapes very different from Lilly Pulitzer's colourful, floral prints. As both Lilly Pulitzer's and Mary Quant's shift dresses catered to different niche markets, the shift dress's simple structure allowed the garment to have a flexible identity as it easily displayed different looks. Lilly Pulitzer dresses express a soft, romantic look with their floral patterns while Mary Quant's dresses suggest a modern vibe with contrasting colours and sharp, geometric shapes. Lilly Pulitzer dresses were popular among the preppies and Mary Quant's dresses were worn by the young mods.

\footnotetext{
${ }^{746}$ Maureen Cleave, 'Mary Quant, Limited-- Kinky Success Story: Mary Quant’, New York Times, 19 March 1967. ProQuest <https://www-proquest-com.vortex3.uco.edu> (p. 8).

747 'Vogue's Own Boutique: Los Angeles: Boutiqueing with the Sparkles/Yes, Elizabeth Ashley...', Vogue, 01 February 1967. ProQuest $<$ https://www-proquest-com.vortex3.uco.edu $>$ (p. 202).; Charlotte Curtis, Special to The New York Times, 'Lilly's Life as Casual as a Lilly Dress: Designer Finds That Her Colorful Shifts Go Anywhere', New York Times, 13 March 1965. ProQuest $<$ https://wwwproquest-com.vortex3.uco.edu> (p. 14).
} 
Prior to the 1920s, dresses in Vogue magazine were predominantly onedimensional looks that expressed extreme femininity through feminine details, such as, gathers, ruffles, bows, and lace sewn onto the garment. I have provided an example in Figure [122] that demonstrates the use of feminine details. ${ }^{748}$ Although these pictorial images depict relatively straight dresses, the use of feminine details express a feminine style. The shift dress is unlike the gowns of the past. Past gowns primarily displayed feminine details, however, the shift dress as it is a modern dress, can display a variety of expressions which can be more relevant in different time periods. Similar to Joanne Entwistle's interpretation that clothing is 'read' by others. Professor Sandra Weber has observed that society perceives specific images or an association of self-identity through our clothes as they provide an outward expression of ourselves. ${ }^{749}$ Unlike dresses in the past that adhered to only feminine design, the shift dress provided many identities for women to express themselves. As shown in Figure [123], a variety of shift dresses are illustrated, some with bows, ruffles and drapery while others were devoid of these elements. ${ }^{750}$ Therefore women could choose to identify with femininity, displaying bows and ruffles, or they could decide to show themselves with less decoration and from a more masculine gendered point of view. Additionally, Weber claimed, how we see ourselves and how we feel when dressed in turn becomes part of who we are, but what Weber did not interpret is that dress is a tool that can make us feel powerful and can evolve ourselves into a new identity or self-belief. ${ }^{751}$ The shift dress with its multiple identities, I argue has the power to do just that, to evolve women into a new self-identity.

\footnotetext{
748 'Fashion: So Say the Paris Openings', Vogue, 15 March 1914. ProQuest <<https://www-proquestcom.vortex3.uco.edu $>$ (p. 37). The study of Middletown which took place in the 1920s noted the shift dress as different from previous styles of gowns, with 'fewer ruffles and tucks, plainer flounces, straight instead of gored skirts, no fitted bodices and sleeves'. Robert S. Lynd and Helen Merrell Lynd, Middletown: A Study in Contemporary American Culture (New York: Harcourt, Brace and Company, 1929), p. 167.

${ }^{749}$ Entwistle, p.116.; Sandra Weber and Claudia Mitchell, 'Theorizing Dress Stories', Counterpoints, 220. (2004), 251-272 (pp. 261, 271-272)< https://www-jstororg.vortex3.uco.edu/stable/pdf/42978316.pdf?ab_segments=0\%252Fbasic_SYC5187\%252Ftest\&refreqid=excelsior\%3A9d51661307e28966b05de6f974e87bee> [accessed 6 July 2020] Dr. Sandra Weber's field of expertise is in education and she has combined the meaning and identity of dress as to how teachers dress and how their dress can be perceived by students. She has looked at other scholars to draw her observation about self-identity and dress, such as, Bahktin, Britzman and Foucault.

750 'Paris Modes Are Launched in New York', Vogue, 15 November 1925. . ProQuest $<<$ https://wwwproquest-com.vortex3.uco.edu> (pp. 92-93).

${ }^{751}$ Sandra Weber and Claudia Mitchell, 'Theorizing Dress Stories', Counterpoints, 220. (2004), 251272 (p. 261) $<$ https://www-jstororg.vortex3.uco.edu/stable/pdf/42978316.pdf?ab_segments=0\%252Fbasic_SYC-
} 
During the 1960s many designers experimented with new techniques, new materials and new patterns on the shift dress as this enabled the silhouette to expand its sense of diverse style and looks. In my research, I have selected a range of shift dresses that depict versatility in their style, looks, and expression.

I have analysed the shift dress from three different perspectives:

1) male gender perspective

2) neutral perspective

3) female gender perspective

The 1960s espoused similar behaviour to the 1920s as the cultural lines between men and women became blurred. Some designers embraced women entering a more dichotomous role, thus they utilized the shift dress to experiment with materials related to the male gender and thus empowered women with a stronger persona. Paco Rabanne, a Spanish fashion designer, experimented with unorthodox materials, such as, metal, paper, and plastic. Rabanne created such unique garments that Vogue cited his gladiator collection as 'Rabanne's dream of change'. 752 Rabanne's gladiator collection consisted of shift dresses made from square aluminium plates and strips of white leather, shown in Figures [124-125]. ${ }^{753}$ Rabanne's gladiator dresses looked similar to the goddess of the hunt's dress which was discussed in chapter 2. His gladiator shift dresses can be compared to a warrior's outfit as the model looks as if she has prepared for battle. The gladiator shift dresses represented strength, power, and courage. Paco Rabanne designed a poker chip dress that was also associated with a male gender identity of the poker game. He used plastic poker chips and connected them in a similar manner as the gladiator shift dresses. ${ }^{754}$ His poker chip dress is shown in Figure [126]. Although, Paco Rabanne’s dresses may not have been wearable by the everyday woman, the shift dress structure enabled him to

5187\%252Ftest\&refreqid=excelsior\%3A9d51661307e28966b05de6f974e87bee> [accessed 6 July 2020].

752 'Fashion: The Now and Future Paco Rabanne', Vogue, 01 March 1967. . ProQuest <<https://wwwproquest-com.vortex3.uco.edu> (p. 204).

${ }_{753}$ Diane Crane, 'Boundaries: Using Cultural Theory to Unravel the Complex Relationship Between Fashion and Art', in Fashion and Art, ed. by Geczy, Adam, and Vicki Karaminas, (London: Berg, 2012), pp. 99-110 (p. 102, plate 15).; 'Fashion: The Now and Future Paco Rabanne', Vogue, 01 March 1967. ProQuest $<$ https://www-proquest-com.vortex3.uco.edu $>$ (pp. 204, 207).

754 'Fashion: Vogue's Eye View: Girl in the Chips', Vogue, 01 April 1966. ProQuest $<$ https://wwwproquest-com.vortex3.uco.edu> (p. 117). 
demonstrate ingenuity in the use of materials and male-dominated themes for a woman's dress. Another example of utilizing the shift dress as a nod to a typical man's sport was seen by GoodYear Tire, as shown in Figure [127]. In their advertisement for the Grand Prix racing circuit, they used a black and white chequered shift dress that was a direct interpretation of a racing start flag. Like Yves Saint Laurent's Mondrian inspired shifts, the black and white chequered shift could also be easily 'read', making an association with racing. Although the dress is a woman's garment, the display of traditionally men's activities, such as poker and racing, exhibits to a degree, women conveying a masculine identity. Steele has noted that women have adopted masculine dress in order to convey male status or professional colleagueship. ${ }^{755}$

A second example of empowering women through male gender themes can be demonstrated by Scott Barrie’s black crepe shift dress in Figure [128]. American designer, Scott Barrie, created a shift dress of black crepe-satin detailed with metal grommets and a cord laced on the front yoke of the dress. ${ }^{756}$ Both leather and satin materials reflect light in the same manner and display a shiny texture, therefore, the appearance of black crepe satin is similar to black leather and can be interpreted as a similar style. During the 1950s, black leather jackets were associated with movies about delinquent teenagers, thus leather symbolized a tough guy attitude. Because of this association of leather to delinquent teenagers, this dress suggests an identity of a tough and rebellious woman. To suggest a relationship of strength or rebellion was relatively new for a woman during this time, as the 1950s teenage movies were the first to portray high school women in a rebellious manner. Vogue chose to use dainty, floral hosiery to accessorize this dress, however, to further associate with the male gender theme leather boots could have been used and this would have expressed an extreme masculine identity. Not only was the shift dress a garment that expressed masculine traits, but the straight structure promoted women looking more neutral or non-gendered and thus aided in the popularity of pants that soon followed the fashion trend of the shift dress. The wide-spread adoption of the shift dress during the 1960s adjusted society's perception that it was okay for women to wear a straight form garment without feminine details.

\footnotetext{
755 Steele, ‘Appearance and Identity’, pp. 16-17.

756 'Fashion: The Best-Looking Girls: Ali MacGraw', Vogue, 01 August 1969. ProQuest < https://wwwproquest-com.vortex3.uco.edu> (p. 114).
} 
The second perspective of expression that was significant for women is from a neutral balanced perspective. The term, neutral balanced, is my own term which I define as utilizing both masculine and feminine elements in unison with the shift dress or utilizing this balance with the use of accessories, thus providing a neutral balanced style. Within this category, the most commonly used materials to achieve a neutral balance are prints and patterns. During the 1960s, paisley and floral prints along with geometric patterns were popular and many examples could be seen in the shift dress. Typically, geometric shapes are an element of masculinity while floral patterns suggest femininity. Not only does the pattern suggest either masculine or feminine characteristics but also colour use on patterns can create a more feminine or more masculine design. For example, designer Ericka Elias, claimed she designed clothes as boyish but used feminine colours in order to create a very young mood. ${ }^{757}$ Shown in Figure [129], Elias’s shift dress is a small grid pattern in a soft, baby pink colour trimmed in grey flannel. The use of the small grid pattern, pink colour combination and grey flannel gave a neutral balance of style as to not over emphasize any one masculine or feminine element. The next example shows a bolder geometric design using bright colours. The bold geometric design created a sense of masculine identity while at the same time the use of bright colours suggested a feminine element. With a neutral balanced shift dress the wearer could decide to accentuate a more masculine or feminine look with the use of accessories. For example in Figure [130], the shift dress is neutral balanced, but with the use of the large, bold jewellery this model expressed a more masculine identity. The last example in this category displays a masculine shift dress with the use of black and white geometric shapes paired with an overtly large, feminine portrait hat which brings a neutral balance to the look, as shown in Figure [132]. The shift dress provided a powerful statement for those women who wanted to express a versatile look of boyish undertones while at the same time display their femininity.

The last category is the shift dress expressing feminine-gendered identity. The shift dresses that are in this category emphasize more feminine traits than masculine ones. A great example are the floral prints from Lily Pulitzer as they not only display a feminine pattern of flowers but also the use of bright, female-gendered colours,

\footnotetext{
757 'Erica Elias Soft and Strict, All At Once', Seventeen, September 1965. ProQuest $<<$ https://wwwproquest-com.vortex3.uco.edu> (pp. 98-99).
} 
typically pink, green, and yellow. Utilizing a floral pattern with a female-gendered colour scheme, such as pink, associates these shift dresses with femininity. At times Lilly Pulitzer's shift dresses also added feminine details such as, lace trim or scalloped hemlines, as shown in Figure [132]. A second example is shown in Figure [133] with a dainty floral shift dress, a small bow at the neckline and accessorized with the identical dainty floral print on a pair of short booties. This ensemble expressed femininity with the use of a small floral pattern, female-gendered colours and the same feminine scheme repeated on the booties. To further convey the feminine expression of the ensemble, the model is posed in a field of flowers.

As an artist utilizes the paintbrush to create their own image, equally, the shift dress allowed women to choose fabric designs to create their own self-identity. The shift dress helped liberate women because it gave them a choice in expression. The shift dress was able to adapt to women's desires of choosing their own style the degree of masculine and feminine elements to accentuate. The experimentation of the shift dress also interpreted it as a modern dress with the use of unorthodox materials, such as metals and plastics which created an avenue for further exploration in fashion design. Vogue claimed that Paco Rabonne's unique materials that he utilized for his shift dresses, such as his gladiator or poker chip dress, were materials that had never been used in fashion. ${ }^{758}$ Initially, fashion incurred a slow process of change with feminine details attached to dresses, however, the shift dress's simple construction provided a blank canvas which allowed more freedom of experimentation, and as a result, has moved fashion toward modern dress. Because of its simplicity, it allowed experimentation in length, materials, and processes that no other garment had provided in the past. The shift dress was the first form of modern dress because it integrated women's lifestyle, communicated various expressions, connected the technological world with fashion and provided a gateway for modern styles.

\section{A Shift in Media}

As the shift dress is multifaceted in its expression, the television series Bewitched also featured various women and a diversity of personalities. Bewitched was significant as it highlighted women from a variety of perspectives in the

\footnotetext{
758 'Fashion: The Now and Future Paco Rabanne', Vogue, 01 March 1967. ProQuest $<\underline{\text { https://www- }}$ proquest-com.vortex3.uco.edu> (pp. 204-207, 228).
} 
influential medium of television. Similar to the lessons that were narrated in the 1920s movies, television shows taught families how to maintain a proper middle-class home and presented realistic family issues with resolution at the end of the program. ${ }^{759}$ Television in the 1950s and 1960s played a significant role in depicting the contemporary culture of the quintessential middle-class suburban family. However, Bewitched was unique as it displayed a middle-class suburban family, but with a twist. Samantha Stevens was not only a housewife, but she was also a witch. Through her witchcraft, coupled with a large number of women characters central to the show, Bewitched emphasized women's lifestyle, women's issues, and world travel that reached into American living rooms every week. Additionally, Bewitched was watched by a large audience as it was consistently ranked as a top performing television series by the Nielsen ratings. Authors, Tim Brooks and Earle Marsh, claimed Bewitched was the 'biggest hit series produced by the ABC network up to that time' ${ }^{760}$ Because of its popularity, Bewitched was influential to society and its characterization provided role models to women.

One of Bewitched's most significant contributions was its demonstration to society of the power of women. Samantha Stevens looked like an everyday housewife but was able to manage her witchcraft at her own discretion, thus she was able to control situations to her liking. She could do simple tasks, such as set the table, make dinner, or change her clothes with a twitch of her nose. She could also perform more complicated tasks with her special powers. For example, appear and disappear to any location or put spells on other individuals. Using her witchcraft made her a powerful woman. Rules did not necessarily apply to Samantha like other women.

Samantha was not the only witch on the show, her warlock family often 'popped-in' for visits. Her mother, Endora, and her cousin, Serena, were both eccentric characters. Endora's experiences often involved world travel and opportunities that were not available to women at the time. For example, she arrived in Samantha's house wearing a NASA astronaut suit and announced that she had just

\footnotetext{
${ }^{759}$ Mary Beth Haralovich, 'Sit-Coms and Suburbs: Positioning the 1950s Homemaker', in Private Screenings: Television and the Female Consumer, ed. by Lynn Spigel and Denise Mann (London: University of Minnesota Press, 1992), pp. 111-141 (pp. 114-116). ProQuest Ebook Central. Reprinted from Quarterly Review of Film and Video, 11.1 (1989), 61-83.

${ }^{760}$ Brooks and Marsh, p. 115. Bewitched first aired in 1964 and lasted for 8 seasons in primetime television.; Nielsen ratings on pp. 1460-1461.
} 
returned from Venus. ${ }^{761}$ Serena was a young, unmarried woman who was continually searching for love. Serena represented similar values of the flapper as she was unattached and always looking for a good time. These warlock women were powerful as they placed spells on Darrin and other men in the series, therefore they demonstrated control over men. Throughout the series, Endora consistently manipulated Darrin through her witchcraft. For instance, she wanted to make Darrin more ambitious, so she cast a spell that made him work with more initiative. She also would place spells on Darrin where he made a fool of himself. For instance, during the episode, 'The Phrase is Familiar', every time Darrin would say a cliché his body would act out that cliché. For example, he said 'I will put my ear to the ground', because of Endora's spell, Darrins's body fell to the ground with his ear firmly placed on the floor. ${ }^{762}$ These instances displayed women as more powerful than men. Equally, Samantha used her witchcraft to her advantage and manipulated the men in the series as well. The show also had traditional characterizations of mortal women, such as, the nosey neighbour, Gladys, or the boss's wife, Louise. The show's primary focus was on the witches, however this unique mix of characterizations provided a platform to analyse different clothing styles associated with different personalities.

The shift dress worn by the women on Bewitched was similar to the shift dress published in Vogue magazine. For example, the most frequent appearances of the shift dress in Vogue magazine occurred from 1966 to 1968 and the shift dress was regularly worn on Bewitched in 1967 and 1968. In its early seasons, Samantha appeared only a few times in the shift dress. However, as the series progressed, Samantha and other women wore the shift dress often. In 1969, appearances of the shift dress in featured articles in Vogue declined, but were still present in advertisements. Characters in Bewitched continued to wear the shift dress into the 1970s. Thus, indicating that Bewitched thought the shift dress as still a premier garment for their women.

In the first two seasons of Bewitched, 1964-1966, the shift dress was shown occasionally. Women in Bewitched wore the shift dress sparsely in the first two

\footnotetext{
761 'What Makes Darrin Run’, Bewitched (Mill Creek Entertainment, 2014) [on DVD]. For American women, NASA had restricted astronaut qualification to men until 1978.

762 'The Phrase is Familiar', Bewitched (Mill Creek Entertainment, 2014) [on DVD].
} 
seasons and was shown in a variety of shift dresses. ${ }^{763}$ Samantha was shown in a small clip wearing a shift dress at Darrin's office. The shift dress was also worn by other women to communicate a sexual manner. In the episode, 'Double Tate', the straight shift was worn by a young woman stepping onto the elevator. After Darrin noticed the young woman, her shift dress was 'zapped' into a bathing suit. ${ }^{764}$ The transformation of the shift dress becoming a bathing suit sexualized women.

Additionally, the episode, 'Divided He Falls', further associated the shift dress with young women and sexuality. Endora had put a spell on Darrin which split his personality into 'fun' Darrin and 'work' Darrin. The fun Darrin attended a dance party where most of the women at the party wore shift dresses. Samantha called Darrin 'irresponsible' in this scene. ${ }^{765}$ In this episode, the reference to the flapper was made as the women wore shift dresses, were a bit reckless, and participated in improvisation dancing. Thus, the shift dress continued to symbolize youth, music, dancing and irresponsibility.

In season three, many combinations of dresses were shown, such as, sheaths, a-lines, and shift dresses. The beginning of season four marked a pivotal point for the shift dress. Not only did most of the characters in season four wear the shift dress, but it was also shown more frequently this season. Season four aired in the fall of 1967, at the same time, the shift dress appearances in Vogue reached its peak. Therefore, the shift dress's frequency on both the show and in Vogue validates that it was a popular garment. Many of the shift dresses in season four were printed with bold geometric designs, large floral patterns, or a splashy watercolour technique, all reflective of the current fashion trends. ${ }^{766}$ The wide variety of prints shown in season four substantiates the shift dress as a versatile silhouette and suggests different types of looks to fit anyone’s personality. The episode, 'Hippie Hippie Hooray', gives a clear example of personality types with the dress. In this episode, Serena shows her hippie side where she participates in a Love In and encourages singing and

\footnotetext{
763 'Oh so Mortgaged', Bewitched (Mill Creek Entertainment, 2014) [on DVD].; 'The Witches Are Out', Bewitched (Mill Creek Entertainment, 2014) [DVD].; 'Divided He Falls', Bewitched (Mill Creek Entertainment, 2014) [DVD].

764 'Double Tate', Bewitched (Mill Creek Entertainment, 2014) [on DVD].

765 'Divided He Falls', Bewitched (Mill Creek Entertainment, 2014) [on DVD].

${ }^{766}$ Bewitched bold patterns were shown the same year that magazines were featuring similar print designs. For example, a multi-page article in Harper's Bazaar featured the importance of prints in its February 1967 issue as season 4 of Bewitched aired from September 1967 through May 1968.; 'The Power of the Print,' Harper's Bazaar, February 1967. ProQuest $<\underline{\text { https://www-proquest- }}$ com.vortex3.uco.edu> (pp. 135-147).
} 
performance with her psychedelic, painted guitar. Serena was shown wearing two outfits in this episode, the first a short, bright pink and blue wide-striped shift dress accessorized with blue tights, and the second a bold, printed paisley with brown tights, this one equally as short as the first. The length of the dress was the shortest seen yet on Bewitched, with it reaching up to the upper thigh area. Conversely, Samantha and Louise, wore not only solid colour shift dresses but their dresses were also longer. Samantha's reached just above the knee and Louise's dress extended just below the knee. Other examples of the shift dress's versatility of design and print were demonstrated in Bewitched, although at times a little more subtle. Louise who played a mortal, traditional housewife wore shift dresses that were much softer in colours and designs than Samantha's shift dresses. For example, Louise wore a soft, pale pink shift dress in the episode, 'Toys in Babeland', whereas Samantha's shift dress was of an art deco influence with a brightly printed geometric design. ${ }^{767}$ This also exemplified the bolder patterns were reserved for the women that held more power. Bewtiched was not the only media source that made this association. Harper's Bazaar published a 12-page article indicating this same comparison that bold prints were powerful. ${ }^{768}$

After season five, 1968-1969, shift dresses became much shorter than in previous years. This was the introduction of the mini shift dress. During this season, the hemline hovered around the thigh area. Samantha and Serena both wore the shorter hemlines. As shown in Figures [134-135], Serena wore a large variety of mini shifts as some were adorned with notions and trims that created attention, such as, sequins and crochet or accessorized with multiple strands of pearls. ${ }^{769}$ Many of Serena's shift dresses were indicative of the flapper, not only the structure of the dress but also as to how she accessorized her outfits. Samantha wore her mini shift dresses in a more conservative manner compared to Serena's, with minimal accessories and more streamlined fabrics, such as, cotton or polyester, as shown in Figure [136]. The

\footnotetext{
767 'Toys in Babeland', Bewitched (Mill Creek Entertainment, 2014) [on DVD].; A sample of Louise watercolor shifts: 'Samantha's Thanksgiving', Bewitched (Mill Creek Entertainment, 2014) [on DVD].; ‘A Prince Of A Guy’, Bewitched (Mill Creek Entertainment, 2014) [on DVD].; A sample of Samantha's bold geometric shifts: 'Long Live The Queen', Bewitched (Mill Creek Entertainment, 2014) [on DVD].; 'Business Italian Style', Bewitched (Mill Creek Entertainment, 2014) [on DVD]. 768 'The Power of The Print', Harper's Bazaar, February 1967. ProQuest <https://www-proquestcom.vortex3.uco.edu> (pp. 135-139).

769 'Serena Stops the Show', Bewitched (Mill Creek Entertainment, 2014) [on DVD].
} 
addition of accessories can be easily interchanged with the shift dress, therefore, allowing further interpretation for the wearer to show their individual personality.

Although the type of fabrics and print of the shift dress indicated a specific personality, the shift dress was also worn by some of the most conservative characters in a variety of designs. Louise, who played a traditional housewife, wore shift dresses mostly in solid colours or soft designs. Her shift dresses were more conservative than Samantha's, not only in design but also in the length, as shown in Figure [137]. Although never stated on the show, Louise was most likely a slightly older character than Samantha, and this conservatism may also be a result of her age. However, in 'Tabitha’s Cranky Spell', Louise wore a bright green sequin shift dress for a dinner event. This episode begins by Louise talking on the phone to Samantha, in a very directive and assertive manner, telling Samantha that she needs to come over for dinner. ${ }^{770}$ Louise had a small and an infrequent part on Bewitched, yet, when she was dressed in this bold, sequin shift dress her personality came out as an assertive woman.

The shift dress allowed women to explore all aspects of its silhouette by changing fabrication, pattern, and length. The shift dress is a progressive and modern garment which has allowed for freedom of movement and freedom of choice. Furthermore, it is a garment that offers versatility and diversity. As shown in Figures [136, 138-139], Samantha's shift dress varied from solid colours and dainty prints to bold geometric shapes, therefore utilizing a wide variation of design showcasing woman's multifaceted personality. What is also important, Bewitched dressed most women on the show in shift dresses, and this demonstrates that the shift dress was versatile as it suited many personalities. ${ }^{771}$ Showcasing these women in bold and versatile clothing demonstrated that women were not one-dimensional, thinking of women as only care takers or symbols of decoration as society had deemed during the Progressive Era, but rather that women were independent, with multi-dimensional personalities. The shift dress was a vehicle for women to become bolder in their fashions and their lifestyle. This was a new perspective and a modern concept. It was

\footnotetext{
770 ‘Tabitha’s Cranky Spell’, Bewitched (Mill Creek Entertainment, 2014) [on DVD].;

${ }^{771}$ I used the word 'most' as some of the guest characters, especially those that appeared on one episode, may not have worn the shift dress. However, the primary cast members of the show, such as Samantha, Endora, Serena, Louise, had worn shifts dress.
} 
now acceptable for women to experiment more, disregard traditional rules and think of them as individuals.

\section{A Shift in Perception}

Like the shift dress, Bewitched was progressive, as it demonstrated women in powerful roles, however, the show also kept within cultural expectations by characterizing women in traditional roles, primarily as housewives. At times, Samantha had to balance both the powerful and traditional roles. She was able to use power through her witchcraft or manipulate the situation, however she also wanted to please her husband and succumbed to traditional behaviour. Samantha in many ways was subservient to Darrin but equally she also was assertive with Darrin. For example, Samantha would prepare Darrin’s breakfast every morning, but in many episodes, she would direct him on what to do in order to resolve a situation. A dichotomous atmosphere was present in Bewitched, as Samantha displayed at times a directive manner over Darrin and other times a more submissive manner. This may have been indicative of society, however, it was positive for women, as the traditional housewife could see herself in a more active role like Samantha had displayed.

As Bewitched depicted women in a positive manner, the show also portrayed housewives much different from the 1950s. Samantha's image in Bewitched was very different from Lucy's characterization in I Love Lucy. Three main themes that displayed differences between Samantha and Lucy were intelligence, travel and activism. First, as discussed in chapter 4, Lucy was portrayed as empty-headed and without business skills even though she could strategically outwit Ricky. Samantha was portrayed with more intelligence than Lucy. For example, many times Samantha would offer suggestions on Darrin's work or direct Darrin on how to fix a situation, whereas, Lucy was repeatedly shown as ignorant in many subject areas. ${ }^{772}$ In the episode, 'The Golf Game’, Lucy and Ethel wanted to learn to play golf, therefore Ricky and Fred 'taught' the women the rules for golf. However, the instructions and rules directed by their husbands were made- up with silly and outlandish antics, for example one rule was that you had to leap frog to the putting green. Lucy and Ethel were too gullible and too ignorant to question these ‘made-up' rules as they believed

\footnotetext{
${ }^{772 ، H e l p, ~ H e l p ~ D o n ’ t ~ S a v e ~ M e ’, ~ B e w i t c h e d, ~(M i l l ~ C r e e k ~ E n t e r t a i n m e n t, ~ 2014) ~[o n ~ D V D] . ; ~ ' S a m a n t h a ~}$ and the Beanstalk', Bewitched (Mill Creek Entertainment, 2014) [on DVD].
} 
they were the standard rules and instructions for golf. ${ }^{773}$ Second, Samantha's experiences encompassed a more central position in the public sphere than Lucy. Samantha travelled to many places and had historical figures from all over the world visit her home, while Lucy primarily was shown in the comfort of her own home and with the company of her neighbour, Ethel. Samantha also talked about places where she had been, for example, she teased Darrin that she had been on the moon. Darrin replied, 'anything is possible with her'. ${ }^{774}$ Darrin reaffirms that Samantha was not confined to her private sphere and that she had endless opportunities. Third, Samantha was portrayed as more progressive than Lucy. On several occasions, Samantha actively protested in her community. In the episode, 'Samantha Fights City Hall', Samantha protests against building a new shopping mall where the town park is located. Samantha and several other housewives were shown picketing and advocating to keep the town's park. During this scene, Samantha was wearing pants but many housewives were wearing the shift dress. ${ }^{775}$ This further demonstrated that the shift dress was worn by housewives and by women that were progressive and active. While Lucy had talked about equal rights, she did not actively fight for the issue. ${ }^{776}$ Additionally, the shift dress was associated with Samantha who was portrayed as a strong woman while the New Look was associated with Lucy who possessed a more female gendered role in her series. Both Samantha's and Lucy's characterization followed closely to the contemporary fashion of their decade and both shows portrayed the current American culture. However, Bewitched featured women with more freedom, but part of this was the social culture of the time. Additionally, women having extensive freedom through the characters of fictitious witches may have made it more acceptable to society for women to obtain these behaviours. As the shift was widely worn without discrimination, with most women wearing it on the show, this demonstrated to society that all women were powerful. Times for women were changing. Lucy’s experiences encompassed a more static, interior world of the home, whereas, Samantha's experiences involved movement and active change among the public sphere.

\footnotetext{
773 'The Golf Game’, I Love Lucy, CBS, 17 May 1954, online video recording, CBS.com, $<$ https://www.cbs.com/shows/i_love_lucy/> [ accessed 15 July 2020].

774 'Sam In the Moon', Bewitched (Mill Creek Entertainment, 2014) [on DVD].

775 'Samantha Fights City Hall', Bewitched (Mill Creek Entertainment, 2014) [on DVD].

776 'Equal Rights', I Love Lucy, CBS, 26 October 1953, online video recording, CBS.com <https://www.cbs.com/shows/i_love lucy/> [accessed 28 October 2020].
} 
As most shows in the 1960s heavily represented men, Bewitched was unique as it was centred around women. Bewitched consistently demonstrated the power of women in the series and the costume designer chose the shift dress as a primary garment for the wardrobe. The 1920s attached sexualisation to the flapper dress and this was expressed in the flapper films. Although the flapper characterization expressed similar mannerisms and behaviour, they continued to evolve throughout the nine-year period. This is demonstrated by Ginger, who temporarily stepped-out to be a flapper, while at the end of the decade Pert was identified as a flapper. This was not the case with Bewitched, as the witches initiated change throughout the series. Initially, Bewitched associated the shift dress to its sexualization, but primarily, it was shown as a versatile dress that suited all personalities. Bewitched reinforced the perception that the shift dress was no longer a dress for debate or subject of sexual display but rather a modern dress that was versatile and adaptable which signified power and freedom.

\section{The Power Shift}

As this chapter has shown, the shift dress consistently represented movement and modernity through the mediums of space, travel, music, art, business ownership and innovative materials and techniques. As this decade's culture embraced movement this provided a gateway for women to see change in their lives. What has not been challenged before in scholarship, is how did the shift dress influence women's lives during the sixties.

Many scholars have explored the causation of the second wave of feminism. Some scholars have attributed Betty Friedan’s book, The Feminine Mystique, as a source of the second wave of feminism. ${ }^{777}$ Scholar Lelia J. Rupp believed three influential factors initiated feminism: President's Commission on the Status of Women in 1961, The Feminine Mystique and the inclusion of sex in title VII. ${ }^{778}$

\footnotetext{
777 Andrew Hunt, “'When Did the Sixties Happen?' Searching for New Directions”, Journal of Social History, 33. 1 (1999), 147-161 (p. 148) <. http://vortex3.uco.edu:2050/login?url=https://www.jstor.org/stable/3789465> [accessed 20 January 2021]. ("Betty Friedan had created the foundation of a woman's liberation movement with her thoughtprovoking bestseller, The Feminine Mystique.”); Linda K. Kerber, “I Was Appalled”: The Invisible Antecedents of Second-Wave Feminism', Journal of Women's History, 14.2 (2002) 90-101 (p. 91) $<$ http://dx.doi.org.vortex3.uco.edu/10.1353/jowh.2002.0047>.

${ }^{778}$ Rupp, p. 57.; see also, Bruce Bawer, 'The Other Sixties', The Wilson Quarterly, 28.2 (2004), 64-84 (p. 67) < http://vortex3.uco.edu:2050/login?url=https:/www.jstor.org/stable/40261250> [accessed 20 January 2021]. (Bawer notes the increasing number of women working in traditionally male jobs);
} 
Many scholars have highlighted women's participation in the social movements of the sixties, such as, the Civil Rights Movement, Students for a Democratic Society movement, Anti-war movements, and the Free Speech Movement, and this triggered women to radicalize and orchestrate a movement for themselves. ${ }^{779}$ Nancy MacLean claimed that specific factors initiated the second wave of feminism, such as, the increased life expectancy among women and children, the increased participation of women in the paid labour force, and a consciousness of women wanting more from men, marriage, education, and themselves. MacLean further stated the long history of women's organizations that originated from the creation of the New York Temperance Woman's Society in 1852 to the silent but ongoing work of women activists during the 1950s which passed crucial legislation and provided important groundwork for the 1960s Women’s Rights Movement. MacLean claimed what was significant about the women's movement in the sixties and what made it unique was the large number of women participants. ${ }^{780}$

In 1968, young women gathered on the boardwalk of Atlantic City during the Miss America Pageant to protest against the sexual display of women. Protesters felt that women on stage were displayed similar to farm animals rather than intelligent and valued human beings. Katerina Bland recognized this event as having 'launched' women's liberation into the 'spotlight'. ${ }^{781}$ This event was significant as the women on the boardwalk appeared on national television and a small cohort of women infiltrated

Andrew Hunt, “' When Did the Sixties Happen?' Searching for New Directions”, Journal of Social History, 33. 1 (1999), 147-161 (p. 148) <.

http://vortex3.uco.edu:2050/login?url=https:/www.jstor.org/stable/3789465> [accessed 20 January 2021].

${ }^{779}$ Beth Bailey and David Farber, 'The Histories They are A-Changin': Sources for Teaching about the Movements of the 1960s', OAH Magazine of History, 20.5 (2006), 8-13 (p. 11)

<http://vortex3.uco.edu:2050/login?url=https://www.jstor.org/stable/25162077> [accessed 20 January 2021].; Voichita Nachescu, 'Radical Feminism and the Nation: History and Space in the Political Imagination of Second-Wave Feminism', Journal for the Study of Radicalism, 3.1 (2009) 29-59 (p. 30)

<http://vortex3.uco.edu:2050/login?url=https://www.jstor.org/stable/41887617> [accessed 20 January 2021].; Sara M. Evans, ‘Women’s Liberation: Seeing the Revolution Clearly’, Feminist Studies, 41.1 (2015), 138-149 (p. 139) <https://doi-org.vortex3.uco.edu/10.15767/feministstudies.41.1.138>. Evans defined Women's Liberation as a radical movement that grew directly out of the New Left, civil rights, antiwar, and other related freedom movements.

${ }^{780}$ Nancy MacLean, 'Gender is Powerful: The Long Reach of Feminism', OAH Magazine of History, 20.5 (2006), 19-23 (pp. 19-20) < http:/vortex3.uco.edu:2050/login?url=https://www.jstor.org/stable/25162079>.

See also, Rupp, pp. 33-58. Rupp also had addressed the importance of the NWP and the foundation they laid prior to the late 1960s.

${ }^{781}$ Karina Bland, 'Movement’s Pivotal Moment: How the 1968 Miss America Protest Put Women’s

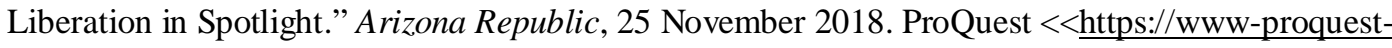
com.vortex3.uco.edu> (p. A8). 
into the arena and shouted 'women's liberation' with the aid of a sign. ${ }^{782}$ Figure [140] depicts women protesting against the Miss America Beauty Pageant. ${ }^{783}$ Two women are wearing shift dresses in the photograph. The media captured the protestors throwing away items in a trash can that represented objects of femininity and the exploitation of women; such as corsets, brassieres and high heels. ${ }^{784}$ It was the shift dress that was responsible for freeing women of all these objects of constraint. These feminine items encouraged the exploitation of women but the discarding of these items gave women choices and the ability to express their own self-identity through clothing as they no longer had to adhere to the feminine standard.

The shift dress, was the first dress, to provide women choices, to allow movement and to encourage freedom. For example, the shift dress was noted as a silhouette which gave women 'freedom of shape choice', to choose either to emphasize the waist, with the aid of a belt, or deemphasize the waist and wear the garment as a straight silhouette. ${ }^{785}$ The choice for a woman to either accentuate her waist or conceal it gave her freedom to choose how to wear the shift dress, and as a result, the shift dress gave women the power to display or mask her womanly figure. The choice as to how to wear the shift dress was powerful as this was the first garment that allowed women to decide their own direction of fashion.

In previous eras, fashion was dictated to women as one particular style was in fashion, leaving little interpretation for women's individual style. Giving women a choice and versatility in clothing design may have inclined women into gaining control over other areas in their lives. Additionally, the shift dress's simplicity in construction allowed any woman to go into business, as these women in the retail industry, transformed the fashion system. Therefore, the simple construction of the shift dress gave women an opportunity to be an active participant in the public sphere. In contrast, the 1950s New Look fashion was worn one way with emphasizing the

\footnotetext{
${ }^{782}$ Awakening: Makers: Women Who Make America, (Films Media Group, 2013), online film recording, Films on Demand, $<$ fod.infobase.com/PortalPlaylists.aspx?wID=103048\&xtid=60713> [accessed 22 November 2020].

${ }^{783}$ Mark Hamilton Lytle, 'Pictures That Changed Our Minds: Writing the History of the Sixties from Images', OAH Magazine of History, 20.4 (2006), 36-39 (p. 37) < http://vortex3.uco.edu:2050/login?url=https://www.jstor.org/stable/25162066> [accessed 20 January 2021].

${ }^{784}$ Awakening: Makers: Women Who Make America, (Films Media Group, 2013), online film recording, Films on Demand, <fod.infobase.com/PortalPlaylists.aspx?wID=103048\&xtid=60713> [accessed 22 November 2020]. (33:50-34:55).

785 'Fashion: Vogue's 20 Answers: What's New to Wear in the U.S.A', Vogue, 01 September 1958. ProQuest <https://www-proquest-com.vortex3.uco.edu> (pp. 181, 250).
} 
waist, while women assumed the only option available was to marry and raise a family. Whereas, in the late 1960s and early 1970s, women had a more positive outlook on their lives within the public sphere. According to the National Longitudinal Survey of Young Women, teenagers in the mid-1960s perceived that their adult lives would differ substantially from those of their mother's generation. ${ }^{786}$ The younger generation in the 1960s believed they had choices on marriage, education, and employment.

Because of the shift dress's modern lines, it was closely associated with power and change. For example, the shift dress's presence in magazines, such as in advertisements or articles, continually encouraged freedom, movement and participation in the public sphere. Media did this through their written slogans which were attached to travel, music, or art. The accompanying text with the shift dress encouraged motion through visuals which encouraged women to participate in not only physical movement but to extend her experiences into the public sphere. As illustrated in Figure [141], an advertisement stated, 'Get going with Sacony. You're on your way through the busiest day of your life...you're here one minute, there the next. ${ }^{787}$ This ad not only evoked movement through its text, 'you're here one minute, there the next', but the model was shown walking in a city with a briefcase in hand, indicating that she was off to work. Another powerful advertisement had a woman wearing a shift dress walking on water and asking '[j]ust how far can a girl go on a promenade? Way out', as shown in Figure [142]. This advertisement suggested that anything is possible for women, as a reference to walking on water, and a girl can extend her realm without limitations, she can go 'way out'.

Betty Friedan discussed the detrimental effects propaganda had on women during the 1950s, as advertisements guided women to stay within the private sphere. ${ }^{788}$ It is important to note the shift dress was communicated as a vehicle for movement and freedom in a variety of magazines during the 1960s. Not only was the shift dress targeted to young readers of Seventeen magazine and the fashionable women who read Vogue, but it also was communicated to mainstream traditional

\footnotetext{
${ }^{786}$ Claudia Goldin, 'The Quiet Revolution That Transformed Women’s Employment, Education, and Family’, The American Economic Review, 96. 2 (2006), 1-21 (pp. 8-9) < http://vortex3.uco.edu:2050/login?url=https:/www.jstor.org/stable/30034606> [accessed 20 January 2021]. 787 'Advertisement', Vogue, 01 September 1967. ProQuest <<https://www-proquestcom.vortex3.uco.edu> (p. 168).

${ }^{788}$ Friedan, pp. 102, 206-32.
} 
women’s magazines, such as, Good Housekeeping and Harper's Bazaar. ${ }^{789}$

Therefore, the message of freedom and movement was reiterated to a large number of women over a span of a decade.

The research on the shift dress exposed movement as one of the most apparent factors that was integrated into the lifestyle of the 1960s. Movement was integrated in magazines women read, dresses women wore, music women danced to, and modern and Pop art women collected and the ongoing women's participation in protests of worker's rights, civil rights, student's rights and the Vietnam war. The presence of the shift dress encouraged freedom of movement, created opportunities for women and gave women a choice in expression which strengthened and inspired many women to start a movement. As MacLean claimed, the difference from the Women's Rights Movements in the 1960s to previous decades was the large number of women behind the movement. ${ }^{790}$

Women came together and formed radical groups across the nation. The radical groups spread quickly throughout the United States and their purpose was to discover each woman's needs. The National Organization for Women consisted of older, more traditional women who advocated change through legislation. The radical groups primarily were made up of younger women and held consciousness raising sessions to explore the different needs and complexity of the variety of women's issues. This group captured the essence of the movement with the slogan, 'The personal is political'. ${ }^{791}$ The liberation of women was deeply connected with the shift dress. Not only did the shift dress free the woman of the brassier, high heels, and corsets, the very same items the women on the boardwalk threw in the trash can, but it also provided women an option to express themselves individually and personally, the same ethos of the Women's liberation movement. As the political became personal, the shift dress represented a blank canvas which allowed women to express personal style.

\footnotetext{
${ }^{789}$ Paul Hannenberg, 'The Sportswear and Leisure Living: Shifts Move into High Gear as More Women Learn Comfort Features; Available at all Prices', Women's Wear Daily, 27 March 1963. ProQuest $<$ https://www-proquest-com.vortex3.uco.edu $>$ (pp. 30, 42).

${ }^{790}$ Nancy MacLean, 'Gender is Powerful: The Long Reach of Feminism', OAH Magazine of History, 20.5 (2006), 19-23 (pp. 19-20) < http:/vortex3.uco.edu:2050/login?url=https://www.jstor.org/stable/25162079>.

${ }^{791}$ Awakening: Makers: Women Who Make America, (Films Media Group, 2013), online film recording, Films on Demand, <fod.infobase.com/PortalPlaylists.aspx?wID=103048\&xtid=60713> [accessed 22 November 2020]. (32:10-32:19).
} 
On August 26, 1970, 10,000 women and men marched down $5^{\text {th }}$ Avenue in New York City to fight for women's equality. Kate Millett, author of Sexual Politics and a leader in the Women's Rights Movement, rallied in front of the 10,000 women and men and declared 'At last we have a movement'. ${ }^{792}$ This was a turning point for the new decade. Women who stood before Kate Millet on August 26, 1970 reached beyond the stereotype of aggressive women that stood for change and represented all women who wanted change. New York Times noted 'every kind of woman you ever see in New York was there', this suggests that women from various backgrounds joined this march. ${ }^{793}$ Not only were women marching for equal rights in New York City on this day, but all across the U.S. in 90 cities and 42 states sister marches were conducted and women marched for equality. ${ }^{794}$ Time magazine claimed this march was 'easily the largest women's right rally since the suffrage protests' ${ }^{795}$ According to photographic evidence, many women wore the shift dress while they marched and fought for equality as shown in Figures [143-144]. The women were armoured with the clothing they chose and they expressed their individual style. The shift dress empowered women. Like the goddess of the hunt, she felt powerful in her shift dress as she was able to move like a warrior. The blank canvas, the straight structure, and versatile length of the shift dress encouraged choice, individuality, and expression for women. The shift dress allowed these liberties among women which created a new time; a time to express themselves freely, a time to become leaders in the public sphere and a time for women to move.

\section{Conclusion}

After youth of the 1920s lost their influence in fashion, the 1960s was a time for them to regain control. If fashion was directed from older professionals in the fashion system during the 1950s, the 1960s gave the power back to the youth as many young men and women opened boutiques. The young boutique owners understood that the youth wanted their own fashions and to control their own fashion decisions,

\footnotetext{
792 'It was a Great Day for Women on the March', New York Times, 30 August 1970. ProQuest $<$ https://www-proquest-com.vortex3.uco.edu $>$ (para 2 of 16).

793 'It was a Great Day for Women on the March', New York Times, 30 August 1970. ProQuest $<$ https://www-proquest-com.vortex3.uco.edu $>$ (para 6 of 16).

${ }^{794}$ Sari Rosenberg, August 26, 1970: Betty Friedan Led the Women's Strike for Equality, (2017), https://www.mylifetime.com/she-did-that/august-26-1970-betty-friedan-led-the-womens-strike-forequality [accessed 29 December 2020] (para 3 of 4).

795 'Women on the March', Time, 07 September 1970, on microfilm reel 84, p. 12.
} 
therefore, the boutique owners completely revolutionized the retail process and utilized the shift dress to do so. Because of the simplicity of the shift dress the boutique owners were able to shorten the retail distribution cycle, democratize fashion and offer a variety of styles and looks to their customers. The creative solutions that the boutique owners provided exemplify that the shift dress provided a modern vehicle. ${ }^{796}$ As mentioned in chapter 2 , the shift dress stemmed from influencers outside of the fashion world, and this in itself, is how modern dress evolves today. During the 1960s, outside influences continued to shape the shift dress in its evolution as the boutique owners primarily were untrained fashion designers and fashion designers reached into other fields of expertise.

The 1960s was a dynamic time of change for innovation, and the simple construction of the shift dress allowed for innovative designs, techniques and experimentation with influences in different areas, such as art, space exploration and men's sporting activities. The shift dress's easiness embodied modernity as it not only provided experimentation for modern clothing but it is a dress that continued to reach beyond the realm of fashion and reinterpreted design in a new way.

The shift dress in the 1960s was a tool that provided women with confidence, choices and encouragement during a decade of extreme change. The shift dress's construction, style and design gave women a choice not only as to how to wear the shift dress, belted or unbelted, but also a choice for a specific look that she wanted to express to society. The shift dress provided a platform which was easier for women without fashion training to enter the industry and start their own business. This further provided women with a more secure financial future and increased her selfconfidence by running a viable business in the public sphere. The media, such as magazines and television, portrayed the shift dress in reference to motion, not only in the sense of physical motion but also encouraging women to participate in the public sphere. Bewitched presented strong women and attached the shift dress to these personalities. Samantha was known for wearing the shift dress and she physically was able to move around the world easily. The messages attached to the shift dress were powerful and communicated strong messages that encouraged women to become active participants in the public sphere and provided them with choices, opportunities

\footnotetext{
796 The boutique's quick response to fashion trends are the same principles utilized today in the fashion industry, known as, 'fast fashion'.
} 
and expression. The foundation of the Women's liberation Movement was about giving women choices, the shift dress reflected this same tone of providing women freedom of choice, freedom of personal identity, and freedom to become active in the public sphere. Through these elements, women gained confidence and encouragement to enter the second wave of feminism. 


\section{Chapter 6: Conclusion: The Movement from the Blank Canvas to the Painted Canvas}

Clothing is an important aspect of American culture, therefore, it is imperative to understand how it begins, how it changes and how it reflects the world around us. The article, 'Though History May Shift, The Shift Dress Remains A Constant Source of Inspiration', prompted this study as it had claimed that although many dress styles have been significant, such as Paul Poiret's hobble skirt and Christian Dior's New Look, the shift dress is a principal garment as designers continually utilize it as a source of inspiration. Not only has this dress been cited as an iconic fashion garment of the 1920s, but it also continues to be a central garment in the fashion industry. With the shift dress noted as a significant and central garment in the fashion industry, it is equally important, to reveal its story in a fashion led narrative and understand how it affected women in their daily lives. As Chafe has eloquently stated, 'it is crucial to remember the continuity of human experience and the degree to which each generation's story - however different it may be from that of its predecessors - builds upon the efforts of those who have gone before.' ${ }^{797}$ Although Chafe was speaking about the Civil Rights Movement, this study utilizes the same philosophy of the continuity of the shift dress, 'which builds upon those who have gone before', and reveals the stories and experiences of women in the twentieth century. Therefore, the purpose of this study is to explore the evolution of the shift dress in two continuous time periods, rather than from a piecemeal manner, and interrogate, record and analyse the impact of the shift dress not only in its role in fashion but also how it assisted in women's place in the public sphere. Considering the shift dress's complexity, this study utilized a multidisciplinary approach which focused deeply on women's work, education and their place in contemporary society, elements and processes of modern fashion and a breadth of information that has extended far beyond fashion and has reached into a broader scope of American history and culture. ${ }^{798}$ To adequately reveal the stories of women and to analyse the complexity

\footnotetext{
${ }^{797}$ William H. Chafe, "Presidential Address: ‘The Gods Bring Threads to Webs Begun.'” The Journal of American History, 86.4 (2000), 1531-1551 (p. 1531) < www.jstor.org/stable/2567576 > [Accessed 26 December 2020].

${ }^{798}$ When I refer to the term 'piecemeal' I mean that many scholars focus on the shift dress for a specific time period, which usually spans over a decade, such as the 1920s. Others have noted the shift dress with a quick overview by topic or theme (see the literature review for specific work).
} 
of the shift dress, this study focused on three main points: first, it analysed and deconstructed the impact the shift dress had on women's lives in terms of their social and cultural roles and their place in contemporary society; second, it revealed the elements of the shift dress that contributed to modernizing dress; and third, it interrogated society's changing perception of and association with the shift dress.

The first research point in this study was to explore, assess, and analyse the impact the shift dress had on women's social and cultural roles and their place in American contemporary society. The research has shown a distinctive pattern of women's place and progress in society within the realm of education, the workplace, and social roles. This pattern revealed that when the shift dress was absent in 1910 and 1950, women were 'placed' in traditional roles, but the following decades, when the shift dress was present in 1920 and 1960 women experienced greater progress. This growth can be seen in education, as the number of women earning a professional degree spiked during both the 1920s and the 1960s. Women did experience significant gains in education during the Progressive Era, but in comparison, the percentage of women earning a college degree was significantly higher in the 1920s and the 1960s, as women accounted for $49 \%$ and $43 \%$ of the student body, respectively. Conversely, the 1950s experienced one of the lowest growth rates for women in college degrees earned, especially in bachelor's and master's degrees as women accounted for $25 \%$ and $28 \%$ of the student body, respectively. ${ }^{799}$ Both during the Progressive Era and in the 1950s, society expected that the woman's place was in the home while the men participated in the public sphere.

This same pattern of women being limited in their choices during the times when the shift dress was absent, but excelling, when the shift dress was present, is exemplified in the women's workplace. The Progressive Era was a time of slow growth for women in the public sphere. Women were strongly segregated and occupied such a low position in the workplace that the media had labelled them as the 'cheapest commodity on the market'. ${ }^{800}$ Many women worked alongside their husbands, brothers or fathers in order to work in their field. This was the case especially for professional women. Some women who could not find jobs after

\footnotetext{
799120 Years of American Education, ed. by Thomas D. Snyder, National Center for Education Statistics, (January 1993), p. 75 < https://nces.ed.gov/pubs93/93442.pdf> [accessed 15 January 2021]. (Table \# 23).

800 'The Cheapest Commodity on The Market', The Masses, December 1911. $<$ http://dlib.nyu.edu/themasses/books/masses012/5> [accessed 12 February 2021] (p. 5).
} 
earning a college degree, became settlement house workers who established accommodations in poor, immigrant communities to help acclimatize those citizens to the United States. In doing this, they became proficient in government legislation and began to change regulations within the cities. However, for most women, the Progressive Era was a time which they were 'placed' in traditional roles with society's perception that women belonged in the home to nurture the family. For women who did work in the public sphere, such as the factory workers, they remained separated from men. Therefore, this environment largely promoted gender segregation, and because of this segregation, women formed organizations, such as the Woman's Christian Temperance Union, The National Women Suffrage Association, and National Consumers League to fight against gender prejudices. The Progressive Era experienced many contradictions, as women increasingly attended college they found few opportunities and little recognition in the workplace. This contradiction can also be seen in clothing during the Progressive Era. The change from the s-bend corset gown to a straighter and freer form of dress was progress for women as they did not have to adhere to such tight corseting. However, feminine details and the long length were still used, thus emphasizing that women were limited in their movement.

The research indicated women's advancement in the workplace during the 1920s and the 1960s. Women were successful in the entrants of new jobs, moving primarily away from agriculture and into clerical positions. By entering clerical positions, women broke down gender desegregation as now women were working alongside men. Women typically remained under male supervision in these positions, but being in the office atmosphere allowed women to seize opportunities for promotion that were not present before. Additionally, the movement of women into offices demonstrated a large shift in the type of jobs women had previously occupied. Several books were published during the 1920s highlighting women's employment in atypical jobs. This demonstrated that increasingly more women were entering the workplace and establishing careers for themselves, rare in the Progressive Era. These books underpinned the success of women by emphasizing a wide-variety of occupations in diverse industries. With the increasing awareness of women working in the office, magazines and newspapers promoted women's work attire, and, in many instances, cited the shift dress as the best option to wear. As Muncy had indicated the suit was 'read' by society as too masculine for women, but the past dress styles were 
'read' as too feminine, therefore, it was difficult to find adequate work attire. The shift dress played a distinctive role as women's workwear as it still abided by society's expectation of a dress, but not as masculine as a suit. Also important too, the shift dress was easily mass produced, similar to a man's suit. ${ }^{801}$ Additionally, Vogue noted the shift dress as the best garment to wear in the workplace for several reasons: it would not snag on drawers or desks, the simplicity of the garment allowed women to be perceived as smart, and its versatility was suitable for many different occupations. ${ }^{802}$ Not only were there literary publications highlighting women in the workplace, but also Vogue noted that women worked in a wide variety of occupations during the 1920s, therefore, emphasizing that women were progressing in the public sphere.

Women in the 1920s largely entered the office setting and by the 1960s women's largest sector for white collar jobs was clerical. Unfortunately, many women did not advance into higher ranking positions. Part of this slow growth was an extension from the 1950s, as education had decreased for women and they were largely 'placed' in the home focusing on raising a family. Although, most women did not advance into supervisor positions by the 1960s, this study revealed significant stories and change for women. Some of the most significant successes were the women who started their own boutiques. These women came from a variety of backgrounds and became entrepreneurs in the public sphere. The simplicity of the shift dress provided a vehicle for women without prior fashion training to design, produce and sell a product in a boutique format. This opportunity created more independence for women as they gained more financial freedom for themselves. Some women created boutiques alongside their husbands, for example Mary Quant. However, these boutiques were largely associated more with the wife than with the husband. Associating largely with the wife was progress for women as in earlier decades many of women's contributions went unnoticed or largely unpublicized as they were subordinate to their husbands. Other women, such as the owners of Boutique Monique, were promoted by the media as two housewives who went into

\footnotetext{
${ }^{801}$ When speaking of women wearing a suit during the Progressive Era the style is a long skirt with a contoured jacket.

802 'Fashion: A Guide to Chic for the Business Woman', Vogue, 15 September 1924. ProQuest <http://vortex3.uco.edu/login?url=https://www-proquest-com.vortex3.uco.edu> (pp. 98 -99, 134). 'Fashion: A Guide to Chic for the Business Woman', Vogue, 15 November 1926. ProQuest $<$ http://vortex3.uco.edu/login?url=https://www-proquest-com.vortex3.uco.edu > (pp. 70-71, 142, 150).
} 
business together, never mentioning their husbands. Additionally, Lily Pulitzer operated her business solely on her own. She discovered beach shifts would be a marketable and viable product to sell. With the shift dress's popularity, this enabled women such as Mary Quant and Lily Pulitzer to grow business empires. For example, Lily Pulitzer's boutiques extended up the eastern U.S. coastline, and Mary Quant's business expanded from King’s Road to U.S. department store chain JcPenny. ${ }^{803}$ Considering that society labelled women as 'the cheapest commodity' in 1911, and by the 1960s, women who were not specially trained, became a dominant force in the public sphere, suggests that women made progress, while at the same time, the shift dress was a vehicle for the empowerment of women.

The shift dress not only was a vehicle that empowered boutique owners, but also the youth. This empowerment was felt by the flappers, as for the first time, they claimed the fashion direction. In the 1920s, the iconic flapper made history when she boldly asserted herself socially and promoted short skirts in a boyish fashion. The loose construction of the shift dress encouraged women to embrace freedom and improvisation in movement. The popularity of the Charleston accompanied with jazz music encouraged dance improvisation as women were permitted and enticed to dance independently not following a partner. Moreover, with their independence the flappers also expressed themselves with a free-spirited attitude through drinking, dancing, and sexual promiscuity. Their socialization led to not only decreasing gender segregation but also promoting women as independent. The spirit of independence went beyond dancing and nightlife as more women began to spend time in sporting activities, such as playing golf or tennis or going auto-riding. The sports theme was so predominant, that advertisements attached the shift dress to an active lifestyle which Vogue featured as women partaking in sporting events. Additionally, for the first time in modern western society, women were reported as participating in active and daring sports such as flying airplanes. As women increased their physical activity, a need for clothing to adapt to the new woman's lifestyle was important. Zoe Barnett, stage actress during the twenties, claimed the current styles are the most suitable clothing women had ever worn as 'women have never walked before. Women have never breathed before. Now that they’ve come into their own, they're going to

\footnotetext{
${ }^{803}$ Victoria and Albert Museum, Introducing Mary Quant, $<$ https://www.vam.ac.uk/articles/introducing-mary-quant $>$ [accessed 28 July 2021] (8 of 9).; see also Quant, pp. 114, 117.
} 
maintain their rights' ${ }^{804}$ The shift dress's freer form and shorter length helped aid in this transition for women. For example, Suzanne Lenglen's knee-length shift dress was one of the first on the tennis court at that length, as it helped her to move quickly. Additionally, F. Scott Fitzgerald used the shift dress to describe and characterize golf pro, Jordan.

As the 1920s youth culture encouraged more freedom for women, the 1950s encouraged a more grown-up attitude as young women married earlier and started a family. Thus, the culture promoted domesticity. Many stories from young homemakers were featured in magazines and newspapers, and many of these women's interests were static. Common activities in the 1950s that women participated in consisted of bingo or going shopping. Additionally, Christian Dior's New Look promoted this static culture with stiff corseted waists and flared-out skirts in a ball-gown style dress that required women to move slowly. This immobility was exemplified in the characterizations of Lucy Ricardo and Samantha Stevens. For example, Lucy primarily appeared in the comfort of her home and in the company of her neighbour, Ethel, however, Samantha travelled to many places as well as had historical figures from all over the world visit her home. During the 1950s, the shift dress was in the fashion industry, but designed primarily for the junior's market and did not gain wide-spread attention in women's fashion. This exemplifies, that not only is the shift dress a style for the youth, but also the lack of popularity in this style underpins that the culture did not emphasize the youth.

A large shift in culture occurred around 1957 where the explosive 1960s provided an atmosphere of change. Frank Lloyd Wright expressed this attitude of change by, 'This is for our time. It is part of a crusade, not only by me but by humanity all over the world’. ${ }^{805}$ Not only was this attitude expressed by Frank Lloyd Wright but President Kennedy also expressed it as a time for new developments and new ideas. With modernity as the central focus of the 1960s, the youth reclaimed their fashion position. The youth became an influential market segment as they had more disposable income than previous generations which equated to an increase in

\footnotetext{
804 'How They Look in Civies: These Are Actual Sketches Made By Our Artist of Actresses in Chicago Last Week’, Chicago Daily Tribune, 18 March 1923. ProQuest <https://www-proquestcom.vortex3.uco.edu> (p. B1).

${ }^{805}$ Herbert Mitgang, 'Sidewalk Views of That Museum: On Upper Fifth Avenue the Talk is of the New Wright-designed Guggenheim Museum. Is it a Marvel or a Monstrosity? Views of That Museum', New York Times, 12 October 1958. ProQuest < https://www-proquest-com.vortex3.uco.edu> (p. 73).
} 
spending power. Therefore, it is not surprising, with the spending power of the youth, they influenced fashion. Not only did the shift to youth culture promote change in the 1960s, but it was a decade where many deep social changes occurred, and challenged democracy and equality. Men and women joined together to fight for civil rights, antiwar movements and other campaigns, and through this, sparked women to stand up for themselves and fight for better wages and gender equality in the workplace. This started the second wave of feminism.

The second research point of this study was to investigate elements of the shift dress that are components of modernity and how it contributed to modernizing dress. Like Mondrian's composition paintings, the shift dress is a garment that is simply constructed which allows fashion to be reinterpreted, redefined and reimagined. The structure of the shift dress allows it to be broadly interpreted across different time periods, a principle of modernity. Additionally, creators of the shift dress pioneered with many 'firsts' for fashion and designed it with elements that can be translated to today's garments. Therefore, suggesting it as garment which played a pivotal role in modernizing fashion through innovation. A significant discovery within this study was that other movements outside of the fashion industry were instrumental in the evolution of the shift dress. The shift dress did not begin with a fashion designer. For example, prior to the flappers, the aesthetic movement and the arts played a significant role in evolving to the straighter form garment. More importantly, the modern dancers, specifically Isadora Duncan, embodied freedom of movement through the straighter form, and she modernized dress by wearing her tunics in a variety of lengths. The variation in lengths is important, as it gave Isadora Duncan a choice to wear either a short or long tunic. Choices for women, even in clothing, is a modern concept, as women did not always have a choice. Isadora Duncan's display in the early 1900s of this fashion would not be enough to popularize it, society's perception and the culture during this time kept women in traditional roles and thus traditional gowns. However, the dynamic 1920s youth culture which embodied jazz music, auto-riding, sporting activities, and the emerging flapper provided a need for the trend of shorter skirts, and as a result, the shift dress was the first dress to be worn short in modern times by a sub-group of women.

Women were offered choices through their clothing, not only to wear a dress with variations in lengths, but also the choice to conceal or reveal, to wear with or without a belt, or the choice to express individuality with a variety of fabrications and 
details. Women could choose either to wear an overtly feminine shift dress or a plain shift dress with little or no details. The 1960s context of women's liberation evoked the personal needs of women, and at the same time, the shift dress expressed their individuality. The choices were important to women so they could decide whether to accent their waists or to conceal it, as well as, express what individual style they wanted to portray to society. The blank canvas of the shift dress enabled individuals to use a variety of fabrics and materials to express personal style. Some chose to use unorthodox materials and experimented with innovative designs. This led to unique dresses and also fostered creativity and ingenuity as it propelled fashion forward with reimagining, reinventing and redefining the shift dress.

The shift dress also was linked with the new emerging technologies in both the 1920 s and the 1960s. The shift dress easily adapted to transportation needs in both decades as it could be worn in confined spaces. This was demonstrated in the flapper films with women hopping in and out of the 1920s automobile, and then adapted for the small spaces of airplanes. Moreover, the shift dress was the best garment to use while traveling as it easily fit into small suitcases and was easy to launder. Additionally, the shift dress is a versatile garment as it can be worn at a variety of places, such as, to the beach, to work, to lunch, to dinner, and to the theatre.

As the 1960s witnessed change, this decade saw many influential technological improvements and discoveries. The shift dress represented many of these technological fields from Andre Courrèges space shifts to Paco Rabonne's poker chip shift. This experimentation in design and fabrication challenged current fashions and pushed innovation and creativity in the fashion industry forward.

The simplicity of the shift dress also presented the garment as an economic and democratic fashion as it was affordable for all women, which can be translated to today's fast fashion model. The shift dress was easy to make, therefore, it lent itself easily to mass production and fuelled Americans' need for conspicuous consumption. As fashion theorists Veblen and Simmel have demonstrated, fashions initially 'trickle-down' from the aristocrat class then to the rest of society. King and Blumer have challenged this theory, claiming it is outdated and not in line with modern fashion. Blumer observed that fashions begin because of collective selection through 
either the fashion system, such as buyers, or the collective taste of the public. ${ }^{806}$ In reference to the shift dress, only part of Blumer's theory holds true, as the public, largely young women did influence the shift dress, possibly because of the culture, however, the buyers initially were not an integral part of promoting the shift dress. The shift dress was the first fashion for women that reversed the 'trickle-down' theory to the 'trickle-up' theory. The shift dress stemmed from the sub-culture of the flapper, largely known as a middle-class working girl, and trickled up to haute couture and the upper class. In the 1960s, again the shift dress was introduced not by the upper class, but as an affordable dress by boutique owners and as a beach cover-up. This is an important factor of modern wear today, as fashion comes from all classes, also known as 'street style'.

Another important aspect of the boutiques was that they were able to reengineer the distribution process of fashion, because the shift dress was easy to make this created a quicker and more streamlined process for the customer to receive new fashions compared to haute couture's arduous and lengthy process of releasing two collections a year. The distribution process and the economics of the shift dress forced haute couture to begin selling products in a ready-to-wear format. A quick distribution process and less expensive prices are vital to modern fashion today. The shift dress's versatility and simplicity contributed to many elements to modernizing fashion, not only in its form and who wore the garment, but also by giving women choices, going beyond the scope of fashion, and reengineering the retail process. The shift dress was instrumental in establishing key principles that created the basis of modern fashion.

The third research point explores the specific meanings the shift dress conveyed to the public and how society perceived women during this time. This research has shown that the shift dress conveyed similar, yet different meanings depending on the specific time period. Barthes introduced how messages relate to fashion through text, visual, and the historical cultural contexts. He further noted that when fashion challenges the historical context which have deep meaning in society,

\footnotetext{
${ }^{806}$ Herbert Blumer, 'Fashion: From Class Differentiation to Collective Selection', Sociological Quarterly, 10.3 (1969), 275-291 (pp. 278-280, 283) <http:/vortex3.uco.edu:2050/login?url=https:/www.jstor.org/stable/4104916> [accessed 30 January 2021]. Reprinted in The Perspectives of Fashion, ed. by George B. Sproles, (Minneapolis, MN: Burgess Publishing, 1981), pp. 49-57.
} 
these fashions are more difficult for society to identify with a new association. ${ }^{807}$ For instance, a new floral print is easily accepted among society but an exaggerated shortened skirt may be more difficult for society to accept as it challenges deep social values. Initially, the shift dress was connected to the identity of the flapper where culturally society perceived the flapper as representative of bad and improper behaviour, similar to the Bohemian women. This type of association of the shift dress, with implied cultural behaviour, was difficult to change. Analysing film media, the flapper was consistently modelled as having a sexualized persona, however, over the course of the decade, the flapper slowly evolved into a woman who upheld her responsibilities and the message changed from disfavour to approval. This is not to say that everyone accepted the flapper, but the films portrayed her as a more widely accepted ideal in America. Society's perception gradually changed over the time span of this study. Although the shift dress continued to be attached to sexual promiscuity, society's perception of what the shift dress symbolized became more diverse throughout the century. An article from The New Yorker revealed that the shift dress remained attached to sexual promiscuity during the 1950s, but also during this decade the media parodied the shift dress and its form. ${ }^{808}$ The media demonstrated that the shift dress was so unflattering that utilizing it for women's fashion seemed laughable, but this also indicated that people began associating the shift dress from a new perspective and through a different lens. This new view of the shift dress was significant as it suggested people’s opinion of the shift dress was changing and provided a larger interpretation for the shift dress to become widely defined. Additionally, the social flux and fabric innovations of the 1960s also created an environment for the shift dress to become broadly associated with other meanings and not attached to such a singular definition. The shift dress consisted of a variety of designs and fabrics, such as dainty prints, bold stripes, or black satin. This allowed each woman to express her own personal style and decide how she wanted to express herself through her clothes. The association of the shift dress changed, advanced and morphed throughout the century as the mainstream culture associated it with a variety of purposes and expressions rather than pinpointing it only as a sexualized garment. During the 1960s, women were largely portrayed in the shift dress as strong,

\footnotetext{
${ }^{807}$ Roland Barthes, The Fashion System, trans by Matthew Ward and Richard Howard. (London: University of California Press, 1983) p.184.

808 'Notes and Comment', The New Yorker, 22 September 1951, p. 23
} 
confident, and attached to the public sphere. Not only did Bewitched emphasize the shift dress with its warlock women but also inclusively with most women on the show, demonstrating that all women were powerful. Additionally, advertisements in print magazines also showed women in shift dresses who were powerful, invincible and active participants in the public sphere.

According to Hollander, 'Fashion was born modern. As it has always been committed to constant change and competitive expression; strong and free visual form was characteristic of it'. ${ }^{809}$ Although fashion continually changes, it is not always modern. When looking at fashion collectively, and as a whole entity, it is modern, as fashion continually changes with the social context of time. However, not all garments are identified as modern. Some garments express tradition while others express innovation. Some garments are reflective of the past while others propel fashion forward. The shift dress is the latter. The shift dress is a powerful garment not only because it modernized fashion through the elements I have discussed, but also because of the impact that it had on women. The shift dress created significant change. The shift dress's simplicity gave women confidence, gave women choices, and gave women unprecedented opportunities. With these elements in place, it must be recognised that this encouraged many women to become 'restless women', to create an atmosphere of change, and begin the second wave of women's liberation. As stated by Nell Greenwood, 'Clothes are your protectors, your armoury, your defense shield and your friend... My clothes give me strength and power. ${ }^{810}$ As demonstrated by Greenwood, clothing is power. As the women were armoured with clothing they chose and expressed their individual style, the shift dress gave power to the woman. Like the goddess of the hunt, women felt powerful in their shift dress as they were able to move like warriors. The shift dress is more than a garment to clothe one's body, it is a vehicle which carried women to a new liberation and to a new time; a time to express themselves freely, a time to become leaders, and a time for women to move. For the New Woman, who are also 'restless women', for all women, this is our armour. The shift dress has moved women forward, it has moved fashion forward,

\footnotetext{
${ }^{809}$ Anne Hollander, 'The Modernization of Fashion', Design Quarterly, no. 154 (1992), 27-33 (p. 27) $<$ https://doi-org.vortex3.uco.edu/10.2307/4091263>.

810 Nell Greenwood, 'The Purple Jumpsuit', in The Memory of Clothes, ed. by Robyn Gibson (Rotterdam; Boston; Taipei: Sense Publishers, 2015, pp. 157-159 (p. 159). ProQuest Ebook Central.
} 
and because of this, it should be considered one of the most significant garments in fashion history. 
The images (pages 241-291) are available upon request for research and private study purposes. Please email the repository via openaccess@swansea.ac.uk for access to the redacted content. 


\section{Primary Sources}

\section{Magazines}

'Advertisement', Vogue, 01 April 1944. ProQuest < $\underline{\text { https://www-proquest- }}$ com.vortex3.uco.edu>

'Advertisement', Vogue, 01 July 1944. ProQuest < $\underline{\text { https://www-proquest- }}$ com.vortex3.uco.edu>

'Advertisement', Vogue, 01 May 1958. ProQuest $<\underline{\text { https://www-proquest- }}$ com.vortex3.uco.edu>

'Advertisement', Vogue, 01 October 1958. ProQuest < $\underline{\text { https://www-proquest- }}$ com.vortex3.uco.edu>

‘Advertisement', Vogue, 01 September 1967. ProQuest < $\underline{\text { https://www-proquest- }}$ com.vortex3.uco.edu>

‘Advertisement: American Stove Company’, Good Housekeeping, May 1950. ProQuest $<$ https://www-proquest-com.vortex3.uco.edu $>$

'Advertisement: Best \& Co. (Best \& Co.)’, Vogue, 01 November 1966. ProQuest $<$ https://www-proquest-com.vortex3.uco.edu $>$

‘Advertisement: Burdine's, Inc. (Eastern Airlines, Inc.)’, Vogue, 01 January 1964. ProQuest $<\underline{\text { https://www-proquest-com.vortex3.uco.edu }}>$

'Advertisement (Catalina)', Women’s Wear Daily, 22 November 1961. ProQuest $<$ https://www-proquest-com.vortex3.uco.edu $>$

‘Advertisement: Corticelli Dress Silks’, Vogue, 01 November 1918. ProQuest $<$ https://www-proquest-com.vortex3.uco.edu $>$ 
‘Advertisement: Costa Del Sol (Best \& Co.)’, Vogue, 01 January 1966. ProQuest $<$ https://www-proquest-com.vortex3.uco.edu $>$

‘Advertisement: Damon’. Vogue, 01 February 1966. ProQuest < $\underline{\text { https://www- }}$ proquest-com.vortex3.uco.edu>

'Advertisements: Darlene Juniors, Inc.', Seventeen, February 1951. ProQuest $<\underline{\text { https://www-proquest-com.vortex3.uco.edu }>}$

‘Advertisement: D. H. Holmes Co., Ltd.’, Seventeen, February 1951. ProQuest $<\underline{\text { https://www-proquest-com.vortex3.uco.edu }>}$

‘Advertisement: Elinor Simmons (Elinor Simmons)’, Vogue, 01 September 1966. ProQuest $<$ https://www-proquest-com.vortex3.uco.edu $>$

'Advertisement: Gay Togs, Inc.', Seventeen, February 1951. ProQuest $<\underline{\text { https://www- }}$ proquest-com.vortex3.uco.edu>

'Advertisement: General Electric’, Better Homes and Gardens, March 1953. ProQuest $<$ https://www-proquest-com.vortex3.uco.edu $>$

‘Advertisement: The Gorham Company’, Seventeen, February 1951. ProQuest $<\underline{\text { https://www-proquest-com.vortex3.uco.edu }>}$

'Advertisement: Grayson-Robinson Stores', Seventeen, February 1951. ProQuest $<\underline{\text { https://www-proquest-com.vortex3.uco.edu }>}$

‘Advertisement: Holiday Inn’, Vogue, 15 November 1965. ProQuest $<\underline{\text { https://www- }}$ proquest-com.vortex3.uco.edu $>$

'Advertisement: Louis Philippe, Inc', Vogue, 01 October 1940. ProQuest $<$ https://www-proquest-com.vortex3.uco.edu $>$ 
'Advertisement: Orion (Du Pont Company, Inc.)', Vogue, 01 February 1958.

ProQuest $<$ https://www-proquest-com.vortex3.uco.edu $>$

‘Advertisement: R. H. Macy \& Co.’, Vogue, 15 April 1925, ProQuest < $\underline{\text { https://www- }}$ proquest-com.vortex3.uco.edu>

‘Advertisement: The Tappan Stove Company’, Ladies' Home Journal, June 1947. ProQuest $<$ https://www-proquest-com.vortex3.uco.edu $>$

'Advertisement: Thermic Ray’, Ladies' Home Journal, November 1948. ProQuest < https://www-proquest-com.vortex3.uco.edu>

‘Advertisement: Villager, Incorporated’, Vogue, 01 February 1964. ProQuest $<$ https://www-proquest-com.vortex3.uco.edu $>$

'Advertisement: Vivo Fashions (Best \& Co., Inc.)', Harper's Bazaar, September 1966. ProQuest $<$ https://www-proquest-com.vortex3.uco.edu $>$

‘Advertisement: Western Stove Company, Inc’, Good Housekeeping, April 1949. ProQuest $<$ https://www-proquest-com.vortex3.uco.edu $>$

'Angela Cash's Pert and Pretty London Look.', Seventeen, March 1965. ProQuest $<$ https://www-proquest-com.vortex3.uco.edu $>$

‘Art', Vogue, 20 December 1900. ProQuest < $\underline{\text { https://www-proquest- }}$ com.vortex3.uco.edu>

'Art: Art', Vogue, 16 May 1901. ProQuest < $\underline{\text { https://www-proquest- }}$ com.vortex3.uco.edu>

Bailey, Ronald, ‘The U.S. Mission to Mars.', Life, 16 January 1965 
Betty, Hannah H., 'Help Wanted: Do You Just Live Through This Destructive, Disobedient Stage’, Ladies Home Journal, July 1951. ProQuest $<\underline{\text { https://www-proquest-com.vortex3.uco.edu }>}$

_ 'Idle Women... Where Are They?’, Ladies' Home Journal, March 1949. ProQuest $<\underline{\text { https://www-proquest-com.vortex3.uco.edu }}>$

Blackmon, Rosemary, 'Features/Articles/People: The Horsey Life in Pakistan’, Vogue, 01 May 1962. ProQuest < $\underline{\text { https://www-proquest-com.vortex3.uco.edu }>}$

Bloomer, Amelia, ““The Bloomer Costume": A Letter from Amelia Bloomer’, Ladies' Home Journal, January 1890. ProQuest < $\underline{\text { https://www-proquest- }}$ com.vortex3.uco.edu>

'British Battle of the Hemline’, Ladies' Home Journal, December 1947. ProQuest $<$ https://www-proquest-com.vortex3.uco.edu $>$

'Caroline Charles's Soft and Skinny London Look’, Seventeen, March 1965. ProQuest $<$ https://www-proquest-com.vortex3.uco.edu $>$

Chambers, Robert W., 'The Restless Sex: A Chronicle of Insurgent Youth." Cosmopolitan, November 1917. ProQuest $<\underline{\text { https://www-proquest- }}$ com.vortex3.uco.edu

'The Cheapest Commodity on the Market', The Masses, December 1911. $<$ http://dlib.nyu.edu/themasses/books/masses012/5 $>$ [accessed 12 February $\underline{20211}$

Cooley, Donald G., 'What’s Your Emotional Breaking Point?’, Cosmopolitan, February 1955. ProQuest < $\underline{\text { https://www-proquest-com.vortex3.uco.edu }>}$

‘Cover: Vogue’, Vogue, 01 August 1956. ProQuest < $\underline{\text { https://www-proquest- }}$ com.vortex3.uco.edu> 
'Designs for Practical Dressmaking', Vogue, 15 April 1925. ProQuest $<$ https://wwwproquest-com.vortex3.uco.edu>

'Designs for Practical Dressmaking: Daytime Frocks may be Straight and Simple', Vogue, 01 August 1926. ProQuest < https://www-proquestcom.vortex3.uco.edu>

'Designs for Practical Dressmaking: The Simple One-Piece Frock for Daytime’, Vogue, 01 February 1927. ProQuest < https://www-proquestcom.vortex3.uco.edu>

Dolson, Hildegarde, 'The Scrambled Housewife’, Ladies' Home Journal, August 1954. ProQuest $<$ https://www-proquest-com.vortex3.uco.edu $>$

'The Dotty Brown Voiles’, Seventeen, March 1965. ProQuest < $\underline{\text { https://www-proquest- }}$ com.vortex3.uco.edu>

Drake, Ruth, ‘You Always Look So Pretty’, Redbook, June 1952. ProQuest $<$ https://www-proquest-com.vortex3.uco.edu>

'Dresses of Moment', Good Housekeeping, October 1953. ProQuest < https://wwwproquest-com.vortex3.uco.edu>

'The Earth Seen from Gemini 5’, Life, 24 September 1965

'Editorial: Social Topics: The Defenseless Theories Regarding Women', Vogue, 19 December 1895. ProQuest < $\underline{\text { https://www-proquest-com.vortex3.uco.edu }>}$

'Editorial: Social Topics: The Eternal Girl Problem’, Vogue, 19 August 1897. ProQuest $<\underline{\text { https://www-proquest-com.vortex3.uco.edu }>}$

'Editorial: Social Topics: A "Womanliness" Panic again’, Vogue, 08 April 1897. ProQuest < $\underline{\text { https://www-proquest-com.vortex3.uco.edu }>}$ 
'Erica Elias Soft and Strict, All at Once', Seventeen, September 1965. ProQuest $<\underline{\text { https://www-proquest-com.vortex3.uco.edu }>}$

'Eye from a Front Row Seat', Life, 26 October 1962

‘Fashion: 1961 New Time Scheme’, Vogue, 01 January 1961. ProQuest $<\underline{\text { https://www-proquest-com.vortex3.uco.edu }>}$

'Fashion: Bargains in chic U.S.A.', Vogue, 01 February 1964. ProQuest $<$ https://www-proquest-com.vortex3.uco.edu $>$

'Fashion: Beach Change: Undiluted Colour', Vogue, 01 January 1958. ProQuest $<\underline{\text { https://www-proquest-com.vortex3.uco.edu }>}$

'Fashion: The Best-Looking Girls: Ali MacGraw', Vogue, 01 August 1969. ProQuest $<$ https://www-proquest-com.vortex3.uco.edu $>$

'Fashion: Chanel Maintains the Normal Lines of the Figure', Vogue, 15 October 1920. ProQuest < $\underline{\text { https://www-proquest-com.vortex3.uco.edu }>}$

'Fashion: Chanel Makes Three Charming Costumes', Vogue, 01 May 1918. ProQuest $<\underline{\text { https://www-proquest-com.vortex3.uco.edu }>}$

'Fashion: Chanel's Winter Collection', Vogue, 01 October 1923. ProQuest $<$ https://www-proquest-com.vortex3.uco.edu $>$

'Fashion: The Conflicting Lines of the Spring Silhouettes', Vogue, 15 February 1915. ProQuest $<\underline{\text { https://www-proquest-com.vortex3.uco.edu }>}$

'Fashion: A Connoisseur of Fashions', Vogue, 01 April 1916. ProQuest $<$ https://www-proquest-com.vortex3.uco.edu $>$

'Fashion: Cover Dress: The Buster Brown Chemise', Vogue, 01April 1958. ProQuest $<$ https://www-proquest-com.vortex3.uco.edu $>$ 
'Fashion: Day Shift, Night Shift', Vogue, 01 November 1938. ProQuest

$<\underline{\text { https://www-proquest-com.vortex3.uco.edu }>}$

'Fashion: Dispatches from the Openings Read', Vogue, 15 September 1913. ProQuest $<\underline{\text { https://www-proquest-com.vortex3.uco.edu }>}$

'Fashion: Dramatis Persona--Dame Fashion’, Vogue, 15 October 1915. ProQuest $<$ https://www-proquest-com.vortex3.uco.edu $>$

'Fashion: Dressing on a Limited Income', Vogue, 15 November 1920. ProQuest $<$ https://www-proquest-com.vortex3.uco.edu $>$

'Fashion: The Early Paris Openings', Vogue, 01 October 1923. ProQuest $<\underline{\text { https://www-proquest-com.vortex3.uco.edu }>}$

'Fashion: A Finger on the Pulse of Fashion.', Vogue, 15 October 1912. ProQuest $<\underline{\text { https://www-proquest-com.vortex3.uco.edu }>}$

'Fashion: For Vogue's Young Nillionaire-The Trans-Season Dress: In Cotton and Silk’, Vogue, 01 July 1953. ProQuest < $\underline{\text { https://www-proquest- }}$ com.vortex3.uco.edu>

'Fashion: A Forecast of the Spring Mode', Vogue, 01 February 1917. ProQuest $<$ https://www-proquest-com.vortex3.uco.edu $>$

'Fashion: Givenchy', Vogue, 15 October 1957. ProQuest < https://www-proquestcom.vortex3.uco.edu>

'Fashion: A Golf Course in Clothes', Vogue, 13 April 1929. ProQuest < $\underline{\text { https://www- }}$ proquest-com.vortex3.uco.edu>

'Fashion: A Guide to Chic for the Business Woman', Vogue, 15 November 1926. ProQuest $<\underline{\text { https://www-proquest-com.vortex3.uco.edu }>}$ 
Fashion: A Guide to Chic for the Business Woman', Vogue, 15 September 1924. ProQuest $<\underline{\text { https://www-proquest-com.vortex3.uco.edu }>}$

'Fashion: Half-Trumpet Skirt / The Chemise Dress', Vogue, 01 September 1950. ProQuest $<$ https://www-proquest-com.vortex3.uco.edu $>$

'Fashion: Lanvin and Slimness and Youth', Vogue, 15 February 1915. ProQuest $<$ https://www-proquest-com.vortex3.uco.edu $>$

'Fashion: The Mode for the Country'. Vogue, 15 October 1924. ProQuest $<$ https://www-proquest-com.vortex3.uco.edu $>$

'Fashion: The Monte Carlo Idea of Clothes for the Sun Places', Vogue, 01 January 1964. ProQuest $<$ https://www-proquest-com.vortex3.uco.edu $>$

'Fashion: More Taste than Money: The Next 32 Fashions', Vogue, 15 September 1954. ProQuest < https://www-proquest-com.vortex3.uco.edu $>$

'Fashion: New Hat Forms, New Art Forms', Vogue, 01 June 1945. ProQuest $<$ https://www-proquest-com.vortex3.uco.edu $>$

'Fashion: A New Look in American Fashion Based on Legs', Vogue, 1 February 1958. ProQuest $<$ https://www-proquest-com.vortex3.uco.edu $>$

'Fashion: The New Paris Collections', Vogue. 01 September 1951. ProQuest $<\underline{\text { https://www-proquest-com.vortex3.uco.edu }>}$

'Fashion: New Take, the T-Shirt Dress', Vogue, 01 August 1953. ProQuest $<$ https://www-proquest-com.vortex3.uco.edu $>$

'Fashion: New York Conforms to New Rules', Vogue, 01 March 1918. ProQuest $<$ https://www-proquest-com.vortex3.uco.edu $>$ 
'Fashion: Noted at the Paquin Opening', Vogue, 01 October 1913. ProQuest $<$ https://www-proquest-com.vortex3.uco.edu $>$

'Fashion: The Now and Future Paco Rabanne', Vogue, 01 March 1967. ProQuest $<\underline{\text { https://www-proquest-com.vortex3.uco.edu }>}$

'Fashion: Paquin Uses Fulness and Tightness, Half and Half', Vogue, 15 February 1915. ProQuest $<$ https://www-proquest-com.vortex3.uco.edu $>$

‘Fashion: Paris Fashions: Molyneux/Paquin', Vogue, 01 November 1944. ProQuest $<\underline{\text { https://www-proquest-com.vortex3.uco.edu }>}$

'Fashion: Paris: First Reports from September Paris Collections', Vogue, 01 October 1946. ProQuest < $\underline{\text { https://www-proquest-com.vortex3.uco.edu }>}$

'Fashion: Paris Modes are Launched in New York', Vogue, 15 November 1925. ProQuest $<$ https://www-proquest-com.vortex3.uco.edu $>$

'Fashion: Paris the News as we See it', Vogue, 01 September 1965. ProQuest $<\underline{\text { https://www-proquest-com.vortex3.uco.edu }>}$

'Fashion: Paris Points', Vogue, 31 August 1929. ProQuest < https://www-proquestcom.vortex3.uco.edu>

'Fashion: Paris Presents the Pageant of the Spring Mode', Vogue, vol. 65, no. 8, 15 April 1925. ProQuest < $\underline{\text { https://www-proquest-com.vortex3.uco.edu }>}$

'Fashion: Paris Quick Report', Vogue, ProQuest $<$ https://search-proquestcom.vortex3.uco.edu>

'Fashion: Parisian Adaptation of Oriental Fashion', Vogue, 01 November 1910. ProQuest $<\underline{\text { https://www-proquest-com.vortex3.uco.edu }>}$ 
'Fashion: Paris: The Return of Coquetry', Vogue, 15 March 1964. ProQuest $<$ https://www-proquest-com.vortex3.uco.edu $>$

'Fashion: A Portfolio from Six Great Creators', Vogue, 15 October 1924. ProQuest $<\underline{\text { https://www-proquest-com.vortex3.uco.edu }>}$

'Fashion: The Position of the Waistline in America', Vogue, 01 February 1952. ProQuest $<$ https://www-proquest-com.vortex3.uco.edu $>$

'Fashion: Pretty Dinner Frocks for Debutantes’, Vogue, 02 April 1908. ProQuest $<$ https://www-proquest-com.vortex3.uco.edu>

'Fashion: Reception and Calling Gowns', Vogue, 02 April 1908. ProQuest $<$ https://www-proquest-com.vortex3.uco.edu>

'Fashion: Revolution in Looks', Vogue, 01 May 1958. ProQuest < $\underline{\text { https://www- }}$ proquest-com.vortex3.uco.edu>

'Fashion: The Robes of Fortuny', Vogue, 15 December 1912. ProQuest $<$ https://www-proquest-com.vortex3.uco.edu $>$

'Fashion: Sandscapes of 1932', Vogue, 01 January 1932. ProQuest $<$ https://wwwproquest-com.vortex3.uco.edu>

'Fashion: Silhouettes Which Inspire the Spring Mode', Vogue, 15 February 1923. ProQuest < $\underline{\text { https://www-proquest-com.vortex3.uco.edu }>}$

'Fashion: Skirt Lines Going South’, Vogue, 15 November 1941. ProQuest $<\underline{\text { https://www-proquest-com.vortex3.uco.edu }>}$

'Fashion: So Say the Paris Openings', Vogue, 15 March 1914. ProQuest $<\underline{\text { https://www-proquest-com.vortex3.uco.edu }>}$ 
'Fashion: Sparks from the Sun Circuit', Vogue, 15 November 1962. ProQuest $<$ https://www-proquest-com.vortex3.uco.edu $>$

'Fashion: Sports Clothes', Vogue, 15 October 1926. ProQuest < https://www-proquestcom.vortex3.uco.edu>

'Fashion: The Spring Mode in Three Chapters: I. Morning Dress', Vogue, 15 April 1922. ProQuest $<$ https://www-proquest-com.vortex3.uco.edu $>$

'Fashion: The Straw Ballot of the Paris Openings', Vogue, 15 September 1916. ProQuest $<$ https://www-proquest-com.vortex3.uco.edu $>$

'Fashion: They all Like Long Sleeves', Vogue, 01 January 1939. ProQuest $<$ https://www-proquest-com.vortex3.uco.edu $>$

'Fashion: A Trousseau from the Spring Collections', Vogue, 01 April 1925. ProQuest $<\underline{\text { https://www-proquest-com.vortex3.uco.edu }>}$

'Fashion: Uncluttered Sweater Look’, Vogue, 01 January 1945. ProQuest $<$ https://www-proquest-com.vortex3.uco.edu $>$

'Fashion: Vogue’s Eye View: Girl in the Chips’, Vogue, 01 April 1966. ProQuest $<\underline{\text { https://www-proquest-com.vortex3.uco.edu }>}$

'Fashion: Vogue's Own Boutique of Suggestions, Finds, and Observations; Tehran: Boutique’, Vogue, 01 December 1969. ProQuest $<\underline{\text { https://www-proquest- }}$ com.vortex3.uco.edu>

'Fashion: Vogue's 20 Answers: What's New to Wear in the U.S.A', Vogue, 01 September 1958. ProQuest < $\underline{\text { https://www-proquest-com.vortex3.uco.edu }>}$

'Fashion: What She Wears', Vogue, 02 April 1908. ProQuest <https://www-proquestcom.vortex3.uco.edu> 
'Fashion: Woman's Work is Everywhere', Vogue, 01 July 1943. ProQuest $<$ https://www-proquest-com.vortex3.uco.edu $>$

'Fashion: Yesterday Costumes the Dances of To-Day’, Vogue, 15 March 1920. ProQuest < $\underline{\text { https://www-proquest-com.vortex3.uco.edu }>}$

'Fashion: Youthful Costumes', Vogue, 11 October 1926. ProQuest < $\underline{\text { https://www- }}$ proquest-com.vortex3.uco.edu>

'Fashions in Living: Decorating Around One Star Piece', Vogue, 15 February 1960. ProQuest $<$ https://www-proquest-com.vortex3.uco.edu $>$

'Fashions: The Midwinter Smash of White’, Vogue, 01 December 1962. ProQuest $<$ https://www-proquest-com.vortex3.uco.edu $>$

'Fashions of the 1920's', Harper's Bazaar, May 1940. ProQuest < $\underline{\text { https://www- }}$ proquest-com.vortex3.uco.edu>

'Features: Advance News for Retailers', Vogue, 15 March 1944. ProQuest $<$ https://www-proquest-com.vortex3.uco.edu $>$

'Features: Alumnae Marriages', Vogue, 22 February 1906. ProQuest $<\underline{\text { https://www- }}$ proquest-com.vortex3.uco.edu>

'Features/Articles/People: The Biggest Hit in Town - the Guggenheim Museum', Vogue, 01 June 1960. ProQuest $<\underline{\text { https://www-proquest-com.vortex3.uco.edu }>}$

'Features: Followers of Summer Sports’, Vogue, 31 August 1929. ProQuest $<\underline{\text { https://www-proquest-com.vortex3.uco.edu }>}$

'Features: Long Island Tennis’, Vogue, 6 July 1929. ProQuest < $\underline{\text { https://www- }}$ proquest-com.vortex3.uco.edu> 
'Features: Paris', Vogue, 02 April 1908. ProQuest < $\underline{\text { https://www-proquest- }}$ com.vortex3.uco.edu>

'Features: Paris (from our Own Correspondent)’, Vogue, 02 April 1908. ProQuest $<$ https://www-proquest-com.vortex3.uco.edu $>$

Fernandez, Jeanne Ramon, 'Fashion: The World and Paris Grow Simpler’, Vogue, 1 March 1918. ProQuest $<\underline{\text { https://www-proquest-com.vortex3.uco.edu }>}$

'Finds of the Fortnight: Southbound-Classics and Revised Classics', Vogue, 01 January 1939. ProQuest < https://www-proquest-com.vortex3.uco.edu $>$

Fisher, Harrison, in ‘Covers’, Ladies Home Journal, August 1912. ProQuest $<$ https://www-proquest-com.vortex3.uco.edu $>$

—_ in 'Covers', Ladies Home Journal, August 1914. ProQuest < $\underline{\text { https://www- }}$ proquest-com.vortex3.uco.edu>

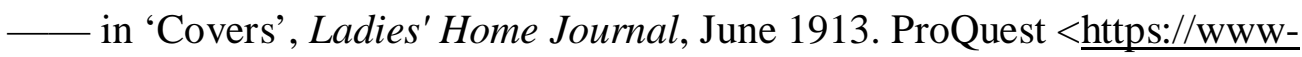
proquest-com.vortex3.uco.edu>

—_ in 'Covers’, Ladies' Home Journal, 15 May 1911. ProQuest < $\underline{\text { https://www- }}$ proquest-com.vortex3.uco.edu>

'The Greatest Period in a Girl's Life: The Honeymoon Abroad', in The Ladies' Home Journal, July 1911. ProQuest < $\underline{\text { https://www-proquest- }}$ com.vortex3.uco.edu>

'The Greatest Period in a Girl's Life: A Series of Six Pictures, of Which This is The Second: The Trousseau', in Ladies' Home Journal, 15 April 1911. ProQuest $<\underline{\text { https://www-proquest-com.vortex3.uco.edu }}>$ 
'The Greatest Period in a Girl's Life: The Supreme Moment--The Proposal', in The Ladies' Home Journal, 15 March 1911. ProQuest < https://www-proquestcom.vortex3.uco.edu>

'The Greatest Period in a Girl's Life: Their First Evening in Their Own Home', in Ladies' Home Journal, August 1911. ProQuest < $\underline{\text { https://www-proquest- }}$ $\underline{\text { com.vortex3.uco.edu }>}$

—_Harrison Fisher's College Girls: The College Girl After the May-Day HoopRolling', in Ladies' Home Journal, March 1908. ProQuest < $\underline{\text { https://www- }}$ proquest-com.vortex3.uco.edu>

_Harrison Fisher's College Girls: The College Girl at Her Studies', in The Ladies’ Home Journal, April 1908. ProQuest < $\underline{\text { https://www-proquest- }}$ com.vortex3.uco.edu>

_ 'Harrison Fisher's College Girls: A Fudge Party', in Ladies' Home Journal, August 1908. ProQuest < https://www-proquest-com.vortex3.uco.edu $>$

__ 'Harrison Fisher's College Girls: The Lady of the Lake’, in Ladies' Home Journal, May 1908. ProQuest < $\underline{\text { https://www-proquest-com.vortex3.uco.edu }>}$

Friend, Margaret Alice, 'Fashion: An Interview with Monsieur Worth’, Vogue, 01 March 1912. ProQuest < $\underline{\text { https://www-proquest-com.vortex3.uco.edu }>}$

'Irene Castle-Star of Patriotic Photo-Play', Cosmopolitan, September 1916. ProQuest $<$ https://www-proquest-com.vortex3.uco.edu $>$

G., E., 'Fashion: Fashion has Met the Enemy and —', Vogue, 01 October 1914. ProQuest $<\underline{\text { https://www-proquest-com.vortex3.uco.edu }>}$

'Happy Birthday!', Seventeen, September 1954. ProQuest $<\underline{\text { https://www-proquest- }}$ com.vortex3.uco.edu> 
'Her Diary’, Ladies' Home Journal, October 1915. ProQuest $<$ https://www-proquestcom.vortex3.uco.edu>

Hillis, Marjorie, 'Fashion: The Spring Mode Drops Hints to Waiting Paris', Vogue, 15 March 1920. ProQuest < $\underline{\text { https://www-proquest-com.vortex3.uco.edu }>}$

Hodges, Parker, 'The Beats: The Beats Like I Think I Know Them’, Seventeen, October 1960. ProQuest <https://www-proquest-com.vortex3.uco.edu $>$

Hooper, Emma M., 'The New Colors and Materials', Ladies Home Journal, September 1893. ProQuest $<\underline{\text { https://www-proquest-com.vortex3.uco.edu }>}$

'How Did It Begin?’, Seventeen, March 1965. ProQuest < $\underline{\text { https://www-proquest- }}$ com.vortex3.uco.edu>

Jordan, Elizabeth, 'In Gay Bohemia’, Good Housekeeping Magazine, March 1914. ProQuest $<\underline{\text { https://www-proquest-com.vortex3.uco.edu }>}$

Klara, Robert, 'Lilly Pulitzer', Adweek, 05 June 2017. ProQuest $<\underline{\text { https://www- }}$ proquest-com.vortex3.uco.edu>

‘Larger Than-Life Prints Go Pop!’, Seventeen, February 1965. ProQuest $<\underline{\text { https://www-proquest-com.vortex3.uco.edu }>}$

L., C.H, 'Fashion: The Survival of the Fittest Fashions', Vogue, 05 April 1912. ProQuest $<$ https://www-proquest-com.vortex3.uco.edu $>$

Lessing, Bruno. “"Alla Napolitana!": Being the Mulberry Street End of a Transoceanic Romance.' Cosmopolitan, August 1908. ProQuest $<$ https://www-proquest-com.vortex3.uco.edu $>$

'The Look of Dior', Town \& Country, March 1997. ProQuest < $\underline{\text { https://www-proquest- }}$ com.vortex3.uco.edu> 
Marcus, Dorothy, 'Both Sides of the Question: Career Wife Versus

Housewife', Hearst's International Combined with Cosmopolitan, January 1947. ProQuest $<$ https://www-proquest-com.vortex3.uco.edu $>$

Mariaux, Hermine, ‘The House That Lilly Lives In’, Town \& Country, January 1968. ProQuest $<$ https://www-proquest-com.vortex3.uco.edu $>$

'Mary Quant's Clean-Cut London Look’, Seventeen, March 1965. ProQuest $<\underline{\text { https://www-proquest-com.vortex3.uco.edu }>}$

‘The Military Look Airs Space-Age Knits’, Seventeen, February 1962. ProQuest $<$ https://www-proquest-com.vortex3.uco.edu $>$

Morris, Gouverneur, ‘The Seven Darlings’, Cosmopolitan, September 1914. ProQuest $<\underline{\text { https://www-proquest-com.vortex3.uco.edu }>}$

Norris, Kathleen, 'My New York: A Little Tale of a Big City’, Ladies' Home Journal, July 1916. ProQuest $<$ https://www-proquest-com.vortex3.uco.edu $>$

'Notes and Comment', The New Yorker, 22 September 1951

Oemler, Marie Conway, ‘Anybody Want this Little Boy?: Why He Longed "Something Terrible" to Live with a Mother', Ladies' Home Journal, February 1915. ProQuest $<$ https://www-proquest-com.vortex3.uco.edu $>$

'Paris Modes Are Launched in New York', Vogue, 15 November 1925. ProQuest $<\underline{\text { https://www-proquest-com.vortex3.uco.edu }}>$

'People and Ideas: Why Aren't You Working?', Vogue, 01 September 1943. ProQuest $<$ https://www-proquest-com.vortex3.uco.edu $>$

'Pick A Card...Any Card', Seventeen, February 1958. ProQuest $<\underline{\text { https://www- }}$ proquest-com.vortex3.uco.edu> 
'Pop Art - Cult of the Commonplace', Time, 03 May 1963. Ebscohost < vortex3.uco.edu/login?url=http://search.ebscohost.com/login.aspx?direct=true $\& \mathrm{db}=$ aph\&AN=54211739\& site=ehost-live $>$ [accessed 12 February 2021]

'Pop! A Belt Can Get You Everywhere', Seventeen, February 1965. ProQuest $<\underline{\text { https://www-proquest-com.vortex3.uco.edu }>}$

'Pop! Belts Go Round The World', Seventeen, February 1965. ProQuest $<$ https://www-proquest-com.vortex3.uco.edu $>$

'Pop! More T's of Every Type', Seventeen, February 1965. ProQuest < $\underline{\text { https://www- }}$ proquest-com.vortex3.uco.edu>

'Pop! What's the Buzz? Zip-Zip-Zip!', Seventeen, February 1965. ProQuest $<\underline{\text { https://www-proquest-com.vortex3.uco.edu }>}$

'Pop! The Zip Looks Always Win', Seventeen, February 1965. ProQuest $<$ https://www-proquest-com.vortex3.uco.edu $>$

'The Power of The Print', Harper's Bazaar, February 1967. ProQuest $<\underline{\text { https://www- }}$ proquest-com.vortex3.uco.edu>

'Room and Board in the Grand Style: Age of World Travel, Part II', Life, 13 July 1962

'Rose Pink, Rose Red: Sea Shirts’, Harper's Bazaar, May 1957. ProQuest $<$ https://www-proquest-com.vortex3.uco.edu $>$

Saarinen, Aline B, 'Features/Articles/People: Explosion of Pop Art', Vogue, 15 April 1963. ProQuest $<$ https://www-proquest-com.vortex3.uco.edu $>$

Schirra, Walter, 'A Real Breakthrough I thought the Capsule was all Mine.’, Life, 26 October 1962 
'Shop Hound: Boutique Hopping...the New York Idea’, Vogue, 15 January 1964.

ProQuest $<$ https://www-proquest-com.vortex3.uco.edu $>$

'Shop Hound: New Sights', Vogue, 01 April 1960. ProQuest < $\underline{\text { https://www-proquest- }}$ com.vortex3.uco.edu>

St. Denis, Ruth, 'Features: The Education of the Dancer', Vogue, 01 April 1917. ProQuest $<$ https://www-proquest-com.vortex3.uco.edu $>$

'Success Story of the Shift Dress', Vogue, 01 December 1938. ProQuest $<$ https://www-proquest-com.vortex3.uco.edu $>$

'Theater: Seen on the Stage', Vogue, 27 August 1908. ProQuest $<\underline{\text { https://www- }}$ proquest-com.vortex3.uco.edu>

'Training for Your Future', Seventeen, June 1953. ProQuest $<$ https://www-proquestcom.vortex3.uco.edu>

Valentine, Helen, 'Seventeen Says Hello’, Seventeen, September 1944. ProQuest $<$ https://www-proquest-com.vortex3.uco.edu $>$

Vogel, Bertram, ‘A Divorce Every Minute!’, Redbook, January 1947. ProQuest < https://www-proquest-com.vortex3.uco.edu >

'Vogue Designs for Dressmaking: Midwinter Pick-Up’, Vogue, 01 January 1939. ProQuest $<$ https://www-proquest-com.vortex3.uco.edu $>$

'Vogue Designs for Dressmaking: Ways to Snip Sewing-Time." Vogue, 15 February 1943. ProQuest < https://www-proquest-com.vortex3.uco.edu $>$

'Vogue's Eye View: The Ten Great Plays of 1938.', Vogue, 01 January 1939. ProQuest < $\underline{\text { https://www-proquest-com.vortex3.uco.edu }>}$ 
'Vogue's Fortnightly Wardrobe', Vogue, 15 June 1927. ProQuest < https://wwwproquest-com.vortex3.uco.edu>

'Vogue's Own Boutique', Vogue, 01 December 1966. ProQuest $<$ https://wwwproquest-com.vortex3.uco.edu>

'Vogue's Own Boutique: A Head of Hair', Vogue, 15 Feburary 1969. ProQuest $<$ https://www-proquest-com.vortex3.uco.edu $>$

'Vogue's Own Boutique: Leaping Lizards', Vogue, 15 October 1969. ProQuest $<$ https://www-proquest-com.vortex3.uco.edu $>$

'Vogue's Own Boutique: Los Angeles: Boutiqueing with the Sparkles/Yes, Elizabeth Ashley...', Vogue, 01 February 1967. ProQuest < https://www-proquestcom.vortex3.uco.edu>

'Vogue’s Society Supplement: Art', Vogue, 03 March 1904. ProQuest < $\underline{\text { https://www- }}$ proquest-com.vortex3.uco.edu>

Weymouth, Margaret J., 'The Perfectionist Housewife: Meet Max and Marjorie Reeves, of Peoria Illinois’, Ladies' Home Journal, September 1946. ProQuest $<\underline{\text { https://www-proquest-com.vortex3.uco.edu }>}$

'Women on the March', Time, 07 September 1970, on microfilm reel 84

Worden, Ann, and Anne Anderson, 'Exciting Trends in Today's Kitchens', Better Homes and Gardens, August 1956. ProQuest < $\underline{\text { https://www-proquest- }}$ com.vortex3.uco.edu>

Wylie, Philip, 'What's Wrong with American Marriages?', Hearst's International Combined with Cosmopolitan, June 1946. ProQuest < https://www-proquestcom.vortex3.uco.edu> 
'You'll Find Yourself Sleeveless', Harper’s Bazaar, April 1944. ProQuest

$<$ https://www-proquest-com.vortex3.uco.edu $>$

'Young Headliners Arrive From England!', Seventeen, September 1963. ProQuest $<\underline{\text { https://www-proquest-com.vortex3.uco.edu }>}$

\section{Newspapers}

‘1947 Brought Revaluation in World of Fashion’, The Globe and Mail, 02 January 1948. ProQuest https://www-proquest-com.vortex3.uco.edu

Andrews, Marshall, 'Family is Losing Importance in Society, Educator Says: Family is Losing Importance in Society, Educator Says', The Washington Post, 07 May 1948. ProQuest < $\underline{\text { https://www-proquest-com.vortex3.uco.edu }>}$

'Ballrooms Lit by Electricity with Colored Rays-White Dress Suits for Men’, New York Times, 09 April 1893. ProQuest $<\underline{\text { https://www-proquest- }}$ com.vortex3.uco.edu>

Barry, Richard. 'Female Labor Arouses Hostility: Union Leader Asserts That Men Workers Regard Substitutions as Exploitation of the Weaker Sex. Unnecessary as Yet and Tending to Cause Industrial Unrest’, New York Times, 20 January 1918. ProQuest < $\underline{\text { https://www-proquest-com.vortex3.uco.edu }>}$

Beck, Joan, 'Many Bid for Teens' Dollars: Book Advises Youth on Spending Wisely’, Chicago Daily Tribune, 01 October 1959. ProQuest < https://www-proquest$\underline{\text { com.vortex3.uco.edu }>}$

_ ‘ Teens are Taking Over and it is just a Beginning’, Chicago Daily Tribune, 08 October 1959. ProQuest < https://www-proquest-com.vortex3.uco.edu $>$ 
Bedwell, Bettina, 'Sheath Dresses Offer Variety; Save Material.’, Chicago Daily

Tribune, 11 April 1943. ProQuest < https://www-proquestcom.vortex3.uco.edu>

Bender, Marylin. 'Is this Courrèges Vision of Space-Age Women?', New York Times, 28 May 1965. ProQuest < $\underline{\text { https://www-proquest-com.vortex3.uco.edu }>}$

'Many Styles of Summer are in Shops: Separates Galore Beach Accessories’, New York Times, 19 July 1962. ProQuest < https://www-proquestcom.vortex3.uco.edu>

'Black Cat Raided By Police Squad:: ....Marked Usually By Bobbed Hair and Smocks', New York Times, 28 November 1920. ProQuest < $\underline{\text { https://www- }}$ proquest-com.vortex3.uco.edu>

Bland, Karina, ‘Movement’s Pivotal Moment: How the 1968 Miss America Protest Put Women’s Liberation in Spotlight', Arizona Republic, 25 November 2018. ProQuest $<<$ https://www-proquest-com.vortex3.uco.edu $>$

Bracker, Milton, Special to The New York Times, 'Vanguard Rocket Burns on Beach; Failure to Launch Test Satellite Assailed as Blow to U.S. Prestige: Sphere Survives But Carrier Rises Only 2 to 4 Feet Before Flames Wreck it Satellite Undamaged Data to be Studied Satellite Rocket Burns on Beach According to Plan’, New York Times, 07 December 1957. < $\underline{\text { https://www-proquest- }}$ com.vortex3.uco.edu>

'Breaks from Old Guard: Givenchy Changes Mind, Opens Boutique', The Globe and Mail, 05 March 1968. ProQuest < https://www-proquest-com.vortex3.uco.edu $>$

Bureau, Paris, ‘St. Laurent: Look Raffiné: Buyers Don’t Give a Fig for Yves’ Eve’, Women’s Wear Daily, 04 August 1964. ProQuest < https://www-proquest$\underline{\text { com.vortex3.uco.edu }>}$ 
Cahill, Jane, 'Patricia Ponders when to Bounce for Spring: Ideas and Fashions for Smaller Stores’, Women’s Wear Daily, 07 December 1962. ProQuest $<\underline{\text { https://www-proquest-com.vortex3.uco.edu }>}$

‘Campaign for Sensible Garb for Business Women’, Women’s Wear, 01 May 1922. ProQuest $<$ https://www-proquest-com.vortex3.uco.edu

Carter, Joyce, 'Long Sleeves for a Winter without Shivers', The Globe and Mail, 08 December 1962. ProQuest < $\underline{\text { https://www-proquest-com.vortex3.uco.edu }>}$

Chatov, Lillian, 'Looking Towards Holiday-Resort...: Juniors: Dresses: Young Designers Air Views’, Women’s Wear Daily, 09 August 1960. ProQuest $<\underline{\text { https://www-proquest-com.vortex3.uco.edu }>}$

'City to Open Dance Halls’, The Christian Science Monitor, 03 May 1913. ProQuest $<$ https://www-proquest-com.vortex3.uco.edu

Cleave, Maureen, 'Mary Quant, Limited-- Kinky Success Story: Mary Quant’, New York Times, 19 March 1967. ProQuest < $\underline{\text { https://www-proquest- }}$ com.vortex3.uco.edu>

Cunningham, Bill, ‘Article 7 -- no Title’, Chicago Tribune, 26 August 1968. ProQuest $<$ https://www-proquest-com.vortex3.uco.edu $>$

'Cupids Teaches American Ways to Emigrants Recent Arrivals in Chicago.', Chicago Tribune, 08 September 1907. ProQuest <https://www-proquestcom.vortex3.uco.edu>

Curtis, Charlotte, 'Beach Shift Now Popular on Terraces', New York Times, 30 May 1962. ProQuest $<$ https://www-proquest-com.vortex3.uco.edu $>$

_- Special to The New York Times, 'Lilly's Life as Casual as a Lilly Dress: Designer Finds That Her Colorful Shifts Go Anywhere', New York Times, 13 March 1965. ProQuest < $\underline{\text { https://www-proquest-com.vortex3.uco.edu }>}$ 
‘Custom Apparel a Feature of Boutique', New York Times, 30 April 1963. ProQuest $<$ https://www-proquest-com.vortex3.uco.edu $>$

‘Dance Halls Invade North Side Society’, Chicago Daily Tribune, 30 October 1910. ProQuest < $\underline{\text { https://www-proquest-com.vortex3.uco.edu }>}$

'Dancing Reform', The Washington Post, 28 October 1912. ProQuest $<\underline{\text { https://www- }}$ proquest-com.vortex3.uco.edu>

de Faucon, Countess, 'New Look’s Creator Goes Conventional', Chicago Daily Tribune, 11 February 1948. ProQuest < $\underline{\text { https://www-proquest- }}$ com.vortex3.uco.edu>

'De Givenchy Goes “Surrealist”', Chicago Daily Tribune, 27 August 1957. ProQuest $<\underline{\text { https://www-proquest-com.vortex3.uco.edu }>}$

'Debutantes Don Frilly Pantaloons at Gay Palm Beach Costume Ball: Ballet-Like Dresses Reaching to Knees, Finished Off by Trousers to the Ankles, Are Worn - One Pretty Girl Appears in Fluffy White Chiffon a la Isadora Duncan', The Washington Post, 09 March 1915. ProQuest $<\underline{\text { https://www-proquest- }}$ com.vortex3.uco.edu>

Decaux, Jacques, ‘The "New Look” In World Politics', The China Weekly Review, 05 June 1948. ProQuest < $\underline{\text { https://www-proquest-com.vortex3.uco.edu }>}$

Devree, Howard, ‘In Retrospect: Mondrian’s Long Voyage of Discovery -Diversity of Modern Sculpture Sculpture Survey', New York Times, 15 December 1957. ProQuest $<$ https://www-proquest-com.vortex3.uco.edu $>$

Diamond, Edwin, 'That Moon Trip: Debate Sharpens: The U.S. Plans to Send Three Men to the Moon within the Decade. _ Now the Question is being Asked: Is this Trip Necessary? That Moon Trip’, New York Times, 28 July 1963, ProQuest $<$ https://www-proquest-com.vortex3.uco.edu $>$ 
Diderich, Joelle, ‘Eye: Palais Galliera Stages First Paris Retrospective on Mariano Fortuny: "Fortuny, a Spaniard Venice" Caps the Fashion Museum's Spanish Season', WWD, 05 October 2017. ProQuest $<\underline{\text { https://www-proquest- }}$ $\underline{\text { com.vortex3.uco.edu }>}$

'Display Ad 7 -- no Title’, New York Times, 28 March 1915. ProQuest < $\underline{\text { https://www- }}$ proquest-com.vortex3.uco.edu>

‘Display Ad 49 -- no Title’, Chicago Daily Tribune, 01 November 1962. ProQuest $<$ https://www-proquest-com.vortex3.uco.edu

‘Dresses: Frock of Ecru Lace’, Women’s Wear, 24 March 1917. ProQuest $<\underline{\text { https://www-proquest-com.vortex3.uco.edu }>}$

'Dresses: Gimbel Brothers in Milwaukee Hold Fashion show for Business Women', Women's Wear Daily, 22 April 1929. ProQuest < https://www-proquestcom.vortex3.uco.edu>

'Dresses: Private Display of Business Women's Wear in Cleveland', Women's Wear, 30 September 1924. ProQuest < https://www-proquest-com.vortex3.uco.edu $>$

'Dresses: Says Misses' Dress Market Can Learn from Juniors: Designer Believes Juniors Give Taste, Freshness, Sophistication, Sizing to Satisfy Customer Demand’, Women’s Wear Daily, 27 April 1954. ProQuest < $\underline{\text { https://www- }}$ proquest-com.vortex3.uco.edu>

'Dresses: To use Poster and Movies to Spur Sales of Dresses: Lefkowitz \& Raschke to Merchandise Frocks by Exploitation of Life-Size Picture of Screen Star on Poster’, Women’s Wear, March 20, 1926. ProQuest < $\underline{\text { https://www-proquest- }}$ com.vortex3.uco.edu>

Duncan, Isadora, ‘The Well-Known American Dancer, and Idealist. "Oh! Shame on America!: Isadora Duncan Leaves Us...."', Washington Post, 14 March 1915. ProQuest $<\underline{\text { https://www-proquest-com.vortex3.uco.edu }>}$ 
'Elinor Glyn Defines “The Perfect Daughter”: Famous Novelist, Mother of Two Charming Girls, Gives Her Conception of the Ideal and Tells What's Wrong with the Younger Generation Today - It is Largely a Matter of Early Training, Says She, Discussing the Flapper Type’, Washington Post, 27 July 1924. ProQuest $<$ https://www-proquest-com.vortex3.uco.edu $>$

Elsie, Janis, ‘If I Know what I Mean’, Washington Post, 24 February 1924. ProQuest $<$ https://www-proquest-com.vortex3.uco.edu $>$

Emerson, Gloria, ‘New Courrèges Boutique: Heaven One Flight Down’, New York Times, 03 March 1967. ProQuest < $\underline{\text { https://www-proquest- }}$ com.vortex3.uco.edu>

‘News of Fashion: New Yves St. Laurent Boutique’, New York Times, 07 October 1965. ProQuest $<$ https://www-proquest-com.vortex3.uco.edu $>$

—_St. Laurent and Givenchy’, New York Times, 03 August 1965. ProQuest $<\underline{\text { https://www-proquest-com.vortex3.uco.edu }>}$

'Exit the Flapper Via Long Skirts: Fifth Avenue Fashion Arbiters Prophesy That Her Type Will Disappear. Fighting a Losing Battle Her Costumes and Manners Destilled to Join Gibson Girl in Attic Trunks. Why Flapper Styles Will Vanish. The Original Flapper’, New York Times, 25 June 1922. ProQuest $<$ https://www-proquest-com.vortex3.uco.edu $>$

‘Eye’, Women’s Wear Daily, 03 September 1964. ProQuest < $\underline{\text { https://www-proquest- }}$ com.vortex3.uco.edu>

‘The Fable of the Flapper', The Mansfield News, 13 August 1922.

$<$ https://newspaperarchive.com/us/ohio/mansfield/mansfield-news/1922/08$\underline{13}>$ [accessed 20 February 2021]

'Fair Sex Travels More Than Men’, The Washington Post, Times Herald, 28 August 1966. ProQuest < https://www-proquest-com.vortex3.uco.edu $>$ 
Fairchild, John B., 'U. S. Style Leaders in Paris Back Shorter Skirt Decree: Top Fashion Minds Forecast Lengths Just Below Knee are due for Spring Selling.', Women's Wear Daily, 01 August 1957. ProQuest < $\underline{\text { https://www- }}$ proquest-com.vortex3.uco.edu>

'Fashions: Style Hints for Fall Draping in Long Lines the Long Cost. Beads for Trimming. Straight Versus Bouffant Lines. Draping in Long Lines. Embroidery. Hats Growing Larger. Length of Skirts’, New York Times, 25 June 1922. ProQuest $<\underline{\text { https://www-proquest-com.vortex3.uco.edu }>}$

'Features: Why Paris is Great: Friday at St. Laurent Salon', Women's Wear Daily, 09 August 1965. ProQuest < $\underline{\text { https://www-proquest-com.vortex3.uco.edu }>}$

'Feminist Inhabitants of a Feminist Village', New York Tribune, 27 December 1914. $<$ https://chroniclingamerica.loc.gov/lccn/sn83030214/1914-12-27/ed-1/seq27/> [accessed 10 February 2021$]$

Finney, John W. 'U.S. Found to Lag in Race to Space: Pentagon Survey Cities Soviet Gain in Ballistics Missiles as Shown by Satellites Soviet Claims Appraised Accuracy is in Doubt U.S. Separates Programs', New York Times, 06 November 1957. < $\underline{\text { https://www-proquest-com.vortex3.uco.edu }>}$

'The First Lady of Fashion: She Was the Most Stylish Presidential Wife in U.S. History - A Truly Global Icon. Fifty Years After the Tragedy that Left Her a Widow at 34, the Pictures that Reveal the Real Woman Behind the Public Face [Eire Region]', Daily Mail, 16 November 2013. ProQuest $<\underline{\text { https://www- }}$ proquest-com.vortex3.uco.edu>

Frankel, Max, ‘Izvestia Gloats at U.S. “Hysteria”: Boasts Satellites Prove Soviet Superiority_Calls Americans Uncultured', New York Times, 21 November 1957. ProQuest < https://www-proquest-com.vortex3.uco.edu $>$ 
Freeman, William M., 'Textile Outlook Termed Brighter: Gainsbrugh Says Industry May Be Able to Halt Drop in Apparel Spending Five Factors Listed Economist Also Tells Cotton Institute Inventories of Retailers Are Low Textile Outlook Termed Brighter', New York Times, 21 March 1959. ProQuest $<\underline{\text { https://www-proquests-com.vortex3.uco.edu }}>$

Froio, Etta, 'Sportswear Designers' Summer Plan: Beach Shifts, No Sleeves, Bold Prints, Lots of White', Women’s Wear Daily, 17 January 1961. ProQuest $<$ https://www-proquest-com.vortex3.uco.edu $>$

'Fur Skirt Latest Novelty.: Poiret Plans to Keep the Flappers Warm Next Winter.', New York Times, 19 June 1927. ProQuest < $\underline{\text { htps://www-proquest- }}$ com.vortex3.uco.edu>

G, C. S., 'Films with Doubtful Influence’, Chicago Daily Tribune, 21 April 1929. ProQuest $<$ https://www-proquest-com.vortex3.uco.edu $>$

A Girl Candidate’, New York Times, 06 November 1927. 'Fable of the Flapper', Mansfield News, 13 August 1922. ProQuest < $\underline{\text { htps://www-proquest- }}$ com.vortex3.uco.edu>

Grandpa's Nightshirt Makes Good', Washington Post and Times Herald, 28 August 1957. ProQuest < https://www-proquest-com.vortex3.uco.edu $>$

Grant, Jane, 'The Charleston Prances Into Favor: New Dance Comes on Swiftly, but it Has Not Reached the Ballrooms of New York', New York Times, 30 August 1925. ProQuest < https://www-proquest-com.vortex3.uco.edu $>$

‘High Honors for Woman Engineer,’ New York Times, 10 January 1926.

ProQuest $<\underline{\text { https://www-proquest-com.vortex3.uco.edu }}>$ 
'Greenwich Village a Quaint Bit of Gotham', Tensas Gazette, 12 January 1917.

$<$ [https://chroniclingamerica.loc.gov/lccn/sn87090131/1917-01-12/ed-1/seq1/\#date1=1836\&index=1\&date2=1922\&searchType=advanced\&language $=\& \mathrm{~s}$ equence $=0 \&$ words $=$ Greenwich + village + Village $\&$ proxdistance $=5 \&$ state $=$ Loui siana\&rows=20\&ortext=\&proxtext=greenwich+village\&phrasetext=\&andtext $=\&$ dateFilterType=yearRange\&page $=1>$ [accessed 10 February 2021] (image 1, col. 3).

Hanenberg, Paul, 'The Sportswear \& Leisure Living: Pop Art may Paint Big Sales “Canvas””, Women's Wear Daily, 03 February 1965. ProQuest < $\underline{\text { https://www- }}$ proquest-com.vortex3.uco.edu>

'The Sportswear and Leisure Living: Shifts Move into High Gear as More Women Learn Comfort Features; Available at all Prices', Women's Wear Daily, 27 March 1963. ProQuest < $\underline{\text { https://www-proquest- }}$ com.vortex3.uco.edu>

‘Harry Collins Talks on “Dress of our Times”', Women’s Wear, 25 April 1922. ProQuest $<$ https://www-proquest-com.vortex3.uco.edu $>$

Her Eternal Youth', New York Times, 02 July 1922. 'Fable of the Flapper', Mansfield News, 13 August 1922. ProQuest < com.vortex3.uco.edu>

Higgins, Shirley R., 'Basic Cruise Rules for Women Who Travel Alone', Chicago Tribune, 28 November 1965. ProQuest < https://www-proquestcom.vortex3.uco.edu>

'Housewives Hit the Road', The Washington Post, Times Herald, 27 March 1966. ProQuest < $\underline{\text { https://www-proquest-com.vortex3.uco.edu }>}$

'How They Look in Civies: These Are Actual Sketches Made By Our Artist of Actresses in Chicago Last Week’, Chicago Daily Tribune, 18 March 1923. ProQuest $<\underline{\text { https://www-proquest-com.vortex3.uco.edu }>}$ 
Huxtable, Ada Louise, ‘That Museum: Wright or Wrong: Frank Lloyd Wright's Unconventional Structure Has Opened Amid Fiery Debate. Is it a Museum, or a Monument to Mr. Wright? That Museum’, New York Times, 25 October 1959. ProQuest $<$ https://www-proquest-com.vortex3.uco.edu $>$

'What should a Museum Be: It Should, Says a Critic, be a Fusion of Art and Architecture. But, in Many New Examples, They Threaten Not to Fuse. What Should A Museum Be?’, New York Times, 08 May 1960. ProQuest $<\underline{\text { https://www-proquest-com.vortex3.uco.edu }>}$

Ida, Jean Kain, 'Three Moderate Meals a Day Will Help You Wear the "New Look” Fashions', Washington Post, 27 September 1947. ProQuest < $\underline{\text { https://www- }}$ proquest-com.vortex3.uco.edu>

'The Infants_-Children: Birmingham Teens Go for Shirt-Shifts', Women's Wear Daily, 06 July 1964. ProQuest < $\underline{\text { https://www-proquest-com.vortex3.uco.edu }>}$

'The Infants_Children: Lytton's Enlarges Pre-Teen Department', Women's Wear Daily, 27 May 1968. ProQuest < https://www-proquest-com.vortex3.uco.edu>

'It was a Great Day for Women on the March', New York Times, 30 August 1970. ProQuest < $\underline{\text { https://www-proquest-com.vortex3.uco.edu }>}$

Jorden, William J., '560 Miles High: Visible with Simple Binoculars, Moscow Statement Says Due Over Moscow Today Five Miles a Second Several Years of Study Soviet Launches Earth Satellite an Aid to Scientists Hinted of Launching', New York Times, 05 October 1957. <https://www-proquestcom.vortex3.uco.edu>

Karr, Arnold J., 'Designer Lilly Pulitzer, 81’, Women’s Wear Daily, 08 April 2013. ProQuest < $\underline{\text { https://www-proquest-com.vortex3.uco.edu }>}$

‘Kaufman's Widens Youth Operation’, Women’s Wear Daily, 06 August 1963. ProQuest $<$ https://www-proquest-com.vortex3.uco.edu $>$ 
Koltun, Frances, 'Pick Travel Buddy with Care: The Woman Traveler', The Washington Post, Times Herald, 28 April 1968. ProQuest < $\underline{\text { https://www- }}$ proquest-com.vortex3.uco.edu>

““La Loie Fuller”: An American Maid Who Has Created a Style in Paris’, Daily American, 02 June 1893. ProQuest < com.vortex3.uco.edu>

Livingstone, Evelyn, 'Paris Silhouette--Just a Hint of Figure--Put on Parade Here’, Chicago Daily Tribune, 10 September 1957. ProQuest $<\underline{\text { https://www- }}$ proquest-com.vortex3.uco.edu>

Lowry, Helen Bullitt, ‘A Conspiracy in Restraint: A Conspiracy in Restraint', New York Times, 09 October 1921. ProQuest < $\underline{\text { https://www-proquest- }}$ com.vortex3.uco.edu>

Luther, Marylou, 'New York Varies Paris Theme: Sack Most Popular at Medium Prices’, Chicago Daily Tribune, 31 December 1957. ProQuest $<\underline{\text { https://www- }}$ proquest-com.vortex3.uco.edu>

'Many Fashions for Women are Created by Mere Man: Male Sex is Best Judge of Feminine Appearance, Says Lucian Lelong, Paris Coutourier’, New York Times, 08 November 1925. ProQuest < $\underline{\text { https://www-proquest- }}$ com.vortex3.uco.edu>

Mantle, Burns, 'The Theatrical Season Gets a Good Start in New York', Chicago Daily Tribune, 25 August 1914. ProQuest < $\underline{\text { https://www-proquest- }}$ com.vortex3.uco.edu>

Martyn, Marguerite, 'My Goodness but a New Rip Van Winkle Would Get a Terrible Shock Today’, St.Louis Post - Dispatch, 19 February 1921. ProQuest $<\underline{\text { https://www-proquest-com.vortex3.uco.edu }>}$ 
MCCarty, Agnes. 'Winners: Young Designers, Youthful Fashions: Quartet of Local Designers Honored with Coty Awards’, New York Times, 03 October 1955. ProQuest $<\underline{\text { https://www-proquest-com.vortex3.uco.edu }>}$

McCormick, Patricia, 'Teen Tastes Count’, Washington Post, Times Herald, 25 May 1960. ProQuest <https://www-proquest-com.vortex3.uco.edu>

McDowell, Mary E., ‘War Opens New Fields of Work for Young Women’, Chicago Daily Tribune, 14 October 1917. ProQuest < https://www-proquestcom.vortex3.uco.edu>

McElliott, Mabel, 'Irene Castle’, Chicago Daily Tribune, 26 August 1918. ProQuest $<\underline{\text { https://www-proquest-com.vortex3.uco.edu }>}$

Menkes, Suzy, 'Dior Takes Manhattan: 50 Years on, a New 'New Look’?, [2 ${ }^{\text {nd }}$ Edition]', International Herald Tribune, 10 December 1996. ProQuest< https://www-proquest-com.vortex3.uco.edu>

Mitgang, Herbert, 'Sidewalk Views of That Museum: On Upper Fifth Avenue the Talk is of the New Wright-designed Guggenheim Museum. Is it a Marvel or a Monstrosity? Views of That Museum’, New York Times, 12 October 1958. ProQuest $<\underline{\text { https: } / / \text { www-proquest-com.vortex3.uco.edu }>}$

Moore, Kathryn Cates, 'Woman Suffrage Was a Long Fought Battle in Nebraska’, Lincoln Journal Star, 14 August 2010. < https://journalstar.com/lifestyles/misc/woman-suffrage-was-a-long-foughtbattle-in-nebraska/article_accee85a-a65f-11df-b727-001cc4c002e0.html> [accessed 10 February 2021]

Morris, Bernadine, 'Chemise Returns at Saint Laurent', New York Times, late edn, 28 July 1983. ProQuest $<$ https://search-proquest-com.vortex3.uco.edu $>$ 
'Mrs. Berlin Writes on The Charleston: Former Ellin Mackay Says Step Captured Fifth Avenue, Which Strives to Learn it. Hails Prestige of Chorus Society Acquiring Respect for the Dancing Girls, She Asserts, by Trying to Rival Them.', New York Times, 07 February 1926. ProQuest < $<$ https://wwwproquest-com.vortex3.uco.edu>

‘Mrs. Castle’s Gowns A Momentous Question’, New York Times, 21 March 1915. ProQuest $<$ https://www-proquest-com.vortex3.uco.edu $>$

Nelson, Lars-Erik, 'Jacqueline Kennedy Onassis - A City Mourns Family Was Her Priority a First Lady Who Charmed a Generation', Newsday, 21 May 1994. ProQuest $<$ https://www-proquest-com.vortex3.uco.edu $>$

Nemy, Enid, 'Everybody, almost, is in the Mondrian Race', New York Times, 20 August 1965. ProQuest < https://www-proquest-com.vortex3.uco.edu $>$

'New Concept in Sweater Makes it Star in any Wardrobe’, New York Times, 19 April 1955. ProQuest < https://www-proquest-com.vortex3.uco.edu $>$

““New Look” Styles Give Gentleness, Rhythm and Symmetry to Women so the Trade Says', The Globe and Mail, 23 September 1947. ProQuest < https://wwwproquest-com.vortex3.uco.edu>

'New York Like Rome: Magistrate Compares Morals to Times of Caesars. Public Drinking Increases Low-Cut Gowns at Opera and Taking of Young Women to Immodest Shows Not Worst of Evil, Which Extends to Dances of Poorer Classes in Public Halls - Aping Dress of Trial Heroine’, Washington Post, 19 January 1908. ProQuest < https://www-proquest-com.vortex3.uco.edu $>$

O’Kane, Lawrence, ‘10,000 Flock to Wright Museum, But Only 6,039 Manage to Get In: Art Lovers and Tourists Queue Up on Upper 5th Ave. -- Some See Just the Cafeteria from the Outside’, New York Times, 26 October 1959. ProQuest $<\underline{\text { https://www-proquest-com.vortex3.uco.edu }>}$ 
Paris Bureau: Cable Fairchild News Services, 'St. Laurent: Look Raffiné: Buyers Don’t Give a Fig for Yves’ Eve', Women’s Wear Daily, 04 August 1964. ProQuest $<\underline{\text { https://www-proquest-com.vortex3.uco.edu }>}$

Phillips, McCandlish, 'Attendance Soars at Museums Here: Revitalized Outlook of Museum Curators Pays Off in Attendance-Records Years Since War Marked by Rise Metropolitan was in a Peak Period Even Before it Brought Rembrandt', New York Times, 27 November 1961. ProQuest < https://wwwproquest-com.vortex3.uco.edu>

Pinsker, Essie, 'Resident Buyers Report:: Active \& Casual Outerwear, Blouses, Skirts, Knitwear, Swimwear Sportswear and Separates: Enthusiasm for Chemise Dress Mounts as Season Gets Under Way: Semi-Fit Styles Best: Knits, Silk, Linen Active’, Women’s Wear Daily, 05 February 1958. ProQuest $<$ https://www-proquest-com.vortex3.uco.edu $>$

‘Polite Dances are Shown to Society’, New York Times, 26 March 1912. ProQuest $<$ https://www-proquest-com.vortex3.uco.edu $>$

'Praise for Flappers', Washington Post, 25 April 1922. ProQuest $<\underline{\text { https://www- }}$ proquest-com.vortex3.uco.edu>

Preston, Stuart, 'First Moves on the 1962 Exhibition Front: Mondrian, Eugenie Baizerman and Some Contemporary Americans Stylistic Poet Happy Union for the Cognoscenti American in Rome', New York Times, 07 January 1962. ProQuest $<\underline{\text { https://www-proquest-com.vortex3.uco.edu }>}$

'The Forerunners: Show Recalls Abstract Beginnings - Contemporary American Artists’, New York Times, 31 January 1960. ProQuest < $\underline{\text { https://www-proquest- }}$ com.vortex3.uco.edu> 
President's Message to Congress Deals with Nearly Every National Problem: Urges Law Specifically Providing for Naturalization of Japanese-If Insurrection Becomes a Habit in Cuba the Island Cannot Remain Independent. More Complete Federal Control of Corporations is Declared Necessary. Takes a Firm Stand on Side of Congress Deals with Nearly Every National Problem Takes a Firm Stand on Side of the Japanese in the School Controversy Recommends Legislation to Control Divorce-Points Out the Wisdom of Ship Subsidy and Favors Change in Currency System, But is Silent on the TariffWould Increase the Navy by Building One Big Battle-Ship a Year', Washington Post, 05 December 1906. ProQuest < $\underline{\text { https://www-proquest- }}$ com.vortex3.uco.edu>

Raymond, Jack. "Bridges and Stennis Seek A Powerful Missiles Chief: Soviet Missiles Assessed Quantity Output Likely Bridges and Stennis Bid U.S. Appoint Powerful Missile Chief Killian Called Adviser’, New York Times, 24 November 1957. < $\underline{\text { https://www-proquest-com.vortex3.uco.edu }>}$

'Recent Activities in the Society World: Triumphal Return of Isadora Recalls Early Life in Chicago', Chicago Tribune, 26 March 1911. ProQuest < $\underline{\text { https://www- }}$ proquest-com.vortex3.uco.edu>

‘Reform in Dance Halls’, Chicago Daily Tribune, 26 November 1914. ProQuest $<\underline{\text { https://www-proquest-com.vortex3.uco.edu }>}$

'Retail Promotion — Store News: Dress Well Slogan used in Business Women's Ads', Women’s Wear Daily, 29 July 1924. ProQuest < $\underline{\text { https://www-proquest- }}$ com.vortex3.uco.edu>

Rosen, Roslyn, 'Housewives-A Little Misery is O.K.', Chicago Daily Tribune, 13 October 1957. ProQuest, <https://search-proquest-com.vortex3.uco.edu>

Ross, Nancy L., 'A Legacy of Fashion: "Suiting Everyone”: “Suiting Everyone”, Appreciating Fashion’s Legacy’, Washington Post, 15 September 1974. ProQuest $<\underline{\text { https://www-proquest-com.vortex3.uco.edu }>}$ 
'Ruth St. Denis Defends Her Art--What She Thinks of Local Critic Who Assailed It', Nashville Tennessean and the Nashville American, 18 April 1914. ProQuest $<\underline{\text { https://www-proquest-com.vortex3.uco.edu }>}$

'Sack's Success: The Men Still Grumble but New Dress Style Passes Big Sales Test Dressmakers, Stores Jubilant; Chemise Also Bows in Bathing Suits, Sweaters Mr. Pepys and a 1669 “Sac” Sack’s Success: Men Still Grumble but Dress Retailers Are Jubilant', Wall Street Journal, 29 April 1958. ProQuest $<$ https://www-proquest-com.vortex3.uco.edu $>$

Samuels, Gertrude, 'Why They Rock 'n' Roll -- And Should They?: The Big Beat is More Insistent Than Ever and the Younger Generation is All Shook Up. A Reporter Attempts to Explain What It All Means. Why They Rock 'n' Roll', New York Times, 12 January 1958. ProQuest < https://www-proquestscom.vortex3.uco.edu>

'Says Business Here Won’t Suffer in War', New York Times, 08 February 1918. ProQuest $<\underline{\text { https://www-proquest-com.vortex3.uco.edu }>}$

Scott-Fisher, Barbara E., ““New Look” Built-Up Waistlines Promoted by Styles in Corsets: Like Old-Time Garters Black Lace Over Satin’, The Christian Science Monitor, 10 December 1947. ProQuest $<\underline{\text { https://www-proquest- }}$ com.vortex3.uco.edu>

Seeger, Rea, 'Curve Control Under “The New Look” is Vital', Chicago Daily Tribune, 16 October 1947. ProQuest < https://www-proquestcom.vortex3.uco.edu>

Settle, Alison, 'Background Of “New Look”: Bid To Focus All Eyes On French Textile Trade', The Scotsman, 18 February 1948. ProQuest < $\underline{\text { https://www- }}$ proquest-com.vortex3.uco.edu> 
'The Paris Shows: “New Look” Established', Observer, 08 February 1948.

ProQuest $<\underline{\text { https://www-proquest-com.vortex3.uco.edu }>}$

'Shirts Over Sheaths, Abstract Inserts', Women’s Wear Daily, 11 February 1959.

ProQuest $<$ https://www-proquest-com.vortex3.uco.edu $>$

'Skirts Will be Shortest Ever, Modesties Say’, Los Angeles Times, 16 March 1925.

ProQuest $<$ https://www-proquest-com.vortex3.uco.edu $>$

Special Cable to The New York Times, 'Dances Shocked Paris: Flimsy Draperies Now Barred-Miss Duncan Coming Home in a Temper’, New York Times, 17

December 1911. ProQuest < $\underline{\text { https://www-proquest-com.vortex3.uco.edu }>}$

Special Cable to the Post-Dispatch and New York World, 'Isadora Duncan's Pupils' Bare Legs Shock Berlin..., St. Louis Post - Dispatch, 14 January 1906.

ProQuest $<$ https://www-proquest-com.vortex3.uco.edu $>$

Special to The Christian Science Monitor from its Western Bureau, 'Work of Women in Minnesota’, The Christian Science Monitor, 21 July 21 1917. ProQuest $<$ https://www-proquest-com.vortex3.uco.edu $>$

Special to the New York Times, 'Fall Fashion Trends from Abroad: Paris: Givenchy Changes Body’s Proportions’, New York Times, 27 August 1957. ProQuest $<$ https://www-proquest-com.vortex3.uco.edu $>$

The Sportswear and Leisure Living: Two Girls from Palm Beach', Women's Wear Daily, 09 October 1962. ProQuest $<$ https://www-proquestcom.vortex3.uco.edu>

St. Denis, Ruth, 'Does the Tango Need a Defender? If So, Here She Is', Chicago Daily Tribune, 15 June 1913. ProQuest <https://www-proquestcom.vortex3.uco.edu> 
'St. Laurent is A Sensation: King Yves Reigns Supreme in Paris', Women's Wear Daily, 03 August 1965. ProQuest $<\underline{\text { https://www-proquest- }}$ com.vortex3.uco.edu>

'Stores, Movies, Mfrs. in Plan to Spur Trade: Report 90 Retailers Throughout Country Already Under Contract to Carry Selected Styles of Various Producers to be Promoted in Films of Fashion Feature Studios', Women's Wear Daily, 14 August 1928. ProQuest < https://www-proquestcom.vortex3.uco.edu>

Table of contents, Women's Wear Daily, 02 August 1965. ProQuest $<\underline{\text { https://www- }}$ proquest-com.vortex3.uco.edu>

Taub, Bernadine, 'Designer Builds A Junior Business Success on the Chemise Dress: Subjective Approach', Women's Wear Daily, 22 August 1957. ProQuest $<$ https://www-proquest-com.vortex3.uco.edu $>$

Taylor, Angela, 'Fashions to Buy, Wear and then Throw Away', New York Times, 19 August 1966. ProQuest < $\underline{\text { https://www-proquest-com.vortex3.uco.edu }}>$

'Texas Women Set to Bar Long Skirts: 1,300 in a New Club at Dallas Unite to Keep Clothes at a Little Below the Knee', New York Times, 18 August 1947. ProQuest https://www-proquest-com.vortex3.uco.edu

'Their Married Life: Helen Pays a Call on Frances at the Letter's Studio and Enjoys a Delightful Afternoon in the Bohemian Atmosphere -- Her Experience a New One’, Washington Post, 28 June 1915. ProQuest < $\underline{\text { https://www-proquest- }}$ com.vortex3.uco.edu>

'They Were Wearing’ in the '20’s’, Women’s Wear Daily, 05 August 1957. ProQuest $<$ https://www-proquest-com.vortex3.uco.edu $>$ 
Times Photo Service, ‘And Now Greenwich Village has Woman Guide!’, New York Times, 07 October 1917. ProQuest < $\underline{\text { https://www-proquest- }}$ com.vortex3.uco.edu>

Tinee, Mae, 'Here are Two Movies Full of Moral Intent: Or "Why be Good?" and "The Godless Girl." "Why Be Good?”', Chicago Daily Tribune, 20 March 1929. ProQuest < $\underline{\text { htps://www-proquest-com.vortex3.uco.edu }>}$

'The Two Worlds: A Day-Long Debate: Nixon: “I Am for Peace” Premier: “Eliminate Bases” The Day-Long Debate Between Vice President Nixon and Premier Khrushchev Visitor and Host Exchange Gibes American Challenges Soviet Leader to Competition in Free Trade of Ideas', New York Times, July 25, 1959. ProQuest $<$ https://www-proquest-com.vortex3.uco.edu $>$

‘Up and Down Broadway’, New York Times, 27 February 1916. ProQuest $<$ https://www-proquest-com.vortex3.uco.edu $>$

Urner, Mabel Herbert, 'The Married Life of Helen and Warren: A Dinner Adventure in Greenwich Village Proves Helen a Poor Bohemian', Washington Post, 23 October 1921. ProQuest < https://www-proquest-com.vortex3.uco.edu $>$

'Village' Stores Attract Clientele from Fifth Ave', New York Times, 16 January 1962. ProQuest $<\underline{\text { https://www-proquest-com.vortex3.uco.edu }>}$

W, 'Municipal Dance Halls’, St. Louis Post - Dispatch, 05 February 1910. ProQuest $<\underline{\text { https://www-proquest-com.vortex3.uco.edu }>}$

Ward, Arch, 'In the Wake of the News', Chicago Daily Tribune, 7 October 1947. ProQuest $<$ https://www-proquest-com.vortex3.uco.edu $>$ (image by Curt Gfroerer). 
Warren, Virginia Lee, ‘Pope Urges Women to Vote and Scorn “Totalitarian” Lure: Calls Them to Political and Social Activity to Combat Misuse of Equal Rights Threat to Home is Seen Pius Warns That Domination by One Class Leads to War and Undermining of Family Gathered in Hall of Benedictions Pope Urges Women to Cast Votes and Shun “Totalitarian” Promises’, New York Times, 22 October 1945. ProQuest < https://www-proquest-com.vortex3.uco.edu $>$

Wells, Margery, 'Flapper Becomes Weary of Sameness in Dress and Changes Her Style’, St. Louis Post - Dispatch, 17 October 1922. 'Fable of the Flapper', Mansfield News, 13 August 1922. ProQuest $<\underline{\text { https://www-proquest- }}$ com.vortex3.uco.edu>

Weis, June, 'Pro and Con Views Expressed, But: Chemise Dress Headed for Spring', Women's Wear Daily, 05 August 1957. ProQuest < https://wwwproquest-com.vortex3.uco.edu>

Wilford, John Noble, Special to The New York Times, 'U.S. Prepares Moon Shot in December: Apollo 7 Splashes Down in Atlantic After 11-Day Earth-Orbiting Test for Moon Shot Perfect Mission’ Buoys Nasa Aides U.S. Prepares for Flight in December That May Send Men Around the Moon’, New York Times, 23 October 1968, ProQuest < $\underline{\text { https://www-proquest-com.vortex3.uco.edu }>}$

Winn, Marcia, 'That Man Who Designed Long Skirts is Here’, Chicago Daily Tribune, 23 September 1947. ProQuest < $\underline{\text { https://www-proquest- }}$ com.vortex3.uco.edu>

'Women in Dallas Deride Long Skirts: Little Below The Knee Club Ties Up Traffic With Parade in Stuffy Garb’, New York Times, 24 August 1947. ProQuest $<$ https://www-proquest-com.vortex3.uco.edu $>$

'Women A Success in Factory Work', Nashville Tennessean and the Nashville American, 18 August 1918. ProQuest $<$ https://www-proquestcom.vortex3.uco.edu> 
'Woman’s Club Acts to Protect City’s Flappers’, Chicago Daily Tribune, 02 October 1918. ProQuest $<$ https://www-proquest-com.vortex3.uco.edu $>$

'Young Juniors (Teens): Omaha Store Sees Profit in Separate Teen, Junior Areas', Women's Wear Daily, 02 September 1959. ProQuest < https://www-proquestcom.vortex3.uco.edu>

Young Juniors (Teens): Strictly Teen Departments Rare in Denver Stores: Best Location', Women’s Wear Daily, 02 September 1959. ProQuest < $\underline{\text { https://www- }}$ proquest-com.vortex3.uco.edu>

‘The Youth Snap: Poor Boy’, Women’s Wear Daily, 02 November 1965. ProQuest $<\underline{\text { https://www-proquest-com.vortex3.uco.edu }>}$

\section{Novels \& Autobiographies}

Allen, Frederick Lewis, Only Yesterday: An Informal History of the NineteenTwenties (London: Harper and Brothers, 1957)

Castle, Irene, Castles in the Air (New York: Doubleday \& Co., Inc., 1958)

Dreiser, Theodore, Sister Carrie (Cambridge, MA: Robert Bentley, Inc., 1971)

Duncan, Irma, Duncan Dancer: An Autobiography (Middletown, CT.: Wesleyan University Press, 1966)

Duncan, Isadora, My Life, (New York: Liveright Publishing Corporation, 2013)

Fitzgerald, F. Scott, The Great Gatsby (New York: Collier Books, 1992)

Friedan, Betty, Feminine Mystique (New York: Norton Publisher, 1963) 
Gilbreth, Lillian M., As I Remember: An Autobiography (Norcross, Georgia: Engineering \& Management Press, 1998)

Quant, Mary. Quant by Quant: The Autobiography of Mary Quant (London: V \& A Publishing, 2018)

Shrimpton, Jean, Jean Shrimpton: An Autobiography (London: Ebury, 1990)

Turnbull, Margaret, The Close-Up (London: Harper and Brothers Publishers, 1918)

\section{Film \& Television}

Awakening: Makers: Women Who Make America, (Films Media Group, 2013), online film recording, Films On Demand, $<$ fod.infobase.com/PortalPlaylists.aspx?wID=103048\&xtid=60713 $>$ [accessed 22 November 2020]

Black Oxen, dir. Frank Lloyd (Frank Lloyd Productions, Inc., A First National Picture, 1923), online film recording, Youtube,

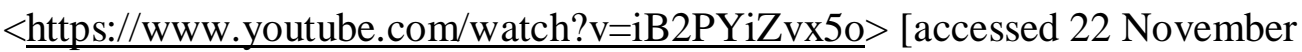
2020]

'Bud Takes Up the Dance'. Father Knows Best, NBC, 3 October 1954, online video recording, Youtube, $<$ https://www.youtube.com/results?search query=Father\%27s+Knows+Best $>$ [accessed 11 February 2021]

'Business Italian Style’, Bewitched (Mill Creek Entertainment, 2014) [on DVD]

'Divided He Falls', Bewitched (Mill Creek Entertainment, 2014) [DVD]

'Double Tate', Bewitched (Mill Creek Entertainment, 2014) [on DVD] 
Dr. Billy Taylor, (Films Media Group, 1991), online film recording, Films On

Demand, $<$ fod.infobase.com/PortalPlaylists.aspx?wID=103048\&xtid=2934> [accessed 10 February 2021]

'Duncan Dances', The Spirit of Dance, Community Television (C3TV), online video recording, Alexander Street, < https://video.alexanderstreet.com/watch/duncan-

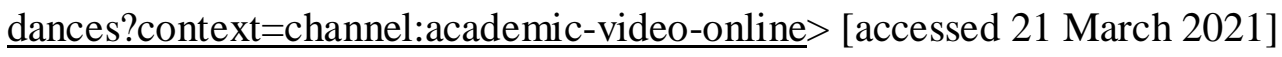

Early Directors on Directing, dir. by Acker, Ally (Reel Women Media, 2014), online film recording, Alexander Street, <https://video-alexanderstreetcom.vortex3.uco.edu/channel/academic-video> [accessed 09 March 2021]

'Equal Rights', I Love Lucy, CBS, 26 October 1953, online video recording, CBS.com $<$ https://www.cbs.com/shows/i_love_lucy/> [accessed 28 October 2020]

Flaming Youth: Fragment of Film with Colleen Moore, dir. by John Francis Dillon (John McCormick Productions, 1923), online film recording, Youtube.com, 31 January 2012, <https://www.youtube.com/watch?v=88PMhS1oYjs> [accessed on 14 September 2020]

The Flapper, dir. by Alan Crosland (Alpha Home Entertainment, 2014) [on DVD]

Flappers: The Birth of the 20th-Century Woman (Films Media Group, 1999) online film recording, Films On Demand, $<$ fod.infobase.com/PortalPlaylists.aspx?wID=103048\&xtid=11563> [Accessed 30 December 2020]

'The Golf Game’, I Love Lucy, CBS, 17 May 1954, online video recording, CBS.com, <https://www.cbs.com/shows/i_love_lucy/> [ accessed 15 July 2020]

‘Help, Help Don’t Save Me’, Bewitched, (Mill Creek Entertainment, 2014) [on DVD] 
High School Hell Cats, dir by Edward L. Bernds (American International Pictures, 1955), online film recording, YouTube, 12 March 2016, $<$ https://www.youtube.com/watch?v=c q44 2jgZE $>$ [accessed 30 October 2020]

How I Play Tennis by Mlle. Suzanne Lenglen (British Pathé Production), online film recording, YouTube, 13 April 2014,

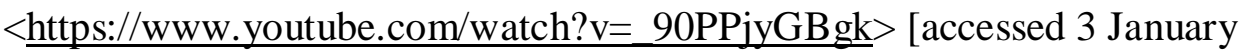
2021]

In Mondrian’s Studio, (Films Media Group, 2010), online film recording, Films On Demand, < $\underline{\text { https://fod-infobase- }}$ com.vortex3.uco.edu/p ViewVideo.aspx? xtid=54995\&tScript $=0>$ [accessed 11 February 2021]

‘Job Switching’, I Love Lucy, CBS, 15 September 1952, online video recording, CBS.com, https://www.cbs.com/shows/i love lucy/> [accessed 28 October 2020]

Lillian Moller Gilbreth: Pioneering Inventor \& Industrial Engineer,1878-1972, online film recording, UNLADYLIKE2020, < $\underline{\text { http://unladylike2020.com> }}$ [accessed 21 March 2021]

A Lily in Bohemia, dir by Wilfrid North (Vitagraph, 1915), online film recording, Youtube, 28 May 2015 $<$ https://www.youtube.com/watch?v=MUrYHKJsPrY\&t=502s $>$ [accessed 10 February 2021]

Lois Weber: Actor, Screenwriter \& First Woman to Direct a Feature Length Film, 1879-1939, online film recording, UNLADYLIKE2020,

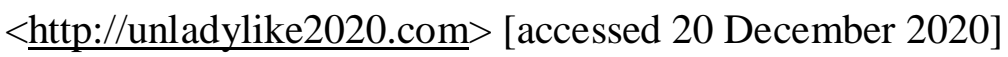

'Long Live the Queen’, Bewitched (Mill Creek Entertainment, 2014) [on DVD] 
'Lucy Gets a Paris Gown’, I Love Lucy, CBS, 19 March 1956, online video recording, CBS.com, < https://www.cbs.com/shows/i_love_lucy/> [accessed 28 October 2020]

'Lucy’s Schedule’, I Love Lucy, CBS, 26 May 1952, online video recording, CBS.com, < https://www.cbs.com/shows/i love lucy/> [accessed 15 July 2020]

'Oh So Mortgaged’, Bewitched (Mill Creek Entertainment, 2014) [on DVD]

'The Phrase is Familiar’, Bewitched (Mill Creek Entertainment, 2014) [on DVD]

Pioneers of the Cinema: The Herstory, dir. by Acker, Ally (Reel Women Media, 2009) online film recording, Kanopy, <uco.kanopy.com> [accessed 05 June 2018]

‘A Prince of a Guy’, Bewitched (Mill Creek Entertainment, 2014) [on DVD]

'The Quiz Show', I Love Lucy, CBS, 12 November 1951, online video recording, CBS.com < https://www.cbs.com/shows/i_love_lucy/> [ accessed 15 July 2020]

Rebel Without a Cause, dir. by Nicholas Ray (Warner Bros., 1955), online film recording, Youtube, 08 July 2014, $<$ https://www.youtube.com/watch?v=9tHbN3fykr0 $>$ [accessed 11 February 2021]

'Sam in the Moon’, Bewitched (Mill Creek Entertainment, 2014) [on DVD].

'Samantha and the Beanstalk', Bewitched (Mill Creek Entertainment, 2014) [on DVD]

'Samantha Fights City Hall’, Bewitched (Mill Creek Entertainment, 2014) [on DVD] 
'Samantha’s Thanksgiving’, Bewitched (Mill Creek Entertainment, 2014) [on DVD]

'Serena Stops the Show', Bewitched (Mill Creek Entertainment, 2014) [on DVD]

The Silent Era, dir. by Ally Acker (Reel Women Media, 2015), online film recording, Alexander Street, $<\underline{\text { https://video-alexanderstreet- }}$ com.vortex3.uco.edu/channel/academic-video-online> [accessed 09 March 2021]

Space Race: Race for a Space Man, (Films Media Group, 2005), online film recording, Films On Demand, < $\underline{\text { https://fod-infobase- }}$ com.vortex3.uco.edu/p ViewVideo.aspx?xtid=199666\&tScript=0 $>$ [accessed 11 February 2021]

‘Tabitha’s Cranky Spell’, Bewitched (Mill Creek Entertainment, 2014) [on DVD]

Twiggy: The face of the 60's, dir. by Philip Priestley (Program33 \& Arte Geie), online film recording, Youtube, 16 September 2016,

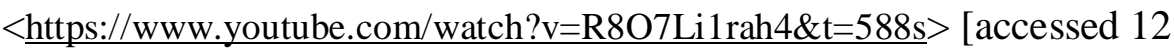
February 2021]

Uncertainty: Modernity and Art, (Films Media Group, 2007), online film recording, Films On Demand, < https://fod-infobasecom.vortex3.uco.edu/p_ViewVideo.aspx? xtid=39858\&tScript $=0>$ [accessed 12 February 2021]

The Unfinished Nation-The Progressive Era, (Films Media Group, 2004), online film recording, Films On Demand, < https://fod-infobasecom.vortex3.uco.edu/p_ViewVideo.aspx?xtid=71435\&tScript $=0>$ [accessed 10 February 2021]

Violent Years, dir by William Morgan (Headliner Productions, 1956), online film recording, YouTube, 31 December 2018, 


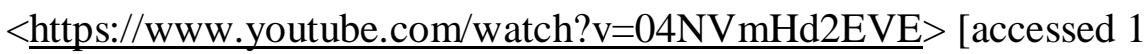

November 2020]

'What Makes Darrin Run’, Bewitched (Mill Creek Entertainment, 2014) [on DVD]

Why Be Good, dir. by William A. Seiter (First National Pictures, 1929) [on DVD]

‘The Witches Are Out', Bewitched (Mill Creek Entertainment, 2014) [DVD]

\section{Secondary Works}

\section{Books}

Acker, Ally, Reel Women: Pioneers of the Cinema 1896 to Present (New York: Continuum, 1991)

The American New Woman Revisited: A Reader, 1894-1930, ed. by Martha H. Patterson (London: Rutgers University Press, 2008), pp. 1-25. ProQuest Ebook Central.

Andrew, John A., III, The Other Side of The Sixties: Young Americans for Freedom and the Rise of Conservative Politics (London: Rutgers University Press, 1997)

Assmann, Stephanie, 'Consumption of Fast Fashion in Japan: Local Brands and Global Environment', in Consuming Life in Post-Bubble Japan: A Transdisciplinary Perspective, ed. by Katarzyna J. Cwiertka and Ewa Machotka (Amsterdam: Amsterdam University Press, 2018), pp. 49-68. < https://doiorg.vortex3.uco.edu/10.2307/j.ctv56fgim.7>

Baines, Barbara Burman, Fashion Revivals: From the Elizabethan Age to the Present Day, (New York: Drama Book Publishers, 1981) 
Banner, Lois W., American Beauty (New York: Alfred A. Knopf, 1983)

Barthes, Roland, The Fashion System, (Berkeley: University of California Press, 1983)

Baxandall, Rosalyn and Elizabeth Ewen, Picture Windows: How the Suburbs Happened (New York: Basic Books, 2000)

Beaton, Cecil, The Glass of Fashion (Garden City, NY: Doubleday \& Co., Inc., 1954)

Beauchamp, Cari, Without Lying Down: Francis Marion and the Powerful Women of Early Hollywood (London: University of California Press, 1997)

Bell, Quentin, On Human Finery, $2^{\text {nd }}$ edn (New York: Schocken Books, 1976)

Bennett, Tony and others, eds, Culture, Ideology, and Social Process: A Reader (London: The Open University Press, 1981)

Bird, Caroline, Enterprising Women (New York: W.W. Norton \& Company, Inc., 1976)

Bloom, Alexander, Long Time Gone: Sixties America Then and Now, (Oxford: Oxford University Press, 2001)

Bowser, Eileen, '1911: Movies and the Stability of the Institution', in American Cinema of the 1910s: Themes and Variations, ed. by Charlie Keil and Ben Singer, 10 vols (London: Rutgers University Press, 2009), II, pp. 48-68. ProQuest Ebook Central 
Brake, Michael, Comparative youth Culture: The Sociology of Youth Cultures and Youth Subcultures in America, Britain and Canada, (London: Routledge \& Kegan Paul, 1985)

Breckinridge, Sophonisba P., Women in the Twentieth Century: A Study of Their Political, Social and Economic Activities (New York: Arno Press, 1972)

Breines, Wini, Young, White, and Miserable: Growing Up Female in the Fifties (Boston, MA: Beacon Press Books, 1992)

Breward, Christopher, The Culture of Fashion: A New History of Fashionable Dress (Manchester: Manchester University Press, 1995)

— Fashion (Oxford: Oxford University Press, 2003)

Brooks, Tim and Earle Marsh, The Complete Directory of Prime Time Network and Cable TV Shows: 1946-Present, $8^{\text {th }}$ edn (New York: Ballantine Books, 2003)

Brunel, Charlotte, The T-Shirt Book (New York: Assouline Publishing, Inc., 2002)

Busnar, Gene, It’s Rock'n'Roll (New York: Julian Messner, 1979)

Chafe, William Henry, The American Woman: Her Changing Social, Economic, and Political Roles, 1920-1970 (London: Oxford University Press, 1972)

— The Unfinished Journey: America Since World War II, $3^{\text {rd }}$ edn (Oxford: Oxford University Press, 1995)

Card, James, Seductive Cinema: The Art of Silent Film (New York: Alfred A. Knopf, 1994)

Clarke, Edward H. MD., Sex in Education: A Fair Chance For The Girls (Boston: James R. Osgood \& Co., 1873) 
Clarke, John and others, 'Sub Cultures, Cultures and Class', in Culture, Ideology and Social Process: A Reader, ed. by Tony Bennett and others, (London: The Open University Press, 1985) pp. 53-79

Cott, Nancy F., The Grounding of Modern Feminism (New Haven: Yale University Press, 1987)

_ Root of Bitterness: Documents of the Social History of American Women (New York: E.P. Dutton \& Co., 1972)

Crane, Diane, 'Boundaries: Using Cultural Theory to Unravel the Complex Relationship Between Fashion and Art', in Fashion and Art, ed. by Geczy, Adam, and Vicki Karaminas, (London: Berg, 2012), pp. 99-110

Curtis, Jim, Rock Eras: Interpretations of Music and Society, 1954-1984 (Bowling Green, OH: Bowling Green State University Popular Press, 1987)

Davis, Allen F., Spearheads for Reform (New York: Oxford University Press, 1976)

Davis, Fred, Fashion, Culture, and Identity (Chicago \& London: The University of Chicago Press, 1992)

Diggins, John Patrick, The Proud Decades: America in War and in Peace, 1941-1960 (London: Norton, 1988)

di Prima, Diane, 'The Quarrel', in A Different Beat: Writings by Women of the Beat Generation, ed. by Richard Peabody (London: High Risk Books, 1997)

— Dinners \& Nightmares (New York: Corinth Books, 1974)

Dougherty, Rachel, Secret Engineer: How Emily Roebling Built the Brooklyn Bridge (New York: Roaring Brook Press, 1988) 
Dumenil, Lynn. The Second Line of Defense: American Women and World War I, (Chapel Hill: The University of North Carolina Press, 2017)

Duncan, Isadora, 'The Greek Theatre', in The Art of The Dance, ed. by Sheldon Cheney (New York: Theatre Art Books, 1969), pp. 86-87

Friedrich Engels, The Origin of the Family, Private Property and the State (New York: Penguin Classics, 2010)

English, Bonnie, A Cultural History of Fashion in the $20^{\text {th }}$ and $21^{\text {st }}$ Centuries: From Catwalk to Sidewalk, $2^{\text {nd }}$ edn (London: Bloomsbury, 2013)

Entwistle, Joanne, The Fashioned Body: Fashion, Dress and Modern Social Theory (Cambridge, UK: Polity Press; Oxford: Blackwell Publishing Ltd, 2000)

Ferretti, Daniela, 'Portrait of a Muse', in Henriette Fortuny: Portrait of a Muse, ed. by Daniela Ferretti (Venice: Palazzo Fortuny, 2015), pp. 11-19

Fink, Leon, Major Problems in the Gilded Age and Progressive Era: Documents and Essays (Lexington, MA: D.C. Heath and Company, 1993)

Fitzpatrick, Ellen F., 'Late-Nineteenth-Century America and the Origins of Muckraking', in Muckraking: Three Landmark Articles, ed. by Ellen F. Fitzpatrick (Boston, New York: Bedford Books, 1994), pp. 1-39

Fontanel, Béatrice, Support and Seduction: The History of Corsets and Bras (New York: Abradale Press, 1997)

Fowler, David, Youth Culture in Modern Britain c, 1920-1970: From Ivory Tower to Global Movement (New York: Palgrave, 2008)

Gilbert, Eugene, Advertising and Marketing to Young People (Pleasantville, NY: Printer’s Ink Books, 1957) 
Gitlin, Todd, The Sixties: Years of Hope, Days of Rage (London: Banton Books, 1987)

Golden, Eve, Vernon and Irene Castle’s Ragtime Revolution (Lexington, KY: University Press of Kentucky, 2007)

Grace, Nancy M. and Ronna C. Johnson, Breaking the Rule of Cool: Interviewing and Reading Women Beat Writers, (Jackson: University Press of Mississippi)

Greenwood, Nell, 'The Purple Jumpsuit', in The Memory of Clothes, ed. by Robyn Gibson (Rotterdam; Boston; Taipei: Sense Publishers, 2015), pp. 157-159. ProQuest Ebook Central

Haralovich, Mary Beth, 'Sit-Coms and Suburbs: Positioning the 1950s Homemaker', in Private Screenings: Television and the Female Consumer, ed. by Lynn Spigel and Denise Mann, New edn. (London: University of Minnesota Press, 1992), pp. 111-141. ProQuest Ebook Central; Reprinted from Quarterly Review of Film and Video, 11.1 (1989), 61-83

Hasse, John Edward, 'Ragtime: From the Top’, in Ragtime: It’s History, Composers, and Music, ed. by John Edward Hasse (New York: Schirmer Books, 1985), pp. 1-39

Hatcher, O. Latham, Ph.D., Occupations for Women: Being the Practical Information Obtained by a Study Made for the Southern Woman's Educational Alliance, $2^{\text {nd }}$ edn (Richmond, VA: L.H. Jenkins, Inc., 1927)

Hear Me Patiently: The Reform Speeches of Amelia Jenks Bloomer, ed. by Anne C. Coon (London: Greenwood Press,1994), pp. 1-36

Hebdige, Dick, Subculture: The Meaning of Style (London: Routledge, 2003) 
Higashi, Sumiko, '1927: Movies and the New Woman as Consumer', in American Cinema of the 1920s: Themes and Variations, ed. by Lucy Fischer, 10 vols (London: Rutgers University Press, 2009), III, pp. 188-210. ProQuest Ebook Central

Higgs, Robert, The Transformation of the American Economy, 1865-1914: An Essay in Interpretation (New York: John Wiley \& Sons, Inc., 1971)

Hodgson, Godfrey, America In Our Time (Garden City, NY: Doubleday \& Company, Inc., 1976)

Hole, Judith and Ellen Levine, Rebirth of Feminism (New York: Quadrangle Books, Incorporated, 1971)

Hollander, Anne, Seeing Through Clothes (Berkeley, Los Angeles and London: University of California Press, 1993)

— Sex \& Suits: The Evolution of Modern Dress (London: Bloomsbury, 2016)

Ingels, Margaret, M.E., 'Petticoats and Slide Rules', in Women in Engineering: Pioneers and Trailblazers, ed. by Margaret E. Layne, P.E. (Reston, VA: ASCE Press, 2009), pp. 85-97

Jackson, Kenneth T., Crabgrass Frontier: The Suburbanization of the United States (Oxford: Oxford University Press, 1985)

Johns, Maxine J., Fred D. Reynolds and William R. Darden, 'Why the Midi Failed', in Perspectives of Fashion, ed. by George B. Sproles (Minneapolis, Minnesota: Burgess Publishing Company, 1981), pp. 93-99

Kidwell, Claudia B. and Margaret C. Christman, Suiting Everyone: The Democratization of Clothing in America, (Washington, D.C.: Smithsonian Institution Press, 1974) 
King, Charles W., 'Fashion Adoption: A Rebuttal to the “Trickle Down” Theory’, in Perspectives of Fashion, ed. by George B. Sproles (Minneapolis, MN: Burgess Publishing Co., 1981), pp. 31-39

Kitch, Carolyn, The Girl on the Magazine Cover: The Origins of Visual Stereotypes in American Mass Media (London: University of North Carolina Press, 2001)

Koda, Harold, Goddess: The Classical Mode (New York: The Metropolitan Museum of Art; London: Yale University Press, 2003)

Koda, Harold and Andrew Bolton, Poiret, (New York: Metropolitan Museum of Art; New Haven: Yale University, 2007)

Köhler, Carl, A History of Costume, (London: Constable and Company, 1963)

Lears, Jackson, Rebirth of A Nation: The Making of Modern America, 1877-1920 (New York: Harper Collins Publisher, 2009)

Levin, Joanna, Bohemia in America, 1858 - 1920 (Stanford, CA: Stanford University Press, 2010).

Lewis, Howard T., The Motion Picture Industry (New York: D.Van Nostrand, 1933)

Lewis, Lloyd, 'The Deluxe Picture Palace', in The Twenties: Fords, Flappers \& Fanatics, ed. by George E. Mowry (Englewood Cliffs, NJ: Prentice-Hall, Inc., 1963), pp. 56-59

Leymarie, Jean, Chanel (New York: Rizzoli International Publications, Inc., 1987)

Lippmann, Walter, A Preface to Politics (Ann Arbor: The University of Michigan Press, 1962) 
Lister, Jenny, ‘Kaleidoscope: Fashion in Sixties London', in Swinging Sixties:

Fashion in London and Beyond, 1955-1970', ed. by Christopher Breward,

David Gilbert and Jenny Lister (London: V \& A Publications, 2006), pp. 22-

41

Lynd Robert S., and Helen Merrell Lynd, Middletown: A Study in Contemporary American Culture (New York: Harcourt, Brace and Company, 1929)

Lynn, Susan, Progressive Women in Conservative Times: Racial Justice, Peace, and Feminism, 1945 to the 1960s (New Brunswick, NJ: Rutgers University, 1992)

Mackrell, Alice, Paul Poiret (New York: Holmes \& Meier, 1990)

Marling, Karal Ann, As Seen on TV: The Visual Culture of Everyday Life in the 1950s (Cambridge, MA: Harvard University Press, 1994)

Marwick, Arthur, The Sixties: Cultural Revolution in Britain, France, Italy, and the U.S., c 1958-1974 (Oxford: Oxford University Press, 1998)

Matthews, Alva T., 'Emily W. Roebling: One of the Builders of the Bridge', in Women in Engineering: Pioneers and Trailblazers, ed. by Margaret E. Layne (Reston, VA.: ASCE Press, 2009), pp. 123-130

Mattingly, Carol. Well-Tempered Women: Nineteenth Century Temperance Rhetoric (Carbondale, IL: Southern Illinois University Press, 1998)

May, Elaine Tyler, Homeward Bound: American Families in the Cold War Era (New York: Basic Books, Inc., 1962)

McRobbie, Angela, 'Settling Accounts with Subcultures: A Feminist Critique’, in Culture, Ideology, and Social Process: A Reader, edited by Tony Bennett and others (London: The Open University Press, 1981) 
Mead, George Herbert, Mind, Self and Society: From the Standpoint of a Social Behaviorist (Chicago: University of Chicago Press, 1934)

Melinkoff, Ellen, What We Wore: An Offbeat Social History of Women's Clothing, 1950-1980 (New York: Quill, 1984)

Mendes, Valerie D. and Amy De La Haye, $20^{\text {th }}$ Century Fashion (London: Thames and Hudson, 1999)

Mortenson, Erik, Capturing the Beat Moment: Cultural Politics and the Poetics of Presence (Carbondale, IL: Southern Illinois University Press, 2011)

Mumford, Lewis, The City in History (New York: Harcourt Brace Jovanovich, 1961)

Muncy, Robyn, Creating a Female Dominion in American Reform 1890 - 1935, (Oxford: Oxford University Press, 1991). Proquest Ebook Central

Nahumch, Nadia Chilkovsky, Isadora Duncan: The Dances (Washington D.C.: The National Museum of Women in the Arts, 1994)

Nystrom, Paul H., Economics of Fashion (New York: The Ronald Press Company, 1928)

Ohmann, Richard, Selling Culture: Magazines, Markets, and Class at the Turn of the Century (London: Verso, 1996)

Oldenziel, Ruth, 'Multiple-Entry Visas: Gender and Engineering in the U.S., 18701945', in Women in Engineering: Pioneers and Trailblazers, ed. by Margaret E. Layne (Reston, VA.: ASCE Press, 2009), pp. 35-77

O’Neill, William L., American High: The Years of Confidence 1945-1960 (New York: The Free Press, 1986) 
Osma, Guillermo de, Mariano Fortuny: His Life and Work, (New York: Rizzoli International Publications, Inc., 1980)

Ouida, 'The New Woman', in The American New Woman Revisited: A Reader, 18941930, ed. by Martha H. Patterson (Piscataway, NJ: Rutgers University Press, 2008), pp. 35-42. ProQuest Ebook Central.

Palladino, Grace, Teenagers: An American History, (New York: Basic Books, 1996)

The Papers of Dwight David Eisenhower: Presidency: Keeping the Peace XVIII, ed. by Elizabeth S. Hughes and others, 21 vols. (London: The Johns Hopkins University Press, 2001), XVIII

Parrish, Michael E., Anxious Decades: America in Prosperity and Depression, 1920 1941 (London: W.W. Norton and Company, 1992)

Patterson, James T., Grand Expectations: The United States, 1945-1974, (Oxford: Oxford University Press, 1996)

Patterson, Martha H., Beyond the Gibson Girl: Reimaging the American New Woman, 1895-1915, (Urbana, IL and Chicago: University of Illinois Press, 2005)

Paulson, A.B., 'Oral Aggression and Splitting', in Modern Critical Interpretations: F. Scott Fitzgerald's The Great Gatsby, ed. by Harold Bloom (New York: Chelsea House Publishers, 1986), pp. 71-85

Perrett, Geoffrey, America in the Twenties: A History (New York: Simon and Schuster, 1982)

Pochna, Marie France, Christian Dior: The Man Who Made the Whole World Look New, (New York: Arcade Publisher, 1996) 
Rosen, Marjorie, Popcorn Venus: Women, Movies, and the American Dream (New York: Coward, McCann \& Geoghegan, 1973)

Ross, Sara, '1922: Movies and the Perilous Future', in American Cinema of the 1920s: Themes and Variations, ed. by Lucy Fischer, 10 vols (London: Rutgers University Press, 2009), III, pp. 70-94. ProQuest Ebook Central

Rouse, Elizabeth, Understanding Fashion (London: BSP Professional Books, 1989)

Rupp, Leila J., 'The Survival of American Feminism: The Women’s Movement in the Postwar Period', in Reshaping America: Society and Institutions, 19451960, ed. by Robert H. Bremner and Gary W. Reichard (Columbus: Ohio State University Press, 1982), pp. 33-65

Sage, Elizabeth, A Study of Costume: From the Days of the Egyptians to Modern Times (New York: Charles Scribner’s Sons, 1926)

Sagert, Kelly Boyer, Flappers: A Guide to an American Subculture (Oxford: Greenwood Press, 2010)

Sapir, Edward, 'Fashion', in Perspectives of Fashion, ed. by George B. Sproles (Minneapolis, MN: Burgess Publishing Co., 1981; repr. New York: Macmillan Publishing Co., Inc., 1931) pp. 23-27

Schreier, Barbara A., Mystique and Identity: Women's Fashions of the 1950s (Norfolk, VA: The Chrysler Museum, 1984)

Siegel, Frederick F., Troubled Journey: From Pearl Harbor to Ronald Regan (New York: Hill and Wang, 1984)

Sklar, Kathryn Kish, ‘The Historical Foundations of Women’s Power in the Creation of the American Welfare State', in Mothers of a New World: Maternalist Politics and the Origins of Welfare States, ed. by Seth Koven and Sonya Michel (New York: Routledge, 1993), pp. 43-93 
Slide, Anthony, 'Afterword', in Reel Women: Pioneers of the Cinema 1896 to Present ((New York: Continuum, 1991), pp.335-336

Slide, Anthony, Early Women Directors (South Brunswick, NJ: A.S. Barnes and Company, 1977)

‘Society of Industrial Engineers, Spring Convention', The Society of Industrial Engineers Bulletin, 3.5 (1949), 1-3

Sorensen, Theodore C. Let The Word Go Forth: The Speeches, Statements, and Writings of John F. Kennedy 1947-1963 (New York: Dell Publishing, 1988)

Sproles, George and Leslie Davis Burns, Changing Appearances: Understanding Dress in Contemporary Society (New York: Fairchild Publications, 1994)

Steele, Valerie, 'Appearance and Identity', in Men and Women: Dressing the Part, ed. by C. G. Kidwell and Valerie Steele, (Washington DC: Smithsonian Institution Press, 1989), pp.6-21

The Black Dress (New York: Collins Design, 2007)

_ The Corset: A Cultural History (London: Yale University Press, 2001)

_ Fashion and Eroticism: Ideals of Feminine Beauty from the Victorian Era to the Jazz Age (New York: Oxford University Press, Inc., 1985)

_ Fifty Years of Fashion: New Look to Now (New Haven: Yale University Press, 2000)

_ Paris Fashion: A Cultural History, rev edn (New York; London: Bloomsbury Publishing, 2017)

The Red Dress (New York: Rizzoli, 2001) 
Sullivan, James, Jeans: A Cultural History of an American Icon (New York: Gotham Books, 2006)

Swinging Sixties: Fashion in London and Beyond, 1955-1970, ed. by Christopher Breward, David Gilbert and Jenny Lister (London: V\&A Publications, 2006)

Tarbell, Ida M., The Business of Being a Woman (New York: The Macmillan Company, 1919)

Thissen, Judith, ‘Beyond the Nickelodeon: Cinemagoing, Everyday Life and Identity Politics', in Audiences: Defining and Researching Screen Entertainment Reception, ed. by Ian Christie, (Amsterdam: Amsterdam University Press, 2012), pp. 45-65. ProQuest Ebook Central

Tortora, Phyllis G and Sara B. Maracketti, Survey of Historic Costume, $6^{\text {th }}$ edn (New York: Bloomsbury Publishing, Inc., 2015)

Trachtenberg, Alan, The Incorporation of America: Culture and Society in the Gilded Age, (New York: Hill and Wang, 1992)

Trescott, Martha Moore, 'Women in the Intellectual Development of Engineering: A Study in Persistence and Systems Thought', in Women in Engineering, Pioneers and Trailblazers, ed. by Margaret E. Layne (Reston, VA.: ASCE Press, 2009), pp. 99-121

Troy, Nancy J., The Afterlife of Piet Mondrian (Chicago: The University of Chicago Press, 2013)

‘Art’, in Fashion and Art, ed. by Adam Geczy and Vicki Karaminas (London: Berg, 2012), pp. 29-41

_ Couture Culture: A Study in Modern Art and Fashion (Cambridge, MA: MIT Press, 2003) 
Veblen, Thorstein, The Theory of the Leisure Class (New Brunswick, N.J.:

Transaction Publishers, 2000)

Wald, Lillian D., The House on Henry Street (New York: Henry Holt and Company, 1915)

Warhol, Andy and Pat Hackett, Popism: The Warhol Sixties (London: A Harvest Book, Harcourt, Inc., 1980)

Wasko, Janet, Movies and Money: Financing the American Film Industry (Norwood, NJ: Ablex Publishing Corporation, 1982)

Watson, Richard L. Jr., The Development of National Power: The United States 1900-1919 (Washington, D.C.: University Press of America, 1982)

Weibel, Kathryn, Mirror Mirror: Images of Women Reflected in Popular Culture (Garden City, NY: Anchor Books, 1977)

Weigold, Marilyn E., Silent Builder: Emily Warren Roebling and the Brooklyn Bridge, (Port Washington, N.Y: Associated Faculty Press, 1984)

Zeitz, Joshua, Flapper: A Madcap Story of Sex, Style, Celebrity, and the Women Who Made American Modern (New York: Crown Publishers, 2006)

\section{Journal Articles}

Anonymous, 'Postwar Outlook for Physicians', Monthly Labor Review, 61.6 (1945), 1094-1111 (p. 1094) ProQuest < https://www-proquest-com.vortex3.uco.edu $>$

Bailey, Beth and David Farber, 'The Histories They Are A-Changin’: Sources for Teaching about the Movements of the 1960s', OAH Magazine of History, 20.5 (2006), 8-13

<http://vortex3.uco.edu:2050/login?url=https://www.jstor.org/stable/25162077> 
Bawer, Bruce, ‘The Other Sixties’, The Wilson Quarterly, 28.2 (2004), 64-84 < http://vortex3.uco.edu:2050/login?url=https://www.jstor.org/stable/40261250> [accessed 20 January 2021]

Behling, Dorothy U. and Lois E. Dickey, 'Haute Couture: A 25-Year Perspective of Fashion Influences, 1900 to 1925’, Home Economics Research Journal, 8.6 (1980), 428-436.

Blumer, Herbert, 'Fashion: From Class Differentiation to Collective Selection', Sociological Quarterly, 10.3 (1969), 275-291 <http://vortex3.uco.edu:2050/login?url=https://www.jstor.org/stable/4104916> [accessed 30 January 2021]

Breward, Christopher, 'Cultural, Identities, Histories: Fashioning a Cultural Approach to Dress', Fashion Theory, 2.4 (1998), 301-313 $<\underline{\text { http://dx.doi.org/10.2752/136270498779476127> }}$

Byatt, A. S. 'Lives Entwined: The Genius of William Morris and Mariano Fortuny’, FT.Com, (2016), 1-8 < http://vortex3.uco.edu/login?url=https://searchproquest-com.vortex3.uco.edu/docview/1806384983?accountid=14516 $>$ [accessed 20 July 2020]

Cachon, Gerard P. and Robert Swinney, 'The Value of Fast Fashion: Quick Response, Enhanced Design, and Strategic Consumer Behavior;, Management Science, 57.4 (2011), 778-795

< $\underline{\text { http://vortex3.uco.edu:2050/login?url=https://www.jstor.org/stable/25835736> }}$ [accessed 7 March 2021].

Chafe, William H., 'Presidential Address: “The Gods Bring Threads to Webs Begun.”' The Journal of American History, 86.4 (2000), 1531-1551

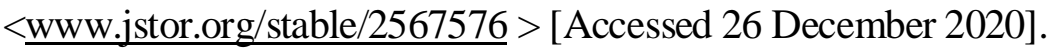


Claudio, Luz, 'Waste Couture: Environmental Impact of the Clothing Industry', Environmental Health Perspectives, 115.9 (2007) A448-A454

$<$ http://vortex3.uco.edu:2050/login?url=https://www.jstor.org/stable/4626880>

[accessed 06 March 2021]

Conekin, Becky E. 'Eugene Vernier and “Vogue” Models in Early “Swinging London”: Creating the Fashionable Look of the 1960s', Women's Studies Quarterly, vol. 41 (2012), 89-107

<http://vortex3.uco.edu:2050/login?url=https://www.jstor.org/stable/23611773> [accessed 20 January 2021]

Crewe, Louise, 'Ugly Beautiful?: Counting the Cost of the Global Fashion Industry’, Geography, 93.1(2008) 25-33

<http://vortex3.uco.edu:2050/login?url=https://www.jstor.org/stable/40574213> [accessed 06 March 2021]

Cubbedge, Robert E., 'Americans on the Go’, Management Review, 49.7 (1960), 26$28<$ https://www-proquest-com.vortex3.uco.edu $>$ [accessed 12 February 2021]

Davis, Fred, 'Herbert Blumer and the Study of Fashion: A Reminiscence and A Critique’, Symbolic Interaction, 14.1 (1991), 1-21 < https://doiorg.vortex3.uco.edu/10.1525/si.1991.14.1.1>

___ 'On the "Symbolic” in Symbolic Interaction', Symbolic Interaction, 5.1 (1982), 111-126 < https://doi-org.vortex3.uco.edu/10.1525/si.1982.5.1.111>

De la Haye, Amy, 'Ethnic Minimalism: a contextual analysis of designs by Shirin Guild', The Journal of the Decorative Arts Society 1850 - the Present, no. 23 (1999), 102-110

<http://vortex3.uco.edu:2050/login?url=https://www.jstor.org/stable/41809287> [accessed 20 January 2021] 
Degler, Carl N., 'Revolution Without Ideology: The Changing Place of Women in America’, Daedalus, 93. 2 (1964), 653-670

< $\underline{\text { http://vortex3.uco.edu:2050/login?url=https://www.jstor.org/stable/20026849 }}$

$>$ [accessed 19 January 2021]

Dickinson, Edward Ross, 'Must we dance naked? Art, Beauty, and Law in Munich and Paris, 1911-1913’, Journal of the History of Sexuality, 20.1 (2011), 95131 (p. 212)

< http://vortex3.uco.edu:2050/login?url=https://www.jstor.org/stable/40986356> [accessed 21 January 2021]

Downey, Lynn, 'My Adventures With Denim: Glimpses into Arizona's Fashion History from the Levi Strauss \& Co. Archives', The Journal of Arizona History, 54.1 (2013), 33-50

<http://vortex3.uco.edu:2050/login?url=https://www.jstor.org/stable/24459197> [accessed 9 February 2021]

Evans, Sara M., 'Women’s Liberation: Seeing the Revolution Clearly’, Feminist Studies, 41.1 (2015), 138-149 <https://doiorg.vortex3.uco.edu/10.15767/feministstudies.41.1.138>

Fishbein, Leslie, 'The failure of feminism in Greenwich Village before World War I', Women Studies, 9.3 (1982), 275-289 <doi:10.1080/00497878.1982.9978572>

Ford, Tanisha, C., 'SNCC Women, Denim, and the Politics of Dress', The Journal of Southern History, 79.3 (2013) 625-658

< http://vortex3.uco.edu:2050/login?url=https://www.jstor.org/stable/23795090> [accessed 10 February 2021]

Freedman, Estelle B, 'The New Woman: Changing Views of Women in the 1920s', The Journal of American History, 61.2 (1974), 372-393 < https://doiorg.vortex3.uco.edu/10.2307/1903954> 
Goldin, Claudia, 'The Quiet Revolution That Transformed Women’s Employment, Education, and Family', The American Economic Review, 96. 2 (2006), 1-21 <http://vortex3.uco.edu:2050/login?url=https://www.jstor.org/stable/30034606> [accessed 20 January 2021]

Gordon, Lynn D., ‘The Gibson Girl Goes to College: Popular Culture and Women’s Higher Education in the Progressive Era, 1890-1920', American Quarterly, 39.2 (1987), 211-230 <https://doi-org.vortex3.uco.edu/10.2307/2712910>

Graham, Laurel D., ‘Lillian Gilbreth’s Psychologically Enriched Scientific Management of Women's Consumers', Journal of Historical Research in Marketing, 5.3 (2013), 351-369 $<$ http://dx.doi.org.vortex3.uco.edu/10.1108/JHRM-02-2013-0009>

Gray, Sally Helvenston, 'Searching for Mother Hubbard: Function and Fashion in Nineteenth-Century Dress', Winterthur Portfolio, 48.1 (2014), 29-74 <www.jstor.org/stable/10.1086/676031> [accessed 5 January 2021]

Green, Dominic, ‘A Victorian Brace’, The New Criterion, 35.2 (2016), 34-39 $<$ http://vortex3.uco.edu/login?url=https://search-proquestcom.vortex3.uco.edu/docview/1831704254?accountid=14516 $>$ [accessed 21 January 2021]

Green, Jonathon, “All Dressed Up: The Sixties 'Youth Revolution’ in Retrospect”, Twentieth Century Architecture, no. 6 (2002), 10-16 <http://vortex3.uco.edu:2050/login?url=https://www.jstor.org/stable/41859186> [accessed 7 January 2021]

Green, Nancy L, ‘Art and Industry: The Language of Modernization in the Production of Fashion', French Historical Studies, 18.3 (1994), 722-748 < $\underline{\text { https://doi- }}$ org.vortex3.uco.edu/10.2307/286690> 
Hallett, Hilary A., 'Based on a True Story: New Western Women and the Birth of Hollywood', Pacific Historical Review, 80.2 (2011), 177-210 $<$ www.jstor.org/stable/10.1525/phr.2011.80.2.177 $>$ [accessed on 12 September 2020

Hillman, Betty Luther, ““The Clothes I Wear Help Me to Know My Own Power”: The Politics of Gender Presentation in the Era of Women's Liberation'. Frontiers: A Journal of Women Studies, 34. 2 (2013), 155-185 $<\underline{\text { https://doi-org.vortex3.uco.edu/10.5250/fronjwomestud.34.2.0155> }}$

Hollander, Anne, ‘The Modernization of Fashion', Design Quarterly, no. 154 (1992), 27-33 < https://doi-org.vortex3.uco.edu/10.2307/4091263>

Hunt, Andrew, “"When Did the Sixties Happen?” Searching for New Directions’, Journal of Social History, 33.1 (1999), 147-161

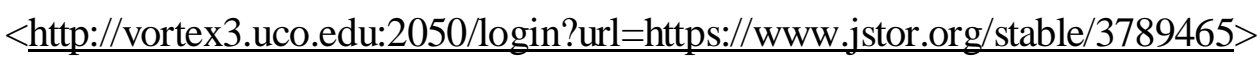
[accessed 20 January 2021]

J.-M.T., D.E.K. and K.C.B., 'Textiles and Costumes', The Museum Year: Annual Report of the Museum of Fine Arts, Boston, vol. 111 (1986-87), 44-45 <http://vortex3.uco.edu:2050/login?url=https://www.jstor.org/stable/43482143> [accessed 20 January 2021]

Jowitt, Deborah, 'Images of Isadora: The Search for Motion', Dance Research Journal, 17.2 (1985) 21-29 < https://doi-org.vortex3.uco.edu/10.2307/1478076>

Kaiser, Susan B., Richard H. Nagassawa and Sandra S. Hutton. 'Construction of an SI Theory of Fashion: Part I Ambivalence and Change', Clothing and Textiles Research Journal, 13.3 (1995), 172-183 < https://doi: $\underline{10.1177 / 0887302 \times 9501300304>}$

Kerber, Linda K. ““I Was Appalled”: The Invisible Antecedents of Second-Wave Feminism', Journal of Women's History, 14.2 (2002) 90-101 $<$ http://dx.doi.org.vortex3.uco.edu/10.1353/jowh.2002.0047> 
Kroeber, A.L., 'On the Principle of Order in Civilization as Exemplified by Changes of Fashion', American Anthropologist, New Series, 21.3 (1919), 235-263 $<$ http://www.jstor.org/stable/660477> [accessed 4 June 2018]

Lowe, John W. G. and Elizabeth D. Lowe, 'Cultural Pattern and Process: A Study of Stylistic Change in Women’s Dress', American Anthropologist, New Series, 84.3 (1982), 521-544

<http://vortex3.uco.edu:2050/login?url=https://www.jstor.org/stable/677331> [accessed 20 January 2021]

Lytle, Mark, 'Making Sense of the Sixties’, Irish Journal of American Studies, 10 (2001), 1-17

$<$ http://vortex3.uco.edu:2050/login?url=https://www.jstor.org/stable/30002230> [accessed 19 January 2020]

Lytle, Mark Hamilton, 'Pictures That Changed Our Minds: Writing the History of the Sixties from Images', OAH Magazine of History, 20.4 (2006), 36-

$39<$ http://vortex3.uco.edu:2050/login?url=https://www.jstor.org/stable/25162066> [accessed 20 January 2021]

MacLean, Nancy, 'Gender is Powerful: The Long Reach of Feminism', OAH Magazine of History, 20.5 (2006), 19-23 < http://vortex3.uco.edu:2050/login?url=https://www.jstor.org/stable/25162079>

Makela, Maria, 'The Rise and Fall of the Flapper Dress: Nationalism and AntiSemitism in Early-Twentieth-Century Discourses on German Fashion', Journal of Popular Culture, 34.3 (2000), 183-208 <http://vortex3.uco.edu/login?url=https://www-proquestcom.vortex3.uco.edu/scholarly-journals/rise-fall-flapper-dress-nationalismanti-semitism/docview/195363481/se-2?accountid=14516 $>$ [accessed 9 February 2021] 
Marwick, Arthur, 'The Cultural Revolution of the Long Sixties: Voices of Reaction, Protest, and Permeation', The International History Review, 27.4 (2005), 780806

< http://vortex3.uco.edu:2050/login?url=https://www.jstor.org/stable/40109676> [accessed 19 January 2021]

Massoni, Kelley, 'Teena Goes to Market: Seventeen Magazine and the Early Construction of the Teen Girl (as) Consumer', The Journal of American Culture, 29.1 (2006), 31-42 <http://vortex3.uco.edu/login?url=https://wwwproquest-com.vortex3.uco.edu/docview/200593656?accountid=14516 > [accessed 11 February 2021]

May, Henry F., 'The Rebellion of the Intellectuals, 1912-1917', American Quarterly, 8.2, (1956), 114-126 <https://doi-org.vortex3.uco.edu/10.2307/2710160>

McGovern, James R., ‘The American Woman’s Pre-World War I Freedom in Manners and Morals', The Journal of American History, 55.2 (1968) $<$ https://doi-org.vortex3.uco.edu/10.2307/1899561>

Mott, George, 'Fortuny Museum, Venice', The GPA Irish Arts Review Yearbook, (1988), 165-168 (p. 165)

< http://vortex3.uco.edu:2050/login?url=https://www.jstor.org/stable/20492062> [accessed 28 February 2021]

Mullenix, Elizabeth Reitz, 'Private Women/Public Acts: Petticoat Government and the Performance of Resistance'. TDR, 46.1 (2002), 104-117 $<\underline{\text { http://vortex3.uco.edu:2050/login?url=https://www.jstor.org/stable/1146948> }}$ > [accessed 16 January 2021]

Nachescu, Voichita, 'Radical Feminism and the Nation: History and Space in the Political Imagination of Second-Wave Feminism', Journal for the Study of Radicalism, 3.1 (2009) 29-59 <http://vortex3.uco.edu:2050/login?url=https://www.jstor.org/stable/41887617> 
Olesen, Bodil Birkebaek, 'When Blue Jeans Went Green’, Anthropology Now, 3.1

(2011), 31-35 < https://doi-

org.vortex3.uco.edu/10.5816/anthropologynow.3.1.0031>

Potter, Michelle, 'Designed for Dance: The Costumes of Léon Bakst and the Art of Isadora Duncan’, Dance Chronicle, 13. 2 (1990), 154-

169 <http://vortex3.uco.edu:2050/login?url=https://www.jstor.org/stable/156773> [accessed 21 January 2021]

Prchal, Tim, 'Reimagining the Melting Pot and the Golden Door: National Identity in Gilded Age and Progressive Era Literature’, MELUS, 32.1 (2007), 29-51 <http://vortex3.uco.edu:2050/login?url=https://www.jstor.org/stable/30029705> [accessed 10 February 2021]

Presley, Ann Beth, ‘Fifty Years of Change: Societal Attitudes and Women’s Fashions, 1900-1950’, The Historian, 60.2 (1998), 307-324 <http://vortex3.uco.edu:2050/login?url=https://www.jstor.org/stable/24451728> [accessed 20 January 2021]

Rabinovitch-Fox, Einav, ‘[Re]Fashioning the New Woman: Women’s Dress, the Oriental Style, and the Construction of American Feminist Imagery in the 1910’s', Journal of Women's History, 27. 2 (2015), 14-36, 194 $<$ http://vortex3.uco.edu/login?url=https://www-proquestcom.vortex3.uco.edu/scholarly-journals/re-fashioning-new-woman-womens-

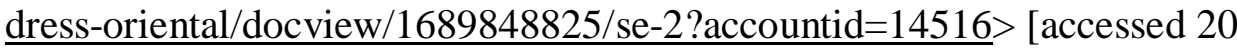
January 2021].

Reinach, Simona Segre, 'China and Italy: Fast Fashion Versus Prêt à Porter: Towards a New Culture in Fashion', Fashion Theory, 9.1 (2005), 43-56 <https://web-bebscohost-com.vortex3.uco.edu>

Reinsch, Ole, ‘Flapper Girls-Feminism and Consumer Society in the 1920’s’, Gender Forum: An Internet Journal for Gender Studies, iss. 40 (2013), 31-40 
<http://genderforum.org/wp-content/uploads/2017/01/2013-40-ConsumerismComplete.pdf $>$ [accessed 20 January 2021]

Riegel, Robert E., ‘Women’s Clothing and Women’s Rights', American Quarterly, 15.3 (1963), 390-401 <https://doi-org.vortex3.uco.edu/10.2307/2711370>

Richards, Lynne, 'The Rise and Fall of it All: The Hemlines and Hiplines of the 1920’s', Clothing and Textiles Research Journal, vol. 2 (1983-84), 42-48

Serena, Mayeri, 'Constitutional Choices: Legal Feminism and the Historical Dynamics of Change', California Law Review, 92.3 (2004), 755-839 < https://doi-org.vortex3.uco.edu/10.2307/3481454>

Sherman, Jane and Christena L. Schlundt, 'Who’s St. Denis? What Is She?', Dance Chronicle, 10.3 (1987), 305-329 < $\underline{\text { http://www.jstor.com/stable/1567763> }}$ [accessed 10 February 2021].

Simmel, Georg, ‘Fashion’, American Journal of Sociology, 62.6 (1957), 541-558 <http://vortex3.uco.edu:2050/login?url=https://www.jstor.org/stable/2773129> [accessed 30 January 2021]

Singer, Ben, 'Manhattan Nickelodeons: New Data on Audiences and Exhibitors', Cinema Journal, 34.3 (1995), 5-35 < https://doiorg.vortex3.uco.edu/10.2307/1225743>

Slowinska, Maria A. 'Consuming Illusion, Illusions of Consumability: American Movie Palaces of the 1920s', American Studies, 50.4 (2005), 575-601 <http://vortex3.uco.edu:2050/login?url=https://www.jstor.org/stable/41158182> [Accessed 21 January 2021]

Sommer, Sally R. 'Loïe Fuller’, The Drama Review: TDR, 19.1 (1975), 53-67 (pp. 5355, 61, 63) <https://doi-org.vortex3.uco.edu/10.2307/1144969> 
'Loie Fuller’s Art of Music and Light', Dance Chronicle, 4.4 (1981), 389-401 < http://vortex3.uco.edu:2050/login?url=https://www.jstor.org/stable/1567418> [accessed 21 January 2021]

Strassel, Anne Marie, 'Designing Women: Feminists Methodologies in American Fashion', Women’s Studies Quarterly, 41.1 \& 2 (2013), 35-39 < http://doi.org/10.1353/wsq.2013.0043>

Thurman, Christa C. Mayer, 'The Magician of Venice-Mariano Fortuny: 1871-1949’, Bulletin of the Art Institute of Chicago, 75.4 (1981), 4-5 (p. 4) <https://doiorg.vortex3.uco.edu/10.2307/4104229>

Trigg, Andrew B., 'Veblen, Bourdieu, and Conspicuous Consumption', Journal of Economic Issues, 35.1 (2001), 99-115

<http://vortex3.uco.edu:2050/login?url=https://www.jstor.org/stable/4227638> [accessed 10 February 2021]

Troy, Nancy J., 'The Logic of Fashion', The Journal of the Decorative Arts Society 1850-the Present, no. 19 (1995), 1-7 < $\underline{\text { http://vortex3.uco.edu:2050/login?url=https://www.jstor.org/stable/41805869> }}$ [accessed 20 January 2021]

Turner, Terence S., 'The Social Skin', HAU: Journal of Ethnographic Theory, 2.2 (2012), 486-504 <http://vortex3.uco.edu/login?url=https://www-proquestcom.vortex3.uco.edu/scholarly-journals/social-skin/docview/1850088748/se-

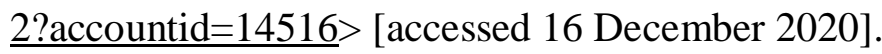

Vanni, Phillip, 'Extending and Broadening Blumer's Conceptualization of Fashion: Adding Notions of Generic Social Process and Semiotic Transformation’, Sociological Focus, 40.3 (2007), 306-319< http://vortex3.uco.edu:2050/login?url=https://www.jstor.org/stable/20832337> [accessed 20 January 2021] 
Vaughan, Heather A., "Icon: Tracing the Path of the 1950s Shirtwaist Dress.” The Journal of American Culture, 32.1 (2009), 29-37 (p. 32)

<http://vortex3.uco.edu/login?url=https://www-proquest-

com.vortex3.uco.edu/scholarly-journals/icon-tracing-path-1950s-shirtwaistdress/docview/200641627/se-2?accountid=14516 $>$ [accessed 20 January 2021].

van Reij, Frederique, 'Wearing Mondrian Yves Saint Laurent's Translation from High Art to Haute Couture', The Rijksmuseum Bulletin, 60.4 (2012), 342-359 < http://vortex3.uco.edu:2050/login?url=https://www.jstor.org/stable/23646887> [accessed 20 January 2021]

Voss, Kimberly Wilmot, ‘Who’s Wearing The Pants? How The New York Times Reported the Changing Dress of Women', Media Report to Women, 39.2 (2011), 12-17,22-23< http://vortex3.uco.edu/login?url=https://www-proquestcom.vortex3.uco.edu/trade-journals/whos-wearing-pants-how-new-yorktimes-reported/docview/868310740/se-2?accountid=14516>

Walsh, Margaret, 'Women’s Place in the American Labour Force, 1870-1995,' History, 82. 268 (1997), 563-581

<http://vortex3.uco.edu:2050/login?url=https://www.jstor.org/stable/24424274> [accessed 19 January 2021 - 15 August 2020]

Weber, Sandra and Claudia Mitchell, 'Theorizing Dress Stories’, Counterpoints, 220.0 (2004), 251-272 <http://vortex3.uco.edu:2050/login?url=https://www.jstor.org/stable/42978316 [accessed 15 March 2021]

Widmer, Kingsley, 'The Rebellious Culture: Reflection on its Functions in American Society', The Centennial Review, 17. 4 (1973), 338-356 <http://vortex3.uco.edu:2050/login?url=https://www.jstor.org/stable/23738089> [accessed 20 January 2021] 
Yellis, Kenneth A., 'Prosperity’s Child: Some Thoughts on the Flapper', American Quarterly, 21.1 (1969), 44-64 < https://doiorg.vortex3.uco.edu/10.2307/2710772>.

Zeitz, J., 'Rejecting the Center: Radical Grassroots Politics in the 1970s — SecondWave Feminism as a Case Study', Journal of Contemporary History, 43.4 (2008), 673-688

<http://vortex3.uco.edu:2050/login?url=https://www.jstor.org/stable/40543229> [accessed 11 February 2021].

\section{Reference Materials}

\section{Dictionaries \& Encyclopedias}

'Aesthetic Movement', in Philip's Encyclopedia [online], $<$ http://vortex3.uco.edu/login?url=https://search.credoreference.com/content/e

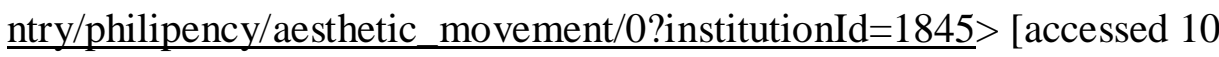
February 2021].

‘Artemis: Greek goddess’, in Encyclopedia Britannica [online], <https://www.britannica.com/topic/Artemis-Greek-goddess $>$ [accessed 24 July 2020]

'Fast fashion', in Merriam-Webster Dictionary [online], <https://www.merriamwebster.com/dictionary/fast\%20fashion> [accessed 5 November 2020]

'Jazz', in Merriam-Webster Dictionary [online], < https://www.merriamwebster.com/dictionary/jazz> [accessed 10 February 2021]

'Modern Dance', in Canadian Encyclopedia [online], ProQuest $<$ https://wwwproquest-com.vortex3.uco.edu>

'Subculture', in Merriam-Webster Dictionary [online], https://www.merriamwebster.com/dictionary/subculture [accessed 7 November 2020] 
Watts, Duncan, Dictionary of American Government and Politics (Edinburgh: Edinburgh University Press, 2010). ProQuest Ebook Central

\section{Government Documents}

120 Years of American Education, ed. by Thomas D. Snyder, National Center for Education Statistics, (January 1993), pp. 68- 70, 83

$<$ https://nces.ed.gov/pubs93/93442.pdf $>$ [accessed 15 January 2021]

U.S. Department of Commerce, Statistical Abstract of the United States: 1910, 'Table No. 137 Population 10 Years of Age and Upward Engaged in Gainful Occupations, Census Years 1890 and 1900: By Sex and Specified Occupations’ (Washington, D.C.: Government Printing Office, 1911), no. 33 $<$ https://www.census.gov/library/publications/1911/compendia/statab/33ed.ht $\underline{\mathrm{ml}}>$ [accessed 14 February 2021]

U.S. Department of Commerce, Statistical Abstract of the United States: 1919, 'Table No. 81 - Professional Schools, School Year 1916: Number of Theological, Law, and Medical Schools, Instructors and Students, by States and Geographical Divisions', (Washington D.C.: Government Printing Office, 1920), no. 42

$<$ https://www.census.gov/library/publications/1920/compendia/statab/42ed.ht $\underline{\mathrm{ml}}>$ [accessed 14 February 2021]

U.S. Department of Commerce, Statistical Abstract of the United States: 1920, 'Undergraduate Students in Universities, Colleges, and School of Technology, 1918’ (Washington, D.C.: Government Printing Office, 1921), no. 43

<https://www.census.gov/library/publications/1921/compendia/statab/43ed.ht $\underline{\mathrm{ml}}>$ [accessed 15 March 2021] 
U.S. Department of Commerce, Statistical Abstract of the United States: 1920, 'Universities, Colleges, and School of Technology, Number and Sex of Instructors and Students, and Total Working Income, 1918', (Washington, D.C.: Government Printing Office, 1921), no. 43 <https://www.census.gov/library/publications/1921/compendia/statab/43ed.ht $\underline{\mathrm{ml}}>$ [accessed 15 March 2021]

U.S. Department of Commerce, Statistical Abstract of the United States: 1929, 'Table No. 130 -Universities, Colleges, and Professional Schools by States' (Washington D.C.: Government Printing Office, 1929), no 51 $<$ https://www.census.gov/library/publications/1929/compendia/statab/51ed.ht $\underline{\mathrm{ml}}>$ [accessed 14 February 2021]

U.S. Department of Commerce, Statistical Abstract of the United States: 1930, 'Table No. 51: Persons 10 Years of Age and Over in Each General Division of Occupations’, (Washington, D.C.: Government Printing Office, 1930), no. 52 $<$ https://www.census.gov/library/publications/1930/compendia/statab/52ed.ht $\underline{\mathrm{ml}}>$ [accessed 14 February 2021]

U.S. Department of Commerce, Statistical Abstract of the United States: 1939, 'Table No. 50 - Gainful Workers 10 Years of Age and Over, By Occupation Groups, By Sex, Continental United States: 1920 And 1930' (Washington D.C.: Government Printing Office, 1940) <https://www.census.gov/library/publications/1940/compendia/statab/61ed.ht $\mathrm{ml}>$ [accessed 14 February 2021]

U.S. Department of Commerce, Statistical Abstract of the United States: 1955, 'Table No. 219 - Gainful Workers, 1910 To 1930, And Total Labor Force, 1940 and 1950, By Age And Sex [Decennially]', (Washington D.C.: Government Printing Office, 1955), no. 75

$<$ https://www.census.gov/library/publications/1955/compendia/statab/76ed.ht $\underline{\mathrm{ml}}>$ [accessed 14 February 2021] 
U.S. Department of Commerce, Statistical Abstract of The United States: 1960,

'Table No. 140: High School And College Graduates, By Sex: 1900 to 1956'

(Washington, D.C., Government Printing Office, 1960), no. 81

$<$ https://www.census.gov/library/publications/1960/compendia/statab/81ed.ht $\underline{\mathrm{ml}}>$ [accessed 14 February 2021]

U.S. Department of Commerce, Statistical Abstract of The United States: 1960, 'Table No. 274: Marital Status of Women in the Civilian Labor Force: 1940 to 1959’ (Washington, D.C., Government Printing Office, 1960), no. 81 $<$ https://www.census.gov/library/publications/1960/compendia/statab/81ed.ht $\underline{\mathrm{ml}}>$ [accessed 14 February 2021]

U.S. Department of Commerce, Statistical Abstract of the United States: 1970, 'Table no. 7: Current And Projected Population, By Age And Sex: 1960 To 1990’ (Washington, D.C., Government Printing Office, 1970), no. 91

< https://www.census.gov/library/publications/1970/compendia/statab/91ed.ht $\underline{\mathrm{ml}}>$ [accessed 14 February 2021]

\section{Other Sources}

\section{Blogs}

FIDM Museum, (12 January 2011), 'Mariano Fortuny’ (blog), <https://blog.fidmmuseum.org/museum/2011/01/mariano-fortuny.html $>$ [accessed on January 20 2021]

Jean Patou: Innovator (2014), < https://exhibitions.fitnyc.edu/1930s-fashionblog/tag/tennis/ > [accessed 4 January 2021] (para 4 of 8) 
Laricks, Kara ‘Though History May Shift, The Shift Dress Remains a Constant Source of Inspiration', 31 August 2015.

$<$ https://www.universityoffashion.com/blog/though-history-may-shift-shiftdress-remains-constant-source-inspiration> [accessed 10 November 2020]

\section{Exhibitions \& Fashion Collections}

Decadence: Fashions from the 1920s hosted by University of North Texas, at Galleria Mall (Dallas, TX, attended on 19 February 2016)

Dior: From Paris to the World, at Dallas Museum of Art (Dallas, TX, attended on 10 August 2019).

Texas Fashion Collection, University of North Texas, at Denton, TX, visited on March 2017

\section{Websites}

American Society of Civil Engineers, Emily Warren Roebling,

$<$ https://www.asce.org/templates/person-bio-detail.aspx?id=11203 $>$ [accessed 15 August 2020]

Arbiter of Style - Lucile, Ltd.

<http://sites.fitnyc.edu/depts/museum/Arbitersofstyle/lucile.poiret.htm> [accessed 10 February 2021]

Bowman, Cynthia Grant, 'Women in the Legal Profession from the 1920s to the 1970s: What Can We Learn From Their Experience About Law and Social Change?', Cornell University Law School Scholarship @ Cornell Law: A Digital Repository, (2009) 1-25

$<\underline{\text { https://scholarship.law.cornell.edu/cgi/viewcontent.cgi?article=1011\&contex }}$ $\underline{\mathrm{t}=\text { facpub }}>$ [accessed 10 February 2021] 
Bressler Editorial Cartoons, Inc., 'Good Work, Sister: We Never Figured You Could Do a Man-Size Job!” America’s Women Have Met the Test!//Packer’, in Library of Congress, “Good Work, Sister: We Never Figured You Could Do a Man-Size Job!” America’s Women Have Met the Test!// Packer (1944), <https://www.loc.gov/item/97515638> [accessed 11 February 2021]

Christy, Howard Chandler, 'Clear the Way' [online] < https://www.metmuseum.org/art/collection/search/391027> [accessed 27 February 2021]

'Fight or Buy Bonds Third Liberty Loan’ [online]

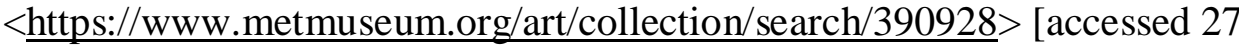
February 2021]

'I Want You for the Navy' [online] < https://www.metmuseum.org/art/collection/search/390926> [accessed 27 February 2021].

Curtis, Susan, Campbell's Soup Paper Dress,

$<$ https://www.ndsu.edu/erhcc/gallery/collection highlights/2010.05.01/15 $>$ [accessed 12 February 2021] (para 1 of 1)

Day Francis, 'Florrie the Flapper' [online] < https://collections.vam.ac.uk/item/O1273369/florrie-the-flapper-sheet-musicfinck/> [accessed 10 March 2021]

Department of Greek and Roman Art, ‘Ancient Greek Dress’ (2003), <http://www.metmuseum.org/toah/hd/grdr/hd_grdr.htm $>$ [accessed 26 January 2021] (para 1 of 2)

‘The Flapper (1920) Photo Gallery’ [online]

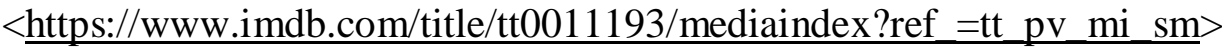
[accessed 30 December 2020] 
Fuzzylizzie, Francesca for Damon (2010), < https://vintagefashionguild.org/labelresource/francesca-for-damon/> [accessed 8 January 2021]

Garber, Steve, The Decision to Go to the Moon: President John F. Kennedy's May 25, 1961 Speech Before a Joint Session of Congress, (2013),

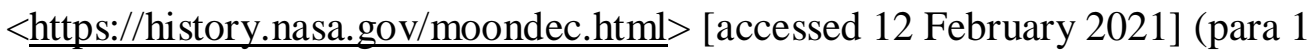
of 3)

IMDb, Black Oxen Full Cast \& Crew, $<$ https://www.imdb.com/title/tt0014721/fullcredits?ref =tt cl sm\#cast $>$ [acces sed 30 December 2020]

IMDb, Why Be Good? Full Cast \& Crew, $<$ https://www.imdb.com/title/tt0020585/fullcredits?ref =tt cl sm\#cast $>$ [accessed 30 December 2020]

May, Elaine Tyler, American Experience: Tupperware!, $<$ https://www.pbs.org/wgbh/americanexperience/features/tupperware-may/> [accessed 11 February 2021] (para 9 of 28)

Powers, Richard. Teen Dances of the 1950s,

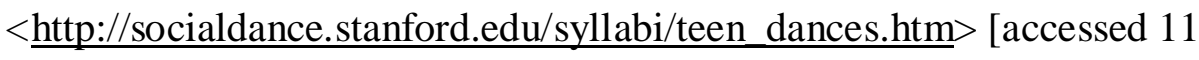
February 2021] (para 1 of 13)

Redigan-Barman, Sydney, Portrayals of Female Teen Rebellion in Hollywood Films of the 1950s, <https://sydneyredigan.com/media-studies/media-studiessamples/portrayals-of-female-teen-rebellion-in-hollywood-films-of-the-

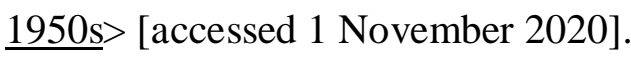

Rosenberg, Sari, August 26, 1970: Betty Friedan Led the Women's Strike for Equality, (2017), https://www.mylifetime.com/she-did-that/august-26-1970- 
betty-friedan-led-the-womens-strike-for-equality [accessed 29 December 2020]

Michael Solomon, Lilly Pulitzer’s Flower Power, (2013),

<https://www.elle.com/fashion/g8322/lilly-pulitzer-flower-power/?slide=1 > [accessed 10 March 2021

Stutesman, Drake, Clare West < https://wfpp.columbia.edu/pioneer/ccp-clare-west/ $>$ [accessed 29 August 2020]

Troedson, David, Elvis Presley Biography: A Comprehensive History of Elvis Presley’s Dynamic Life: Historical Television Guest Appearances (2016), $<$ https://www.elvispresleymusic.com.au/pictures/1956-september-9-edsullivan-show.html> [accessed 11 February 2021] (para 4 of 6)

University of Virginia Miller Center, Presidential Speeches: December 3, 1906: Sixth Annual Message, <https://millercenter.org/the-presidency/presidentialspeeches/december-3-1906-sixth-annual-message> [accessed 27 February 2021] (para 56 of 113)

Victoria and Albert Museum, Introducing Mary Quant, $<\underline{\text { https://www.vam.ac.uk/articles/introducing-mary-quant }}>$ [accessed 28 July 2021] (8 of 9)

\section{Dissertations or Theses}

Finamore, Michelle T., Fashioning Early Cinema: Dress and Representation in American Film, 1905-1930, (unpublished doctoral thesis, University of Michigan at Ann Arbor, 2010) in ProQuest Dissertations and Theses Global < http://vortex3.uco.edu/login?url=https://search-proquestcom.vortex3.uco.edu/docview/250272906?accountid=14516 $>$ [accessed on 15 September 2020] 
Johns, Maxine James, ‘Women’s Functional Swimwear, 1860-1920’, (unpublished doctoral thesis, Iowa State University, 1997) in ProQuest Dissertations and Theses Global < http://vortex3.uco.edu/login?url=https://www-proquestcom.vortex3.uco.edu/dissertations-theses/womens-functional-swimwear-1860-

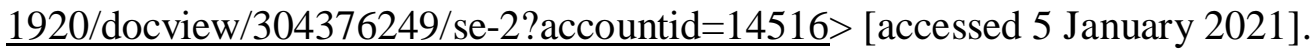

Park, Soohyun, 'Flapper Fashion: In The Context Of Cultural Changes Of America In The 1920s' (unpublished master’s thesis, The City University Of New York, 2014) in ProQuest Dissertation and Theses Global $<$ http://vortex3.uco.edu/login?url=https://www-proquestcom.vortex3.uco.edu/dissertations-theses/flapper-fashion-context-culturalchanges-america/docview/1551498384/se-2?accountid=14516 $>$ [accessed January 2 2021].

Robinson, Eugene, 'Industrial Role Models and Matinee Idols: Their Significance And Hollywood’s Role In The Burgeoning Industrial Dream’, (unpublished doctoral thesis, University of Maryland: College Park, 1984) in ProQuest Dissertations and Theses Global $<$ https://search-proquestcom.vortex3.uco.edu/pqdtglobal/docview/303330034/8B8BFBF2354F4B99P Q/1?accountid=14516 $>$ [accessed 10 February 2021]

Robinson, Rebecca J., ‘American Sportswear: A Study of the Origins and Women Designers From the 1930’s to the 1960’s', (unpublished master thesis, University of Cincinnati, 2003) in ProQuest Dissertations and Theses Global $<\underline{\text { http://vortex3.uco.edu/login?url=https://www-proquest- }}$ com.vortex3.uco.edu/dissertations-theses/american-sportswear-study-originswomen-designers/docview/305329576/se-2?accountid=14516 $>$ [accessed 11 February 2021] 
Ross, Sara, 'Banking the Flames of Youth: The Hollywood Flapper 1920-1930' (unpublished doctoral dissertation, University of Wisconsin-Madison, 2000) in ProQuest Dissertations \& Theses Global <

http://vortex3.uco.edu/login?url=https://www-proquestcom.vortex3.uco.edu/docview/304639450?accountid=14516> [accessed 30 May 2018]

Schwarz, Caitlin Mackenzie, 'Body and Soul: How Mariano Fortuny Redefined the “Classical”', (unpublished master thesis, University of California: Davis, 2019) in ProQuest Dissertations and Theses Global <https://search-proquestcom.vortex3.uco.edu/pqdtglobal/docview/2299779579/D3FD41F32EF44134P Q/1?accountid=14516> [accessed 10 February 2021]

\section{Page by Page Tracking Method}

\section{Vogue}

Vogue, 19 April 1900. ProQuest < $\underline{\text { https://www-proquest-com.vortex3.uco.edu }>}$

Vogue, 06 September 1900. ProQuest < $\underline{\text { https://www-proquest-com.vortex3.uco.edu }>}$

Vogue, 18 April 1901. ProQuest < https://www-proquest-com.vortex3.uco.edu $>$

Vogue, 12 September 1901. ProQuest < $\underline{\text { https://www-proquest-com.vortex3.uco.edu }>}$

Vogue, 17 April 1902. ProQuest < https://www-proquest-com.vortex3.uco.edu $>$

Vogue, 18 September 1902. ProQuest $<\underline{\text { https://www-proquest-com.vortex3.uco.edu }>}$

Vogue, 16 April 1903. ProQuest < https://www-proquest-com.vortex3.uco.edu $>$

Vogue, 24 September 1903. ProQuest < $\underline{\text { https://www-proquest-com.vortex3.uco.edu }>}$ 
Vogue, 07 July 1904. ProQuest $<\underline{\text { https://www-proquest-com.vortex3.uco.edu }>}$

Vogue, 14 July 1904. ProQuest $<\underline{\text { https://www-proquest-com.vortex3.uco.edu }>}$

Vogue, 21 July 1904. ProQuest < $\underline{\text { https://www-proquest-com.vortex3.uco.edu }>}$

Vogue, 15 September 1904. ProQuest < $\underline{\text { https://www-proquest-com.vortex3.uco.edu }>}$

Vogue, 05 January 1905. ProQuest < https://www-proquest-com.vortex3.uco.edu $>$

Vogue, 12 January 1905. ProQuest <https://www-proquest-com.vortex3.uco.edu $>$

Vogue, 30 January 1905. ProQuest < $\underline{\text { https://www-proquest-com.vortex3.uco.edu }>}$

Vogue, 30 March 1905. ProQuest $<\underline{\text { https://www-proquest-com.vortex3.uco.edu }>}$

Vogue, 03 August 1905. ProQuest < https://www-proquest-com.vortex3.uco.edu $>$

Vogue, 17 August 1905. ProQuest < $\underline{\text { https://www-proquest-com.vortex3.uco.edu }>}$

Vogue, 24 August 1905. ProQuest < $\underline{\text { https://www-proquest-com.vortex3.uco.edu }>}$

Vogue, 14 September 1905. ProQuest < $\underline{\text { https://www-proquest-com.vortex3.uco.edu }>}$

Vogue, 22 February 1906. ProQuest $<\underline{\text { https://www-proquest-com.vortex3.uco.edu }>}$

Vogue, 30 September 1906. ProQuest $<\underline{\text { https://www-proquest-com.vortex3.uco.edu }>}$

Vogue, 11 October 1906. ProQuest < https://www-proquest-com.vortex3.uco.edu $>$

Vogue, 18 October 1906. ProQuest < $\underline{\text { https://www-proquest-com.vortex3.uco.edu }>}$

Vogue, 21 March 1907. ProQuest < $\underline{\text { https://www-proquest-com.vortex3.uco.edu }>}$ 
Vogue, 04 April 1907. ProQuest < https://www-proquest-com.vortex3.uco.edu $>$

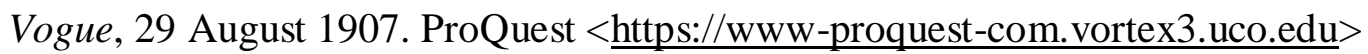

Vogue, 05 September 1907. ProQuest < $\underline{\text { https://www-proquest-com.vortex3.uco.edu }>}$

Vogue, 12 September 1907. ProQuest < $\underline{\text { https://www-proquest-com.vortex3.uco.edu }>}$

Vogue, 27 February 1908. ProQuest < $\underline{\text { https://www-proquest-com.vortex3.uco.edu }}>$

Vogue, 05 March 1908. ProQuest < $\underline{\text { https://www-proquest-com.vortex3.uco.edu }>}$

Vogue, 11 March 1908. ProQuest < $\underline{\text { https://www-proquest-com.vortex3.uco.edu }>}$

Vogue, 02 April 1908. ProQuest < https://www-proquest-com.vortex3.uco.edu>

Vogue, 11 June 1908. ProQuest < https://www-proquest-com.vortex3.uco.edu $>$

Vogue, 23 July 1908. ProQuest < $\underline{\text { https://www-proquest-com.vortex3.uco.edu }>}$

Vogue, 27 August 1908. ProQuest < $\underline{\text { https://www-proquest-com.vortex3.uco.edu }>}$

Vogue, 15 October 1908. ProQuest < $\underline{\text { https://www-proquest-com.vortex3.uco.edu }>}$

Vogue, 22 October 1908. ProQuest < $\underline{\text { https://www-proquest-com.vortex3.uco.edu }>}$

Vogue, 15 April 1909. ProQuest < $\underline{\text { https://www-proquest-com.vortex3.uco.edu }>}$

Vogue, 01 July 1909. ProQuest < $\underline{\text { https://www-proquest-com.vortex3.uco.edu }>}$

Vogue, 16 October 1909. ProQuest < $\underline{\text { https://www-proquest-com.vortex3.uco.edu }}>$

Vogue, 05 February 1910. ProQuest $<\underline{\text { https://www-proquest-com.vortex3.uco.edu }>}$ 
Vogue, 10 February 1910. ProQuest < $\underline{\text { https://www-proquest-com.vortex3.uco.edu }>}$

Vogue, 01 March 1910. ProQuest $<\underline{\text { https://www-proquest-com.vortex3.uco.edu }>}$

Vogue, 01 October 1910. ProQuest < $\underline{\text { https://www-proquest-com.vortex3.uco.edu }>}$

Vogue, 15 April 1911. ProQuest < https://www-proquest-com.vortex3.uco.edu>

Vogue, 01 October 1911. ProQuest < $\underline{\text { https://www-proquest-com.vortex3.uco.edu }>}$

Vogue, 15 April 1912. ProQuest < https://www-proquest-com.vortex3.uco.edu $>$

Vogue, 15 September 1912. ProQuest < $\underline{\text { https://www-proquest-com.vortex3.uco.edu }>}$

Vogue, 15 April 1913. ProQuest < https://www-proquest-com.vortex3.uco.edu>

Vogue, 01 October 1913. ProQuest < $\underline{\text { https://www-proquest-com.vortex3.uco.edu }>}$

Vogue, 15 October 1913. ProQuest < $\underline{\text { https://www-proquest-com.vortex3.uco.edu }>}$

Vogue, 01 April 1914. ProQuest < https://www-proquest-com.vortex3.uco.edu $>$

Vogue, 01 August 1914. ProQuest < $\underline{\text { https://www-proquest-com.vortex3.uco.edu }>}$

Vogue, 01 October 1914. ProQuest < $\underline{\text { https://www-proquest-com.vortex3.uco.edu }>}$

Vogue, 01 February 1915. ProQuest $<\underline{\text { https://www-proquest-com.vortex3.uco.edu }>}$

Vogue, 01 September 1915. ProQuest < $\underline{\text { https://www-proquest-com.vortex3.uco.edu }>}$

Vogue, 15 September 1915. ProQuest < $\underline{\text { https://www-proquest-com.vortex3.uco.edu }>}$

Vogue, 01 October 1915. ProQuest < $\underline{\text { https://www-proquest-com.vortex3.uco.edu }>}$ 
Vogue, 18 February 1916. ProQuest < $\underline{\text { https://www-proquest-com.vortex3.uco.edu }>}$

Vogue, 01 March 1916. ProQuest $<\underline{\text { https://www-proquest-com.vortex3.uco.edu }>}$

Vogue, 15 September 1916. ProQuest < $\underline{\text { https://www-proquest-com.vortex3.uco.edu }>}$

Vogue, 01 October 1916. ProQuest < $\underline{\text { https://www-proquest-com.vortex3.uco.edu }>}$

Vogue, 15 October 1916. ProQuest < $\underline{\text { https://www-proquest-com.vortex3.uco.edu }>}$

Vogue, 01 February 1917. ProQuest < $\underline{\text { https://www-proquest-com.vortex3.uco.edu }>}$

Vogue, 01 October 1917. ProQuest < $\underline{\text { https://www-proquest-com.vortex3.uco.edu }>}$

Vogue, 01 February 1918. ProQuest $<\underline{\text { https://www-proquest-com.vortex3.uco.edu }>}$

Vogue, 15 February 1918. ProQuest < $\underline{\text { https://www-proquest-com.vortex3.uco.edu }>}$

Vogue, 01 March 1918. ProQuest < $\underline{\text { https://www-proquest-com.vortex3.uco.edu }>}$

Vogue, 15 March 1918. ProQuest < $\underline{\text { https://www-proquest-com.vortex3.uco.edu }>}$

Vogue, 16 August 1918. ProQuest < $\underline{\text { https://www-proquest-com.vortex3.uco.edu }>}$

Vogue, 01 October 1918. ProQuest < $\underline{\text { https://www-proquest-com.vortex3.uco.edu }>}$

Vogue, 15 October 1918. ProQuest < $\underline{\text { https://www-proquest-com.vortex3.uco.edu }>}$

Vogue, 01 November 1918. ProQuest < $\underline{\text { https://www-proquest-com.vortex3.uco.edu }>}$

Vogue, 01 April 1919. ProQuest < https://www-proquest-com.vortex3.uco.edu>

Vogue, 15 October 1919. ProQuest < $\underline{\text { https://www-proquest-com.vortex3.uco.edu }>}$ 
Vogue, 15 February 1920. ProQuest < $\underline{\text { https://www-proquest-com.vortex3.uco.edu }>}$

Vogue, 15 March 1920. ProQuest < $\underline{\text { https://www-proquest-com.vortex3.uco.edu }>}$

Vogue, 15 April 1920. ProQuest < https://www-proquest-com.vortex3.uco.edu $>$

Vogue, 15 October 1920. ProQuest $<$ https://www-proquest-com.vortex3.uco.edu $>$

Vogue, 15 March 1921. ProQuest < $\underline{\text { https://www-proquest-com.vortex3.uco.edu }>}$

Vogue, 15 April 1921. ProQuest < https://www-proquest-com.vortex3.uco.edu $>$

Vogue, 15 October 1921. ProQuest < $\underline{\text { https://www-proquest-com.vortex3.uco.edu }>}$

Vogue, 15 April 1922. ProQuest < https://www-proquest-com.vortex3.uco.edu $>$

Vogue, 15 October 1922. ProQuest < https://www-proquest-com.vortex3.uco.edu $>$

Vogue, 01 January 1923. ProQuest < $\underline{\text { https://www-proquest-com.vortex3.uco.edu }>}$

Vogue, 01 April 1923. ProQuest < $\underline{\text { https://www-proquest-com.vortex3.uco.edu }>}$

Vogue, 15 April 1923. ProQuest < https://www-proquest-com.vortex3.uco.edu $>$

Vogue, 01 October 1923. ProQuest < $\underline{\text { https://www-proquest-com.vortex3.uco.edu }>}$

Vogue, 15 October 1923. ProQuest < $\underline{\text { https://www-proquest-com.vortex3.uco.edu }>}$

Vogue, 01 April 1924. ProQuest < https://www-proquest-com.vortex3.uco.edu $>$

Vogue, 15 April 1924. ProQuest < $\underline{\text { htps://www-proquest-com.vortex3.uco.edu }>}$

Vogue, 01 July 1924. ProQuest < $\underline{\text { https://www-proquest-com.vortex3.uco.edu }>}$ 
Vogue, 15 July 1924. ProQuest < $\underline{\text { https://www-proquest-com.vortex3.uco.edu }>}$

Vogue, 01 August 1924. ProQuest < $\underline{\text { https://www-proquest-com.vortex3.uco.edu }>}$

Vogue, 15 September 1924. ProQuest < $\underline{\text { https://www-proquest-com.vortex3.uco.edu }>}$

Vogue, 01 October 1924. ProQuest $<\underline{\text { https://www-proquest-com.vortex3.uco.edu }>}$

Vogue, 15 October 1924. ProQuest < $\underline{\text { https://www-proquest-com.vortex3.uco.edu }>}$

Vogue, 01 November 1924. ProQuest < $\underline{\text { https://www-proquest-com.vortex3.uco.edu }>}$

Vogue, 01 April 1925. ProQuest < https://www-proquest-com.vortex3.uco.edu $>$

Vogue, 15 April 1925. ProQuest < https://www-proquest-com.vortex3.uco.edu $>$

Vogue, 15 October 1925. ProQuest < https://www-proquest-com.vortex3.uco.edu $>$

Vogue, 01 November 1925. ProQuest < $\underline{\text { https://www-proquest-com.vortex3.uco.edu }>}$

Vogue, 01 April 1926. ProQuest < https://www-proquest-com.vortex3.uco.edu $>$

Vogue, 15 April 1926. ProQuest < https://www-proquest-com.vortex3.uco.edu $>$

Vogue, 15 October 1926. ProQuest < $\underline{\text { https://www-proquest-com.vortex3.uco.edu }>}$

Vogue, 15 April 1927. ProQuest < https://www-proquest-com.vortex3.uco.edu $>$

Vogue, 15 October 1927. ProQuest <https://www-proquest-com.vortex3.uco.edu $>$

Vogue, 15 April 1928. ProQuest < $\underline{\text { https://www-proquest-com.vortex3.uco.edu }>}$

Vogue, 13 October 1928. ProQuest < $\underline{\text { https://www-proquest-com.vortex3.uco.edu }>}$ 
Vogue, 13 April 1929. ProQuest < https://www-proquest-com.vortex3.uco.edu>

Vogue, 12 October 1929. ProQuest < https://www-proquest-com.vortex3.uco.edu $>$

Vogue, 01 February 1950. ProQuest $<\underline{\text { https://www-proquest-com.vortex3.uco.edu }>}$

Vogue, 01 September 1950. ProQuest $<\underline{\text { https://www-proquest-com.vortex3.uco.edu }>}$

Vogue, 01 February 1951. ProQuest $<\underline{\text { https://www-proquest-com.vortex3.uco.edu }>}$

Vogue, 01 September 1951. ProQuest < $\underline{\text { https://www-proquest-com.vortex3.uco.edu }>}$

Vogue, 01 February 1952. ProQuest < $\underline{\text { https://www-proquest-com.vortex3.uco.edu }>}$

Vogue, 01 September 1952. ProQuest < $\underline{\text { https://www-proquest-com.vortex3.uco.edu }>}$

Vogue, 01 February 1953. ProQuest < $\underline{\text { https://www-proquest-com.vortex3.uco.edu }>}$

Vogue, 01 September 1953. ProQuest < $\underline{\text { https://www-proquest-com.vortex3.uco.edu }>}$

Vogue, 01 February 1954. ProQuest $<\underline{\text { https://www-proquest-com.vortex3.uco.edu }>}$

Vogue, 01 September 1954. ProQuest < $\underline{\text { https://www-proquest-com.vortex3.uco.edu }>}$

Vogue, 01 February 1955. ProQuest $<$ https://www-proquest-com.vortex3.uco.edu $>$

Vogue, 01 September 1955. ProQuest < $\underline{\text { https://www-proquest-com.vortex3.uco.edu }>}$

Vogue, 01 February 1956. ProQuest < $\underline{\text { https://www-proquest-com.vortex3.uco.edu }}>$

Vogue, 01 September 1956. ProQuest < $\underline{\text { https://www-proquest-com.vortex3.uco.edu }>}$

Vogue, 01 February 1957. ProQuest < $\underline{\text { https://www-proquest-com.vortex3.uco.edu }>}$ 
Vogue, 01 September 1957. ProQuest $<$ https://www-proquest-com.vortex3.uco.edu $>$

Vogue, 01 February 1958. ProQuest $<\underline{\text { https://www-proquest-com.vortex3.uco.edu }>}$

Vogue, 01 September 1958. ProQuest $<\underline{\text { https://www-proquest-com.vortex3.uco.edu }>}$

Vogue, 01 February 1959. ProQuest $<$ https://www-proquest-com.vortex3.uco.edu $>$

Vogue, 01 September 1959. ProQuest $<\underline{\text { https: } / / \text { www-proquest-com.vortex3.uco.edu }>}$

Vogue, 01 February 1960. ProQuest $<$ https://www-proquest-com.vortex3.uco.edu $>$

Vogue, 01 September 1960. ProQuest $<$ https://www-proquest-com.vortex3.uco.edu $>$

Vogue, 01 February 1961. ProQuest $<$ https://www-proquest-com.vortex3.uco.edu $>$

Vogue, 01 September 1961. ProQuest $<\underline{\text { https://www-proquest-com.vortex3.uco.edu }>}$

Vogue, 01 February 1962. ProQuest $<$ https://www-proquest-com.vortex3.uco.edu $>$

Vogue, 01 September 1962. ProQuest $<\underline{\text { https://www-proquest-com.vortex3.uco.edu }>}$

Vogue, 01 February 1963. ProQuest $<$ https://www-proquest-com.vortex3.uco.edu $>$

Vogue, 01 September 1963. ProQuest $<\underline{\text { https://www-proquest-com.vortex3.uco.edu }>}$

Vogue, 01 February 1964. ProQuest $<\underline{\text { https://www-proquest-com.vortex3.uco.edu }>}$

Vogue, 01 September 1964. ProQuest $<$ https://www-proquest-com.vortex3.uco.edu $>$

Vogue, 01 February 1965. ProQuest $<$ https://www-proquest-com.vortex3.uco.edu $>$

Vogue, 01 September 1965. ProQuest $<\underline{\text { https://www-proquest-com.vortex3.uco.edu }>}$ 
Vogue, 01 February 1966. ProQuest < $\underline{\text { https://www-proquest-com.vortex3.uco.edu }>}$

Vogue, 01 September 1966. ProQuest < $\underline{\text { https://www-proquest-com.vortex3.uco.edu }>}$

Vogue, 01 February 1967. ProQuest $<\underline{\text { https://www-proquest-com.vortex3.uco.edu }>}$

Vogue, 01 September 1967. ProQuest < $\underline{\text { https://www-proquest-com.vortex3.uco.edu }>}$

Vogue, 01 February 1968. ProQuest < $\underline{\text { https://www-proquest-com.vortex3.uco.edu }>}$

Vogue, 01 September 1968. ProQuest < $\underline{\text { https://www-proquest-com.vortex3.uco.edu }>}$

Vogue, 01 February 1969. ProQuest < https://www-proquest-com.vortex3.uco.edu $>$

Vogue, 01 September 1969. ProQuest < $\underline{\text { https://www-proquest-com.vortex3.uco.edu }>}$

\section{Seventeen}

Seventeen, February 1950. ProQuest < $\underline{\text { htps://www-proquest-com.vortex3.uco.edu }>}$

Seventeen, September 1950. ProQuest < $\underline{\text { https://www-proquest-com.vortex3.uco.edu }>}$

Seventeen, February 1951. ProQuest < $\underline{\text { htps://www-proquest-com.vortex3.uco.edu }>}$

Seventeen, September 1951. ProQuest $<\underline{\text { https://www-proquest-com.vortex3.uco.edu }>}$

Seventeen, February 1952. ProQuest $<$ https://www-proquest-com.vortex3.uco.edu $>$

Seventeen, September 1952. ProQuest < $\underline{\text { https://www-proquest-com.vortex3.uco.edu }>}$

Seventeen, February 1953. ProQuest < $\underline{\text { https://www-proquest-com.vortex3.uco.edu }>}$ 
Seventeen, September 1953. ProQuest $<\underline{\text { https://www-proquest-com.vortex3.uco.edu }>}$

Seventeen, February 1954. ProQuest $<$ https://www-proquest-com.vortex3.uco.edu $>$

Seventeen, September 1954. ProQuest < $\underline{\text { https://www-proquest-com.vortex3.uco.edu }>}$

Seventeen, February 1955. ProQuest $<\underline{\text { https://www-proquest-com.vortex3.uco.edu }>}$

Seventeen, September 1955. ProQuest $<\underline{\text { https://www-proquest-com.vortex3.uco.edu }>}$

Seventeen, February 1956. ProQuest < https://www-proquest-com.vortex3.uco.edu $>$

Seventeen, September 1956. ProQuest $<\underline{\text { https://www-proquest-com.vortex3.uco.edu }>}$

Seventeen, February 1957. ProQuest < https://www-proquest-com.vortex3.uco.edu $>$

Seventeen, September 1957. ProQuest $<\underline{\text { https://www-proquest-com.vortex3.uco.edu }>}$

Seventeen, February 1958. ProQuest < $\underline{\text { https://www-proquest-com.vortex3.uco.edu }>}$

Seventeen, September 1958. ProQuest $<\underline{\text { https://www-proquest-com.vortex3.uco.edu }>}$

Seventeen, February 1959. ProQuest < https://www-proquest-com.vortex3.uco.edu $>$

Seventeen, September 1959. ProQuest $<\underline{\text { https://www-proquest-com.vortex3.uco.edu }>}$

Seventeen, February 1960. ProQuest < $\underline{\text { https://www-proquest-com.vortex3.uco.edu }>}$

Seventeen, September 1960. ProQuest $<\underline{\text { https://www-proquest-com.vortex3.uco.edu }>}$

Seventeen, February 1961. ProQuest < $\underline{\text { htps://www-proquest-com.vortex3.uco.edu }>}$

Seventeen, September 1961. ProQuest < $\underline{\text { https://www-proquest-com.vortex3.uco.edu }>}$ 
Seventeen, February 1962. ProQuest $<$ https://www-proquest-com.vortex3.uco.edu $>$

Seventeen, September 1962. ProQuest $<\underline{\text { https: } / / \text { www-proquest-com.vortex3.uco.edu }>}$

Seventeen, February 1963. ProQuest $<\underline{\text { https://www-proquest-com.vortex3.uco.edu }>}$

Seventeen, September 1963. ProQuest $<\underline{\text { https://www-proquest-com.vortex3.uco.edu }>}$

Seventeen, February 1964. ProQuest < https://www-proquest-com.vortex3.uco.edu $>$

Seventeen, September 1964. ProQuest $<$ https://www-proquest-com.vortex3.uco.edu $>$

Seventeen, February 1965. ProQuest $<\underline{\text { https://www-proquest-com.vortex3.uco.edu }>}$

Seventeen, September 1965. ProQuest $<\underline{\text { https://www-proquest-com.vortex3.uco.edu }>}$

Seventeen, February 1966. ProQuest < https://www-proquest-com.vortex3.uco.edu $>$

Seventeen, September 1966. ProQuest $<$ https://www-proquest-com.vortex3.uco.edu $>$

Seventeen, February 1967. ProQuest $<$ https://www-proquest-com.vortex3.uco.edu $>$

Seventeen, September 1967. ProQuest $<\underline{\text { https://www-proquest-com.vortex3.uco.edu }>}$

Seventeen, February 1968. ProQuest $<\underline{\text { https://www-proquest-com.vortex3.uco.edu }}>$

Seventeen, September 1968. ProQuest < $\underline{\text { https://www-proquest-com.vortex3.uco.edu }>}$

Seventeen, February 1969. ProQuest < https://www-proquest-com.vortex3.uco.edu $>$

Seventeen, September 1969. ProQuest $<\underline{\text { https://www-proquest-com.vortex3.uco.edu }>}$ 


\section{Figures}

Figure [1]

UNT College of Visual Arts + Design, “"Petrooli” Dress’,

<https://digital.library.unt.edu/ark:/67531/metadc1639265/> [accessed 28

November 2020]

Figure [2]

UNT College of Visual Arts + Design, 'Day Dress',

$<$ https://digital.library.unt.edu/ark:/67531/metadc461780/> [accessed 28

November 2020]

Figure [3]

UNT College of Visual Arts + Design, 'Dress',

<https://digital.library.unt.edu/ark:/67531/metadc701527/> [accessed 28

November 2020]

Figure [4]

UNT College of Visual Arts + Design, 'Dress',

<https://digital.library.unt.edu/ark:/67531/metadc461839/> [accessed 28

November 2020]

Figure [5]

UNT College of Visual Arts + Design, 'Day Dress',

<https://digital.library.unt.edu/ark:/67531/metadc503756/> [accessed 28

November 2020]

Figure [6]

‘Advertisement: Damon’, Vogue, 01 February 1966. ProQuest < $\underline{\text { htps://www- }}$ proquest-com.vortex3.uco.edu> 
Figure [7]

'Advertisement: Damon', Vogue, 01 February 1966. ProQuest < https://wwwproquest-com.vortex3.uco.edu>>

Figure [8]

The Miriam and Ira D. Wallach Division of Art, Prints and Photographs: Photography Collection, The New York Public Library, 'Corner of a Broadway flower factory’ [online] < https://digitalcollections.nypl.org/items/510d47d9-4e5da3d9-e040-e00a18064a99> [accessed 21 February 2021]

Figure [9]

The Cheapest Commodity on The Market', The Masses, December 1911.

$<\underline{\text { http://dlib.nyu.edu/themasses/books/masses012/5> [accessed } 12 \text { February }}$ 2021]

Figure [10]

Cogpunk Steamscribe, Emily Warren Roebling: A Steampunk Feminist Perspective, (2015). < https://cogpunksteamscribe.wordpress.com/2015/01/18/emilywarren-roebling-a-steampunk-feminist-persepective/> [accessed 20 January 2021]

Figure [11]

McDowell, Callie, Frank Bunker Gilbreth, Sr. and Lillian Evelyn Moller Gilbreth. $<$ https://www.changemanagementreview.com/frank-bunker-gilbreth-sr-andlillian- evelyn-moller-gilbreth/> [accessed 21 February 2021]

Figure [12]

'Cupid Teaches American Ways', Chicago Tribune, 8 September 1907. ProQuest $<\underline{\text { https://www-proquest-com.vortex3.uco.edu }>}$

Figure [13]

““Fore” by Charles Dana Gibson Painting Print, Wayfair, <wayfair.com/buyenlargeFore-by-Charles-Dana-Gibson-Painting-Print> [accessed 07 March 2021] 
Figure [14]

Harrison, Fisher, ‘Harrison Fisher’s College Girls’, Ladies Home Journal, June 1908. ProQuest $<<\underline{\text { https://www-proquest-com.vortex3.uco.edu }>}$

Figure [15]

'Harrison Fisher’s Camping Girls', Ladies Home Journal, August 1912. ProQuest $<<$ https://www-proquest-com.vortex3.uco.edu $>$

Figure [16]

'Our Harrison Fisher Cover’, Ladies Home Journal, August 1914. ProQuest $<$ https://www-proquest-com.vortex3.uco.edu $>$

Figure [17]

Crabben, Jan van der, 'Artemis, Goddess of the Hunt', in World History Encyclopedia (2019), <https://www.ancient.eu/image/10157/artemis-goddess-of-the-hunt/> [accessed 07 March 2021]

Figure [18]

The Miriam and Ira D. Wallach Division of Art, Prints and Photographs: Picture Collection, The New York Public Library, 'Diana with Bow and Hunting Dog' [online] <https://digitalcollections.nypl.org/items/510d47e4-0c52-a3d9e040-e00a18064a99> [accessed 21 February 2021]

Figure [19]

The Miriam and Ira D. Wallach Division of Art, Prints and Photographs: Picture Collection, The New York Public Library, 'Danza Bacchica’ [online] <https://digitalcollections.nypl.org/items/510d47e4-3799-a3d9-e040e00a18064a99> [accessed 21 February 2021]

Figure [20]

The Miriam and Ira D. Wallach Division of Art, Prints and Photographs: Picture Collection, The New York Public Library, 'Nozze di Penelope e di Ulisse' [online] < https://digitalcollections.nypl.org/items/510d47e4-2fe7-a3d9-e040e00a18064a99 $>$ [accessed 21 February 2021] 
Figure [21]

Sommer, Sally R. 'Loïe Fuller’, The Drama Review: TDR, 19.1 (1975), 53-67 (pp. 5355, 61, 63) <https://doi-org.vortex3.uco.edu/10.2307/1144969>

Figure [22]

Jerome Robbins Dance Division, The New York Public Library, La Danse Blanche, [online] <https://digitalcollections.nypl.org/items/8653bb60-3046-0131-31b958d385a7b928> [accessed 21 February 2021]

Figure [23]

The New York Public Library: Digital Collections, Isadora Duncan: Studies $<$ https://digitalcollections.nypl.org/items/510d47da-5a09-a3d9-e040e00a18064a99> [accessed 07 March 2020]

Figure [24]

Jane Sherman and Christena L. Schlundt, 'Who’s St. Denis? What Is She?', Dance Chronicle, 10.3 (1987), 305-329 (p. 310)

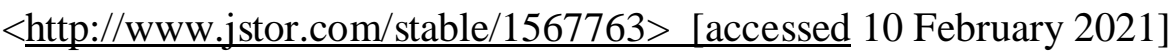

Figure [25]

Jane Sherman and Christena L. Schlundt, 'Who’s St. Denis? What Is She?', Dance Chronicle, 10.3 (1987), 305-329 (p. 311)

<http://www.jstor.com/stable/1567763> [accessed 10 February 2021]

Figure [26]

Jane Sherman and Christena L. Schlundt, 'Who’s St. Denis? What Is She?’, Dance Chronicle, 10.3 (1987), 305-329 (p. 311)

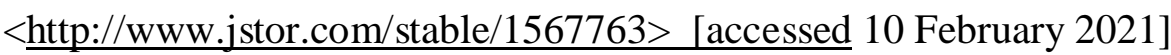

Figure [27]

Jane Sherman and Christena L. Schlundt, 'Who’s St. Denis? What Is She?', Dance

Chronicle, 10.3 (1987), 305-329 (p. 307)

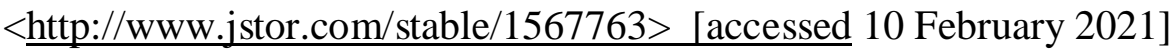


Figure [28]

Flapper dress, 1928, Kerry Taylor, Bermondsey, London, SE1 4PR, [online]

$<$ https://www-bloomsburyfashioncentral-com.vortex3.uco.edu/products/bergfashion-library/museum/kerry-taylor/flapper-dress>

Figure [29]

'Theater: Seen on the Stage', Vogue, 27 August 1908. ProQuest < https://wwwproquest-com.vortex3.uco.edu>

Figure [30]

Brooklyn Museum Costume Collection at The Metropolitan Museum of Art, 'Delphos' [online]

$<$ https://www.metmuseum.org/art/collection/search/157451 $>$ [accessed 08 March 2020]

Figure [31]

The Miriam and Ira D. Wallach Division of Art, Prints and Photographs: Picture Collection, The New York Public Library, 'The quartette’ [online] $<$ https://digitalcollections.nypl.org/items/510d47e3-3934-a3d9-e040e00a18064a99 $>$ [accessed 21 February 2021]

Figure [32]

Sir Edward Burne-Jones, ‘The Mirror of Venus’, [online] $<$ https://www.metmuseum.org/art/collection/search/630995?searchField=All\& amp;sortBy=Relevance\&amp;ft=Sir+Edward+BurneJones\&amp;offset=20\&amp;rpp=20\&amp;pos=26> [accessed 08 March 2021]

Figure [33]

Isadora Duncan Archive, Margot Duncan,

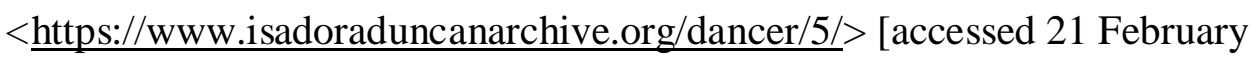
2021] 
Figure [34]

Jerome Robbins Dance Division, The New York Public Library, 'Ruth St Denis in St

Denis Mazurka’ [online]

$<$ https://digitalcollections.nypl.org/items/510d47df- 85e9-a3d9-e040-

e00a18064a99> [accessed 08 March 2021]

Figure [35 and 36]

Wong, Joanne, '2-Piece Gown by Mariano Fortuny’, taken at the exhibit: Decadence:

Fashions from the 1920s hosted by University of North Texas, (Dallas, TX, 22 January 2016 to 28 February 2016)

Figure [37]

'Features: Paris (from our Own Correspondent)', Vogue, 02 April 1908. ProQuest $<$ https://www-proquest-com.vortex3.uco.edu $>$

Figure [38]

‘Cover: Vogue’, Vogue, 05 January 1905. ProQuest $<\underline{\text { https://www-proquest- }}$ com.vortex3.uco.edu>

Figure [39]

'Fashion: Three Paul Poiret’s Models', Vogue, 01 December 1910. ProQuest $<\underline{\text { https://www-proquest-com.vortex3.uco.edu }>}$

Figure [40]

Poiret, Paul, 'Fancy Dress Costume’ [online]

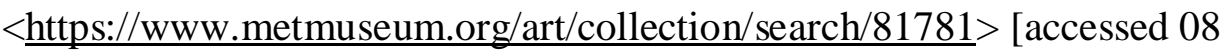
March 2021]

Figure [41]

Poiret, Paul, 'Dress', [online]

<https://www.metmuseum.org/art/collection/search/123612 > [accessed 08 March 2021] 
Figure [42]

Poiret, Paul, ‘Théâtre des Champs-Élysées’, [online]

$<$ https://www.metmuseum.org/art/collection/search/121172 $>$ [accessed 08 March 2021]

Figure [43]

'Fashion: Paul Poiret’s Gowns', Vogue, 01 April 1911. ProQuest < $\underline{\text { https://www- }}$ proquest-com.vortex3.uco.edu>

Figure [44]

Monovisions Black \& White Photography Magazine, Vintage: New York’s Bohemian Greenwich Village, 1910s-1920 (2016), <https://monovisions.com/new-yorksbohemian-greenwich-village-1910s-1920s-jessie-tarbox-beals/> [accessed 08 March 2021]

Figure [45]

Monovisions Black \& White Photography Magazine, Vintage: New York’s Bohemian Greenwich Village, 1910s-1920 (2016), <https://monovisions.com/new-yorksbohemian-greenwich-village-1910s-1920s-jessie-tarbox-beals/> [accessed 08 March 2021]

Figure [46 and 47]

Stamp, Shelley, Lois Weber, <https://wfpp.columbia.edu/pioneer/ccp-lois-weber/> [accessed 08 March 2021]

Figure [48]

‘Vernon and Irene Castle’, [online] <https://www.loc.gov/item/2004677281/> [accessed 08 March 2021]

Figure [49]

Lucile, ‘Dance Dress’ [online]

$<$ https://www.metmuseum.org/art/collection/search/94665> [accessed 08 March 2021] 
Figure [50]

'Fashion: Paris Presents the Pageant of the Spring Mode', Vogue, 15 April 1925.

ProQuest $<\underline{\text { https://www-proquest-com.vortex3.uco.edu }>}$

Figure [51 and 52]

'Designs for Practical Dressmaking', Vogue, 15 April 1925. ProQuest $<\underline{\text { https://www- }}$ proquest-com.vortex3.uco.edu>

Figure [53]

Pintrest, 'Throwback Thursday: 1920s Illustrations of John Held, Jr.', <https://www.pinterest.ch/pin/347269821253231791/> [accessed 09 March 2021]

Figure [54]

'Fashion: New York Conforms to New Rules', Vogue, 01 March 1918. ProQuest $<$ https://www-proquest-com.vortex3.uco.edu $>$

Figure [55 and 56]

‘Fashion: The World Grow Simpler’, Vogue, 01 March 1918. ProQuest $<$ https://www-proquest-com.vortex3.uco.edu $>$

Figure [57]

'Fashion: Silhouettes which Inspire the Spring Mode’, Vogue, 15 February 1923. ProQuest $<\underline{\text { https://www-proquest-com.vortex3.uco.edu }}>$

Figure [58]

'Fashion: Doeuillet Emphasizes Velvet and Bead Embroidery in his Winter Evening Gowns', Vogue, 15 October 1923. ProQuest $<\underline{\text { https://www-proquest- }}$ com.vortex3.uco.edu>

Figure [59 and 60]

'Fashion: A Portfolio from Six Great Creators', Vogue, 15 October 1924. ProQuest $<$ https://www-proquest-com.vortex3.uco.edu $>$ 
Fashion [61]

'Fashion: The Mode for the Country', Vogue, 15 October 1924. ProQuest

$<\underline{\text { https://www-proquest-com.vortex3.uco.edu }>}$

Figure [62]

Iriart, Elodie, Suzanne Lenglen, The First Diva of Tennis (2018),

$<$ https://www.rolandgarros.com/en-us/article/suzanne-lenglen-first-diva-of-

tennis $>$ [accessed 03 January 2021] (image 3 of 3)

Figure [63]

Helen Bullitt Lowry, 'A Conspiracy in Restraint: A Conspiracy in Restraint', New York Times, 09 October 1921. ProQuest < $\underline{\text { https://www-proquest- }}$ com.vortex3.uco.edu>

Figure [64]

Peach, Lushie, Photos (2008),

< https://www.flickr.com/photos/lushiepeach/2289335847/> [accessed 09 March 2021]

Figure [65]

Library of Congress, Cover Illustration, Life Magazine, February 18, 1926, Showing

a Well Dressed Old Man Dancing With a Flapper/John Held, Jr.,

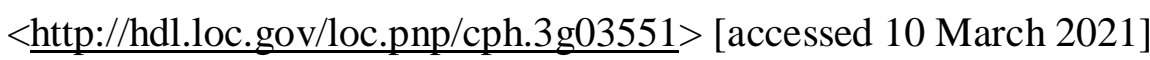

Figure [66]

'Fashion: A Trousseau from the Spring Collections', Vogue, 01 April 1925. ProQuest $<$ https://www-proquest-com.vortex3.uco.edu $>$

Fashion [67]

'Paris Modes are Launched in New York', Vogue, 01 April 1925. ProQuest

$<$ https://www-proquest-com.vortex3.uco.edu $>$ 
Figure [68 and 69]

IMDb, The Flapper (1920), <https://www.imdb.com/title/tt0011193/> [accessed 10 March 2021]

Figure [70]

Wass Jann, Black Oxen (2018), <https://scifist.net/2018/06/04/black-oxen/> [accessed 10 March 2021] (image 4 of 12)

Figure [71]

Hillis, Marjorie, 'Fashion: The Evening Mode’, Vogue, 15 October 1923. ProQuest $<$ https://www-proquest-com.vortex3.uco.edu $>$

Figure [72]

blogcolettehq.com, Vintage Style Inspiration: Colleen Moore (2013), < https://blog.colettehq.com/inspiration/vintage-style-inspiration-colleen-

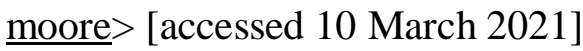

Figure [73]

Ferdinand, Marilyn, Why Be Good? (2015), < https://silentfilm.org/why-be-good/> [accessed 10 March 2021]

Figure [74]

'Fashion: Sandscapes of 1932', Vogue, 01 January 1932. ProQuest < https://wwwproquest-com.vortex3.uco.edu>

Figure [75]

'Success Story of the Shift Dress', Vogue, 01 December 1938. Proquest $<$ http://vortex3.uco.edu/login?url=https://search-proquestcom.vortex3.uco.edu>

Figure [76]

'Fashion: Day Shift, Night Shift', Vogue, 01 November 1938. ProQuest $<$ https://www-proquest-com.vortex3.uco.edu $>$ 
Figure [77]

'Vogue's Eye View: The Ten Great Plays of 1938.', Vogue, 01 January 1939.

ProQuest $<$ https://www-proquest-com.vortex3.uco.edu $>$

Figure [78]

'Fashion: They all Like Long Sleeves', Vogue, 01 January 1939. ProQuest

$<$ https://www-proquest-com.vortex3.uco.edu $>$

Figure [79]

'Finds of the Fortnight: Southbound-Classics and Revised Classics', Vogue, 01 January 1939. ProQuest < https://www-proquest-com.vortex3.uco.edu $>$

Figure [80]

'Vogue Designs for Dressmaking: Midwinter Pick-Up', Vogue, 01 January 1939. ProQuest $<$ https://www-proquest-com.vortex3.uco.edu $>$

Figure [81]

'Fashion: Skirt Lines Going South’, Vogue, 15 November 1941. ProQuest $<$ https://www-proquest-com.vortex3.uco.edu $>$

Figure [82]

'Fashion: Bare Backs', Vogue, 01 January 1944. ProQuest < $\underline{\text { https://www-proquest- }}$ com.vortex3.uco.edu>

Figure [83]

'Fashion: Little Black Dress/July to January', Vogue, 01 July 1944. ProQuest $<\underline{\text { https://www-proquest-com.vortex3.uco.edu }}>$

Figure [84]

'Fashion: Paris Collections', Vogue, 01 April 1947. ProQuest < $\underline{\text { https://www-proquest- }}$ com.vortex3.uco.edu> 
Figure [85]

'Fashion: Paris Collections', Vogue, 01 April 1947. ProQuest < $\underline{\text { https://www-proquest- }}$ com.vortex3.uco.edu>

Figure [86]

Lipstick lettuce lycra, Little Below the Knee Club 920130,

<https://www.lipsticklettucelycra.co.uk/blog/2013/04/12/little-below-theknee-club-2/> [accessed 10 March 2021] (image 1 of 3)

Figure [87]

Old Magazine Articles, The Little Below the Knee Clubs Held-Fast Against Dior's

'New Look', <http://www.oldmagazinearticles.com/article-

summary/Little_Below_the_Knee_Club_rebeled_against_CHRISTIAN_DIOR

_NEW_LOOK\#.YEmAqLRKhFx> [accessed 10 March 2021] (image 2 of 7)

Figure [88]

Gfroerer, Curt, 'Comic', in 'In the Wake of the News', Chicago Daily Tribune, 7 October 1947. ProQuest < http://vortex3.uco.edu/login?url=https://wwwproquest-com.vortex3.uco.edu/docview/177449261?accountid=14516>

Figure [89-92]

Drake, Ruth, 'You Always Look So Pretty: You're a Busy Housewife, but You Want to Look Your Best. You Shop Carefully so You can have Pretty Clothes for Every Occasion', Redbook, June 1952. ProQuest < $\underline{\text { https://www-proquest- }}$ com.vortex3.uco.edu>

Figure [93]

Advertisement: Self-Polishing Simoniz For Floors’, Woman’s Day, June 1949. ProQuest $<$ https://www-proquest-com.vortex3.uco.edu $>$

Figure [94]

'Fashion: Half-Trumpet Skirt / The Chemise Dress’, Vogue, 01 September 1950. ProQuest < $\underline{\text { https://www-proquest-com.vortex3.uco.edu }>}$ 
Figure [95-96]

'Fashion: The New Paris Collections', Vogue. 01 September 1951. ProQuest $<\underline{\text { https://www-proquest-com.vortex3.uco.edu }>}$

Figure [97]

'Fashion: Revolution in Looks', Vogue, 01 May 1958. ProQuest $<\underline{\text { https://www- }}$ proquest-com.vortex3.uco.edu $>$

Figure [98]

'Fashion: Givenchy', Vogue, 15 October 1957. ProQuest < $\underline{\text { https://www-proquest- }}$ com.vortex3.uco.edu>

Figure [99]

'Fashion: Balenciaga', Vogue, 15 October 1957. ProQuest < $\underline{\text { https://www-proquest- }}$ com.vortex3.uco.edu>

Figure [100]

'Advertisement', Vogue, 01 October 1958. ProQuest < $\underline{\text { https://www-proquest- }}$ com.vortex3.uco.edu>

Figure [101]

The Metropolitan Museum of Art, Dress:1955-56,

$<$ https://www.metmuseum.org/art/collection/search/81464> [accessed 10 March 2020]

Figure [102]

The Metropolitan Museum of Art, Evening Dress: ca. 1957, $<$ https://www.metmuseum.org/art/collection/search/85943> [accessed 10 March 2020]

Figure [103]

Victoria and Albert Museum, Dress (2005), <https://collections.vam.ac.uk/item/O109277/dress-cristóbal-balenciaga/> [accessed 10 March 2020] 
Figure [104]

The Metropolitan Museum of Art, Cocktail Dress: Spring/Summer 1958, $<$ https://www.metmuseum.org/art/collection/search/85315> [accessed 10 March 2020]

Figure [105]

Bender, Marylin. "Is this Courrèges Vision of Space-Age Women?" New York Times, 28 May 1965. ProQuest < https://www-proquest-com.vortex3.uco.edu $>$

Figure [106]

'Advertisement: The Villager, Inc., Vogue, 01 February 1964. ProQuest $<$ https://www-proquest-com.vortex3.uco.edu $>$

Figure [107]

'Fashion: Paris the News as we See it', Vogue, 01 September 1965. ProQuest $<$ https://www-proquest-com.vortex3.uco.edu $>$

Figure [108]

van Reij, Frederique, 'Wearing Mondrian Yves Saint Laurent’s Translation from High Art to Haute Couture', The Rijksmuseum Bulletin, 60.4 (2012), 342-359 < http://vortex3.uco.edu:2050/login?url=https://www.jstor.org/stable/23646887> [accessed 20 January 2021]

Figure [109]

'New Concept in Sweater Makes it Star in Any Wardrobe', New York Times, 19 April 1955. ProQuest $<$ https://www-proquest-com.vortex3.uco.edu $>$

Figure [110]

van Reij, Frederique, ‘Wearing Mondrian Yves Saint Laurent’s Translation from High Art to Haute Couture', The Rijksmuseum Bulletin, 60.4 (2012), 342-359 < http://vortex3.uco.edu:2050/login?url=https://www.jstor.org/stable/23646887> [accessed 20 January 2021] 
Figure [111]

Susan Curtis, Campbell's Soup Paper Dress,

< https://www.ndsu.edu/erhcc/gallery/collection highlights/2010.05.01/15 >

[accessed 12 February 2021]

Figure [112]

'Larger Than-Life Prints Go Pop!', Seventeen, February 1965. ProQuest < ProQuest $<$ https://www-proquest-com.vortex3.uco.edu $>$

Figure [113]

'Advertisement: Burdine's, Inc. (Eastern Airlines, Inc.)', Vogue, 01 January 1964.

ProQuest $<\underline{\text { https://www-proquest-com.vortex3.uco.edu }}>$

Figure [114]

'Fashion: Beach Change: Undiluted Colour', Vogue, 01 January 1958. ProQuest $<\underline{\text { https://www-proquest-com.vortex3.uco.edu }>}$

Figure [115]

Elle, Lilly Pulitzer's Flower Power (2013),

< $\underline{\text { https://www.elle.com/fashion/g8322/lilly-pulitzer-flower-power/?slide=1 }>}$

[accessed 10 March 2021]

Figure [116]

'Young Headliners Arrive from England!', Seventeen, September 1963. ProQuest $<\underline{\text { https://www-proquest-com.vortex3.uco.edu }>}$

Figure [117]

'Mary Quant's Clean-Cut London Look’, Seventeen, March 1965. ProQuest

<http://vortex3.uco.edu/login?url=https://search-proquest-

com.vortex3.uco.edu>

Figure [118]

'Mary Quant Pop Art Meets Pure Jazz', Seventeen, September 1965. ProQuest

$<\underline{\text { https://www-proquest-com.vortex3.uco.edu }>}$ 
Figure [119]

'Advertisement: Lilly Pulitzer', Vogue, 01 June 1968. ProQuest $<\underline{\text { https://www- }}$ proquest-com.vortex3.uco.edu>

Figure [120]

'Advertisement: Lilly Pulitzer’, Vogue, 01 November 1968. ProQuest $<\underline{\text { https://www-proquest-com.vortex3.uco.edu }>}$

Figure [121]

'Advertisement: Lilly Pulitzer (Lilly Catalogs)', Vogue, 15 November 1969. ProQuest $<$ https://www-proquest-com.vortex3.uco.edu $>$

Figure [122]

'Fashion: So Say the Paris Openings', Vogue, 15 March 1914. ProQuest $<\underline{\text { https://www-proquest-com.vortex3.uco.edu }>}$

Figure [123]

'Paris Modes are Launched in New York', Vogue, 01 April 1925. ProQuest $<\underline{\text { https://www-proquest-com.vortex3.uco.edu }>}$

Figure [124-125]

'Fashion: The Now and Future Paco Rabanne', Vogue, 01 March 1967. ProQuest $<\underline{\text { https://www-proquest-com.vortex3.uco.edu }>}$

Figure [126]

'Fashion: Vogue’s Eye View: Girl in the Chips’, Vogue, 01 April 1966. ProQuest $<$ https://www-proquest-com.vortex3.uco.edu $>$

Figure [127]

'Advertisement', Vogue, 01 February 1967. ProQuest < $\underline{\text { https://www-proquest- }}$ com.vortex3.uco.edu> 
Figure [128]

'Fashion: The Best-Looking Girls: Ali MacGraw', Vogue, 01 August 1969. ProQuest $<\underline{\text { https://www-proquest-com.vortex3.uco.edu }>}$

Figure [129]

'Erica Elias Soft and Strict, All at Once', Seventeen, September 1965. ProQuest $<$ https://www-proquest-com.vortex3.uco.edu $>$

Figure [130]

'Advertisement: Richtone Knits’, Vogue, 01 November 1966. ProQuest $<$ https://www-proquest-com.vortex3.uco.edu $>$

Figure [131]

'Fashion: The Freshest Looks in Town’, Vogue, 01 May 1966. ProQuest $<$ https://www-proquest-com.vortex3.uco.edu $>$

Figure [132]

'Advertisement: Lilly Pulitzer', Vogue, 01 June 1968. ProQuest $<\underline{\text { https://www- }}$ proquest-com.vortex3.uco.edu>

‘Advertisement: Lilly Pulitzer’, Vogue, 01 November 1968. ProQuest < $\underline{\text { https://www- }}$ proquest-com.vortex3.uco.edu>

Figure [133]

'Advertisement', Vogue, 01 April 1966. ProQuest < $\underline{\text { https://www-proquest- }}$ com.vortex3.uco.edu>

Figure [134]

Getty Images, Serena Stops the Show, < https://www.gettyimages.ie/photos/serenastops-the-show?phrase=serena\%20stops\%20the $\% 20$ show \& sort=mostpopular $>$ [accessed 20 March 2021] 
Figure [135]

Sitcoms Online, Bewitched - Serena Stops the Show,

$<$ https://www.sitcomsonline.com/photopost/showphoto.php/photo/77377/ppus er/37041> [accessed 11 March 2021]

Figure [136]

Shondaland, Bewitched's Eight Season of Fashion Magic: Clashing Patterns (and Personalities) (2018), <https://www.shondaland.com/live/style/a19705623/bewitched-fashion/> [accessed 10 March 2021] (image 19 of 26)

Figure [137]

Youtube, Toys in Babeland (2013),

$<$ https://www.youtube.com/watch?app=desktop\&v=8Ls2LxPRRg4> [accessed 12 March 2021]

Figure [138]

Pintrest, Agnes Moorehead 2021, <https://www.pinterest.com/pin/288863763572348326/> [accessed 12 March 2021]

Figure [139]

Shondaland, Bewitched's Eight Season of Fashion Magic: Clashing Patterns (and Personalities) (2018), <https://www.shondaland.com/live/style/a19705623/bewitched-fashion/> [accessed 10 March 2021] (image 22 of 26)

Figure [140]

Lytle, Mark Hamilton, 'Pictures That Changed Our Mind', OAH Magazine of History, 20.4 (2006), 36-39

< $\underline{\text { http://vortex3.uco.edu:2050/login?url=https://www.jstor.org/stable/25162066> }}$ [accessed 12 March 2021] 
Figure [141]

‘Advertisement', Vogue, 01 September 1967. ProQuest < https://www-proquestcom.vortex3.uco.edu>

Figure [142]

‘Advertisement: Promenade Ltd. (Promenade, Ltd.)’, Vogue, 01 February 1967. ProQuest $<$ https://www-proquest-com.vortex3.uco.edu $>$

Figure [143]

Leffler, Warren K., ‘Women’s Lib[eration] March from Farrugut Sq[uare] to Layfette [i.e., Lafayette] P[ark]/[WKL]', < https://www.loc.gov/item/2003673992/> [accessed 12 March 2021]

Figure [144]

Past Daily: News, History, Music and Enormous Sound Archive, August 26, 1970 Women's Strike for Equality (2020), $<$ https://pastdaily.com/2020/08/26/august-26-1970-womens-strike-forequality-celebrating-50th-anniversay-passage-19th-amendment/> [accessed 12 March 2021] 